\title{
The Protection of
}

\section{Wilderness and Aesthetic Values in Antarctica}

\section{Rupert Matthew Valentine SUMMERSON}

Submitted in total fulfilment of the requirements of the degree of Doctor of Philosophy

September 2013

Faculty of Architecture, Building and Planning

The University of Melbourne 


\section{Abstract}

The protection of wilderness and aesthetic values in Antarctica was mandated by the Protocol on Environmental Protection to the Antarctic Treaty, the "Madrid Protocol", which came into force in January 1998. Implementation of protection has, however, been delayed by problems of definition and assessment. A survey of the history of Antarctic exploration shows that from almost the earliest days of exploration visitors to Antarctica have been struck by the vast, aweinspiring and beautiful landscapes and those attitudes have persisted to the present. The history of the development of the Madrid Protocol demonstrates that the desire to protect these values can be traced to guidelines for managing human impacts dating from the mid-1980s. Human impacts in Antarctica derive mainly from the operations of national Antarctic programs (NAPs) and although tourists now outnumber staff in NAPs, to date their impact has been confined to ten or twenty favourite landing sites and a small number of sites where tourism companies have established land-based facilities. NAP facilities, by contrast, are widespread, especially in coastal ice-free areas and are characterised by the establishment of permanent infrastructure.

It was hypothesised that it is the establishment of infrastructure that detracts from wilderness and aesthetic values more than transient activity. A strong case can be made that all Antarctica is wilderness unless it has been degraded by human activity, i.e. the construction of infrastructure. In terms of wilderness degradation, therefore, the area which has been degraded is that from which infrastructure is visible. In order to test this hypothesis, a series of surveys were carried out, the final survey being established on the Internet and based on the use of digital images of Antarctic landscapes. The images in the survey were also categorised by landscape type, derived from the Environmental Domains of Antarctica (EDA) regionalisation. The survey comprised three components: a) perceptions of wilderness, in which respondents were asked to decide whether or not the scene in the image constituted wilderness; b) to give an aesthetic preference rating on a seven-point scale; and c) to assess the suitability of a number of adjectives for each scene. Some demographic information was also collected. The survey was made available in four languages: English, Japanese, French and Spanish. Over 500 respondents from 24 countries contributed to the surveys.

The results of the Internet survey, in particular, show that human presence was found to make images significantly less likely to be considered as wilderness and also reduced their aesthetic rating; people therefore preferred natural landscapes. Coastal ice-free areas were less valued aesthetically than mountainous and ice-covered terrains. Human presence was consistently detected in responses to questions on perception of wilderness, aesthetic preference and in the semantic responses. The results were extended by terrain modelling to analyse the areas degraded by visibility of infrastructure. The results of this research show, inter alia, that 
wilderness and aesthetic values and human impacts on these values are measureable and therefore amenable to the development of policies to protect them. 


\section{Declaration}

This is to certify that:

i. the thesis comprises only my original work towards the $\mathrm{PhD}$,

ii. due acknowledgement has been made in the text to all other material used,

iii. the thesis is fewer than 100000 words in length, exclusive of tables, maps, bibliographies and appendices.

Rupert Matthew Valentine SUMMERSON

September 2013 


\section{Preface}

The pre-cursor of this thesis was a three month pilot project on wilderness and aesthetic values under contract to the Australian Antarctic Division during 1997. 


\section{Acknowledgements}

I would like to gratefully acknowledge the generous support and contributions to this research from many people in many countries. My supervisors Prof. Ian Bishop, Prof. Catherin Bull, Dr Martin Riddle and Dr Roger Bradbury provided every support and encouragement. I would like to particularly thank Prof. Ian Bishop for his patience over a very long time. Ms Jane Trewin at the research support Faculty of Architecture, Building and Planning, The University of Melbourne provided sterling support throughout my time at the Faculty.

The logistic support of Antarctic fieldwork through the Australian Antarctic Science Grants Program is gratefully acknowledged (project no. 2250). The voyage and field staff in Antarctica were unfailingly helpful and I would like to particularly thank Gary Kuehn at Casey, Kym Newbery at Mawson and Andy Reid at Davis; our walk through the Vestfold Hills was inspiring.

At the Australian Antarctic Division Dr Martin Riddle, Mr Ewan McIvor, Mr Tom Maggs, Mr David Smith, Mr Henk Brolsma, Dr Andy Smithies, Dr Lee Belbin and the staff at the Australian Antarctic Data Centre unstintingly provided me with help and advice.

I am indebted to Ms Patty Hobsbawn who designed, built and helped maintain the code for the Internet survey and to Ms France Meyer, Ms Noriko Sakai and Mrs Diana McPhetres who translated the Internet survey into French, Japanese and Spanish, respectively. Mrs Moko Eade and Ms Amelia Fielden helped with the Japanese version of the Internet survey.

Many people helped promote the Internet survey but I would like to especially thank the following: Prof. David Walton (UK), Prof. Julian Dowdeswell (UK), Mr Jason Anthony (US), Dr Robert Stephenson (US), Dr Harvey Marchant, Dr Julian Paren (UK), Ms Robyn Mundy, Dr David Kirby, Dr Harry Keys (NZ), Mr Benj Whitworth, Mr Martin Butterfield and Dr Adrian Howkins (US). I would also like to thank all the respondents who took the time to complete the surveys.

A number of people kindly loaned me their photographs to use in the Internet survey and I would like to thank Dr Frederique Oliver, Mr Dick Barwick, the USAP Photo Library, Mr Matthew Lazzara (University of Wisconsin) and Mr Brian Vasel (NOAA).

Mr Mark Chambers, Dr Peter Caley and Mr Phil Tennant provided me with invaluable instruction in statistics and I am very grateful to them. 
Dr Rob Lesslie, Mr John Hyslop and Ms Astrida Mednis kindly gave their time to act as a focus group.

I have had many useful discussions about wilderness and aesthetic values and I gratefully acknowledge Dr Rob Lesslie, Dr Lisa Roberts, Dr Alan Hemmings, Dr Tina Tin (France), Dr Rosamunde Codling (UK), Dr Bernadette Hince, Ms Claire Beynon (NZ) and Ms Diane Erceg.

I would like to thank my colleagues in BRS/ABARES for their patience and understanding, especially Dr Gavin Begg and Dr Ilona Stobutzski.

Finally, and my no means least, I would like to thank my wife, Dr Janet Hughes and my three children, Isabelle, Huon and Iona for their patience, encouragement and support. 


\section{Table of contents}

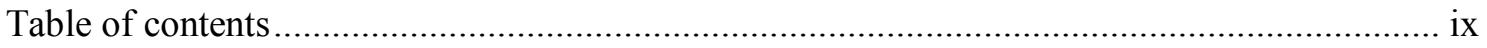

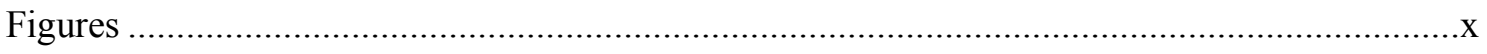

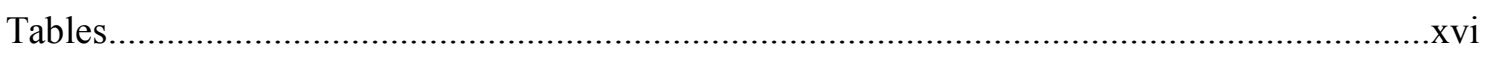

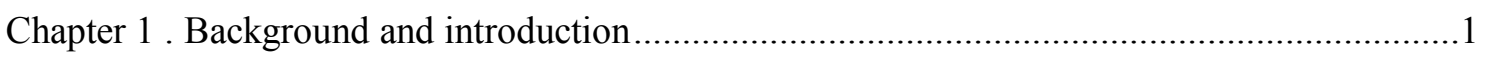

Chapter 2 . A History of Antarctic Landscape Descriptions ...................................................10

Chapter 3 . Development of the Madrid Protocol and the origins of the desire to protect wilderness

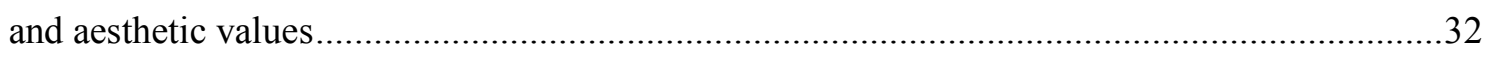

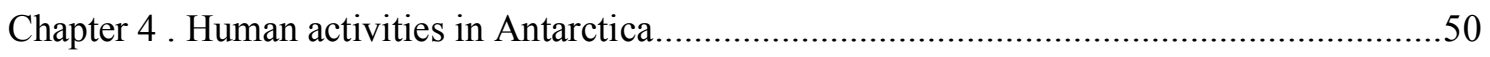

Chapter 5 . Intrinsic, wilderness and aesthetic values ....................................................... 78

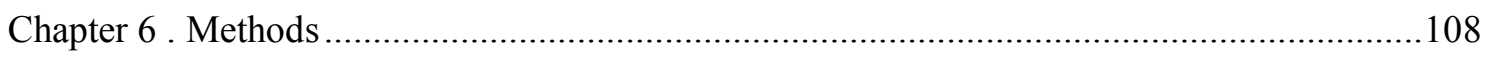

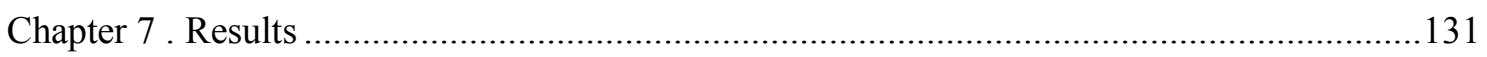

Chapter 8 . Spatial modelling and mapping of areas of wilderness and aesthetic value ...........200

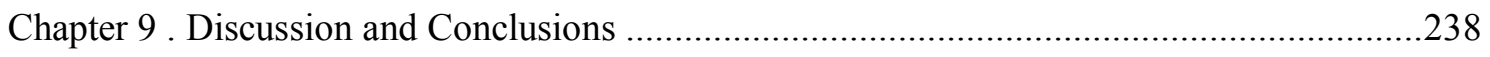

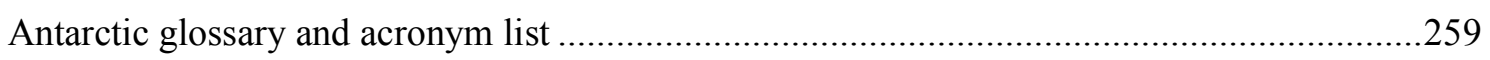

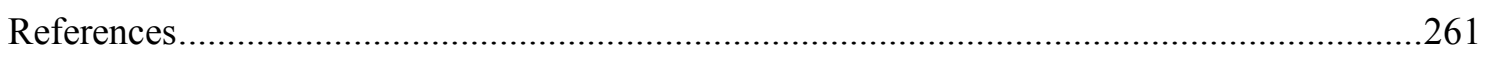

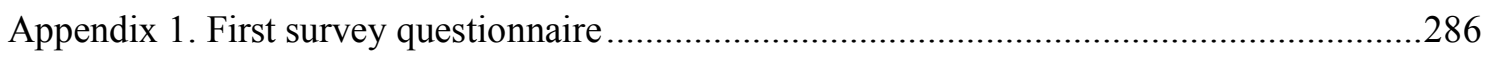

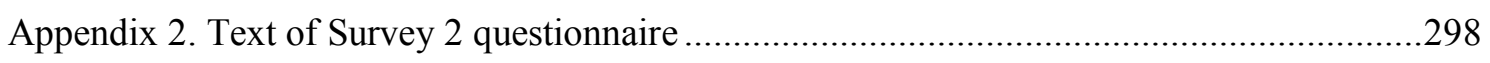

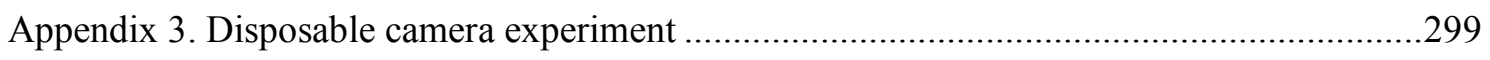

Appendix 4. Surveys $2 \& 3$ photos \& summary results .............................................................. 301

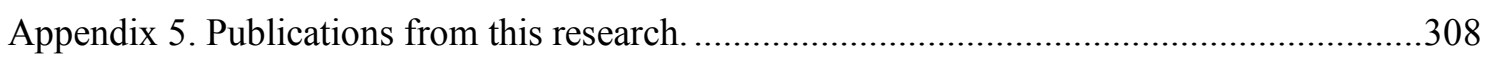




\section{Figures}

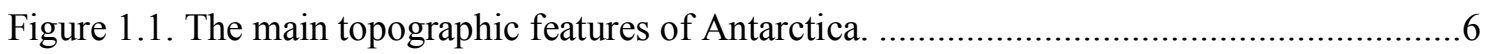

Figure 1.2. Canada Glacier in the Transantarctic Mountains. (Photo: Dave Haney. USAP Photo

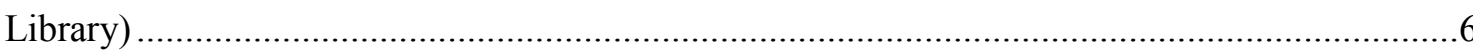

Figure 1.3. Sastrugi carved by the wind. (Photo: Brian Vasel (digitally manipulated to remove

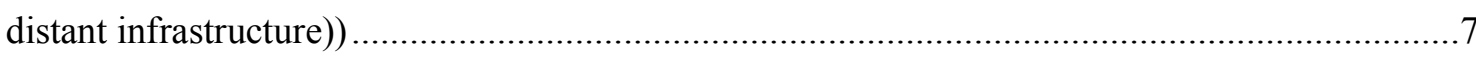

Figure 1.4. Crevasse. (Photo: Russ Alger/CRREL \& USAP Photo Library)................................

Figure 1.5. Coastal ice cliffs (Rupert Summerson).............................................................

Figure 1.6. Interior of the Vestfold Hills. Davis Station is situated on the coast of the Vestfold

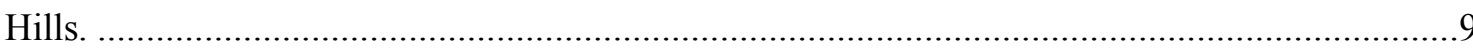

Figure 2.1. The approximate locations where the landscape descriptions quoted were made. ...13

Figure 3.1. Protected areas in Antarctica. The numbers refer to the ATS protected areas database (http://www.ats.aq/devPH/apa/ep_protected.aspx?lang=e) ........................................49

Figure 4.1. Stations and facilities operated by national Antarctic programs in $2012 \ldots \ldots \ldots \ldots \ldots \ldots . . .51$

Figure 4.2. Tourism sites, including landings, non-landing ship cruises and land-based tourism,

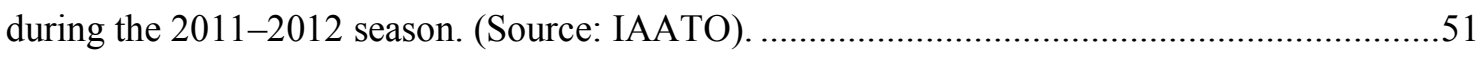

Figure 4.3. Antarctic stations occupied during the International Geophysical Year 1957-58 (Law 1959).

Figure 4.4. Diagrammatic representation of the types of scientific activity in terms of the infrastructure support required. Solid orange boxes indicate that infrastructure is required; partially filled boxes indicate that some temporary infrastructure may be required. All offstation activity requires the resources of a station or a ship to support it

Figure 4.5. Left: Holes left after rock cores were taken. Near Mt Stalker, Vestfold Hills. The holes are about $75 \mathrm{~mm}$ in diameter. (Photo: Rupert Summerson). Right: LIDAR (light detection and ranging) sounding of the upper atmosphere in operation at Davis. (Photo: Zupy/ Australian Antarctic Division. (C) Commonwealth of Australia 2013) ........................................................56

Figure 4.6. Davis Station (Australia) in 2000. (Photo: Davis 2000 winterers). ..........................57

Figure 4.7. Lake Stinear, Vestfold Hills, approximately 5km ENE of Davis Station. (Photo:

Rupert Summerson). 
Figure 4.8. Aurora Australis during resupply at Davis Station, 2007. (Photo: Didier

Monselesan/Australian Antarctic Division. (C) Commonwealth of Australia 2013)

Figure 4.9. A319 Airbus (inter-continental flights) and CASA 212 (intra-continental flights) at Wilkins Runway near Casey Station. (Photo: Thomas Delfatti/ Australian Antarctic Division. (C) Commonwealth of Australia 2013).

Figure 4.10. Locations of airfields that are currently, or planned to be, capable of landing intercontinental aircraft.

Figure 4.11. Rothera Research Station (UK). The runway crosses the image from left to right in front of the buildings. (Photo: www.photo.antarctica.ac.uk) .62

Figure 4.12. Air routes in Antarctica, as published by COMNAP and Antarctic Treaty Exchange Information. As noted above, this represents the "backbone" of air operations. Many more flights are flown to field camps, field parties and on scientific research projects such as radioecho sounding, aero-magnetic studies, aerial photography and other research projects.

Figure 4.13. Botanists working on moss beds close to Casey (Photo: G. Dixon/Australian Antarctic Division. (C) Commonwealth of Australia 2013).

Figure 4.14. BAS geophysical field party, Larsen Ice Shelf, 1985. (Photo: Rupert Summerson).

Figure 4.15. Tourists from the Marina Svetlaeva land on an ice floe near Coulman Island, Ross Sea. (Photo: Richard Barwick).

Figure 4.16. Trends in numbers of tourists from 1992-93 to 2012-13 (the numbers for 2012-13 are preliminary). Overflight numbers are not included.

Figure 4.17. The 10 most visited tourism sites over the period 2003-2004 to 2011-2012.........71

Figure 4.18. The number of visits by yachts to Port Lockroy between 1996-1997 and 20112012. Source: Antarctic Treaty Secretariat (2011b).

Figure 6.1. Original Environmental Domains of Antarctica regionalisation (left) and reclassified environmental regions (right).

Figure 6.2. Locations of images used in the survey and their placement in the derived EDA regions.

Figure 6.3. Flow diagram for the Internet survey.

Figure 6.4.The main question page of the survey showing the image to be assessed and the three sets of questions below it. 
Figure 6.5. Evident terrain modification rules out an attempt to remove complex infrastructure in an image such as this of McMurdo. (Photo: Bob Koch/NSF Antarctic Photo Library).

Figure 6.6. Examples of original and digitally modified images. Items that were digitally removed that may be difficult to discern at this scale have been circled. CIF $=$ coastal ice free. MIF $=$ mountainous ice-free. IS $=$ Ice shelf. $\mathrm{PIF}=$ Peninsula Ice Fields. CIS $=$ Central Antarctic ice sheet. (Photos: CIF: Rupert Summerson, MIF: Australian Antarctic Division, IS: John Penney (NSF Antarctic Photo Library), PIF: Rupert Summerson, CIS: Brian Vasel (NOAA).)

Figure 7.1. Left: $15 \%$ of respondents considered this scene as wilderness (photo: Rupert Summerson). Right: $96 \%$ of respondents considered this scene as wilderness (photo: Elaine Hood/NSF).

Figure 7.2. Ranges of assessments of 'wilderness' among images with human content, grouped by human content type. Complex infrastructure is defined as multiple buildings and structures, e.g. stations; minor infrastructure is one or two buildings and/or structures, e.g. field huts; major transient is defined as ships, aircraft or heavy vehicles; minor transient is light vehicles or people on foot; and tracks only are tracks in snow only. The figures in brackets are the numbers of images in each group. The vertical bars represent the range of assessments in each group: minimum to maximum; the mean is represented by the cross-bar. The range of assessments of 'wilderness' of the 44 images without human content is shown on the right for comparison...146 Figure 7.3. Percentage assessments of wilderness - all images with and without human presence aggregated by EDA region. The red columns are the percentages of responses perceived as wilderness of all images with human presence. The blue columns are the percentages of assessments of wilderness of all images in each EDA region without human presence.

Figure 7.4. Percentages of assessments of wilderness for each image pair in the 16 pairs of images. The pairs are clustered by EDA region (Figure 6.2): $\mathrm{CIF}=$ coastal ice free, MIF = mountainous ice free, $\mathrm{CCM}=$ coastal continental margin, $\mathrm{PIF}=$ peninsula ice fields, $\mathrm{IS}=$ ice shelves and CIS = central Antarctic ice sheet. The type of human presence in the original images is either infrastructure (I) or transient activity (A). Red $=$ human presence, blue $=$ no human presence.

Figure 7.5. Comparison profile of $Z$ scores and raw aesthetic preference scores showing numbers for each integer value.

Figure 7.6. Mean aesthetic $(Z)$ scores for each EDA region, differentiated by the type of human presence. No human $=$ no human presence. Transient $=$ transient human activity. Infrastructure $=$ presence of infrastructure. 
Figure 7.7. Scatter plot of averaged responses to wilderness and aesthetic value of all 90 images. Perception of wilderness is expressed as a percentage of responses as wilderness to each image and aesthetic values as mean $\mathrm{Z}$ scores.

Figure 7.8. Radar graph of all semantic responses aggregated into two classes: those from images with human presence and those without. The zero line is indicated in red for reference.

Figure 7.9. Averaged semantics scores for all images in the Coastal Ice-Free region without human presence. (Photos: Top: Windmill Islands (Frédérique Olivier), centre: Vestfold Hills (Rupert Summerson), bottom: Larsemann Hills (Ewan McIvor)).

Figure 7.10. Averaged semantics scores for all images in the Mountainous Ice-Free region without human presence. (Photos. Top: Framnes Mountains (Frédérique Olivier), centre: Transantarctic Mountains (Dave Haney/NSF), bottom: Prince Charles Mountains (AAD)), ...166 Figure 7.11. Averaged semantics scores for all images in the Peninsula Ice Fields Region without human presence. (Photos. Top: Lully Foothills (Rupert Summerson), centre: Sierra du Fief (John Brack/NSF), bottom: Antarctic Peninsula (Melissa Rider/NSF)).

Figure 7.12. Averaged semantics scores for all images in the Coastal Continental Margin Region without human presence. (Photos. Top: Ice cliffs near Mawson (AAD), centre: McMurdo Sound (Kristan Hutchison/NSF), bottom: Windmill Islands (Rupert Summerson)).

Figure 7.13. Averaged semantics scores for all images in the Ice Shelves Region without human presence. (Photos. Top: Ross Ice Shelf (John Penney/NSF), centre: Larsen Ice Shelf (Rupert Summerson), bottom: Ross Ice Shelf (Robyn Waserman)). 169

Figure 7.14. Averaged semantics scores for all images in the Central Antarctic Ice Sheet region without human presence.

Figure 7.15. Semantics plot of all six regions, plotted at the same scale.

Figure 7.16. Radar graph of semantic responses to the image with the highest $\mathrm{Z}$ score (image 324). (Photo: Paul Thur/NSF).

Figure 7.17. Image 213. Radar graphs of semantics scores all respondents (upper right) and respondents with Antarctic experience with ANARE (lower right). A zero line (in red) and the shape of the mean aggregated results for all images without human presence in the coastal icefree region (see below) have been included for reference. (Photo: Rupert Summerson). 
Figure 7.18. Effect of an item of infrastructure (automatic weather station (AWS)), above, and digitally removed, below.

Figure 7.19. Effect of a transient activity (a field party). (Photo: Rupert Summerson).

Figure 7.20. Image 111 without human presence (above) and Image 309 with a human figure (below). Image 111, $\mathrm{N}=72$. Image 309, $\mathrm{N}=87$. (Photos: Ewan McIvor).

Figure 7.21. Radar graphs of semantic responses to two field huts. Upper: Rumdoodle Hut, Framnes Mountains (photo: Australian Antarctic Division), Lower: Mt Henderson Hut, Framnes Mountains (photo: Rupert Summerson). The sample sizes relate to the number of people who viewed the images; the numbers of semantic assessments were generally four times greater as each person was allocated four adjectives for each image. 178

Figure 7.22. Responses to the French version of the semantics component of the survey plotted in a radar graph. The word order is the same as in the English version.

Figure 7.23.a. Plot of the multidimensional scaling output of the 20 adjectives of all images (both with and without human content) to reveal Dimensions 1 and 2

Figure 7.24. Plot of MDS dimensions $1 \& 2$ of human and non-human images separately.

Dimension $1=\mathrm{x}$ axis, Dimension $2=\mathrm{y}$ axis.

Figure 7.25. Multidimensional scaling of semantic responses to images by people who have visited Antarctica in any capacity (red stars) and those who have not visited Antarctica (blue circles).

Figure 7.26. Correlations between MDS Dimension 1 and the adjective suitability scores, where the correlation is significant.

Figure 7.27. Correlations between MDS Dimension 2 and the adjective suitability scores, where the correlation is significant.

Figure 7.28. Correlations between MDS Dimension 3 and the adjective suitability scores, where the correlation is significant.

Figure 7.29. Multidimensional scaling of semantic responses to images of nine field huts

Figure 7.30. Multidimensional scaling of semantic responses to images of five field huts and their manipulated counterparts. Human (red) = images with field huts, no human (blue) = images without field huts.

Figure 7.31. Classification tree plot of human presence and demographic factors in perceptions of wilderness. 
Figure 7.32. Regression tree plot of human presence and demographic factors in aesthetic preference $(Z)$ scores

Figure 7.33. Regression tree plot of demographic factors in aesthetic preference $(Z)$ scores for images without human presence.

Figure 8.1. Five options defining the footprint of a station: minimum bounding ellipse, minimum bounding rectangle, convex hull polygon, station limits and recreational limits. (Based on a map of Casey Station (AUS)).

Figure 8.2. Satellite infrastructure around Casey Station (AUS).

Figure 8.3. Masts at Casey Station (2000). The masts in the foreground are part of an ionosonde array. There are other masts out of the picture. (Photo: Rupert Summerson).....

Figure 8.4. Output of the visibility model of station infrastructure (left) and (right) Casey Station and all satellite infrastructure in the Windmill Islands.

Figure 8.5. Visibility model of Davis Station, i.e. radio masts at Davis and satellite infrastructure in the Vestfold Hills.

Figure 8.6. Wind turbines at Mawson Station. Photo taken at a range of about 2km. (Photo:

Frederique Olivier).

Figure 8.7. Output of the visibility model of the wind turbines at Mawson Station. The visibility of satellite infrastructure in the Framnes Mountains and elsewhere is not included.

Figure 8.8. Map showing the limit of audibility of the generators at Casey and the location of Jack's Donga field hut.

Figure 8.9. An abandoned survey mark in the Windmill Islands; typical of unrecorded infrastructure (Photo: Rupert Summerson).

Figure 8.10. Visibility areas of all known infrastructure, calculated by buffering by the distances given in Table 8.4. The visibility areas of the smaller items of infrastructure are not visible at this scale. The inset shows the buffered visibility footprint of all infrastructure in the Vestfold Hills. (Compare with Figure 8.5. Visibility model of Davis Station, i.e. radio masts at Davis and satellite infrastructure in the Vestfold Hills.)

Figure 8.11. Tourism landing sites at the northern end of the Antarctic Peninsula. 228

Figure 8.12. Two methods of calculating the limit of visibility of the Ellsworth Mountains: by theoretical distance to the horizon equation from the summit of Vinson Massif, the highest mountain in the range (and in Antarctica) and using the VIEWSHED routine in ArcGIS Spatial Analyst extension. 
Figure 8.13. Visibility regionalisation of mountains in Antarctica.

Figure 8.14. The reclassified EDA regions with mountain visibility overlaid. The original mountainous ice free layer is overlain on top of the visibility layer.

Figure 9.1. Vehicle tracks in the Vestfold Hills. Evidence of widespread human activity. ......246

Figure 9.2. Davis Station, the field huts and other features in the Vestfold Hills.

Figure 9.3. Image of a coastal ice free region including water. (Pauk Lake, a freshwater lake in the Vestfold Hills. Photo: Rupert Summerson.) 256

\section{Tables}

Table 3.3.1. ASPAs and ASMAs that include wilderness and/or aesthetic values as values to be protected.

Table 4.1. ATCM recommendations relating to tourism.

Table 6.6.1. Content of the 45 images in Survey 2.

Table 6.6.2. The adjectives presented to respondents as part of the semantic assessments. .....130

Table 7.1. Summary of responses on Wilderness Part 1

Table 7.2. Responses to W1. Experienced expeditioners.

Table 7.3. Responses to W2. Experienced expeditioners

Table 7.4. Responses to W3. Experienced expeditioners

Table 7.5. Summary results of Question A1. (Results are in percentages)

Table 7.6. Summary results of the favourite places part of the questionnaire

Table 7.7. Results of Chi-square tests for independence of comparisons of images of human presence with images with no human presence.

Table 7.8. Results of independent samples t-tests for respondents to the first visual survey comparing aesthetic ( $\mathrm{Z}$ score) responses to all images with and without human presence by people who had visited Antarctica and those who had not.

Table 7.9. summarises the content and preference ratings of images 16,17 and 18

Table 7.10. Nominations for favourite places.

Table 7.11. Count of respondents that viewed at least one image in each of the three sets.

Table 7.12. Demographic details of respondents by age range, gender and education level. ...142 
Table 7.13. Nationalities and numbers of survey respondents.

Table 7.14. Numbers of respondents to each language version of the survey.

Table 7.15. Results of chi-square tests comparing assessments of wilderness and not-wilderness between all images aggregated by EDA region, differentiated by all images (both transient \& infrastructure), images containing transient activity and images containing infrastructure. $\chi^{2}=$ Pearson chi-square test with Yates' continuity correction, $p=$ significance, $p h i(\Phi)=$ effect size. $\alpha=0.05$. The non-significant result is indicated in bold type

Table 7.16. Results of chi-square tests of responses on perceptions of wilderness of the 17 pairs of digitally manipulated pairs of images. EDA $=$ EDA region. Infra/trans. $=$ infrastructure or transient activity. $\mathrm{N}_{\text {human }}=$ sample size images with human presence. $\mathrm{N}_{\text {natural }}=$ sample size images without human presence. $\chi^{2}, p$ and $\Phi$ as in Table 7.15. Values of $p$ in italics are results from Fisher's Exact Test, used in place of $\chi^{2}$ owing to frequencies $<5$ in cells in contingency tables. $\mathrm{N}_{\text {penguins }}=$ sample size images with penguins. $\mathrm{N}_{\text {o_penguins. }}=$ sample size images without penguins. Bold $=$ not significant.

Table 7.17. Aesthetic $(Z)$ scores for the aggregated EDA regions, with t-test results comparing images with no human content and all images with human presence, $95 \%$ confidence levels and effect sizes (ES).

Table 7.18. Aesthetic $(Z)$ scores for the aggregated EDA regions, with t-test results comparing images with no human content and images with transient human activity. 95\% confidence levels and effect sizes (ES) are included.

Table 7.19. Aesthetic $(Z)$ scores for the aggregated EDA regions, with t-test results comparing images containing no human content and images with infrastructure. 95\% confidence levels and effect sizes (ES) are included.

Table 7.20. Results of t-tests between the aesthetic $(Z)$ scores of images with human presence and manipulated (natural) images.

Table 7.21. Lists of adjectives used in the semantic descriptors component of the survey.

Table 7.22. Conversion of word rankings into scores. "Austere" and image 228 are used here only as examples. In reality there are 30 assessments of "Austere" in image 228.

Table 7.23. Formatting of input data for classification and regression tree analyses. 190

Table 7.24. Nationality groupings

Table 7.25. Results of independent samples t-tests of aesthetic preference ratings (as $Z$ scores) of, top, all images combined, centre, images of the coastal ice free region and bottom, images of 
the central Antarctic ice sheet. Each group of images is divided into images with human presence and those without human presence and comparisons conducted of people who have visited Antarctica and those who have not. $\mathrm{n}=$ sample size; $\mathrm{sd}=$ standard deviation; $\mathrm{t}=\mathrm{t}$ statistic; $\mathrm{df}=$ degrees of freedom; $95 \% \mathrm{CI} \mathrm{L/U}=95 \%$ confidence interval, lower and upper...198 Table 8.1. Percentages of assessments of wilderness in images of six stations from Survey 3.207 Table 8.2. Types of infrastructure. 220

Table 8.3. Types of infrastructure used to model the human Antarctic visibility footprint and sources of data

Table 8.4. Maximum visibility distances. Distances are planar, i.e. no correction was made for curvature of the earth.

Table 8.5. Areas of regions aggregated from EDA domains, in $\mathrm{km}^{2}$, and areas and percentages estimated to be non-wilderness.

Table 8.6. Mean aesthetic preference (raw scores), standard deviation and image count for each of the six regions of the EDA. 230 


\section{Chapter 1. Background and introduction}

\subsection{Introduction}

On 4 October 1991 the Consultative Parties to the Antarctic Treaty ${ }^{1}$ signed the Protocol on Environmental Protection to the Antarctic Treaty and on 14 January 1998 the Protocol came into force, thereby bringing to an end an unusually turbulent period in international relationships on Antarctica, which had been known for quiet consensus ever since the signing of the Antarctic Treaty in 1961. The "Madrid Protocol", as it has become known as because it was signed in Madrid, is the latest in a series of conventions built upon the foundations of the Antarctic Treaty. The Protocol introduces strict environmental standards for operations in Antarctica, requiring, amongst other things, an environmental impact assessment to be carried out for each and every operation.

Amongst the provisions of the Madrid Protocol ${ }^{2}$ is the requirement to protect the "wilderness and aesthetic values", within the context of the protection of "the intrinsic value of Antarctica". No definitions of any of these terms are given in the text of the Madrid Protocol, nor any guidance given how these values should be judged, nor how impacts on them should be assessed.

The Protocol introduced the requirement to protect these values in two ways. First, by including the evaluation of potential human impacts on the wilderness and aesthetic values before any activity can be approved. This requirement is laid out in the environmental principles of the Protocol (Article 3):

\section{Article 3 \\ Environmental Principles}

1 The protection of the Antarctic environment and dependent and associated ecosystems and the intrinsic value of Antarctica, including its wilderness and aesthetic values and its value as an area for the conduct of scientific research, in particular research essential to understanding the global environment, shall be fundamental considerations in the planning and conduct of all activities in the Antarctic Treaty area.

2 To this end:

\footnotetext{
${ }^{1}$ Argentina, Australia, Belgium, Chile, France, Japan, New Zealand, Norway, South Africa, Russia, United Kingdom and United States of America.

${ }^{2}$ The full text of the Madrid Protocol can be found on the website of the Antarctic Treaty Secretariat (http://www.ats.aq/documents/recatt/Att006_e.pdf).
} 
(a) activities in the Antarctic Treaty area shall be planned and conducted so as to limit adverse impacts on the Antarctic environment and dependent and associated ecosystems;

(b) activities in the Antarctic Treaty area shall be planned and conducted so as to avoid:

(i) .....

(vi) degradation of, or substantial risk to, areas of biological, scientific, historic, aesthetic or wilderness significance;

The second requirement is in Annex V (Area Protection and Management) of the Protocol, which encourages signatories to the Protocol to designate protected areas for the protection of wilderness and aesthetic values:

\section{Article 3}

\section{Antarctic Specially Protected Areas}

1. Any area, including any marine area, may be designated as an Antarctic Specially Protected Area to protect outstanding environmental, scientific, historic, aesthetic or wilderness values, any combination of those values, or ongoing or planned scientific research.

2 Parties shall seek to identify, within a systematic environmental-geographical framework, and to include in the series of Antarctic Specially Protected Areas:

(a) $\ldots$...

(g) areas of outstanding aesthetic and wilderness value;

The system of protected areas in Antarctica was first introduced as part of the Agreed Measures for the Conservation of Antarctic Fauna and Flora in 1964 (Lewis Smith 1994). The first category of protected area was the Specially Protected Area (SPA) and this was extended in 1975 to include Sites of Special Scientific Interest (SSSI) (Lewis Smith 1994). Various other designations were mooted over time including Site of Special Tourism Interest, introduced at VIII ATCM (Oslo, 1975) and Specially Reserved Area, introduced at XV ATCM (Paris, 1989), which included the provision for the protection of "...outstanding ... aesthetic, scenic, or wilderness value". This provision did not come into effect, however. The Madrid Protocol introduced two new designations for protected area, which replaced the old designations of SSSI and SPA: Antarctic Specially Protected Area (ASPA) and Antarctic Specially Managed Area (ASMA) and as Article 3 of Annex V (above) states, ASPAs may be designated to protect "areas of outstanding aesthetic and wilderness value". The history of the development of the Madrid Protocol and the requirement to protect wilderness and aesthetic values are described in detail in Chapter 3.

The Madrid Protocol is therefore the first legal instrument in Antarctica that has afforded landscapes the same degree of protection as flora, fauna, ecosystems and historic sites in Antarctica. The value of landscape is implicit in the term "wilderness and aesthetic values" though the terms "wilderness" and "aesthetics" imply more than just the quality of the landscape 
and by no means exclude the fauna and flora that inhabit it. The history of the development of the Madrid Protocol and the origins of the desire to protect wilderness and aesthetic values follows in Chapter 3 and an analysis of the phrasing in the Madrid Protocol follows in Chapter 5.

The Madrid Protocol, therefore, is the both the genesis and motivation for this thesis. My aim is to help with the implementation of the Protocol by providing environmental managers with useful definitions for the term "wilderness and aesthetic values", methods of determining where places with high wilderness and aesthetic values are to be found, methods of measuring potential impact of proposed activities on these values and, ultimately, to contribute to their protection. In addition, this thesis will contribute to the body of scholarly knowledge on wilderness and landscape aesthetics more generally and I hope that the ideas originating from this research will contribute to theories on landscape aesthetics in particular.

\subsection{The aim of this research and of this thesis}

The underlying aim of the research reported here is to assist the Australian Government Antarctic Division with implementation of the Madrid Protocol as follows:

1. To provide an interpretation of what is meant by the phrase "wilderness and aesthetic values".

2. To develop a set of tools and procedures which will help Antarctic Division Environmental Managers assess the potential impact of proposed activities on the wilderness and aesthetic values, as required under Article 3 of the Protocol.

3. To identify areas of outstanding wilderness and aesthetic values and

4. To develop a method for nominating areas for inclusion in the Antarctic Specially Protected Areas System.

Specific research questions are given in Chapter 6.

\subsection{Structure of the thesis}

The thesis is in two parts:

Part One of the thesis comprises Chapters $1-5$. In this section I describe the background and the theoretical

Chapter 1 provides the background to this research, the origin of the phrase "Wilderness and Aesthetic Values of Antarctica", describes the structure of this thesis and a brief introduction to the topography of Antarctica. 
Chapter 2 is a history of Antarctica with respect to responses of explorers and visitors to Antarctic landscapes. In this chapter I trace the attitudes to Antarctic landscapes and the ways that they have been described from the earliest views of Antarctica to the present Chapter 3 is a history of the development of the Protocol on Environmental Protection to the Antarctic Treaty, the "Madrid Protocol", which introduced protection for the wilderness and aesthetic values of Antarctica. In this chapter I also trace the development of the desire to protect wilderness and aesthetic values.

Chapter 4 is a description of human activities in Antarctica, which are the causes of actual and potential impacts on wilderness and aesthetic values.

Chapter 5 examines values systems and gives an interpretation of the meaning of the phrase "wilderness and aesthetic values" and provides an interpretation of how "wilderness and aesthetic values" can be consistent with concepts of "intrinsic value".

Part Two comprises Chapters 6-9, which describe the empirical component of this research Chapter 6 describes the research questions and the methods used to carry out the research, which were principally based on three surveys.

Chapter 7 provides a complete description of the results obtained from the surveys and the analyses of the results.

Chapter 8 describes the spatial modelling used to extrapolate from the results to cover the whole of Antarctica.

Chapter 9 discusses the results and makes conclusions arising from them.

There are 5 appendices (survey questionnaire forms, the images used and summary results for each image and the papers published from this research). 


\subsection{Topography of Antarctica}

Antarctica is often described as the coldest, highest, windiest and most remote of the continents. The most remote is not just in terms of remoteness from human settlement, it is also the most remote from other land masses; the northernmost tip of the Antarctic Peninsula is about 500 nautical miles ( 800 kilometres) from the southernmost tip of South America. The main topographical features are shown in Figure 1.1. The average elevation of Antarctica is $2300 \mathrm{~m}$ above sea level and the mean ice thickness is $2160 \mathrm{~m}$ (Drewry 1982). This height is due entirely to the ice cap that has built up such that in places in reaches $4776 \mathrm{~m}$ in depth (Drewry, 1982) and at its highest point, Dome A, it reaches an altitude of $4093 \mathrm{~m}$ (Figure 1.1). The South Pole itself is at $2830 \mathrm{~m}$. The highest mountain in Antarctica, Vinson Massif (4892 m) in the Ellsworth Mountains (Figure 1.1), is only $799 \mathrm{~m}$ higher than the highest point of the ice cap. There is, perhaps, a reason why Antarctica, which has several chains of mountains, does not have any peaks of a similar scale to those in most of the other continents and that is that the great weight of the ice cap has depressed the continental crust so much that in places it is below sea level (Drewry, 1982).

Antarctica is therefore dominated by ice which covers all but $0.33 \%$ of its land surface (Fox \& Cooper 1994). There are also many mountain ranges; by far largest being the Transantarctic Mountains which extend $3500 \mathrm{~km}$ from the coast in Oates Land to the Theron Mountains near the Weddell Sea (Figure 1.2). The second largest range comprises the mountains of the Antarctic Peninsula. Other notable mountain ranges are the Ellsworth Mountains, the mountains of Alexander Island, the Prince Charles Mountains and the mountain ranges in Dronning Maud Land, e.g. the Sør-Rondane Mountains. There are two large ice shelves: the Ronne/Berkner Ice Shelf that occupies the head of the Weddell Sea embayment and the Ross Ice Shelf at the head of the Ross Sea. The Ross Ice Shelf, at 507,727 km² (Fox and Cooper, 1994), is slightly larger than Spain $\left(505,370 \mathrm{~km}^{2}\right)$ (CIA 2013). There are several other smaller ice shelves such as the Amery Ice Shelf, the Shackleton Ice Shelf and other fringing ice shelves such as the Brunt and Larsen Ice Shelves. Ice shelves are created from glaciers that coalesce once they reach the sea. The ice is partially attached to the land but floats on the sea. The seaward edge of ice shelves almost invariably forms a line of cliffs, varying in height from about $2 \mathrm{~m}$ to $50 \mathrm{~m}$ (Armstrong et al. 1973). It was the ice front of what is now called the Ross Ice Shelf that James Clark Ross himself described as the Great Ice Barrier (Ross 1969 [1847]). 


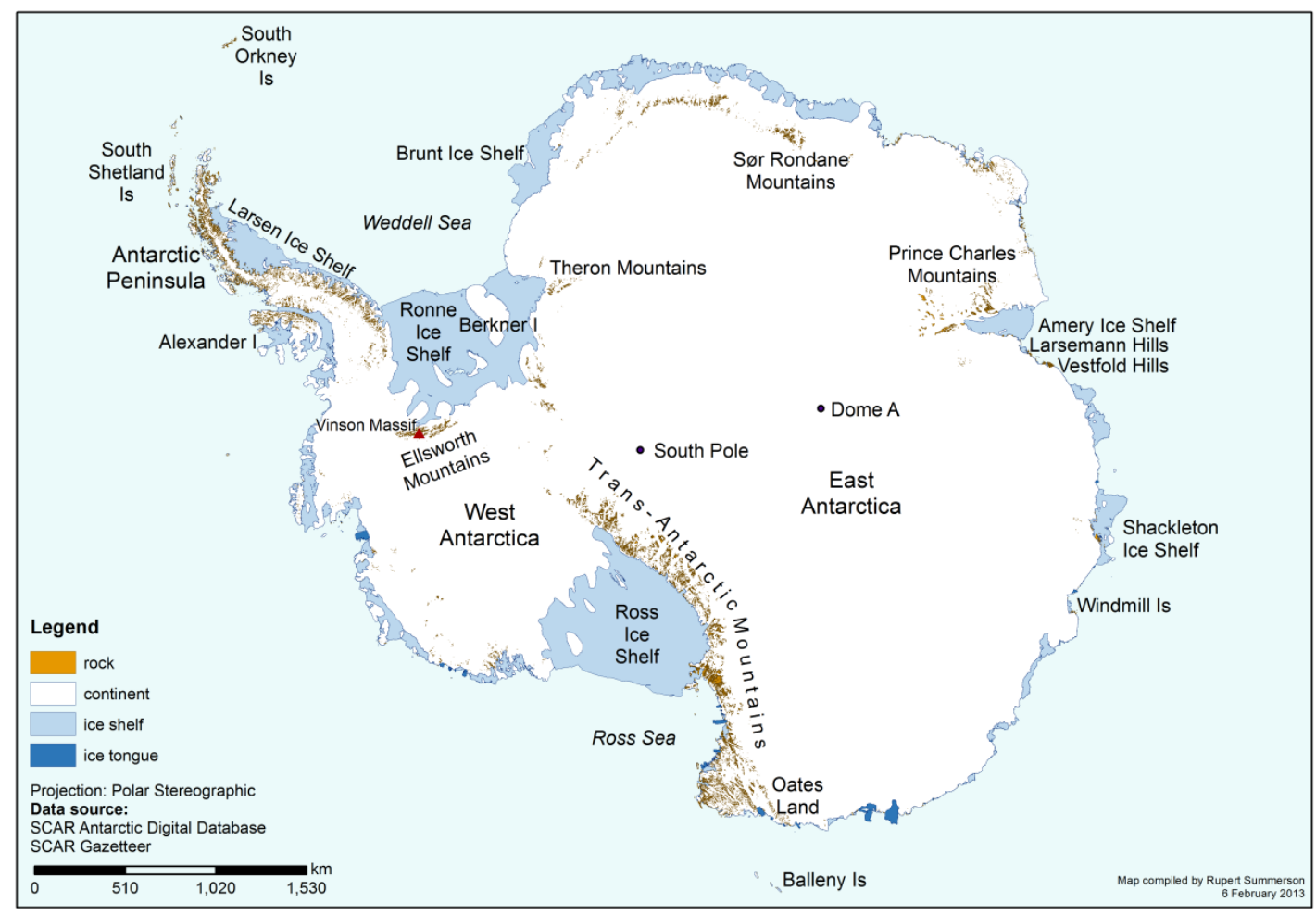

Figure 1.1. The main topographic features of Antarctica.

Aside from mountain ranges, parts of which may be clear of snow or ice, the main ice free areas are to be found along the coast. There are also large numbers of nunataks (isolated rock peaks), which occur both singly and in groups.

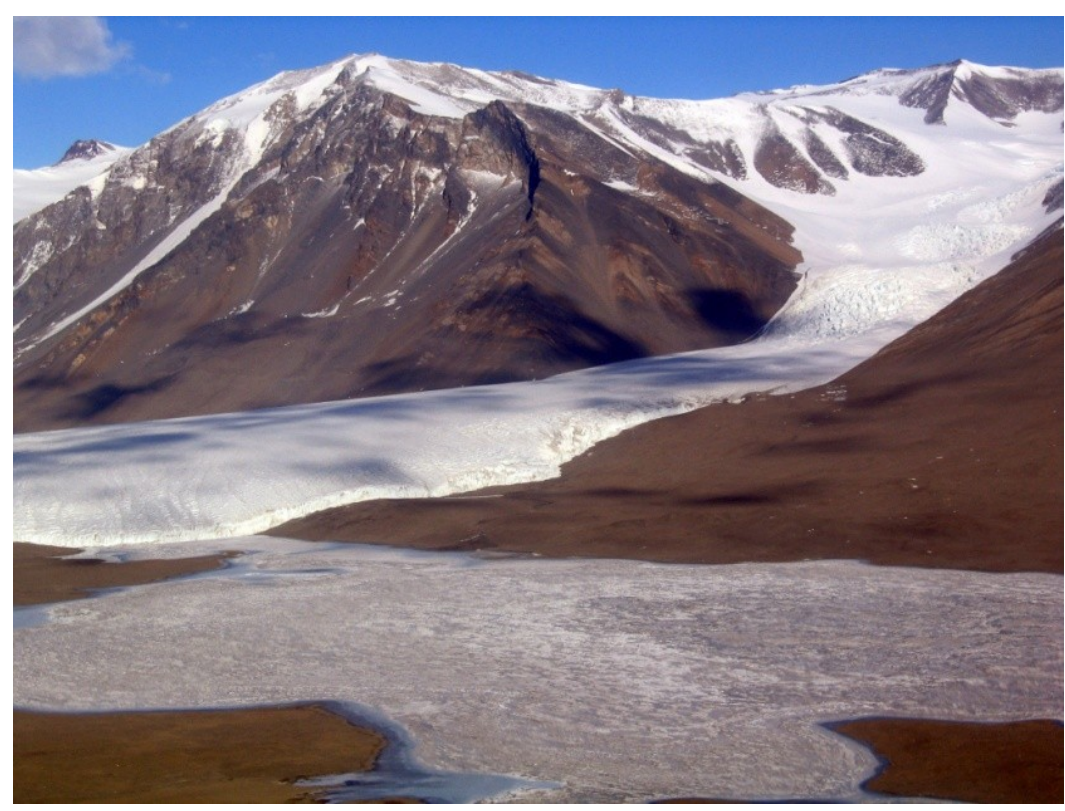

Figure 1.2. Canada Glacier in the Transantarctic Mountains. (Photo: Dave Haney. USAP Photo Library) 
$>99 \%$ of Antarctica is covered by ice (Fox and Cooper 1994) so glacial processes are an important part of the formation of Antarctic topography. Most of the Antarctic ice caps (the largest single ice cap being in East Antarctica) comprise a very low surface gradient and are therefore perceived as being featureless except at a micro-scale where the topography of ice is greatly influenced by the wind, especially the gravity fed katabatic winds (Markov et al. 1970: 333). The wind carves the surface of the ice into wave-like shapes called sastrugi (Figure 1.3).

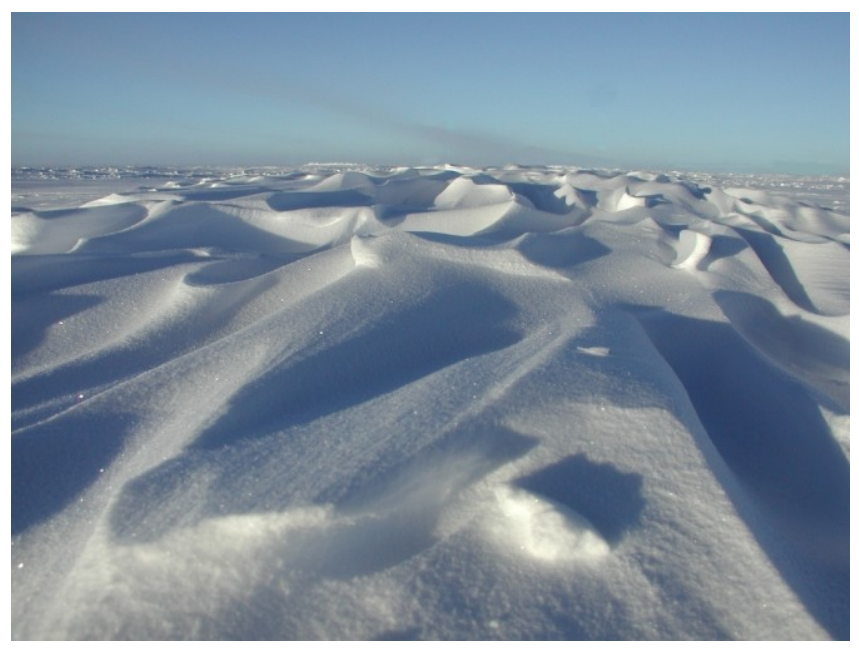

Figure 1.3. Sastrugi carved by the wind. (Photo: Brian Vasel (digitally manipulated to remove distant infrastructure))

The ice flows downhill under its own weight (except where it is trapped in a basin); where it is forced between mountains or sub-surface features the accelerated flow regime is known as a glacier or ice stream. If a glacier or ice stream encounters an obstacle or a change in slope, it often causes the ice to crack forming crevasses or ice falls. Crevasses (Figure 1.4) are cracks in the ice which may be up to 10 metres wide, hundreds of metres long, many 10 s of metres deep and, after a heavy snowfall, utterly invisible thereby representing one of the greatest hazards to travel in Antarctica. 


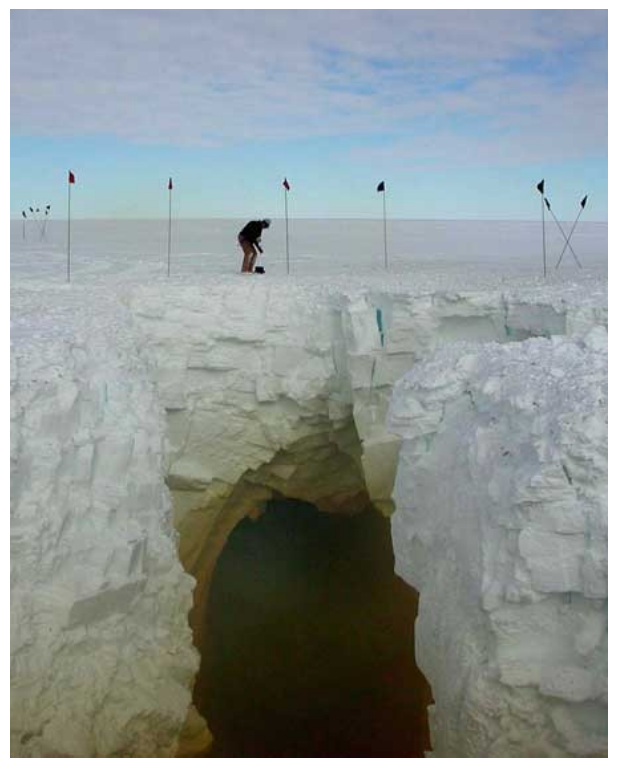

Figure 1.4. Crevasse. (Photo: Russ Alger/CRREL \& USAP Photo Library).

Most of the ice cap eventually disgorges into the sea, forming a coastal fringe of ice cliffs (Figure 1.5). On a late summer's afternoon with the sun glistening on them, rendering them shades of orange, green and blue, ice cliffs are a source of great delight to visitors to Antarctica but wary ships' captains will avoid going too close in case of a sudden calving event, when part of an ice cliff drops off and becomes an ice berg, sometimes generating a damaging large wave. In one recent incident in the Arctic, a tourist ship sailed too close to an ice cliff and a large piece of ice fell onto the deck injuring some of the passengers ${ }^{3}$.

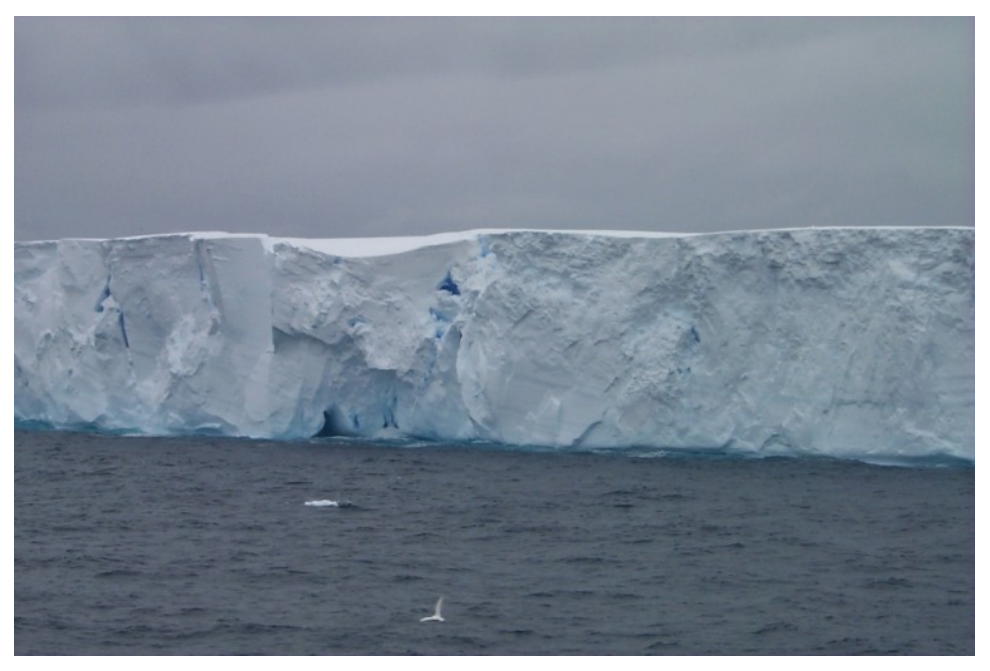

Figure 1.5. Coastal ice cliffs (Rupert Summerson).

\footnotetext{
${ }^{3}$ http://www.telegraph.co.uk/news/worldnews/1559826/British-cruise-tourists-hit-by-glacier-ice-fall.html
} 
A topographic feature that will be discussed extensively is coastal ice free area or "oasis" (Figure 1.6) (Pickard 1986), though as Law and Béchervaise (1957: 16) describe, the term is "quite misleading. They are more accurately described as deserts." By virtue of comprising bare rock next to the sea many Antarctic stations have been built in them.

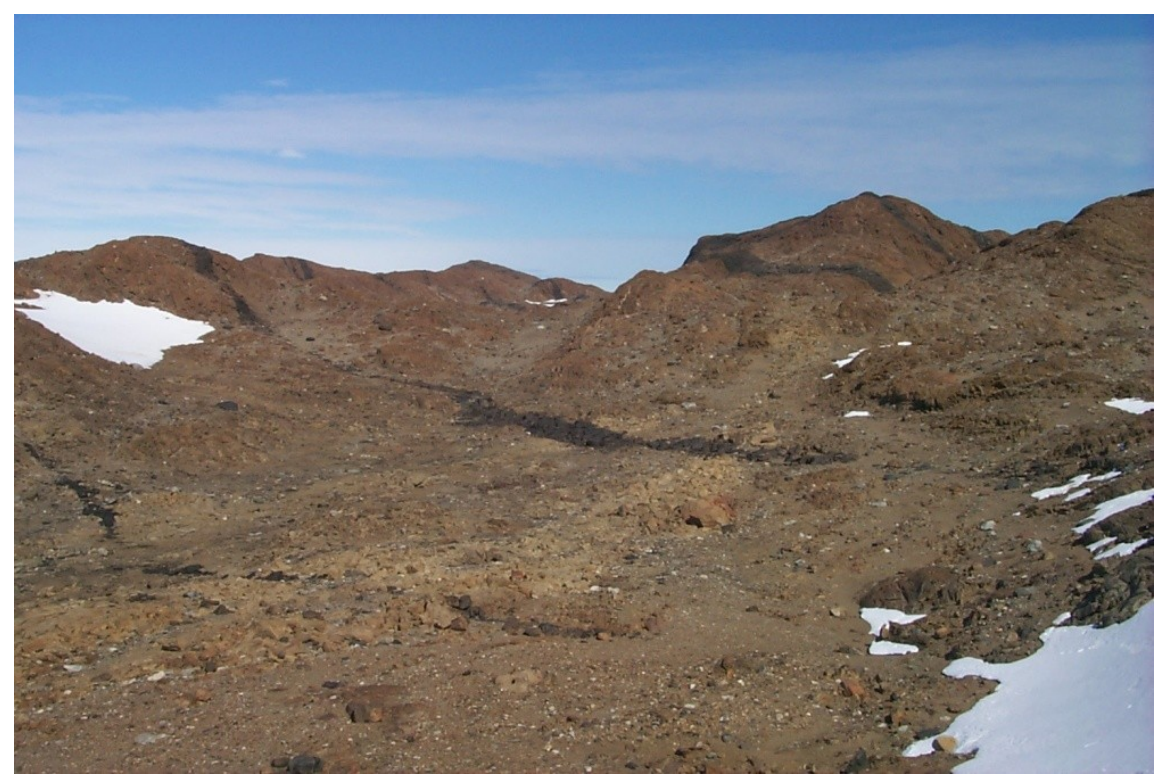

Figure 1.6. Interior of the Vestfold Hills. Davis Station is situated on the coast of the Vestfold Hills. 


\section{Chapter 2. A History of Antarctic Landscape Descriptions}

\subsection{Introduction}

In this chapter I review the history of Antarctic exploration with specific reference to the responses of explorers, scientists and others to the Antarctic landscape. This history is dominated by Europe and the United States as, until the $20^{\text {th }}$ century, that is where most of the expeditions originated. It is not possible to document the writings from every expedition; a selection has therefore been made. As far as possible, bias towards any one nationality or culture has been avoided but European and American accounts naturally predominate until the middle of the $20^{\text {th }}$ century. There are many histories of the early exploration of Antarctica. Headland (2009) lists expeditions in chronological order from the earliest times to the International Polar Years (2007-2009). King (1969), Readers Digest (1985), Fogg and Smith (1990), Gurney (Gurney 1997, 2000), Martin (1996) and others all provide excellent histories. Each has its own focus and bias and none should be recommended over the others. A number of other books and essays analyse human responses to the Antarctic environment: Pyne (1987), Spufford (1996), Lopez (1999) and Fox (2005) are important in this regard.

\subsection{Antarctic literature review}

One avenue of approach to the problem of defining the term "wilderness and aesthetic values" is to research Antarctic literature to find out what it is about Antarctica that has impressed the explorers, scientists and others who have visited it. What can be revealed from the writings of visitors over the past two centuries? While compiling this review, I looked for descriptions of the landscape from the late-eighteenth century to the twentieth century.

There are no indigenous inhabitants of the Antarctic continent (Walton 1987), nor, so far as anyone has discovered to date, have there ever been Antarctic indigenes. All visitors to Antarctica, for whatever purpose, are therefore just that - visitors. The longest continually occupied station in Antarctica is Orcadas, which was established by the Scottish National Antarctic Expedition in 1903 on Laurie Island in the South Orkneys. William Bruce, the expedition leader, gave the station to Argentina as a meteorological station in 1904 and it has operated continuously ever since (Martin 1996).

A brief detour to discuss definitions of Antarctica is necessary. Hince (2000: 6-7) proposes two definitions: the Antarctic continent and the Antarctic regions. The Antarctic continent comprises two large sub-regions, which have been variously termed Greater and Lesser Antarctica, Major and Minor Antarctica or East and West Antarctica (Markov et al. 1970: 327; 
McGonigal \& Woodworth 2001) (Figure 1.1). There are a number of islands in varying degrees of proximity which can lay claim to being Antarctic. Berkner Island $\left(79^{\circ} \mathrm{S} 50^{\circ} \mathrm{W}\right)$ is wholly enclosed within the Ronne Ice Shelf, while Alexander Island $\left(71^{\circ} \mathrm{S} 70^{\circ} \mathrm{W}\right)$ is attached to the Antarctic Peninsula by the George VI Ice Shelf. Both islands have characteristics indistinguishable from the continent nearby. Even islands further away from the continent, such as King George Island $\left(62^{\circ} \mathrm{S} 60^{\circ} \mathrm{W}\right)$ and the Balleny Islands $\left(68^{\circ} \mathrm{S} 165^{\circ} \mathrm{E}\right)$ maintain permanent snow and ice at sea level, which is a defining characteristic of Antarctic regions. The Antarctic Circle, the line of latitude at which the sun does not set at the summer solstice, nor rise above it at the winter solstice, is defined as being at $66^{\circ} 33$ 'S. There are areas of both the Antarctic continent and some offshore islands north of the Antarctic Circle, e.g. King George Island, which have Antarctic characteristics so this is not a useful definition. The area where the Antarctic Treaty applies is all areas south of $60^{\circ} \mathrm{S}$ (Antarctic Treaty, 1960). As this thesis is devoted to issues raised by the Protocol on Environmental Protection to the Antarctic Treaty, hereafter the term Antarctica is applied to the Antarctic Treaty area, i.e. all areas south of $60^{\circ} \mathrm{S}$.

\subsubsection{Early history}

The name "Antarctica" is said to be derived from "Antarktos", a word coined by Aristotle to mean "opposite Arktos" (Fox 2005). Arktos means "bear" in ancient Greek and refers to the constellation the Great Bear that circles the Pole Star in the northern hemisphere night sky.

Headland (2009) and others mention the legend of the voyage of Ui-te-Rangiora, a Rarotongan Polynesian, who is said to have sailed as far south as the sea ice zone. The first recorded crossing of the Antarctic Circle, however, was by James Cook in January 1773. In 1774, after spending the winter in New Zealand, Cook achieved a farthest south of $71^{\circ} 10^{\prime} \mathrm{S}$. Cook never saw the Antarctic continent but one of the great achievements of his voyages was to severely reduce the size of the postulated Terra Australis Incognita. Cook was famously unimpressed by the Antarctic regions, writing:

The risk one runs in exploreing a coast in these unknown and Icy seas, is so very great, that I can be bold to say that, no man will ever venture farther than I have done and that the lands which may lie to the South will never be explored. Thick fogs, Snow storms, Intense Cold and every other thing that can render Navigation dangerous one has to encounter and these difficulties are greatly heightened by the enexpressible horrid aspect of the Country, a Country doomed by Nature never once to feel the warmth of the Suns rays, but to lie forever buried under everlasting snow and ice. (Beaglehole 1974: 431).

Following Cook's explorations and possibly as a consequence of the independence of the United States from Great Britain in 1776, there then followed an era of sealing and, to a lesser extent, whaling in the Southern Ocean. Competition was rife between sealers from the US, Britain and South America. With this hunt for skins and blubber came the exploration of first 
the sub-Antarctic islands and then the extremities of the Antarctic continent. For the next one hundred years huge numbers of fur seals, elephant seals and, later penguins, were taken for their skins and oil from the shores of the sub-Antarctic islands and from the more accessible parts of Antarctica, particularly the Antarctic Peninsula. Scientific exploration took second place behind this rapacious exploitation and much of the new geographical discoveries the sealers must have made was deliberately kept secret to hide new sealing grounds.

In 1819, William Smith discovered the South Shetland Islands, the northernmost Antarctic islands, i.e. islands south of $60^{\circ} \mathrm{S}$. This discovery led to the wholesale slaughter of fur seals in this island group. In the 1820 s, a number of expeditions made some important discoveries, not the least of which was to see the Antarctic continent for the first time. Jones (1982) has analysed the records of three expeditions: Nathaniel Palmer (US), William Smith (UK) and Thaddeus von Bellingshausen (Russia) all of whom laid claim to this honour. Jones awarded the laurel to Bellingshausen who, on 27 January 1820 saw Kronprincesse Märtha Kyst. On 30 January 1820, three days later, William Smith and Edward Bransfield saw the coast of Trinity Peninsula at the northern end of the Antarctic Peninsula. Records of Palmer's observations are scanty but it seems certain that he saw the Antarctic Peninsula in November 1820.

Bellingshausen's descriptions of Macquarie Island and the parts of Antarctica he saw, including the South Shetlands suggest that he shared Cook's outlook. Of Macquarie Island he wrote:

We had supposed that we should find Macquarie Island, like South Georgia, covered with eternal snow and ice, because both are in the same latitude. To our great surprise, we found that Macquarie Island was beautifully green, with the exception of rocky cliffs, which were of a dreary dark colour. (Debenham 1945).

His descriptions of the land he discovered are almost invariably written in plain language, simply describing what he saw. For example, his description of what Jones (1982) proposes is the first sighting of the Antarctic continent is typically unembellished:

The ice towards the south-south-west adjoined the high icebergs which were stationary. Its edge was perpendicular and formed into little coves, whilst the surface sloped upwards towards the south to a distance so far that its end was out of sight even from the masthead (Debenham 1945). (Location 1 in Figure 2.1).

With regards to a passage written the following day:

In the further distance we saw ice-covered mountains similar to those mentioned above and probably forming a continuation of them. (Debenham 1945).

Debenham himself comments: 
This important phrase has also been rendered by different translators as "ice-peaks",

"mountainous ice" and "mountain ranges of ice". There seems little doubt that again they were looking at the rolls of ice-covered land typical of the continental fringe. (Debenham 1945).

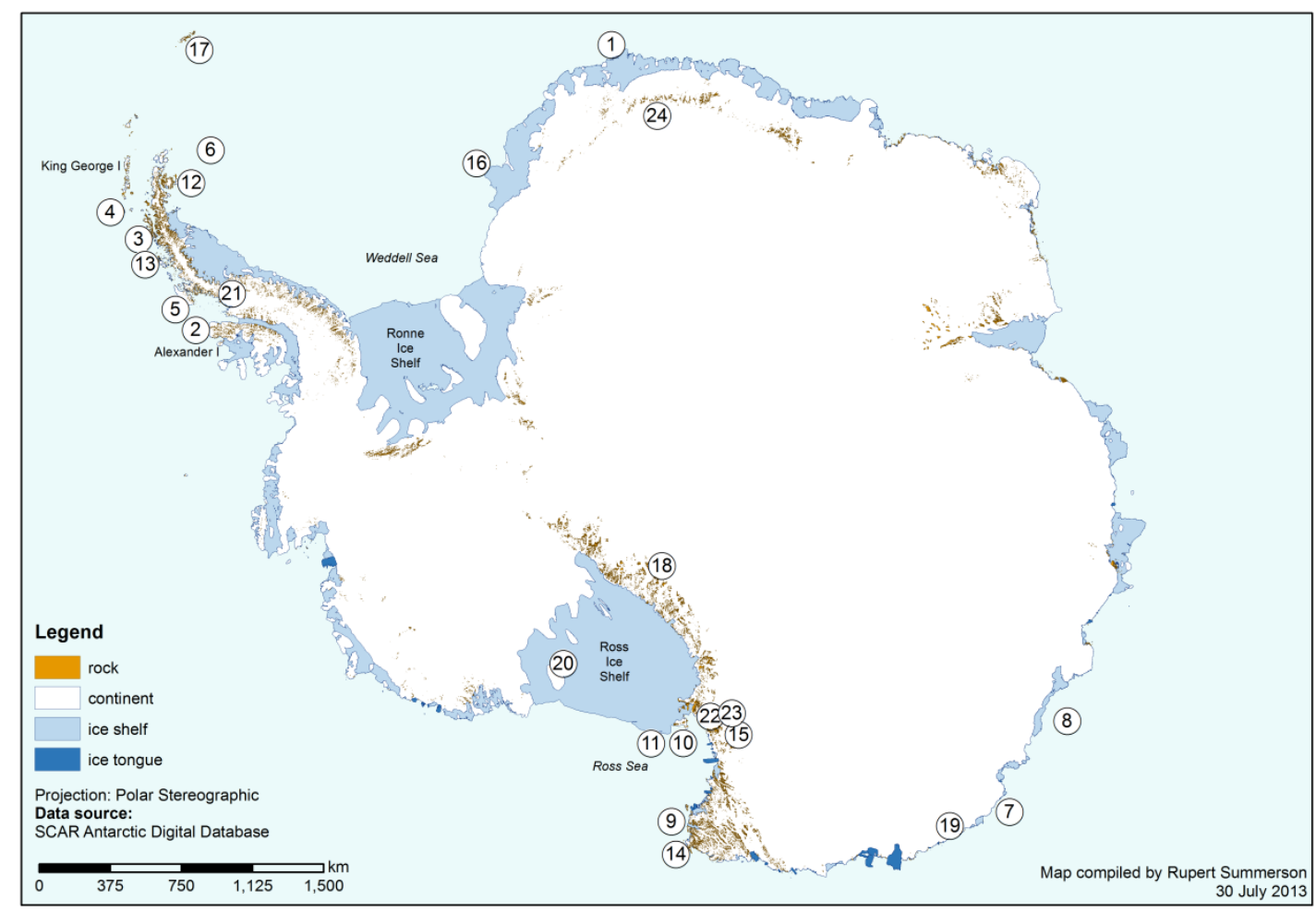

Figure 2.1. The approximate locations where the landscape descriptions quoted were made.

Nonetheless, Bellingshausen was clearly not all dour seafarer. In his description of the discovery of what is now known as Alexander Island $\left(70^{\circ} \mathrm{S}, 70^{\circ} \mathrm{W}\right)$, he wrote:

At 11.0 a.m. we sighted land. One of its headlands stretched to the northward and ended in a high mountain which was separated by an isthmus from another mountain chain extending to the south-west. I advised Mr Lazarev of this. It was the most beautiful day that could have been desired in high southern latitudes. (Debenham 1945). (Location 2 in Figure 2.1).

On 7 February 1821 the American John Davis made a landing at Hughes Bay (64. $01^{\prime}$ S) on the west coast of the Antarctic Peninsula. His log entry for that day was:

Commences with open Cloudy Weather and Light winds a standing for a Large Body of Land in that direction SE at 10 A.M. close in with it, out Boat and Sent her on Shore to look for Seal at 11 A.M. the Boat returned but found no signs of Seal at noon our Latitude was $64^{\circ} 01^{\prime} \mathrm{S}$. Stood up a Large Bay, the Land high and covered intirely with snow ... Ends with Strong Gales at ENE with Cloudy unpleasant weather attended with Snow and a heavy Sea. Concluded to make the Best of our way for the Ship. I think this Southern Land to be a Continent (Stackpole 1955). (Location 3 in Figure 2.1). 
In this laconic entry, we can visualise a large bay, surrounded perhaps with snow-covered mountains, devoid even of seals, the weather thick and snowy. The epitome perhaps of wilderness.

Few of the sealers left written records and observations. In 1822-23, James Weddell, a sealing captain, made a remarkable voyage into the sea which is named after him, reaching an unprecedented high latitude $\left(74^{\circ} 15^{\prime} \mathrm{S}\right)$. He was also one of the few to leave a written account of his explorations (Weddell 1827). Although he did not see the Antarctic continent, Weddell seemed content with his record southing.

After their successful exit from the Weddell Sea, the ships made their way to South Georgia. In many ways South Georgia is similar to the Antarctic Peninsula with a deeply indented coastline and high glacierised mountains. Weddell's description included:

Notwithstanding the forbidding appearance of this land, every one I believe, in the two vessels, feasted his eyes upon it... Our arrival here, though it was not a country the most indulgent, we considered it to be a very happy event.

The tops of the mountains are lofty, and perpetually covered with snow; but in the valleys, during the summer season vegetation is rather abundant. (Weddell 1827)

Weddell used the same adjective, "forbidding", in his description of James Island in the South Shetland Islands. (Location 4 in Figure 2.1). (He named this island after himself as he was the first to have landed on it in 1820. It has since been re-named Smith Island in honour of its first discoverer). Weddell visited this group of islands at least three times during the years $1820-$ 1824 during the peak of sealing activities (Headland 2009: 126, 135, 138), so he must have been reasonably familiar with at least parts of its coasts. "Forbidding" is part of the lexicon of the sublime, the complementary component of landscape appreciation to the beautiful. These two species of aesthetic response were first theorised and expounded by Edmund Burke in 1757 (Burke 1998 [1759]). The beautiful and the sublime and their relevance to Antarctica will be discussed in more detail in Chapter 5.

The gruesome trade of sealing continued through most of the $19^{\text {th }}$ century. The Enderby Brothers were sealing magnates based in London. In addition to their commercial interests, they were also interested in geographic exploration and a number of their captains made important contributions to Antarctic exploration. John Biscoe was one of their captains. During the years 1830 to 1833, Biscoe led an expedition of two vessels, the Tula and the Lively, that circumnavigated Antarctica. In February 1831, he discovered Enderby Land, part of the Antarctic continent in the region of $50^{\circ} \mathrm{E}$. The crews of these two vessels suffered terribly from the cold and the exposure and retreated to Australia, in doing so becoming separated, Biscoe in the Tula making for Hobart and Avery in the Lively arriving at Port Phillip Bay. The following 
season, they continued their circumnavigation, discovering and naming Adelaide Island. Biscoe wrote:

This Island being the farthest known Land to the Southward I have honor'd it with the name of H.M.G. Majesty Queen Adelaide, it has a most imposing and beautiful appearance having one very high Peak running up into the clouds and occasionally appearing both above and below them ... about one third of the Mountains which are about 4 Miles in extent from North to South have only a thin scattering of Snow over their summits ... We could now see high mountains to the Southward, and the West being particularly clear must have been at least 90 miles off (Jones 1992: 74). (Location 5 in Figure 2.1).

This passage is notable in that it seems to be the first recorded instance where a feature of the Antarctic landscape was described as being beautiful but the word "imposing" is the language of the sublime.

The late 1830s and early 1840s saw three major expeditions: the United States Exploring Expedition under Charles Wilkes, a British expedition under James Clark Ross and a French expedition under Jules Sébastien-César Dumont D’Urville. Wilkes' expedition explored over $1600 \mathrm{~km}$ of coastline from about $164^{\circ} 30^{\prime} \mathrm{E}$ westwards to about $98^{\circ} \mathrm{E}$. Dumont D'Urville first explored the northern tip of the Antarctic Peninsula, then, the following year explored a shorter section of the coastline in the same region as Wilkes, what is now called Terre Adelie, indeed their vessels passed each other off the coast of Adelie Land without exchanging greetings. James Clark Ross's expedition discovered the Ross Sea, penetrating as far south as McMurdo Sound, Ross Island and the edge of the Ross Ice Shelf, leading the way for the great terrestrial expeditions of Borchgrevinck and Scott, Shackleton and Amundsen in the late $19^{\text {th }}$ and early $20^{\text {th }}$ centuries. In their second Antarctic season, Ross's expedition made important discoveries at the northern end of the Antarctic Peninsula.

Dumont D'Urville's first attempt to explore the Weddell Sea, in January 1838, was frustrated by solid pack-ice at only $63^{\circ} 23^{\prime} \mathrm{S}$. He wrote about the scenery that it was:

Austere and grandiose beyond words, while stirring the imagination, it filled us with an involuntary feeling of dread; nowhere else can one feel so strongly the sense of his own impotence ... everything threatens man with annihilation... Profound silence reigns over these icy plains and life is only represented by a few petrels, gliding soundlessly, or by whales whose loud, ominous spouting occasional breaks its sad monotony (Rosenman 1992). (Location 6 in Figure 2.1).

This, again, is the language of the sublime: an imposing landscape invoking feelings of dread. This passage is also interesting in its mention of "profound silence". At this point Dumont D'Urville's ships were becalmed at the edge of the pack ice so there would not have been any of the noise that the wind usually makes in a wooden sailing ship. Silence is one of the key characteristics of Antarctica that explorers have repeatedly noticed and described. 
Dumont D'Urville's second season in Antarctica, after over-wintering in Hobart, was more successful, reaching land that he named Terre Adelie. As they approached the coast Dumont D’Urville wrote:

The wind had completely dropped; the sea, flattened by the weight of these enormous masses of ice, was as calm and smooth as a lake. The sun was shining brilliantly, and its rays, reflecting on the crystal walls surrounding us, produced a ravishing and magical effect. (Rosenman 1992). (Location 7 in Figure 2.1).

This passage describes the otherworldliness that many visitors to Antarctica experience. This experience was reinforced on the following day (21 January 1840) when they landed on an island just off the coast at Pointe Géologie. Here Enseigne Duroch, one of the ship's officers, uses the term "sublime" openly.

Never shall I forget the magical spectacle that then unfolded before our eyes ... We are in fact sailing amidst gigantic ruins, which assume the most bizarre forms: here temples, palaces with shattered colonnades and arcades, further on, the minaret of a mosque, the pointed steeples of a Roman basilica ... over these ruins there reigns a deathly stillness, an eternal silence ... Surrounded by this sublime spectacle, our boats, the French flag on the prow glide in. (Quoted verbatim from Rosenman 1992).

The United States Exploring Expedition, led by Charles Wilkes was embroiled in controversy, confusion and dispute from the outset. The expedition, comprising six ships of widely differing sizes and capabilities departed from Virginia in August 1838 making their way first to Orange Harbour in Tierra del Fuego. Here Wilkes divided the expedition into three; two vessels explored the tip of South America, two vessels sailed southwestwards to try and better Cook's record southing of $71^{\circ} 10^{\prime} \mathrm{S}$ and two others headed southwards and explored around the South Shetland and South Orkney Islands. They were late in the season, however, and not much was achieved. They sailed northwards for the winter, exploring the west coast of South America, many Pacific Islands, eventually arriving in Sydney in November 1839 in poor condition. The expedition departed again on 26 December 1839 and headed south, stopping first at Macquarie Island.

On 16 January 1840, land was sighted by the lookouts but there seems to have been some doubt because, as Wilkes wrote:

On this day [16 January 1840] appearances at the time to be land, were visible from all the three vessels and the comparison of the three observations, when taken in connexion with the more positive proofs of its existence afterwards obtained, has left no doubt that the appearance was not deceptive. (Wilkes 1844)

In common with most expeditions of this era, Wilkes was not able to approach close to land and indeed, in the sector where he was exploring, it is now known that the ice cap descends right 
down to the coast and that there are no mountains. While he explored a long stretch of coastline, he did not see much land.

The otherworldiness, that Dumont D'Urville and others had recorded, affected Wilkes also:

These tabular bergs are like masses of beautiful alabaster. (Wilkes 1844).

The time and circumstances under which we were viewing them [icebergs], threading our way through these vast bergs, we knew not to what end, left an impression upon me of these icy and desolate regions that can never be forgotten. (Wilkes 1844).

We had a beautiful and unusual sight presented to us this night: the sun and moon appeared above the horizon at the same time, and each throwing its light abroad. (Wilkes 1844). (Location 8 in Figure 2.1).

There are many atmospheric phenomena that are peculiar to the polar regions and whilst not strictly attributable to the landscape, nevertheless form part of it and make Antarctica seem different to other parts of the world.

The expedition led by James Clark Ross by contrast with that of Wilkes, was well organised, well equipped and led by a highly experienced Arctic explorer, who had a number of experienced officers among his ships crews. Ross had already spent eight winters and fourteen summers in the Arctic. The expedition, whose principal aims were to map the Earth's magnetic field and to determine the location of the south magnetic pole, departed Chatham in September 1839 and made their way via Kerguelen Island to Hobart, arriving there in August 1840. While in Hobart, Ross was able to review some of the results of Wilkes' and Dumont D'Urville's expeditions. These previous voyages forced Ross to explore further to the east which led to the discovery of the Ross Sea. His vessels, Erebus and Terror, were sturdy enough to allow him to penetrate the pack ice beyond which lay open water as far south as the front of what is now known as the Ross Ice Shelf, but which he named the "Great Icy Barrier". Ross' discoveries in the Ross Sea opened the way for the expeditions of Scott, Shackleton, Amundsen and others in the late $19^{\text {th }}$ and early $20^{\text {th }}$ centuries and ultimately to the discovery of the South Pole in 1911. The coastline of the western shore of the Ross Sea is fringed with the mountains of the Admiralty Range that form the northern, or eastern, end of the Transantarctic Mountains. These mountains were Ross' first sight of land, seen on 11 January 1841. "The highest mountain of that range" Ross named Mount Sabine (Ross 1847). Mount Sabine is situated at the entrance to the Ross Sea and, at $3600 \mathrm{~m}$, is the highest in the range. It forms a conspicuous landmark that was frequently remarked on by subsequent expeditions. Later that day, Ross described the scene:

It was a beautifully clear evening and we had a most enchanting view of the two magnificent ranges of mountains, whose lofty peaks, perfectly covered with eternal snow rose to elevations 
varying from seven to ten thousand feet above the level of the ocean. (Ross, 1847). (Location 9

in Figure 2.1).

Four days later, and still apparently describing the Admiralty Range, Ross wrote:

Early this morning we had a fine view of the magnificent chain of mountains we had seen stretching away to the southward some days before, but then more imperfectly. With a moderate southerly wind we had beautifully clear weather, and we now saw them to great advantage; and as we stood towards them, we gazed with feelings of indescribable delight upon a scene of grandeur and magnificence far beyond anything we had before seen or could have conceived. These mountains also were completely covered to their sharply-pointed summits with snow, and the elevation that were measured roughly, varied from twelve to upwards of fourteen thousand feet." (Ross, 1847).

The scene that Ross described clearly made a deep impression on the ships' crews.

"Indescribable delight" suggest a deep emotional response to the landscape and yet, they seem to tend more towards describing a scene of great beauty, rather than one of the sublime. Ross (1994), in his biography of James Clark Ross, commented on this passage and related a description by Cornelius Sullivan, the blacksmith of the Erebus.

My friend if I could only view and Steady the Sublimity of nature - but lo I had to pull the brails $^{4}$. The noble battery of Ice that fortifyd. The land two hundred feet high and floating islands in all directions this Strange Scenery was Remarkably Striking and Grand. The bold masses of Ice that walld. In the Land Rendered this Scene Quite Enchanting. This mountain is most perpendicular mountain in world - we have seen it at night a hundred and fifty miles Distant. (Ross (1994), quoting from a manuscript held at Scott Polar Research Institute, Cambridge (MS 367/22).)

This passage needs some interpreting, which is quite difficult without the original. It is tempting to suggest that "Steady" means "study". The language that Sullivan uses is almost a parody of the language used by Ross, when he used a phrase like "Rendered this Scene Quite Enchanting" but it does appear that he was serious. In either case, the language is of both the beautiful ("enchanting") and the sublime ("striking and grand"). There is no law that says that a scene cannot contain elements of both the beautiful and the sublime.

The discovery of Mount Erebus, a conical mountain nearly 2800m high and an active volcano, yet Ross describes it almost in passing:

With a favourable breeze, and very clear weather, we stood to the southward, close to some land which had been in sight since the preceding noon, and which we then called the "High Island;" it

\footnotetext{
${ }^{4}$ Ropes fitted for trussing or gathering a sail to spill the wind. Burgess, F H. 1961. A Dictionary of Sailing London: Penguin..
} 
proved to be a mountain twelve thousand four hundred feet of elevation above the level of the sea, emitting flame and smoke in great profusion; at first the smoke appeared like a snow drift, but as we drew nearer, its true character became manifest. (Location 10 in Figure 2.1).

The discovery of an active volcano in so high a southern latitude cannot but be esteemed a circumstance of high geological importance and interest, and contribute to throw some further light on the physical construction of our globe. I named it "Mount Erebus", and an extinct volcano to the eastward, little inferior in height, being by measurement ten thousand nine hundred feet high, was called "Mount Terror". (Ross, 1847).

Bill Green, an American limnologist, who has been active in Antarctica over a long period, described Mount Erebus as having

“on this island ... something of the same influence as Japan's Fuji, a constant presence, a thing of wonder" (Green 1995: 198).

Mount Erebus certainly features prominently in the art of Edward Wilson, George Marston and Herbert Ponting during the expeditions of Scott and Shackleton in the early $20^{\text {th }}$ century. Perhaps Ross was overwhelmed by the sheer number and scale of discoveries.

The discovery of the "Great Icy Barrier" seems to have made a deeper impression, perhaps partly because it represented a barrier to sailing farther south and partly because it was nothing like he had ever seen before:

As we approached the land under all studding-sails ${ }^{5}$, we perceived a low white line extending from its eastern extreme point as far as the eye could discern to the eastward It presented an extraordinary appearance, gradually increasing in height, as we got nearer to it, proving at length to be a perpendicular cliff of ice, between one hundred and two hundred feet above the level of the sea, perfectly flat and level at the top, and without any fissures or promontories on its seaward face. What was beyond it we could not imagine; for being much higher than our masthead, we could not see anything except the summit of a lofty range of mountains extending to the southward as far as the seventy-ninth degree of latitude. (Ross, 1847). (Location 11 in Figure 2.1).

After five days sailing to the west, the ships achieved their farthest south, $78^{\circ} 4^{\prime}$ S. They had proved that the "Barrier" was at least two hundred and fifty miles long (presumably nautical miles $=460 \mathrm{~km})$. Ross wrote "extraordinary" about it a number of times, for example:

But this extraordinary barrier of ice, of probably more than a thousand feet in thickness, crushes the undulations of the waves, and disregards their violence: it is a mighty and wonderful object, far beyond any thing we could have thought or conceived. (Ross, 1847).

\footnotetext{
${ }^{5}$ Extra small sails used in light winds. (Burgess 1961)
} 
Such a large, unusual feature as the Barrier must have contributed to the otherworldliness that was becoming typical of Antarctica. A brief aside is warranted at this point. Ross discovered a bay in the Barrier that they were able to sail into and observe the upper surface of the Barrier. Shackleton found the same bay some 67 years later and Amundsen, reading and pondering both Shackleton's and Ross' accounts, concluded that the Bay of Whales, as Shackleton called it, was stable and safe enough to build his base there in 1911, thus placing him $110 \mathrm{~km}$ further south than his rival for the South Pole, Robert Falcon Scott (Amundsen 1912).

At the conclusion of his first Antarctic season's explorations Ross returned to Hobart for the winter and was a guest of Sir John Franklin, the Governor of Tasmania, or Van Diemen's Land, as it was then called. On one of the excursions he made by yacht was to the southern end of the D'Entrecasteaux Channel. Here he remarked:

The shores of the inlet are extremely beautiful - their picturesque and broken outline, and the luxuriance of the vegetation, whose dingy green colour we had now become so accustomed to, as almost to have forgotten the rich and varied verdure of our own forests, impressed the mind with feelings of regret that so charming a country should remain a useless desolate wilderness, although capable of producing an abundance of food for a large population. (Ross 1847).

This passage reveals a number of things about Ross' attitudes to landscape. The first is his concept of the beautiful: an indented coastline and most likely forested. The use of the word "picturesque" implies that it conformed in some ways to the theory of the Picturesque in landscape (see Chapter 5), indeed a "broken outline" is a feature of the Picturesque. His use of the word "wilderness", qualified by the adjectives "useless" and "desolate" is typical of that era. For a detailed description of the history of the word "wilderness" see Chapter 5.

Ross' second season in the Antarctic was less successful than the first in that having chosen to sail southwards to the east of his operations the previous year, the ships became beset in the pack ice for 56 days. At one stage they were subjected to a gale in the pack-ice. Ross wrote:

... our ships still rolling and groaning amidst the heavy fragments of crushing bergs, over which the ocean rolled its mountainous waves, throwing huge masses one upon another, and then again burying them deep beneath its foaming waters, dashing them and grinding them together with fearful violence. The awful grandeur of such a scene can neither be imagined nor described, far less can the feelings of those who witnessed it be understood. (Ross 1847).

While this passage has nothing to do with Antarctic landscape, it nevertheless contributed to the aura of danger surrounding Antarctica and the heroism of those who explored it.

Ross' third Antarctic season was embarked upon after wintering in the Falkland Islands and he directed his efforts to the Antarctic Peninsula and the Weddell Sea, hoping, with his stronger ships to better Weddell's own record southing. On this he was disappointed due to heavy pack- 
ice. He discovered the islands to the east of the northern tip of the Peninsula, including what is now named James Ross Island, Seymour Island and Snow Hill Island. As usual, he scattered names around like colonial confetti. Of 1 January 1843 he wrote:

At this time it was perfectly calm, and we had a most beautiful view of the magnificent mountain which forms the most striking feature of our new discoveries. It was named Mount Haddington, after the Right Honourable the Earl of Haddington, the First Lord of the Admiralty. (Ross, 1847). (Location 12 in Figure 2.1).

It is notable that Ross made no comments about desolation or wilderness regarding Antarctica. Amundsen wrote about Ross' first Antarctic voyage:

What a fairyland this must have seemed to the first voyagers who approached it! Mighty mountain-ranges with summits from 7,000 to 10,000 feet high, some covered with snow, some covered with snow and some quite bare - lofty and rugged, precipitous and wild (Amundsen 1912).

\subsubsection{The Heroic Age}

The so-called Heroic Age of Antarctic exploration covers roughly the period from the late 1890 s to the early 1920 s. I propose that the era covers the period from the first expedition to overwinter in the Antarctic, that of the Belgica expedition, that entered Antarctic waters in 1898 to the death of Sir Ernest Shackleton in 1922. This is not to say that earlier or even later expeditions were not heroic! There were seventeen Antarctic expeditions during this era (Rosove 2001). The literature of this period is immense; the primary narrative literature, written by those who took part in these expeditions, nearly reaches 50 volumes, and that does not include publications of diaries, etc, long after the event (Rosove, 2001). The secondary literature is probably ten times that number with the expeditions of Scott and Shackleton coming under particular and continuing scrutiny; there have been biographies of both leaders within recent years (Fiennes 2003; Riffenburgh 2004). There is also a large body of scientific literature with each expedition publishing series of reports. The Australasian Antarctic Expedition (1911 - 1914), for example, eventually produced 91 scientific reports (Rosove, 2001).

It is outwith the scope of this thesis to analyse the landscape responses by every individual on every expedition. In this section, therefore, I confine my analysis to two regions: the Antarctic Peninsula and the Ross Sea. The northern end of the former is now the most popular destination for tourist cruises and is, by any measure, very beautiful. The latter is also a tourist 
destination but, being further away from the "gateway" ports ${ }^{6}$ (Rubin 1996), is less frequently visited.

The era opened with the voyage of the Belgica under the command of Adrien de Gerlache from Belgium. The Belgica sailed from South America in January 1898 and explored the west coast of the Antarctic Peninsula as far south as Alexander Island before becoming trapped in the pack-ice where it remained for the duration of the winter of 1898 . There are three accounts of this expedition, the best known being that of Frederick Cook (Cook 1900). Cook was the expedition doctor and even though he was later denounced as a charlatan for claiming that he had been the first to climb Mt McKinley in Alaska and reach the North Pole, he was liked and respected by the crew of the Belgica (Reader's Digest 1985). The expedition's discoveries were, in the main, confined to small-scale discoveries along the west coast of the Antarctic Peninsula, such as the discovery of the Gerlache Strait, which is the channel between Brabant and Anvers Islands and the mainland and clarifications of the discoveries by Eduard Dallmann, a German sealer operating in the area in 1873-4.

Perhaps the most notable feature on the west side of the Peninsula is the Lemaire Channel, a narrow waterway between Booth Island and the mainland. It was first discovered by Dallmann but as there is no first-hand account of this expedition, the first description is by de Gerlache. It is not clear whether Dallmann sailed the length of the Lemaire Channel; it was named by de Gerlache (after a Belgian explorer of central Africa). Curiously for such a remarkable feature, Cook does not mention the traverse through the Channel in his book. De Gerlache described it as follows:

12 February, after having rounded the superb Cape Renard we came near this remarkable point which marks the exit of the channel to the Pacific and made the 20th and last landing. Then we enter the Lemaire Channel which separates Danco Land from the Dannenbrog Islands (thus named in recognition of the support that the Expedition had found in Denmark). The channel is about three quarters of a mile wide, ice-free and flanked by sheer cliffs at the foot of which were, here and there, small flat glaciers. It is safe but its exit into the South Pacific is hampered by reefs between which we must commit ourselves to make our way offshore and on which the swell of the ocean breaks with a crash.

After having fortunately crossed reefs travelling if delicate access the Pacific by the Lemaire channel, we continue southwards and sail as close as possible to the coast where the pack which defends it permits (de Gerlache 1902). (Location 13 in Figure 2.1).

\footnotetext{
${ }^{6}$ Gateway ports are principally Ushuaia (Argentina), Punta Arenas (Chile), Stanley (Falkland Islands), Cape Town (South Africa), Hobart (Australia), Bluff and Lyttelton (New Zealand).
} 
It seems that, from this passage, de Gerlache was more concerned about navigating the Channel safely than admiring its aesthetic qualities. Contrast his terse description with that in an Antarctic tourist guidebook:

This features on most Antarctic cruises which visit the Peninsula side of the continent and it must rank as one of the most photogenic places on the planet. Have plenty of film in your pocket when you go out on deck for this. (Wheeler 1997)

The first expedition to overwinter on the Antarctic continent was led by Carsten Borchgrevink, an expatriate Norwegian living in Australia. Borchgrevink was not popular in England as he undermined Sir Clements Markham's attempts to mount a much grander expedition, nor was he popular with his own men and his writing style in the official account of the expedition (Borchgrevink 1901) did nothing to make up for these deficiencies. Louis Bernacchi, the expedition's physicist, wrote his own account which is much more engaging and descriptive.

It was nearly midnight when Mr Hugh Evans and I commenced the ascent of Cape Adare. The light was still fairly strong at the time, nor was the temperature at all low. By following a ridge of craggy rocks we found the climbing tolerably easy and reached the top in less than an hour. We were thus the first human beings to set foot on the summit of South Victoria Land, and we felt full compensation for our climb.

The scene before us looked inexpressibly desolate. A more barren desert cannot be conceived, but one of immense interest from a geological point of view.

From the end of the Cape to the foot of the mountain range beyond, a great waste of hollows and ridges lay before our eyes; ridges rising beyond ridges like ocean waves, whose tumult had been suddenly frozen into stone. Beds of snow and ice filled up some of these extensive hollows, which had been scooped out by glacier action.

The prospect from where we were was extensive, but scarcely beautiful. Down at our feet lay the sea, almost free of ice-pack. Huge stranded icebergs, defying the power of the solar beams, were visible in various directions along the coast. Behind us lay the great Antarctic Land; snow peaks rising beyond one another until by distance they dwindled to insignificancy. The silence and immobility of the scene was impressive; not the slightest animation or vitality anywhere. It was like a mental image of our globe in its primitive state - a spectacle of Chaos.

Around us ice and snow and the remnants of internal fires; above, a sinister sky; below the sombre sea; and over all, the silence of the sepulchre! (Bernacchi 1991 [1901]). (Location 14 in Figure 2.1).

Sir Clements Markham was ultimately successful in mounting a large-scale British expedition. The National Antarctic Expedition (the "Discovery" expedition), led by Commander Robert 
Scott had multifarious aims, both exploratory and scientific. It departed Britain in the Discovery in August 1901 and eventually reached winter quarters at Hut Point on Ross Island in March 1902. The ship was frozen in for two winters before being released from the ice in February 1904. It would be difficult to overestimate the achievements of the expedition. The expedition reached a new furthest south record of $82^{\circ} 16^{\prime} \mathrm{S}$ after a long sledging journey across the Ross Ice Shelf, but that was only one of many sledging journeys undertaken during the expedition; another reached the polar plateau after ascending the Ferrar Glacier and the first of the Dry Valleys was discovered. The expedition produced more than 80 scientific reports across a range of disciplines including geology, biology, geophysics and meteorology. (Rosove, 2001). The expedition laid the groundwork for a number of subsequent expeditions including Ernest Shackleton's expedition in 1907 and Scott's own later expedition in 1912.

The expedition's first landing in Antarctica was at Cape Adare, the scene of Bernacchi's observations above. Scott wrote:

The scene in the bay after we had returned for our late evening meal was very beautiful; the surface was calm and placid, beyond it the sunlight fell on the bold peaks and splendid glaciers of the Admiralty Range, the sharp summits of Mounts Minto and Adam were well defined against a clear sky, whilst the lofty peak of Sabine was lost in a mystery of fleecy cloud (Scott 1905). (Location 14 in Figure 2.1).

On a page headed "Scenic Grandeur" Scott wrote:

To describe the wildly beautiful scene that is about us tonight is a task that is far beyond my pen. Away behind us is the gorge by which we have come; but now above and beyond its splendid cliffs we can see rising fold on fold the white snow-clad slopes of Mount Lister. Only at the very top of its broad, blunt summit is there a sign of bare rock, and that is 11,000 feet above our present elevated position; so clear is the air that one seems to see every wrinkle and crease in the rolling masses of névé beneath (Scott, 1905). (Location 15 in Figure 2.1).

On the other side of Antarctica the Scottish National Antarctic expedition (1903-1904) established a base on Laurie Island in the South Orkney Islands. At the end of the expedition, the base was handed over to Argentina and it has been continually operated as a meteorological station ever since. The expedition explored the South Orkney Islands and discovered the eastern shore of the Weddell Sea, which they named Coats Land, after their principal sponsor. Coats Land appeared to be another ice shelf like the Great Ice Barrier discovered by Ross.

To the south lay the Great Barrier, sublime and mysterious, inclining one to be in pensive mood brooding over its awful silent loneliness ... (Brown et al. 1906). (Location 16 in Figure 2.1). In an earlier passage, written as the ship was first exploring the South Orkneys, Rudmose Brown wrote: 
The scene about us is the same as we have seen for many a day, and shall see for many a day to come - a scene so wildly and awfully desolate that it cannot fail to impress one with gloomy thoughts.

All early records of these islands mention the bleak and forbidding appearance they have; Weddell even speaks of their "terrific appearance," comparing them unfavourably to other Antarctic islands. But polar scenery is always forbidding in the usual grey weather which seems to predominate in these regions; though in fine sunny days, which we sometimes had, I can imagine nothing more perfectly beautiful than the glittering snow-tipped ranges rising in a sea of peaks into the blue sky, perhaps with its veil of soft fleecy clouds, while around one on the sealevel runs a line of azure-blue ice-cliffs, clear cut or crumbling into fairy caverns, or on the verge of tumbling in huge titanic blocks on to the undulating plain of sea-ice stretching to the horizon. Far out to sea that plain is broken here and there with monster icebergs, firm prisoners until the gales and waves of spring release them.

Little rock was to be seen at most seasons but in sheer precipices. It was only in summer that all along the shore-line, where glaciers did not meet the sea, rocks made their appearance, some greeny grey with lichen, and others brilliant orange. Too often all was shadowed in the gloom of grey skies or mist or snow, a weary and depressing landscape, it is true, and one that made me often long for some colour - any colour - to rest my eyes upon; then the black hull of the ship was a delightful relief, or still better, the bright red of Copeland Observatory. The evening and early morning colours are not for a pen to describe: it requires the magic touch of an artist's brush to paint those deep violets on the ice-floe at evening, or the delicate blush o'erspreading the snowy ranges at sunset, or still more, those amazing skies which, tinged with every colour of the rainbow, are one of the greatest wonders of the Antarctic, - itself a world of wonders, - and of which it is so difficult to convince the unseeing and unimaginative of the reality. There is, I feel sure, no region in the world more grand in its scenery than the Antarctic, and no place more transcendent in its beauty. It is a vast wonderland laid out on a vast scale, in which littleness has no place; but its very vastness, no less than its beauty, while it quickens the traveller's daily wonder and deepens his reverence, forces him to feel that it is a world he can never conquer, a world in which the forces of nature are too tremendous to overcome, and must resignedly be bowed before in the hope that they will suffer him to come and pass again unscathed (Brown et al. 1906). (Location 17 in Figure 2.1).

This is one of the most descriptive passages about the Antarctic landscape in the whole of the Heroic Age literature and it traverses the gamut of the aesthetic from the beautiful to the sublime. The influence of weather on how the landscape is perceived is interesting: in poor weather the description of the landscape is sublime, whereas when the sun comes out the landscape is transformed into beauty. The unreality or otherworldiness of Antarctica is also stressed. Finally, the vast scale makes humans seem puny and insignificant. 
Roald Amundsen had originally planned an expedition to the North Pole but when he heard that both Cook and Peary had achieved it, he decided on a change of plan and shifted his focus to the South Pole instead. His ship, Fram, departed Norway in August 1910 arriving at the Bay of Whales in the "Barrier" (the Ross Ice Shelf) at the head of the Ross Sea in January 1911. The late part of the summer was spent establishing depots on the Barrier as far south as $82^{\circ} \mathrm{S}$. Amundsen chose a route due south from his base which would take him across unknown terrain. He anticipated encountering the Transantarctic Mountains but did not know if it would be possible to find a route through them. His party arrived at the South Pole on 17 December 1911. The route could be considered as having three parts: the traverse of the Barrier, the ascent (and descent) through the mountains and the traverse of the polar plateau between the mountains and the pole itself.

It was a grand and imposing sight we had when we came out on the ridge under which - far below - our tent stood. Surrounded on all sides by huge crevasses and gaping chasms, it could not be said that the site of our camp looked very inviting. The wildness of the landscape seen from this point is not to be described; chasm after chasm, crevasse after crevasse, with great blocks of ice scattered promiscuously about, gave one the impression that here Nature was too powerful for us. ...

It was not without a certain satisfaction that we stood there and contemplated the scene. The little dark speck down there - our tent - in the midst of this chaos, gave us a feeling of strength and power.

The altitude was 8,960 feet above the sea. The sun was now in the west, and shining directly upon the huge mountain masses. It was a fairy landscape in blue and white, red and black, a play of colours that defies description....

Mount Nilsen - ah! anything more beautiful, taking it all together, I have never seen. Peaks of the most varied forms rose high into the air, partly covered with driving clouds. Some were sharp, but most were long and rounded. Here and there one saw bright, shining glaciers plunging wildly down the steep sides, and merging into the underlying ground in fearful confusion. But most remarkable of them all was Mount Helmer Hanssen; its top was as round as the bottom of a bowl, and covered by an extraordinary ice-sheet, which was so broken up and disturbed that the blocks of ice bristled in every direction like the quills of a porcupine. It glittered and burned in the sunlight - a glorious spectacle. There could only be one such mountain in the world, and as a landmark it was priceless. (Amundsen 1912). (Location 18 in Figure 2.1).

The second expedition led by Captain Robert Scott achieved legendary status in British imperial mythology. After being beaten to the South Pole by Roald Amundsen by almost exactly a month, Scott's five-man polar party perished on the return journey. The circumstances and manners of their deaths and the diaries they left behind ensured their place in polar history. As 
with most expedition narratives, the emphasis is mostly on what was achieved and the hardships endured by the expedition members. The following passage is therefore unusual:

Thursday, February 2. [1911]

Impressions

The eternal silence of the great white desert. Cloudy columns of snow drift advancing from the south, pale yellow wraiths, heralding the coming storm, blotting out one by one the sharp-cut lines of the land.

The blizzard, Nature's protest - the crevasse, Nature's pitfall - that grim trap for the unwary - no hunter could conceal his snare so perfectly--the light rippled snow bridge gives no hint or sign of the hidden danger, its position unguessable till man or beast is floundering, clawing and struggling for foothold on the brink.

The vast silence broken only by the mellow sounds of the marching column. (Scott 1913)

Scott had recently arrived in Antarctica and was laying depots in preparation for the next summer's journey to the South Pole. He mentions silence twice as this is clearly an important feature and he mentions two of the hazards of travel in Antarctica: blizzards and crevasses. Having had personal experience of falling into a hidden crevasse is he obviously very much aware of the danger they represent.

On the other side of the continent the members of the Australasian Antarctic Expedition, led by Douglas Mawson, were also suffering their own tribulations. Unlike either of Scott's accounts of the expeditions led by him, Mawson used the word wilderness on a number of occasions, for example:

We had found an accursed country. On the fringe of an unspanned continent along whose gelid coast our comrades had made their home--we knew not where--we dwelt where the chill breath of a vast, Polar wilderness, quickening to the rushing might of eternal blizzards, surged to the northern seas. Already, and for long months we were beneath "frost-fettered Winter's frown". Awed and amazed, we beheld the lone vastness of it all and were mute. Rising out of the flat wilderness over which we had travelled was a mammoth vertical barrier of rock rearing its head to the skies above. The whole face for five miles was one magnificent series of organ-pipes. The deep shade was heightened by the icy glare beyond it. Here was indeed a Cathedral of Nature, where the "still, small voice" spoke amid an ineffable calm (Mawson 1915). (Location 19 in Figure 2.1).

In the first passage, under the slightly florid and ponderous prose one senses fear. In the second, written by Cecil Madigan who led the East Coast Sledge Journey, the language of the sublime: "awed" and "lone vastness", is again employed. The use of the word "wilderness" in association 
with "still, small voice", itself a quote from the Bible (1 Kings 19:12) gives this passage a biblical feel.

\subsubsection{The Modern Era}

The modern era could be said to have started with the first use of aircraft in the Antarctic. The pioneers were Hubert Wilkins, Richard Byrd and Lincoln Ellsworth, credit for the first flight in Antarctica going to Wilkins, the first flight to the South Pole to Byrd and the first traverse of Antarctica to Ellsworth.

Richard Evelyn Byrd led three Antarctic Expeditions in the 1920s and 1930s. Having first set up his base, Little America, at the Bay of Whales in late 1928, in November 1929 he and his air crew became the first people to fly over the South Pole. Byrd's second expedition returned to Little America in 1934 and in that winter Byrd installed himself alone at Bolling Advance Weather Station about 200km south of Little America. His experiences were the subject of one of the most extraordinary books in polar literature. Titled "Alone" and first published in 1938, it is still in print. "Alone" charts Byrd's experiences as he settled into the routine of manning the base. The most luminous passages are at the beginning because, as winter progressed, he became more and more sick with carbon monoxide poisoning, barely surviving the ordeal (Byrd 1939).

This has been a beautiful day. Although the sky was almost cloudless, an impalpable haze hung in the air, doubtless from falling crystals. In mid-afternoon it disappeared, and the Barrier to the north flooded with a rare pink light, pastel in its delicacy. The horizon line was a long slash of crimson, brighter than blood; and over this welled a straw-yellow ocean whose shores were the boundless blue of the night. I watched the sky a long time, concluding that such beauty was reserved for distant, dangerous places, and that nature has good reason for exacting her own special sacrifices from those determined to witness them (Byrd 1939: 124). (Location 20 in Figure 2.1).

At the beginning of this era, geographic exploration was still the prime goal, but as time went on, science replaced exploration as the rationale for mounting expeditions to Antarctica. The culmination of this shift was the International Geophysical Year (IGY) in 1957-58. The international scientific cooperation that had been stimulated by IGY led directly to the establishment of the Scientific Committee on Antarctic Research (SCAR) to continue the work started during IGY. This in turn led to the signing of the Antarctic Treaty in 1959 by the 12 original nations that had participated in IGY. Since then, the number of nations that have signed the Antarctic Treaty has increased to 46, 27 of which are Consultative Parties, i.e. participate in decision making on the basis of their conducting substantial research in Antarctica. The Antarctic Treaty System (ATS) has grown into a large international organisation with a permanent secretariat and several affiliated organisations. The ATS and the 
conventions that have been developed by it, leading to the Madrid Protocol will be described in more detail in Chapter 4. In the years following the signing of the Antarctic Treaty, science became the supreme motivation for mounting operations in Antarctica. Expeditions were mounted by national governments and for the next 40 years scientists and scientific support staff were the most numerous visitors to Antarctica.

Paradoxically, the literature of Antarctica has declined during this era as, despite the greater number of scientists and others working in Antarctica, not so many seemed inclined to write about their experiences. There were, of course, some notable exceptions. Kevin Walton's Two Years in the Antarctic (Walton 1957) has remained a classic. This book describes the renaissance of British Antarctic exploration in the years immediately after the Second World War. As with many accounts, the focus is on the action but he was by no means insensitive to the landscape as the following passage shows:

We were climbing in a group of mountains to the south of Neny Fjord, and the view from the local "Matterhorn" is one I shall never forget. It was calm and bitterly cold, and the air was clearer than I had ever seen it. Forty miles to the south lay the Terra Firma Islands, which had taken us seven days to reach during the previous spring. Sixty-five miles away was Cape Berteaux, beyond which still lay the remains of the crashed aircraft, and right across the horizon stretched the mountainous coastline of Alexander Island, pink and clear in the rising sun. Northwards across the deep shadow of the Graham Land plateau could be seen the base, a manmade cancer in this beautiful land (Walton 1957: 180). (Location 21 in Figure 2.1).

This passage describes a number of features that have come to represent what is typical about Antarctica: the bitter cold, the clarity of the atmosphere giving very clear visibility over long distances and the light and shadow caused by the low sun angle. Walton's comment about the base being "a man-made cancer in this beautiful land" represents the first stirrings of concern about the impact of human activities on the Antarctic environment.

Bill Green is a geochemist who has spent over seven field seasons working in the Dry Valleys in Antarctica. He has written a memoir called "Water, Ice and Stone" (Green 1995) about his work, his life and his experiences in Antarctica. This type of literature is much more unusual than it should be, given the paucity of opportunities.

I wanted to know where the metals had gone, right here, in this one lake, not much larger than Walden, yet intensely and austerely more beautiful; this one lake, in all the world, completely removed from art and commerce and industry, its shores unsettled and unvisited; its howling emptiness in this valley for which "wilderness" is far too tame a word. (p 254) (Location 22 in Figure 2.1).

On the scale of the map, Victoria Land was a mere stitching, a seam and a border. In our work we had hardly touched the prairie vastness of the continent beyond the mountains. Yet that 
vastness had seemed always present to us as power and purity. "A silent and infinite force" ... It was like this, something to which you gave obeisance, out of instinct, out of something deep and primal and unplanned. What lay beyond seemed God-struck, the whiteness and blueness of the earth, its true colours unbrushed, its true sound the sound of wind over ice and water, its true structure the structures of hydrogen and oxygen, linked and bonded and vibrating ... And through these, as through the glass of a cathedral, come intimations of, and longings for, things as yet unnamed; an emotion of one's smallness, of an overwhelming might (Green 1995).

James Gorman is a writer who visited the Antarctic under the auspices of the US National Science Foundation Artists and Writers Program. He wrote a book called "Ocean Enough and Time" (Gorman 1995):

Back home, after the trip was over, friends would ask me if I had loved it - the Antarctic. Not exactly, I would say, trying to tell the truth without poor-mouthing my extraordinary good luck. I found it grim and harsh, I said. It seemed to me a good place to learn how inconsiderate Nature is of human beings. It's a common conceit of modern nature lovers that the world apart from humankind is somehow as beneficent as it was once considered malevolent. It seemed quite clear in the Antarctic that nature is thoroughly and completely indifferent.

That may, in fact, be the point of travelling to places of over-whelming grandeur - the bliss of being ignored. In the presence of cold immensity a traveller can't help but feel finally, blessedly, insignificant, and thus relieved of a host of worries. (Gorman, 1995: 3).

Barry Lopez was also the recipient of a NSF Artists and Writers Program fellowship. Lopez wrote one of the modern classics of the Arctic: "Arctic Dreams" and is well known as a nature writer. His description of his journey to Antarctica, "Informed by Indifference", was published in a book of essays titled "About this Life" (Lopez 1999).

I took several long walks in the Wright and adjacent Taylor Valleys. I did not feel insignificant on these journeys, dwarfed or shrugged off by the land, but superfluous. It is a difficult landscape to enter, to develop a rapport with. It is not inimical or hostile, but indifferent, utterly remote, even as you stand in it. The light itself is aloof.

The dry valleys are breathtakingly beautiful. The air is so clear the eye can fasten effortlessly on the details, the sharp break of shadow creases, in distant mountains, making binoculars redundant. The hues of yellow and brown, the tints of orange and red that elevate the sedimentary rocks above the igneous layers of granite, take the starkness out of the land but do not alter its line, which is bold, balanced, serene. Classic.

The stillness that permeates the valleys is visual as well as acoustical. ...

I had sought this stillness; but unlike the stillness I'd found in similarly austere and deserted regions of the Earth - on the tundra of Ellesmere Island, in the Namib Desert - this stillness had an edge to it. ... 
The only really animate force here is the wind. ...

Whatever one might impute to this landscape, of beauty or horror, seemed hardly to take hold; my entreaties for conversation met almost always with monumental indifference. ... And yet this land informs, some would say teaches, for all its indifference. ...

Over the years, one comes to measure a place, too, not just for the beauty it may give, the balminess of its breezes, the insouciance and relaxation it encourages, the sublime pleasures it offers, but for what it teaches. The way in which it alters our perception of the human. It is not so much that you want to return to indifferent or difficult places, but that you do not want to forget.

If you returned it would be to pay your respects, for not being welcomed (Lopez, 1999: 66-72). (Location 23 in Figure 2.1).

Finally, I have chosen something completely different. "Antarctica on a plate" by Alexa Thomson (Thomson 2003). This is a description of her experiences as a chef at Blue 1, a temporary field camp established in Dronning Maud Land by Adventure Network International, a private company that supports private expeditions in Antarctica. Thomson had no previous experience of Antarctica; indeed she described herself as "five-star-living urban uberfrau". In the following passage Thomson describes her arrival at Blue 1:

It is the realm of Hans Christian Anderson. I am looking at the home of the Ice Queen. I stand at the door and gulp at a panorama of ice and snow. There are mountain ranges to the south that send a shiver of awe through me. Every book on Antarctica emphasises that it is the highest, flattest, driest, coldest...I knew it was the land of extremities but it's one thing to read about it and quite another to bear witness to its blazing frigid perfection. I stand at the exit of the plane and gaze mutely about me.

... There is a clean cold breeze that scalds my nostrils with its freezing touch. I sniff to clear my nostrils and I feel my face tightening with the caress of the icy wind. The air hints of nothing. There are no smells to remind me of civilisation: no traffic fumes, no scent of plants or trees and the vastness has drowned any fuel smells from the plane (Thomson 2003: 54-55). (Location 24 in Figure 2.1).

\subsection{Conclusions}

The inclusion of the protection of wilderness and aesthetic values in the Madrid Protocol was unlikely to be the result of a whim on the part of the Protocol authors and as can be seen from the descriptions reproduced above, visitors rarely leave Antarctica unmoved and unimpressed. The adjectives that have been employed to describe Antarctic landscapes have been used in research to develop concepts of aesthetic responses and to gain further insights into how people respond to Antarctic landscapes; these are described in later chapters. 


\section{Chapter 3. Development of the Madrid Protocol and the origins of the desire to protect wilderness and aesthetic values}

\subsection{Introduction}

As noted in Chapter One, it was the Protocol on Environmental Protection to the Antarctic Treaty, the "Madrid Protocol", that set out the requirement for the protection of the wilderness and aesthetic values of Antarctica. In this chapter I review the development of the Antarctic Treaty and subsequent allied conventions including the Madrid Protocol and its immediate antecedent, the Convention on the Regulation of Antarctic Mineral Resource Activities. The history of political developments in Antarctica during the 1970s and 1980s sheds a great deal of light on why the protection of the wilderness and aesthetic values was included in the Madrid Protocol.

In 1991 the Consultative Parties to the Antarctic Treaty signed the Protocol on Environmental Protection to the Antarctic Treaty. The Protocol was signed in Madrid and thereafter was known as the "Madrid Protocol". The lead up to the signing of the Madrid Protocol had been extraordinary. The Antarctic Treaty Consultative Parties (ATCPs), the nations with "consultative status" at Antarctic Treaty Consultative Meetings (ATCMs) had been working on a new convention in the Antarctic Treaty System on minerals resources since 1982. The new convention, named the Convention on the Regulation of Antarctic Mineral Resource Activities ("CRAMRA") was developed over 12 sessions of Special Antarctic Treaty Consultative Meeting (SATCM) IV (ATS 2012a). The aim of this convention was to protect the Antarctic environment from mineral extraction activities and to resolve issues relating to sovereignty, royalties and liability in the event of mineral extraction proceeding. Discussions about the potential damage from mineral extraction activities had in fact been initiated at ATCM VII in Wellington, NZ in 1972 (ATS 1972). The working assumption amongst ATCPs had been that mineral resource extraction was inevitable so the best way to protect the Antarctic environment was to put in place an environmental protection regime before any resource extraction activities began. ATCPs feared a scramble for mineral riches with disputes over rights that would destroy the Antarctic Treaty System (Auburn 1984: 272-283). Six years later in 1988 the text of CRAMRA was opened for signature at a conference in Wellington. The following year Australia and France broke with tradition instead of adopting the consensus (Heap 1990: 44), declared that they would not sign CRAMRA. They favoured the development of a different convention providing comprehensive environmental protection with a total ban on mining. A flurry of diplomatic activity in an atmosphere of intense public interest and sustained lobbying 
by environmental non-government organisations (e.g. Cook 1990; Herr et al. 1990; Mosley 1986; Suter 1991) took place over the following two years as the new comprehensive environmental protection convention was developed until its signature in Madrid in 1991 (Boyce \& Press 2011; Jackson \& Boyce 2011). There are a number of accounts of the discussions that were held during the period while the minerals resource convention was being developed (e.g. Harris 1984; Vicuña 1983), during the aftermath of the abandonment of CRAMRA and whilst the Madrid Protocol was being developed (e.g. Cook 1990; Herr et al. 1990). There were also large numbers of manifestos written by environmental nongovernmental organisations to bolster their case for the rejection of CRAMRA (e.g. Adams 1990; Brewster 1982; Mosley 1986; Suter 1991). There were also cases presented in favour of CRAMRA (e.g. Beeby 1990; Heap 1990; Law 1990).

\subsection{The Antarctic Treaty}

The origins of the Antarctic Treaty have often been said to lie in the International Geophysical Year (Fogg 1992; Martin 1996), which took place from 1 July 1957 to 31 December 1958 to coincide with a maximum of solar activity (Fifield 1987: 1; Fogg 1992: 168). This was a program of internationally coordinated scientific research, focussed principally on the upper atmosphere. 12 countries $^{7}$ constructed a total of 48 stations in Antarctica to carry out the research. The highly successful international scientific cooperation led directly first to the formation of the Special (later Scientific) Committee on Antarctic Research ("SCAR") and later to the signing of the Antarctic Treaty in 1959, with the Treaty coming into force in 1961 (Fogg 1992: 176). The 12 countries signing the Antarctic Treaty became the 12 Consultative Parties who took on the role of managing human activities in Antarctica.

The Antarctic Treaty comprises 14 articles which can be briefly summarised as follows:

1. Usage for peaceful purposes only

2. Freedom of scientific investigation

3. Exchange of information, personnel and data

4. Territorial claims in abeyance

5. Nuclear explosions banned

6. Treaty area south of $60^{\circ}$

7. Treaty observers and inspections

\footnotetext{
${ }^{7}$ Argentina, Australia, Belgium, Chile, France, Japan, New Zealand, Norway, South Africa, United Kingdom, USA, USSR (now Russia)
} 
8. Jurisdiction over nationals

9. Meetings of Contracting Parties

10. Undertaking to ensure no one acts contrary to the principles of the Treaty

11. Conflict resolution

12. Modification or amendment

13. Ratification

14. Treaty languages

The full text of the Antarctic Treaty is available on the Antarctic Treaty Secretariat website (ATS 1959). The Antarctic Treaty has many admirable characteristics for such a groundbreaking agreement, however measures relating to conservation are restricted to one line in Article IX:

1. Representatives of the Contracting Parties ...shall meet ... at suitable intervals and places, for the purpose of exchanging information, ... measures in furtherance of the principles and objectives of the Treaty, including measures regarding:

f. preservation and conservation of living resources in Antarctica.

Another important feature about the Antarctic Treaty is Article XII, Section 2 (a), which reads:

If after the expiration of thirty years from the date of entry into force of the Antarctic Treaty, any of the Contracting Parties whose representatives are entitled to participate in the meetings provided for under Article IX so requests by a communication addressed to the depositary government (USA), a Conference of all the Contracting Parties shall be held as soon as practicable to review the operation of the Treaty (ATS 1959).

Thirty years from the date that the Antarctic Treaty came into force was 1991. The significance of this date is discussed below. There was widespread misunderstanding about this section in the Antarctic Treaty, especially among the media, as it was (incorrectly) thought that the Antarctic Treaty expired in 1991 (e.g. Ariadne 1987).

\subsection{Agreed Measures for the Conservation of Antarctic Fauna and Flora}

In 1964, three years after the signing of the Antarctic Treaty, the Agreed Measures for the Conservation of Antarctic Fauna and Flora ("Agreed Measures") were signed. As the name implies, the measures agreed on were for the conservation of flora and fauna but, despite the comment by Martin Holdgate (1983) that, at the Second SCAR Symposium on Antarctic 
Biology, held in 1968, it was stated that "three objectives for conservation were implicit in the Treaty and had been developed in part by the Agreed Measures ...", the first of which was "the protection of the landscape, flora and fauna south of latitude $60^{\circ} \mathrm{S} . . . "$, no protection was given to the Antarctic landscape. The Agreed Measures also established the Specially Protected Area system which was later to be continued and expanded under the Madrid Protocol. As Article VIII of the Agreed Measures stipulates:

The areas of outstanding scientific interest listed in Annex B shall be designated "Specially Protected Areas" and shall be accorded special protection by the Participating Governments in order to preserve their unique natural ecological system (ATS 1964).

In the Proceedings volume for the $2^{\text {nd }}$ SCAR Symposium on Antarctic Biology, Holdgate had written:

The objectives of conservation in the Antarctic regions have never been set out clearly, but it is evident in the records of the Antarctic Treaty Consultative Meetings [...], the SCAR Working Group on Biology, the International Whaling Commission and other bodies that the following have been generally recognized:

1. The general protection of the scenic beauty of the Antarctic regions south of $60^{\circ}$ South latitude, and of their birds, mammals and terrestrial and freshwater life.

... (Holdgate 1970: 925)

The change of emphasis from "scenic beauty" to "landscape" is noteworthy and may have related to the context of the first quotation, which was in a volume devoted to Antarctic Resources Policy (Vicuña 1983) in which "scenic beauty" may have sounded trivial.

\subsection{Living Natural Resource Conventions}

The Agreed Measures were followed by the Convention on the Conservation of Antarctic Seals (CCAS), which was signed in 1972 (but did not come into effect until 1978). The purpose of this convention was to establish regulations prior to the anticipated re-commencement of sealing in Antarctica. CCAS was followed by the Convention on the Conservation of Antarctic Marine Living Resources (CCAMLR), which was signed in 1980 and came into force two years later. These conventions are not relevant to the discussion on wilderness and aesthetic values and are only included for completeness. 


\subsection{Development of the Convention on the Regulation of Antarctic Mineral Resource Activities (CRAMRA)}

Ten years earlier, in 1972, at Antarctic Treaty Consultative Meeting VII ${ }^{8}$, the Antarctic Treaty Consultative Parties (ATCP) had opened discussion on the possibility of exploration for minerals in the Antarctic Treaty area:

Noting the technological developments in polar mineral exploration and the increasing interest in the possibility of there being exploitable minerals in the Antarctic Treaty Area; $\cdots$

Recognising that mineral exploration is likely to raise problems of an environmental nature and that the Consultative Parties should assume responsibility for the protection of the environment and the wise use of resources;

Recommend to their Governments that the subject "Antarctic Resources - Effects of Mineral Exploration" be carefully studied and included on the Agenda of the Eighth Consultative Meeting. Recommendation VII-6

Nine years later, at ATCM XI in 1981, a recommendation (XI-1) was put to ATCM governments that included the following statement:

A regime on Antarctic mineral resources should be concluded as a matter of urgency. In 1982 a conference on Antarctic Resources Policy was held at the Chilean Teniente Marsh Station in Antarctica (Vicuña 1983). Over the next six years the subject was discussed at each Antarctic Treaty Consultative Meeting and was the sole focus of 12 sessions of Special Antarctic Consultative Meeting (SATCM) IV (Antarctic Mineral Resources) from June 1982 culminating in the Convention on the Regulation of Antarctic Mineral Resource Activities (CRAMRA) being presented at SATCM-VII in Wellington in 1988.

The process of drafting the text of an international treaty can be a long drawn out one: it took six years to draft CRAMRA. The Antarctic Treaty has been built on consensus so the tradition is that all consultative parties must be satisfied with the contents. During the development of CRAMRA, Christopher Beeby, the chairman of the drafting committee, drew up a revised version of the draft convention after each meeting and circulated it for comment and approval. These drafts became known as the "Beeby drafts" (Joyner 1987). When, finally, the text has

\footnotetext{
${ }^{8}$ Antarctic Treaty Consultative Meetings are numbered consecutively with Roman numerals.

Recommendations arising ACTMs are numbered with the Roman numerals of the ATCM followed by the recommendation number in Arabic numerals, for example XI-1.
} 
been refined to every country's satisfaction, and this is often at the expense of clarity, the treaty (or convention, protocol, etc) is open for signature, usually at a conference and covered by a "final act". The next stage is called ratification and is when each country draws up domestic legislation to enshrine the intent of the treaty. A treaty finally comes into force when a specified number of signatories have ratified it (DFAT 2000). The Madrid Protocol came into force on 14 January 1998 after all the ATCPs that had signed it had ratified it (ATS 1998a). Modifications may be made to the Madrid Protocol at any time by following the procedures laid down in the Antarctic Treaty, otherwise it will remain in force until at least 14 January 2048 (50 years after it came into force) at which time, if any ATCP wishes it, a conference will be organised to review how the Protocol is operating (ATS 1998b).

\subsection{Consultative Parties and Acceding Parties}

During this period other events were taking place that started to shake up the Antarctic Treaty Consultative Parties. The main issue was that of consultative status and the rights of the original 12 Consultative Parties to manage, and, by implication, benefit from any resources discovered and to determine which other countries were to be allowed to join the "club". It was not until 1977 that Poland achieved consultative status, by which time it and six other countries ${ }^{9}$ had acceded to the Treaty but until that point had not been granted consultative status (Auburn 1984: 514; Suter 1991: 23). The issue came to a head in 1982 when Malaysia raised the status of ATCPs at the United Nations, as what became known as "The Antarctic Question" (Tepper \& Haward 2005), challenging the rights of ATCPs to continue to manage Antarctica. With the date that the Antarctic Treaty was scheduled to be reviewed approaching and the prospect of mineral resource exploitation being allowed, there was widespread interest in becoming a member of the Antarctic Treaty "club", in order, it is often presumed, to have a seat at the table when resource negotiations opened (Scully 2011: 37). 18 countries acceded to the Antarctic Treaty during the period 1981 to 1991 , nine of which went on to acquire full consultative status (ATS 2012b). It is not possible to know what the motives were of each country wishing to accede to the Antarctic Treaty and there were other factors such as the break-up of the former Soviet Union, but it seems reasonable to suppose that some countries' newly found interest in Antarctica was motivated at least partly by an interest in Antarctica's mineral resource potential.

\subsection{Origins of the phrase "wilderness and aesthetic values"}

The protection of "aesthetic or wilderness values" was included in the final draft of CRAMRA (ATS 1988). It is mentioned three times:

\footnotetext{
${ }^{9}$ Brazil, Czechoslovakia, Denmark, Netherlands, Romania, East Germany
} 
In the Preamble:

The States Parties to this Convention, hereinafter referred to as the Parties:

Recalling the provisions of the Antarctic Treaty;

Noting the unique ecological, scientific and wilderness value of Antarctica;

HAVE AGREED as follows:

In Article 2:

Objectives and General Principles

3. In relation to Antarctic mineral resource activities, should they occur, the Parties acknowledge the special responsibility of the Antarctic Treaty Consultative Parties for the protection of the environment and the need to:

(d) respect Antarctica's scientific value and aesthetic and wilderness qualities;

And in Article 4:

Principles concerning judgments on Antarctic mineral resource activities

2. No Antarctic mineral resource activity shall take place until it is judged, based on upon assessment of its possible impacts on the Antarctic environment and on dependent and on associated ecosystems, that the activity in question would not cause:

(e) degradation of, or substantial risk to, areas of special biological, scientific, historic, aesthetic or wilderness significance.

It seems reasonable to conclude that if these values were deemed to be important enough to warrant protection in a convention devoted to regulating mineral resources activities, they would also be important enough to be included in a convention (or protocol) devoted to comprehensive environmental protection.

Whence did impetus to protect these values originate? Beeby (1983) makes no mention of such values nor is there any mention of them in what might be conceived of as the commissioning document for the development of the minerals convention (Recommendation XI-1 of ATCM XI 
(1981)), which recommended, amongst other things that a Special Consultative Meeting be convened, which became SATCM IV (ATS 2012a). SATCM IV Session 1 met in June 1982.

At ATCM XII, however, Recommendation XII-3 (Canberra, 1983) reads:

\section{MAN'S IMPACT ON THE ANTARCTIC ENVIRONMENT}

The Representatives, ...

Recommend to their Governments that:

3. through their National Committees, they invite the Scientific Committee on Antarctic Research (SCAR) to offer:

(i) scientific advice regarding the definition of categories of research and logistic activity in Antarctica which might reasonably be expected to have a significant impact on the environment.

(ATS 1983)

The result of this was a report titled Man's Impact on the Antarctic Environment: a procedure for evaluating impacts from scientific and logistic activities (Benninghoff \& Bonner 1985). This report was published by SCAR as a glossy pamphlet and was widely distributed. Both wilderness and aesthetic value are discussed throughout the report. The following are some extracts:

The Antarctic is the epitome of wilderness, yet it has contributed much to human welfare through the scientific discoveries made there. Continued use of the Antarctic, especially if increased, could erode or destroy some of the natural qualities of this unspoilt wilderness unless special care is taken to avoid or reduce the effects of new activities. (p 3)

Wherever Man's activities impinge on natural systems, the wilderness included, a management plan and regimen are necessary to keep degradations of the natural condition to a minimum. For wilderness ecosystems, scientific knowledge and continuing investigation are essential to guide national and international policies and activities. (p 18)

In practice, some impact assessments deal with environmental problems although they clearly do not involve living organisms other than Man (e.g. ... degradation of the aesthetic values of landscapes). (p 19)

Degradation or defacing of natural features and landscapes, thereby decreasing their aesthetic values, as by painting rocks or permitting 'urban sprawl' of stations, or by the storage and/or disposal of wastes. (p20).

Although the aesthetic and tourist (recreational) value of the Antarctic continent's vast wilderness should not be overlooked, the continent's prime value is as a unique source of information that it continues to provide in areas of geophysics, geology and biology useful to all of mankind. (p21). 
Another impact, which lies outside the biologically-centred definition used in this report, concerns man-made features, which although biologically neutral, are aesthetically intrusive. The proliferation of such features should be subject to review. ( $\mathrm{p} 45$ )

... The terrestrial Antarctic is a very different matter as, unlike the marine system, it has not been subject to resource exploitation. It is the world's greatest wilderness and the ultimate in cold environments that are both natural and accessible. (p 50) (Benninghoff and Bonner, 1985).

At least one of the authors had already formed views that were sympathetic to wilderness and aesthetic values some time before this report was published. Benninghoff (1974) wrote that:

"Stepping still farther from my own speciality, I would hazard the opinion that we are ready to raise esthetic qualities of landscapes into our valuation lists. Polar landscapes in their natural states seldom fail to impress their beholder; therefore they might have intrinsic esthetic value. This value might be expected to increase as the wilderness areas of lower latitudes undergo the continuing attrition and damage that shows no sign of slackening.” (Benninghoff 1974: 97).

It is only fair to state that he went on to express the view that signs of limited human habitation in wilderness areas increased their aesthetic value; a view that is not now universally shared.

The SCAR report was pre-dated by another report by the SCAR Working Group on Biology Conservation Subcommittee: A Visitor's Introduction to Antarctica and its Environment

(Bonner et al. 1986). The report begins:

Introduction

Antarctica, the last continent to be explored and exploited - the continent about which still least is known - has many unusual, interesting and beautiful features (p1).

Conservation in the Antarctic

The need for conservation is probably be better understood today than ever before. The pressure of increasing human populations on the environment has produced a general awareness of the value of unspoilt nature or wilderness. The last remaining extensive wilderness is the Antarctic.

The continent used to be protected by its remoteness and inaccessibility but now, technological advances have enabled increasing numbers of visitors to penetrate it. Some come as members of scientific expeditions, some as tourists wishing to visit an area unique both in its scenery and wildlife. Most, if not all, will value their stay in the Antarctic for the way in which it brought them in contact with nature at its simplest and most imposing.

But life in the Antarctic has to contend with some of the world's harshest environments, and is pressed to its limits without the added stress that can be imposed by man. If those who seek the wilderness are not to destroy what they search for, some controls based on an understanding of the system and a respect for its components are essential. 
The Antarctic is not totally unspoiled and pristine, though it is more nearly so than any other equivalent area of the world's surface. Man's influence is most apparent at the scattered scientific stations and sites of intensive research. The construction and operation of stations, with the associated problems of waste disposal, energy generation, transport and resupply, present an obvious threat to the nature and the aesthetic value of the environment (p 30). (Bonner et al., 1986)

It seems highly likely that this report, written by two highly respected Antarctic scientists, published by SCAR during the development of the minerals convention and widely distributed would have been very influential. I contend that it may well have been the origin of the inclusion of wilderness and aesthetic values as values to be protected. The words of Martin Holdgate (Holdgate 1970) should also be recalled in that it was said that the objectives of conservation implicit in the Antarctic Treaty itself included protection of the scenic beauty of the Antarctic Regions.

\subsection{Development of the Madrid Protocol}

It seems likely that the stimulus to protect wilderness and aesthetic values in Antarctica probably arose from the SCAR publication Man's impact on the Antarctic environment (Benninghoff \& Bonner 1985) and that these were enshrined in the text of CRAMRA.

At the Special Antarctic Treaty Consultative Meeting in Wellington in 1988 CRAMRA was signed but in August of the following year both France and Australia announced that they would not ratify it. The next two years saw frenetic activity as Australia and France sought to influence the other ATCPs. It is beyond the scope of this chapter to analyse the reasons behind France's and Australia's decision to abandon CRAMRA. Bob Hawke, Australia's Prime Minister at the time, gave his reasons:

For all the strength of natural forces at play there, the Antarctic environment is paradoxically fragile. Upsetting this delicate balance could threaten changes that would alter the world in quite dramatic ways. We must therefore preserve the Antarctic environment. The question is how best to do it.

The most urgent and relevant action we can take is to ensure that this irreplaceable environment is never put at risk by mining. That is why Australia has decided not to sign the Minerals Convention (Hawke 1990).

At about this time SCAR, in the SCAR Bulletin (93, April 1989), published Objectives of Conservation in the Antarctica [identified by the SCAR ad hoc Group on Additional Protective Measures and endorsed by the Working Group on Biology] (SCAR ad hoc Group on Additional Protective Measures 1987). The background to this report was the publication in 1980 of the 
World Conservation Strategy by the IUCN and other institutions (IUCN 1980). The SCAR report comments that:

\section{Background}

1.3. WCS is concerned with resource conservation; it is a strategy to allow material processes of life on this planet to continue. Other, aesthetic, factors are also important to mankind, however. With a human population increasingly concentrated in urban centres, a trend which seems likely to continue, 'wilderness' is seen to have intrinsic value. Scenic resources (which may overlap with wilderness) are also valued for their aesthetic appeal (p 7)....

1.5. Antarctica comprises the last remaining extensive terrestrial wilderness on Earth and while not entirely pristine, is the area by far the least affected by human activity. As such, it is a reference standard for monitoring studies which assess the way in which industrial societies are affecting the global environment (p 7)...

1.6. The scenic values of the Antarctic are especially high and it has some, though because of its recent discovery, few, historical and cultural sites (sic) ( $\mathrm{p} 7)$.

\section{Objectives}

The objectives of conservation in the Antarctic are to minimise disturbance by human activity so that:

2.5. cultural values, such as scenic beauty, inspirational quality, wilderness status and recreational potential can be maintained (p 8) (SCAR ad hoc Group on Additional Protective Measures 1987).

It is notable that a SCAR Working Group identified wilderness as having intrinsic value. The issue of intrinsic value and wilderness is discussed in detail in Chapter 5. It seems highly likely that these reports, written by highly respected Antarctic scientists, and published by SCAR during the development of the minerals convention and widely distributed, would have been very influential. SCAR itself has developed a number of Principles of Protection of the Antarctic Environment, which are still current (SCAR 2010). They are reproduced in full below:

The primary objective in protecting the Antarctic is to avoid or minimize disturbance by human activity. The principles recommended by SCAR to achieve this comprise:

- the conservation of the diversity and integrity of natural phenomena and systems, both in the context of the Antarctic and Planet Earth;

- preservation of the genetic diversity of indigenous biota by ensuring that adequate representative populations of animals and plants are maintained in situ; 
- prevention of the introduction and establishment of non-indigenous species to the greatest extent possible;

- conservation of unique natural features, localities or complexes of features and sites of historical importance, which should remain undisturbed;

- protection of cultural values, such as scenic beauty and inspirational quality, wilderness status and recreational potential. (SCAR 2010)

There is, therefore, a clear path from Man's Impact on the Antarctic Environment: a procedure for evaluating impacts from scientific and logistic activities (Benninghoff \& Bonner 1985) to $A$ Visitor's Introduction to Antarctica and its Environment (Bonner et al. 1986) to The Protected Area System in the Antarctic (SCAR ad hoc Group on Additional Protective Measures 1987) and then to CRAMRA and finally the Madrid Protocol.

The situation at ATCM XV in October 1989, two months after Australia's and France's announcements can be summarised as follows:

Taking note of proposals made at XVth Consultative Meeting by France and Australia for a comprehensive Convention for the Protection of the Antarctic Environment which would establish Antarctica as a natural reserve, land of science; by the United States for comprehensive measures building on the components of the Antarctic Treaty system; by Chile on comprehensive measures, which include the development of the concept of Antarctica as a Special Conservation Area; by New Zealand for comprehensive measures constituting an integrated and binding environmental protection regime; and by Sweden relating to common elements for environmental protection (ATS 1989).

At this ATCM, it was recommended (XV-1) to ATCP governments that:

1. They undertake as a priority objective the further elaboration, maintenance and effective implementation of a comprehensive system for the protection of the Antarctic environment and its dependent and associated ecosystems aimed at ensuring that human activity does not have adverse impacts on the Antarctic environment or its dependent or associated ecosystems or compromise the scientific, aesthetic or wilderness values of Antarctica (ATS 1989)

This recommendation is significant in that the parent governments of Antarctic Treaty Consultative Parties were being asked to prepare a comprehensive system to ensure that human activity does not compromise the aesthetic or wilderness values of Antarctica.

Recommendation XV-1 from ATCM XV began:

Convinced of the need to preserve the Antarctic Treaty system so as to ensure that Antarctica does not become the scene or object of international discord; ... (ATS 1989) 
It seems very likely that ATCPs were anxious to avoid a political vacuum following the abandonment of CRAMRA and it was therefore imperative to move quickly to replace it with a new convention on protecting the Antarctic environment. Any delay or further major disagreement could easily have led to "international discord."

There then followed Special Antarctic Consultative Meetings at Viña del Mar in Chile in November 1990 and Madrid in April, June and October 1991, at the last meeting of which the Protocol on Environmental Protection to the Antarctic Treaty, the "Madrid Protocol", was signed. The Protocol was not quite complete, however, and two more annexes have subsequently been negotiated. Annex V, on area protection, was not signed until ATCM XVI at Bonn in October 1991 and came into force on 24 May 2002 (ATS 2012c). Annex VI, on liability arising from environmental emergencies, was signed at ATCM XXVIII in Stockholm in 2005 but has not yet come into force (ATS 2011).

While very little of the original text of CRAMRA was retained, it seems likely that at least some of the ideas relating to environmental protection that had been agreed during the negotiations of the Convention would have been retained. Protection of the wilderness and aesthetic values seems hardly to be controversial so phrases like the following in the preamble to CRAMRA:

Noting the unique ecological, scientific and wilderness value of Antarctica and the importance of Antarctica to the global environment; (ATS 1988)

could easily be re-phrased into

The protection of the Antarctic environment and dependent and associated ecosystems and the intrinsic value of Antarctica, including its wilderness and aesthetic values and its value as an area for the conduct of scientific research, ... (Madrid Protocol, Article 3).

It should be noted that the reference to "intrinsic value" arose during the development of the Madrid Protocol, after CRAMRA.

A final point to note about the Madrid Protocol is the establishment of the Committee for Environmental Protection (CEP). The CEP was established by Article 11 of the Madrid Protocol. The functions of the CEP are laid out in Article 12, which are:

To provide advice and formulate recommendations to the Parties in connection with the implementation of this Protocol, including the operation of its Annexes, for consideration at Antarctic Treaty Consultative Meetings, and to perform such other functions as may be referred to it by the Antarctic Treaty Consultative Meetings (ATS 1998b).

There follows a list of 11 issues for which advice will be particularly required. These can be grouped into issues relating to the effectiveness of the Madrid Protocol and the need for 
additional measures, implementation of environmental impact assessment procedures, environmental emergencies, further development of the protected area system, issues relating to inspections, information collection and exchange, the state of the Antarctic environment and scientific research in support of the implementation of the Madrid Protocol. The significance of this is that any recommendations for protecting the wilderness and aesthetic values arising from this thesis will need to be considered first by the CEP.

\subsection{Implementation of protection for wilderness and aesthetic values}

From the perspective of 2013, it does not seem like a great conceptual leap from the SCAR report on Man's Impact on the Antarctic Environment published in 1985 (Benninghoff \& Bonner 1985) to the body of the Protocol on Environmental Protection to the Antarctic Treaty signed six years later (ATS 1998b). If this is the case, what does it mean for the implementation of the Madrid Protocol and in particular, what were the intentions of its signatories?

The first conclusion that can be drawn is that wilderness and aesthetic values were identified by SCAR as values worthy of protection at least six years before the signing of the Madrid Protocol. The second observation is that since the Madrid Protocol was signed, there have been several instances where the protection of wilderness and aesthetic values has been reinforced. For example, Recommendation XVIII-1 of ATCM XVIII (Kyoto, 1994) sets out "Guidance for Visitors to the Antarctic" and "Guidance for those Organising and Conducting Tourism and Non-governmental Activities in the Antarctic." (ATS 1994). The former document includes the following statements:

The Environmental Protocol applies to tourism and non-governmental activities as well as governmental activities in the Antarctic Treaty Area. It is intended to ensure that these activities do not have adverse impacts on the Antarctic environment, or on its scientific and aesthetic values (para 3).

\section{E) KEEP ANTARCTICA PRISTINE}

Antarctica remains relatively pristine, and has not yet been subjected to large scale human perturbations. It is the largest wilderness area on earth. Please keep it that way. (Section E).

Guidance for tourism operators, the latter document, includes the following:

Antarctica is the largest wilderness area on earth, unaffected by large scale human activities. Accordingly, this unique and pristine environment has been afforded special protection. (para 1). The Environmental Protocol designates Antarctica as a natural reserve devoted to peace and science, and applies to both governmental and non-governmental activities in the Antarctic 
Treaty Area. The Protocol seeks to ensure that human activities, including tourism, do not have adverse impacts on the Antarctic environment, nor on its scientific and aesthetic values (para 4).

The recurrence of such statements lends weight to the original intention of the ATCPs to protect these values.

\subsection{Implementation of the Madrid Protocol with respect to wilderness and aesthetic values}

Since the ratification of the Madrid Protocol in 1998, Antarctic Treaty Consultative Parties have been implementing the measures that it introduced, as evidenced by the creation of the Committee for Environmental Protection (CEP) (required under Article 11 of the Madrid Protocol), the requirement for environmental impact assessments for all activities in Antarctica (required under Article 8), the acceptance of the Environmental Domains of Antarctica dataset as a basis for developing a systematic environmental-geographical framework for the Protected Areas System, and many other measures. There is not, however, much evidence of progress with the protection of wilderness and aesthetic values. The Guide to the Preparation of Management Plans for Antarctic Specially Protected Areas, prepared under the auspices of the Committee for Environmental Protection, includes a reminder that wilderness and aesthetic values are values that may be protected in a Specially Protected Area and that those values should be described in the appropriate part of the management plan. The most tangible evidence is the inclusion of wilderness and aesthetic values as values to be protected in the management plans for a number of Antarctic Specially Protected Areas (ASPA) and Antarctic Specially Managed Areas (ASMA). The management plans for 12 ASPAs and five ASMAs include protection of wilderness and/or aesthetic values. As of 2012, there are in total 72 ASPAs and seven ASMAs listed on the Antarctic Treaty Secretariat website (http://www.ats.aq/documents/ATCM35/WW/atcm35_ww004_e.pdf). Table 3.1 lists these ASPAs and AMSAs and the types of values protected. 
Table 3.3.1. ASPAs and ASMAs that include wilderness and/or aesthetic values as values to be protected.

\begin{tabular}{|c|c|c|c|}
\hline $\begin{array}{l}\text { ASPA } \\
\text { No. }\end{array}$ & Name/Locality & $\begin{array}{l}\text { Values protected } \\
\text { (W = wilderness values } \\
A=\text { aesthetic values) }\end{array}$ & Country nominating \\
\hline 106 & Cape Hallett & $\mathrm{W} \& \mathrm{~A}$ & USA \\
\hline 119 & Davis Valley, Dufek Massif & $\mathrm{W} \& \mathrm{~A}$ & USA \\
\hline 120 & Pointe Geologie & A & France \\
\hline 123 & Barwick Valley. Dry Valleys & $\mathrm{W} \& \mathrm{~A}$ & USA \\
\hline 128 & Western shore Admiralty Bay & A & Poland \\
\hline 134 & Cierva Point & A & Argentina \\
\hline 143 & Marine Plain & $\mathrm{W} \& \mathrm{~A}$ & Australia \\
\hline 157 & Backdoor Bay, Cape Royds & A & New Zealand \\
\hline 159 & Cape Adare & A & New Zealand \\
\hline 164 & Scullin and Murray Monoliths & $\mathrm{W} \& \mathrm{~A}$ & Australia \\
\hline 168 & Mt Harding, Grove Mountains & $\mathrm{W} \& \mathrm{~A}$ & China \\
\hline 171 & $\begin{array}{l}\text { Narebski Point, King George } \\
\text { Island }\end{array}$ & A & Republic of Korea \\
\hline 172 & $\begin{array}{l}\text { Lower Taylor Glacier and Blood } \\
\text { Falls, } \\
\text { McMurdo Dry Valleys, Victoria } \\
\text { Land }\end{array}$ & $\mathrm{A}$ & USA \\
\hline
\end{tabular}




\begin{tabular}{|l|l|l|l|}
\hline $\begin{array}{l}\text { ASMA } \\
\text { No. }\end{array}$ & Name/Locality & Values protected & Country nominating \\
\hline 1 & $\begin{array}{l}\text { Admiralty Bay, King George } \\
\text { Island }\end{array}$ & A & $\begin{array}{l}\text { Brazil, Poland, Ecuador, } \\
\text { Peru }\end{array}$ \\
\hline 2 & McMurdo Dry Valleys & W \& A & USA, New Zealand \\
\hline 3 & Cape Denison & A & Australia \\
\hline 4 & Deception Island & W \& A & $\begin{array}{l}\text { Argentina, Chile, } \\
\text { Norway, Spain, UK, } \\
\text { USA }\end{array}$ \\
\hline 6 & Larsemann Hills & W \& A & $\begin{array}{l}\text { Australia, China, Russia, } \\
\text { Romania, India }\end{array}$ \\
\hline
\end{tabular}

Only 7\% of ASPAs but over $70 \%$ of ASMAs include the protection of wilderness and/or aesthetic values in their management plans. Most of the ASPAs, including most of those that also protect wilderness and/or aesthetic values, were nominated primarily to provide protection for flora or fauna; not one ASPA has been nominated solely to provide protection for wilderness and/or aesthetic values. The purpose of ASMAs is to "assist in the planning and co-ordination of activities, avoid possible conflicts, improve co-operation between Parties or minimize environmental impacts" (ATS 2010). ASMAs are generally developed where there are stations of a number of Parties located within the same discrete area, for example in the Larsemann Hills, where there are stations from 6 Treaty Parties. 


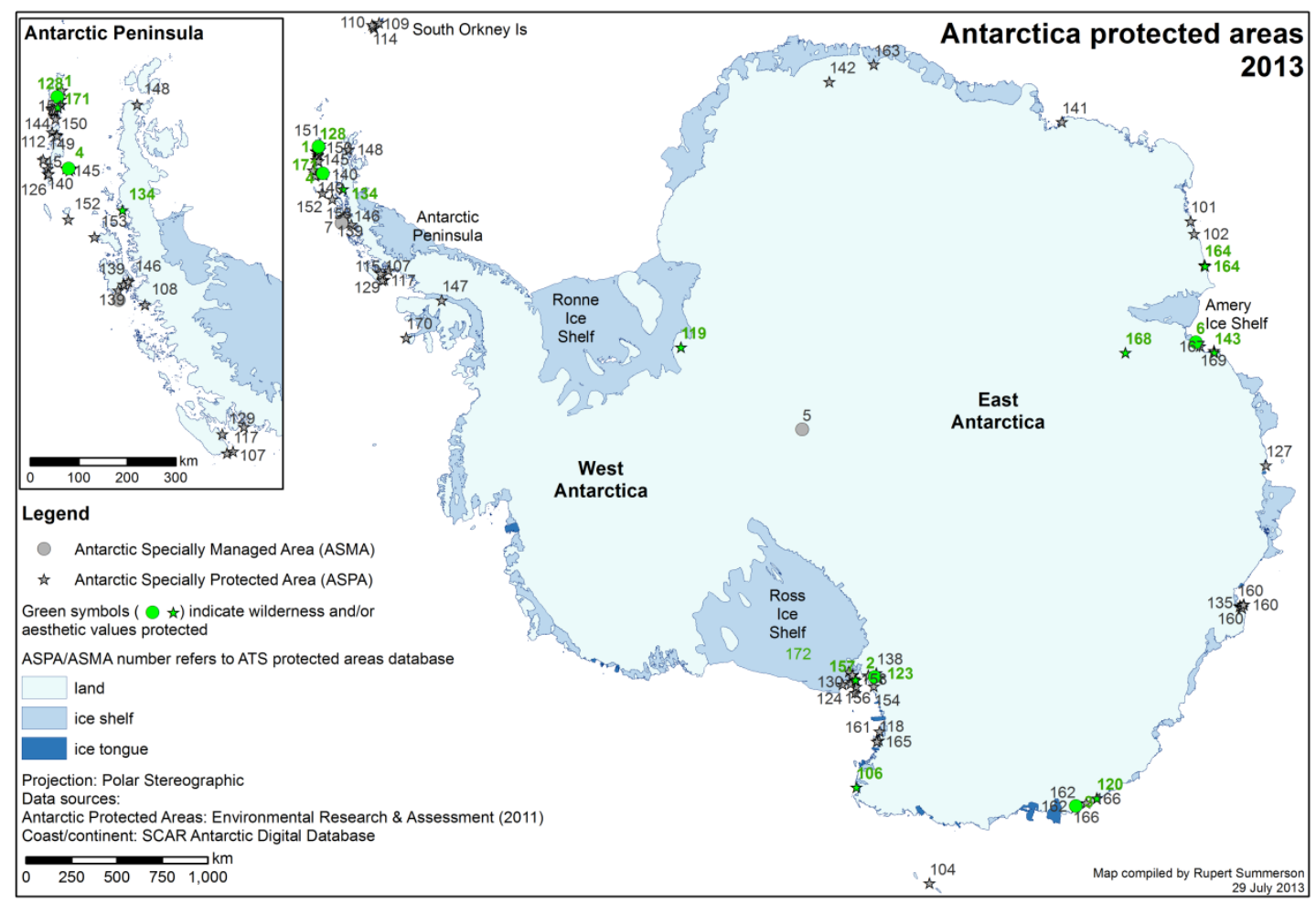

Figure 3.1. Protected areas in Antarctica. The numbers refer to the ATS protected areas database (http://www.ats.aq/devPH/apa/ep protected.aspx?lang=e).

It is noteworthy that 'aesthetic values' and 'wilderness and aesthetic values' have been nominated as values to be protected but not solely wilderness values. At the risk of speculation and yet attempting to provide an interpretation for the reason for this, it may be that aesthetic values are more apparent than wilderness values. Aesthetic values, by their very nature, invoke an affective response to the landscape; wilderness values, by contrast, at least in the Antarctic context, represent the absence of human activity. Wilderness values, in Antarctica, are also more pervasive; wilderness is the "default" condition and therefore, perhaps, not sufficiently remarkable to warrant special protection, especially at remote sites. In the Antarctic context, wilderness values are most apparent when juxtaposed against an area of human influence. This issue is discussed in detail in Chapter 5. 


\section{Chapter 4. Human activities in Antarctica}

\subsection{Introduction and background}

No discussion of the protection of wilderness and aesthetic values can be made without understanding the nature and extent of human activities that can potentially detract from these values. In this chapter I describe human activities in Antarctica, focussing on those that have the potential to have the greatest impact on wilderness and aesthetic values: national Antarctic programs and tourism.

In any one year there may be up to five classes of human activity carried out within the Antarctic Treaty area:

- National Antarctic programs

- Tourism

- Non-governmental organisation projects

- Commercial fishing

- Japanese "scientific" whaling

Tourism and national Antarctic programs contribute by far the most visitors to Antarctica. Activities carried out by national Antarctic programs are reasonably evenly spaced around Antarctica, especially around the coast (Figure 4.1). Most tourism activities are concentrated at the northern end of the Antarctic Peninsula and to a lesser extent towards the central section of the Antarctic Peninsula and in the Ross Sea (Figure 4.2). 


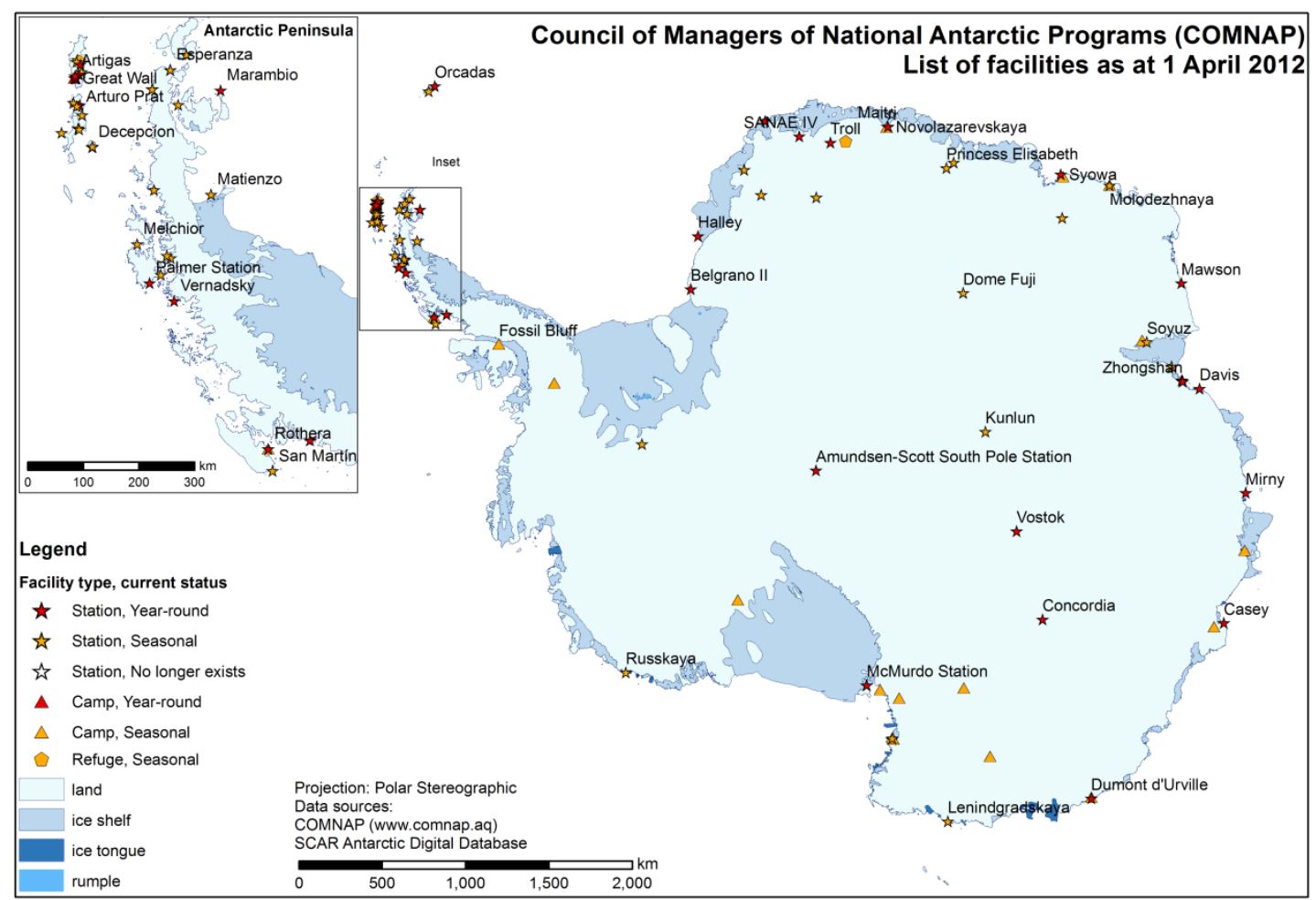

Figure 4.1. Stations and facilities operated by national Antarctic programs in 2012.

(Source: COMNAP.)

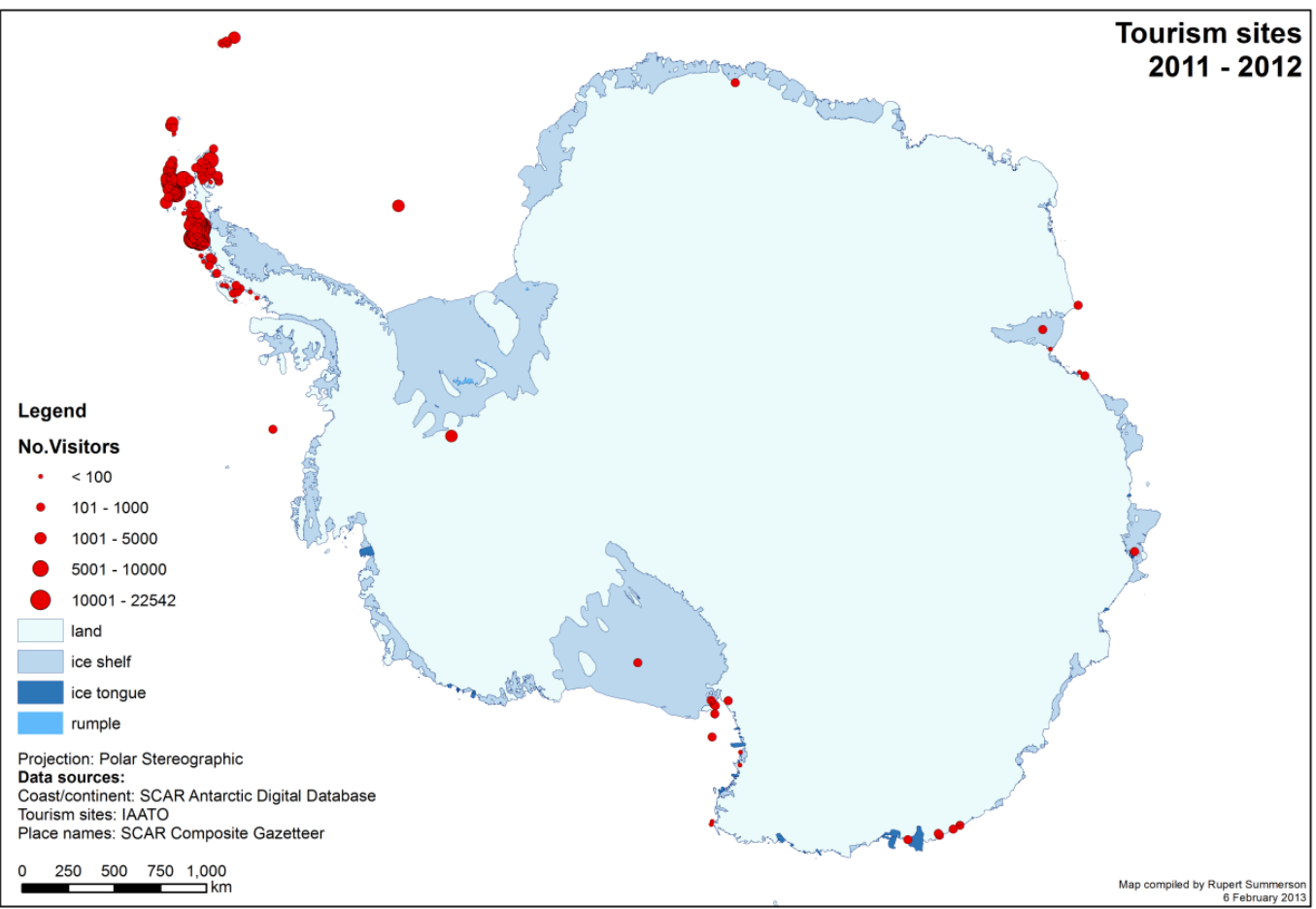

Figure 4.2. Tourism sites, including landings, non-landing ship cruises and land-based tourism, during the 2011-2012 season. (Source: IAATO). 


\subsection{Politics}

Science, it has been said, is the currency of credibility in Antarctica (Davis 1990: 39); however, as Davis went on to say, "Antarctica is and will remain primarily a continent for politics". The Antarctic Treaty, signed in 1959, was a triumph of diplomacy that has deferred for over 50 years the "Antarctic problem" (Hunter Christie 1951) of over-lapping and un-recognised territorial claims. The Antarctic Treaty gives precedence to science (e.g. Preamble, Articles II, III and IX) and bans a number of other activities, notably all military activity (Article I). The Madrid Protocol similarly gives precedence to science (Article 3) and bans any activity relating to mineral resources (Article 7). The Antarctic Treaty System (Scully 2011) has continued to develop new instruments to implement the measures introduced by the Antarctic Treaty, for example the protection of the Antarctic environment through the Madrid Protocol (ATS 1998) and to respond, albeit slowly (Huber 2011), to contemporary issues such as tourism and bioprospecting (see below). The Antarctic Treaty System has survived the upheaval caused by the failure of CRAMRA (Chapter 3) and the challenge to its legitimacy initiated by Malaysia in 1982 (Tepper \& Haward 2005). Since 1959 the original 12 Antarctic Treaty signatories have been joined by another 16 Consultative Parties (defined in Chapter 3) who meet annually at Antarctic Treaty Consultative Meetings to discuss management arrangements under the various legal instruments and announce new measures, resolutions and decisions (ATS 2011a). Although politics is not an Antarctic activity as such, it underpins every activity through the support for national Antarctic programs, the science they undertake, the location and number of stations and other facilities, the cooperation undertaken with other national Antarctic programs, the names given to topographic features and on maps and in a myriad of other ways.

Many countries are overt about their policies in and for Antarctica. Australia's current national interests in Antarctica, as published on the Australian Antarctic Division website (www.antarctica.gov.au), are to:

- Preserve our sovereignty over the Australian Antarctic Territory, including our sovereign rights over the adjacent offshore areas;

- Maintain Antarctica free from strategic and/or political confrontation;

- Protect the Antarctic environment, having regard to its special qualities and effects on our region;

- Take advantage of the special opportunities Antarctica offers for scientific research;

- Be informed about and able to influence developments in a region geographically close to Australia; and

- Derive any reasonable economic benefits from the living and non-living resources of the Antarctic (excluding mining and oil drilling). 


\subsection{National Antarctic programs}

National Antarctic programs (NAPs) are the means whereby ATCPs put their policies into practice in Antarctica. Two main activities are carried out by NAPs: science and operations, ostensibly in support of science. Surveying (e.g. for mapping) is included as a scientific activity because it comes within the ambit of SCAR, whose Standing Committee on Antarctic Geographic Information coordinates a number of international programs. It is one of the provisions of the Antarctic Treaty (Article IX) that, to accede to the Treaty as a Consultative Party, [a country] must demonstrate "its interest in Antarctica by conducting substantial scientific research activity there, such as the establishment of a scientific station or the despatch of a scientific expedition" (ATS 1959).

As described in Chapter 3, the Antarctic Treaty grew out of the International Geophysical Year (1957-58) (Fogg 1992: 168) when 12 countries $^{10}$ established a total of 51 stations (Law 1959) (Figure 4.3). These 12 countries were the original signatories of the Antarctic Treaty which enshrined science as the predominant activity in Antarctica. At the time of the IGY a number of stations had already been established, including Mawson (AUS) which was established in 1954 (Law \& Béchervaise 1957: 56) and is now the longest running station on the Antarctic continent.

\footnotetext{
${ }^{10}$ Argentina, Australia, Chile, Belgium, France, Japan, New Zealand, Norway, UK, USA \& USSR (now Russia)
} 


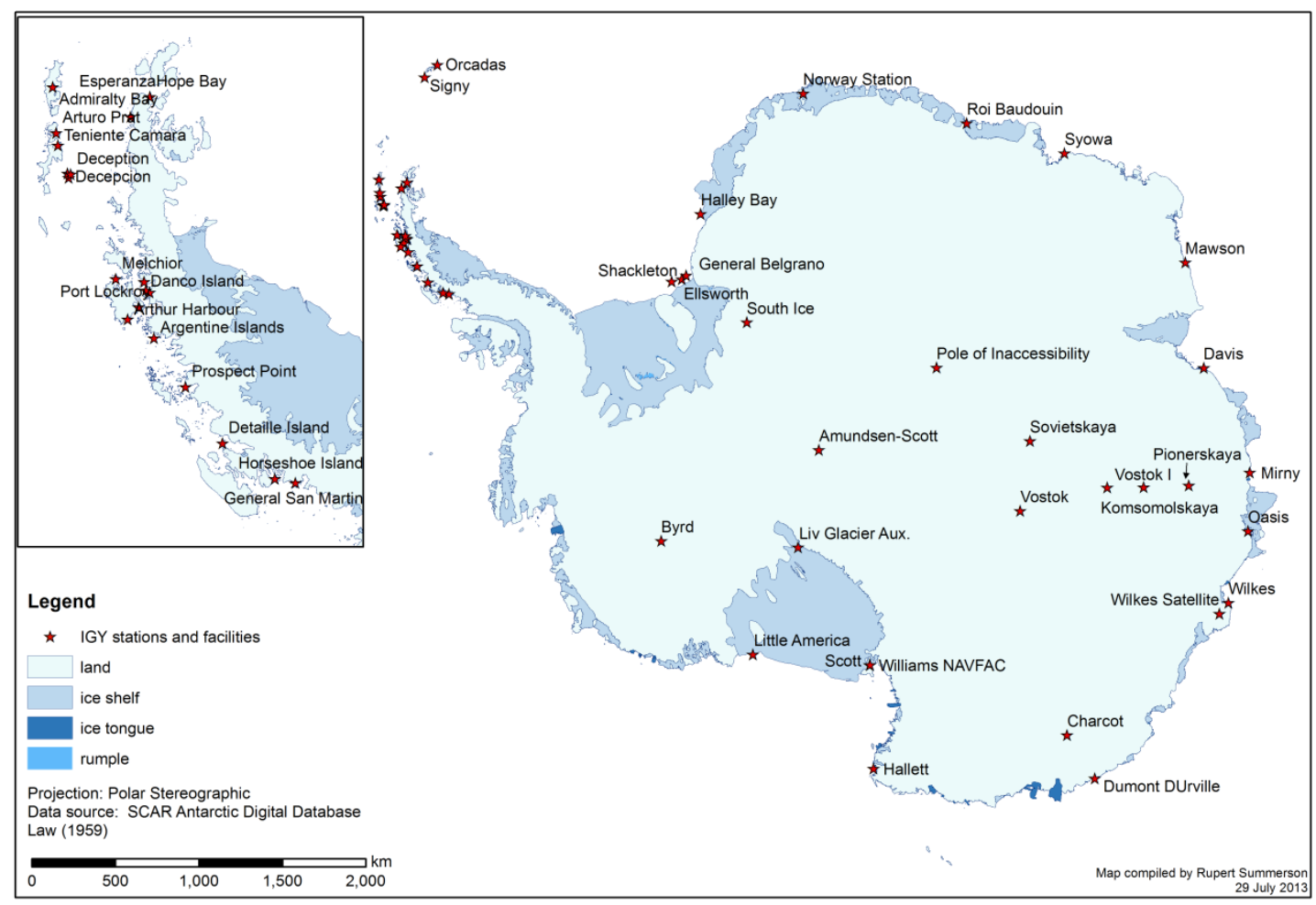

Figure 4.3. Antarctic stations occupied during the International Geophysical Year 1957-58 (Law 1959).

This tradition of science in Antarctica, at least in terms of geographical extent and budgetary outlay, continues to be an important feature of the management of the continent. In terms of numbers of visitors, however, tourists began to outnumber NAP staff in the early 1990s (Enzenbacher 1992: 19), to be described below. At the international level, science is coordinated by the Scientific Committee on Antarctic Research which is a permanent observer at, and advisor to, ATCMs (Walton 2011). SCAR is a member of the International Council of Scientific Unions (ICSU) and is independent of the Antarctic Treaty System and national Antarctic programs. The science programs conducted by NAPs may contribute to projects coordinated by SCAR or fulfil national objectives, or both. Most science programs run by NAPs have multi-year strategic plans and these can be found on their websites ${ }^{11}$. (The website of the Antarctic Treaty Secretariat has links to the websites of all NAPs (ATS 2012b)).

\subsubsection{Science}

The scope of scientific activity carried out by NAPs is highly varied and could be said to range from astronomy to zoology. Walton (1987) and Fogg (1992) describe the range of research

\footnotetext{
${ }^{11}$ The current Australian Antarctic science strategic plan is here:

http://www.antarctica.gov.au/science/australian-antarctic-science-strategic-plan-201112-202021
} 
carried out in Antarctica, though somewhat dated and with a UK perspective; Fifield (1987), although also dated, takes a more international view. Marchant et al. (2002) review 50 years of Australian Antarctic science. Many volumes of proceedings of discipline-specific conferences have been published, many of which have been under the auspices of SCAR (e.g. Davison et al. 1998).

There is a hierarchy of activity from research that is carried out entirely at the station to research where data is collected off the station but is analysed on station, to research that is carried out entirely off station. The impacts on wilderness and aesthetic values from each of these types of scientific activity are therefore likely to be quite different. Fieldwork might be entirely impactfree or it may result in scars, e.g. Figure 4.5 (left), whereas station-based research usually requires the installation of infrastructure e.g. Figure 4.5 (right). Research off station can be in two broad categories: mobile or static. Mobile research might comprise a geological survey of an area or a linear geophysical traverse; static research may be for an ice drilling project or for research on a particular penguin colony. A diagram laying out the types of infrastructure support required is at Figure 4.4.

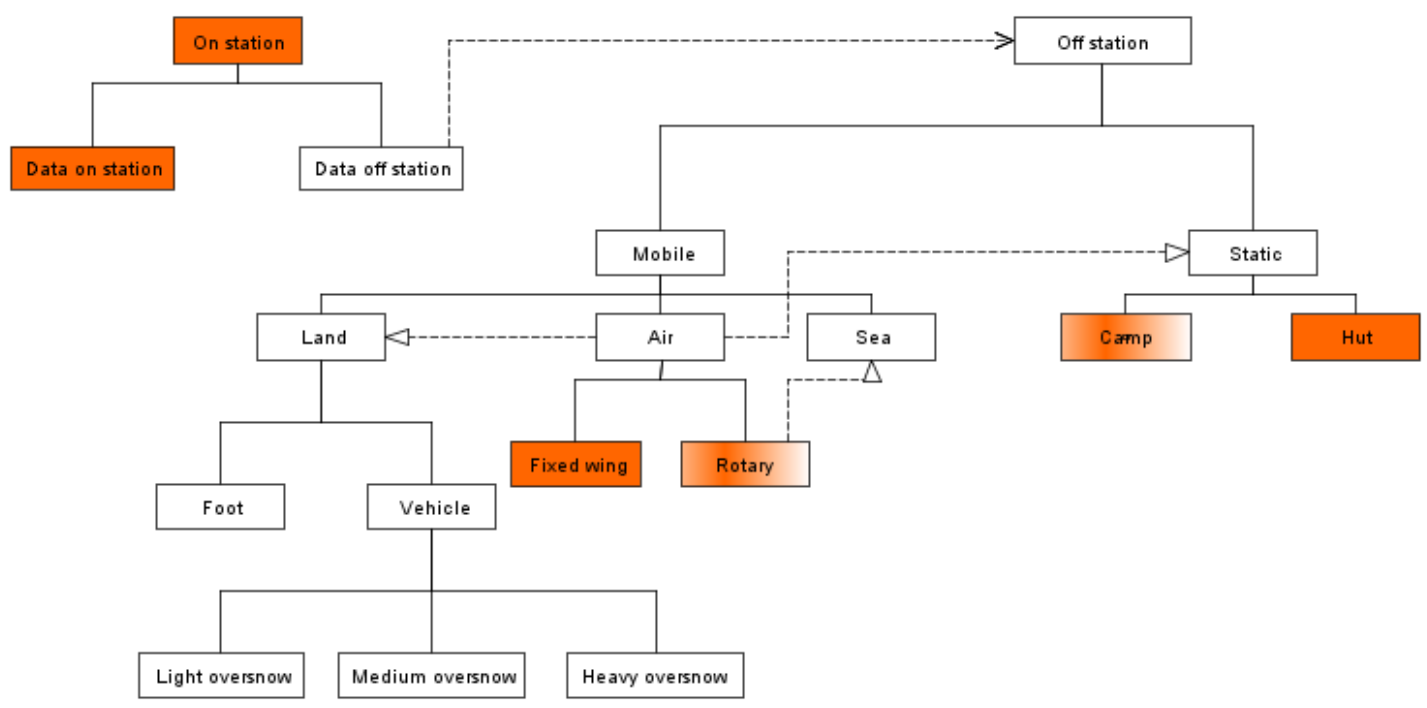

Figure 4.4. Diagrammatic representation of the types of scientific activity in terms of the infrastructure support required. Solid orange boxes indicate that infrastructure is required; partially filled boxes indicate that some temporary infrastructure may be required. All offstation activity requires the resources of a station or a ship to support it. 

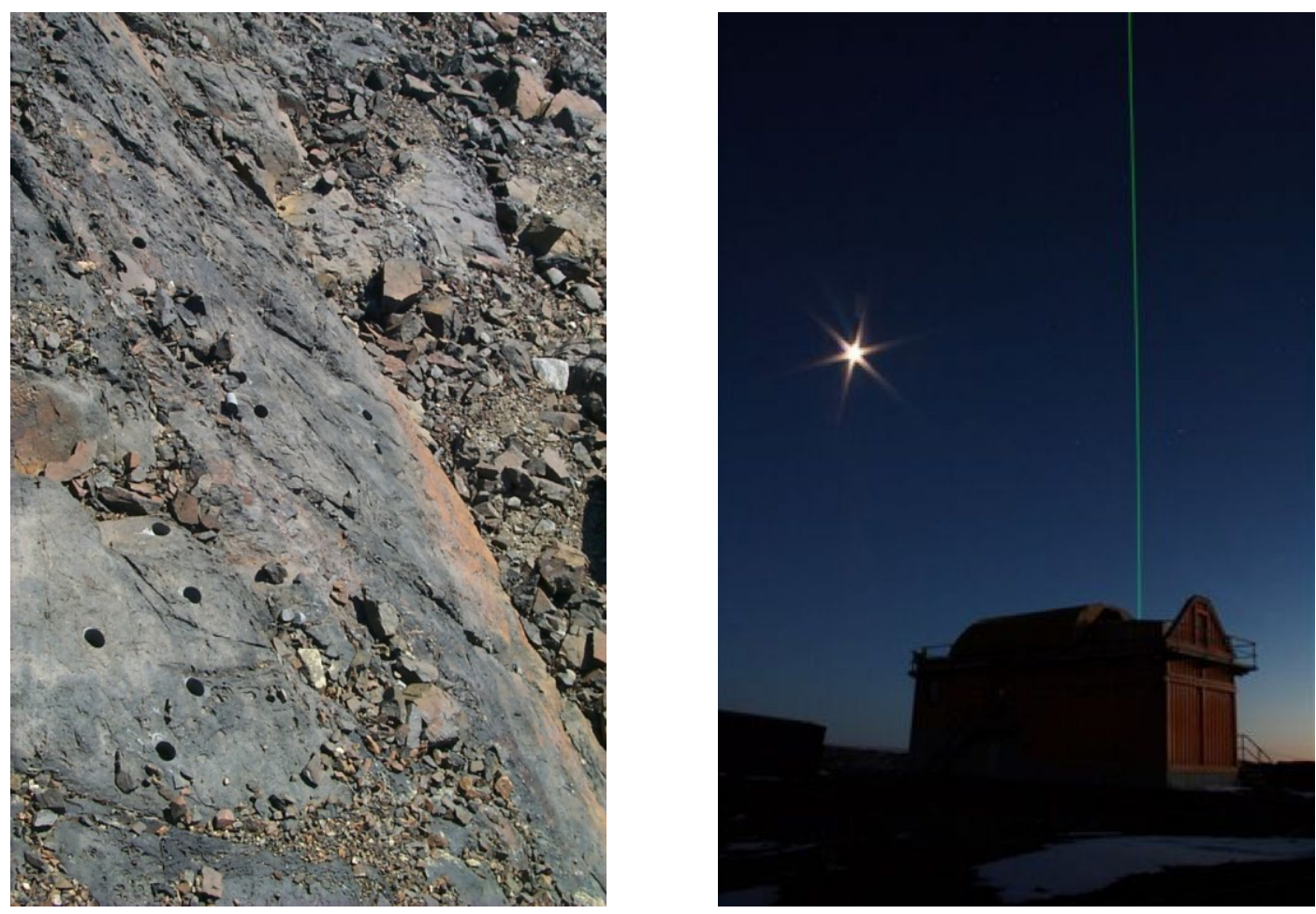

Figure 4.5. Left: Holes left after rock cores were taken. Near Mt Stalker, Vestfold Hills. The holes are about $75 \mathrm{~mm}$ in diameter. (Photo: Rupert Summerson). Right: LIDAR (light detection and ranging) sounding of the upper atmosphere in operation at Davis. (Photo: Zupy/ Australian Antarctic Division. (C) Commonwealth of Australia 2013).

At some stations the only science carried out is at the station itself, for example, upper atmosphere physics, which requires masts, antennae, probes, etc to sample the upper atmosphere (e.g. Figure 4.5 (right)). Other stations are hubs for fieldwork, for example for geology and glaciology, and require air transport facilities (helipads or runways for fixed-wing aircraft). Rothera Station (UK), for example, is the base for UK field parties which are deployed by aircraft from a gravel runway (Figure 4.11) (constructed in the late 1980s) to anywhere on the Antarctic Peninsula, from as far south as the Ellsworth Mountains, or even further, to the northern end of the Antarctic Peninsula. At Davis Station (AUS) (Figure 4.6), by contrast, for example, most fieldwork is carried out within the Vestfold Hills (Figure 4.7), the ice-free area that surrounds Davis station. 


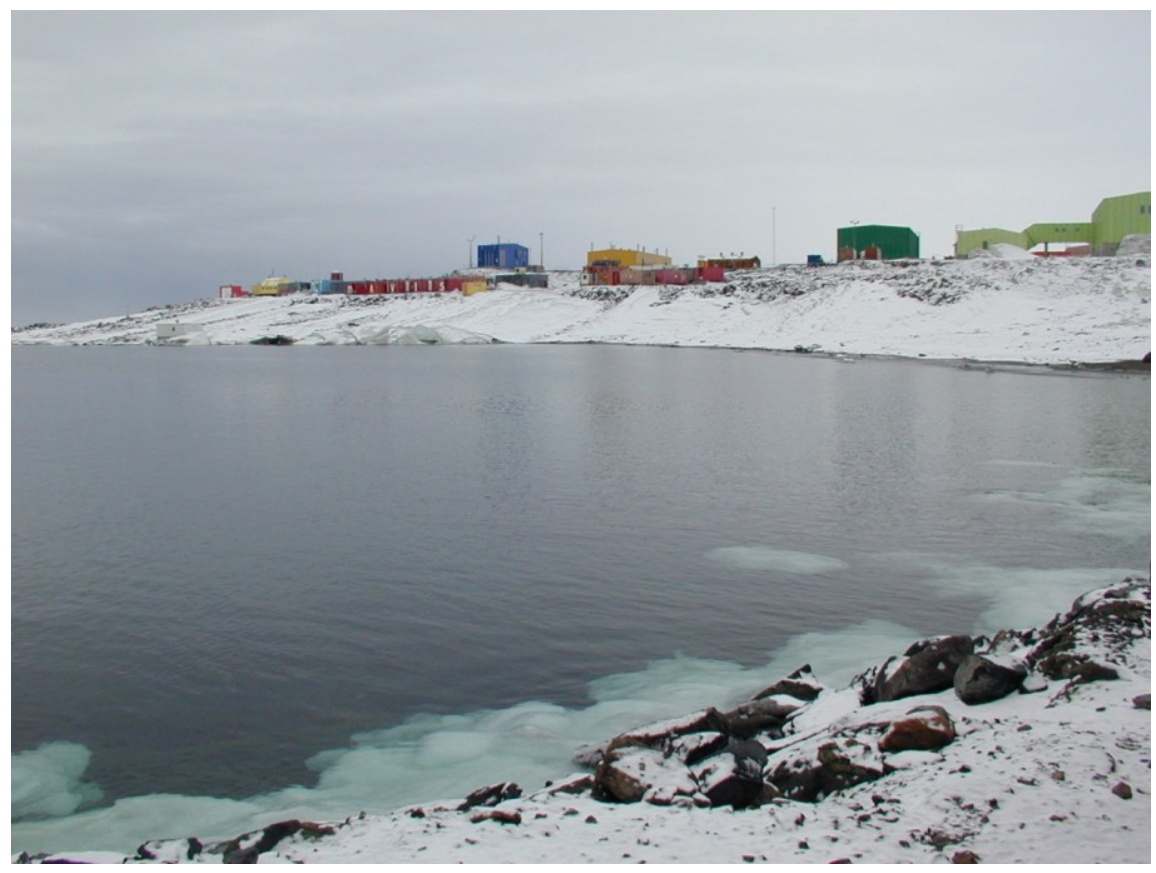

Figure 4.6. Davis Station (Australia) in 2000. (Photo: Davis 2000 winterers).

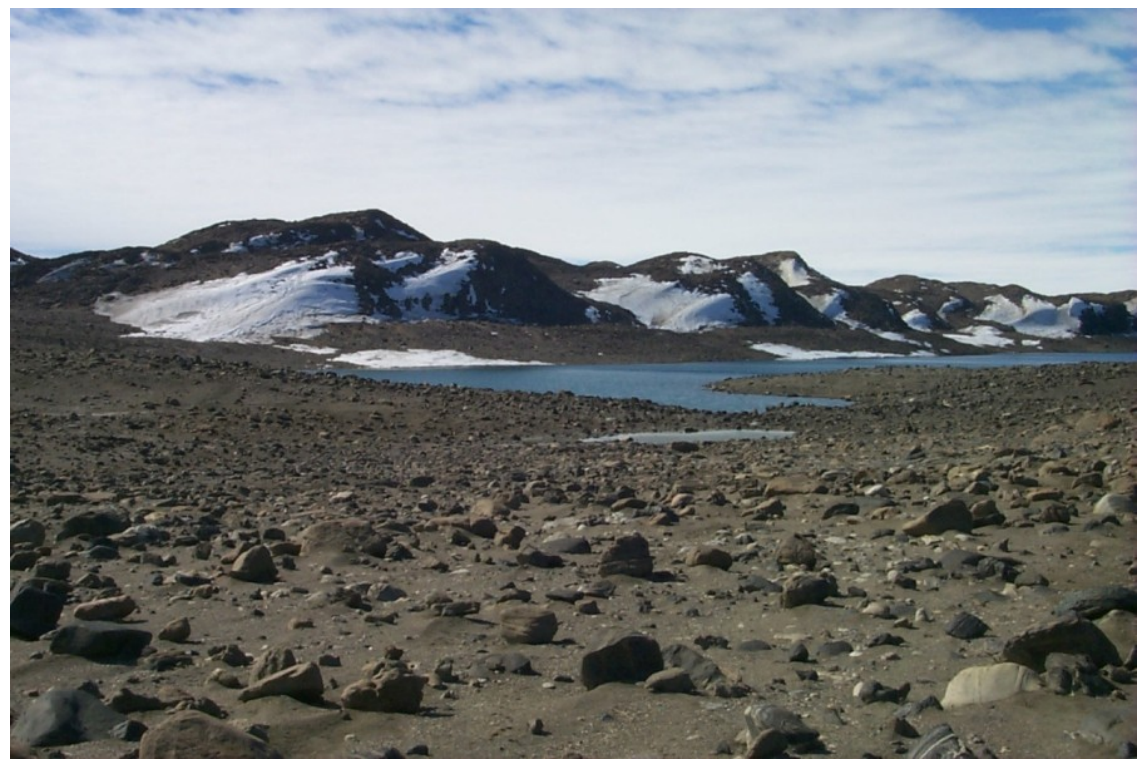

Figure 4.7. Lake Stinear, Vestfold Hills, approximately 5km ENE of Davis Station. (Photo:

Rupert Summerson).

Davis also supports fieldwork based at Law Base, a summer-only base in the Larsemann Hills, $120 \mathrm{~km}$ to the south-east. Support from Davis is provided either by helicopter or, for programs sufficiently near to the station, the scientists simply walk to their field sites. Vehicular traffic is not allowed on ice free areas in the Vestfold Hills. There are 11 field huts in the Vestfold Hills and Rauer Islands (ATS 2012a) and during the summer field season many science projects are based in these huts. The situation is similar at Casey Station and Mawson Station where most of the science is carried out on or near the station. At these stations, there are also remote field 
sites that are supported by each of the stations, e.g. Law Dome drill site supported from Casey and Beaver Lake that is supported from Mawson. There are also field huts around each of these stations.

An important component of Australian science is the marine science carried out from Aurora Australis. There is usually at least one dedicated marine science cruise each year. Marine science cruises are usually, but not always, conducted in the open ocean. Apart from the temporary presence of the ship there is no impact on wilderness or aesthetic values.

\subsubsection{Operations}

In a continent where humans are "well beyond their biome" (Griffiths 2007: 259), 'operations', i.e. the transport, logistics and other support needed to maintain a living environment where scientists and support staff can work in safety and comfort, both in the field and on base, is essential. From the "Heroic Era" to the present day operational support has been an integral part of Antarctic exploration and research.

As with science, an international coordinating group of national Antarctic programs, the Council of Managers of National Antarctic Programs (COMNAP) ${ }^{12}$, was formed (in 1988) to "develop and promote best practice in managing the support of scientific research in Antarctica". There are currently 29 members of COMNAP: the 28 ATCPs plus Canada. Canada has acceded to the Antarctic Treaty but is not an ATCP; its membership of COMNAP is possibly because of its experience in the Arctic.

\subsubsection{Stations}

As of April 2012, there were 39 stations operating year-round, 41 seasonal stations, 19 seasonal camps or refuges and one year-round camp (COMNAP 2012). Figure 4.1 shows the locations of all the seasonal and year-round stations and facilities as listed by COMNAP. Of course these numbers are dynamic but they do not include refuges, field huts, abandoned stations, historic sites and buildings, depots, automatic weather stations, wrecked aircraft and a plethora of other sites, objects and facilities, in use or not. The totality of human artefacts and infrastructure is described in detail and its impact discussed in Chapter 8.

The size of Antarctic stations is highly variable: McMurdo (USA) is the largest station in Antarctica with a winter population of about 250 and a maximum capacity of 1000 (COMNAP 2012). The average over-wintering population at a station is about 28 and the average summer maximum population is about 64 (calculated from COMNAP, 2012). The infrastructure associated with Antarctic stations includes buildings, radio masts, helipads, roads and tracks,

\footnotetext{
12 www.comnap.aq
} 
pipelines, sewage works, fuel storage, electricity generators, water supply fixtures and, at three stations, crushed rock runways. Most Antarctic stations are built close to the sea (Figure 4.1, photo: Figure 4.6); of the 39 permanently occupied stations, 30 (over 75\%) are built within $100 \mathrm{~m}$ vertical elevation of sea level (COMNAP 2012). Of the 53 seasonally occupied stations, $33(62 \%)$ are built within $100 \mathrm{~m}$ vertical elevation of sea level. The principal reason for building close to the sea is the ease of re-supply by ship. Seasonally occupied stations are principally used for the support of field parties and may be some distance inland.

\subsubsection{Shipping operations}

Most shipping in support of national Antarctic programs has two roles: a logistics role to transport people, equipment and provisions to Antarctic stations and a marine science role. Infrastructure related to shipping is generally of two types: navigational and landing. Many stations have navigational beacons, including leading lines, to indicate safe channels. Most stations do not have extensive infrastructure for landing because of the risk of damage by sea ice during the winter. Ships may be able to discharge cargo direct to shore where there is a wharf, for example at Rothera Station (UK) where ships can moor alongside the end of the runway, and at McMurdo (US) where a large ice-proof wharf has been constructed. Otherwise cargo can be unloaded onto the sea ice, if it is strong enough (Figure 4.8), or by barge if the sea is ice free. Sometimes provisions have to be flown in by helicopter, which is an expensive procedure. At the Australian stations, if ice conditions allow the ship to approach close enough, fuel is pumped ashore via a pipeline or it has to be ferried ashore in a fuel barge.

The numbers of shipping operations is quite variable and depends on such factors as the scientific programs being conducted, operational programs, ship availability and budget. There is considerable year to year variability in shipping operations in the Australian program but as a rule of thumb, there is one re-supply voyage to each station and a marine science voyage but there can also be a variety of permutations of re-supply and marine science as well as combined re-supplies to more than one station ${ }^{13}$.

\footnotetext{
${ }^{13}$ http://www.antarctica.gov.au/living-and-working/travel-and-logistics/shipping-and-air-schedules
} 


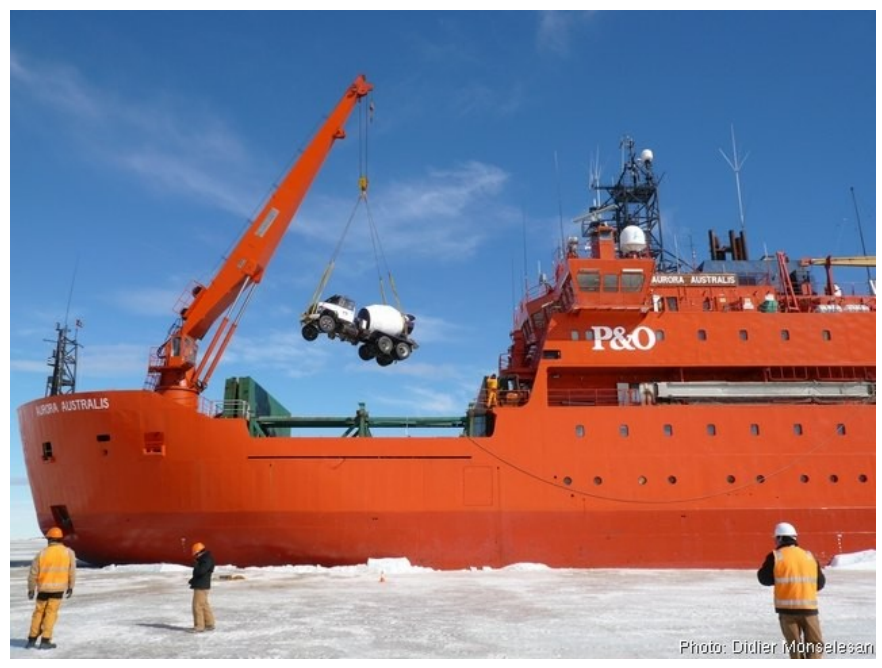

Figure 4.8. Aurora Australis during resupply at Davis Station, 2007. (Photo: Didier

Monselesan/Australian Antarctic Division. (C) Commonwealth of Australia 2013)

A number of countries, including Argentina, Chile and the UK operate naval vessels in Antarctica for search and rescue missions, hydrographic surveying and in support of research programs. The US traditionally used US Coast Guard heavy icebreakers to cut open the passage through the sea ice into McMurdo to allow resupply freighters through, but their icebreaker fleet has aged and has not been replaced and NSF has had to contract foreign icebreakers such as Odin from Sweden. USCGC Polar Star, one of the heavy icebreakers, is scheduled to return to service in 2013 after a major refit (O'Rourke 2012).

\subsubsection{Air operations}

Nine countries (USA, UK, Russia, Germany, South Africa, New Zealand, Argentina, Chile and Australia) and at least three private companies (ANI-ALE, ALCI ${ }^{14}$ and Aerovías DAP ${ }^{15}$ ) operate fixed wing operations that land in Antarctica. COMNAP publishes the Antarctic Flight Information Manual (AFIM) (COMNAP 1995), which lists detailed coordinates on air routes and aircraft landing facilities. Unfortunately the information provided is patchy; some countries list the waypoints delineating all their major routes while others do not. Other information on air routes can be found in Antarctic Treaty Exchange Information and on the websites of national Antarctic programs.

\footnotetext{
${ }^{14}$ Antarctic Logistics Centre International (ALCI) is a South African company providing an aviation logistics service between Cape Town and Novolazarevskaya in Antarctic. The company also services the Dronning Maud Land air network (DROMLAN).

${ }^{15}$ A Chilean airline that operates flights from Punta Arenas to Marsh aerodrome on King George Island.
} 
Inter-continental aircraft tend to be large jet-engined aircraft; the US operates Lockheed C5 Galaxy and C-130 aircraft, Russia operates Ilyushin IL-76s and Australia operates an A319 Airbus (Figure 4.9). BAS operates a turbo-prop DHC-Dash 7 between Stanley and Rothera. Intra-continental aircraft include the DHC-6 Twin Otter, Basler BT-67 conversion, CASA 212 (Figure 4.9), and many makes and models of helicopter. Intra-continental aircraft are almost invariably fitted with skis so they can land at field sites and do not need special runways. Air operations require much more infrastructure than shipping and none more so than intercontinental aircraft. There are currently 11 airfields capable of landing inter-continental aircraft (Figure 4.10), though there are potentially many more sites capable of accepting long-range aircraft, some needing very little modification of the terrain (Mellor 1993; Swithinbank 1991).

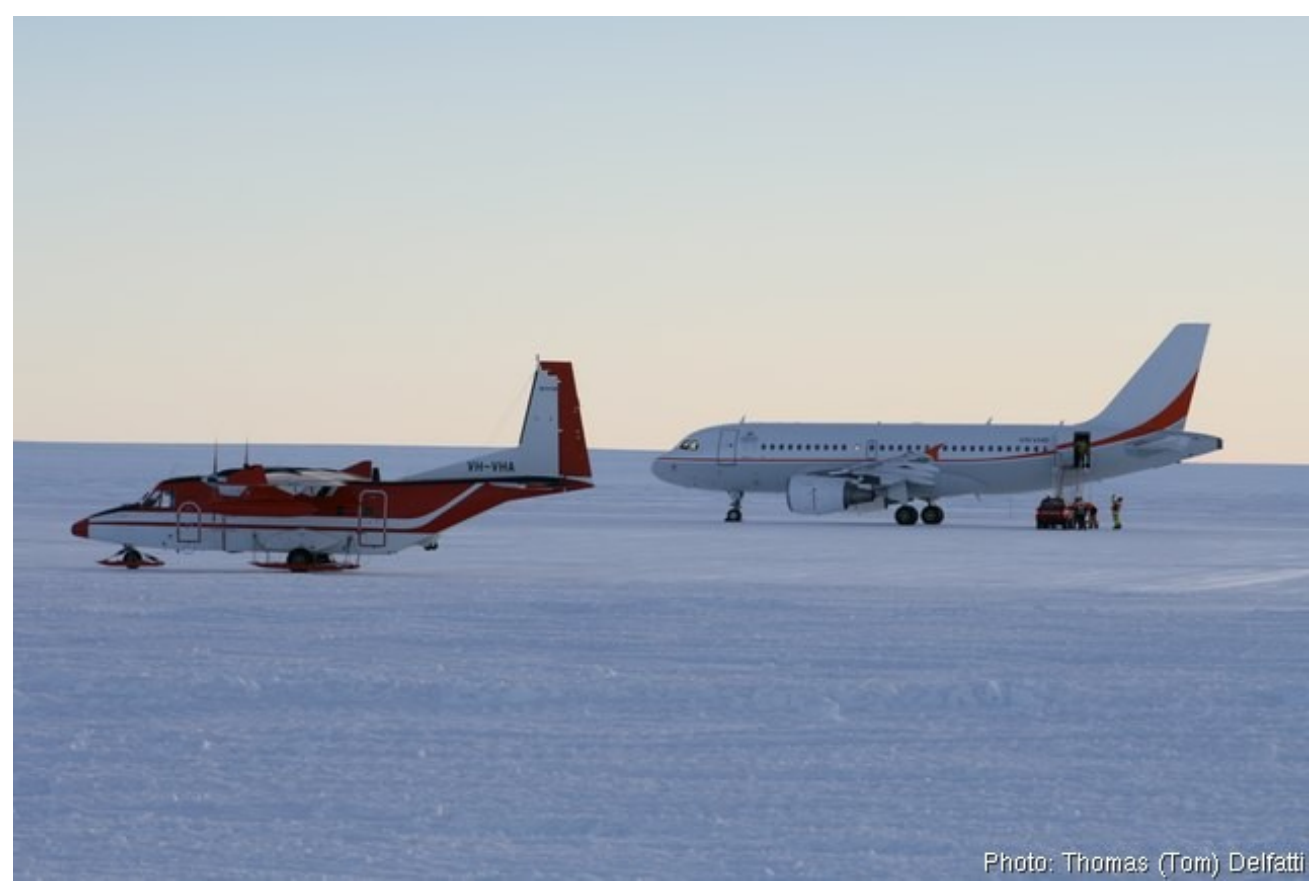

Figure 4.9. A319 Airbus (inter-continental flights) and CASA 212 (intra-continental flights) at Wilkins Runway near Casey Station. (Photo: Thomas Delfatti/ Australian Antarctic Division. (C) Commonwealth of Australia 2013). 


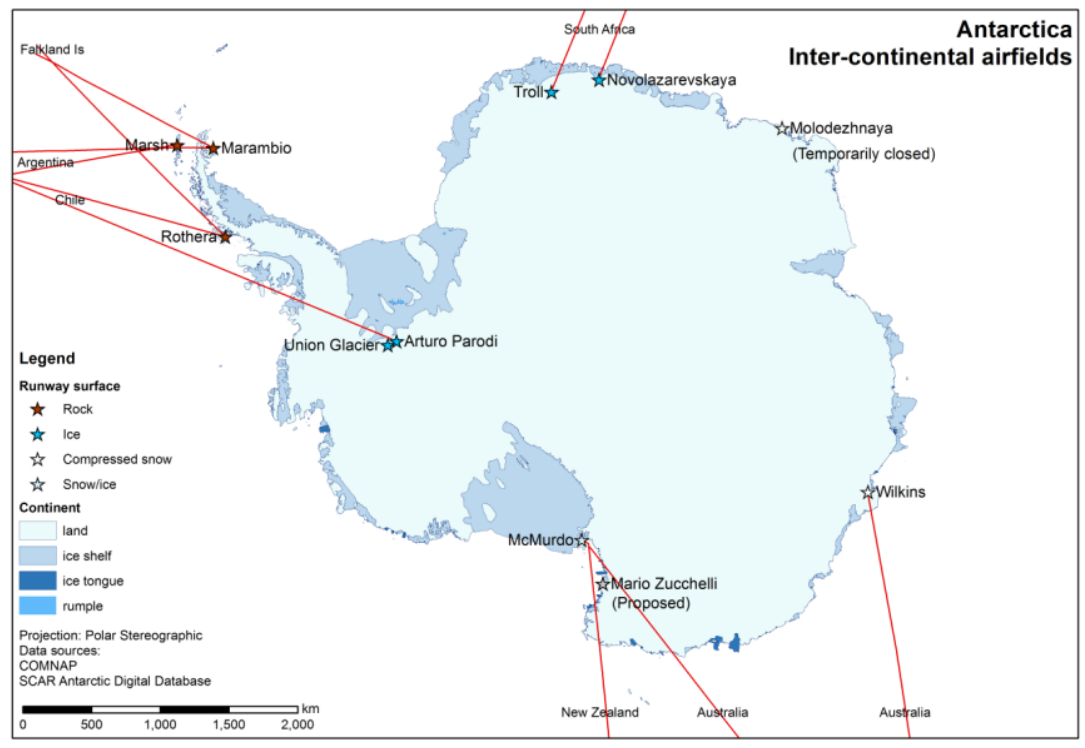

Figure 4.10. Locations of airfields that are currently, or planned to be, capable of landing intercontinental aircraft.

Three of the airfields are formed from gravel or crushed rock: Marsh (Chile), Marambio (Argentina) and Rothera (UK) (

Figure 4.11). Most of the inter-continental airfields are operated by national Antarctic programs; two exceptions are Union Glacier, which is operated by ALE, and Novolazarevskaya, which is operated by ALCI, apparently on behalf of the Russian Antarctic program but, with its sister company, The Antarctic Company, also flies in tourists and private expeditions. The latter airfield is part of DROMLAN (Dronning Maud Land Air Network) which is a cooperative network to provide air support for 12 stations from Halley (UK) in the west to Syowa (Japan) in the east (Figure 4.1).

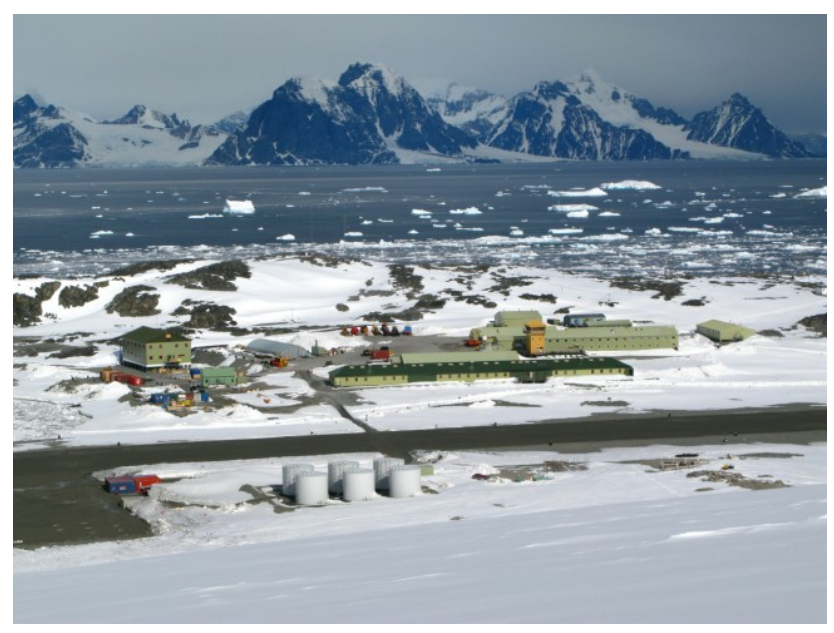

Figure 4.11. Rothera Research Station (UK). The runway crosses the image from left to right in front of the buildings. (Photo: www.photo.antarctica.ac.uk) 
National Antarctic programs such as USAP, BAS, ANARE and others have extensive field programs that are supported by air. Figure 4.12 shows regular air routes flown by a number of NAPs.

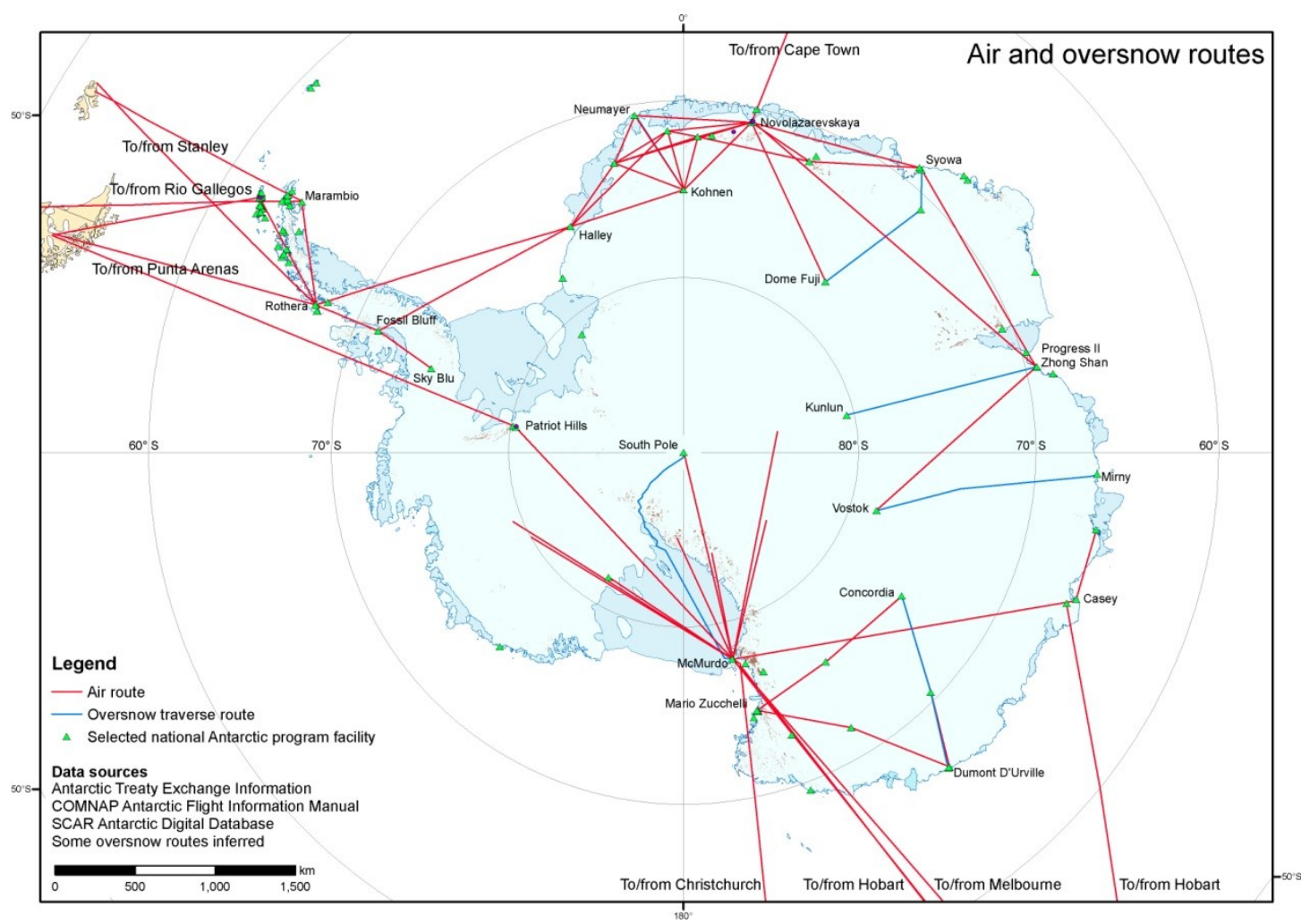

Figure 4.12. Air routes in Antarctica, as published by COMNAP and Antarctic Treaty Exchange Information. As noted above, this represents the "backbone" of air operations. Many more flights are flown to field camps, field parties and on scientific research projects such as radioecho sounding, aero-magnetic studies, aerial photography and other research projects.

\subsubsection{Field operations}

As noted above, a lot of Antarctic research involves going out into "the field", i.e. not on the station. While some fieldwork is carried out in close proximity to a station (Figure 4.13), other fieldwork can be carried out hundreds of kilometres from the station and will involve considerable logistical effort, perhaps involving laying intermediate fuel depots between the station and the fieldwork site to provide sufficient range for the aircraft to reach the site (Figure 4.14). 


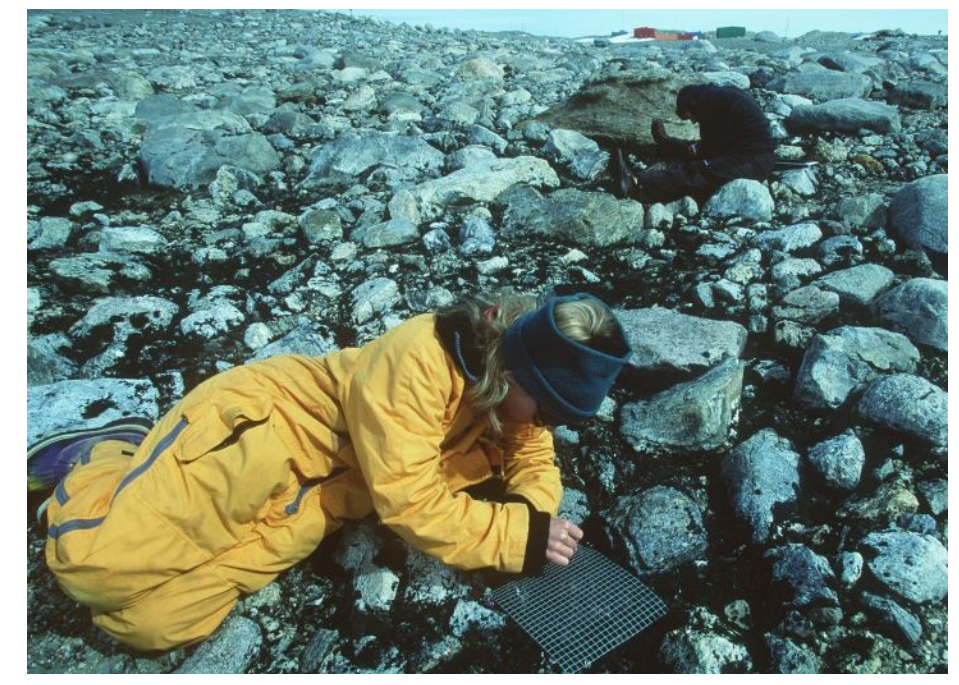

Figure 4.13. Botanists working on moss beds close to Casey (Photo: G. Dixon/Australian Antarctic Division. (C) Commonwealth of Australia 2013).

For example, the UK Lake Ellsworth drilling project, the aim of which was to drill through $3000 \mathrm{~m}$ of ice to reach a sub-glacial lake, was at a site over $1300 \mathrm{~km}$ from Rothera Station $(\mathrm{UK})^{16}$. Ultimately, the type of fieldwork depends on the research being carried out and it will be similarly varied.

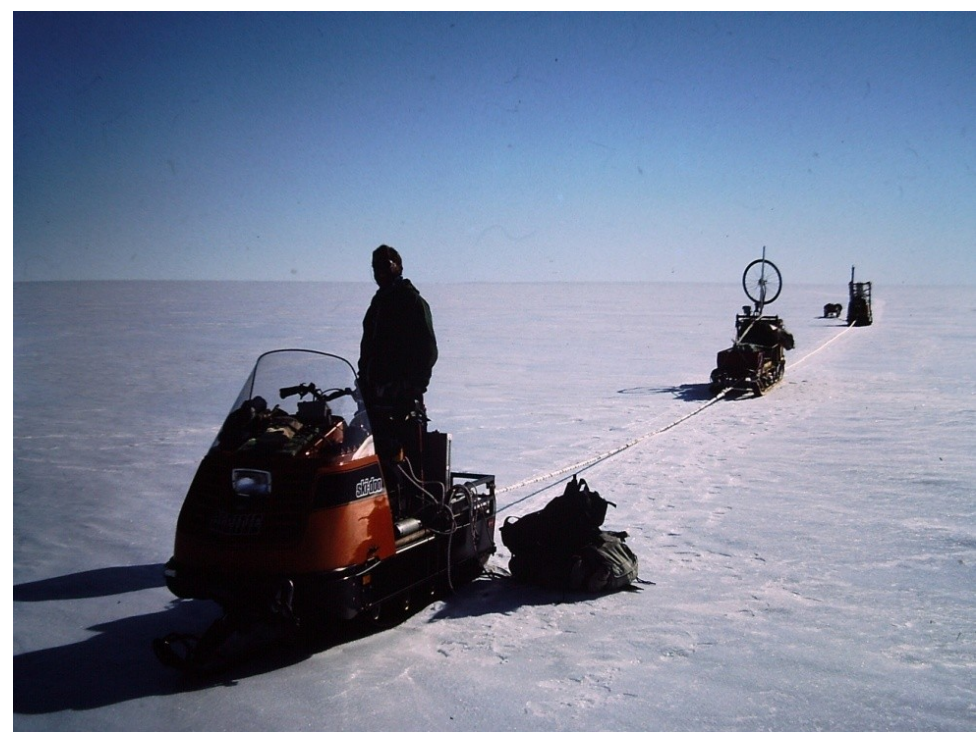

Figure 4.14. BAS geophysical field party, Larsen Ice Shelf, 1985. (Photo: Rupert Summerson). A number of national Antarctic programs operate long-distance over-snow routes (Figure 4.12). The ground route from McMurdo to the South Pole was completed in 2005 (Rejcek 2006); the route from Mirny to Vostok has been operated by Russia since the establishment of Vostok in 1957 (McGonigal \& Woodworth 2001: 143); France operates an oversnow route from Dumont

\footnotetext{
${ }^{16}$ http://www.ellsworth.org.uk/index.html
} 
D'Urville to Concordia (McGonigal \& Woodworth 2001: 143), Japan from Syowa to Dome Fuji (e.g. Headland 2009: 538) and China has established Kunlun, a summer-only station at Dome Argus ("Dome A"), the highest point on the Antarctic ice cap (Figure 4.1), by overland traverse from Zhong Shan in the Larsemann Hills, and it is understood that this will be the method of transport there in the future ${ }^{17}$.

\subsubsection{Other national Antarctic program activities}

Many, if not all national Antarctic programs organize VIP visits by politicians and other senior government figures, no doubt to bolster support for their programs and budgets. Several countries $^{18}$ also offer artists and writers programs. Barry Lopez, Eliot Porter, Peter Matthiesson, Sir Peter Maxwell-Davies, Sydney Nolan, Jan Senbergs, Galen Rowell, Kim Stanley Robinson, Bea Maddocks, Alice Giles and Bill Manhire are some of the well-known writers, artists and musicians that have taken part. In most cases these people come and go without leaving any trace but occasionally an artist wishes to create an art object that has more of an impact, e.g. the bronze sculpture described by Neumann \& Bunge (2006). As the authors describe, such projects are a challenge for the management of Antarctica.

In conclusion, national Antarctic programs have developed complex and sophisticated systems to carry out research in Antarctica and the support required is equally complex and expensive. Becoming an Antarctic Treaty Consultative Party requires making a considerable commitment of resources to establish transport to Antarctica, the erection of a station and the conduct of scientific research and the support of the scientists and other staff that make it happen.

\subsection{Tourism}

Advertising for Antarctic cruises frequently uses expressions like:

Antarctica is the largest protected wilderness in the world ...

(http://www.adventureassociates.com/pdf/Antarctica.pdf)

Antarctica remains the last vast wilderness on the planet. A continent encircled by pack ice, ranked by huge tabular icebergs and covered with an ice sheet miles deep. It is a place of beauty and mystery, enticing explorers, adventurers and dreamers over the years.

(http://www.adventure-network.com/)

Mysterious and alluring, Antarctica inspires explorers, scientists, adventurers and dreamers.

(http://www.auroraexpeditions.com.au/destination/antarctica.aspx)

\footnotetext{
${ }^{17}$ http://mcba11.phys.unsw.edu.au/ plato/plato.html

${ }^{18}$ United States, United Kingdom, Argentina, Australia and New Zealand have these programs.
} 
The Antarctic wilderness and its aesthetic values are important components of what it is that attracts people to visit and experience it.

There are a number of issues relating to tourism and the protection of wilderness and aesthetic values:

1. Tourists form by far the greatest number of visitors to the Antarctic Treaty area;

2. Tourists are the greatest "consumers" of wilderness and aesthetic values;

3. Except for three inland camps ${ }^{19}$, most tourism is based on cruise ships and, to date, there has been no other development of infrastructure ashore;

4. Tourists could damage the wilderness and aesthetic values by leaving litter, graffiti, footprints, etc and ship-borne tourism operations can potentially introduce invasive marine species, discharge sewage and affect air quality;

5. Paradoxically, tourists can threaten the appreciation of the wilderness and aesthetic values of other tourists, both directly if one ship or landing party comes into view of another and indirectly by leaving traces of visits such as large numbers of footprints.

Tourism, like all activities in Antarctica is governed by the Antarctic Treaty and its supplementary conventions, especially the Madrid Protocol. To a large extent tourism has been self-regulating thanks in no small measure to IAATO's leadership and while it has been the cause of much angst among some ATCPs and debate at ATCMs (Table 4.1), there has been reluctance at ATCMs to impose additional regulations (Lamers 2009: Chapter 1; Landau 2011). Three main concerns have been expressed by ATCPs: safety to ships and passengers (in 2007, the M/S Explorer sank in Bransfield Strait after hitting an ice berg, fortunately without any casualties), impacts on the Antarctic environment and impacts on national Antarctic program stations and research programs. A number of guidelines have been agreed with IAATO but a number of authors have criticised ATCM responses to emerging potential problems with tourism as weak, slow and potentially ineffective, i.e. not legally binding (Lamers 2009). There have been a number of definitions of what constitutes tourism in Antarctica. Hall (1992) defined Antarctic tourism as:

In the Antarctic context, tourism may be defined as all existing human activities other than those directly involved in scientific research and the normal operations of government bases. Such a definition covers the activities of commercial tourism operations, nongovernment expeditions, and the recreational activities of government personnel (Hall 1992: 4).

\footnotetext{
${ }^{19}$ ANI/ALE camp at Union Glacier, "White Desert" and "Blue One" in Dronning Maud Land.
} 
Enzenbacher (1992), however, defined tourists as follows:

Tourists are defined as visitors who are not affiliated in an official capacity with an established National Antarctic Program. They include both fare-paying passengers, whose numbers are usually reliably reported by tour operators, and private expedition members and adventurers aboard sea or airborne vessels, whose numbers are more difficult to determine. Off-duty Antarctic personnel, official inspection team members, distinguished visitors, tour operator crew and staff members, and air passengers overflying parts of the continent, are not included in this survey (Enzenbacher 1992: 17).

It is not clear from the last sentence in Enzenbacher's definition whether she considers off-duty Antarctic personnel, etc as being excluded from the definition of tourists, or just from the survey. Given that almost all personnel in national Antarctic programs will enjoy some form of recreation during their time in Antarctica, especially if they over-winter, and given the other disparities between those personnel and fare-paying passengers, a definition that groups these together is not tenable. Enzenbacher's definition is therefore preferred. Off-duty Antarctic personnel, inspection team members and distinguished visitors should not be considered as tourists. A case can be made, however, for considering tour operator crew and staff members as a third category of visitor, distinct from both tourists and national Antarctic program staff given their distinct role in Antarctica. People in this category, referred to as "tourism industry", are treated separately in the research to be described in Chapter 6 and following.

Tourism is therefore considered to be an activity that is quite distinct from national Antarctic programs. It can be divided into four categories:

1. Ship-based;

2. Land-based tourism and private expeditions;

3. Visits by yachts, both chartered and privately-owned;

4. Over-flights in commercial airlines.

Most tourism companies are members of the International Association of Antarctic Tourism Operators (IAATO). IAATO was founded in 1991 "to advocate, promote and practice safe and environmentally responsible private-sector travel to the Antarctic" (IAATO 2009). IAATO is a respected organization that attends Antarctic Treaty Consultative Meetings as an Expert Member and clearly aims to preserve the Antarctic environment, and of course it is in the best interests of its members to do so. As it states on its website:

"Our agreed best practices demonstrate that first-hand, environmentally responsible tourism is possible in remote and fragile wilderness areas. Our focus on protection, management and education promotes a greater worldwide understanding and protection of the Antarctic - leaving it as pristine and as majestic for future generations as it is today" (IAATO 2010) 


\subsubsection{Ship-based tourism}

Ship-based tourism comprises three sub-sectors:

- "Expedition"-style cruising, with landings at sites of interest;

- "Conventional" cruises that do not land passengers; and

- "Fly/cruise" tourists who fly to Marsh aerodrome (Chile) on King George Island and embark on a cruise ship there.

"Expedition"-style ship-based tourism, where tourists are landed at sites of interest, is the mainstream of Antarctic tourism (Figure 4.15).

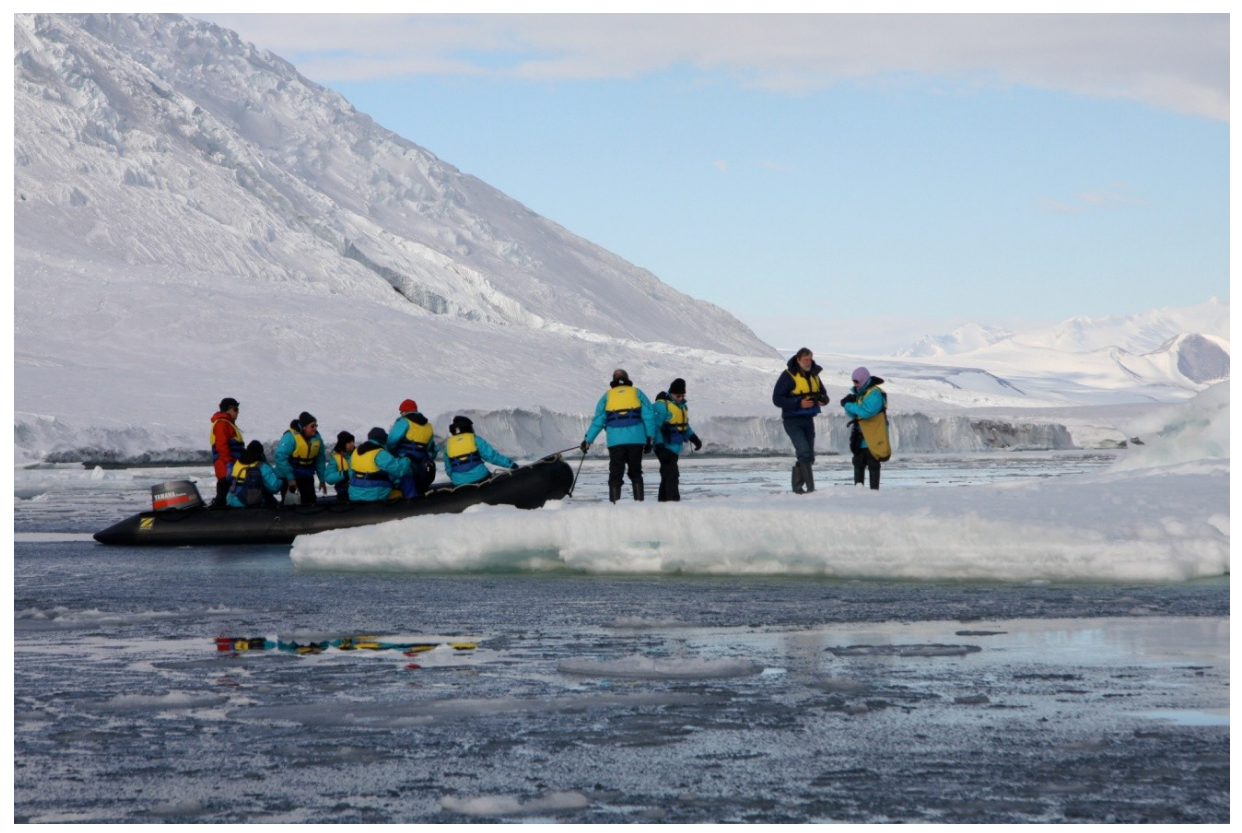

Figure 4.15. Tourists from the Marina Svetlaeva land on an ice floe near Coulman Island, Ross Sea. (Photo: Richard Barwick).

It is difficult to put a precise date on when tourism started in Antarctica, or indeed defining who the first tourists were. IAATO itself states that "modern Antarctic tourism" started in 1969 (IAATO 2010) but Enzenbacher (1992) states that tours to Antarctica began in 1957-58. Headland (2009: 363) gives the date as January 1958 when an Argentinian vessel, Les Eclaireurs, visited the South Shetland Islands and the west coast of the Antarctic Peninsula. Codling (1995), citing Capdevila (1984), noted that an Argentinean ship, the Pampa, took a group of tourists to the meteorological station "Orcadas" in the South Orkney Islands in 1933 on a resupply voyage. Headland (2009: 296) says that "A party of tourists was reported as accompanying the voyage". The first cruise organised by Lars-Eric Lindblad, the founder of modern "expedition-style" tourism (Splettstoesser \& Folks 1994: 231), took place in 1966 in the Lapataia (Headland 2009: 402). The industry developed slowly at first but by about 1990-91 as many tourists were visiting Antarctica as members of national Antarctic programs, i.e. over 
4000 (Enzenbacher 1992). Since then the industry has developed rapidly. Tourism now accounts for by far the greatest number of visitors to Antarctica. In the austral summer of 20112012 25,061 tourists, 2,096 staff and 14,212 ships' crews ${ }^{20}$ visited 206 sites in Antarctica in 233 cruises by sea (IAATO 2012b). By contrast, the peak population of all stations of all national Antarctic programs in 2012 was 4,397 (COMNAP 2012). This may be an underestimate of the total number as resupply voyages and field parties come and go during the summer field season. It is apparent from the statistics made available by IAATO ${ }^{21}$ that the numbers of tourists are starting to recover from the downturn in numbers brought on by the global financial crisis. Figure 4.16 shows the trend in tourist numbers from 1992-93-2012-13.

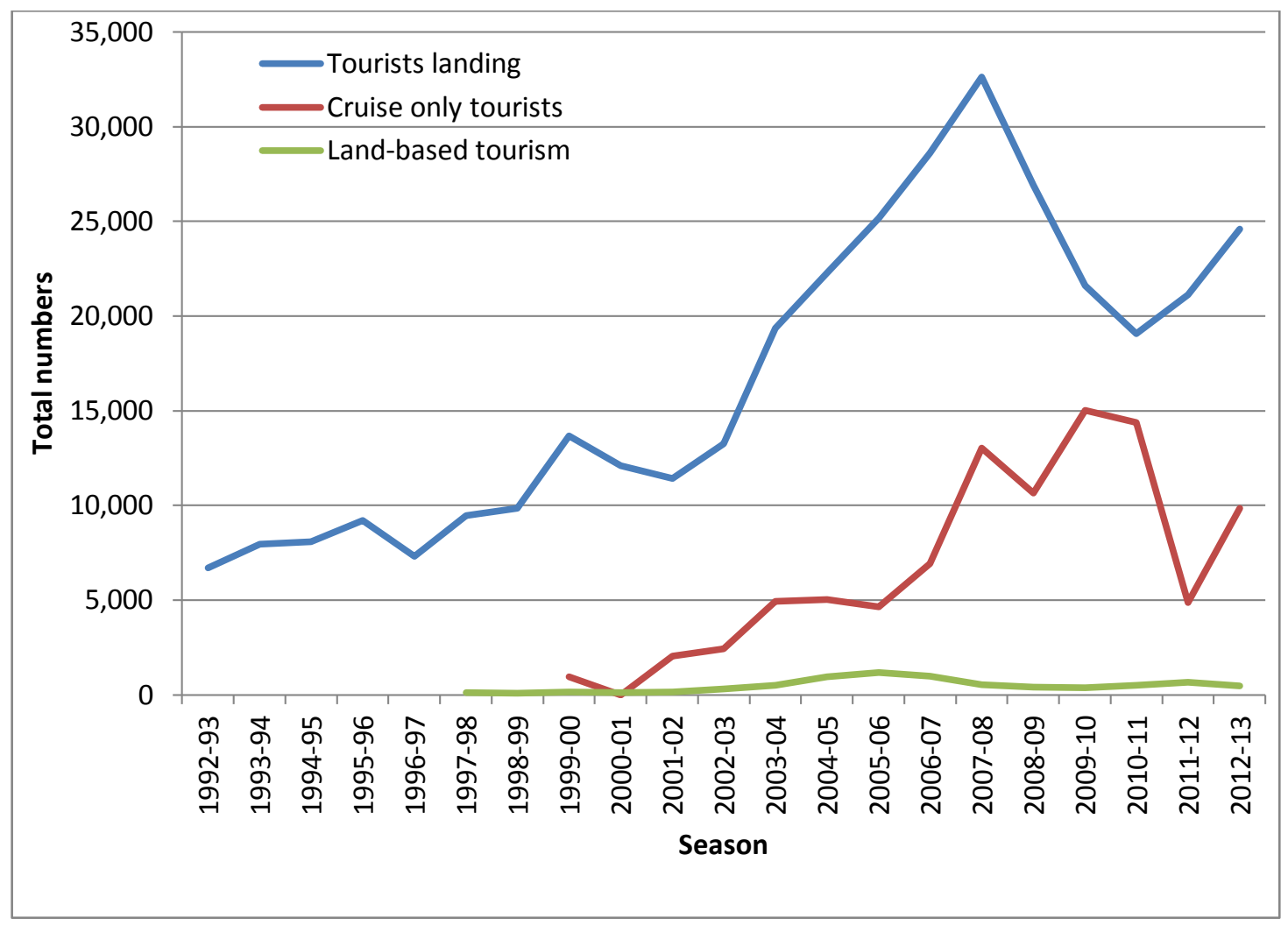

Figure 4.16. Trends in numbers of tourists from 1992-93 to 2012-13 (the numbers for 2012-13 are preliminary). Overflight numbers are not included.

\footnotetext{
${ }^{20}$ Ships' crews include catering staff and stewards to look after the passengers. It is to be expected that many of the ships' crews will remain on board for more than one voyage so this number is likely to be an over-estimate of the number of individual people.

${ }^{21}$ http://iaato.org/tourism-statistics
} 
IAATO maintains comprehensive records of the sites visited, the names of the vessels that visited these sites and the numbers of tourists that landed (IAATO 2012b). IAATO provides information about the activities the tourists carry out at each site (e.g. walking, climbing, kayaking, station visits, but not wildlife watching, etc) but does not provide information about the attractions each site offers. Penguin colonies and other wildlife aggregations are obvious attractions, as are historic sites, research stations and localities for carrying out various activities such as walking, climbing, kayaking, camping and skiing. Figure 4.2 shows the location of these sites.

Oceanites Inc., a non-profit foundation based in the USA, has prepared a guide to popular sites on the Antarctic Peninsula and offshore islands (Naveen 2005), so by comparing the IAATO landing data with the Oceanites site guide and Antarctic Treaty list of historic sites and monuments, it is possible to deduce the main points of interest.

Figure 4.17 shows the trends in visitation rates at the 10 most visited sites over the period 20032004 to 2011-2012. The eight favourite landing sites in order of popularity in 2011-2012 are as follows: Goudier Island, Neko Harbor, Whalers Bay, Couverville Island, Half Moon Island, Jougla Point, Almirante Brown Station (Paradise Bay) and Palmer Station. Petermann Island, which had been in the top 10 every season from 2003-2004 to 2010-2011, dropped to $15^{\text {th }}$ most popular in 2011-2012. Goudier Island and Jougla Point are both in Port Lockroy ${ }^{22}$ and are about $100 \mathrm{~m}$ apart. The presence of unusually thick pack ice or a grounded ice berg blocking access are the some of the reasons why a site may not be visited as often one year as in other years. Most ship-based tourist cruises visit sites on the Antarctic Peninsula and mostly at the northern end of the Peninsula. A smaller number visit the Ross Sea area and much fewer numbers other sites. The main features of interest for tourist cruises are aggregations of wildlife, especially penguin colonies, research stations, historic sites and some particularly scenic localities.

\footnotetext{
${ }^{22}$ There is an abandoned British base on Goudier Island (Base ' $\mathrm{A}$ ') that has been restored and is now a museum which is opened with a caretaker during the summer (Burton, Robert. 2008. The Story of Port Lockroy: United Kingdom Antarctic Heritage Trust).
} 


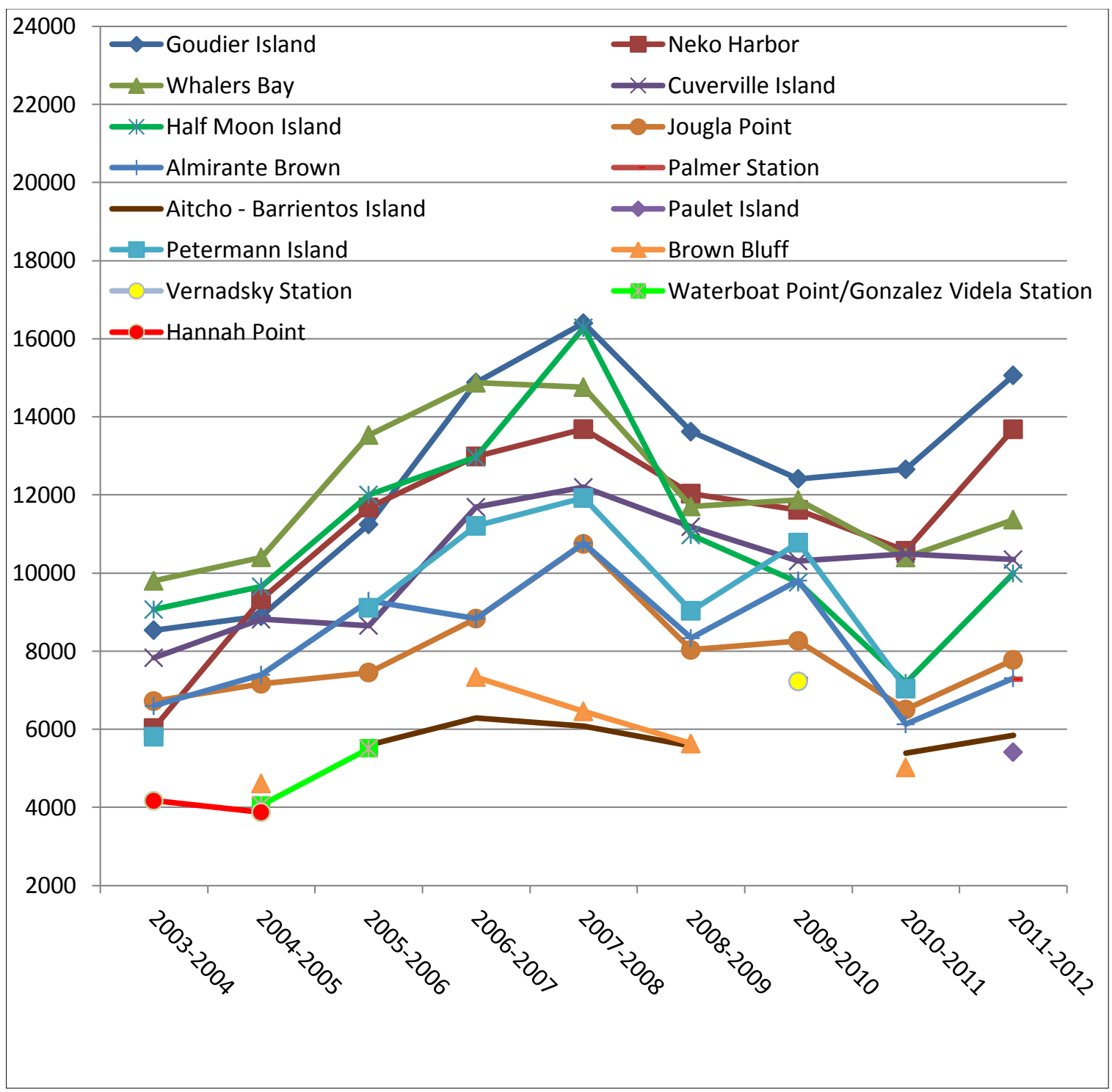

Figure 4.17. The 10 most visited tourism sites over the period 2003-2004 to 2011-2012.

$(\mathrm{Y}$ axis $=$ numbers of tourists landed $)$.

\subsubsection{Land-based tourism and private expeditions}

In addition to the 41,369 tourists, crew, etc that visited Antarctica by sea in 2011-2012, a further 692 visited by air on programs offered by the four tourism operators in continental Antarctica: Antarctic Logistics and Expeditions (ALE), The Antarctic Company (TAC) and White Desert. Antarctic Logistics and Expeditions (http://www.antarctic-logistics.com/), which also owns Adventure Network International (http://www.adventure-network.com/), operates from a base on the Union Glacier in the Ellsworth Mountains (Figure 4.10) and erects temporary camps at the base of Vinson Massif (also in the Ellsworth Mountains), at the South Pole and near an emperor penguin colony near Berkner Island on the Weddell Sea. Their clients are flown in to the airfield at Union Glacier by Russian Ilyushin IL-76 aircraft. They also offer flights and activities at even more remote sites such as Mt Sidley in Marie Byrd Land 
(http://www.adventure-network.com/experiences/). ALE also supports private expeditions: in 2011-2012 18 ski expeditions were planned from various points of departure, all of which had reaching the South Pole as their aim (ALE 2012). Many of these expeditions were commemorative expeditions, it being the centenary of Roald Amundsen and Robert Scott reaching the South Pole. ALE/ANI also organises an annual marathon and other activities. The Antarctic Company (TAC) (http://www.antarctic-company.info ) and White Desert (http://www.white-desert.com/) operate in Dronning Maud Land (Figure 4.10). It is difficult to obtain definitive information on who operates where in Dronning Maud Land; the information that follows is partly derived from a report of an official Norwegian inspection of a number of facilities in Dronning Maud Land (ATS 2010) and partly from websites of the companies concerned and other sources on the Internet. TAC and White Desert are both based near Novolazarevskaya Airfield and offer tours and adventurous activities and support for private expeditions in Dronning Maud Land, include visiting Schirmacher Oasis (a small ice free area), climbing trips to mountain ranges such as the Drygalski Mountains and trips to the South Pole.

TAC is a sister company of Antarctic Logistics Centre International (ALCI) (they share the same address in Cape Town), a private company that operates the flights and associated logistics between Cape Town and Novolazarevskaya Airfield. Novolazarevskaya airfield itself is operated by Russia.

Another organisation, '2041', has been operating in Antarctica since 2003, running leadership and educational programs at "E-Base", which has been built next to Bellingshausen Station (Russia) on King George Island. According to Bastmeijer et al. (2008) the activities conducted at "E-Base" fall within the definition of tourism.

The significance of these operators is that they all have semi-permanent, i.e. more or less permanent, facilities as well as temporary camps that are established for the summer tourism season. The impact on wilderness and aesthetic values of these operators is considerably greater than virtually all ship-based tourism, most if not all of which operates without infrastructure. While it is true that ships may interfere with each other's perceptions of wilderness and that shipping is not without impact on the Antarctic environment (Eijgelaar et al. 2010; Lynch et al. 2009), the infrastructure associated with these operators is fixed.

There are other private expeditions from time to time, some of which are self-supporting and others which use tourist vessels as transport to and/or from Antarctica. Even more occasionally there are non-government scientific expeditions. The UK Joint Services Expeditions to Elephant Island (1970-71), Brabant Island (1985-86) and the Antarctic Peninsula 2012 (BSES 2012) are examples. 


\subsubsection{Yachts}

The earliest record of a yachting cruise to Antarctica since the Second World War was by Bill Tillman in Mischief in 1966-1987 (Headland 2009: 404). Thereafter there were sporadic visits until the late 1970s from when there were visits by yachts most years. The numbers rapidly increased during the 1980s and 1990s and in 2000-2001, 20 yacht cruises were listed by Headland (Headland 2009: 604). Figure 4.18 shows the number of visits by yachts to Port Lockroy between 1996-1997 and 2011-2012 (ATS 2011b). The more than doubling of the number of yachts reported at Port Lockroy in 2006-2007 in comparison with previous years is remarkable but it is not known whether this is due to the number of yachts actually increasing or differences in the way recording was carried out.

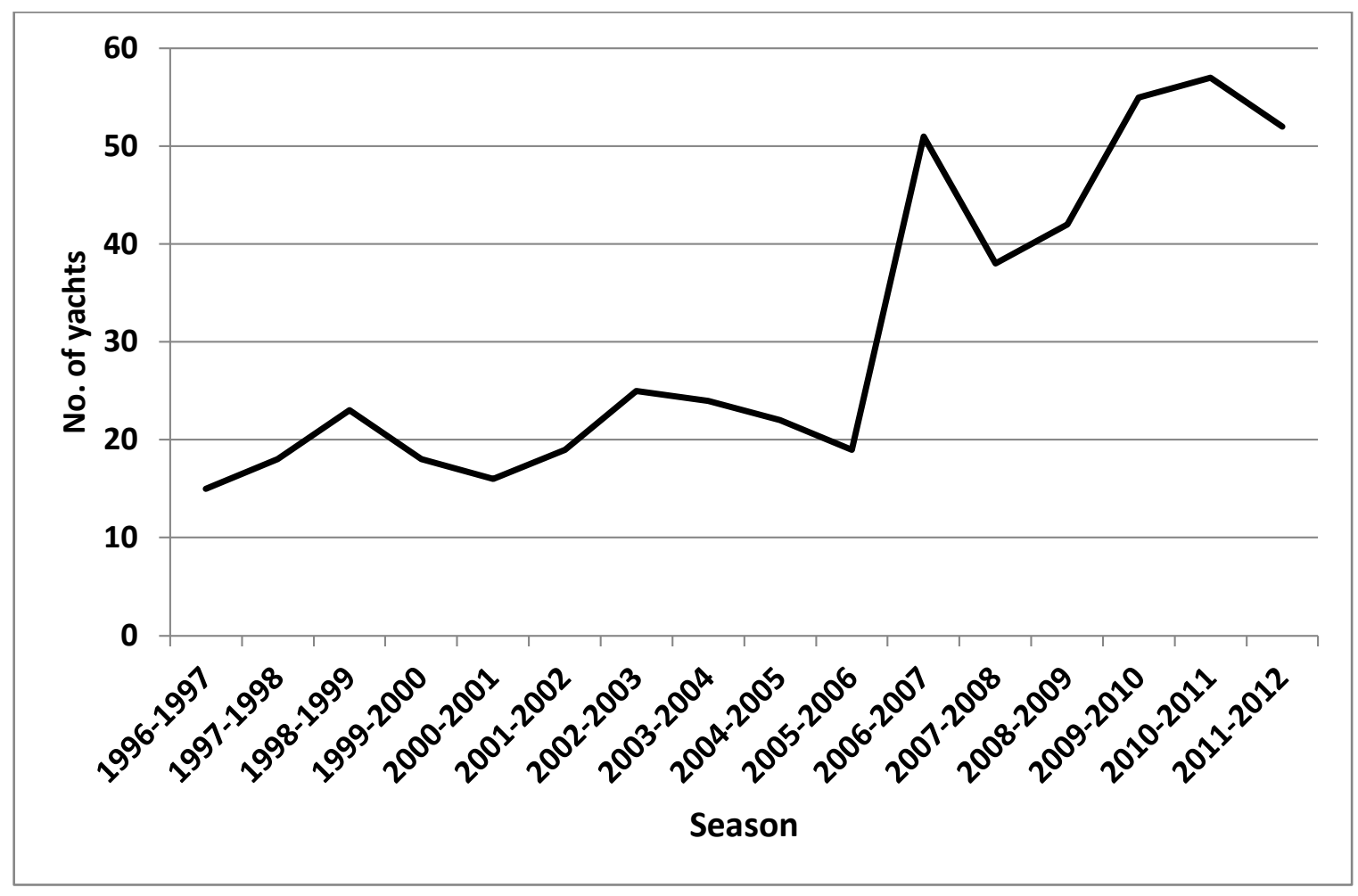

Figure 4.18. The number of visits by yachts to Port Lockroy between 1996-1997 and 20112012. Source: Antarctic Treaty Secretariat (2011b).

Some of the yachts are for charter and some are privately-owned. Of the 50 vessels registered as member vessels by IAATO, 18 are yachts (IAATO 2012a). A number of these yachts provide transport for private expeditions, especially climbing expeditions, so this category overlaps with the previous one. The Antarctic Peninsula is the most popular region for yacht visits because of its relative proximity to South America, spectacular scenery and plethora of peaks to climb. A number of concerns have been expressed by Antarctic Treaty Consultative Parties about the numbers of yachts visiting Antarctica, partly because of concerns for their safety and the potential for resources to be diverted from science programs to mount search and rescue 
missions and partly because of environmental concerns including the introduction of alien species and other impacts. Another concern is that a number of yachts have been visiting without authorisation from an Antarctic Treaty signatory country. It is assumed that, like the other aspects of tourism, the number of yachts visiting Antarctica will increase.

\subsubsection{Antarctic over-flights}

Over-flights of Antarctica in chartered commercial airliners have been a relatively inexpensive way of seeing Antarctica. Chartered aircraft from Australia and New Zealand offered overflights starting in 1977-78 but the crash of an Air New Zealand DC-10 on Mt Erebus in 1979 brought that to a halt. Over-flights from Australia recommenced in 1994 and since then there have been 73 sight-seeing flights. In 2011-12 there were only three over-flights from Australia (ATS 2012a).

Table 4.1. ATCM recommendations relating to tourism.

\begin{tabular}{|l|l|l|l|}
\hline ATCM Meeting No. Place & Year & Measure & Subject \\
\hline IV Santiago & 1966 & R27 & Regulation of Antarctic Tourism \\
\hline VI Tokyo & 1970 & R7 & Regulation of Antarctic tourism \\
\hline VII Wellington & 1972 & R4 & Effects of tourist activity \\
\hline VIII Oslo & 1975 & R9 & $\begin{array}{l}\text { Statement of accepted practices in } \\
\text { tourism }\end{array}$ \\
\hline X Washington & 1979 & R8 & Tourist regulation \\
\hline XI Buenos Aires & 1981 & R3 & Mount Erebus declared a tomb \\
\hline XIII Brussels & 1985 & R3 & $\begin{array}{l}\text { Timetable for the exchange of } \\
\text { information }\end{array}$ \\
\hline XVI Bonn & 1991 & R13 & Intersessional meeting on tourism \\
\hline XVIII Kyoto & 1994 & R1 & Guidelines for tourism \\
\hline XIX Seoul & 1995 & R3 & Tourist reporting \\
\hline XX Utrecht & 1996 & R2 & Educational and cultural activities \\
\hline XXI Christchurch & 1997 & R3 & $\begin{array}{l}\text { Tourism reporting form } \\
\text { activities } \\
\text { Tourist guidelines }\end{array}$ \\
\hline XXVI Madrid & 2003 & D5 & Expert Meeting on tourism \\
\hline XXVII Cape Town & 2004 & M4 & R3 \\
\hline
\end{tabular}




\begin{tabular}{|c|c|c|c|}
\hline XXVIII Stockholm & 2005 & $\begin{array}{l}\text { R5 } \\
\text { R6 }\end{array}$ & $\begin{array}{l}\text { Site guidelines for visitors } \\
\text { Post visit site report form }\end{array}$ \\
\hline XXIX Edinburgh & 2006 & $\begin{array}{l}\text { R1 } \\
\text { R2 } \\
\text { R4 } \\
\text { R5 }\end{array}$ & $\begin{array}{l}\text { Site guidelines for visitors } \\
\text { Site guidelines for visitors } \\
\text { Ship-based Tourism } \\
\text { Long-term effects of tourism }\end{array}$ \\
\hline XXXI Kyiv & 2008 & $\begin{array}{l}\text { R2 } \\
\text { R6 }\end{array}$ & $\begin{array}{l}\text { Site Guidelines for visitors } \\
\text { Maritime Rescue Coordination } \\
\text { Centres and Search and Rescue in the } \\
\text { Antarctic Treaty Area }\end{array}$ \\
\hline XXXII Baltimore & 2009 & $\begin{array}{l}\text { R4 } \\
\text { R7 } \\
\text { R8 } \\
\text { M15 } \\
\text { D7 }\end{array}$ & $\begin{array}{l}\text { Site guidelines for visitors } \\
\text { General principles of Antarctic } \\
\text { Tourism } \\
\text { Antarctic shipping code } \\
\text { Landing of persons from passenger } \\
\text { vessels } \\
\text { Meeting of experts on ship-borne } \\
\text { tourism }\end{array}$ \\
\hline XXXIII Punta del Este & 2010 & $\begin{array}{l}\text { R1 } \\
\text { R7 }\end{array}$ & $\begin{array}{l}\text { Site guidelines for visitors } \\
\text { Enhancement of port State control for } \\
\text { passenger vessels bound for the } \\
\text { Antarctic Treaty area }\end{array}$ \\
\hline XXXIV Buenos Aires & 2011 & $\begin{array}{l}\text { R3 } \\
\text { R4 }\end{array}$ & $\begin{array}{l}\text { General guidelines for visitors to the } \\
\text { Antarctic } \\
\text { Site guidelines for visitors }\end{array}$ \\
\hline XXXV Hobart & 2012 & $\begin{array}{l}\text { R4 } \\
\text { R5 }\end{array}$ & $\begin{array}{l}\text { Site guidelines for visitors } \\
\text { Barrientos Island - Aitcho Islands } \\
\text { visitor site guidelines } \\
\text { The assessment of land-based } \\
\text { expeditionary activities } \\
\text { Yachting guidelines } \\
\text { Checklist for visitors' in-field } \\
\text { activities }\end{array}$ \\
\hline
\end{tabular}

\subsection{Non-Government Organisations}

Non-government organisations (NGOs), especially environmental NGOs, have had a longstanding interest in Antarctica. The Antarctic and Southern Ocean Coalition was founded in 1978 to preserve the Antarctic and Southern Ocean environments (www.asoc.org). As its name 
implies, it is a coalition of more than 30 environmental groups including the Australian Conservation Foundation, Friends of the Earth, Greenpeace and the World Wide Fund for Nature. ASOC was accorded the status of "invited expert" at Antarctic Treaty Consultative Meetings. Greenpeace in particular has had an active role in drawing the world's attention to poor waste management practices at Antarctic stations, demonstrating against the construction of an airstrip and harassing Japanese whalers (Brown 1991). Greenpeace operated a small Antarctic station, World Park Base, from 1987 to 1992, which was during the period from when CRAMRA was open to signature to the signing of the Madrid Protocol. The purpose of World Park Base was partly to use the credibility of having established and operated a permanent base in the Antarctic as the basis for presenting the case for conserving Antarctica as a World Park and partly to attempt to achieve Consultative Party or "at least Observer" status for Greenpeace under the terms of Article IX (Section 2) of the Antarctic Treaty. As Roger Wilson, a senior staff member in Greenpeace, said:

"It is our contention, having established a base, staffing it through winter and conducting a scientific programme, that we, at the very least, deserve observer status in the various institutions of the Antarctic Treaty System. We have demonstrated an interest towards and concern for the Antarctic that is the equal of some of the small countries involved in the Antarctic Treaty System. Some have done very little to justify their consultative status". (May 1989: 172)

After the signing of the Madrid Protocol Greenpeace removed its station but it has periodically carried out voyages to Antarctica to inspect Antarctic stations.

\subsection{Commercial fishing}

Commercial fishing in the Antarctic regions is managed through the Convention on the Conservation of Antarctic Marine Living Resources (CCAMLR). The CCAMLR area extends from the waters surrounding the continent to $60^{\circ} \mathrm{S}$ in one quadrant and as far north as $45^{\circ} \mathrm{S}$ in other quadrants. Most fishing occurs in these more northerly areas around the sub-Antarctic islands and suitable sub-sea features. To date there has been very little fishing conducted at anything but a considerable distance offshore. As commercial fishing is managed by CCAMLR and is only subject to the provisions of the Madrid Protocol at latitudes higher than $60^{\circ} \mathrm{S}$, where little fishing occurs, it will not be considered further.

\subsection{Japanese scientific whaling}

Each year, for at least the past 20 years, Japan has taken over 200 minke whales in the Southern Ocean under the IWC scientific permit system. It has been the only nation to do so. Some whaling has taken place within sight of land. Management of whaling in the Antarctic is, 
however, carried out by the International Whaling Commission under the auspices of the

International Convention for the Regulation of Whaling (1946) and is not subject to the Madrid Protocol so it will not be considered further. 


\section{Chapter 5. Intrinsic, wilderness and aesthetic values}

\subsection{Introduction}

This chapter reviews values theory, intrinsic value, wilderness values and aesthetic values. I investigate the history of these terms, their current usage and how they may be applied in Antarctica.

As described in Chapter 3, the Madrid Protocol was negotiated to provide comprehensive environmental protection for Antarctica after the collapse in support for the Convention on the Regulation of Antarctic Mineral Resources Activities (CRAMRA) in 1989. The Madrid Protocol states that:

\footnotetext{
The protection of the Antarctic environment and dependent and associated ecosystems and the intrinsic value of Antarctica, including its wilderness and aesthetic values and its value as an area for the conduct of scientific research, in particular research essential to understanding the global environment, shall be fundamental considerations in the planning and conduct of all activities in the Antarctic Treaty area. (ATS 1998: Article 3, Section 1.)
}

It later specifies that "activities in the Antarctic Treaty area shall be planned and conducted so as to avoid ... degradation of, or substantial risk to, areas of ... aesthetic or wilderness significance." (Article 3, Section 2b, Sub-Section vi). The first stage is therefore to deconstruct the phrasing in the Protocol to come to an understanding of what the authors of the Protocol's intentions were and what the Antarctic Treaty Consultative Parties signed up to.

The phrasing in Article 3 is given as "wilderness and aesthetic values" and as "aesthetic or wilderness significance". In Annex V it is given as "aesthetic or wilderness values" and "aesthetic and wilderness value", so there are four permutations in all. The inclusion of the conjunction "or" implies alternatives: wilderness value(s) - or - aesthetic value(s) so from this analysis it is possible to conclude that two sets of values are involved. Leaving aside this preliminary conclusion, there are three possible interpretations on what these values or sets of values might represent:

1. Wilderness and aesthetic values as a grouped set of values;

2. Wilderness values and aesthetic values as separate sets of values;

3. As a "basket" term that incorporates other concepts such as spiritual, symbolic or inspirational values. 
It is not clear what a grouped set of "wilderness and aesthetic values" might comprise given that there is no precedent elsewhere in the world. These values have conventionally been considered as separate sets of values. Wilderness is generally thought of as being large natural areas undisturbed by humans (; Hendee et al. 1978; Nash 1975; Washington 2006) whereas aesthetics relates to scenic or environmental beauty (pace proponents of ecological aesthetics) (Carlson 2009; Parsons 2008). That is not to say that wilderness does not have aesthetic value, though many authors believe that wilderness should be protected on the basis of ecological values, with aesthetic values taking second place (e.g. Gobster et al. 2007; Hill \& Daniel 2008; Saito 1998). On the other hand aesthetic values are found in areas that are not necessarily wilderness - some of the historic huts in Antarctica may have high aesthetic values, Base 'A' at Port Lockroy, for example. There is no evidence in any published material relating to the development of the Madrid Protocol, or CRAMRA, that "wilderness and aesthetic values" was intended to encompass other systems of values such as symbolic or inspirational value. These values are, however, sometimes included as elements of wilderness values (e.g. Cole 2005).

As, conceptually, wilderness values are distinct from aesthetic values, though noting that, for example, aesthetic values may be found in wilderness areas, wilderness and aesthetic values in Antarctica will be treated as separate sets of values. Codling (1999) also concluded that wilderness and aesthetic values were two separate sets of values on the basis that not all areas with aesthetic value are wilderness and not all wilderness areas have "widely accepted" aesthetic value ( $\mathrm{p}$ 18). She also concluded that, commenting on the complications caused by combining wilderness and aesthetic values, “... this phrase, presumably used as a summary for larger underlying concepts, is in the Protocol" (p 18). This is the same as point 3 above and, as noted above, no evidence can be found for this conclusion.

The phrasing in the Madrid Protocol implies that "wilderness and aesthetic" are adjectives describing the noun "values". Why is it that wilderness and aesthetic values are to be protected and not, for example, wilderness per se? This phrasing has troubled some commentators and caused some confusion (Neufeld et al. 2013: sect. 4.4.1.2). There has been a general recognition that the Protocol contains some inconsistencies, ambiguities and flaws, many of which are a result of the haste with which the Protocol was negotiated (Jackson \& Kriwoken 2011: 316). Nevertheless, there is some merit in specifying, or at least implying, that wilderness and aesthetics must be valued in order to merit protection. This interpretation is consistent with the re-phrasing in Article 3, Section 2b, Sub-Section VI as "aesthetic or wilderness significance". Further interpretation is however required on what wilderness significance might be in Antarctica and this will be discussed in the section on wilderness below. 
The relationship between wilderness and aesthetic values and intrinsic value is much more complex. The phrasing in the Madrid Protocol implies that wilderness and aesthetic values should be considered as varieties, or sub-species, of intrinsic value: “ $\ldots$ and the intrinsic value of Antarctica, including its wilderness and aesthetic values ..." (Article 3, Section 1). There are two ways to approach this: the first is to assume that the authors of the Madrid Protocol and the delegates from the Antarctic Treaty Consultative Parties were familiar with the arguments for intrinsic value but nevertheless chose to mandate protection for the intrinsic values of Antarctica and to position wilderness and aesthetic values as varieties of intrinsic value. The second possibility is that the authors of the Protocol were NOT familiar with the philosophical arguments surrounding intrinsic value so used it in a non-technical sense, i.e. to mean something like the natural values or the values unique to Antarctica. The minutes of the special Antarctic Treaty Consultative Meetings held during the negotiations leading up to the Madrid Protocol have not yet been published so it is not yet possible to determine what the intentions of the authors of the Madrid Protocol were in this regard. It is not, however, considered safe to presume that the authors of the Madrid Protocol intended anything other than what they signed. For that reason, and because an approach developed within the debate on intrinsic value will result in a stronger position, it will be assumed that the delegates wanted wilderness and aesthetic values to be considered within the main philosophical tradition of intrinsic value.

\subsection{Value and values}

Value theory is a complex field with theories of values developing independently in the fields of social psychology and philosophy. There is a body of literature devoted to values theory which attempts to define the characteristics of human values (e.g. Mayton et al. 1994; Rokeach 1973; Schwartz 1994). Humans have developed value systems over the full range of human activities including scientific values, religious values, political values, and family values. In the realm of social psychology Milton Rokeach developed the Rokeach Values Survey as a means of measuring values and systems of values (Rokeach 1973). Shalom Schwartz, also a social psychologist, states that "there is widespread agreement in the literature regarding five features of the conceptual definition of values" (Schwartz 1994). He enumerates these five features as follows:

1. A belief;

2. Pertaining to desirable end states or modes of conduct;

3. Transcends specific situations;

4. Guides selection or evaluation of behaviour, people and events;

5. Is ordered by importance relative to other values to form a system of value priorities. 
Schwartz identifies ten motivational types and three universal requirements of human existence from which each type of value has been derived. It seems that, from the context of the Madrid Protocol, and the over-arching motivation of protecting the Antarctic environment, that wilderness and aesthetic values fall within the Universalism type of value, which he defines as "understanding, appreciation, tolerance, and protection for the welfare of all people and for nature". As might be expected, these are contrary to other motivational types such as "Power" and "Achievement" but fall well within the ethic put forward by the Antarctic Treaty of "Recognizing that it is in the interest of all mankind that Antarctica shall continue forever to be used exclusively for peaceful purposes ..." (ATS 1959).

According to Thomas (1998), in philosophy there are three main traditions in the theory of value: subjectivism, which holds that only humans can ascribe value; objectivism, which states that while values must be human-related they can exist independently; and neo-Kantian rationalism which states that value is based on practical reason. Axiology (the theory of value) has been neglected as a field of philosophical inquiry (Smith \& Thomas 1998). Velasquez (2005) however states that "values are a fundamental concern of philosophy". It seems therefore that while study of the theory of values has been neglected, values themselves are the subject of active debate. The field of philosophy where discussion of intrinsic value is most relevant to the requirements of the Madrid Protocol is in environmental philosophy, a recently developed branch of philosophical inquiry (Callicott \& Ames 1989) which is a branch of ethics or moral philosophy, which, according to many authors (e.g. Baggini \& Southwell 2012; Velasquez 2005), is one of the key areas of inquiry in Western philosophy. In a more pragmatic sense, Perry (1926: 115) proposed that "Any object, whatever it be, acquires value when any interest, whatever it be, is taken in it". Hetherington et al. (1994: 537) take this idea further, arguing that values cannot be directly observed, whereas "preference- related value," "the setting by an individual of one thing before or above another thing because of a notion of betterness" is empirically measurable. Preference is an important concept in this context; in making judgments about landscapes we do not make an absolute judgement about the scenic beauty, for example, of a particular landscape, only a relative judgement. Kaplan and Kaplan (1995: 9-11) discuss the role and importance of preference in detail.

Rolston (1988: 3) created an "inventory" of 15 values carried by nature: life-support, economic, recreational, scientific, aesthetic, genetic-diversity, historical, cultural-symbolization, characterbuilding, diversity-unity, stability and spontaneity, dialectical, life, religious. Other values could be added to the list such as inspirational value (Gair 1999). Many of these values are to be found in wilderness, for example, life-support, recreational, scientific, genetic-diversity and aesthetic. 
There are many other inventories of values to be obtained from the natural environment (e.g. Hall 1992: 50); Fox (1990: 160), however, frames many such values as instrumental values, which is one of the two major classes of value that philosophers recognise, the other being intrinsic value. The distinction between these two classes of value and their relationship with wilderness and aesthetic values is discussed below.

\subsection{Intrinsic value}

It is not necessary, and not possible in the space available, to develop a case for what intrinsic values might be found in Antarctica. My aim, therefore, is twofold:

1. To demonstrate that wilderness and aesthetic values can be considered as intrinsic values, especially in Antarctica; and

2. Therefore to provide additional theoretical support for the Madrid Protocol and the protection that it provides for these values.

The inclusion of intrinsic value in the Madrid Protocol adds considerable complexity, especially when the wording in the Protocol appears to have confused intrinsic and instrumental values. The Protocol is however the source of protection for wilderness and aesthetic values so in developing a theoretical position about wilderness and aesthetic values it is important not to undermine it. Is it possible, therefore, to construct a theoretical position that is consistent with current environmental and philosophical thinking which also supports the phrasing of the Madrid Protocol? In other words, can wilderness and aesthetic values be considered as being consistent with current ideas about intrinsic value or are they irredeemably instrumental values?

The categorisation of values into instrumental and intrinsic value is one of the most widely debated fields in value theory (Smith 1998) but also one of the most fundamental. In environmental philosophy the distinction between intrinsic value and instrumental value (discussed below) is central to environmental ethics (Afeissa 2009), which itself is the cornerstone of environmental philosophy and is discussed in detail below. Rokeach (1973) prefers the terms instrumental value and terminal value, where instrumental values are means to an end and terminal values are desirable end states of existence. Intrinsic value and terminal value are therefore more or less synonymous. Intrinsic values, in brief, are those things that are valued for their own sake, not for any benefit they might confer on anyone or anything (Bowman 2002; Zimmerman 2001). Instrumental values, also known as extrinsic values, are usually easier to identify and conceptualise because they are often things of material value to people such as trees for the timber they produce, rivers for the water they provide, etc (Zimmerman 2010). Traditionally only humans were thought to have intrinsic value (Vilkka 1997: 3) and that Nature was created for Man to "have dominion over the fish of the sea, and over the fowl of the air, and over every living thing that moveth upon the earth" (Genesis 1:28), 
i.e. to be of instrumental value only. The role of this and other passages in Genesis in forming Western attitudes to the natural world has been much discussed, including by Glacken (1967: Chapter 4), White (1967: 1205), Thomas (1984: 17-18), Nash (1990: 88-91) and Krebs (1999: 129-132); the latter three also discuss White's seminal role, though as Thomas points out (fn $\mathrm{p}$. 23), others before him had made similar accusations. It is only fair to point out that the idea of dominion as expressed in Genesis as the origin of destructive Western environmental attitudes is disputed, e.g. Steffen (1992).

The publication of White's paper, "The historical roots of our ecologic crisis" and "The tragedy of the commons" by Garrett Hardin (Hardin 1968) have been cited as forming the origins of the concept of environmental values (e.g. Katz 1991: 80). The field of environmental philosophy emerged in the early 1970s and with it the concept of an environmental ethic. As Katie McShane put it, “. . in the early days of environmental ethics, intrinsic value (and that of nature in particular) was the theoretical holy grail" (McShane 2007): 46). Intrinsic value is essentially an ethical position; as John O’Neill put it: “To hold an environmental ethic is to hold that nonhuman beings and states of affairs in the natural world have intrinsic value" (O'Neill 1992: 119). The position of intrinsic value in environmental philosophy is a controversial topic which is still the subject of debate (e.g. Christoff et al. 2001; Godfrey-Smith 1980; McShane 2007; Morito 2003; Rolston 1988; Vilkka 1997; Zimmerman 2001). At its heart is the issue of whether only humans are able to attribute or possess intrinsic value. Zimmerman (2010) reviews many of the positions - there is a very large body of literature on this subject from Plato in the $4^{\text {th }} \mathrm{C} \mathrm{BCE}$ to the present. In order to develop a position with regards to intrinsic value that supports the Madrid Protocol but does not conflict substantially with established thinking, a brief account of some of the main schools of thought on intrinsic value in environmental philosophy follows.

Paul Taylor proposes that to have "an attitude of respect for nature is to regard the wild plants and animals of the Earth's natural ecosystems as possessing inherent worth" (Taylor 1986: 71). Taylor uses three terms for describing non-instrumental value: intrinsic value, inherent value and inherent worth. As he himself acknowledges: "The terms being used to designate the three concepts are not uniformly agreed upon" ( $\mathrm{p} 72$ ). Inherent worth, according to his definition is that which possesses such worth regardless of any instrumental or inherent value it may have and without any reference to the good of other beings. Intrinsic value, by contrast, is when "humans or other conscious beings place positive value on an event or condition in their lives which they directly experience to be enjoyable in and of itself." “... Intrinsic value is likewise placed on goals that conscious beings seek to bring about as ends in themselves and also on interests they pursue as intrinsically worthwhile." Inherent value is the "value we place on an object or a place ... that we believe should be preserved, not because of its usefulness or its 
commercial value but simply because it has beauty, or historical importance or cultural significance ... living things themselves can be judged to have inherent value" (Taylor 1986: 74).

John O’Neill (1992: 119-120) identifies three meanings for intrinsic value:

1. As a synonym for non-instrumental value;

2. The value an object has solely in virtue of its intrinsic properties;

3. As a synonym for objective value, i.e. the value that an object possess independently of the valuations of others.

There is some common ground between the two authors; Taylor's definition of inherent worth is close to O'Neill's first definition for intrinsic value. Hargrove (1992) describes a number of forms of intrinsic value distinguishing nonanthropocentric intrinsic value from anthropocentric intrinsic value, which is the conventional human-centred type that considers that only humans can have intrinsic value. Nonanthropocentric intrinsic value is the type of intrinsic value that environmental philosophers search for. Hargrove further distinguishes two types of nonanthropocentric intrinsic value: objectivist and subjectivist. He suggests that Paul Taylor and Holmes Rolston III belong to the objectivist school and J Baird Callicott to the subjectivist school. The difference between the two schools of thought, very briefly summarised, being that in the subjectivist school values are "projected" onto the natural world by humans whereas in the objectivist school values are to be found independent of human valuing. As Hargrove remarks, most nonanthropocentric value theories are in various ways really anthropocentric. Hargrove criticises Rolston for his weak treatment of natural beauty, which Hargrove regards as "truly unfortunate" (p 193). This appears to have come about because of Rolston's goal of deriving an objectivist position in which it is difficult to accommodate subjective aesthetic value (p 191).

Holmes Rolston III, in discussing whether values can be objective or are only subjective, states that "values exist only where a subject has an object of interest" (Rolston 1982). He cites Barton Perry (1926) who stated "Any object, whatever it be, acquires value when any interest, whatever it be, is taken in it." Rolston believes that intrinsic value may be found in two situations: first, in a human experience which is enjoyable in itself and does not require any additional instrumental interest and, second, in some natural event that does not have any human input, by which he means that an organism (the example he gives is a loon) can continue to express whatever pains or pleasures it feels, without the need for any human contribution.

Rolston is one of only two philosophers to have written about philosophical issues in Antarctica (Johnson 2003; Rolston 2002). As Callicott says (Callicott 1992), Rolston pursues a theoretical 
quest to identify and validate intrinsic value in nature, something which Rolston alleges modern human attitudes do not recognise (Rolston 1988).

On the subject of intrinsic value in Antarctic he remarked:

"We humans seem to be resolving to keep the one nonhuman continent as pristine as possible. Philosophers have much argued about intrinsic value, and they will wonder just what is meant here. But it is impressive to have a consensus of several dozen nations resolved to protect the intrinsic value of Antarctica" (Rolston 2002).

Rolston's pursuit does not, however, extend beyond the biotic to the abiotic. Lee (2007), in reviewing Rolston's work, discusses his reaction to Antarctica. Lee notes that "the focus of Rolston's writing is in the domain of the biotic" (p 18) and also that he is interested in Antarctica. However she also notes that the Antarctic continent is predominantly composed of ice and therefore, with the exception of the coastal fringe, harbours little life. This, she notes, means that Rolston has to confront the limits of his environmental philosophy when thinking about Antarctica as he does not give much consideration to the abiotic. Rolston advocates a "soft" anthropocentrism for Antarctica (Lee 2007) in which he allows non-human nature to have instrumental value in terms of its aesthetics. Lee goes on to explore the ways in which abiotic nature can have value and, commenting that "abiotic entities, i.e. rocks, ice, etc, are not intrinsically valuable either "in themselves", like humans, or "for themselves" like plants and animals, and settles on the term "independent value" for abiotic entities, which may be valuable "by themselves" (Lee 2007). This is possibly an example of the philosophical - or prepositional - hair-splitting that Christoff, Plumwood et al. objected to (Christoff et al. 2001). The question of whether abiotic entities can have intrinsic value is important when considering that more than 99\% of Antarctica comprises ice (Fox \& Cooper 1994), most of which is abiotic.

Val Plumwood, cuts through the philosophical hair-splitting and offers a sensible and practical definition when she says "in my own work the meaning intended in claiming that an item is intrinsically valuable is that its value cannot be explained by or reduced to instrumental considerations" (Plumwood 1991: 141). She refutes the idea that intrinsic value is necessarily objective, i.e. that it is not dependent on an individual's personal preferences or taste (Thompson 1990: 148). To be intrinsically valuable does not, therefore, require the absence of a valuer. If this definition can serve as the definition for intrinsic value in Antarctica, wilderness and aesthetic values would be values that cannot be "explained by or reduced to instrumental considerations"? In other words, wilderness and aesthetic values should be valued simply for what they are, not for any benefit to be obtained from them. That would only be satisfactory if these values can be demonstrated not to be wholly instrumental. 
If instrumental and intrinsic values are species of value, there must also be ways of valuing. As noted above, there are (outside moral/environmental philosophy) other types of values, therefore there cannot be the same way to value things - there must be different ways of valuing, for example love and respect. McShane (2007) takes up this argument, first using love as an example of an attitude commonly attributed to intrinsic value. She goes on to include "Respect, and (at least in some manifestations) reverence and awe seem to have a similar structure" [to love] (p 53). Plumwood (1991: 147) "find[s] no great difficulty with the suggestion that we should respect rocks, mountains, and ecosystems ..." Respect and awe are certainly two attitudes that are worth having in Antarctica, though, as the first example shows, this may be more for instrumental reasons, i.e. survival, than for intrinsic value. Cecil Madigan, the meteorologist on the Australasian Antarctic Expedition wrote:

Early that day we had our first experience of the treacherous crevasse. Correll went down a fissure about three feet wide. I had jumped across it, thinking the bridge looked thin, but Correll stepped on it and went through. He dropped vertically down the full length of his harness--six feet. McLean and I soon had him out. The icy walls fell sheer for about sixty feet, where snow could be seen in the blue depths. Our respect for crevasses rapidly increased after this, and we took greater precautions (Mawson 1914: 313 (Vol. I)).

... and later:

Awed and amazed, we beheld the lone vastness of it all and were mute. Rising out of the flat wilderness over which we had travelled was a mammoth vertical barrier of rock rearing its head to the skies above. The whole face for five miles was one magnificent series of organ- pipes. The deep shade was heightened by the icy glare beyond it (Mawson 1914: 334 (Vol. I)).

Given that there are many positions on intrinsic value ranging from anthropocentric intrinsic value to objectivist nonanthropocentric intrinsic value, each one being liable to criticism by believers in other schools of thought, no one position will satisfy everyone. The over-riding concern must however be the implementation of the Madrid Protocol and protection of wilderness and aesthetic values. The quest for objective nonanthropocentric intrinsic value to underpin wilderness and aesthetic values such that can be agreed to by all 28 Antarctic Treaty Consultative Parties is essentially unachievable. The diversity of languages and cultures as well as the different aims and aspirations of each country, the tradition of consensus in decisionmaking and the conservative attitude of national delegations (Huber 2011) all militate against the introduction of the relatively radical objective version of nonanthropocentric intrinsic value. It is to be expected that a subjective version, based on what may be considered universal values, may be more acceptable. 


\subsection{Wilderness and wilderness values}

\subsubsection{History}

The history of the concept of wilderness has been recounted by a number of environmental historians, e.g. Nash (1975), Oelschlaeger (1991), (Hall 1992) and its position in environmental thought still widely debated, e.g. Callicott \& Nelson (1998), (Guha 1989) and Low (2002). Nash (1975) has compiled the definitive account of the history of the idea of wilderness in the USA, tracing its usage and how it has changed from the days of the early colonists, to the successful passing of the US Wilderness Act in 1964. Nash describes how wilderness had a pejorative meaning in the early days of colonising North America. Wilderness was a dangerous place; where natives and the Devil lurked, where the bonds of society were loosened. The wilderness was a place to be feared and therefore a place to conquer. As the colonies expanded and started to push westwards and the ideas of the Enlightenment arrived from Europe, natural landscapes began to be appreciated for their own sakes. In the mid-nineteenth century appreciation of wilderness on one hand and horror of it on the other were still unevenly spread, as is evidenced by Henry Thoreau, whom Nash lists as the first of the giants of American wilderness appreciation, who remarked that:

"For one that comes with a pencil to sketch or sing, a thousand come with an axe or a rifle" (Thoreau 1972: 119).

Hendee et al. (1978) review the history of changing ideas of wilderness in the US and then canvass many of the issues involved in managing wilderness, including whether, and to what extent, humans should intervene in wilderness management. Thomas (1984) analyses changing attitudes to the natural world in Britain. Simon Schama's monumental work "Landscape and Memory" (Schama 1995) does the same across the length and breadth of Western culture. Oelschlaeger (1991) analyses changes in the concept of wilderness from the Palaeolithic to the present. Hall (1992) covers changing attitudes to wilderness in Australia. The contributors to Callicott and Nelson (Callicott $\&$ Nelson 1998) re-consider wilderness from a late $20^{\text {th }}$ century perspective, as well as re-capitulating old ideas. A number of authors have had difficulty with the concept of wilderness, for example Guha (1989), who considers wilderness to be another form of Western imperialism, Cronon (1995), who thinks that the focus on wilderness distracts from the protection of nature close to home and Low (2002), who believes that conservation of biodiversity is more important than protection of large areas, often with little biodiversity. These, and other arguments, have some validity but it is unlikely that any conservationist would allow existing wilderness areas to be destroyed. There are undoubtedly some problematic connotations with the word 'wilderness' (explored by Washington (2006)) but in the absence of 
any other word that means a large area unmodified by human activity then wilderness and the "cultural baggage" that goes with it will have to do.

\subsubsection{Definitions of wilderness}

In this section I review a number of the many definitions of wilderness. Among the definitions offered by the Oxford English Dictionary the following are most relevant to Antarctica:

1. Wild or uncultivated land;

2. A wild or uncultivated region or tract of land, uninhabited or inhabited only by wild animals. (OED 1989)

The US Wilderness Act (1964) makes the following definition of wilderness:

A wilderness, in contrast with those areas where man and his own works dominate the landscape, is hereby recognized as an area where the earth and its community of life are untrammeled by man, where man himself is a visitor who does not remain. An area of wilderness is further defined to mean in this Act an area of undeveloped Federal land retaining its primeval character and influence, without permanent improvements or human habitation, which is protected and managed so as to retain its natural conditions and which:

(1) generally appears to have been affected primarily by the forces of nature, with the imprint of man's work substantially unnoticeable;

(2) has outstanding opportunities for solitude or a primitive and unconfined type of recreation;

(3) has at least five thousand acres of land or is of sufficient size as to make practicable its preservation and use in an unimpaired conditions; and

(4) may also contain ecological, geological, or other features of scientific, educational, scenic or historical value. (US Wilderness Act 1964).

The key word in this definition; the first adjective describing what type of area a wilderness might be, is "untrammelled". This unusual word is derived from an old French word for a net. A trammel now means, amongst other things, "anything that confines". As Mark Harvey in his biography of Zahniser describes, Zahniser took immense care in his choice of words whilst drafting the Wilderness bill:

"To take a prime example, consider the word that he [Zahniser] chose to define the essence of wilderness. Zahniser thought it crucial to find just the right word, and he had done so in 1956 during a conversation with his friend and fellow wilderness advocate from Seattle, Polly Dyer, who has used "untrammelled" to describe the ocean near Olympic National Park. He liked the word at once, and repeatedly defended its use in the wilderness bill.” (Harvey 2005: 202) 
Washington (2006) reviews many of the modern definitions and proposes "large natural intact area" as a simple definition.

The most valuable definitions of wilderness in this context are those that have been enshrined in legislation.

The Wilderness Society in America defines wilderness as:

... [the] legal definition laid out in the Wilderness Act of 1964. In short, Wilderness is designated by Congress on federal public lands - National Parks, Forests, and Wildlife Refuges, and Bureau of Land Management lands - and is the highest form of protection for federal lands. No roads or permanent structures are allowed in Wilderness, nor activities like logging, mining, or most vehicular traffic (Wilderness Society 2009)

The International Union for the Conservation of Nature (IUCN) has laid out six categories of protected area with the first category of strict protection being divided into two sub-categories: Strict Nature Reserve (Ia) and Wilderness Area (Ib). IUCN Category Ib Wilderness is defined as a:

"A large area of unmodified or slightly modified land, and/or sea, retaining its natural character and influence, without permanent or significant habitation, which is protected and managed so as to preserve its natural condition." (Dudley 2008).

The World Database on Protected Areas at UNEP-WCMC in Cambridge ${ }^{23}$, UK lists 57 protected areas in Antarctica; 26 categorised as IUCN 1a (Strict Nature Reserve) and 31 as not categorised. There are no areas categorised as IUCN $1 \mathrm{~b}$ (Wilderness area).

The Wild Foundation, the organisation that publishes the International Journal of Wilderness and organises the World Wilderness Congresses defines wilderness areas as:

"The most intact, undisturbed wild natural areas left on our planet - those last truly wild places that humans do not control and have not developed with roads, pipelines or other industrial infrastructure" (Wild 2013).

Definitions that take no account of indigenous peoples, who have lived in areas "where man himself is a visitor who does not remain" for centuries, are no longer acceptable and this phrasing in the Wilderness Act has been much criticised (e.g. Denevan 1995). In the Antarctic, however, where there have never been any indigenous people, such definitions as "where man himself is a visitor who does not remain" and "generally appears to have been affected primarily by the forces of nature, with the imprint of man's work substantially unnoticeable" seem appropriate. The adjective untrammelled, with its connotations of boundaries and fences is

\footnotetext{
${ }^{23}$ http://www.protectedplanet.net. Accessed 14 April 2013.
} 
not, however, the right choice of word for Antarctica. The implication that the purpose of wilderness is to provide opportunities for recreation does not sit easily with notions of protecting intrinsic value and value for science, even though tourists now easily outnumber scientists and support personnel. It is to be hoped that loftier ambitions hold sway for the seventh continent.

In Australia, wilderness no longer seems to be the concern of the Commonwealth Government. There are only two pieces of current legislation in the list of Commonwealth of Australia consolidated acts (www.austlii.edu.au): the Antarctic Treaty (Environment Protection) Act 1980, which is domestic legislation to ratify agreements made under the Antarctic Treaty such as the Convention for the Conservation of Antarctic Seals and the Madrid Protocol, and the Regional Forest Agreements Act 2002. This is to be contrasted with a major development in wilderness identification which began in the 1980s. In 1986 the Australian Heritage Commission, which was agency of the Commonwealth Government at the time, embarked on a project to identify wilderness quality throughout Australia. This project became known as the National Wilderness Inventory (Lesslie \& Maslen 1995). Further development was abandoned in the mid-1990s following funding cuts (Buckley 2000).

The Colong Foundation for Wilderness, a foundation established in New South Wales as an advocate for the protection of wilderness was established in 1986, though its antecedents go back to the National Parks and Primitive Areas Council established by Myles Dunphy in 1932 (Colley \& Gold 2004: 10). The definition of wilderness preferred by the Colong Foundation is: "Wilderness comprises that last substantial remnants of the ecologically complete environment that once covered the earth.” (Colong Foundation 2013)

New South Wales enacted a Wilderness Act in $1987^{24}$ largely as a result of lobbying by the Colong Foundation. Wilderness in this Act is defined more by what it is not that what it is, for example:

(1) An area of land shall not be identified as wilderness by the Director unless the Director is of the opinion that:

(a) the area is, together with its plant and animal communities, in a state that has not been substantially modified by humans and their works or is capable of being restored to such a state,

(b) the area is of a sufficient size to make its maintenance in such a state feasible, and

(c) the area is capable of providing opportunities for solitude and appropriate self-reliant recreation.

\footnotetext{
${ }^{24}$ http://www.austlii.edu.au/au/legis/nsw/consol_act/wa1987139/
} 
(Part 2. Section 6. Identification of wilderness)

There are also, however, metaphysical definitions of wilderness. Nash, in describing the potential need to limit human visitors to wilderness areas by a quota system, wrote that "The quality of freedom so frequently associated with wilderness is diminished, if not destroyed, by regulation. Campgrounds become sleeping-bag motels with defined capacities and check-out times. The point is underscored by the fact that wilderness, in the final analysis, is a state of mind (Nash 1975: 273)." Yi-Fu Tuan wrote: “'Wilderness' cannot be defined objectively: it is as much a state of mind as a description of nature" (Tuan 1974: 112). Anthony Smith, quoting Eivind Svoyen of the (US) National Park Service, wrote: "Wilderness is a physical condition, it is also a state of mind" (Smith 1978: 183). Smith and Watson (1979) propose that wilderness is defined by experience. Exactly what that "state of mind" might be is not stated but Smith (1978: 183) characterised "absence of restraint" as being the "most singular joy in wilderness". Paradoxically, from my own experience, "absence of restraint" is hard to achieve in Antarctica; as the sub-title of Smith (2009) says "No one goes to Antarctica alone". The logistical difficulties of getting to Antarctica, the hostile climate, the dangers of travel, the fact of being doubly remote and the high cost and risks of rescue in the event of an accident result more in feelings of responsibility than freedom. In national Antarctic programs the obligations of responsibility for one's companions' safety and the success of the program or activity being undertaken at very large cost do not loosen the shackles of restraint. That is not to say that the experience of Antarctica cannot be awe-inspiring and many other intense feelings but it is not like a wilderness experience elsewhere. Bill Green, an American geochemist with seven years experience of Antarctica wrote about Lake Vanda in the Dry Valleys:

“... this one lake, not much larger than Walden, yet intensely and austerely more beautiful; this one lake, in all the world, completely removed from art and commerce and industry, its shores unsettled and unvisited; its howling emptiness in this valley for which "wilderness" is far too tame a word" (Green 1995: 254)

The word "wilderness" may have become degraded in his mind through its application to relatively small areas of land in the US; there are 128 wilderness areas in the US with an area of less that $25 \mathrm{~km}^{2}$ (Wilderness 1996). Antarctica, however, is the least disturbed continent and the world's largest desert (Schofield 1972: 193) so wilderness is an appropriate term for its undisturbed areas. In addition, given the relatively low human impact and the intentions of the Madrid Protocol, a higher standard of care should be expected of its custodians.

Bastmeijer (2008) also weighs the "state of mind" versus "real place" arguments and notes that the "state of mind" arguments, that emphasise subjective judgments of wilderness, have been criticised as being inadequate bases for law and policy making but that "real place" arguments such as physical dimensions, the lack of human developments and intact ecosystems have been 
used successfully, for example in the US Wilderness Act. He also notes the conclusions reached by Codling (1998) and Keys (1999) (also by Summerson and Riddle (2000)) that "most of the Antarctic must be considered wilderness with the exception of, in particular, the areas where research stations are located" (Bastmeijer 2008: 9). This argument is developed further below.

\subsubsection{Precedents for protection}

There are precedents for the protection of wilderness in national legislation in many countries that are Consultative Parties to the Antarctic Treaty. Landres et al. (2008) list wilderness protection legislation in 11 countries, the earliest of which is the US Wilderness Act of 1964, the enactment of which stimulated the identification and protection of wilderness and wilderness values on federal lands in the United States. Of these countries seven are Antarctic Treaty Consultative Parties: Australia, Finland, Japan, New Zealand, Russia, South Africa and the USA; Canada has acceded to the Antarctic Treaty but is not a consultative party. The remaining countries, Iceland, Mexico and Sri Lanka are not part of the Antarctic Treaty System. Finland is the only European country with wilderness legislation though some other countries, e.g. Norway and Sweden recognise wilderness as a concept and provide for its protection, but not formally as "wilderness" (Vistad \& Vorkinn 2012). There is therefore widespread experience with wilderness in domestic legislation which could be applied to developing policies relating to wilderness in Antarctica. In the absence of any other information, it has to be assumed that the authors of the Madrid Protocol intended wilderness values in Antarctica to encompass similar concepts to those on the settled continents with which a number of Antarctic Treaty Consultative Parties have had experience.

Not everyone agrees with the concept of wilderness in Antarctica, however. Dr Phillip Law, the director of the Australian Antarctic Division in the 1950s and 1960s, was scathing of the idea of wilderness in Antarctica, making statements such as:

"The proposal to declare Antarctica a World Wilderness Park is absurd."

"The sheer absurdity of the Antarctic Wilderness proposal would lead us to regard it as something of a joke if it were not for the fact that support by the Australian Government for this proposal and the Government's decision not to sign CRAMRA (the Antarctic mining convention) could have very serious consequences."

"There is absolutely no chance of the Wilderness idea being internationally accepted." (Law 1990)

Law was clearly out of step with the mood of the ATCM delegates in Madrid in 1991. The Madrid Protocol did not establish a World Park but it did provide comprehensive protection for the Antarctic environment including its wilderness values. 


\subsubsection{Development of techniques for identification of wilderness}

There have been a number of attempts to define wilderness in terms of landscape properties, i.e. objective criteria. Lesslie \& Maslen (1995: 4) proposed four indicators: remoteness from settlement, remoteness from access, apparent naturalness and biophysical naturalness. Kliskey (1998: 81) distinguished four general properties of wilderness: artefactualism, naturalness, remoteness and solitude. Machado (2004) developed an eleven-point index of naturalness from $100 \%$ cultural to $100 \%$ natural. Although the use of indicators is not always appropriate (Bradbury 1996), the selection of characteristics, that are either directly or indirectly measurable, is an established procedure with which to evaluate wilderness.

In the current study, a different approach to defining the boundaries of wilderness was adopted, which is based on the assumption that the default condition in Antarctica is wilderness so the approach taken was to identify the conditions that are perceived to be non-wilderness through a survey. This approach is described in detail in Chapter 6 (Methods).

\subsubsection{Concepts of wilderness in Antarctica}

"But most of the continent is seldom if ever visited. If any such wilderness remains on Earth, surely it is here" (Rolston 2002: 129).

Humans are only relatively recent visitors to Antarctica; there are no records of indigenous peoples in Antarctica (Walton 1987: vii). The first landing on the continent is thought to have been in 1821 (Headland 2009: 132), and the first party to spend a winter on the Antarctic continent was not until 1899 (Headland 2009: 231). The history of human occupation in Antarctica is therefore relatively short and the physical human footprint, i.e. the extent of infrastructure establishment in Antarctica is concomitantly relatively small in comparison with the other continents, as described in Chapter 4.

Since, as noted above, wilderness is generally defined as a lack of human presence, the whole of Antarctica can be defined as wilderness, with the exception of those parts where the intensity of human activity has rendered the term wilderness inappropriate. Such areas can be characterised by the erection of infrastructure which implies a long-term, if not permanent presence (e.g. Kormos \& Locke 2008: 5). This is contrasted with transient activity which leaves no permanent traces. There are also intermediate cases, for example summer field camps which may be in operation for a number of years, e.g. the West Antarctic Ice Sheet (WAIS) Divide project (WAIS 2012). In such cases wilderness may be degraded by the fact of human presence for the duration of occupation but once the camp is closed it will quickly revert to wilderness as the traces of human presence become buried by snow. 
Antarctica is defined as the Antarctic Treaty area, i.e. south of $60^{\circ}$ South (ATS 1959). All land areas and quasi-land areas such as ice shelves can potentially be wilderness areas. The application of the concept of wilderness to marine environments is not well developed (Sloan 2002) but the sea ice zone that surrounds Antarctica during the winter and spring months has similar characteristics to Antarctic terrestrial wilderness and should not be omitted from consideration, despite the unusual characteristic that it disappears each summer (Summerson 2012: 89).

If wilderness can be characterised as all those parts of Antarctica beyond sight and sound of human infrastructure, what is it about these places that we value? In other words, what are their wilderness values, and how can human activities degrade them? The literature of Antarctic exploration reveals a number of perceptual characteristics of the Antarctic landscape that relate to the absence of humans:

\subsubsection{Remoteness}

Antarctica is remote from the other continents, which, together with the sparse human population and the cold, hostile climate makes it seem especially remote.

Wild called a goodbye to the Captn [Davis] and "hope for a safe voyage!" Davis retorted grimly, "If we don't get to port, you will never be found again!" A truth we had already realised! ... A last cheer, the ensign dipped, the siren screamed "Good Luck" and the old ship steamed off along the Barrier, while we turned to the wilderness of ice and snow behind us. (Charles Harrisson, quoted in Rossiter 2011: 53).

\subsubsection{Silence}

Silence is frequently mentioned as one of the defining characteristics of Antarctic wilderness, apart from the ice and cold, and is mentioned by almost every visitor. That is not to assert, however, that Antarctica is perpetually silent; the sound of the wind and the calls of birds and seals around the coast cut into it. Silence is frequently the antithesis of human activity, however, which is usually characterized by noise - of aircraft, vehicles, and of humans ourselves.

Austere and grandiose beyond words, while stirring the imagination, it filled us with an involuntary feeling of dread; nowhere else can one feel so strongly the sense of his own impotence ... everything threatens man with annihilation... Profound silence reigns over these icy plains and life is only represented by a few petrels, gliding soundlessly, or by whales whose loud, ominous spouting occasional breaks its sad monotony. (Dumont D’Urville, quoted in Rosenman 1992: 126).

The prospect from where we were was extensive, but scarcely beautiful. Down at our feet lay the sea, almost free of ice-pack. Huge stranded icebergs, defying the power of the solar beams, were visible in various directions along the coast. Behind us lay the great Antarctic Land; snow 
peaks rising beyond one another until by distance they dwindled to insignificancy. The silence and immobility of the scene was impressive; not the slightest animation or vitality anywhere. It was like a mental image of our globe in its primitive state - a spectacle of Chaos. (Bernacchi 1991 [1901]: 78).

The eternal silence of the great white desert. ... The vast silence broken only by the mellow sounds of the marching column. (Scott 1913: 153, 154)

A couple of hours out of Davis, homeward bound. This morning before we left was beautiful: snow gently falling, and with no gear working and no helicopter everything was laid under that Antarctic silence which many say is the true characteristic of the continent. "The silence roared in our ears," wrote Borchgrevink, “it was centuries of heaped-up solitude.” (Murray-Smith 1988: 194).

\subsubsection{Clarity of the air}

The clarity of the air which allows the visibility of features at great distances is another defining characteristic of Antarctica and has also been commented on by many visitors to the continent.

All old cairns were visible a tremendous distance, six or seven miles at least for big ones. Mount Terror lay straight ahead and looked so clear that it seemed impossible to imagine it 70 miles away. (Cherry-Garrard 1922).

\subsubsection{Unafraid wildlife}

Most visitors to Antarctica are enchanted by the wildlife, especially the penguins, which appeared not to be afraid of man like the wildlife in the settled continents. This is invariably ascribed to the lack of contact with humans.

Since the discovery of Antarctica, our species has abused its nonchalant penguin neighbors. Having evolved in a realm without terrestrial predators, penguins have no instinctive fear of humans, and submit innocently to club and gun. (Campbell 1992: 75).

The few we saw were almost all Adélie penguins. While we were at work making the ship fast, a flock of them suddenly shot up out of the water and on to the ice. ... They did not appear to be the least afraid of us, and for the most part we left them in peace. (Amundsen 1912).

Codling (1999) has examined wilderness and aesthetic values in Antarctica in detail and canvassed most of the details. In Chapter 5 she summarises her position on wilderness as follows:

It is proposed to proceed on the premise that the Antarctic is a wilderness, in the general understanding of the word, and that the implications of this approach require examination and development (Codling 1999: 104).

She concludes Chapter 6 "Wilderness in the Antarctic" with the following conclusions: 


\begin{abstract}
6.6 Wilderness status
Many wilderness considerations are not easy to handle, and the ATCPs should be commended for including such aspects in their deliberations. However, it is considered that the Protocol's requirement to identify 'areas of outstanding ... wilderness value' is inappropriate and that reference to 'wilderness' or 'wilderness status' is preferable. Initially, it is necessary to accept that the Antarctic is a wilderness, prior to identifying Areas of human influence which would be excluded from designation. Management plans would be the mechanism by which motor vehicles would be controlled. This would result in the designation of a very high proportion of the Antarctic as having wilderness status. It is offered as a procedure that recognises the natural wildness of the continent, yet also accommodates the needs of scientific workers. Ideally, boundaries should relate to areas defined under landscape assessment procedures (chapters 8-10) (Codling 1999: 117).
\end{abstract}

\title{
5.4.6. Implementation issues in Antarctica
}

The principle issue with regards to implementation of protection for wilderness in Antarctica is whether, as Summerson and Riddle (2000), Codling (2001a; 2001b) and Summerson (2012) have argued, it will be accepted in ATCM/CEP forums that the default condition of Antarctica should be recognised as wilderness. The scientific rationale for such an approach and the implications that might flow from it are discussed in later chapters.

\subsection{Aesthetic value}

Three questions need to be asked at the outset: what does 'aesthetic values' mean; what are aesthetic values in the Antarctic context and what did the authors of the Madrid Protocol have in mind when proposing protection of these values, which leads to the question how can the aesthetic values of Antarctica be best protected? In order to answer these questions, some understanding of the history of beauty and aesthetic theory is essential.

\subsubsection{History}

Many authors, from Plato to the present, have tried to understand what beauty is and why we humans are so captivated by it. It was not until the eighteenth century that Western philosophers started to give thought to the subject of beauty. According to William Knight (Knight 1903), the first philosopher of note in the English language to attempt an understanding of beauty was the first Lord Shaftesbury, who in 1709 published a treatise titled Moralists, a Philosophical Rhapsody. In this and a later work, Miscellaneous Reflections (1714), Shaftesbury established three degrees, or orders, of beauty: dead forms, living forms and parent or creative beauty (Knight, 1903: 165). Like many who were to follow, Shaftesbury laid down lists of characteristics which he thought conformed to his ideals. In 1753 William Hogarth published The Analysis of Beauty in which he defends his theory of "the line of beauty" (a serpentine line) 
and proposes six principles (fitness, variety, uniformity, simplicity, intricacy and quality) that together create beauty (Knight 1903: 174). In 1757 Edmund Burke published A Philosophical Enquiry into the Origins of our Ideas of the Sublime and Beautiful (Burke 1998 [1759]), and there were works by Francis Hutcheson, David Hume and Sir Joshua Reynolds and others in England. Similarly, in Germany, Leibnitz, Baumgarten and Mendelssohn and in France, Boileau-Despreaux, Crousaz, Andre and Diderot were concerned with taste, morality and similar philosophical considerations variously related to beauty (Knight 1903).

Burke's Philosophical Enquiry is possibly the first attempt to analyse human responses to landscape, although landscape is not treated explicitly. In this treatise Burke distinguishes between the beautiful and the sublime. Things of beauty, according to his theory, tend to be (relatively) small, smooth, curved, light in colour and tend to induce feelings of pleasure. By contrast, the sublime is large, overwhelming even, rough, angular, dark and tend to induce feelings of terror. The idea of the sublime arose in ancient Greece where it meant a rhetorical device to denote a high-minded or noble act. It was first described by Longinus (213-273) in a work called Peri Hupsos (On the Sublime) (Shaw 2006: 4). The idea was revived by the French philosopher Nicolas Boileau-Despreaux who translated Longinus' work in 1674 and made it available for Western readers (Shaw 2006: 13).

The word 'aesthetic' was coined in 1735 by Alexander Gottlieb Baumgarten (1714-1762) as "the science of how things are to be cognized by means of the senses"(Guyer 1998). Baumgarten derived the word from the Greek $\alpha \ddot{v} \sigma \theta \eta \sigma l \varsigma$ (aisthanomai) which means able to be sensed or perceived, as opposed to be conceived, imagined or thought. In 1750 he published a book, Aesthetica ${ }^{25}$, in which he broadened this definition to include "the theory of the liberal arts, the logic of the lower faculty of cognition, the art of thinking beautifully and the art of the analogue of reason" (Guyer 1998). Baumgarten's theory defined beauty as perfection, a definition that has not entirely been abandoned. The word 'aesthetic', however, has gone through a series of mutations in interpretation and meaning, shedding association with the other members of Plato's trinity, truth and goodness, and in the late $20^{\text {th }}$ century even beauty itself (Morgan 2006). Its meaning transcended the study and appreciation of art in the $18^{\text {th }}$ century when Kant and later others included the natural environment in its field of study. Kant himself used aesthetic to describe the way we experience something rather than a means of describing whether the object viewed is pleasurable. Thus in the opening lines of the Critique of Judgment, he wrote:

\footnotetext{
${ }^{25}$ There is no translation of this work in English.
} 
"If we wish to decide whether something is beautiful or not, we do not use understanding to refer the presentation to the object so as to give rise to cognition; rather, we use imagination (perhaps in connection with understanding) to refer the presentation to the subject and his feeling of pleasure or displeasure. Hence a judgment of taste is not a cognitive judgment and so is not a logical judgment but an aesthetic one, by which we mean a judgment whose determining basis cannot be other than subjective" (Kant 1987 [1776]: 44).

As Roger Scruton says, the Critique of Judgment is a "disorganised and repetitious work" (Scruton 2001: 97). It is also possibly the most important work on aesthetics as Kant was the first to give aesthetics a central role in modern philosophy (Scruton, 2001: 97). Kant was also responsible for one of the most important concepts in aesthetics: disinterestedness. He also attempted to distinguish between the subjective and the objective in responses to beauty and to resolve the contradiction between the individual and the universal aesthetic response. The concept of the disinterestedness of aesthetics is simply that when we witness something beautiful we experience pleasure at the sight or sound of whatever it is we are witnessing but we have no other interest it. Consider, for example, a typical scene on the west coast of the Antarctic Peninsula: high mountains, glistening glaciers, blue sky reflected off still waters. We would call the scene beautiful (or sublime) but we have no other interest other than, perhaps, to prolong or repeat the experience. The experience provides no material reward or advantage. One of the consequences of disinterestedness is the perception by some philosophers that this leads to disengagement from the natural environment (e.g. Parsons 2008). Berleant (1992), for example, considers that traditional aesthetics are an inadequate model for appreciating nature on the basis that disinterestedness requires the placement of some distance between observer and scene. This may indeed be the way that large numbers of tourists experience Antarctica - from the decks of tourist ships. The "expedition-style" of tourist experience, however, encourages tourists to land at penguin colonies and other localities where Antarctica can be engaged with, at least for a short while.

Kant also maintained the separation between the beautiful and sublime initiated by Burke (1998 [1759]) and divided the sublime into two concepts: the mathematical and the dynamic. The relevance of these concepts have declined but Kant still has a commanding role in modern aesthetic philosophy but that is not to say that later philosophers have not disagreed with him on a number of key points, including disinterestedness.

There have been several major developments in aesthetics during the $20^{\text {th }}$ Century. During the first half of the century most discussion about aesthetics related to art and it was not until the publication of Ronald Hepburn's essay "Contemporary aesthetics and the neglect of natural beauty" (Hepburn 2004 [1966]) that attention started to be turned to the natural environment (Berleant 2004). 
Aesthetic responses to Antarctic landscapes can be characterised as including both the beautiful and the sublime (Summerson \& Bishop 2011). Parsons prefers the term "aesthetic quality" to beauty, in order to include concepts such as the picturesque. He defines aesthetic quality as: "A visual or auditory appearance that is pleasing or displeasing for its own sake." (Parsons 2008: 17). Scruton (2009a: 140) notes that "the aesthetic is a realm of value" (his italics). This leads to the conclusion that the "many modes of beauty" could, in fact, be re-defined as "aesthetic values". As noted in the section on wilderness above, the phrasing of the Madrid Protocol implies that wilderness and aesthetic values are sub-components of intrinsic value (noted also by Tin and Hemmings (2011: 148). This being the case, aesthetic value relates to that which is intrinsic in Antarctica, i.e. the natural environment.

\subsubsection{Definitions of aesthetic}

The word aesthetic took a long time to achieve acceptance, especially in the English-speaking world, and in the process generated a considerable amount of confusion about what it meant and what it referred to. Its definition, never very clear in the first place, has been muddied by indecision on whether it is a study of art or beauty. It is still not clear in the 21 st Century whether aesthetic is a synonym for beauty, a theory of beauty, a theory of art, a philosophy of art and whether or not it referred solely to the study of works of $\operatorname{art}^{26}$. Stolnitz (1965: 1), for example, wrote: “... anything like a definition I might offer would be either arbitrary or else so general that it would be worthless. ... Like all philosophy, aesthetics is a process, not an end product, an inquiry, not an almanac". The implementation of protection for aesthetic value in Antarctica depends on, not only a definition, but one that is acceptable to all ATCPs. A "process" is unlikely to be satisfactory to hard-nosed treaty delegates.

Roger Scruton, who has written extensively on aesthetics, (e.g. Scruton 2007), asked the question "What exactly does the word 'aesthetic' mean?" (Scruton 2009a), a question that he then fails to answer. Admittedly he goes on to say:

"These questions [relating to aesthetics] are among the most difficult that philosophers have to confront - which perhaps explains why no philosophers now confront them. You cannot expect an impregnable theory of the aesthetic in two pages. Nevertheless, we need a theory of some kind, and what follows is the best I can do.” (Scruton 2009a)

Is there any point, therefore, in attempting a definition? The answer has to be 'Yes' for three reasons. The first and most important is that the Madrid Protocol calls for the protection of the

\footnotetext{
${ }^{26}$ A similar confusion could be found in the words poem, poetry, etc, which are derived from the Greek word poieein which means to make. The difference is that English has adopted the German word machen for make and uses poieein only for making poetry.
} 
aesthetic values of Antarctica. In order to support the intention of the Protocol and its implementation a definition is required. It will not otherwise be possible to determine whether a proposed activity in Antarctica will have an impact on the aesthetic values of the area where the activity is to take place, if it is not clear what aesthetic values are? Second, the process of attempting a definition of aesthetics in Antarctica will stimulate debate about aesthetic values, which will, hopefully, lead to a fuller and richer definition and a better understanding of the intentions of the Madrid Protocol. Third, Stolnitz might be wrong! He has given an opinion but there is no reason not to challenge it, especially given the advances in science and philosophy over the past 30 years.

Among the definitions of aesthetic listed by the Oxford English Dictionary is the following:

"The philosophy or theory of taste, or of the perception of the beautiful in nature and art." (OED 1989) (Definition B. 2.)

The concept of the sublime makes this definition inadequate, however. As noted throughout Chapter 3, the lexicon of the sublime is frequently used to describe Antarctic landscapes. The role, nature and impact of the sublime have been much discussed through time. Summerson and Bishop (2011) review the history of the beautiful and the sublime and note that they were two separate concepts more or less unless they became opposed in the $18^{\text {th }}$ Century in the works of Burke (1998 [1759]) and Kant (1987 [1776]). Bradley (1950: 40) rejected this antithetical approach, instead describing the sublime as one of "five of the many modes of beauty."

Parsons (2008) discusses definitions of natural beauty and after reviewing what is meant by both natural and beauty, decides that, in order to incorporate concepts such as the picturesque and the sublime, "aesthetic quality" is a preferable term to beauty. Parsons goes on to define aesthetic quality as: "A visual or auditory appearance that is pleasing or displeasing for its own sake." Parsons (2008: 17). Displeasure arises, apparently, through the agency of the sublime. While it is interesting in that it incorporates the idea of intrinsic value, i.e. "for its own sake", it is otherwise an unsatisfactory definition as it could describe any sight or sound, natural or of human origin.

Carlson (1977: 131) seems quite clear in defining aesthetic in relation to the natural environment as scenic beauty: “... These themes involve objectivity, quantification, public opinion, and formalism and the way in which each of these relate to the aesthetic quality or scenic beauty of the natural environment."

Sepanmaa (1986: 2), in attempting to define aesthetic, identifies three research traditions: the philosophy of beauty, the philosophy of art and the philosophy of criticism or metacriticism. He places environmental aesthetics at the "intersection" of research into the environment and aesthetics. 
Arnold Berleant (1992) promotes the idea of "the aesthetics of engagement" in which rather observing nature as one would do with a work of art, we become engaged with it - become part of it. He suggests that "perhaps the sublime offers a clue for identifying a distinctive aesthetics of nature that is unconstrained by the traditional theory of the arts" (p 167). Later, however, he says that "it is not the sublime alone that encourages an aesthetics of engagement, natural beauty can do so as well, once we are liberated from the formalistic requirements of discreteness and order" (p 171). Berleant does not therefore offer a definition of aesthetics but rather a way of life that is engaged with nature.

A definition of aesthetic value continues to be elusive, therefore. Any definition must include the following concepts to be relevant to the requirements of the Madrid Protocol: beauty, sublimity, natural environment, appreciation (as a form of enjoyment), respect and, following Baumgarten, sensory perception.

\subsubsection{Precedents for protection}

Precedents for the preservation of aesthetic values are to be found in the designation of 'Areas of Outstanding Natural Beauty' under the UK National Parks and Access to the Countryside Act (1949) and updated by the Countryside and Rights of Way Act (2000), the US National Environmental Policy Act (1969) and the UNESCO World Heritage Convention (1972). In the United Kingdom, Areas of Outstanding Natural Beauty (AONB) were established under the National Parks and Access to the Countryside Act (1949). There are 46 Areas of Outstanding Natural Beauty in England, Wales and Northern Ireland (Natural England 2013) and 40 National Scenic Areas in Scotland (SNH 2013). As Anderson (1980: 3) observed: " As their name implies, all AONBs have been chosen for the attractiveness of their landscape - a quality which, in spite of numerous attempts, has so far not been satisfactorily quantified." The Landscape Character Assessment process (Swanwick \& Land Use Consultants 2002) has made some progress towards quantification, but the process is essentially a descriptive one. The National Scenic Areas in Scotland were designated in 1978 after a series of processes which, “ ... as the selectors honestly described, a process of subjective judgements based on informed consensus" (quoted from David Tyldesley and Associates 2007: 10).

The enactment of the US National Environmental Policy Act (NEPA) (1969) is an important milestone in the development of the development of techniques to identify aesthetic value. This Act states:

In order to carry out the policy set forth in this Act, it is the continuing responsibility of the Federal Government to use all practicable means, consistent with other essential considerations of national policy, to improve and coordinate Federal plans, functions, programs, and resources to the end that the Nation may ... 
2. assure for all Americans safe, healthful, productive, and aesthetically and culturally pleasing surroundings. (NEPA 1969)

The World Heritage Convention (1972) recognises the aesthetic value of both cultural and natural sites, including natural beauty, as follows:

Article 2 of section 1. Definition of the cultural and natural heritage

For the purposes of this Convention, the following shall be considered as "natural heritage": natural features consisting of physical and biological formations or groups of such formations, which are of outstanding universal value from the aesthetic or scientific point of view;

natural sites or precisely delineated natural areas of outstanding universal value from the point of view of science, conservation or natural beauty (UNESCO 2011).

In Australian the EPBC Act (1999) provides a legal framework to protect and manage nationally and internationally important flora, fauna, ecological communities and heritage places - defined in the EPBC Act as matters of national environmental significance. Included in the definitions is the following definition of heritage value:

The heritage value of a place includes the place's natural and cultural environment having aesthetic, historic, scientific or social significance, or other significance, for current and future generations of Australians. (EPBC 1999)

As these examples demonstrate, there are several precedents, both national and internationally, of protection being provided by legislation to natural areas with aesthetic value.

\subsubsection{Development of techniques for the identification of aesthetic value}

The enactment of the National Environmental Policy Act (NEPA) in 1969 stimulated the development of techniques to measure aesthetic value, especially in national forest lands (Arthur 1977; Daniel 1990). There have been a large number of reviews of the development of aesthetic assessment procedures, including Arthur et al. (1977), Zube et al. (1982), Daniel and Vining (1983) Kaplan and Kaplan (1995) and Lothian (1999). There have also been many reviews of individual techniques and comparisons between techniques (e.g. Hull et al. 1984; Miller 1984).

There are many ways of thinking about landscapes and their aesthetic properties but two main schools of thought concerning aesthetics in general and landscape aesthetics in particular have emerged to respond to the question of whether beauty is intrinsic in the landscape or solely in the eye of the beholder? The former school includes 'formalists' who look for objective measures of scenic beauty in terms of the formal properties, i.e. the shapes and forms, of a landscape (e.g. Shafer \& Brush 1977) and the latter school who assume that it is the human 
response to the environment that is important. The Scenic Beauty Estimation method (Daniel \& Boster 1976), for example, was developed using psychophysical methods to survey people about their aesthetic preferences and then aggregate their results, perhaps adopting the Kantian principle of universalism. Lothian (1999) neatly divides these two camps into 'objectivists' (the 'formalists' and others) and 'subjectivists', who use psychophysical methods (e.g. surveys) to sample people's aesthetic preferences. Porteous (1996: Chapter 3) also reviews the various approaches and draws a similar but slightly more nuanced distinction - between "Expert Input" and "Public Input" (p 204). Lothian notes that "experts" tend to use "objective" methods, which he describes as "subjectivity presented as objectivity" (as opposed to "objective evaluation of subjectivity") (p 178). Landscape Character Assessment (Swanwick \& Land Use Consultants 2002), the technique adopted by Codling (Codling 2001a; Codling 2001b), falls into the "Expert Input" class. A third paradigm, that of integrating subjective and objective methods, has also been developed, which perhaps more than the other techniques relies on computer technology. The methods developed by Bishop and Hulse (1994), Wu et al.(2006) and Frank et al. (2013) integrate subjective psychophysical methods with objective mapped data in geographical information systems (GIS). In Bishop and Hulse's study, they reported a high level of prediction of scenic beauty values using five variables derived from the GIS data ( $p$ 66), though they acknowledged that some of the results needed to be better understood.

\subsubsection{Theories related to human evolution}

There have been a number of authors who have proposed that preference for landscapes developed during human evolution. Appleton (1975) developed a theory that he called "Prospect-Refuge Theory". This theory is predicated on the belief that modern humans retain an atavistic sensibility to landscape from an earlier period in evolution by preferring places that offer a good prospect, in other words a good view of the surroundings, and a refuge into which they can retreat and feel safe. A sense of pleasure is felt when these conditions are met. Appleton has attempted to apply prospect-refuge theory to the aesthetic appreciation of Antarctica (Appleton 2006) in which he sets out three "symbols of prospect" (light, atmospheric conditions (e.g. white out and clarity) and surfaces (reflective, white, distant horizons devoid of vegetation)), "symbols of refuge" which are "extremely weak" and essentially man-made, e.g. field huts and three "symbols of hazard" (deficiency hazards (especially "refuge-deficiency") and physical hazards, both meteorological and terrestrial. Together these form not so much a theory as a "bran-tub of ideas". Whether any of Appleton's or other evolutionary ideas will stand up to the evidence arising from the empirical research to be described remains to be seen. 


\subsubsection{Concepts of aesthetic value in Antarctica}

On the face of it and perhaps to the uninitiated, the Antarctic would seem to be an unlikely candidate for a locale with high aesthetic values: perpetually cold, perpetually windy, bleak, hostile, endlessly and monotonously white. The literature surveyed in Chapter 2 provides many concepts and views of aesthetic values in Antarctica. A number of terms have been used repeatedly and can therefore be thought to represent the main concepts; these include vastness, grandeur, beauty, hostility and desolation. Wildlife, which has not been given much consideration, for reasons to be outlined, also has aesthetic value. Robert Carrick, one of the architects of the Agreed Measures for the Conservation of Antarctic Fauna and Flora, included among the Aims of Conservation:

Aesthetic. The aesthetic appeal of most forms of wildlife justifies their conservation, and this is especially true of the Antarctic fauna. Penguins, albatrosses and seals enliven the bleak landscape and open sea, they often occur in spectacular numbers while many are closely approachable and pursue their private purposes regardless of our presence. The intrinsic attractiveness of penguins, enhanced by their upright gait and reciprocal curiosity toward us, places them high indeed on the list of birds that particularly merit our protection.

No less important is the mental and spiritual recuperation derived from contact with living nature, especially to those who are becoming introspective, worried and stressed. Even in ordinary life, where avenues of escape are more plentiful, this often proves an effective one, to which psychiatrists and many people in all walks of life have paid tribute. In the isolation of an Antarctic party, where there are few outside interests capable of filling the mind with pleasant, objective and impersonal thoughts, and of helping to restore perspective, the social value of the local wildlife cannot be overestimated. (Carrick 1960: 301)

This passage is significant as it was the first time aesthetic value of any kind was proposed for conservation in Antarctica, coming one year after the signing of the Antarctic Treaty in 1959.

\subsubsection{Implementation issues in Antarctica}

Since the Madrid Protocol was implemented in 1998, there has been very little discussion of aesthetic values. Codling (2001), in discussing wilderness and aesthetic values, side-stepped the question on aesthetic values by referring to a procedure developed in the United Kingdom (UK) called landscape character assessment. This technique involves a description of landscape according to a set of guidelines. It is particularly appropriate in areas with complex landforms, with a long history of settlement and history, such as the UK, where all the elements of the landscape, including its history, current land uses, vegetation types, etc need to be identified and described before an assessment can be made. In Antarctica, where the landscapes are very simple (Pyne 1987), where there have generally been very short durations of occupation with very little in the way of modifications of the landscape. 
To illustrate some of the complexities and misunderstandings involved in implementing protection for aesthetic values, in 1996, at ATCM XX at Utrecht in Holland, aesthetic values in Antarctica was raised by Chile. The following is a record of the discussion from the minutes of the meeting:

\section{Item 14}

\section{Cultural and aesthetic values of the Antarctic}

(112) Chile introduced Working Paper 23 (XX ATCM/WP 23) stressing the symbolic value of Antarctica. The purpose of the Working Paper was to raise the question how the cultural and aesthetic values of the Antarctic could be highlighted.

The Working Paper also contained a draft resolution to that end.

(113) There was consensus that the issues raised in the Working Paper are of great importance, a fact which is also reflected in various parts of the Protocol. Therefore, a Resolution was adopted. Resolution II (1996) is attached to this Final Report.

(114) It was generally recognised that the special value of Antarctica could be promoted by educating young people and by the work of artists.

(115) As regards to the possible role to be played by the Parties, several delegates indicated their support for measures to actively promote trips by writers and artists in general. Some delegates suggested, however, that in order to focus attention on the cultural and aesthetic values, writers and artists should be included in national expeditions. In so doing, the Parties should concentrate particularly on those forms of artistic and cultural expression which would convey the beauty of Antarctica to people who had not been there.

(116) ASOC noted that in the discussions on practical matters such as monitoring, liability and Environmental Impact Assessment, factors such as intrinsic, aesthetic and wilderness values were too often considered too complex; ASOC expressed the hope that future discussion of this agenda item would contribute to a better understanding of how to deal with these values, as required by the Protocol (notably Article 3(1) and Annex 1, Article 3). (ATCM XX, 2006).

It was completely reasonable for Chile to propose this initiative but it is generally understood (e.g. Codling 2001b; Summerson 2012; Tin \& Hemmings 2011) that aesthetic values relates to the aesthetic values of landscape rather than artistic representations of Antarctica.

Finally, Kakabadse (2000: 16), in describing the challenges in putting Annex V (of the Madrid Protocol) into place included "Aesthetic value: Appreciation of the harmony, beauty, and profound meaning found in nature." She went on to say:

"Please note: The important issue is the protection not the semantics. It is more important to get experience in designating appropriate areas and develop as wide an 
understanding as possible by acting, rather than delaying actual designation until consensus on words for definitions is reached."

\subsection{Conclusion: wilderness and aesthetic values as intrinsic values}

Given that wilderness is the antithesis of human presence, it is an appropriate candidate for intrinsic value, on condition that the wilderness is protected for its own sake, not for instrumental reasons. One of the reasons to think that wilderness has instrumental value is that the US Wilderness Act also defines wilderness as an area that “... has outstanding opportunities for solitude or a primitive and unconfined type of recreation." (US Wilderness Act, 1964).

While it is true that there is a thriving tourism industry in Antarctica and Antarctic wilderness is one of the major drawcards for tourists, the vast majority of tourists visit Antarctica by ship and land at a relatively small number of sites where they spend a few hours ashore (Mortimer 2004). There is no suggestion that the purpose of protecting wilderness by the Madrid Protocol is to benefit tourists.

The position of aesthetic value is more complex. Godfrey-Smith (1979: 310) and Fox (1990: 155), argue that aesthetic pleasure is an instrumental argument for the preservation of the nonhuman world, though Godfrey-Smith acknowledges that his "cathedral" argument for protecting wilderness, which includes "aesthetic delight", frequently approaches an intrinsic value attitude (Godfrey-Smith, 1979: 311). Kant (1987 [1776]: 45), however, argued that an aesthetic judgement is a disinterested judgement and therefore has no instrumental consideration. The concept of disinterestedness is central to aesthetic theory (Scruton 2009b: 18; Stolnitz 1961) though it has been criticised by a number of environmental philosophers including, for example, Arnold Berleant who rejects it in favour of what he terms the aesthetics of engagement (Berleant 2004: 77). Most contemporary environmental philosophers, e.g. Carlson (2009: 99) accept the concept of disinterestedness, subject to a number of conditions, perhaps best expressed by Emily Brady who says “... the logic of disinterestedness does not entail abstraction or passive contemplation, but only that we value the object for its aesthetic qualities rather than how it might serve our ends." (Brady 2004: 169). Scruton (2012) goes further and says that:

"It is a long-standing thesis of philosophy that beauty is an intrinsic value. To look on a thing as beautiful is to value it for what it is, not for what it does or for the purposes it serves. It does not follow from this that beauty is useless. On the contrary, it is the intrinsic value of beautiful things that renders them useful. ...

The intrinsic value of beauty confers a long-term utility on beautiful things, a utility that comes only when you do not pursue it." (Scruton 2012: 254-255). 
Even though consensus is lacking, a strong case can be made for aesthetic value being an intrinsic value on the basis of disinterestedness.

The Madrid Protocol, in mandating the protection of the intrinsic values of Antarctica, is evoking an ethical position and thereby calling for respect. The Protocol also calls for the protection of the wilderness and aesthetic values, which are two ways in which we humans can value this continent for itself. Wilderness values are those which relate to the absence of human infrastructure. Aesthetic values, while being human-centred, are also disinterested (Kant, 1987 [1776]: 45) so can therefore be considered as non-instrumental and therefore, by Plumwood's definition, as being intrinsic. 


\section{Chapter 6. Methods}

\subsection{Introduction}

In Chapter 5 I outlined definitions and theories of wilderness and landscape and environmental aesthetics. In this chapter I describe the methods used to answer five critical research questions:

1. What is wilderness in the Antarctic context - and therefore what area or areas can be designated as wilderness?

2. How can human impacts on wilderness values be defined and measured?

3. What are aesthetic values in the Antarctic context?

4. Are some landscape types more highly valued aesthetically than others?

5. How can human impacts on aesthetic values be defined and measured?

The methods adopted evolved during the course of this research, partly as my thinking matured and partly as information and communications technology developed and became more widely available to enable technological solutions to the problems of reaching a world-wide audience.

\subsection{General considerations}

In considering the most appropriate method to answer these questions, a number of factors had to be considered.

1. The nature and duration of people's experience in Antarctica;

2. The level of interest in Antarctica in the general public;

3. The international nature of Antarctica both in terms of individual national commitment in Antarctica and governance;

4. The tradition of consensus in Antarctic decision-making; and

5. The high cost and logistical constraints in carrying out fieldwork in Antarctica.

As with much of this research, approaches to providing answers to the problems of defining wilderness and aesthetic values differed but remained related, in other words were amenable to the same approach. This has generally not been the case in approaches to wilderness and aesthetic value elsewhere in the world. The definition of wilderness in a spatial sense, as opposed to the philosophical question of what wilderness is, has usually been carried out with land use data in a geographical information system. For example, the National Wilderness Inventory system developed in Australia (Lesslie \& Maslen 1995) uses four weighted indicators: remoteness from access, remoteness from settlement, apparent naturalness and 
biophysical naturalness. There have been several approaches to defining aesthetic value, all of which are quite different to those used to defining wilderness since they require the evaluation of the locality either in situ or using surrogate methods such as photographs.

Much of the ground-breaking research into evaluating landscape aesthetics was carried out in the US Forest Service in the late 1960s and 1970s in response, initially, to the National Environmental Policy Act (1969) that required the Federal Government to "assure for all Americans safe, healthful, productive, and aesthetically and culturally pleasing surroundings" (Daniel 1990). This mandate led to the development of a large number of new techniques for evaluating landscape quality (Daniel 1990; Daniel \& Vining 1983). Arthur et al. (1977) proposed that there are three broad approaches to landscape assessment: descriptive inventories, public preference models and economic analyses. The two former approaches have both quantitative and non-quantitative methods. Zube et al. (1982) identified four general landscape perception paradigms: expert, psychophysical, cognitive and experiential.

In the UK the descriptive inventory approach has been the dominant paradigm as exemplified by the landscape character assessments that have been widely carried out in England and Scotland (Swanwick \& Land Use Consultants 2002). This approach was adopted by Rosamunde Codling in her work on wilderness and aesthetic values in Antarctica (Codling 2001). I rejected this approach for four reasons: first, unlike the settled continents with a long history of occupation, Antarctic landscapes are essentially very simple. As Pyne (1987) says, “... its [Antarctica's] topography and dynamics [are] the simplest on Earth" and, by comparison with the predominantly cultural landscapes in the UK, there would be little to describe. Second, the requirements of the Madrid Protocol are for the protection of the wilderness and aesthetic values; the more elaborate approach of landscape character assessment is largely irrelevant. Third, in a continent that is managed by the 28 countries that are Antarctic Treaty Consultative Parties (ATS 2012), a process that at least invites contributions from as wide a consultation base as possible would be more likely to succeed than a descriptive inventory or inventories carried out by one person. Fourth, it would not be logistically feasible to attempt to describe landscapes across the whole of Antarctica or to interview people across so many nationalities and cultures and there seemed to be little chance that the views of one "expert" would be accepted but that a process that had engaged a large number of people with an interest in Antarctica would be more likely to succeed.

The public preference model of landscape aesthetic assessment, which is the use of surveys to canvass opinions or preferences from stakeholders (Arthur et al. 1977), was therefore considered to be the most suitable approach for use in Antarctica. Stakeholders here refers to anyone with an interest in Antarctica, which includes scientists, policy-makers and operations 
staff working in national Antarctic programs, research institutes and universities; tourists; tourism operators and interested members of the general public. Of the various qualitative and quantitative types of public preference engagement, psychophysical methods, "the scientific study of the relation between stimulus and sensation" (Gescheider 1976), have become the dominant quantitative approach in landscape aesthetic assessment (1977; Daniel 1990; Daniel 2001) and these methods have been adopted in this research, not only for evaluation of aesthetic value but also perceptions of wilderness.

Unlike Codling, who rejected the use of photographs as the empirical basis on which to develop concepts of wilderness and aesthetic values in Antarctica (Codling 1999), I have chosen to use photographs as the principal empirical basis with which to test a series of hypotheses to answer the research questions listed above. There have been numerous studies based on photographs and their modern equivalent, the digital image displayed on a personal computer, e.g. (Arriaza et al. 2004; Arthur et al. 1977; Daniel \& Boster 1976; Habron 1998; Shuttleworth 1980; Wherrett 1999; Wherrett 2000; Wu et al. 2006). Kaplan \& Kaplan (1995) cite 32 studies all of which use photographic media. There have also been questions about the validity of using photographs in landscape preference research and there have been a number of studies that compared in situ responses with those to photographs, e.g. Shuttleworth (1980), Stamps (1990), Stewart et al. (1984), Hull \& Stewart (1992), Kroh \& Gimblett (1992), Palmer \& Hoffman (2001) and most recently by Sevenant \& Antrop (2011).

Shuttleworth (1980) "considered evidence for the extent to which photographs of landscapes provoke responses which replicate responses to the landscapes themselves, an issue of critical importance in much landscape preference and evaluation research". He reviewed eight earlier studies, evaluating them against six criteria, the last of which was that the experimental design should involve taking the people being sampled to the actual viewpoints so that a direct comparison could be made. Of the eight studies, only one met this last criterion but, as he noted, it had severe statistical limitations. His own study, the ninth under consideration, did however meet this criterion. In his study, 93 students viewed 12 scenes in the laboratory and in the field with varying order of viewing. The laboratory study included the use of both black and white and colour prints. Respondents were asked to complete visual preference and semantic differential ratings. The results were then analysed using Spearman's $p$ rank order correlation coefficient. It should be noted that the scenes being assessed were on the campus of the University of East Anglia with which it may be assumed that the students were familiar, which may have influenced the results as the respondents may have already formed opinions about some of the scenes. Shuttleworth concluded that there were no differences between the patterns of response from the semantic differential test and the overall evaluations of scenic quality, that there were very few differences between the responses to photographs and the actual scenes and 
that responses to black and white photographs evoked more extreme responses than did the colour photographs, which related more closely to the actual scenes.

Stamps (1990) conducted a meta-analysis of 11 papers, from a total of 1300 papers or articles, which correlated responses to landscapes, 10 or which were natural landscapes, with photographs. His conclusion was that the combined correlation between preference obtained by the use of photographs and those obtained in situ was 0.86 . He went on to say that to negate this result, i.e. to demonstrate that the use of photographs were "distorting" for environmental preferences, it would require a minimum of 448 studies of environments where the correlation between photographs and in situ evaluations was -.05 .

Kroh and Gimblett (1992) compared live experience with photographs. Their study used 25 students who were taken to a rural area off-campus and led around a circuit with 16 viewing points, at which they were asked to complete a questionnaire which included a five-point preference rating and a free text description. Two weeks later, in a laboratory, the same students were shown slides taken at the same viewing points and asked to complete the same questionnaire. It may be assumed that the students were not familiar with the area being evaluated as the experiment involved "making a trail". The data was analysed with Multi Dimensional Scaling (MDS), raw mean scores from the preference ratings and diversity and frequency analysis of the free text descriptions. A number of criticisms could be levelled at this study, for example the risk of biasing the results using the same set of students for both parts of the experiment and the lack of a statistical test on the preference scores.

Kaplan and Kaplan (1995) discussed the issue of responses to photographs versus responses to actual scenes at length, arguing that people are sufficiently used to seeing three-dimensional environments reduced to two dimensions in print and on screens, that responses are "surprisingly similar" and that site visits may pose a number of problems that are obviated by the use of photographs. This is certainly the case in Antarctica where it would be logistically impossible to survey any more than a few people at a very few sites.

Palmer and Hoffman (2001) referred to a US Supreme Court judgment that "experts from all fields of knowledge must demonstrate the reliability and validity of their testimony". They examine two issues: rating reliability, i.e. the degree of similarity between professionals carrying out the evaluation, and representation validity, i.e. how well judgements made from photographs equate to those made in the field. Of particular concern were professional evaluations of a number of visible landscape attributes, not just scenic preferences. The authors point out a number of concerns with using photographs but these relate to how they are used and they do not suggest that they should not be used. They conclude with three recommendations, which include establishing the reliability of professional ratings and 
establishing the validity of each landscape representation. In the research being described here, the public preference model obviates the former and the latter is addressed by having multiple replicates of each Antarctic landscape type.

Sevenant \& Antrop (2011) reviewed many of the studies referred to above and conducted their own empirical study comparing responses to two types of photographic views, standard and panoramic, with those made on site across 16 variables, one of which was scenic beauty. 27 respondents were asked to provide preference ratings for 16 variables, including beautiful, vast, unspoiled and human-influenced (attributes that could be important in assessing Antarctic landscapes) for 12 landscapes, which were a mixture of urban (3 scenes) and rural landscapes ( 9 scenes). With one possible exception, all the scenes appear to include some form of distinguishable human presence. A high degree of correlation was found, for example, between mean scores for beautiful between the panoramic photographs and on-site observations and slightly less well correlated between standard photographs and on-site observations.

Of all the available methods, it is only the use of photographs, when built into a survey, that can generate aesthetic preference ratings in sufficient numbers to allow statistically significant results. Similarly, the use of digitally manipulated photographs allows the direct testing of wilderness value where responses to two scenes, one that contains human activity and the other from which the evidence has been digitally removed can be directly compared. The Internet offers unparalleled opportunities to survey large numbers of people under more or less identical conditions. Wherrett (1999) researched issues relating to the use of the Internet, identifying 12 issues:

- The medium of display, i.e. computer monitor versus photographic slide or print;

- Computer-based questionnaires versus paper questionnaires;

- Computer graphics formats ;

- Colour resolution and perception;

- Pixel resolution and screen size;

- Screen size and resolution;

- Respondent honesty;

- Respondent sample;

- Socio-demographic profiles;

- Survey design;

- Response rate and time of log-in and completion; and 
- The wider audience.

In the more than 10 years since Wherrett's research, the use of and familiarity with the Internet has increased dramatically. Personal computer hardware and software and communication technology have continued to improve while the price of most components has fallen. In 2010$11,79 \%$ of Australian households had access to the Internet at home and $73 \%$ of Australian households had access to broadband Internet (ABS 2012). On a global scale, as at 31 December 2011 there were over 2,267 million users of the Internet worldwide, which represents nearly $33 \%$ of the world's population. Distribution of users by continent is very uneven, however, with North America having the greatest penetration as a percentage of the population at $78.6 \%$ with Africa having the lowest penetration at $13.5 \%$. Since 2000 there has been a $528.1 \%$ growth in users of the Internet worldwide and this trend is likely to continue.

Many of the issues that Wherrett investigated such as the ability of personal computers to display digital images with accurate colour rendition and at sufficient resolution to create crisp imagery are no longer considered to be issues of concern. Still pertinent, however, are issues such as survey design, respondent selection, respondent honesty and sample size.

Reips (2002) proposes 16 standards for Internet-based surveys which can be grouped into three issues: technical issues relating to cross-platform usability, the prevention of respondents dropping out before completing the survey and the prevention of multiple submissions. Roth (2006) adopted these techniques and reported that "the scenic quality categories of visual variety, beauty, visual naturalness as well as overall scenic quality can be validly recorded on the Internet ..."

Most of these issues were incorporated into the design of the survey of wilderness and aesthetic values of Antarctica, including a method of capturing data in the event of a respondent not completing the full set of scene evaluations. Consideration was given to offering a reward but since responses were anonymous this was difficult to achieve and was not included. Since there was no apparent advantage in multiple submissions, no technique was adopted to prevent them and no entries have been detected that might lead one to suspect that there were from the same source. A set of three home-made "CAPTCHAs" (Wikipedia, 2010), where respondents are required to copy a set of letters and numbers in an image as a login procedure, were established to appear in random order on the entry page to defend against attacks by malicious Internet software (e.g. "web bots").

The issues of respondent selection and sample size are potentially problematic. My approach has been to adopt an approach based on the concept of "The Wisdom of the Crowd" (Surowiecki 2012). In this book the author outlines a theorem that more people contributing 
ideas or opinions leads to a better result than restricting consultation to a few experts. This is similar to "The Law of Large Numbers" which states that the larger the sample size the greater the probability that the sample mean will be close to the population mean (Gravetter \& Wallnau 2010). The application of the wisdom of the crowd concept in this case has been to collect as many responses as possible from as wide a variety of experience, background, interest and nationality. The consequence of adopting this approach has been that a large amount of time and energy has been spent promoting the survey.

\subsection{Development of hypotheses}

I propose two hypotheses; one relating to the perception of wilderness values and one relating to aesthetic values.

My hypothesis relating to wilderness values as, discussed previously, is that all Antarctica can be considered wilderness unless it has been degraded by human activities, principally the construction of infrastructure.

With regards to aesthetic values, my hypothesis is in two parts:

(a) All of Antarctica has aesthetic value;

(b) Aesthetic value is diminished by human activities

\subsection{Summary of methods chosen:}

1. Text-based survey on ANARE voyage (Survey 1);

2. Visual survey on ANARE voyage plus some ex-Antarcticans (Survey 2);

3. Disposable camera experiment;

4. Favourite places questionnaire; and

5. Internet-based survey (Survey 3).

\subsubsection{Survey 1}

The first questionnaire sought input into the question of what constitutes wilderness in the Antarctic context. The questionnaire was distributed among 40 members of ANARE voyage 6 1999-2000 which was a round-trip to Casey Station in Antarctica and Macquarie Island. The questionnaire sought written responses to a series of questions about perceptions of wilderness and landscape aesthetics in Antarctica. There were two slightly different questionnaires: for expeditioners who had already visited Antarctica before and for first time visitors. The difference lay in the experiences and perceptions the "old hands" had formed and the 
expectations of the first-time visitors. The questionnaire forms are in Appendix 1. The questions asked and summary responses given are detailed in Chapter 7.

\subsubsection{Survey 2 (First visual survey)}

A "visual" survey was carried out in the following Antarctic season and was distributed first to members of ANARE Voyage 4 2000-2001, which was a voyage from Fremantle to Heard Island, Mawson Station and Davis Station, both in Antarctica and then on to Hobart. A further six respondents were recruited later in Canberra, all of whom had had Antarctic experience with ANARE within the past 10 years. This survey was experimental in delivering a questionnaire to Antarctic expedition personnel for whom a fully Internet based questionnaire was not, at that time, logistically possible. It was also an opportunity to develop experience in this type of survey.

The survey was provided on CD-ROM with a separate paper form to be filled in. A human ethics approval form was also made available on the $\mathrm{CD}$. The contents of the $\mathrm{CD}$ were structured using simple html (hyper text mark up language) coding. The text and images used in the survey are in Appendix 2.

The survey comprised an introduction and statement of purpose, a preview of all the scenes on one page, provide so the respondent could see the range of images to be assessed, and then the images individually, which were accessed by scrolling down the page. A paper questionnaire form to record the assessments were also provided. Some demographic information was also sought such as age range, education, role in Antarctica, etc.

The survey comprised 45 photographs of Antarctic landscapes, of which I took 39. Five were from other personal collections and one was from the Australian Antarctic Division photographic library. Many were digitised $35 \mathrm{~mm}$ colour slides so the quality was not very good. The photographs were taken in three main regions of Antarctica: the Antarctic Peninsula (including Alexander Island), the Ross Island area and the Windmill Islands. Four contributed images came from the area around Mawson Station. The images were chosen to represent a wide range of Antarctic landscapes from scenes in the vicinity of Antarctic stations with human artefacts visible to scenes of remote landscapes. The type of human and other content of the images is shown in Table 6.6.1.

Table 6.6.1. Content of the 45 images in Survey 2.

\begin{tabular}{|l|l|l|l|}
\hline No human content & Human - transient & $\begin{array}{l}\text { Human - } \\
\text { infrastructure }\end{array}$ & Wildlife \\
\hline 18 & 8 & 19 & 4 \\
\hline
\end{tabular}


Respondents were asked the following question:

"Study each image separately and provide your rating on scenic beauty and whether you think the scene in the view is wilderness or not wilderness."

The phrasing was intended to direct the respondents' attention to what could be seen in the view rather than what might be known about the location if a particular respondent recognised it. Respondents were asked to rate each image as either wilderness or not wilderness and to rate their aesthetic preference on a scale of 1 to 7 , where 1 is least-preferred and 7 is most-preferred. The null hypothesis to be tested with this part of the survey was as follows:

The presence of infrastructure in the scene does not detract from the perception that the scene is wilderness.

This survey was intended to be a pilot study for a much larger survey and much valuable experience was gained, including the limitations of this survey. For example, one of the unfortunate aspects of the design of the survey was that it was not possible to randomise the order that respondents viewed the scenes in, so in all cases the order was identical.

\subsubsection{Disposable camera survey}

10 disposable cameras were purchased prior to ANARE Voyage 4 2000-2001. These were a standard disposable camera pre-loaded with $35 \mathrm{~mm}$ film, each having 24 exposures. The aim of the survey with these cameras was to gain some insights into what ANARE expeditioners found beautiful in the Antarctic landscape and what they find ugly. Each person with the camera had the opportunity to take six photos of places or scenes they found scenically beautiful and six scenes which they find ugly. The camera kits included instructions and small notebooks in which to record the details of each photograph. The instructions for the disposable camera experiment are in Appendix 3.

Five cameras each were given to expeditioners staying at Mawson and Davis. The intention was that the cameras would be shared between two people so in total, this should sample the preferences of 20 expeditioners. The expeditioners who volunteered to take part were a mixture of experienced and first time visitors to Antarctica.

\subsubsection{Favourite place questionnaire}

In addition to the visual questionnaire, another survey was distributed to the expeditioners on board ANARE Voyage 4 2000-2001. This survey was on areas of local aesthetic appeal. The survey was in three parts: Part One asked for demographic details such as whether the respondent was a summer visitor or was going to stay for the winter, how many visits to 
Antarctica the respondent had already made and his or her role. Part Two asked for a list of favourite places and Part Three asked why these places were special.

The purpose of this survey was partly to determine if there were a number of key localities that were highly favoured among the expeditioners and partly to discover what the characteristics of these places were.

\subsubsection{Survey 3 (Internet survey - worldwide)}

As Antarctica is managed as international territory with 48 countries having acceded to the Antarctic Treaty, it was decided that, in order to obtain the opinions of as large a number people with an interest in Antarctica as possible, it was decided to make the final survey an Internet survey. It was compiled during 2008 - 2009 and was launched on 17 September 2009 on a University of Melbourne website (currently http://people.eng.unimelb.edu.au/idbishop/Antarctica).

The aim was threefold:

1. To test the hypothesis that all of Antarctica could be considered wilderness unless modified by human activity with a much larger respondent base and especially one which targets the four postulated Antarctic communities: Antarctic professionals, tourists, tourism industry and interested members of the general public.

2. To obtain aesthetic preference ratings for a wide range of landscapes, grouped into six broad environmental types using the Environmental Domains of Antarctica.

3. To attempt to understand how landscapes are appreciated by using a series of adjectives broadly divided into two groups: adjectives related to the sublime and adjectives related to the beautiful.

\subsubsection{Environmental regionalisation}

Annex V of the Madrid Protocol (Area Protection and Management) calls for the development of a "systematic environmental-geographical framework" within which to identify areas suitable for protection. Such a framework should include "representative examples of major terrestrial ... ecosystems" and "areas of outstanding aesthetic and wilderness value". In response to this requirement the Environmental Domains of Antarctica (EDA) was developed by Landcare Research in New Zealand (Morgan et al. 2007). The Committee for Environmental Protection recommends that "the "Environmental Domains Analysis for the Antarctic Continent" ..., be used consistently and in conjunction with other tools agreed within the Antarctic Treaty System as a dynamic model for the identification of areas that could be designated as Antarctic Specially Protected Areas ...” Resolution 3 (2008) - ATCM XXXI - CEP XI, Kyiv (ATS 2008). 
The EDA has a number of limitations as a regionalisation for human landscape perception research, however. First, many of the original bio-climatic environments are perceptually identical and are likely to evoke similar aesthetic responses. For example, there is little to distinguish Region N (East Antarctic inland ice sheet), Region O (West Antarctic ice sheet) and Region Q (East Antarctic high interior ice sheet) in terms of types of terrain (Figure 6.1, left). Second, where the visibility of regions overlaps, it is not clear which region is dominant. Third, there is no common region for coastal ice-free environments, which is where most Antarctic stations have been built (COMNAP 2012). In order to optimise the EDA regionalisation for landscape perception research, i.e. to research into wilderness and aesthetic values, the environments were re-classified into six regions (Figure 6.1, right):

- Central Antarctic ice sheet

- Coastal-continental margin

- Ice shelf and other floating glaciers

- Mountainous ice free

- Antarctic Peninsula ice fields

- Coastal ice-free (the so-called “oases" e.g. (Pickard 1986))

The logic of this re-classification is to group environments into regions that are, as far as possible, perceptually similar. 


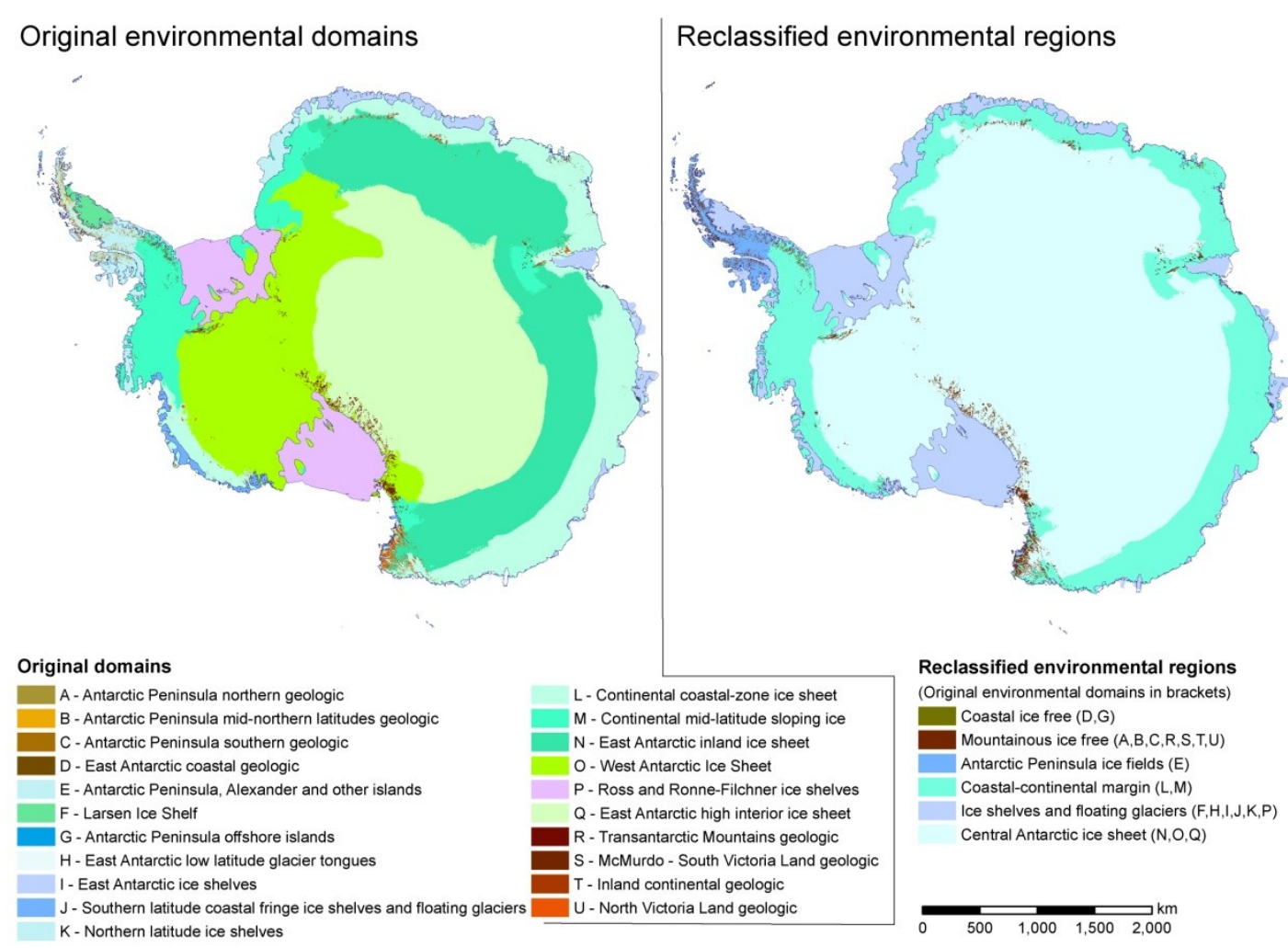

Figure 6.1. Original Environmental Domains of Antarctica regionalisation (left) and reclassified environmental regions (right).

\subsubsection{Survey design}

The second visual survey was designed to address most of the issues that emerged from the first visual survey. These include the following points, each which will be discussed in greater detail.

1. A clear set of research questions;

2. Survey designed to test a series of hypotheses relating to the research questions;

3. Much larger sample size to encompass the four postulated "communities of interest";

4. Much wider choice of imagery;

5. Integration of the survey with the EDA domains;

6. Randomised imagery presentation to the respondents;

7. Three part questionnaire addressing perceptions of wilderness, aesthetic preference and semantic descriptors; and

8. The inclusion of 17 manipulated pairs of images that allowed a direct comparison.

Research questions. The research questions are as outlined in the introduction to this chapter.

Sample size. The choice of an Internet-based survey allowed for a much larger sample size which would not be possible with a paper survey or set of interviews. With appropriate 
advertisement, it was possible to reach the four communities with an interest in Antarctic issues by means of invitations to participate sent by e-mail to national Antarctic programs (Antarctic professionals), to the International Association of Antarctica Tour Operators (IAATO) and to individual tourism companies (tourists and tourism professionals) and to the operators of a number of Antarctic news web sites (interested members of the general public).

Randomised imagery presentation. Respondents accessing the survey were presented with imagery randomised in three ways:

- There were three sets of imagery and the choice of the set to be evaluated was randomised.

- The order that the imagery is presented is randomised

- presentation of the semantic descriptors.

Selection of imagery. I made the choices of the images used in the survey. The images were obtained from a wide variety of sources including institutional photographic libraries, individuals contacted through the Internet, and personal collections, including my own. Special reference should be made to the USAP Antarctic Photo Library (http://photolibrary.usap.gov/), which holds a vast collection of freely available high quality images.

Larger image selection. The total number of images selected for use in this survey was 90 . These come from a wide range of sources and photographers. This was a deliberate choice in order to prevent a level of bias although, of course, there is a risk of introduction of bias through the selection of the images. This is partly reduced by selecting images from other photographers, especially when that offers the opportunity of using imagery from localities I have not visited. The images come from a wide variety of localities (Figure 6.2) providing a reasonable cross-section of Antarctic landscapes though it has not been possible to be totally representative. There is no imagery from Dronning Maud Land (roughly the quadrant south of South Africa), for example. 


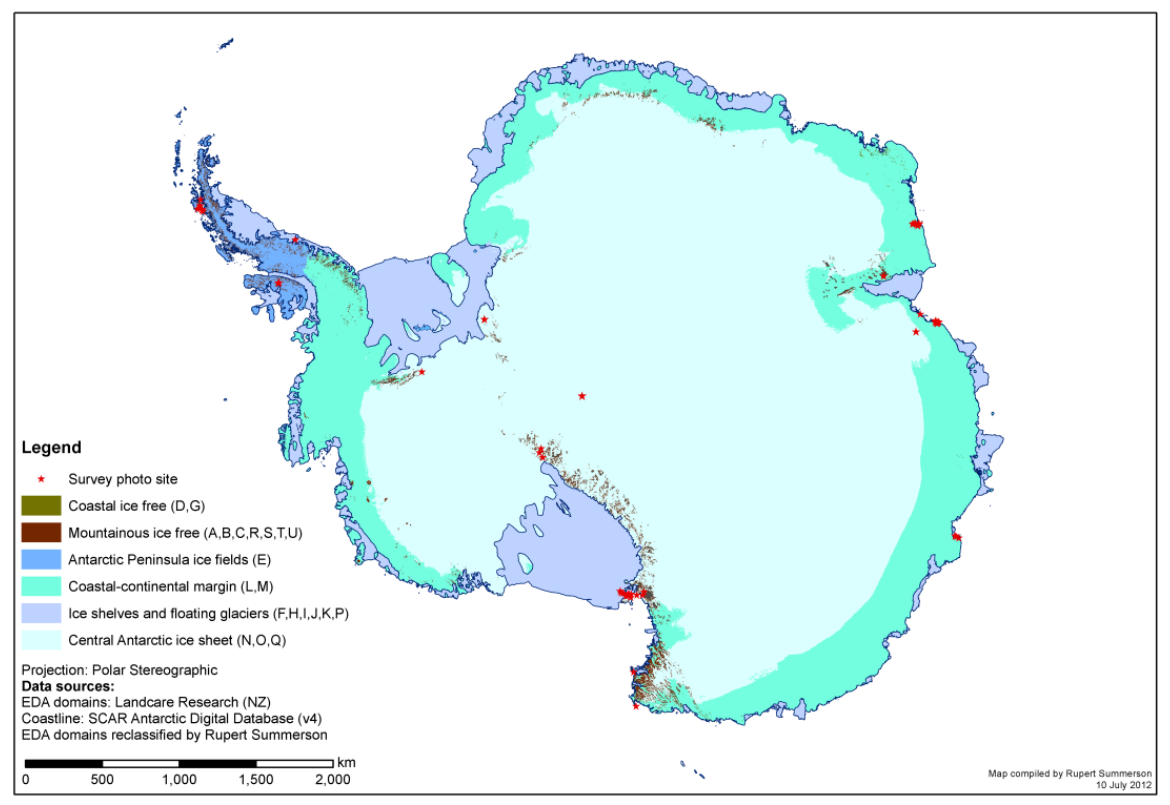

Figure 6.2. Locations of images used in the survey and their placement in the derived EDA regions.

Integration with EDA domains. The imagery selected was placed into one of each EDA domains (coastal ice-free, mountain ice-free, coastal-continental margin, Antarctic Peninsula ice fields, ice shelves and central Antarctic ice sheet). The number of images selected for each domain varied, partly as a consequence of the availability of imagery, which reflects the areas of human activity and is not well distributed across the EDA domains, and partly reflecting the relative amount of human interaction with that domain. The images were not therefore selected at random from each EDA domain. Most human activity takes place in the coastal ice free domain so there was more imagery representing as many different landscape types as possible. Each domain included pairs of images that had been manipulated so that one of the pair included human activity or human infrastructure while the other did not. One of the purposes of the questionnaire is to find out if there is a distinction between transitory activity and permanent infrastructure.

Three part questionnaire. The questionnaire included three questions: a seven point aesthetic preference scale, a Yes/No question on whether the scene represents wilderness in the Antarctic context and a semantic descriptors question. This part of the survey is described in detail below. This survey was posted on a University of Melbourne website on 1 August 2009 following approval from the University of Melbourne Human Research Ethics Committee. The website and database were tested by the author and others to ensure that they functioned correctly before invitations to participate were sent out. Invitations to participate in the survey were sent to the following institutes and organisations: 
Australian Antarctic Division, University of Tasmania Institute of Antarctic and Southern Ocean Studies, British Antarctic Survey, University of Cambridge Scott Polar Research Institute, Antarctica NZ, National Science Foundation (US), University of Minnesota, all 100 members of the International Association of Antarctic Tourism Operators (IAATO), three Antarctic related websites: Antarctic Circle (www.antarctic-circle.org), Cool Antarctica (www.coolantarctica.com) and Ohio State University Byrd Polar Research Center (http://bprc.osu.edu/polar_pointers/), the Russian Arctic and Antarctic Institute and the National Institute for Polar Research (Japan). Two Non-Government Organisations were invited to participate: the Antarctic and Southern Ocean Coalition, itself a coalition of 30 other NGOs, and 2041, an organisation whose aim is "to work towards the continuing protection of the Antarctic Treaty so that the last great wilderness on earth is never exploited." (www.2041.com). Meta $\operatorname{tags}^{27}$ were also written into the home page of the survey to enable the survey to be picked up by someone doing a web search.

Numerous individuals were invited to participate. Everyone was encouraged to invite other people who might also be interested in the general themes in the survey, i.e. wilderness, scenic beauty and Antarctica.

Recognising that Antarctica is an international continent and that cultures other than Englishspeaking or European have had long histories of engagement with Antarctica, it was decided to extend to the survey by translating it into other languages. Japanese was chosen as Japan was one of the original 13 signatories to the Antarctic Treaty and has remained a committed participant in Antarctica ever since. The Japanese version of the survey was launched on 29 January 2010. It was translated directly from the English version by Ms Noriko Sakai, a Japanese teacher and translator, who is resident in Canberra. The semantic descriptors were translated as accurately as possible but, because of cultural differences, it was felt that there may be nuances that may be unwittingly lost or attributed that would make the adjectives not directly comparable. Some comments on the survey were received from Dr Mitsuo Fukuchi, a scientist at the National Institute for Polar Research in Tokyo, in April 2010, who had been approached by a former Australian colleague to help promulgate the survey in Japan. As a consequence, the semantic descriptors were re-examined by two Japanese speakers in Canberra, but no changes were made as they both independently agreed that the original translation was accurate.

\footnotetext{
${ }^{27}$ Keywords included in a web page that are designed to be picked up by search engines. They are hidden in the source code and are not visible in a browser.
} 
France was also an original signatory to the Antarctic Treaty. A French version was launched on 26 March 2010. It was translated by Mme France Meyer, a professional French translator, who is also resident in Canberra. Six Spanish-speaking countries are Antarctic Treaty Consultative Parties (Argentina, Chile, Peru, Ecuador, Uruguay and Spain), two of which (Argentina and Chile) were original signatories; a Spanish version of the survey, translated by Mrs Diana McPhetres, a native Spanish speaker, was launched on 23 May 2012.

Roth (2006), following Reips (2002), outlines a flow diagram for a web questionnaire. A similar structure was adopted for this survey (Figure 6.3).

Dropout (Reips, 2002), where respondents leave the survey before the end, is a common problem with web surveys. A number of measures were taken to reduce the chances of dropout and to minimise the effects. A "high-hurdle" technique was adopted by directing the survey towards people with an interest in Antarctica who would therefore be more likely to be motivated to take part and complete the survey. The background page, which includes an extract from the Madrid Protocol and a statement on how respondents' results will be used to help develop procedures for implementing the Protocol, provides further motivation. A "warm-up" technique was also adopted by starting the actual evaluation phase eight pages into the survey. Reips advises that most dropouts occur at the beginning of a survey so by placing the evaluation pages well into the survey, most people who are not motivated to complete the survey will dropout before reaching those pages. The inclusion of a page asking for demographic data before the evaluation pages also tends to ensure commitment.

The survey code was written in PHP (php.net) so no plug-in was required by respondents. Unlike many other online surveys (e.g. Roth, 2006), this survey did not offer a reward. The survey was anonymous so offering a reward would have meant identifying respondents. No comments have been made about the suitability of a reward but it may have stimulated more responses. 
1.Home page. Includes a login screen to deter automated access.

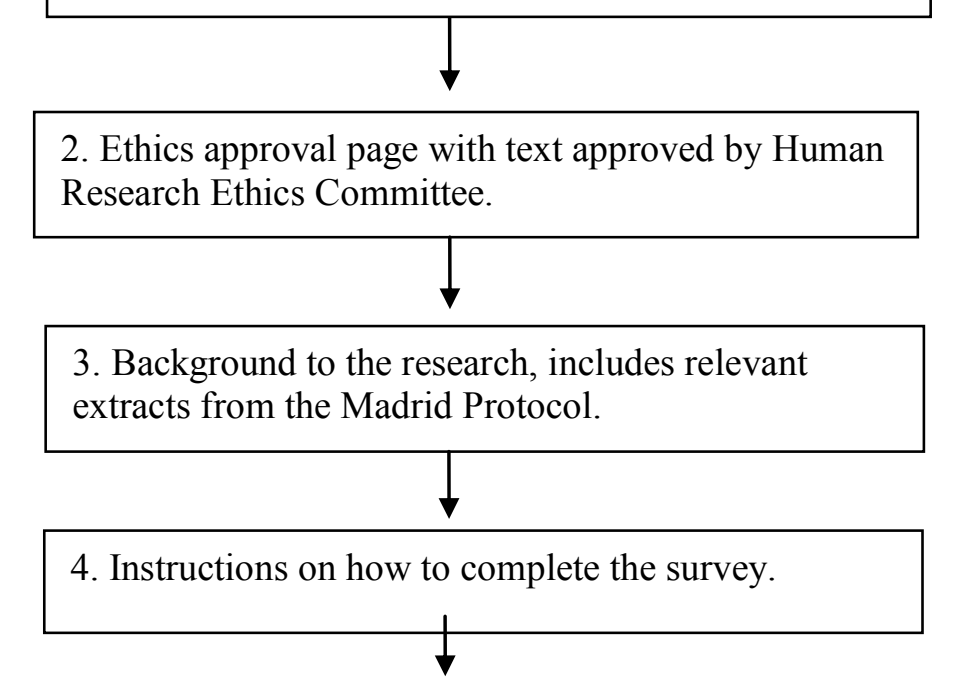

5. Profile page. Collects demographic data.

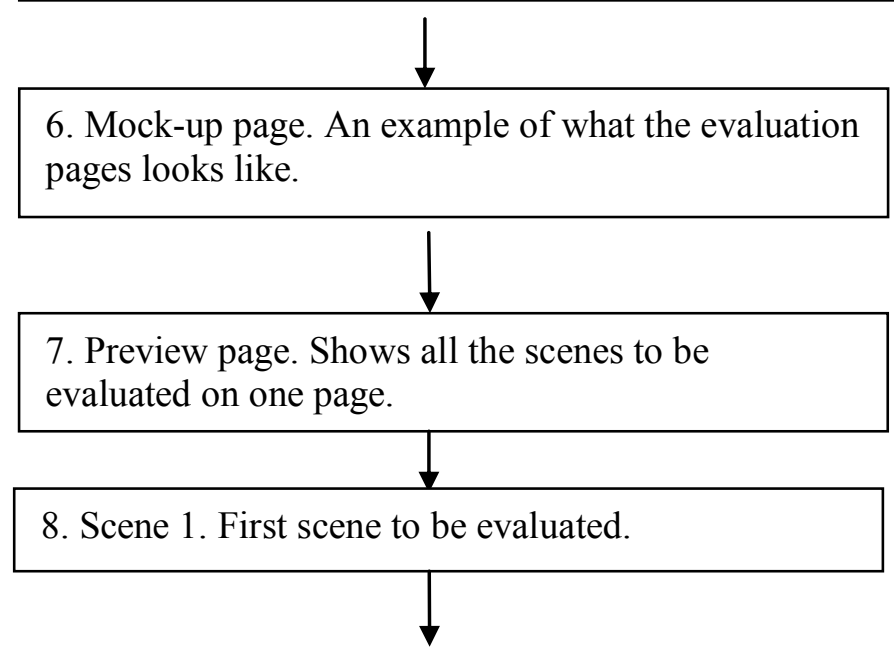

9. Scene 2 - Scene 30 . The survey can be finished at any time by clicking on the 'Finish' button. When the 'Finish' button is pressed the results are written to a database.

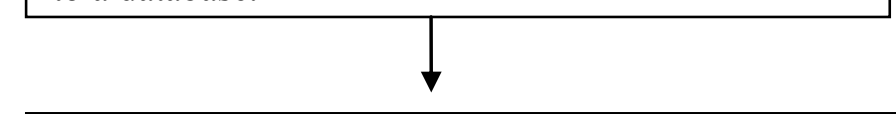

10.Finish. The results are written to a database. Includes thanks and acknowledgements.

Also includes an invitation to contact the author.

Figure 6.3. Flow diagram for the Internet survey. 


\subsubsection{Components of the survey}

There are three parts to the survey:

1. Perceptions of wilderness

Question: "Does this scene represent wilderness to you?"

Response: Yes/No

2. Perceptions of aesthetic quality

Question: "Please select your preference rating on a scale of 1(low) to 7(high)"

Response: 1-7

3. Semantic descriptors

Question: "How well does each of the following words describe this scene?"

Response: Not at all, Not well, Neutral, Well, Very well

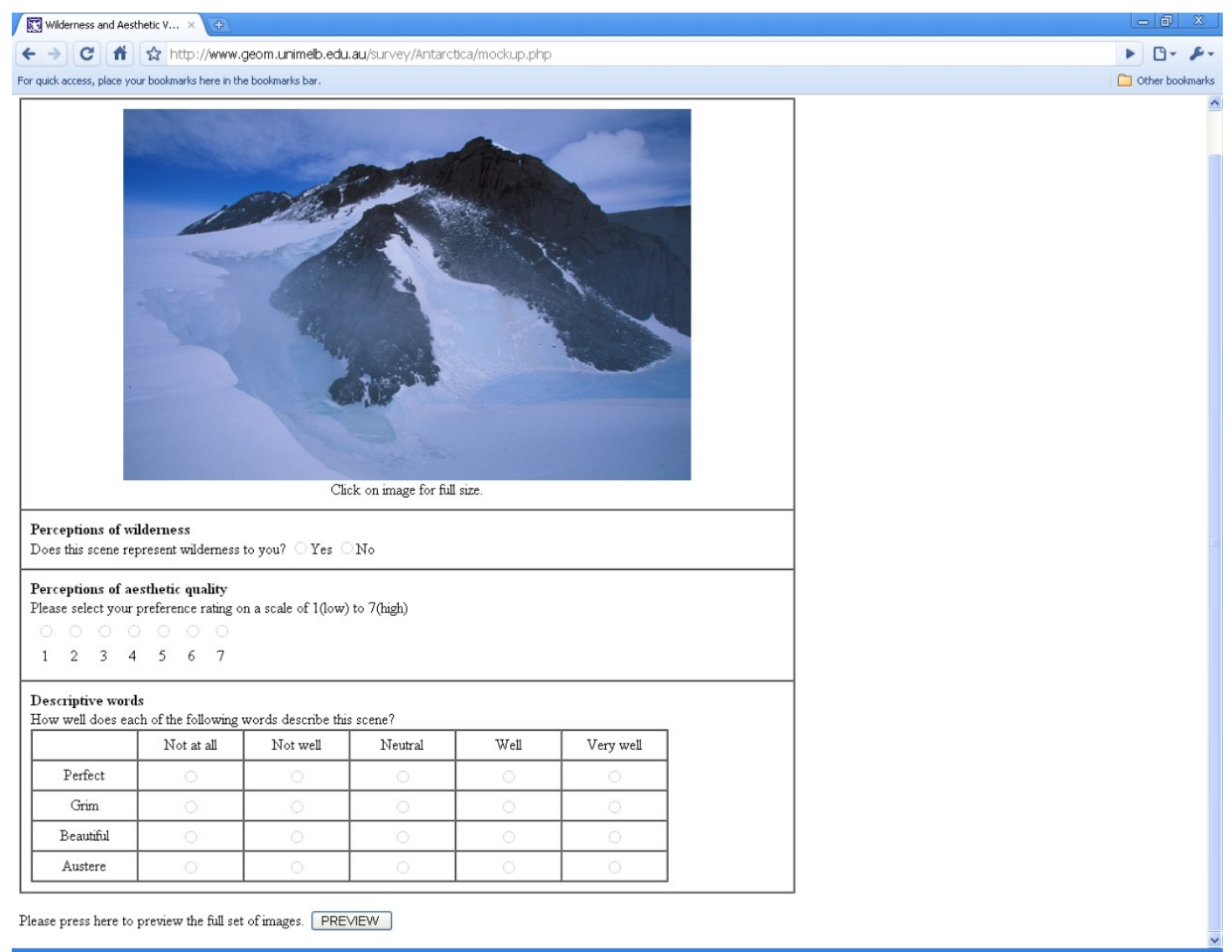

Figure 6.4.The main question page of the survey showing the image to be assessed and the three sets of questions below it. 
A 'yes/no' response for perceptions of wilderness, as opposed to a scaled response on an npoint scale, was sought on the basis that if it is the presence of infrastructure that degrades wilderness, then a 'yes/no' response should be sufficient to test that hypothesis. The author's personal observations in the field in Antarctica has been that only where there is no sight or sound of permanent infrastructure is a feeling of wilderness possible. It is recognised, however, that not all people think this way and it is also recognised that the setting of policy regarding wilderness is still under development (CEP 2010) so grades of wilderness (e.g. Lesslie \& Taylor 1985) may be desirable. In terms of testing the hypothesis that visible infrastructure degrades wilderness the binary approach is, however, sufficient.

There is no standard rating scale for aesthetic preference. Kaplan \& Kaplan (1995) used a five point scale for their preference studies; Roth (2006) used an 11 point scale for aesthetics (and other descriptive terms) and Sevenant \& Antrop (2011) used a 10 point scale for beauty. A seven point scale for aesthetic preference was chosen on the basis that it was thought to provide sufficient resolution for aesthetic responses, giving the equivalent of three levels of like and dislike on either side of a central, neutral position.

Included in the 90 images were 16 pairs where infrastructure or human activity was removed by digitally manipulation from one of the pair, or in one case infrastructure was added to an otherwise natural scene. Digitally manipulated pairs of images, where evidence of human presence has been removed from, or added to, one of the pair, provide the most direct assessment of the impact of human presence in landscape imagery (Grêt-Regamey et al. 2007; Rodiek \& Fried 2005). The manipulated pairs were randomly distributed throughout the survey with the manipulated image in one set and the original in another set so that no respondent saw both the original and manipulated versions. The images in each pair are identical except for the human activity (infrastructure or transient activity) which was removed from one of the pair and replaced with the best possible approximation of the natural environment. Since this is the only difference between each pair, any differences in ratings must be due to the presence/absence of infrastructure or transient activity. A complication in carrying out the digital manipulations was replacing the object removed with a realistic background. Since it was not possible to replace the natural background in images of complex infrastructure, such as an Antarctic station in an ice-free area (e.g. Figure 6.5) because of probable disturbance to the underlying terrain (GERG 2003) it was decided not to attempt manipulations of such images. 


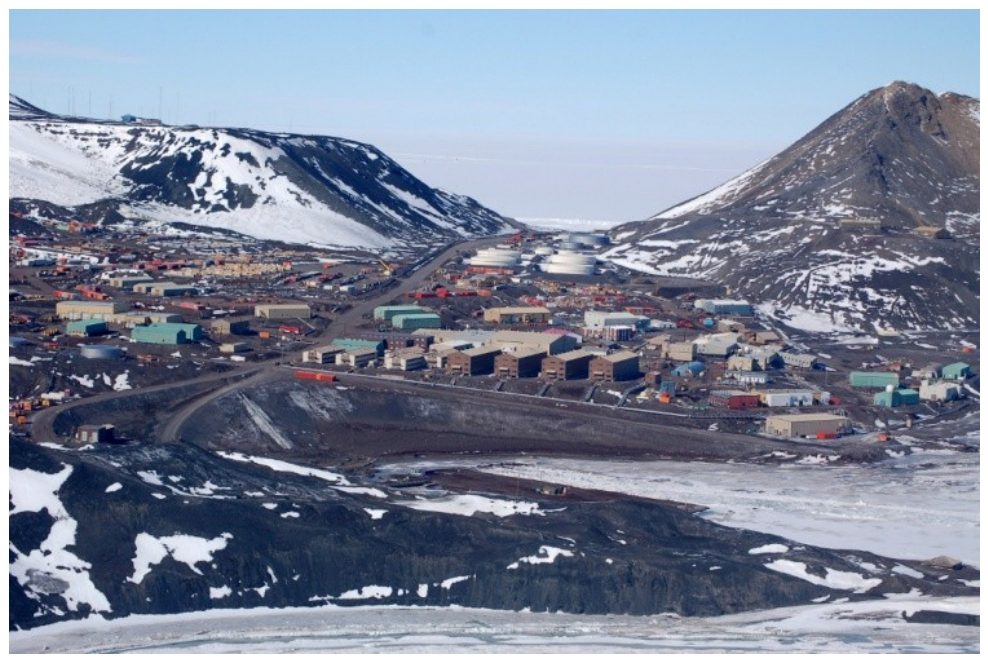

Figure 6.5. Evident terrain modification rules out an attempt to remove complex infrastructure in an image such as this of McMurdo. (Photo: Bob Koch/NSF Antarctic Photo Library).

One further scene was digitally manipulated - a landscape which included a large number of penguins. The penguins were digitally removed for a preliminary comparison of the effect of wildlife on aesthetic preference. Digital manipulation was carried out using GIMP (GNU Image Manipulation Program) version 2.6.6 (GIMP 2009). Examples of the original and manipulated images from each of the EDA regions are shown in Figure 6.6.

Original images
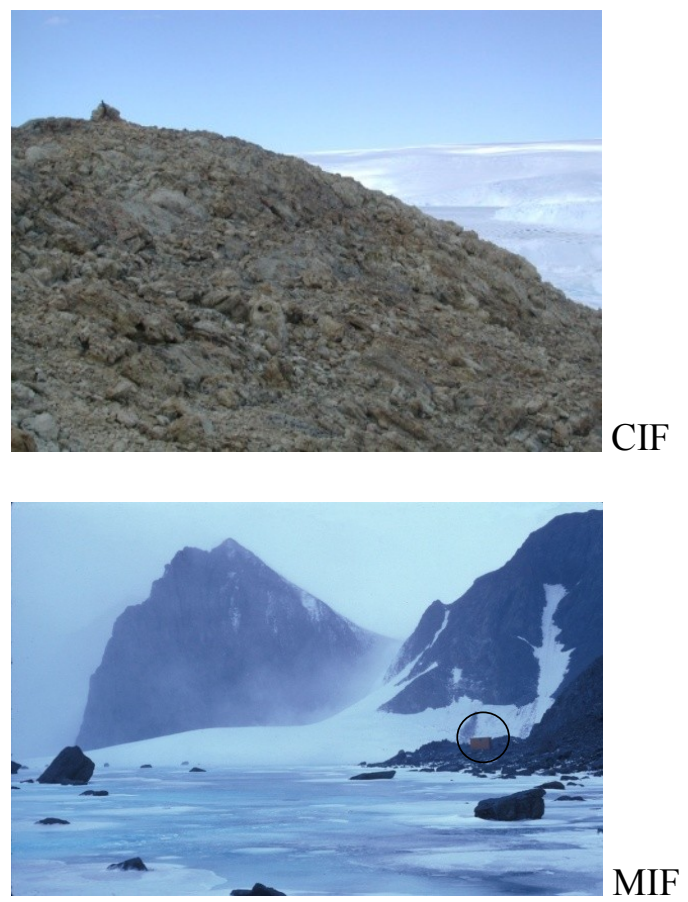

Modified images
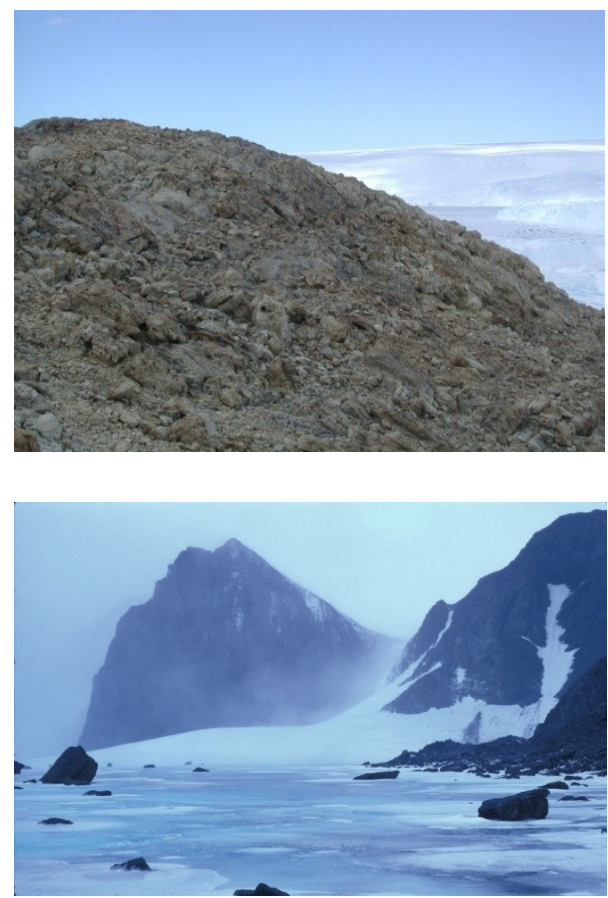

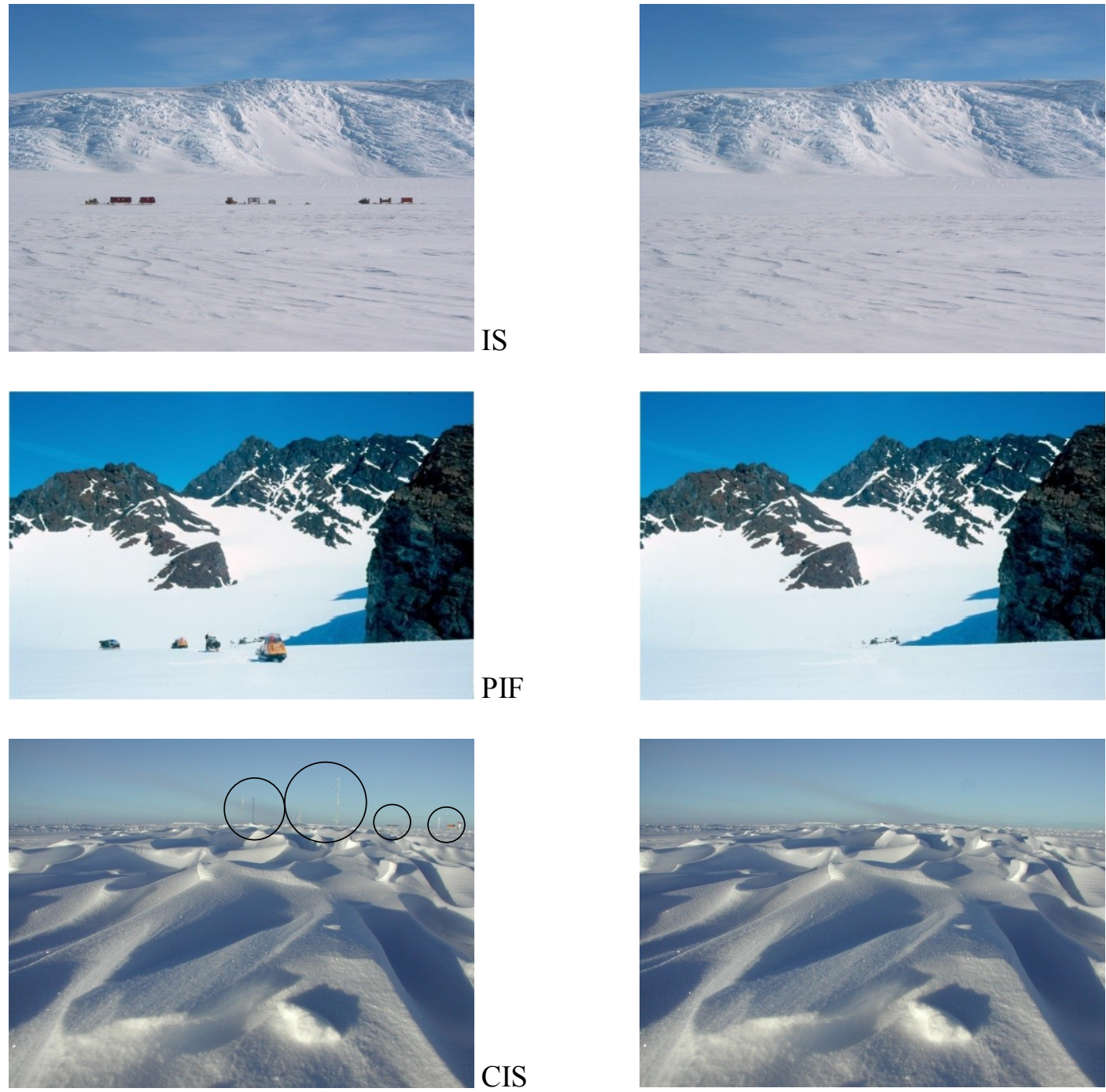

Figure 6.6. Examples of original and digitally modified images. Items that were digitally removed that may be difficult to discern at this scale have been circled. CIF $=$ coastal ice free. MIF $=$ mountainous ice-free. $I S=$ Ice shelf. PIF $=$ Peninsula Ice Fields. CIS $=$ Central Antarctic ice sheet. (Photos: CIF: Rupert Summerson, MIF: Australian Antarctic Division, IS: John Penney (NSF Antarctic Photo Library), PIF: Rupert Summerson, CIS: Brian Vasel (NOAA).)

The third part of the survey was designed to gain insights into how people respond to landscapes in Antarctica. The underlying premise was that adjectives associated with the sublime were more likely to be appropriate in Antarctica than, perhaps, words associated with the beautiful. 20 adjectives that had been used to describe Antarctic landscapes were chosen from the Antarctic literature. The literature surveyed included books from the "Heroic Era", i.e. the late nineteenth and early twentieth centuries, as well as contemporary accounts, including notes in field hut log books. Examples of such usage (from hut log books) include: 
“...before going for a walk half way up Fang Peak - breathtaking views and a lot of photos

taken”. (Fang Hut log, 10 September 1995)

"Shame to be leaving as the moon is full and the sunsets spectacular". (Fang Hut log, 5 March 1995)

“...its surely a truly beautiful spot”. (Bandit’s Hut log, 30 July 1997).

"XXX showed me the most pretty spot of [sic] I've ever seen in Vestfolds without doubt ..."

(Platcha Hut log, 11 November 1982).

No frequency or any other analysis was carried out on these adjectives, nor was there any attempt made to determine how representative they are of current usage. In fact, it was quite difficult to find 20 adjectives, and in the end two additional adjectives, "ugly" and "unpleasant", were included in order to provide respondents with some negative adjectives, which is consistent with Kant's proposition that aesthetic judgment is the feeling of both pleasure and displeasure. As Jay Shurley described, negative responses, especially to human presence in Antarctica seem inevitable.

"Any casual visitor to inland Antarctic stations is exposed en route to an ironical combination of sights: some of the world's most breathtakingly beautiful natural scenery in its purest, most virgin state; but when he reaches the station of his destination, he is greeted by scenes of nearly indescribable litter of supplies and solid wastes, the sight and smell of air pollution, the taste of water pollution, the silence-shattering noise pollution of massive engines, and the unseen hazards of toxic gases, especially carbon monoxide, in the confined spaces there.

Against this purest, whitest, cleanest, noise-free background, man's litter and pollution stand out with particular clarity as an affront to his esthetic sensibilities, to his altruism and his conscience.” (Shurley 1972)

The adjectives were grouped into two lists: words generally associated with the beautiful and words often associated with the sublime. The adjective "sublime" itself was not included, partly because it is not a word in common usage, except perhaps as a higher or more rarefied form of beauty, and partly because there was a risk of confusion between those who understood it as such and those who understood it in its Burkean or Kantian meaning. It was anticipated that by using words associated with the sublime, but not "sublime" itself, a more informative result would be achieved. Four words were offered to each respondent with each image; two from the "beautiful" list and two from the "sublime" list. The adjectives presented were selected randomly from each list (Table 6.6.2). 
Table 6.6.2. The adjectives presented to respondents as part of the semantic assessments.

\begin{tabular}{|l|l|}
\hline Beautiful & Sublime \\
\hline Beautiful & Austere \\
\hline Delightful & Barren \\
\hline Lovely & Bleak \\
\hline Pleasant & Desolate \\
\hline Pretty & Breathtaking \\
\hline Glorious & Grand \\
\hline Wonderful & Impressive \\
\hline Magnificent & Spectacular \\
\hline Ugly & Vast \\
\hline Unpleasant & Awesome \\
\hline
\end{tabular}

Respondents were asked to rate the suitability of each these words to describe each image on a five point Likert scale (Figure 6.4).

\section{5. Conclusions}

As described above, an empirical approach was taken to address the research questions with five surveys, each one building on the responses to and the lessons learnt from the previous one. The surveys incorporated features described in the literature but included a number of innovations, for example the semantic component of the survey using adjectives drawn from Antarctic literature. The underlying philosophy was to involve as many people as possible in providing responses to these questions so to achieve this, the last survey, built on the Internet, was promulgated widely. Versions of the Internet survey were built in four languages: English, French, Japanese and Spanish. 


\section{Chapter 7. Results}

\subsection{Introduction}

This chapter describes the results from three surveys carried out over the course of this research, from the first paper questionnaire to a large scale Internet survey. The Internet survey draws on the experiences and lessons of the first two surveys and provides a large data resource for a range of statistical tests on aesthetic preferences, perceptions of wilderness, semantic assessments of Antarctic landscapes and the impacts of human activities on these values. The results of the earlier surveys also provide some useful insights and data and strongly support the results of the Internet survey.

\subsection{Survey 1. ANARE Voyage 5 January - February 2000}

A total of 40 expeditioners on this voyage completed the questionnaire, of these 13 were on their first voyage to Antarctica and 27 were experienced expeditioners. The questionnaire form is at Appendix 1.

This questionnaire did not include any imagery. The first part of the questionnaire related to perceptions of wilderness. There were three parts to the wilderness section.

\subsubsection{Wilderness.}

Part 1. The first set of questions was as follows:

Would you consider that wilderness, in an Antarctic context, means:

Q 1. No sign, sound or any other evidence of human presence.

Q 2. Sight or sound or human activity is acceptable so long as they do not dominate the landscape.

Q 3. Antarctica is such a harsh place that even station areas are part of the wilderness A summary of the results of Part 1 are in Table 7.1. (Some respondents chose to answer more than one question.) 
Table 7.1. Summary of responses on Wilderness Part 1.

\begin{tabular}{|l|l|l|}
\hline Question & $\begin{array}{l}\text { Novices (\% of } \\
\text { respondents) }(\mathbf{N}=\mathbf{1 3})\end{array}$ & $\begin{array}{l}\text { Experienced (\% of } \\
\text { respondents) (N= 27) }\end{array}$ \\
\hline Q 1. & $43.75 \%$ & $56 \%$ \\
\hline Q 2. & $37.5 \%$ & $41 \%$ \\
\hline Q 3. & $18.75 \%$ & $19 \%$ \\
\hline
\end{tabular}

The next two parts of the wilderness part of the questionnaire follow on from the first part and were meant to be dependent on the responses given but some respondents answered them anyway.

\section{W1: You have indicated that wilderness in an Antarctic context means "No sign, sound or any other evidence of human presence", but:}

Table 7.2. Responses to W1. Experienced expeditioners.

\begin{tabular}{|l|l|l|l|l|}
\hline Questions & N & Yes & No & Remarks \\
\hline $\begin{array}{l}\text { 1. Would the knowledge that the snow contains } \\
\text { (sometimes minute) traces of human activities (eg } \\
\text { radioactive fallout from nuclear weapons testing } \\
\text { in the 1950s) detract from wilderness? }\end{array}$ & 16 & $31 \%$ & $69 \%$ & $\begin{array}{l}80 \% \text { of those who said yes said } \\
\text { that that knowledge would } \\
\text { detract 'slightly' or } \\
\text { 'marginally' }\end{array}$ \\
\hline $\begin{array}{l}\text { 2. Would you consider that if a single distant } \\
\text { feature, such as a radio mast, was visible, even } \\
\text { though you could turn your back on it and see no } \\
\text { other evidence of human activities, it would still } \\
\text { detract from your appreciation of wilderness? }\end{array}$ & 15 & $73 \%$ & $27 \%$ & \\
\hline $\begin{array}{l}\text { 3. Do you consider that temporary traces of } \\
\text { human activity e.g. vehicle or foot tracks in the } \\
\text { snow detract from wilderness? }\end{array}$ & 16 & $56 \%$ & $44 \%$ & \\
\hline $\begin{array}{l}\text { 4. Do you consider that your safety overrides the } \\
\text { maintenance of wilderness, e.g.would you } \\
\text { consider a route marker an infringement on } \\
\text { wilderness? }\end{array}$ & 15 & $47 \%$ & $53 \%$ & \\
\hline $\begin{array}{l}\text { 5. Would vapour trails from high flying aircraft } \\
\text { detract from your sense of wilderness? }\end{array}$ & 15 & $43 \%$ & $57 \%$ & \\
\hline
\end{tabular}


W 2. If you think that Wilderness, in the Antarctic context, means that "Sight or sound of human activity is acceptable so long as they do not dominate the landscape", please answer the following questions:

Table 7.3. Responses to W2. Experienced expeditioners

\begin{tabular}{|c|c|c|c|c|}
\hline Questions & $\mathbf{N}$ & Yes & No & Remarks $^{28}$ \\
\hline \multicolumn{5}{|l|}{$\begin{array}{l}\text { 1. Would any of the following infringe on your } \\
\text { perception of wilderness?: }\end{array}$} \\
\hline Route marker & 15 & $27 \%$ & $73 \%$ & \\
\hline Vehicle track in ice free area & 15 & $47 \%$ & $53 \%$ & \\
\hline $\begin{array}{l}\text { Signs of past scientific activity eg taking of rock } \\
\text { samples }\end{array}$ & 14 & $43 \%$ & $57 \%$ & \\
\hline Field hut & 14 & $36 \%$ & $64 \%$ & \\
\hline Vehicle track in snow & 14 & $14 \%$ & $86 \%$ & \\
\hline Signs of camp sites & 14 & $43 \%$ & $57 \%$ & \\
\hline $\begin{array}{l}\text { 2. Would your safety influence your perception } \\
\text { of wilderness? }\end{array}$ & 14 & $71 \%$ & $29 \%$ & \\
\hline $\begin{array}{l}\text { 3. What level of noise emanating from human } \\
\text { activities (eg helicopters, reversing alarms) would } \\
\text { be acceptable } \\
\text { eg none, just audible, clearly audible? }\end{array}$ & 13 & $38 \%$ & $62 \%$ & $\begin{array}{l}\text { Many respondents equivocated } \\
\text { saying it depended on the level } \\
\text { of noise. Most thought that } \\
\text { temporary sounds would be OK. }\end{array}$ \\
\hline
\end{tabular}

\section{W 3. Antarctica is such a harsh place that even station areas are part of the wilderness}

Table 7.4. Responses to W3. Experienced expeditioners

\begin{tabular}{|l|l|l|l|l|}
\hline Questions & N & Yes & No & Remarks \\
\hline $\begin{array}{l}\text { 1. Would you feel that the presence of roads, } \\
\text { vehicles and buildings were part of } \\
\text { wilderness? }\end{array}$ & 9 & $44 \%$ & $56 \%$ & \\
\hline
\end{tabular}

\footnotetext{
${ }^{28}$ Most of the responses were accompanied by remarks such as "It depends on the level ..." The percentages do not capture the full detail of the responses.
} 


\begin{tabular}{|c|c|c|c|}
\hline $\begin{array}{l}\text { 2. Would you consider that the presence of } \\
\text { humans enhances the sensation of wilderness } \\
\text { through the contrast between the small size } \\
\text { of human settlement and the vast size of } \\
\text { Antarctica? }\end{array}$ & 9 & $33 \%$ & $67 \%$ \\
\hline $\begin{array}{l}\text { 3. Do you think that humans have as much } \\
\text { right to be in the wilderness as other species? }\end{array}$ & 1 & $92 \%$ & $8 \%$ \\
\hline $\begin{array}{l}\text { 4. What level of activity would change this } \\
\text { view e.g. the construction of an airport, } \\
\text { hotel, mining/industrial complex? }\end{array}$ & 1 & $9 \%$ & $91 \%$ \\
\hline
\end{tabular}

\subsubsection{Aesthetics}

The second part of the questionnaire related to aesthetics. Question A1 asked for first time visitors (novices): What elements of the Antarctic landscape are you hoping to experience? And for experienced expeditioners: What elements of the Antarctic landscape do you find most pleasing? The results of this section are shown in Table 7.5.

Table 7.5. Summary results of Question A1. (Results are in percentages)

\begin{tabular}{|l|l|l|}
\hline $\begin{array}{l}\text { Landscape } \\
\text { elements }\end{array}$ & Novices & $\begin{array}{l}\text { Experienced } \\
\text { expeditioners }\end{array}$ \\
\hline Icebergs & 100 & 100 \\
\hline Pack ice & 100 & 100 \\
\hline Wildlife & 100 & 100 \\
\hline Ice cliffs & 84.6 & 96.3 \\
\hline Glaciers & 84.6 & 96.3 \\
\hline Rocky areas & 84.6 & 81.5 \\
\hline Historic sites & 76.9 & 66.7 \\
\hline Ice cap & 76.9 & 77.8 \\
\hline Ice shelves & 69.2 & 70.4 \\
\hline $\begin{array}{l}\text { Sites of human } \\
\text { activities }\end{array}$ & 69.2 & 40.7 \\
\hline Crevasse fields & 61.5 & 85.2 \\
\hline $\begin{array}{l}\text { Snow-covered } \\
\text { mountains }\end{array}$ & 53.8 & 77.8 \\
\hline
\end{tabular}

\section{Note}

$\% \mathrm{TOTAL}=\%$ of respondents who prefer this landscape type.

Question A2 asked experienced expeditioners if they had a favourite place they liked to visit?

22 experienced expeditioners responded by nominating a specific locality or localities.

Table 7.6Table 7.6 summarises the results. 
Table 7.6. Summary results of the favourite places part of the questionnaire

\begin{tabular}{|c|c|c|c|}
\hline Location & No. nominations & Landscape type & Remarks \\
\hline $\begin{array}{c}\text { Casey/Windmill } \\
\text { Islands }\end{array}$ & 21 & $\begin{array}{c}16 \text { coastal ice free } \\
3 \text { central ice sheet } \\
1 \text { coastal continental } \\
\text { margin } \\
1 \text { offshore }\end{array}$ & $\begin{array}{c}8 \text { nominations for } \\
\text { Browning Peninsula/ } \\
\text { Peterson Island }\end{array}$ \\
\hline Vestfold Hills & 4 & 4 coastal ice free & \\
\hline Mawson area & 3 & $\begin{array}{c}1 \text { mountain ice free } \\
2 \text { coastal continental } \\
\text { margin }\end{array}$ & \\
\hline
\end{tabular}

The voyage this survey was carried out on was a round trip to Casey and therefore it was to be expected that sites in the Windmill Islands would be particularly favoured.

The localities nominated have been aggregated by landscape type. Half of the localities nominated in the coastal ice free environment around Casey were for Browning Peninsula or Peterson Island. These localities are adjacent and are connected by sea ice for much of the year. They are also about as far as it is possible to go from Casey Station within the Windmill Islands and three people commented on that fact. Three people nominated inland sites: Law Dome (the site of a glaciological research project) or places en route there. Many people commented on the views to be had from their favourite places: "great views", "views up to the plateau" and "uninterrupted views towards the ocean". A number of people also made comments like: "No view of station". Many of the places nominated have field huts: e.g. Browning Peninsula, Peterson Island, Robinson's Ridge. Trajer Ridge and Jack’s Donga. A few people mentioned huts specifically: "comfortable hut" but others enjoyed being out in the open: "You can sleep on a cliff site and wake up to the Vanderford Glacier on one side and penguins and seals on the other. It is a breathtaking spot." (Peterson Island).

Many also commented on the difficulty of nominating a particular place and made comments such as:

\footnotetext{
"Anywhere away from the station has magic in it - whether for the 'unreal' uniformity (e.g. the white on white) or diversity of icebergs with pack, rock vs snow - and that feeling of vastness, alien and vulnerability." (Anonymous respondent).
} 


\section{3. Disposable camera experiment}

Six cameras were returned from Antarctica with a total of 95 images.

The hypothesis behind this experiment was that the scenes people would photograph and classify as beautiful would be scenes without evidence of human activity and the "ugly" scenes would include infrastructure and artefacts.

Unfortunately this experiment was unsuccessful in that none of the participants kept accurate records of what they photographed and why. Some of the cameras were returned without notebooks. Even the best documented set was mostly unusable as, apart from the first five images, it was not possible to reconcile the features in the photographs with what was recorded in the notebook. It appears that the user had taken additional photographs but had forgotten to record what each one contained.

This experiment was conducted on the cusp of the transition from film to digital cameras. Such an experiment would be conducted differently now with the widespread use of digital cameras, which would make the participant photo process much easier, especially as cameras increasingly include GPS and orientation sensors.

\section{4. Survey 2. First survey using images of Antarctica}

\subsubsection{Introduction}

There were 52 respondents in all; 46 respondents from ANARE Voyage 4 2000-2001 plus a further six ex-Antarcticans from Canberra. Apart from not actually participating in a voyage to Antarctica at the time of completing the survey, there was no other difference between the two sets of respondents so their results have been pooled. By far the greatest number of respondents was Australian (39) with eight other nationalities: Netherlands (2), France (1), Sweden (1), Switzerland (1), USA (1), Canada (1), South Africa (1) and New Zealand (1). The demographic details supplied by the respondents showed that 33 had visited Antarctica at least once previously and 16 were on their first visit. Three did not supply any demographic information. The number of previous visits by individuals ranged from one to 19. There were 38 males and 12 females.

\subsubsection{Wilderness}

The aim of the wilderness part of the survey was to explore the impact of human activity in various forms on perceptions of wilderness. Out of 45 scenes, 27 included some form of human activity, from a single human figure to a large Antarctic station. A series of Chi-square tests for 
independence (with Yates Continuity Corrections) were carried out to test perceptions of wilderness as laid out in Table 7.7.

Table 7.7. Results of Chi-square tests for independence of comparisons of images of human presence with images with no human presence.

\begin{tabular}{|l|l|l|l|l|l|l|}
\hline Purpose & Set & $\chi^{2}$ & df & n & p & phi \\
\hline $\begin{array}{l}\text { Human presence compared with } \\
\text { natural }\end{array}$ & All & 186.334 & 1 & 2163 & 0.000 & 0.295 \\
\hline As above & Visited & 129.402 & 1 & 1310 & 0.000 & 0.316 \\
\hline As above & Not visited & 53.124 & 1 & 718 & 0.000 & 0.277 \\
\hline Infrastructure compared with natural & All & 268.018 & 1 & 1729 & 0.000 & 0.395 \\
\hline Transient compared with natural & All & 2.478 & 1 & 1248 & 0.115 & 0.05 \\
\hline
\end{tabular}

\subsubsection{Aesthetics}

In order to correct for scaling differences between respondents, a problem inherent in raw ordinal aesthetic preference scores (Daniel \& Boster 1976), the responses were first converted to $\mathrm{Z}$ scores $(\mathrm{Z}=$ (mean of all respondent's scores - respondent's image score) / standard deviation of all respondent's scores). The resulting $\mathrm{Z}$ scores were then treated as interval data as a number of authors, e.g. Schroeder (1984) and Arriaza et al. (2004), have reported that there is little or no error in treating ordinal aesthetic preference data as interval data.

An independent samples t-test was carried out on the $\mathrm{Z}$ scores of all responses to compare aesthetic responses to images showing some form of human presence to those without any evidence of human presence. The difference between the scores was significant and as follows. Images with human presence: mean $=-0.29, \mathrm{SD}=1.021$; natural images: mean $=0.43, \mathrm{SD}=$ $0.76 ; \mathrm{t}(\mathrm{df}=2166) 18.727, p=0.000$, two-tailed. The magnitude of the differences in the means (mean difference $=0.713,95 \%$ CI: 0.639 to 0.788 ) was moderate to large (Cohen's $d=0.78$ ). Independent samples t-tests were also carried out separately on responses to the same images by people who had visited Antarctica and those who had not. In both cases, the differences in responses to images with human presence and those without human presence were significant for both groups of people as laid out in Table 7.8. 
Table 7.8. Results of independent samples t-tests for respondents to the first visual survey comparing aesthetic ( $\mathrm{Z}$ score) responses to all images with and without human presence by people who had visited Antarctica and those who had not.

\begin{tabular}{|c|c|c|c|c|c|c|c|c|}
\hline $\begin{array}{c}\text { Visited } \\
\text { Antarctica? }\end{array}$ & $\begin{array}{l}\text { Human } \\
\text { presence }\end{array}$ & $\mathrm{N}$ & Mean & SD & $\mathrm{t}$ & $p$ & Mean diff. & Cohen's d \\
\hline Yes & Yes & 592 & -0.31 & 1.009 & \multirow{2}{*}{16.902} & \multirow{2}{*}{0.000} & \multirow{2}{*}{0.775} & \multirow{2}{*}{$0.84(\mathrm{~L})$} \\
\hline Yes & No & 882 & 0.46 & 0.749 & & & & \\
\hline No & Yes & 429 & -0.24 & 1.046 & \multirow{2}{*}{8.615} & \multirow{2}{*}{0.000} & \multirow{2}{*}{0.587} & \multirow{2}{*}{$0.62(\mathrm{M})$} \\
\hline No & No & 288 & 0.35 & 0.776 & & & & \\
\hline
\end{tabular}

\subsubsection{Visual prominence}

One of the difficulties in assessing the results of this survey was uncertainty as to what feature or features in the images the people completing the survey were responding to. For example, images 16, 17 and 18 are of the same place: Wiencke Island, Gerlache Strait and Anvers Island in the distance. Image 16 ranked second, image 17 ranked $10^{\text {th }}$ and Image 18 ranked $27^{\text {th }}$. Images 16 and 17 both include human activity in the form of a ship and Image 17 also includes a hut with human figures. Both images were taken in cloudy weather whereas Image 16 was taken in clear weather with spectacular lighting effects (Table 7.9).

Table 7.9. summarises the content and preference ratings of images 16, 17 and 18

\begin{tabular}{|l|l|l|l|}
\hline $\begin{array}{l}\text { Image } \\
\text { no. }\end{array}$ & Image & $\begin{array}{l}\text { Average } \\
\text { aesthetic } \\
\text { preference }\end{array}$ & Wilderness \\
\hline 16 & 0.3 & 6.3 & $100 \%$ \\
\hline
\end{tabular}




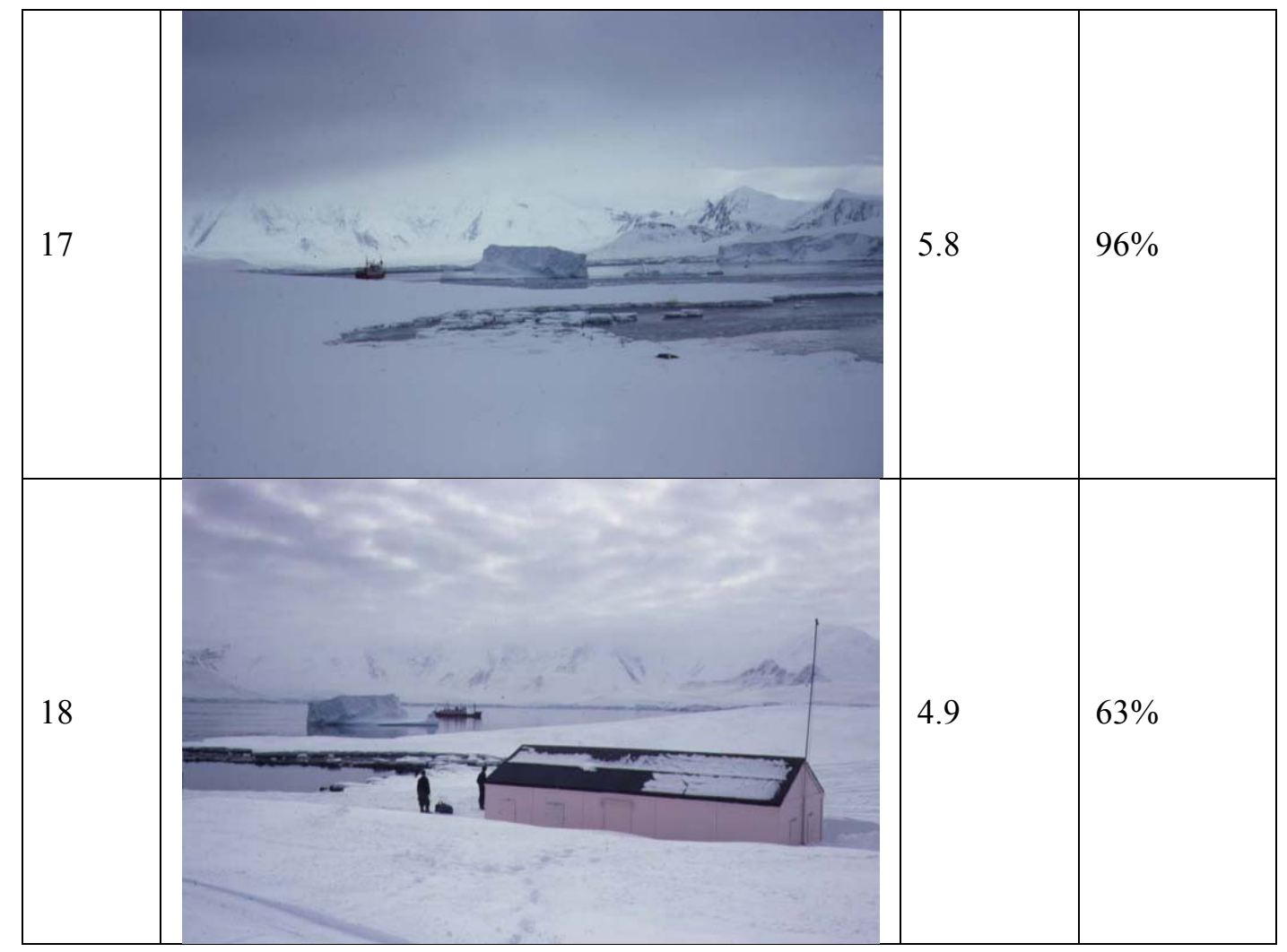

It seems quite clear from this set of images that the reduction in aesthetic preference ratings between Images 16 and 17 is due to the dramatic lighting effects in Image 16 and the low cloud in Image 17 which obscures the upper part of Mount Français. The reduction in wilderness value, especially between Images 17 and 18 is due to the presence of Damoy Hut. The presence of the ship in Image 17 resulted in a 4\% reduction in wilderness value and as the same ship is present in Image 18, the loss of wilderness value must be due to the building and human figures and perhaps also the vehicle tracks in the snow.

In order to determine what elements in the photographs people were responding to, a visual prominence experiment was conducted. The same 45 images that were used in the questionnaire were provided to a focus group of three people who were asked to rate the visual prominence of up to 14 elements in each scene on a scale of 1 to 10 . Elements included mountains, buildings, human figures and wildlife. Not all components were present in every scene. The three people chosen to form the focus group comprised a mixture of age, gender, Antarctic experience and landscape assessment experience. Assessments by the focus group of visual prominence varied widely throughout the 45 images. Out of the 289 assessments (not every element occurred in every image) $46 \%$ had standard deviations $>=2.0$. As a point of comparison, the highest standard deviation of the aesthetic preferences from the survey was 1.88 . Two issues became apparent: the first was that members of the focus group had difficulty interpreting the images, some of which it is acknowledged were not very good quality, and second, the size of the focus 
group was much too small for statistically significant results. Uncertainty about whether the inconsistency experienced with the initial group would be repeated in a larger group and the amount of time taken to recruit another 20 members led to this approach being abandoned. Some useful lessons were learnt, however, which included the importance of good quality imagery and the avoidance of ambiguity.

\subsection{Second favourite place questionnaire}

Another favourite place questionnaire was handed out during ANARE 4 2000-2001 and responses were received from 10 people. The questionnaire asked for brief demographic information which showed that 5 people had previously visited Antarctica for summers only and 5 people had over-wintered. Of the summer-only visitors, one was a scientist who had been to Antarctica five times previously and four were science support or tradespeople. Of the winterers, three had not been to Antarctica previously and comprised a scientist, a doctor and a tradesperson and two had been to Antarctica previously, one seven times and the other twice; one was operations staff and the other in science support. There was therefore a range of experience and a range of occupations. Twenty three places were nominated as favourites. Table 7.10 lists the places nominated as favourite places.

Table 7.10. Nominations for favourite places.

\begin{tabular}{|c|c|c|c|}
\hline Location & $\begin{array}{c}\text { No. } \\
\text { nominations }\end{array}$ & Landscape type & Remarks \\
\hline $\begin{array}{c}\text { Vestfold Hills } \\
\&\end{array}$ & 11 & coastal ice free & Field huts nominated three times \\
Rauer Islands & 7 & $\begin{array}{c}3 \text { mountain ice free } \\
\text { coastal continental } \\
\text { margin }\end{array}$ & $\begin{array}{c}\text { All include field huts } \\
1 \text { field hut nominated }\end{array}$ \\
\hline Mawson area & 2 & $\begin{array}{c}1 \text { coastal ice free } \\
\text { coastal continental } \\
\text { margin }\end{array}$ & \\
\hline Pack ice & 1 & & Not within Antarctic Treaty area \\
\hline Heard Island & 2 & & \\
\hline
\end{tabular}

It is notable that many of the places nominated as 'favourite' were in the coastal ice free region and that field huts were nominated seven times. These points will be picked up in the Discussion in Chapter 9. 


\subsection{Survey 3. Second (Internet) survey using images of Antarctic landscapes}

\subsubsection{Introduction}

The second visual survey was based on the Internet as described in Chapter 6 (Methods). An initial target of 270 responses was set which equates to each of the three sets of 30 images being viewed 90 times. As the set of images that each respondent is presented with when they log on is randomised ${ }^{29}$, every set is not viewed exactly the same number of times. The numbers of respondents for each of the three sets of photos is in Table 7.11. Not every respondent evaluated all 30 images in the set so there were a total of 11,281 evaluations (out of a total possible number of 13,050), which gives a high degree of statistical power (the probably of detecting the phenomenon under test (Cohen 1988)) to the survey results. The average number of images responded to by all respondents was 25.93 or $86.43 \%$ of the total number. A total number of 435 respondents from 24 countries plus a number of unknown nationalities took part in the survey (Table 7.13).

Table 7.11. Count of respondents that viewed at least one image in each of the three sets.

\begin{tabular}{|r|r|}
\hline \multicolumn{1}{|c|}{ Set } & Count of responses \\
\hline \hline $1(101-130)$ & 120 \\
\hline $2(201-230)$ & 165 \\
\hline $3(301-330)$ & 150 \\
\hline
\end{tabular}

\subsubsection{Demographic information}

The survey asked for some brief demographic details prior to commencing the survey itself: age range, gender, education level, nationality and Antarctic experience. Table 7.12 lists percentages of respondent by age range, gender and education level. Table 7.13 lists the numbers and nationalities of the respondents.

Australians were by far the largest number of respondents. This was probably due both to the relatively high level of personal contacts but also to the access I was permitted to staff at the

\footnotetext{
${ }^{29}$ Judging by the distribution of responses in Table 7.11, it would appear that the randomisation algorithm was not very effective. It would have been more effective to allocate each respondent to a set in turn.
} 
Antarctic Division, at the Australian Antarctic stations and contacts within other institutions such as the Institute of Antarctic and Southern Ocean Studies at the University of Tasmania. Similarly, but to a lesser extent, access to staff at the British Antarctic Survey (BAS), staff and students at the Scott Polar Research Institute and members of the BAS Club (club for British Antarctic Survey veterans) helped with the numbers from the UK. Contacts in the US, New Zealand and Japan were instrumental in obtaining responses from those countries. No attempt was made, however, to determine how respondents had heard about the survey.

Table 7.12. Demographic details of respondents by age range, gender and education level.

\begin{tabular}{|l|l|}
\hline Demographic & Percentage of respondents \\
\hline Age range & \\
\hline $18-25$ & 9 \\
\hline $26-35$ & 17 \\
\hline $36-45$ & 18 \\
\hline $36-55$ & 23 \\
\hline$>55$ & 34 \\
\hline & \\
\hline Gender & \\
\hline Male & 55 \\
\hline Female & 45 \\
\hline & \\
\hline Education level & \\
\hline Secondary & 5 \\
\hline College & 16 \\
\hline Tertiary & 26 \\
\hline Higher degree & 54 \\
\hline
\end{tabular}

Table 7.13. Nationalities and numbers of survey respondents.

\begin{tabular}{|l|r|l|r|}
\hline Nationality & \multicolumn{1}{|c|}{ Count } & Nationality & \multicolumn{1}{c|}{ Count } \\
\hline Australia & 174 & Ireland & 3 \\
\hline UK & 64 & Italy & 3 \\
\hline USA & 60 & Russia & 3 \\
\hline France & 31 & South Africa & 3 \\
\hline Japan & 19 & Switzerland & 2 \\
\hline Unknown & 16 & India & 1 \\
\hline New Zealand & 16 & Portugal & 1 \\
\hline Canada & 10 & Denmark & 1 \\
\hline Germany & 9 & Colombia & 1 \\
\hline Argentina & 5 & Spain & 1 \\
\hline Peru & 4 & Sweden & 1 \\
\hline Brazil & 3 & Mexico & 1 \\
\hline Chile & 3 & TOTAL & $\mathbf{4 3 5}$ \\
\hline
\end{tabular}


15 of the 17 Japanese respondents took part in the Japanese version of the survey; the others took part in the English version. The numbers of respondents to each language version are in Table 7.14.

Table 7.14. Numbers of respondents to each language version of the survey.

\begin{tabular}{|l|r|}
\hline \multicolumn{1}{|c|}{ Language } & Count \\
\hline English & 382 \\
\hline French & 29 \\
\hline Japanese & 17 \\
\hline Spanish & 7 \\
\hline
\end{tabular}

Respondents were also asked for their Antarctic experience: whether or not they have visited Antarctica and their roles and numbers of visits in each role: as scientist, science support, operations, tourist, tourism industry, private expedition or other.

The following is a summary of respondents broken down by type of Antarctic experience, i.e. national Antarctic program, tourist, tourism industry staff, etc.

- 306 people ( $70 \%$ of all respondents) who have experienced Antarctica

- 129 people (30\% of all respondents) who have not experienced Antarctica

- Of the people with Antarctic experience:

- 203 were scientists, science support \& operations staff (national Antarctic programs)

- 83 were tourists, of which 20 had experience with national Antarctic programs

- 41 were tourism industry (guides, ships' crew, etc), of which 28 had experience with national Antarctic programs. 23 of these were either scientists or science support and 5 were operations staff.

- 21 were from private expeditions, of whom 9 had experience with national Antarctic programs

- 33 were others or not specified, of which 17 had experience with national Antarctic programs

337 respondents (77\%) completed the full survey i.e. all 30 images in the set. A further $37(8 \%)$ completed more than half the survey. 22 respondents (5\%) completed fewer than 5 image evaluations.

\subsubsection{Analyses}

The analyses of the results are described as follows:

1. Perceptions of wilderness

2. Assessments of aesthetic quality. 
3. Semantic assessments

4. Development of a generalised linear model

5. Demographic effects on perceptions of wilderness and aesthetic quality

Analyses were mostly carried out using PASW (formerly and again SPSS) Statistics 18 (http://www.ibm.com/spss). R (R Development Core Team 2004) was used in the analyses of demographic effects.

\subsubsection{Wilderness}

\subsubsection{All images}

A chi-square test for independence (with Yates continuity correction) was carried out on all assessments to test the effect of human presence on wilderness. As noted above, half of the images in the survey included evidence of human presence. A significant difference was found in the ratings of 'wilderness' or 'not wilderness' between images with human presence, which was not differentiated into transient or activity or infrastructure, and images without human presence, $\chi^{2}(1, \mathrm{n}=11,219)=891.082, p=0.000, \mathrm{phi}=0.282$. Effect size, a measurement of the absolute magnitude of a treatment effect independent of the size of the sample being used, was calculated using the phi coefficient $(\Phi)$ (Gravetter \& Wallnau 2010). 0.1 is a small effect, 0.3 a moderate effect and 0.5 a large effect(Cohen 1988). (The sign of the phi value is meaningless because of the arbitrary assignment of 0 and 1 to the binary variables in the phi-coefficient calculation (Gravetter \& Wallnau 2010).) Similar tests were carried out to compare, separately, all images with no human presence with images containing, respectively, scenes of transient activity and infrastructure. Significant differences were found between both groups: transient activity, $\chi^{2}(1, \mathrm{n}=8262)=327.156, p=0.000$, phi $=-0.199$ and infrastructure: $\chi^{2}(1, \mathrm{n}=8412)$ $=1214.876, p=0.000, \mathrm{phi}=-0.38$. A further chi-square test for independence, also with continuity correction, was carried out on to compare assessments of wilderness between images of transient activity and images of infrastructure and a significant difference was found between them: $\chi^{2}(1, \mathrm{n}=5764)=202.106, p=0.000$, phi $=-0.188$.

There is, however, more complexity than these figures might suggest. There is considerable variability in assessments of 'wilderness' within the set of 46 images containing human presence; from under 15\% of responses (an image of an Antarctic station, Figure 7.1, left) to over 96\% (vehicle tracks in snow, Figure 7.1, right). 


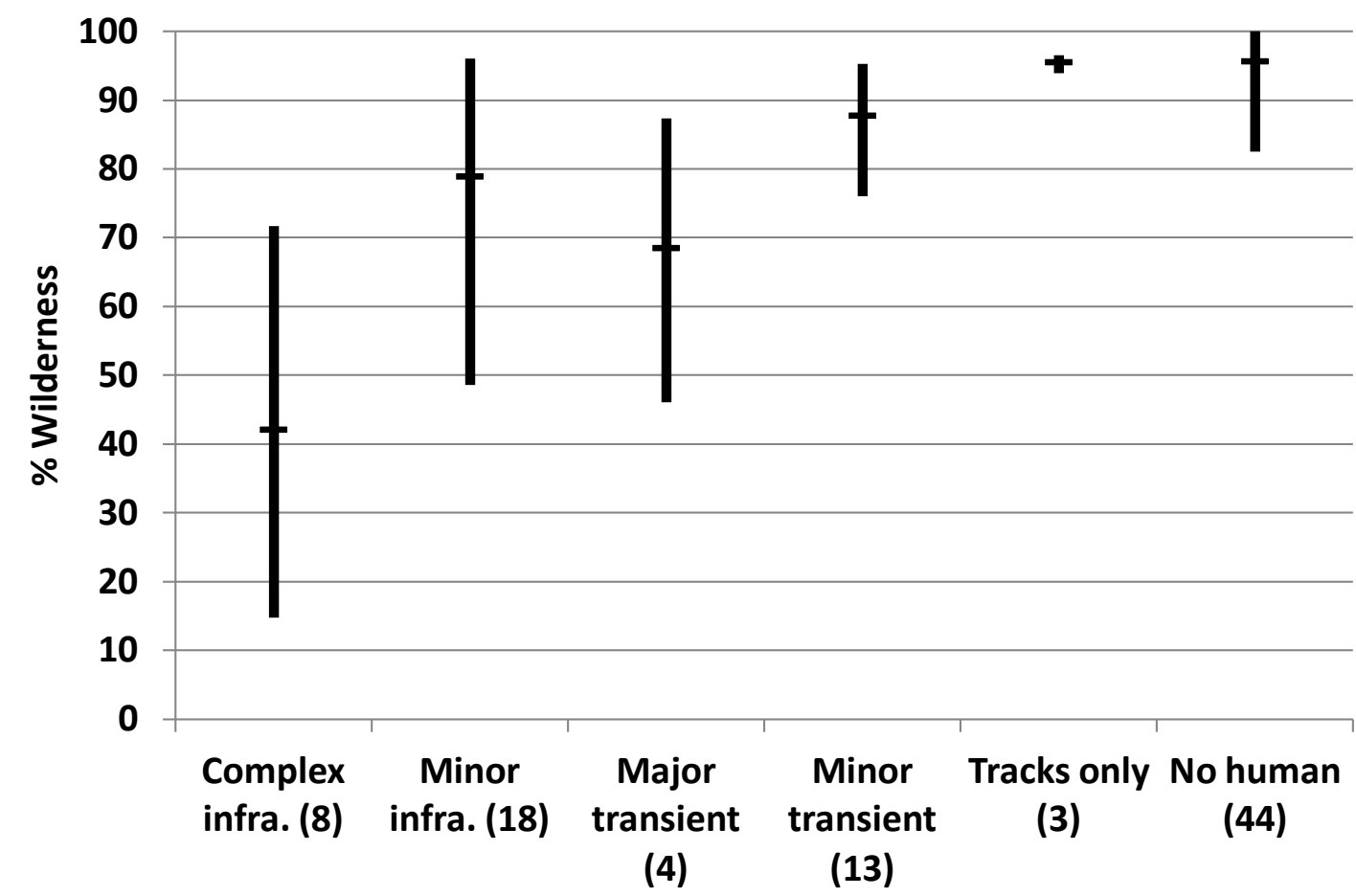

Figure 7.2 is a breakdown of the type of human content in the images, but does not include categorisation of proximity. By contrast, there is very little variety in the set of 44 images without human presence (Figure 7.2 right hand column). Assessments of 'wilderness', i.e. that the scene represents wilderness, range from $82 \%$ of responses to $100 \%$, with over $68 \%$ of images having $>95 \%$ assessments of 'wilderness'.

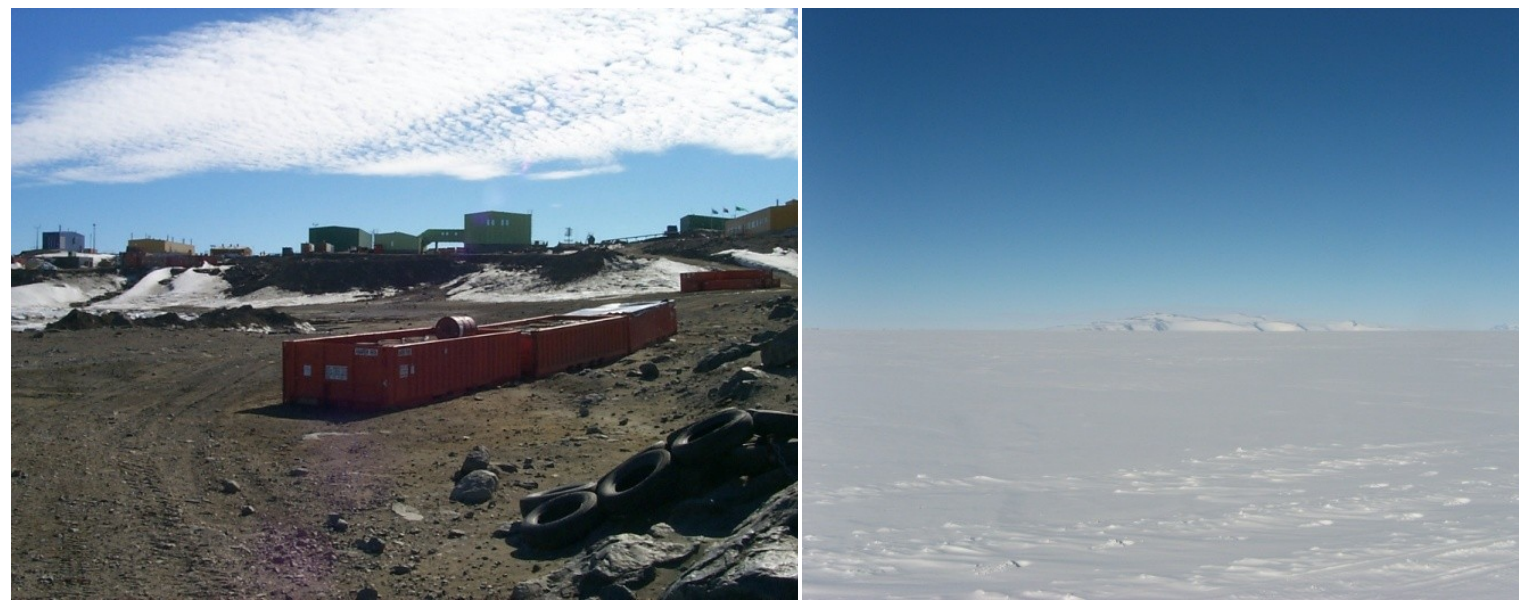

Figure 7.1. Left: $15 \%$ of respondents considered this scene as wilderness (photo: Rupert Summerson). Right: $96 \%$ of respondents considered this scene as wilderness (photo: Elaine Hood/NSF). 


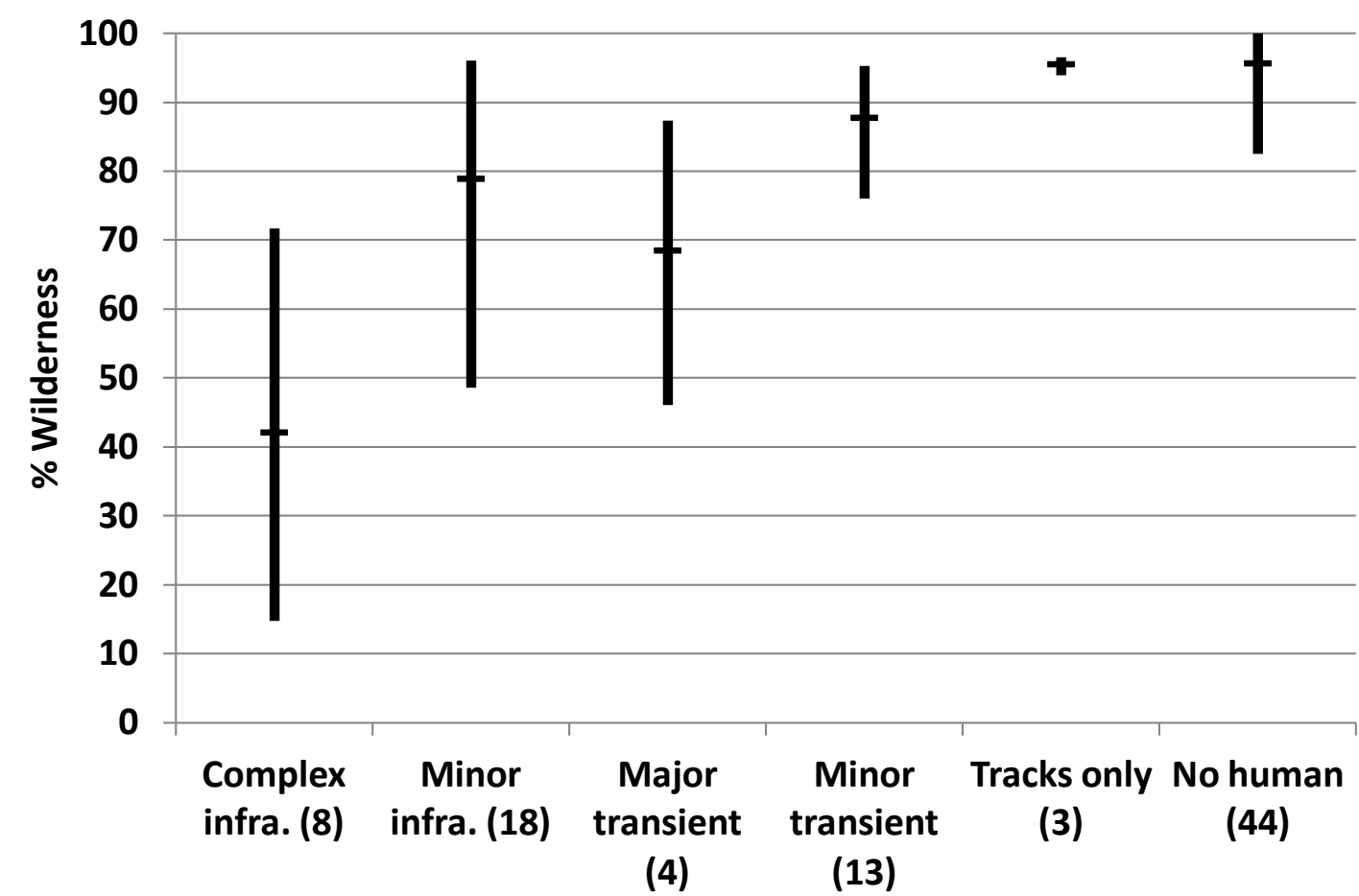

Figure 7.2. Ranges of assessments of 'wilderness' among images with human content, grouped by human content type. Complex infrastructure is defined as multiple buildings and structures, e.g. stations; minor infrastructure is one or two buildings and/or structures, e.g. field huts; major transient is defined as ships, aircraft or heavy vehicles; minor transient is light vehicles or people on foot; and tracks only are tracks in snow only. The figures in brackets are the numbers of images in each group. The vertical bars represent the range of assessments in each group: minimum to maximum; the mean is represented by the cross-bar. The range of assessments of 'wilderness' of the 44 images without human content is shown on the right for comparison.

\subsubsection{Images aggregated by EDA region}

In order to test the effects of different landscape types on perceptions of 'wilderness' and 'notwilderness', assessments of wilderness were analysed by EDA region. Percentages of assessments of wilderness for each EDA region are shown in Figure 7.3. The type of human presence is undifferentiated. 


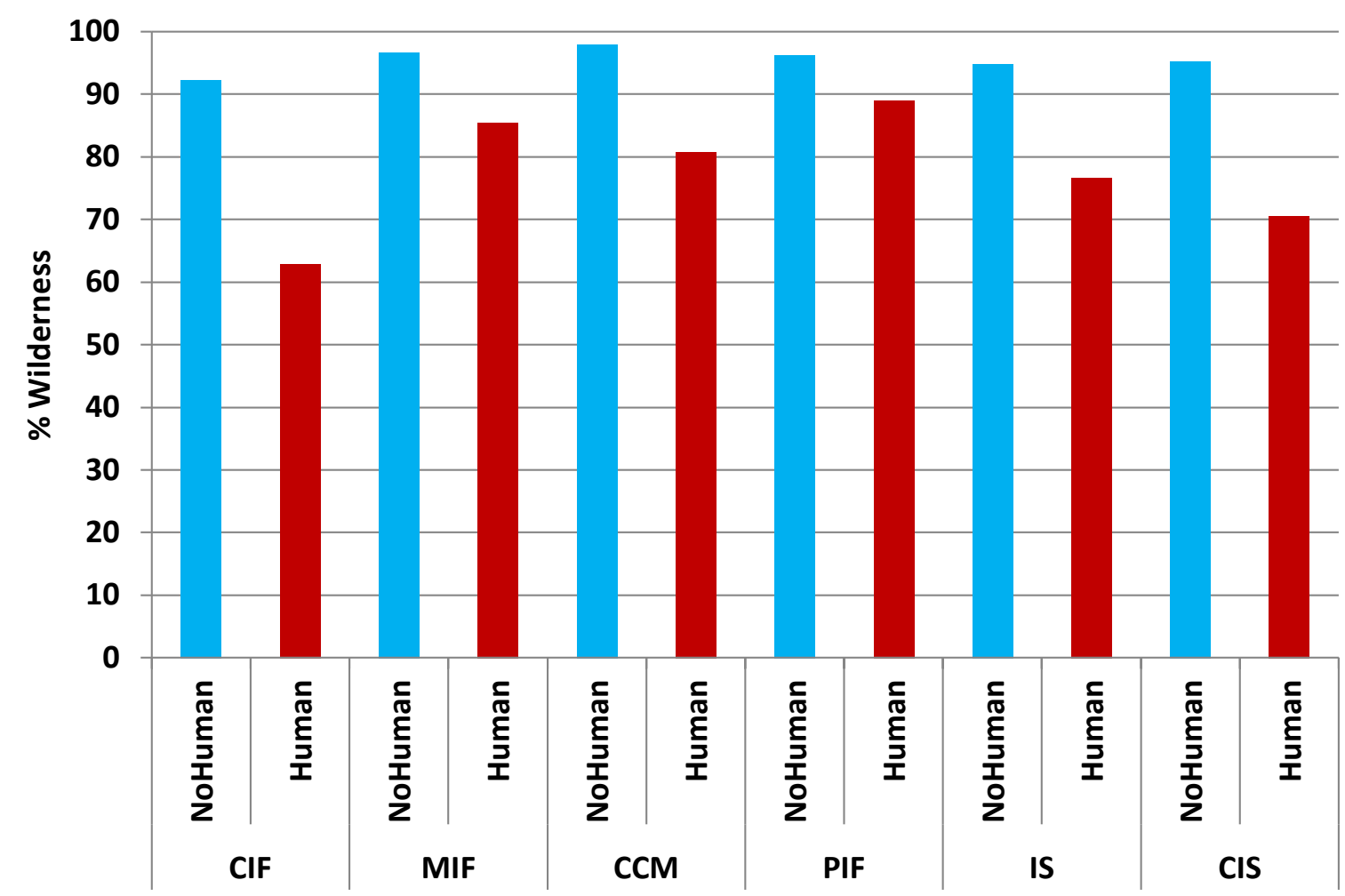

Figure 7.3. Percentage assessments of wilderness - all images with and without human presence aggregated by EDA region. The red columns are the percentages of responses perceived as wilderness of all images with human presence. The blue columns are the percentages of assessments of wilderness of all images in each EDA region without human presence.

Chi-square tests were carried out to compare assessments of 'wilderness' and 'not wilderness' in each EDA region in order to determine whether human presence has a significant effect. Tests were carried out on all images and then, separately, on images containing infrastructure (complex and minor combined) and images showing transient activity. The comparisons were made with all images with no human presence from that EDA region. Images that showed both infrastructure and transient activity were treated as infrastructure. Table 7.15 shows the results of chi-square tests comparing assessments of wilderness and not-wilderness between all images aggregated by EDA region, differentiated by all images (both transient $\&$ infrastructure), images containing transient activity and images containing infrastructure. 
Table 7.15. Results of chi-square tests comparing assessments of wilderness and not-wilderness between all images aggregated by EDA region, differentiated by all images (both transient \& infrastructure), images containing transient activity and images containing infrastructure. $\chi^{2}=$ Pearson chi-square test with Yates' continuity correction, $p=$ significance, $p h i(\Phi)=$ effect size. $\alpha=0.05$. The non-significant result is indicated in bold type.

\begin{tabular}{|c|c|c|c|c|c|c|c|c|c|c|c|c|}
\hline \multirow[t]{2}{*}{ EDA } & \multicolumn{4}{|c|}{ All } & \multicolumn{4}{|c|}{ Transient activity } & \multicolumn{4}{|c|}{ Infrastructure } \\
\hline & $\mathrm{n}$ & $\chi^{2}$ & $p$ & $\Phi$ & $\mathrm{n}$ & $\chi^{2}$ & $p$ & $\Phi$ & $\mathrm{n}$ & $\chi^{2}$ & $p$ & $\Phi$ \\
\hline CIF & 2631 & 353 & 0.000 & -0.37 & 1527 & 1.4 & 0.243 & -0.03 & 2356 & 458 & 0.000 & -0.44 \\
\hline MIF & 2247 & 92.91 & 0.000 & -0.20 & 1712 & 25.09 & 0.000 & -0.12 & 1853 & 118 & 0.000 & -0.25 \\
\hline PIF & 1624 & 31.87 & 0.000 & -0.14 & 1395 & 29.27 & 0.000 & -0.15 & 1257 & 14.29 & 0.000 & -0.11 \\
\hline $\mathrm{CCM}$ & 1721 & 112 & 0.000 & -0.25 & 1206 & 122.3 & 0.000 & -0.32 & 1221 & 81.45 & 0.000 & -0.26 \\
\hline IS & 1644 & 114 & 0.000 & -0.26 & 1272 & 4.83 & 0.028 & -0.06 & 1275 & 221 & 0.000 & -0.42 \\
\hline CIS & 1352 & 97.39 & 0.000 & -0.27 & 853 & 48.85 & 0.000 & -0.24 & 894 & 127 & 0.000 & -0.38 \\
\hline
\end{tabular}

\subsubsection{Manipulated pairs}

Figure 7.4 shows the percentages of assessments of wilderness, i.e. the percentage of assessments of wilderness as a proportion of the total number of assessments of both the manipulated images, which were perceived as being natural, and assessments of their counterpart unmodified images. The latter included some form of human presence, either infrastructure or transient activity. In all cases the percentage ratings of wilderness of the images with human presence were lower than those of their counterpart images that were apparently natural. Eleven of the image pairs included scenes of infrastructure and of these the differences between pairs of nine images were judged to be statistically significant $(\alpha=0.05, p$ $<0.05$ ). Of the five pairs of images which included transient activity, the differences between three pairs were significant. It is notable that the percentage assessments of wilderness of the apparently natural images of coastal ice free areas are generally lower than images from other EDA regions. This is consistent with the findings from the semantic assessment of the survey (Summerson \& Bishop 2011). 


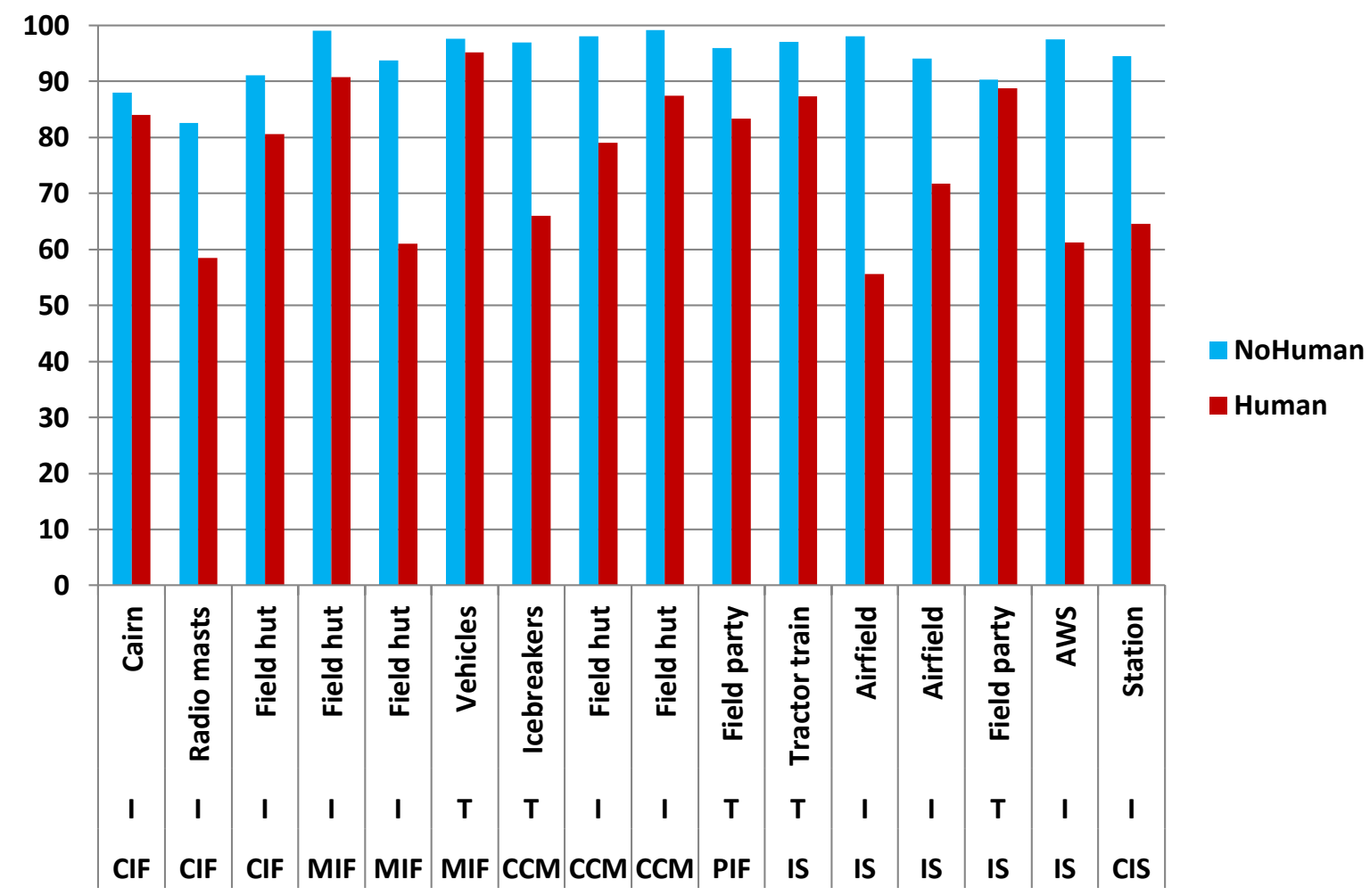

Figure 7.4. Percentages of assessments of wilderness for each image pair in the 16 pairs of images. The pairs are clustered by EDA region (Figure 6.2): $\mathrm{CIF}=$ coastal ice free, MIF = mountainous ice free, $\mathrm{CCM}=$ coastal continental margin, $\mathrm{PIF}=$ peninsula ice fields, $\mathrm{IS}=$ ice shelves and CIS = central Antarctic ice sheet. The type of human presence in the original images is either infrastructure (I) or transient activity (A). Red $=$ human presence, blue $=$ no human presence.

Chi-square tests were carried out on the 17 pairs of images that had been digitally manipulated (examples in Figure 6.6); the results are shown in Table 7.16. One other pair of images was manipulated: penguins were digitally removed from an image as a preliminary test of the impact of wildlife on assessments of wilderness. $99 \%$ of responses of the original scene with penguins indicated that it represented wilderness, whereas of the responses of the manipulated image from which the penguins had been removed, $94 \%$ of responses were that it represented wilderness - a non-significant difference. This is confirmed by the chi-square test which showed a non-significant difference (Table 7.16). 
Table 7.16. Results of chi-square tests of responses on perceptions of wilderness of the 17 pairs of digitally manipulated pairs of images. EDA = EDA region. Infra/trans. = infrastructure or transient activity. $\mathrm{N}_{\text {human }}=$ sample size images with human presence. $\mathrm{N}_{\text {natural }}=$ sample size images without human presence. $\chi^{2}, p$ and $\Phi$ as in Table 7.15. Values of $p$ in italics are results from Fisher's Exact Test, used in place of $\chi^{2}$ owing to frequencies $<5$ in cells in contingency tables. $\mathrm{N}_{\text {penguins }}=$ sample size images with penguins. $\mathrm{N}_{\text {o_penguins. }}=$ sample size images without penguins. Bold = not significant.

\begin{tabular}{|c|c|c|c|c|c|c|c|c|c|}
\hline No. & EDA & Subject & Image numbers & Infra./trans. & $\mathbf{N}_{\text {human }}$ & $\mathbf{N}_{\text {natural }}$ & $\chi^{2}$ & $\boldsymbol{p}$ & $\boldsymbol{\Phi}$ \\
\hline 1 & CCM & Icebreakers & $105-207$ & T & 147 & 100 & 32.15 & 0.000 & 0.37 \\
\hline 2 & CCM & Field hut & $107-307$ & I & 124 & 104 & 17.32 & 0.000 & 0.289 \\
\hline 3 & IS & Tractor train & $117-316$ & I & 126 & 104 & 6.0 & 0.014 & 0.177 \\
\hline 4 & IS & Parked aircraft & $119-319$ & I & 126 & 103 & 51.9 & 0.000 & 0.486 \\
\hline 5 & MIF & Field hut & $120-220$ & I & 141 & 103 & 6.04 & 0.014 & 0.175 \\
\hline 6 & PIF & Field party & $127-326$ & T & 126 & 100 & 7.85 & 0.005 & 0.201 \\
\hline 7 & CIS & Station & $204-303$ & T & 127 & 146 & 37.06 & 0.000 & 0.378 \\
\hline 8 & CCM & Field hut & $205-305$ & I & 143 & 129 & 12.8 & 0.000 & -0.231 \\
\hline 9 & CIF & Cairn & $109-310$ & I & 100 & 125 & 0.449 & $\mathbf{0 . 5}$ & 0.058 \\
\hline 10 & IS & Airfield & $116-216$ & I & 151 & 99 & 21.89 & 0.000 & 0.307 \\
\hline 11 & IS & Field party & $118-218$ & T & 98 & 144 & 0.026 & $\mathbf{0 . 8 7}$ & 0.024 \\
\hline 13 & CIF & Masts & $211-314$ & I & 130 & 149 & 18.54 & 0.000 & 0.266 \\
\hline 14 & CIF & Field hut & $113-312$ & I & 103 & 124 & 4.45 & 0.035 & 0.153 \\
\hline 15 & IS & AWS & $219-318$ & I & 147 & 123 & 49.07 & 0.000 & 0.435 \\
\hline 16 & MIF & Field hut & $222-322$ & I & 136 & 129 & 38.29 & 0.000 & 0.389 \\
\hline 17 & MIF & Vehicles & $225-325$ & T & 147 & 127 & - & $\mathbf{0 . 3 4 8}$ & 0.064 \\
\hline & & & & & & & & & \\
\hline No. & EDA & Subject & Image numbers & Infra/trans. & $\mathbf{N}_{\text {penguins }}$ & $\mathbf{N}_{\text {n_penguins }}$ & $\chi^{2}$ & $\boldsymbol{p}$ & $\boldsymbol{\Phi}$ \\
\hline 12 & PIF & Penguins & $229-327$ & - & 125 & 145 & 3.275 & $\mathbf{0 . 0 7}$ & -0.128 \\
\hline
\end{tabular}




\subsubsection{Aesthetic preferences}

As noted above, in order to correct for scaling differences between respondents, the responses were first converted to $Z$ scores $(Z=$ (mean of all respondent's scores - respondent's image score) / standard deviation of all respondent's scores). Raw aesthetic preference data was acquired on a scale of one to seven; when converted to $\mathrm{Z}$ scores the scale of responses was from -5.13 to 2.56 (Figure 7.5. Comparison profile of $Z$ scores and raw aesthetic preference scores showing numbers for each integer value.Figure 7.5). Effect size was calculated using Cohen's $d$ (the mean difference divided by the standard deviation (Cohen 1988)), where $0.2=$ small effect, $0.5=$ moderate effect, $0.8=$ large effect. The aesthetic preference scores for all 90 of the scenes in the survey, transformed into $\mathrm{Z}$ scores, and their rankings are listed in Appendix 4.

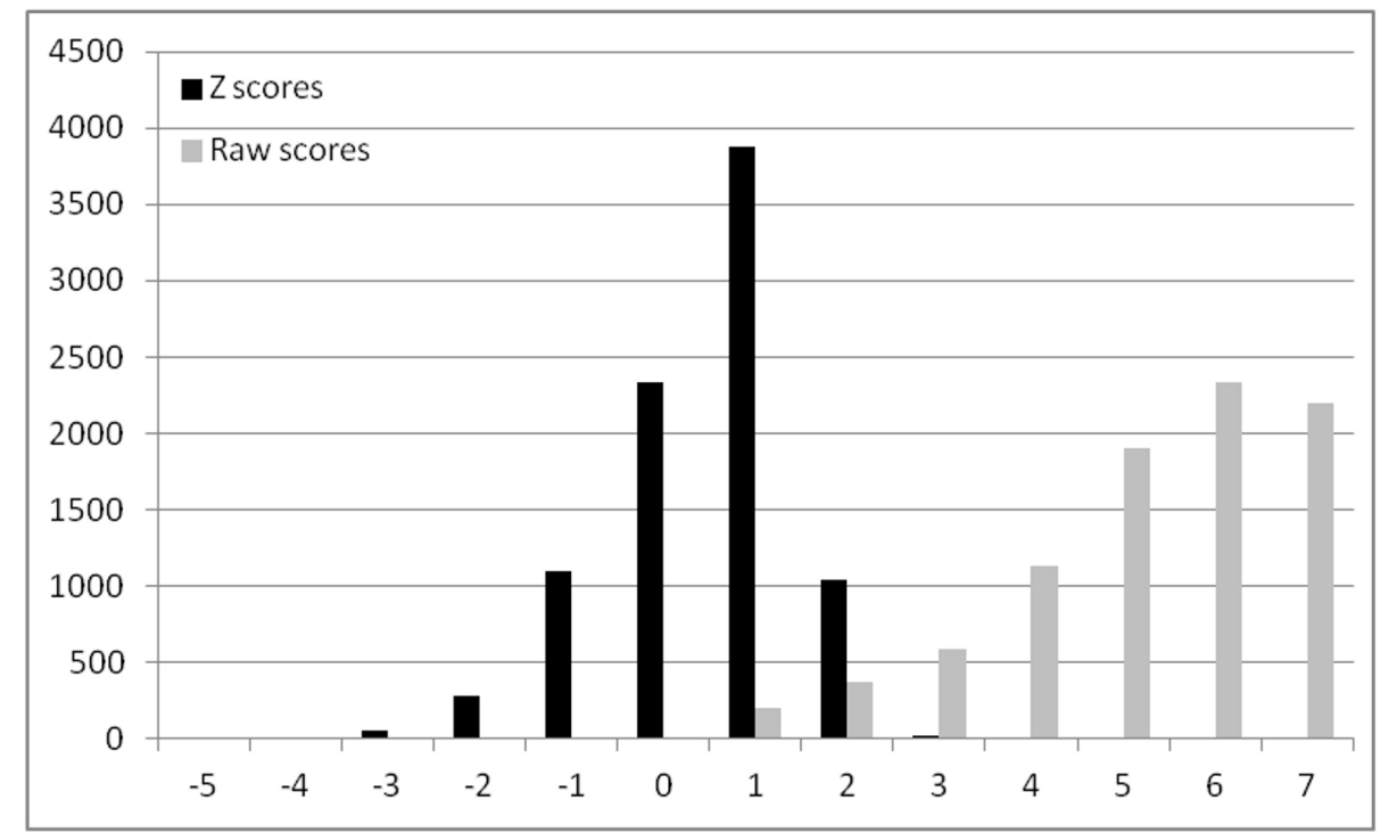

Figure 7.5. Comparison profile of $Z$ scores and raw aesthetic preference scores showing numbers for each integer value.

\subsubsection{All images}

An independent samples t-test was carried out on the $\mathrm{Z}$ scores of all responses to compare aesthetic responses to images with some form of human presence to those without any evidence of human presence. The difference between the scores was significant and as follows. Images with human presence: mean $=-0.298, \mathrm{SD}=1.06$; natural images: mean $=0.299, \mathrm{SD}=0.796$; $\mathrm{t}$ $(\mathrm{df}=10,295) 33.445, \mathrm{p}=0.00$, two-tailed. The magnitude of the differences in the means (mean difference $=0.596,95 \%$ CI: 0.561 to 0.631$)$ was moderate (Cohen's $d=0.63)$. Independent samples t-tests were also carried out between all images with no human presence (natural images) and, separately, images containing transient activity, or evidence of transient activity, 
i.e. tracks in the snow, and images containing infrastructure. The differences between the scores of both transient activity and infrastructure and images with no human presence were significant and as follows. Images with transient activity: mean $=-0.048, \mathrm{SD}=0.907$; natural images: mean $=0.299, \mathrm{SD}=0.796 ; \mathrm{t}(\mathrm{df}=3904) 16.03, \mathrm{p}=0.00$, two-tailed. The magnitude of the differences in the means (mean difference $=0.347,95 \%$ CI: 0.304 to 0.389 ) was small to moderate (Cohen's $d=0.42$ ). Images with infrastructure: mean $=-0.478, \mathrm{SD}=1.102$; natural images: mean $=0.299, \mathrm{SD}=0.796 ; \mathrm{t}(\mathrm{df}=5117) 34.39, p=0.00$, two-tailed. The magnitude of the differences in the means (mean difference $=0.776,95 \%$ CI: 0.732 to 0.821 ) was large (Cohen's d = 0.83).

\subsubsection{EDA regions}

The mean aesthetic $(Z)$ scores of all natural scenes and scenes with human content, differentiated by whether it is transient or infrastructure and aggregated by EDA region, is shown as Figure 7.6. It can be seen that, first, mean aesthetic scores of the images without human presence that the coastal ice-free (CIF) EDA region has a substantially lower mean score than all the other regions, which, second, have similar mean scores, and third, the mean scores of images with human content are demonstrably lower than images of natural scenes.

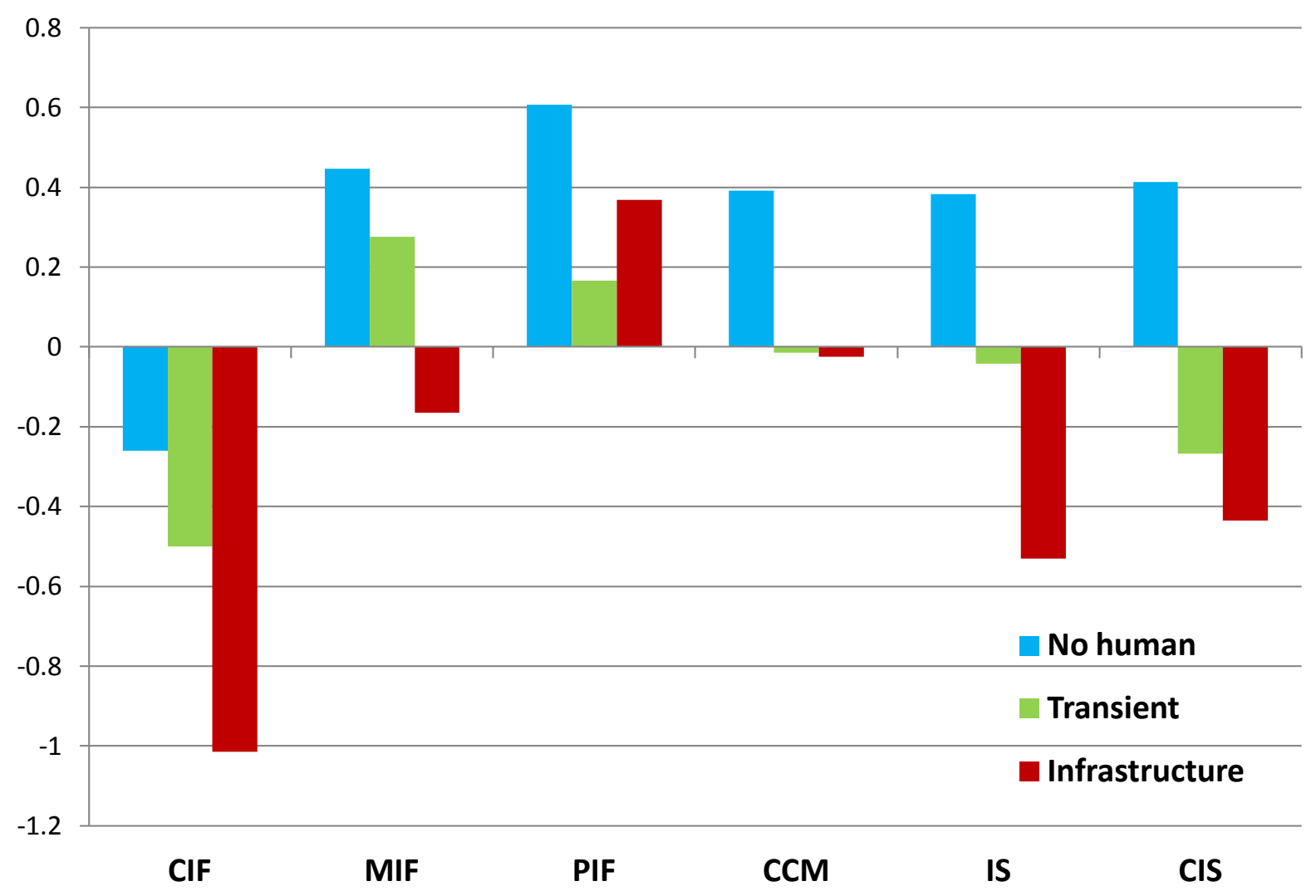

Figure 7.6. Mean aesthetic (Z) scores for each EDA region, differentiated by the type of human presence. No human $=$ no human presence . Transient $=$ transient human activity. Infrastructure $=$ presence of infrastructure. 
Independent samples t-tests were carried out on the $\mathrm{Z}$ scores of all images in each of the six EDA regions, comparing images of natural scenes with images of human presence divided into transient activity and infrastructure (Table 7.17, Table 7.18 and Table 7.19). In addition to the ttests, $95 \%$ confidence limits about the means and effect sizes were also calculated. Effect size (ES) was calculated using pooled standard deviation. 
Table 7.17. Aesthetic (Z) scores for the aggregated EDA regions, with t-test results comparing images with no human content and all images with human presence, $95 \%$ confidence levels and effect sizes (ES).

\begin{tabular}{|c|c|c|c|c|c|c|c|c|c|c|c|}
\hline EDA & $\begin{array}{l}\text { Human } \\
\text { content }\end{array}$ & $\mathbf{N}$ & $\begin{array}{c}\text { Mean } \\
\text { Z score }\end{array}$ & SD & $\mathbf{t}$ & df & $\begin{array}{l}\text { Sig. (2 } \\
\text { tailed) }\end{array}$ & $\begin{array}{c}\text { Mean } \\
\text { difference }\end{array}$ & $\begin{array}{c}95 \% \text { CI } \\
\text { Lower }\end{array}$ & $\begin{array}{c}95 \% \text { CI } \\
\text { Upper }\end{array}$ & ES \\
\hline \multirow[t]{2}{*}{ CIF } & Yes & 1373 & -0.912 & 1.167 & \multirow[t]{2}{*}{16.674} & \multirow[t]{2}{*}{2459} & \multirow[t]{2}{*}{0.000} & \multirow[t]{2}{*}{0.652} & \multirow[t]{2}{*}{0.575} & \multirow[t]{2}{*}{0.729} & \multirow[t]{2}{*}{0.64} \\
\hline & No & 1239 & -0.260 & 0.815 & & & & & & & \\
\hline \multirow{2}{*}{ MIF } & Yes & 914 & 0.022 & 0.832 & \multirow{2}{*}{12.27} & \multirow{2}{*}{1843} & \multirow{2}{*}{0.000} & \multirow{2}{*}{0.424} & \multirow{2}{*}{0.357} & \multirow{2}{*}{0.492} & \multirow{2}{*}{0.54} \\
\hline & No & 1303 & 0.447 & 0.756 & & & & & & & \\
\hline \multirow{2}{*}{ PIF } & Yes & 590 & 0.245 & 0.736 & \multirow{2}{*}{9.861} & \multirow{2}{*}{1129} & \multirow{2}{*}{0.000} & \multirow{2}{*}{0.362} & \multirow{2}{*}{0.29} & \multirow{2}{*}{0.434} & \multirow{2}{*}{0.52} \\
\hline & No & 1019 & 0.607 & 0.663 & & & & & & & \\
\hline \multirow{2}{*}{$\mathrm{CCM}$} & Yes & 1001 & -0.02 & 0.894 & \multirow{2}{*}{10.741} & \multirow{2}{*}{1677} & \multirow{2}{*}{0.000} & \multirow{2}{*}{0.412} & \multirow{2}{*}{0.337} & \multirow{2}{*}{0.488} & \multirow{2}{*}{0.51} \\
\hline & No & 695 & 0.392 & 0.686 & & & & & & & \\
\hline \multirow{2}{*}{ IS } & Yes & 732 & -0.288 & 0.948 & \multirow{2}{*}{15.977} & \multirow{2}{*}{1305} & \multirow{2}{*}{0.000} & \multirow{2}{*}{0.671} & 0589 & 0754 & 089 \\
\hline & No & 891 & 0.383 & 0.691 & & & & & 0.509 & 0.134 & 0.09 \\
\hline & Yes & 946 & -0.355 & 1.098 & & & & & & & \\
\hline CIS & No & 393 & 0.413 & 0.742 & 14.844 & 1064 & 0.000 & 0.768 & 0.666 & 0.869 & 0.76 \\
\hline
\end{tabular}


Table 7.18. Aesthetic (Z) scores for the aggregated EDA regions, with t-test results comparing images with no human content and images with transient human activity. 95\% confidence levels and effect sizes (ES) are included.

\begin{tabular}{|c|c|c|c|c|c|c|c|c|c|c|c|}
\hline EDA & $\begin{array}{l}\text { Human } \\
\text { content }\end{array}$ & $\mathbf{N}$ & $\begin{array}{c}\text { Mean } \\
\text { Z score }\end{array}$ & SD & $\mathbf{t}$ & df & $\begin{array}{l}\text { Sig. (2 } \\
\text { tailed) }\end{array}$ & $\begin{array}{c}\text { Mean } \\
\text { difference }\end{array}$ & $\begin{array}{c}\text { 95\% CI } \\
\text { Lower }\end{array}$ & $\begin{array}{c}95 \% \text { CI } \\
\text { Upper }\end{array}$ & ES \\
\hline \multirow[t]{2}{*}{ CIF } & Yes & 273 & -0.5 & & \multirow[t]{2}{*}{4.384} & \multirow[t]{2}{*}{399} & \multirow[t]{2}{*}{0.000} & \multirow[t]{2}{*}{0.24} & \multirow[t]{2}{*}{0.132} & \multirow[t]{2}{*}{0.347} & \multirow[t]{2}{*}{0.25} \\
\hline & No & 1239 & -0.26 & 0.815 & & & & & & & \\
\hline \multirow{2}{*}{ MIF } & Yes & 387 & 0.276 & 0.7 & \multirow{2}{*}{4.123} & \multirow{2}{*}{675} & \multirow{2}{*}{0.000} & \multirow{2}{*}{0.17} & \multirow{2}{*}{0.09} & \multirow{2}{*}{0.251} & \multirow{2}{*}{0.23} \\
\hline & No & 1303 & 0.447 & 0.756 & & & & & & & \\
\hline \multirow{2}{*}{ PIF } & Yes & 361 & 0.166 & 0.757 & \multirow{2}{*}{9.816} & \multirow{2}{*}{568} & \multirow{2}{*}{0.000} & \multirow{2}{*}{0.441} & \multirow{2}{*}{0.353} & \multirow{2}{*}{0.53} & \multirow{2}{*}{0.64} \\
\hline & No & 1019 & 0.607 & 0.663 & & & & & & & \\
\hline \multirow{2}{*}{$\mathrm{CCM}$} & Yes & 492 & -0.015 & 0.969 & \multirow{2}{*}{8.007} & \multirow{2}{*}{827} & \multirow{2}{*}{0.000} & \multirow{2}{*}{0.407} & \multirow{2}{*}{0.307} & \multirow{2}{*}{0.507} & \multirow{2}{*}{0.5} \\
\hline & No & 695 & 0.392 & 0.686 & & & & & & & \\
\hline \multirow{2}{*}{ IS } & Yes & 364 & -0.415 & 0.777 & \multirow{2}{*}{9.066} & \multirow{2}{*}{610} & \multirow{2}{*}{0.000} & \multirow{2}{*}{0.425} & & & \\
\hline & No & 891 & 0.383 & 0.691 & & & & & 0.333 & 0.517 & 1.11 \\
\hline & Yes & 451 & -0.266 & 1.078 & & & & & & & \\
\hline CIS & No & 393 & 0.413 & 0.742 & 10.772 & 801 & 0.000 & 0.679 & 0.555 & 0.803 & 0.73 \\
\hline
\end{tabular}


Table 7.19. Aesthetic (Z) scores for the aggregated EDA regions, with t-test results comparing images containing no human content and images with infrastructure. 95\% confidence levels and effect sizes (ES) are included.

\begin{tabular}{|c|c|c|c|c|c|c|c|c|c|c|c|}
\hline EDA & $\begin{array}{l}\text { Human } \\
\text { content }\end{array}$ & $\mathbf{N}$ & $\begin{array}{c}\text { Mean } \\
Z \text { score }\end{array}$ & SD & $\mathbf{t}$ & df & $\begin{array}{l}\text { Sig. (2 } \\
\text { tailed) }\end{array}$ & $\begin{array}{c}\text { Mean } \\
\text { difference }\end{array}$ & $\begin{array}{c}95 \% \text { CI } \\
\mathrm{L}\end{array}$ & $\begin{array}{c}95 \% \text { CI } \\
\mathrm{U}\end{array}$ & ES \\
\hline \multirow[t]{2}{*}{ CIF } & Yes & 1100 & & & \multirow{2}{*}{17.377} & \multirow[t]{2}{*}{1883} & \multirow[t]{2}{*}{0.000} & \multirow{2}{*}{0.754} & \multirow[t]{2}{*}{0.67} & \multirow[t]{2}{*}{0.839} & \multirow[t]{2}{*}{0.74} \\
\hline & No & 1239 & -0.26 & 0.815 & & & & & & & \\
\hline \multirow{2}{*}{ MIF } & Yes & 527 & -0.165 & 0.872 & \multirow{2}{*}{14.09} & \multirow{2}{*}{862} & \multirow{2}{*}{0.000} & \multirow{2}{*}{0.611} & \multirow{2}{*}{0.526} & \multirow{2}{*}{0.696} & \multirow{2}{*}{0.77} \\
\hline & No & 1303 & 0.446 & 0.756 & & & & & & & \\
\hline \multirow{2}{*}{ PIF } & Yes & 229 & 0.369 & 0.684 & \multirow{2}{*}{4.78} & \multirow{2}{*}{331} & \multirow{2}{*}{0.000} & \multirow{2}{*}{0.238} & \multirow{2}{*}{0.14} & \multirow{2}{*}{0.336} & \multirow{2}{*}{0.36} \\
\hline & No & 1019 & 0.607 & 0.663 & & & & & & & \\
\hline \multirow{2}{*}{$\mathrm{CCM}$} & Yes & 509 & -0.025 & 0.815 & \multirow{2}{*}{9.381} & \multirow{2}{*}{979} & \multirow{2}{*}{0.000} & \multirow{2}{*}{0.418} & \multirow{2}{*}{0.33} & \multirow{2}{*}{0.505} & \multirow{2}{*}{0.56} \\
\hline & No & 695 & 0.392 & 0.686 & & & & & & & \\
\hline \multirow{2}{*}{ IS } & Yes & 368 & -0.531 & 1.036 & \multirow{2}{*}{15.567} & \multirow{2}{*}{507} & \multirow{2}{*}{0.000} & \multirow{2}{*}{0.915} & 0700 & 102 & 112 \\
\hline & No & 891 & 0.383 & 0.691 & & & & & 0.13 & $1.0 \mathrm{~J}$ & 1.15 \\
\hline CIS & Yes & 495 & -0.435 & 1.11 & 12505 & 867 & $0 \Omega 0 \Omega$ & 00 & 0726 & 007 & 000 \\
\hline Cis & No & 393 & 0.413 & 0.742 & נצנ.Jו & 002 & 0.000 & 0.040 & 0.120 & 0.31 & 0.00 \\
\hline
\end{tabular}




\subsubsection{Manipulated pairs}

Independent samples t- tests were carried out on aesthetic ratings ( $\mathrm{Z}$ scores) of the 17 pairs of digitally manipulated images. The results, grouped by EDA region and indicating whether the scene is of infrastructure or transient activity, are shown in Table 7.20. The small differences in the numbers of respondents between this table and Table 7.16 are due to some respondents not answering all questions. The differences in the means between the original images, with human presence, and the manipulated images, which respondents perceive as being natural, are mostly negative because the mean values of the images with human presence are mostly lower than the mean values of the images which are perceived as natural. This indicates that scenes with human presence generally have lower aesthetic value than natural scenes. In one case, however, the presence of a cairn has increased the aesthetic ratings. The differences in the means in all manipulated pairs, with three exceptions (indicated in bold in Table 7.20), are significant. Effect sizes (d) (Cohen 1988) are also shown.

An independent samples t-test to compare the aesthetic ratings ( $\mathrm{Z}$ scores) of the manipulated images with the penguins was also carried out. There was a significant difference between scores for the image with penguins $(M=0.80, S D=0.641)$ and without penguins $(M=0.44$, $\mathrm{SD}=0.549 ; \mathrm{t}(206)=-4.35, \mathrm{p}=0.000$, two-tailed). The image with penguins was therefore significantly more preferred than the image without. The effect size was 0.49 which is a moderate effect. 
Table 7.20. Results of t-tests between the aesthetic (Z) scores of images with human presence and manipulated (natural) images.

Type: $\mathrm{I}=$ infrastructure, $\mathrm{T}=$ transient activity. $\mathrm{N} / \mathrm{h}=$ number of respondents to the images with human content. $\mathrm{N} / \mathrm{p}=$ number of respondents to images with penguins (pair 17). $\mathrm{N} / \mathrm{n}=$ number of respondents to the natural (manipulated) images. $\mathrm{T}=\mathrm{t}$-test. Sig. $=$ significance $(\alpha=0.05)$. Mean diff. $=$ mean difference between each pair of images. 95\% CI $=95 \%$ confidence intervals (upper and lower) about the mean differences. $d=$ Cohen's $d .0 .2=$ small effect, $0.5=$ moderate effect, $0.8=$ large effect. Image numbers relate to the numbers in Appendix 4.

\begin{tabular}{|c|c|c|c|c|c|c|c|c|c|c|c|c|}
\hline Pair & Content & Images & Type & EDA & $\mathbf{N} / \mathbf{h}$ & $\mathbf{N} / \mathbf{n}$ & $\mathbf{t}$ & Sig. & $\begin{array}{c}\text { Mean } \\
\text { Diff. }\end{array}$ & $\begin{array}{l}\text { 95\% CI } \\
\text { lower }\end{array}$ & $\begin{array}{l}95 \% \text { CI } \\
\text { upper }\end{array}$ & $d$ \\
\hline 1 & Icebreakers & $105-207$ & $\mathrm{~T}$ & $\mathrm{CCM}$ & 144 & 99 & 7.413 & 0.000 & 0.782 & 0.574 & 0.99 & 0.89 \\
\hline 2 & Field hut & $107-307$ & I & $\mathrm{CCM}$ & 122 & 103 & 2.362 & 0.019 & 0.204 & 0.034 & 0.375 & 0.31 \\
\hline 3 & Tractor train & $117-316$ & $\mathrm{~T}$ & IS & 123 & 103 & 2.015 & 0.045 & 0.183 & 0.004 & 0.363 & 0.27 \\
\hline 4 & Parked aircraft & $119-319$ & I & IS & 124 & 101 & 8.631 & 0.000 & 0.930 & 0.718 & 1.143 & 1.11 \\
\hline 5 & Field hut & $120-220$ & I & MIF & 139 & 102 & 3.721 & 0.000 & 0.288 & 0.136 & 0.44 & 0.49 \\
\hline 6 & Field party & $127-326$ & $\mathrm{~T}$ & PIF & 122 & 98 & 1.665 & 0.097 & 0.15 & -0.027 & 0.328 & 0.22 \\
\hline 7 & Station & $204-303$ & I & CIS & 124 & 145 & 7.24 & 0.000 & 0.786 & 0.572 & 1.0 & 0.92 \\
\hline 8 & Field hut & $205-305$ & I & $\mathrm{CCM}$ & 141 & 123 & 5.143 & 0.000 & 0.474 & 0.293 & 0.656 & 0.64 \\
\hline 9 & Cairn & $109-310$ & I & CIF & 100 & 124 & -2.552 & 0.011 & -0.292 & -0.518 & -0.068 & 0.34 \\
\hline 10 & Airfield & $116-216$ & I & IS & 99 & 150 & 7.103 & 0.000 & 0.792 & 0.571 & 1.012 & 1.0 \\
\hline 11 & Field party & $118-218$ & $\mathrm{~T}$ & IS & 98 & 142 & 1.052 & 0.294 & 0.099 & -0.087 & 0.286 & 0.14 \\
\hline 13 & Radio masts & $211-314$ & $\mathrm{I}$ & CIF & 130 & 149 & 0.845 & 0.399 & 0.083 & -0.111 & 0.277 & 0.1 \\
\hline 14 & Field hut & $113-312$ & I & CIF & 103 & 121 & 1.906 & 0.058 & 0.186 & -0.006 & 0.378 & 0.26 \\
\hline 15 & AWS & $219-318$ & I & IS & 145 & 120 & 12.779 & 0.000 & 1.29 & 1.091 & 1.489 & 1.53 \\
\hline 16 & Field hut & $222-322$ & I & MIF & 136 & 124 & 5.263 & 0.000 & 0.558 & 0.349 & 0.766 & 0.66 \\
\hline 17 & Vehicles & $225-325$ & $\mathrm{~T}$ & MIF & 144 & 126 & 3.92 & 0.000 & 0.308 & 0.153 & 0.462 & 0.48 \\
\hline & Content & & & EDA & $\mathbf{N} / \mathbf{p}$ & $\mathbf{N} / \mathbf{n}$ & $\mathbf{t}$ & Sig. & $\begin{array}{c}\text { Mean } \\
\text { diff. }\end{array}$ & $\begin{array}{c}95 \% \text { CI } \\
\text { lower }\end{array}$ & $\begin{array}{c}95 \% \text { CI } \\
\text { upper }\end{array}$ & $d$ \\
\hline 12 & Penguins & $229-327$ & - & PIF & 125 & 142 & -4.017 & 0.000 & -0.314 & -0.467 & -0.160 & 0.49 \\
\hline
\end{tabular}




\subsubsection{Pseudoreplication, independent samples and alpha slippage}

Pseudoreplication is where inferential statistics are used "to test for treatment effects with data from experiments where either treatments are not replicated (though samples may be) or replicates are not statistically independent" (Hurlbert 1984). Hurlbert $(1984,2004)$ and many others have criticised published results from unreplicated or pseudoreplicated experiments as being statistically invalid. Not everyone agrees that pseudoreplication is a problem (Oksanen 2001) but it is clear that in many cases pseudoreplication can undermine an experiment's validity. In the survey being described, respondents were asked to provide perceptions of wilderness and aesthetic preference ratings for a set of 30 images. As described in Chapter 6 (Methods) respondents were asked to judge images of landscapes across six EDA regions, with and without human presence and which included a number of images that were parts of manipulated pairs. There were also replicates of images from each EDA region in each set in order to test for stability in each respondent's response set. There is, however, potential for pseudoreplication when all the data are used together and when the degrees of freedom relate to the number of photos being used rather than the number of respondents.

In order to test that pseudoreplication was not giving a false positive effect on the wilderness scores, a Chi-square test for independence (with Yates continuity correction) was carried out to compare a randomly selected sample of wilderness perception responses from two images per respondent, one of an image with and one of an image without human presence. A significant difference was found in the wilderness perception ratings between images with human presence and those images without: $\chi^{2}(1, n=753)=51.394, p=0.000, p h i=-0.265$, which is a small to moderate effect.

In order to test that pseudoreplication was not giving a false positive effect on the aesthetic scores, an independent samples t-test was carried out to compare a different randomly selected sample of aesthetic responses from two images per respondent, one of an image with human presence and one of an image without human presence. A significant difference was found between images with human presence $(M=4.78, S D=1.639)$ and those images without human presence $(\mathrm{M}=5.52, \mathrm{SD}=1.555) \mathrm{t}(749)=-6.287, \mathrm{p}=0.000$, two-tailed. The magnitude of the difference in the means (mean difference $=-0.733,95 \%$ CI: -0.962 to -0.504 ) was moderate. Effect size (Cohen's d) $=0.46$. These tests demonstrate that even if there is pseudoreplication, the results are still statistically significant.

A related potential problem is that of whether by asking respondents to review 30 images, the conditions for independence of samples has been breached. Since each respondent is independent of the others this is not the case. The use of a) an overview of all the scenes to allow each respondent to gauge the range of responses and b) $\mathrm{Z}$ scores to standardise ratings 
addresses some of the possible issues raised by what may be considered to be a hybrid independent samples-repeated measures approach. The use of $Z$ scores does however introduce other problems when respondents are asked to rate areas that differ in scenic beauty (Daniel \& Boster 1976: 11). Given that most people would be unfamiliar with most of the scenes in this survey, or to put it another way, most people would at best be familiar with only a few scenes, it was assumed that respondents would approach images of Antarctica in a single frame of mind.

"Alpha slippage", also known as "familywise error rate", may occur when a large number of statistical tests, such as t-tests are carried out. The problem is that one or more of the tests may show a Type I error by chance because of the number of tests being carried out. This can be controlled, to an extent, by using a Bonferroni adjustment, which reduces the $\alpha$ level proportionally by the number of tests (Pallant 2011: 209). There is little guidance on what constitutes a large number and there did not seem to be sufficient justification to apply a correction to the 16 tests carried out. 


\subsubsection{Relationship between wilderness perception and aesthetic preference}

As described in Chapter 5, the assumption was made that wilderness and aesthetic values are separate sets of values. Nevertheless, as Figure 7.7 shows, there is a clear relationship between perception of wilderness and aesthetic preference.

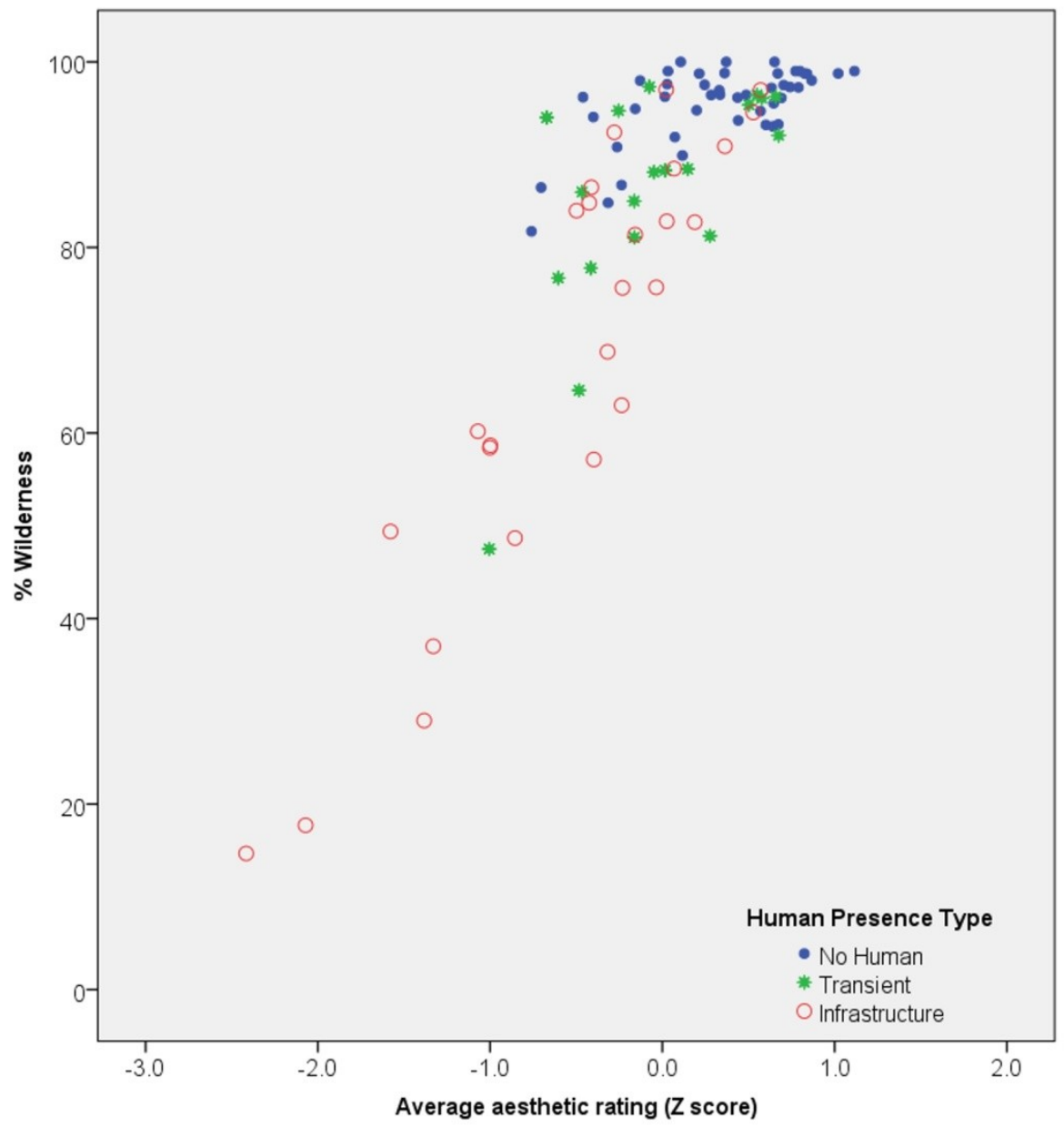

Figure 7.7. Scatter plot of averaged responses to wilderness and aesthetic value of all 90 images. Perception of wilderness is expressed as a percentage of responses as wilderness to each image and aesthetic values as mean $\mathrm{Z}$ scores.

The relationship is strongest among the images including infrastructure (Figure 7.7). This is confirmed with an analysis using Pearson product-moment correlation coefficient. There was a strong positive correlation between average aesthetic rating ( $\mathrm{Z}$ score) and percentage of responses of wilderness to each image, $r=0.918, n=26, p<0.0005$. The relationships between these two variables among images with transient activity and images without human presence were also investigated using the same technique. The results are as follows:

- Transient activity: $\mathrm{r}=0.680, \mathrm{n}=19, \mathrm{p}=0.001$

- No human presence: $\mathrm{r}=0.640, \mathrm{n}=45, \mathrm{p}<0.0005$ 
It can be demonstrated, therefore, that human presence or evidence thereof in the images has a negative impact on both perceptions of wilderness and aesthetic preference and it is strongest in images which include infrastructure. The images with the lowest ratings of both wilderness and aesthetic value among the set that included infrastructure (open red circles in Figure 7.7) and the set without human presence (closed blue circles) were from the coastal ice free region, whereas the lowest rating images in the transient activity set (closed green circles) were of heavy transport activity (icebreakers and a low flying Hercules). It seems therefore that in addition to human presence, landscape type is an additional factor in the relationship between wilderness and aesthetic preference. This relationship will be explored using the results of the semantic assessment component of the survey as described below.

\subsubsection{Semantic assessments}

As described in Chapter 7, Methods, the survey included a semantic descriptors component. The adjectives used are listed in Table 7.21.

Table 7.21. Lists of adjectives used in the semantic descriptors component of the survey.

\begin{tabular}{|l|l|}
\hline Beautiful & Sublime \\
\hline Beautiful & Austere \\
\hline Delightful & Barren \\
\hline Lovely & Bleak \\
\hline Pleasant & Desolate \\
\hline Pretty & Breathtaking \\
\hline Glorious & Grand \\
\hline Wonderful & Impressive \\
\hline Magnificent & Spectacular \\
\hline Ugly & Vast \\
\hline Unpleasant & Awesome \\
\hline
\end{tabular}

Only the English responses were used in the analyses described below, owing to a) uncertainty how well the adjectives used translated into other languages and what other meanings or connotations they may have and b) the sample sizes for all but the French survey were too small. The semantic responses from the French survey are described separately below. It is hoped that continuing efforts to recruit more respondents to the survey in other languages will result in large enough sample sizes for separate analyses. 
This part of the survey was experimental and representing the results also required some experimentation. This part of the survey used a Likert scale, where the people being surveyed were asked to respond to the question "How well does each of the following words describe the scene?" The results were processed to convert the Likert responses to numerical values as follows:

Not at all. $\quad$ Score $=-2$

Not well. $\quad$ Score $=-1$

Neutral. $\quad$ Score $=0$

Well. $\quad$ Score $=1$

Very well. $\quad$ Score $=2$

Table 7.22 demonstrates how the rankings were converted into scores.

Table 7.22. Conversion of word rankings into scores. "Austere" and image 228 are used here only as examples. In reality there are 30 assessments of "Austere" in image 228.

\begin{tabular}{|r|r|r|r|r|r|r|r|r|r|}
\hline $\begin{array}{c}\text { Photo } \\
\text { no. }\end{array}$ & word & $\begin{array}{r}\text { Word } \\
\text { ranking }\end{array}$ & $\begin{array}{c}\text { Not at } \\
\text { all }\end{array}$ & $\begin{array}{c}\text { Not } \\
\text { well }\end{array}$ & Neutral & Well & $\begin{array}{c}\text { Very } \\
\text { well }\end{array}$ & Count & $\begin{array}{c}\text { Final } \\
\text { score }\end{array}$ \\
\hline 228 & Austere & 1 & -2 & & & & & 4 & -8 \\
\hline 228 & Austere & 2 & & -1 & & & & 3 & -3 \\
\hline 228 & Austere & 3 & & & 0 & & & 6 & 0 \\
\hline 228 & Austere & 4 & & & & 1 & & 4 & 4 \\
\hline 228 & Austere & 5 & & & & & 2 & 6 & 12 \\
\hline TOTALS & - & - & & & & & & 23 & 5 \\
\hline
\end{tabular}

The final score for "Austere" (in this example) $=5 / 23=0.22$. In order for an adjective to be rated as suitable or better for an image (and for a region when aggregated), it must score greater than 0 .

As noted earlier, unfortunately the randomisation algorithm that allocated sets of scenes to respondents to the survey as they logged on did not allocate the sets evenly. Also, not every respondent completed each full set of 30 images. In order, therefore, to standardise the results and enable comparisons between different images it was necessary to average the final scores by dividing the final scores by the number of respondents to each image 
The radar graphing system in Microsoft Excel 2007 provides a useful method of displaying the 20 adjectives around a circle. The evaluation of their suitability by the respondents, reduced to an average for each of the adjectives, is plotted within the circle with the zero line, which demarcates between suitability and unsuitability, picked out in red.

\subsubsection{All semantic responses combined}

Figure 7.8 shows all responses aggregated by whether the images included human presence or not. Adjectives that were considered suitable have values greater than zero.

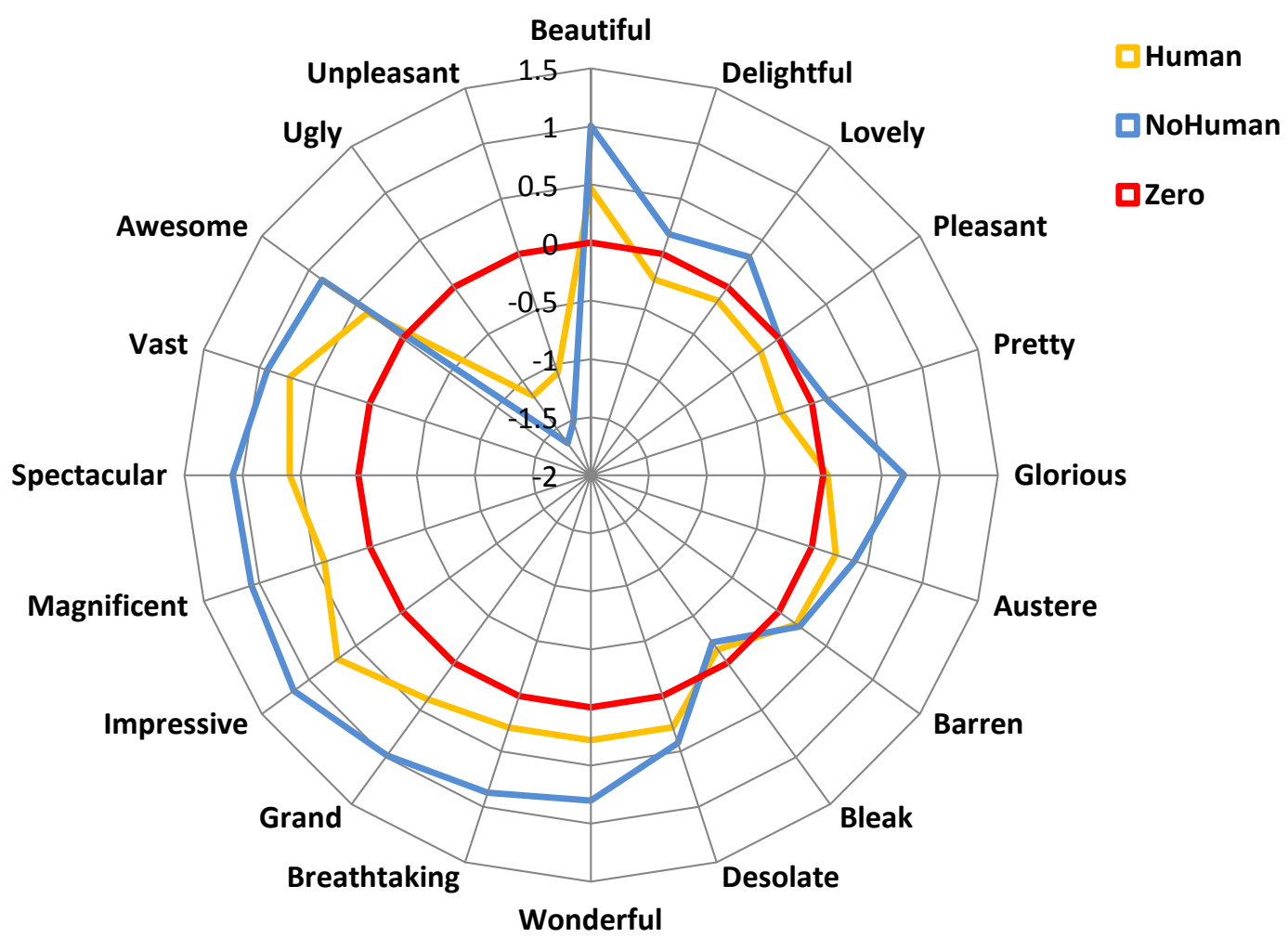

Figure 7.8. Radar graph of all semantic responses aggregated into two classes: those from images with human presence and those without. The zero line is indicated in red for reference.

Chi-square tests for independence were conducted on the raw semantic scores of each adjective to determine whether the differences seen in Figure 7.8 were statistically significant. The differences in the scores between all the adjectives were statistically significant $(p>0.05)$ except for three adjectives: "Barren", "Bleak" and "Desolate". The role of this group of words is discussed further below.

\subsubsection{Semantic responses aggregated by Environmental Domains of}

\section{Antarctica regionalisation}

As described in Chapter 6, the Environmental Domains of Antarctic regionalisation, as refined by the author (Figure 6.1 (right)), has been adopted as the method of grouping Antarctic 
landscape types. In this section radar graphs have been drawn up from the mean of aggregated responses to each region for only the images that do not include human presence because, as Figure 7.18 demonstrates, human infrastructure can distort responses.
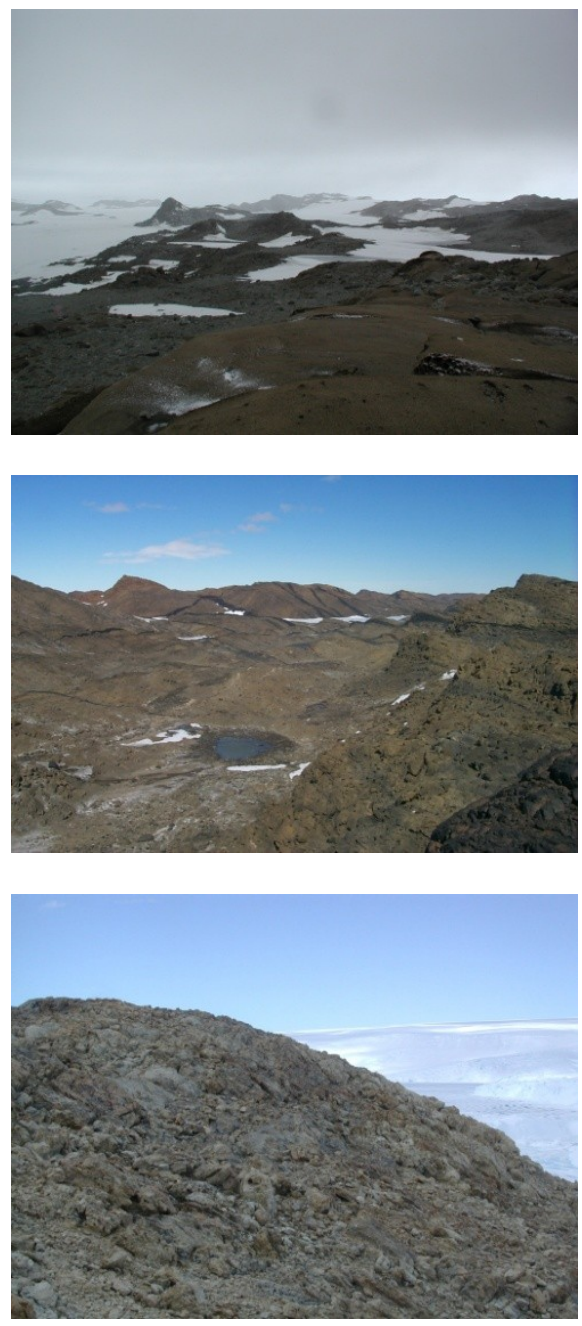

\section{Coastal Ice-Free - no human presence}

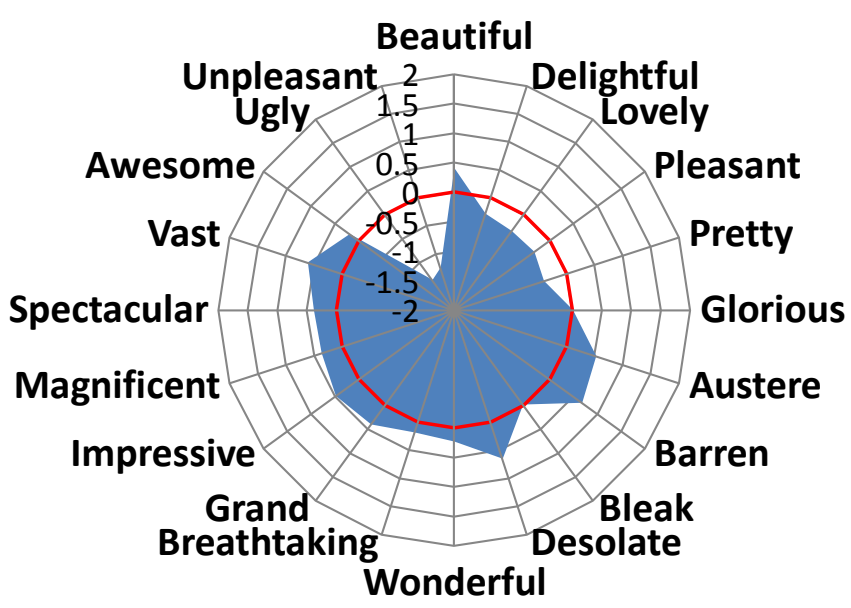

Figure 7.9. Averaged semantics scores for all images in the Coastal Ice-Free region without human presence. (Photos: Top: Windmill Islands (Frédérique Olivier), centre: Vestfold Hills (Rupert Summerson), bottom: Larsemann Hills (Ewan McIvor)).

There were 21 images of coastal ice-free areas in the survey, which reflects their importance, not only as sites for the construction of stations, but also as habitat for endemic fauna and flora. Of these 21 images, 12 images did not include infrastructure or had had infrastructure digitally removed. 401 respondents evaluated the images without infrastructure and there were a total of 4,440 semantic assessments. The shape of the radar graph is quite different to that of the Mountainous Ice-Free Region. With the exception of this region - and the images of human presence - all the other radar graphs are a similar shape and scale. 

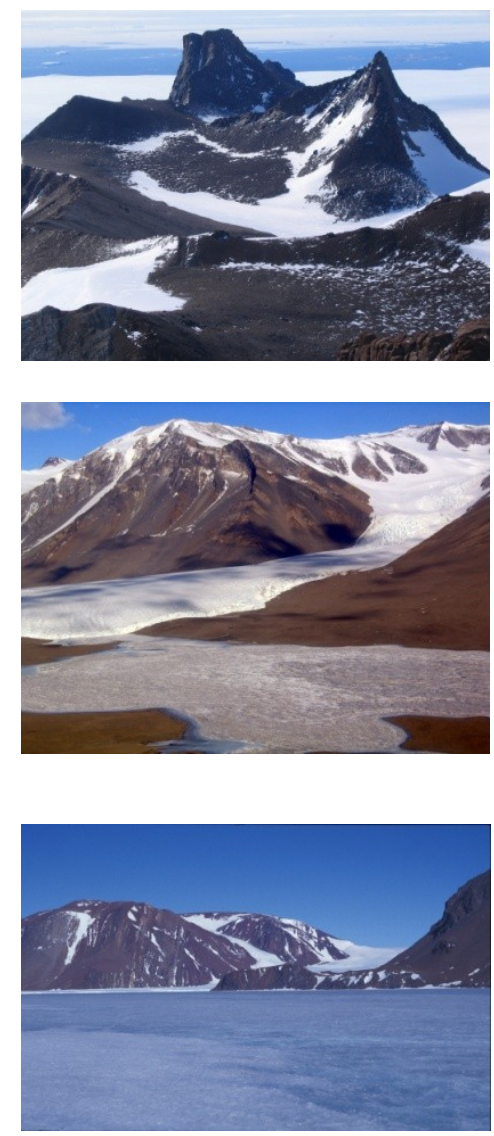

\section{Mountainous Ice-Free - no human presence}

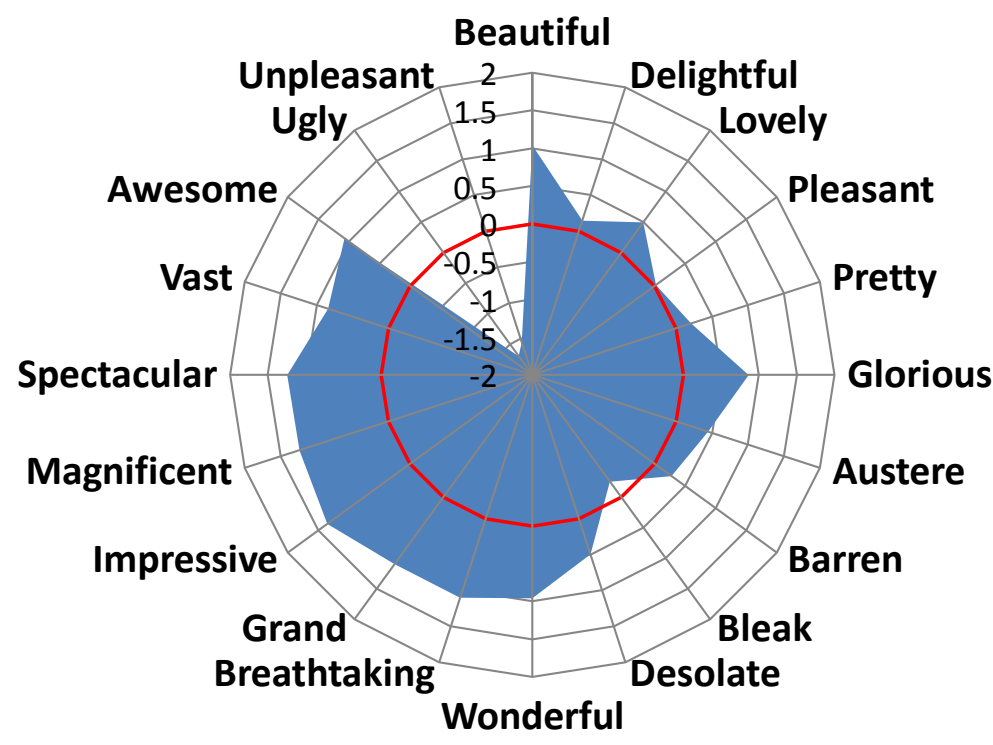

Figure 7.10. Averaged semantics scores for all images in the Mountainous Ice-Free region without human presence. (Photos. Top: Framnes Mountains (Frédérique Olivier), centre: Transantarctic Mountains (Dave Haney/NSF), bottom: Prince Charles Mountains (AAD)).

Mountainous ice-free regions comprise not only the main ranges such as the Transantarctic Mountains and Prince Charles Mountains but also the smaller ranges like the Framnes Mountains and individual nunataks. The mountainous ice-free region was compiled from all of the "geologic" regions in the EDA, with the exception of the East Antarctic coastal geologic and the Antarctic Peninsula offshore islands regions (regions D and G). In practical and perceptual terms the difference lies in the magnitude of the elevation of the features and the distance from the coast. It is intended that these region includes all mountain ranges, including those that are predominantly snow-covered. 


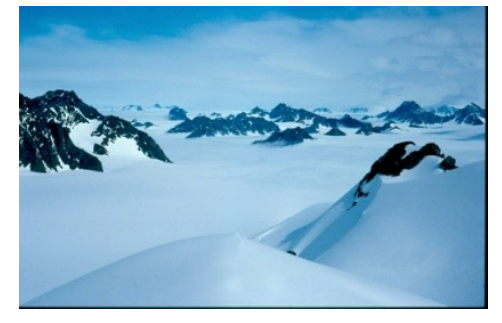

Peninsula Ice Fields - no human presence
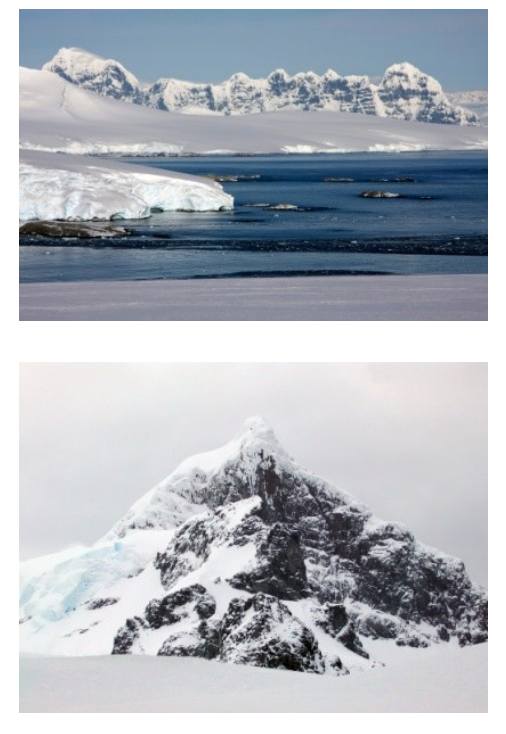

Figure 7.11. Averaged semantics scores for all images in the Peninsula Ice Fields Region without human presence. (Photos. Top: Lully Foothills (Rupert Summerson), centre: Sierra du Fief (John Brack/NSF), bottom: Antarctic Peninsula (Melissa Rider/NSF)).

The results from this region are similar to the mountainous ice-free region, which is to be expected as they both contain mountainous terrains. This illustrates the difficulty of using a climate-physical regionalisation in human perception research. These two regions:

(mountainous ice-free and peninsula ice fields) could potentially be combined. Even though this region also includes mountainous areas, it is notable that "Vast" is considered a less suitable adjective than, say, "Spectacular", "Magnificent" and "Grand". This reinforces the idea that "Vast" is considered a suitable adjective for landscapes that are vast in the horizontal, rather than vertical sense. 


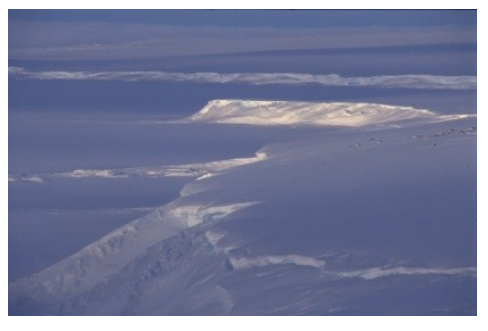

\section{Coastal Continental Margin - no human presence}
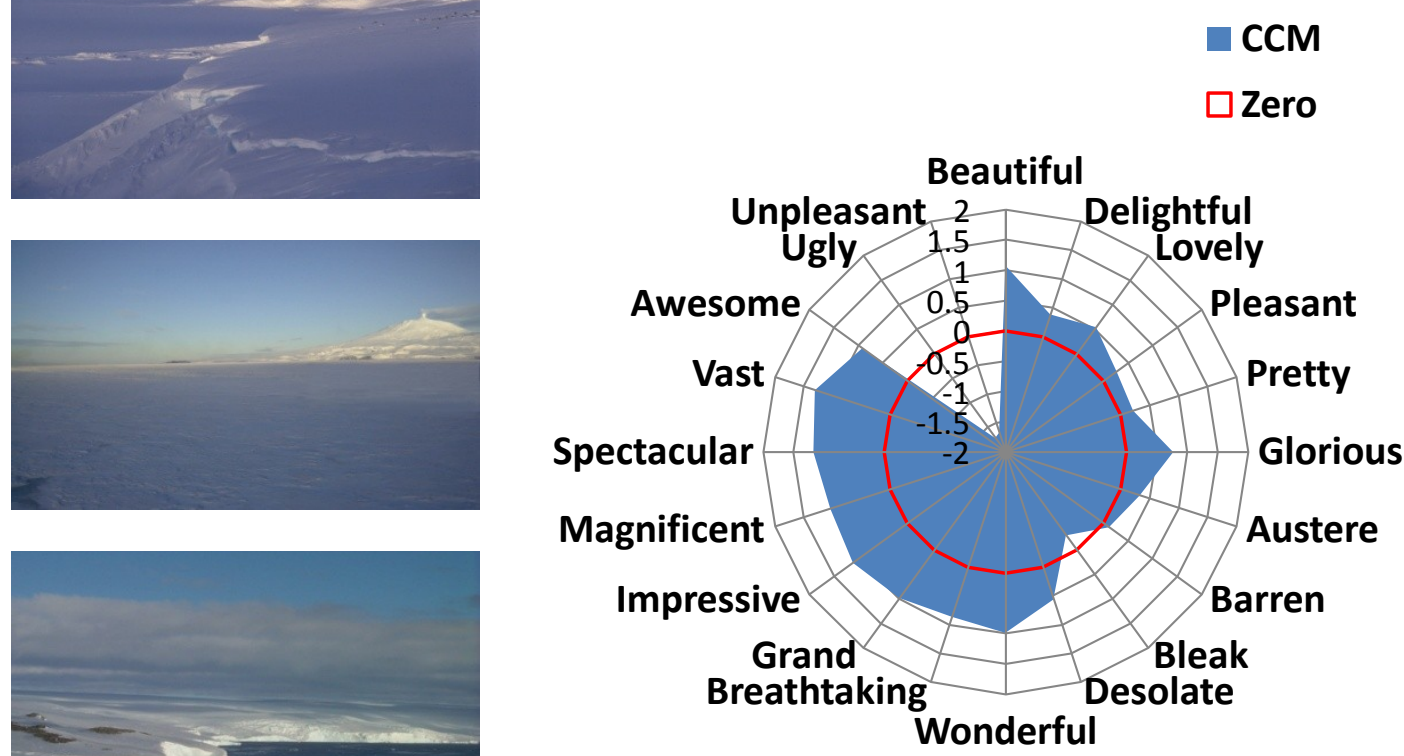

Figure 7.12. Averaged semantics scores for all images in the Coastal Continental Margin Region without human presence. (Photos. Top: Ice cliffs near Mawson (AAD), centre: McMurdo Sound (Kristan Hutchison/NSF), bottom: Windmill Islands (Rupert Summerson)). As the name implies, the coastal continental margin region covers the areas on the margins between the continental ice sheet and the surrounding ocean. The responses to scenes from this region are very similar to those of other ice-covered terrains. The "austerity" group is marginally less preferred than in other regions. 


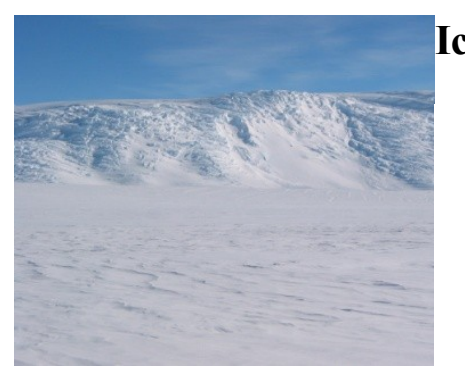

\section{Ice shelves - no human presence}
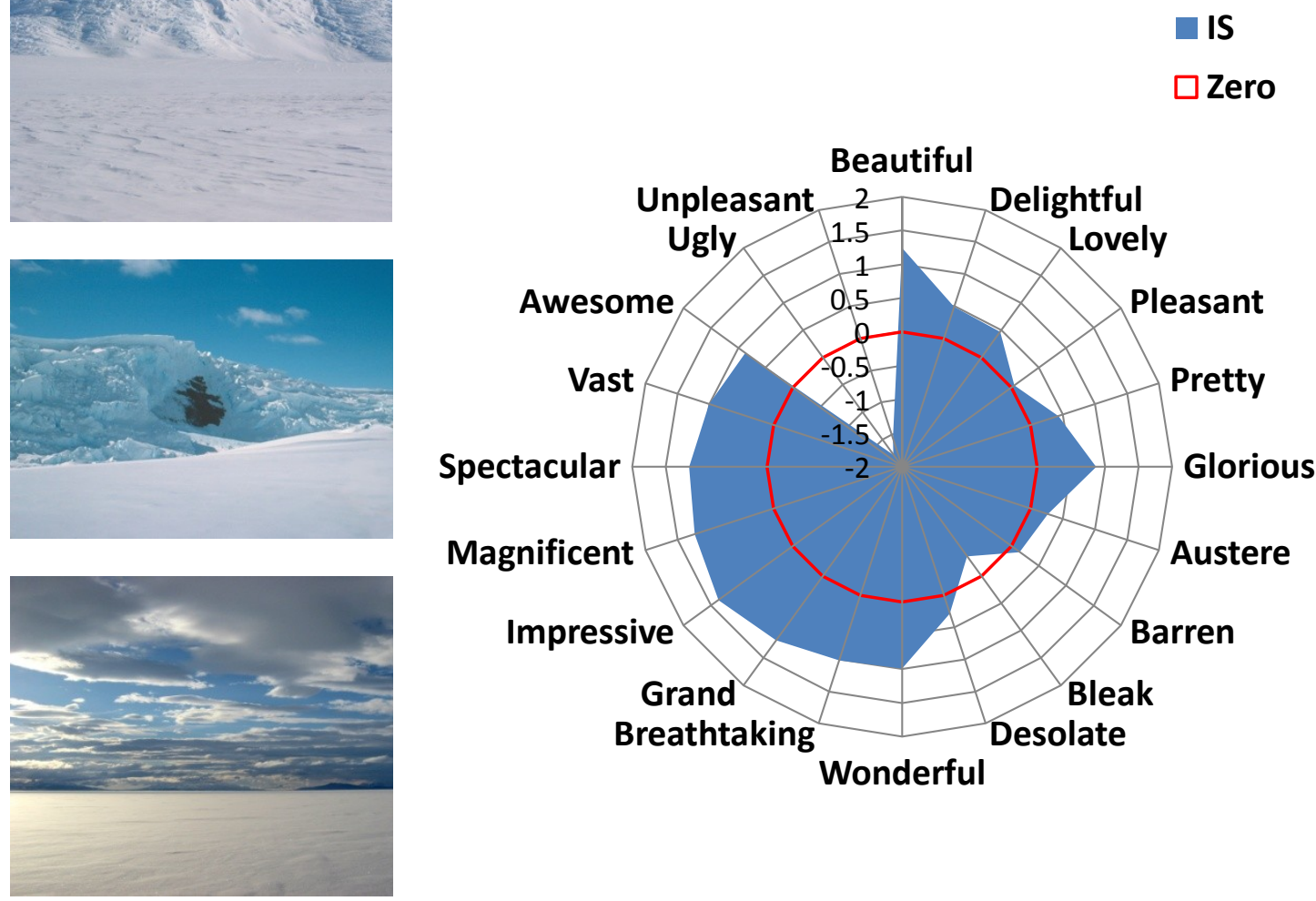

Figure 7.13. Averaged semantics scores for all images in the Ice Shelves Region without human presence. (Photos. Top: Ross Ice Shelf (John Penney/NSF), centre: Larsen Ice Shelf (Rupert Summerson), bottom: Ross Ice Shelf (Robyn Waserman)).

Two of the three of the scenes in the examples above are from the Ross Ice Shelf, the other is from the Larsen Ice Shelf. The lower scene above includes the mountains of the Transantarctic Mountain Range in the distance and illustrates the difficulty of overlapping regions. Once out of sight of land, there is nothing to distinguish one ice shelf from another. Ice shelves account for approximately $11 \%$ of the total area of Antarctica. 


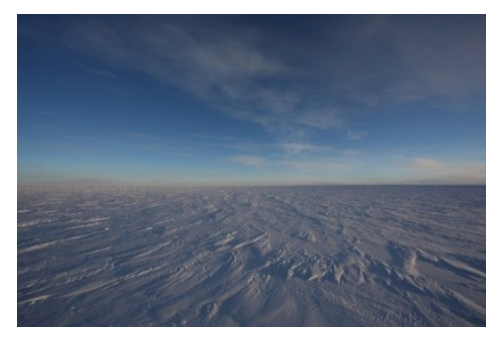

\section{Central Antarctic Ice Sheet - no human presence}
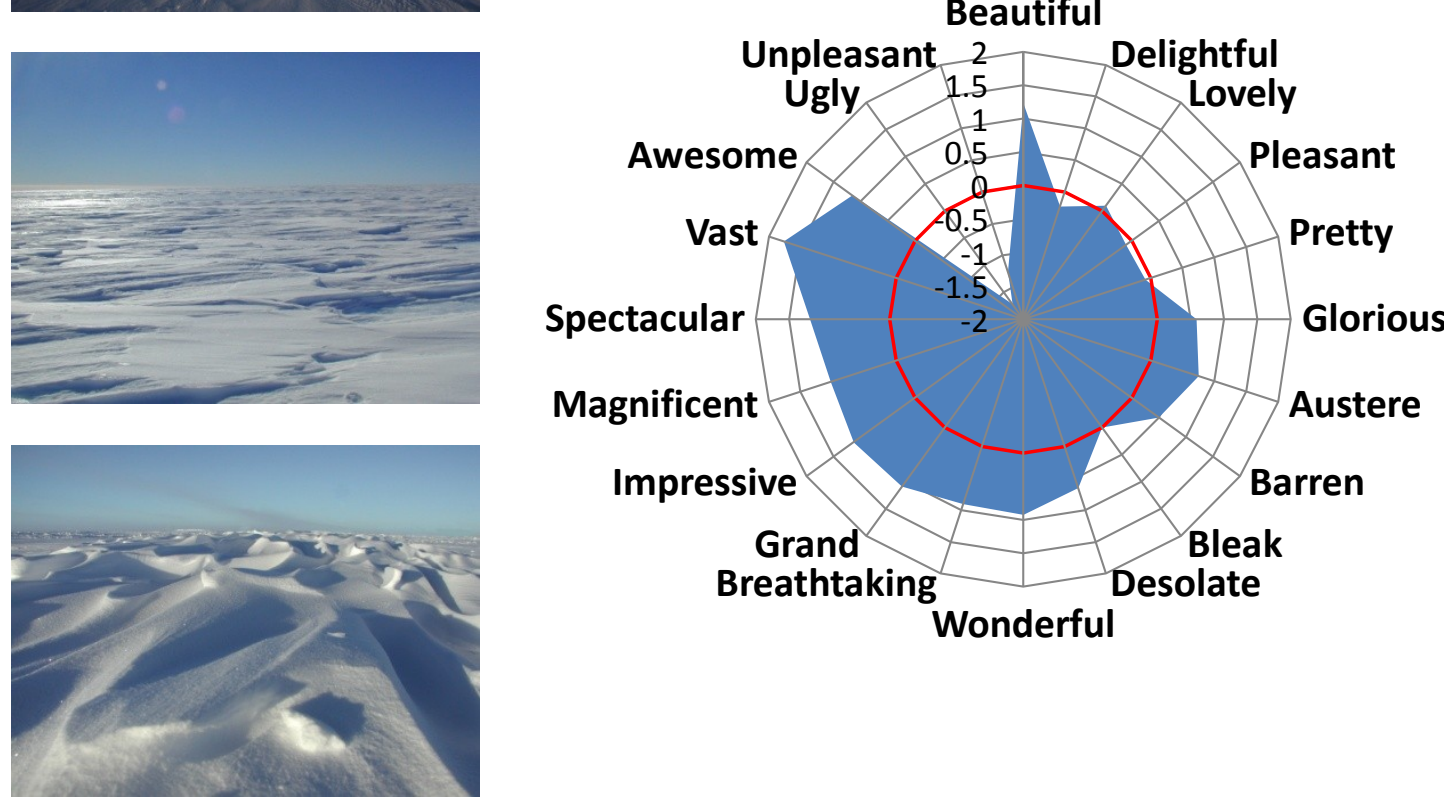

Grand

Breathtaking

Wonderful

Bleak

Desolate

CIS

Zero 
When the semantic suitability ratings for all six regions are plotted together at the same scale (Figure 7.15) the difference between the coastal ice-free region and the other regions becomes apparent. The other regions are by no means identical with some marked differences in individual adjectives, such as "Vast" in the central ice sheet region, but in general they have the same shape.

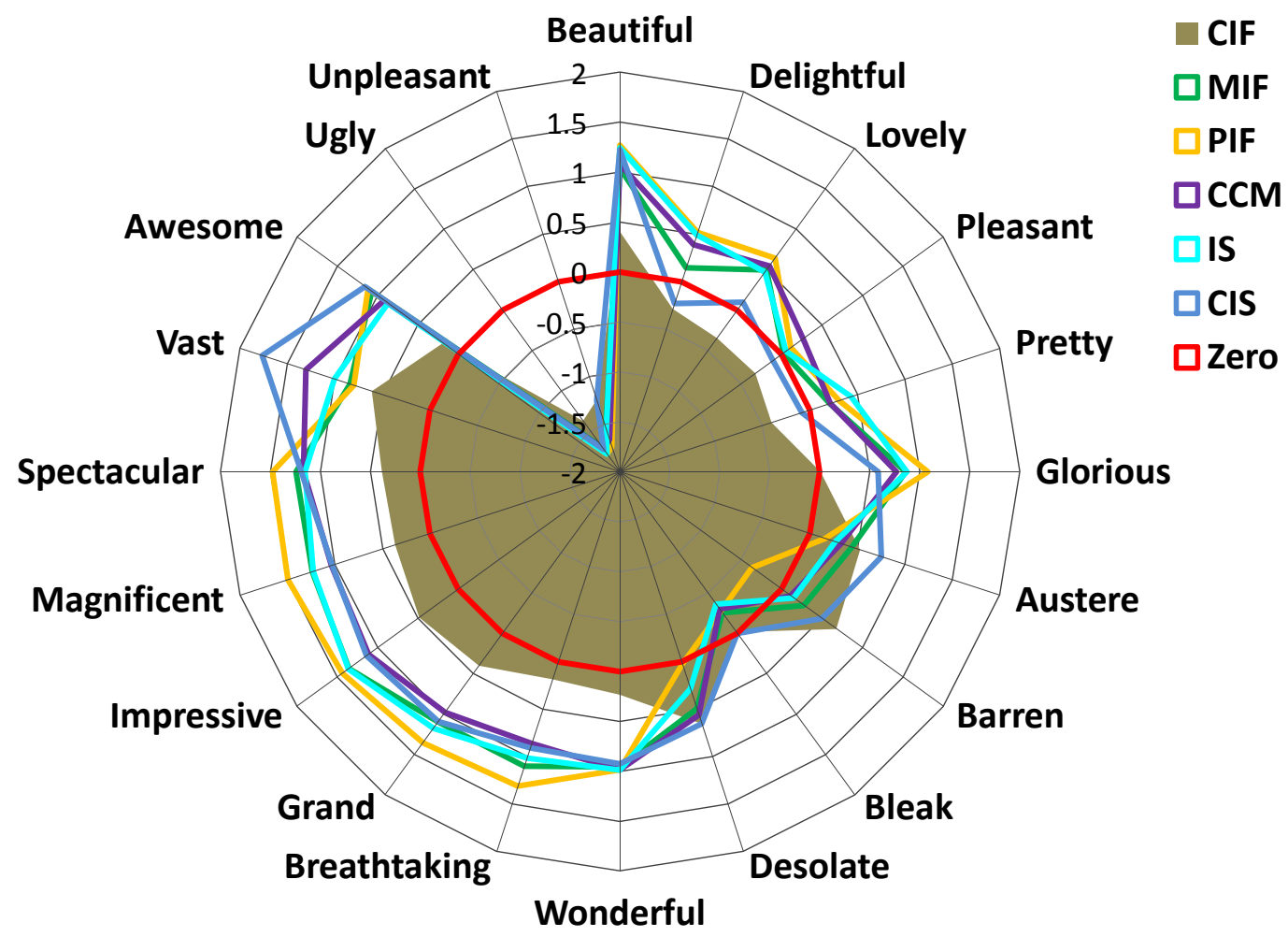

Figure 7.15. Semantics plot of all six regions, plotted at the same scale.

CIF: Coastal Ice Free. MIF: Mountainous Ice-Free. PIF: Peninsula Ice Fields. CCM: Coastal-Continental Margin. IS: Ice shelves and floating glaciers.CIS: Central Antarctic Ice Sheet.

It is notable that the suitability ratings of most of the adjectives in the Coastal Ice-Free region are substantially lower than those in the other regions. Only two adjectives have been rated as more suitable in this region than in the others: "Barren" and "Ugly". While the coastal ice-free areas are important breeding habitat for Antarctica's endemic wildlife, including seals and penguins, there are also large tracts that appear more or less lifeless (Adamson \& Pickard 1986), Figure 7.20, which may explain why Barren was thought of as being suitable.

\subsubsection{Human impact on semantic assessments}

Figure 7.16 shows the results of Image 324, which ranked as the highest $\mathrm{Z}$ score. In this image all the adjectives were rated as suitable or better, though to varying degrees, with the exception 
of "Ugly" and "Unpleasant". The semantic assessments match very closely the general shape of the average assessments of scene in the Mountainous Ice-Free region (green in Figure 7.16). As may be expected, the scores for all positive adjectives (i.e. all but "Ugly" and "Unpleasant") exceed the average scores. In almost all cases the adjectives associated with the sublime are rated more highly, i.e. more suitable than those associated with the beautiful. Of the "austerity" adjectives ("Austere", "Barren", "Bleak" and "Desolate") only "Barren" was rated as being a more suitable adjective than average for the mountainous ice-free region.
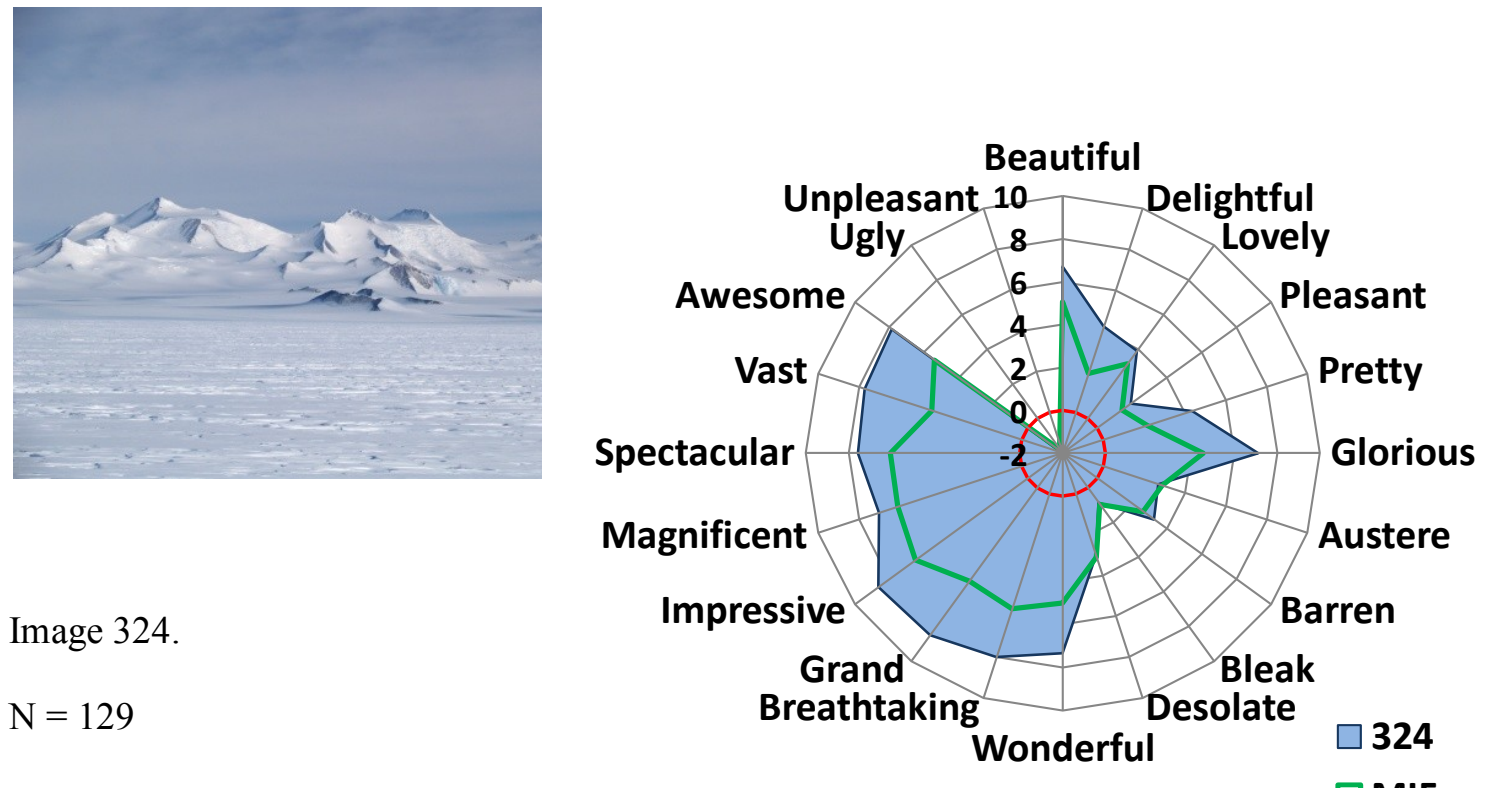

Mean Z score: 0.976

Figure 7.16. Radar graph of semantic responses to the image with the highest $\mathrm{Z}$ score (image 324). (Photo: Paul Thur/NSF).

Image 213 (Davis Station, Figure 7.17) has the lowest aesthetic rating in the survey. The shape of the radar graph is very different to the shape of the previous figure. This and other images with high levels of human infrastructure were the only scenes where "Ugly" was rated as a suitable adjective. All the adjectives associated with the beautiful and the sublime have been marked right down. In order to test whether the assessments of all respondents was also typical of Australian respondents, many of which may have spent some time at this station and may therefore have some affection for it that may bias their ratings, a separate assessment was done of all Australian respondents with Antarctic experience in science, science support or operations roles, i.e. with ANARE. As can be seen above, the results from ANARE respondents align reasonably closely with all respondents, most of the difference between them can probably be 
put down to the quite large disparity in numbers: 31 ANARE respondents versus 143 all respondents (which includes the ANARE respondents).
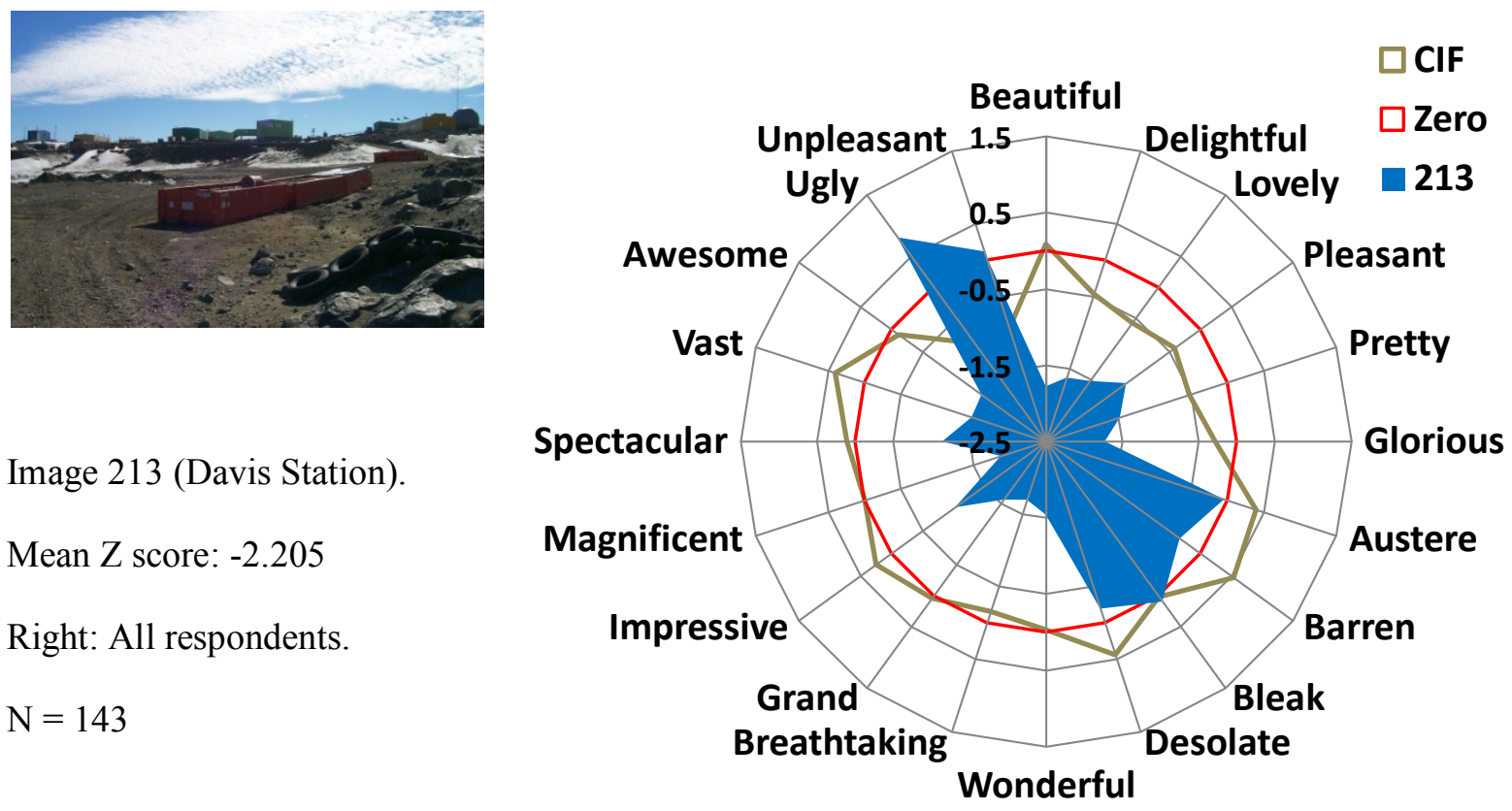

Right: ANARE respondents.

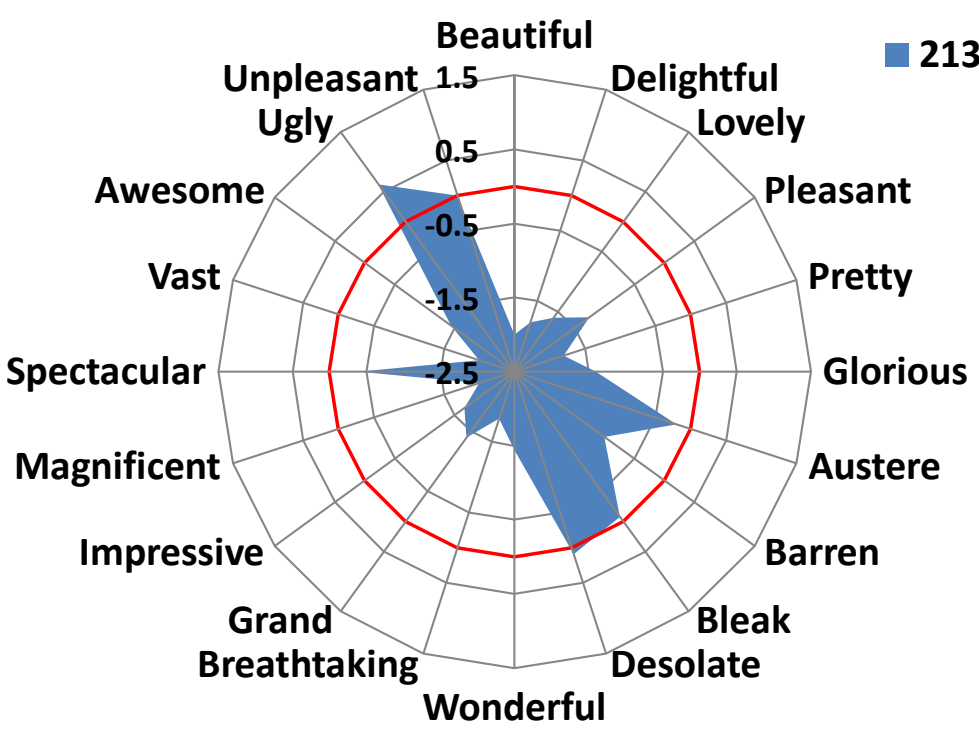

Figure 7.17. Image 213. Radar graphs of semantics scores all respondents (upper right) and respondents with Antarctic experience with ANARE (lower right). A zero line (in red) and the shape of the mean aggregated results for all images without human presence in the coastal icefree region (see below) have been included for reference. (Photo: Rupert Summerson).

Radar graphs were also drawn up to compare responses to manipulated image pairs. Figure 7.18 shows responses to a pair of images of infrastructure, one of which includes an automatic weather station (AWS) and its correlate. 

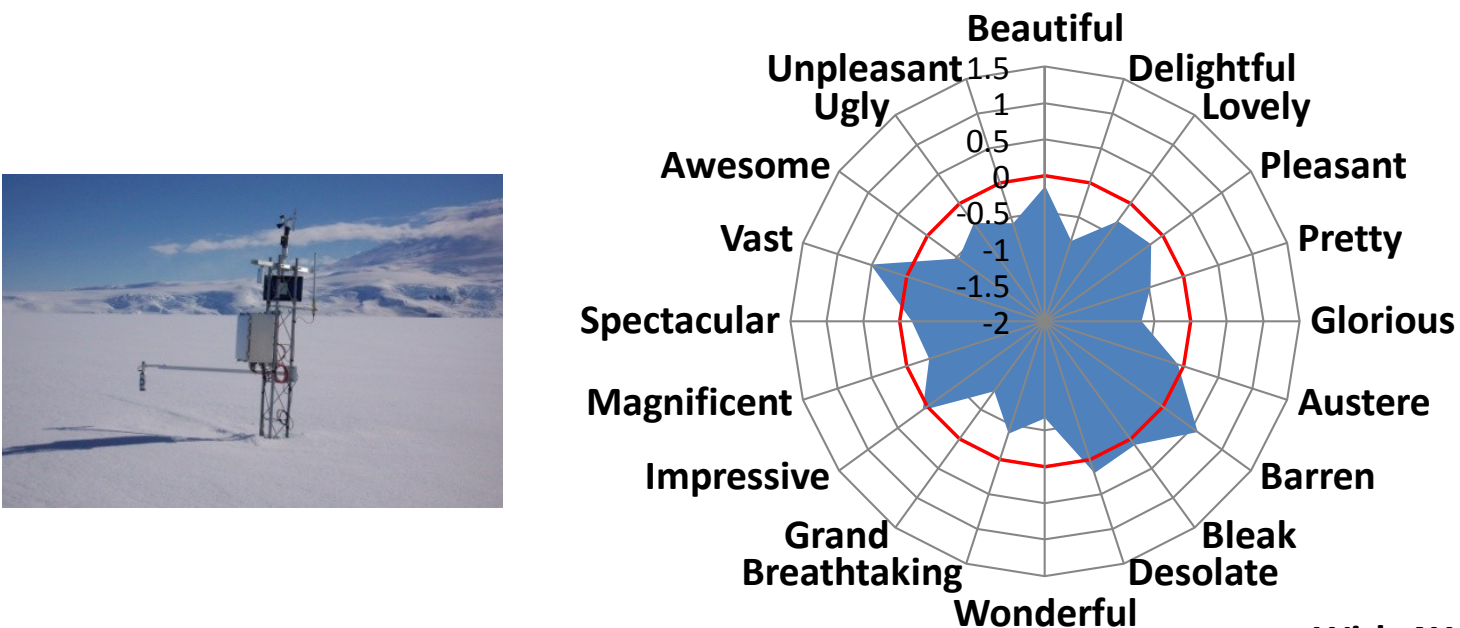

With AWS

$\square$ Zero
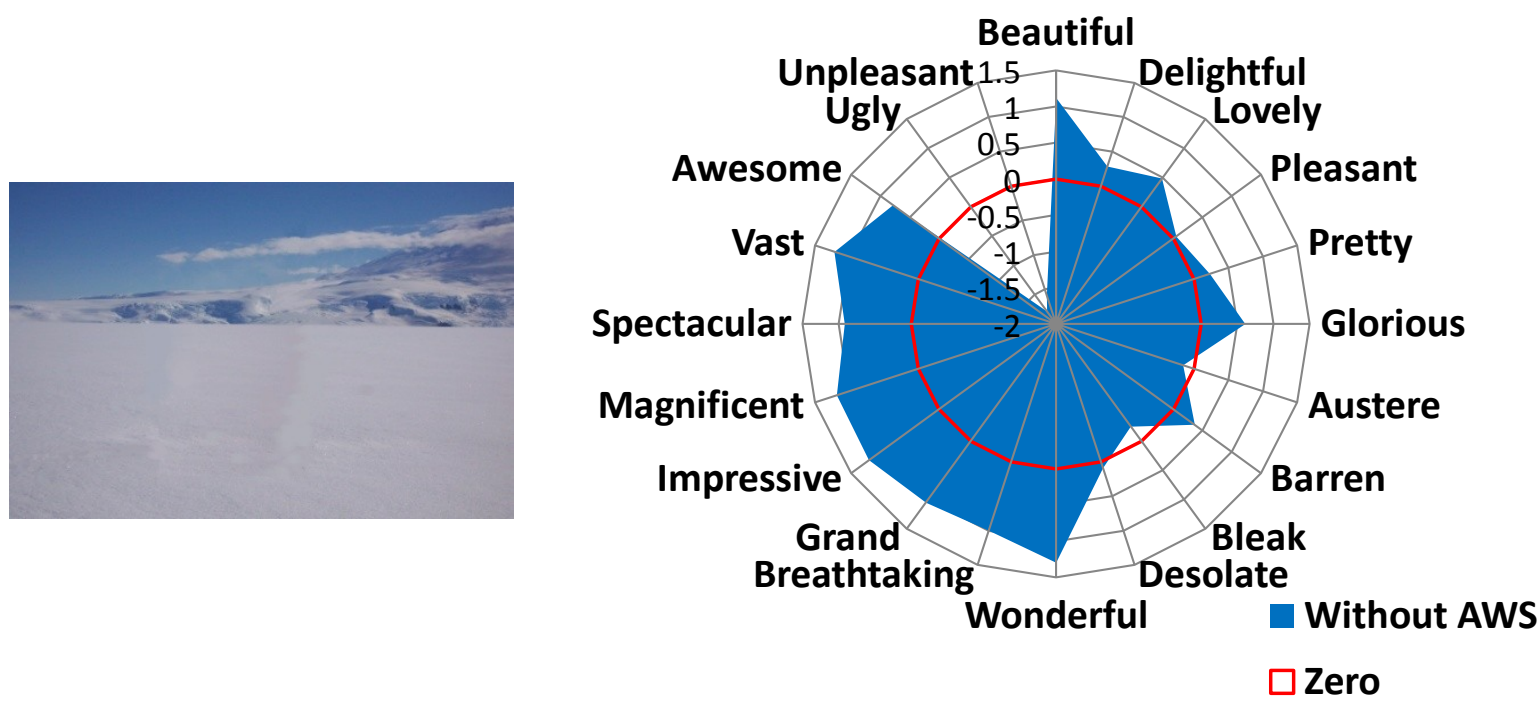

Figure 7.18. Effect of an item of infrastructure (automatic weather station (AWS)), above, and digitally removed, below.

(Photo: Antarctic Meteorological Research Center, Space Science and Engineering Center, University of Wisconsin-Madison).

A Chi-square test for independence between the semantic assessments of the image without the AWS (removed by digital manipulation) and the image with the AWS indicated a significant difference between the two images: $\chi^{2}(4, \mathrm{~N}=960)=91.27, p=0.000$, phi $=0.308$. Inspection of the radar graphs shows that suitability assessments of most of the adjectives were considerably diminished in the image with the AWS by comparison with the image from which it had been digitally removed. The suitability of 'Barren' appears to have increased but a Chisquare test for independence indicated that the difference was not significant: $\chi^{2}(4, N=43)=$ 
2.26, $p=0.687, p h i=0.229$. By contrast the suitability of 'Ugly' in the image with the AWS was significantly different (greater) than the manipulated image: $\chi^{2}(4, \mathrm{~N}=52)=22.33, p=$ $0.000, p h i=0.655$.

Figure 7.19 shows responses to a pair of images one of which includes transient activity, in this case a field party on the Larsen Ice Shelf.
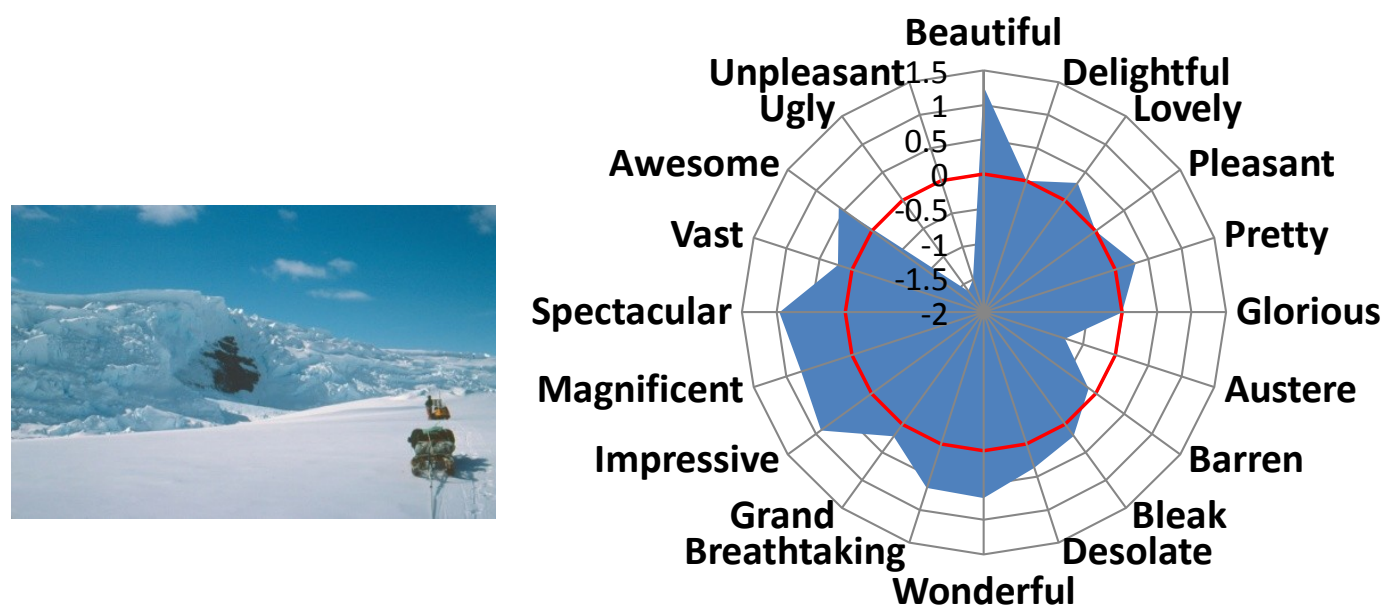

Field party

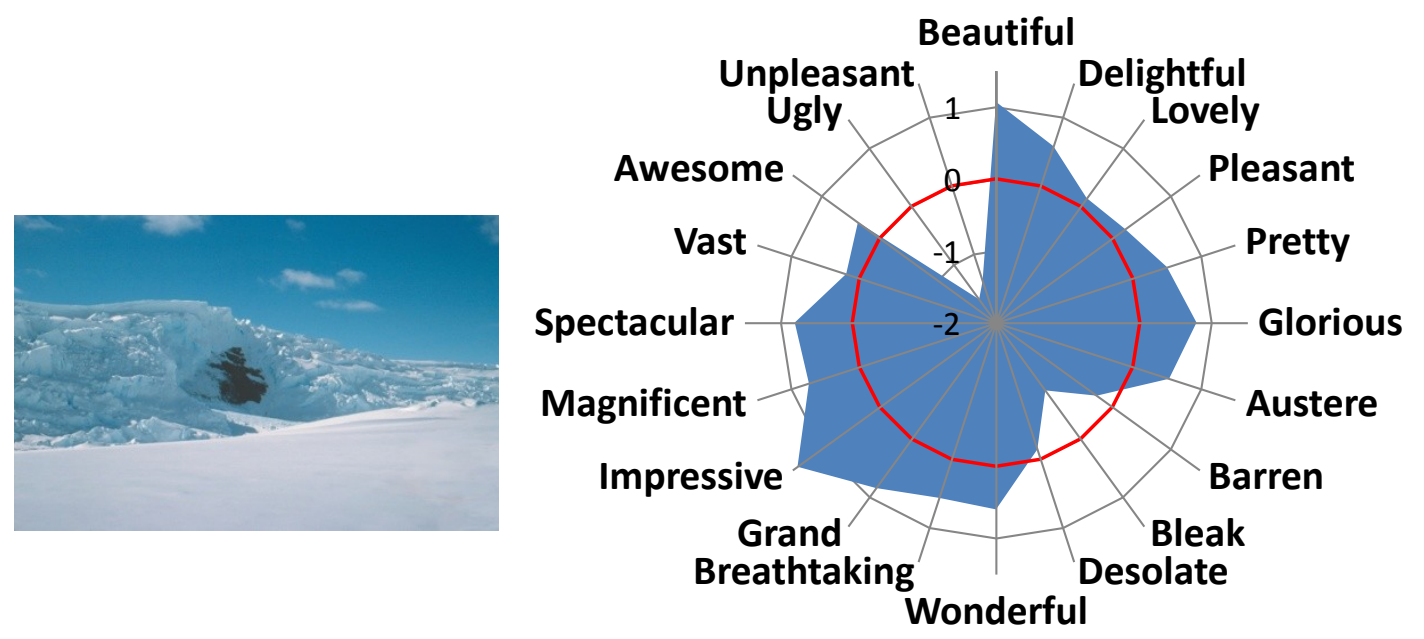

No field party

Figure 7.19. Effect of a transient activity (a field party). (Photo: Rupert Summerson).

A Chi-square test for independence between the semantic assessments of the image without the field party (removed by digital manipulation) and the image with the field party indicated no significant difference in semantic assessments between the two images: $\chi^{2}(4, \mathrm{~N}=860)=7.05$, $p=0.133, p h i=0.091$. The differences in semantic assessments between the two images is 
more complex than in Figure 7.18 and while some assessments of suitability have diminished in the image with the field party (e.g. 'Delightful', 'Glorious' and 'Austere'), some assessments have increased (e.g. 'Bleak'). In order to determine whether some of these changes are significant, a Chi-square test for independence as carried out on the semantic assessments of 'Impressive', which showed that the difference between the two images was only just significant: $\chi^{2}(3, \mathrm{~N}=50)=7.913, p=0.048$, phi $=0.398$.

Many of the graphs shown above suggest that the group of adjectives "Austere", "Barren", "Bleak" and "Desolate" are never suitable. Figure 7.20 shows when they are suitable adjectives. Images 111 and 309 (Appendix 4) were found to have the highest scores for this group of adjectives. They form a natural pair of images taken of Marine Plain in the southern Vestfold Hills. Image 309 includes a lone human figure; Image 111 has no human presence. A radar graph of the semantic scores shows that for both of these images the "Bleak" group of adjectives (as above) were all considered suitable adjectives. It is interesting to note that "Vast" in the image with the human figure scored the highest value and that "Beautiful" was rated as suitable for the image without human presence, but only just suitable. "Beautiful" was not rated as suitable for the image with the human figure. There are a number of other differences in the adjectives between the images which may not be significant. 

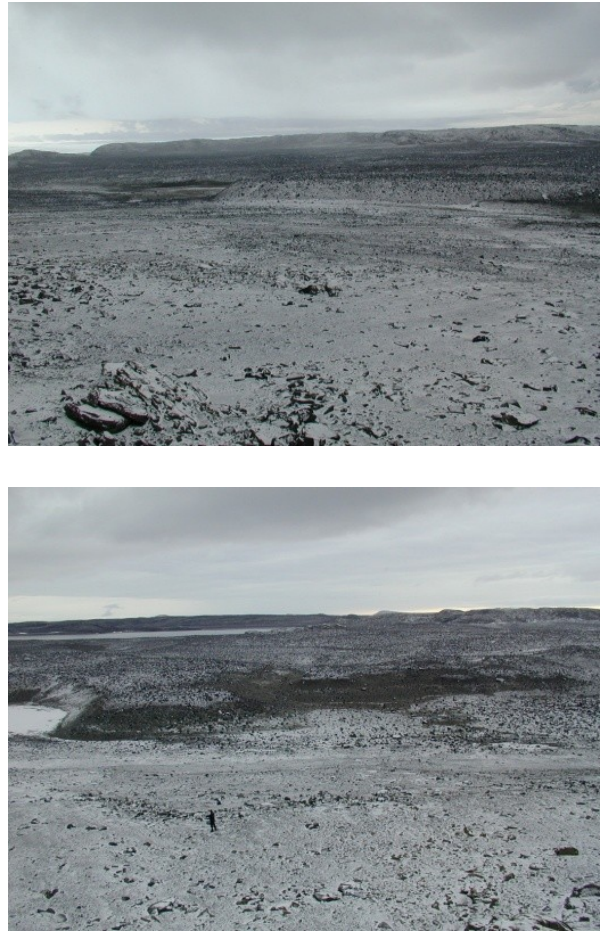

\section{No human presence}

$\square$ Human figure

口Zero

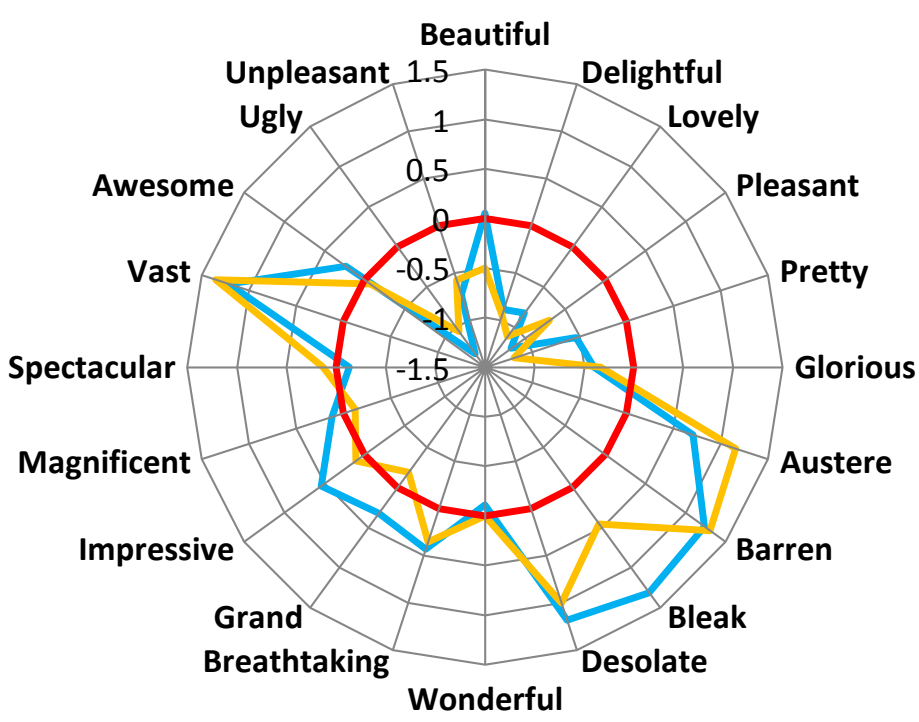

Figure 7.20. Image 111 without human presence (above) and Image 309 with a human figure (below). Image 111, $\mathrm{N}=72$. Image 309, $\mathrm{N}=87$. (Photos: Ewan McIvor).

\subsubsection{Field huts}

Field huts are a type of Antarctic infrastructure that is difficult to categorise as a hut may be officially designated in Antarctic Treaty Exchange Information (ATS 2012) as a refuge, camp, summer station, historic site, land-based tourism facility, abandoned station (or part of) or not mentioned at all. An audit in 2010 of field huts/refuges listed in Antarctic Treaty exchange information found information on 131 field huts in Antarctica. It is difficult to verify this information given that only eight countries listed refuges and two field huts that the author knows of were missing from the list (Cape Denison and Rothera snow runway). In the Australian Antarctic program field huts are a popular destination for both summer and winter recreation trips (personal observation) and are regularly used during summer months by scientific field parties. Modern field huts such as the Igloo Satellite Cabin (www.icewall.com.au), also known as "Apples" (and variants), are designed to be transportable and a number of field huts have been positioned to act as bases for field work, e.g. at Marine Plain in the Vestfold Hills. Field huts therefore have considerable drawing power for visitors and their placement in the landscape may evoke ambivalent feelings such as intrusion into the wilderness but also safety and protection from the elements. 
There were ten images of field huts in the survey, which included two historic huts. Of these images, 5 were included in the manipulated pairs part of the survey. As demonstrated in Table 7.16, all the field huts in the manipulated pairs part of the survey detracted significantly from wilderness and all but one (Image 113) detracted significantly from aesthetic value (Table 7.20).

Two contrasting sets of semantic responses are shown in Figure 7.21. In Figure 7.21.upper, Rumdoodle Hut is barely visible in an atmospheric photo of snow blowing through the mountain peaks. The plots of the semantic responses to the image that includes the hut and its manipulated counterpart from which the hut has been removed are quite similar. Two adjectives are notably different: "Wonderful" and "Barren". In Figure 7.21.lower, however, the semantic assessments for the image with the hut are lower than those for the image without the hut for almost all the adjectives with the exceptions of "Ugly" and "Unpleasant".

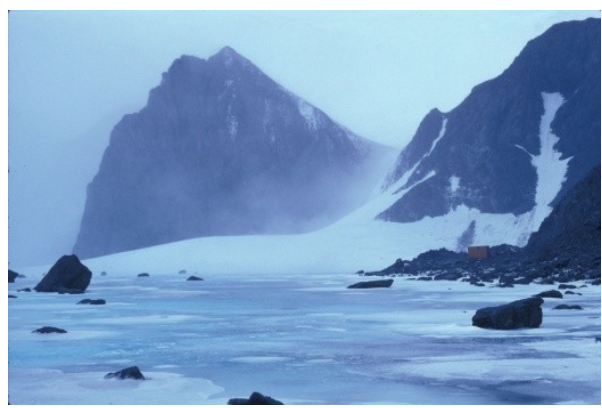

$\mathrm{N}_{\text {no hut }}=103$

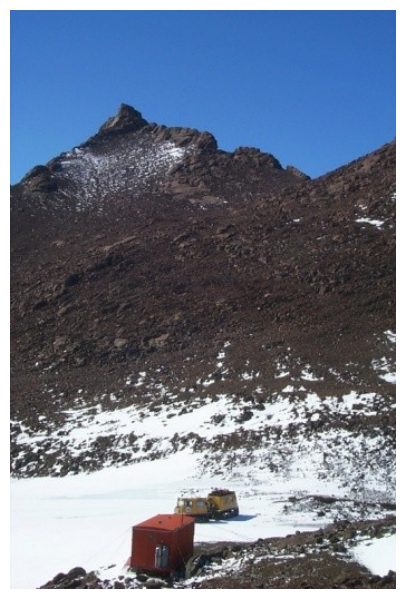

$\mathrm{N}_{\text {no hut }}=129$
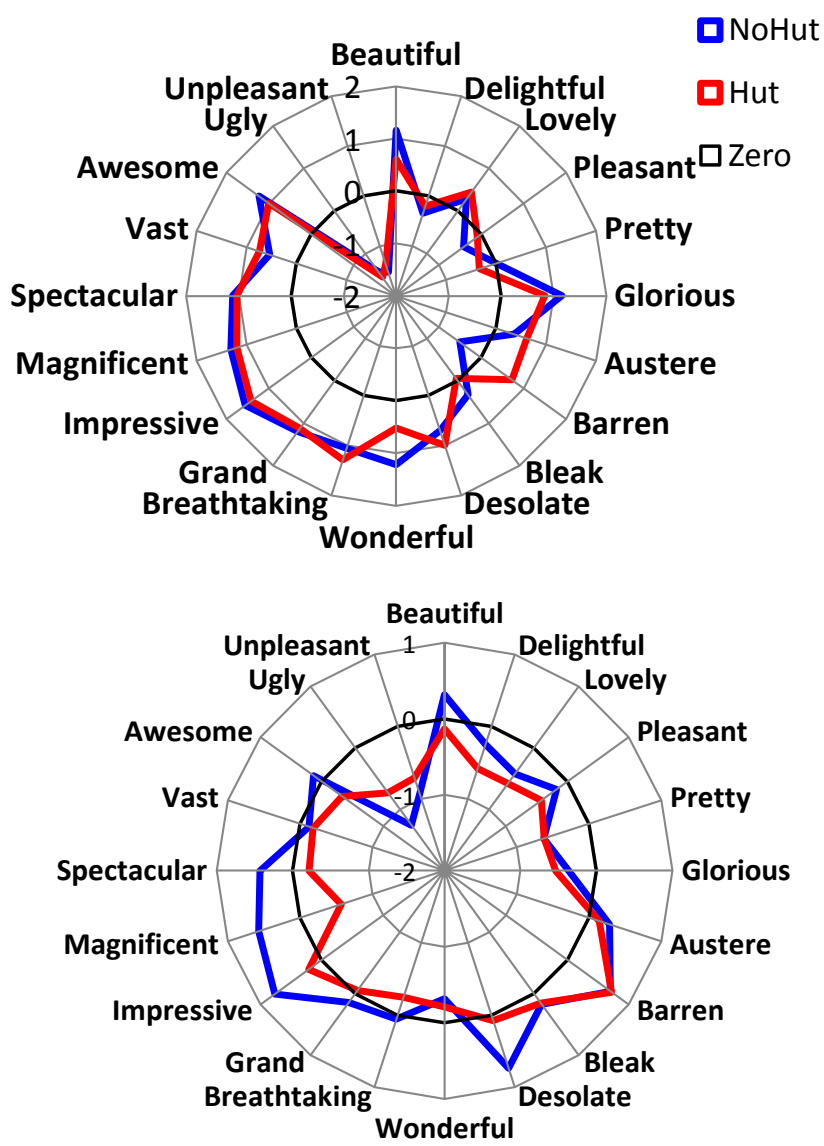

Figure 7.21. Radar graphs of semantic responses to two field huts. Upper: Rumdoodle Hut, Framnes Mountains (photo: Australian Antarctic Division), Lower: Mt Henderson Hut, Framnes Mountains (photo: Rupert Summerson). The sample sizes relate to the number of 
people who viewed the images; the numbers of semantic assessments were generally four times greater as each person was allocated four adjectives for each image.

The reason for the differences between the two huts is most likely because of the difference in visual prominence between the two huts. Although the hut as reproduced in Figure 7.21.upper is quite difficult to see, at the resolution the image was displayed in the survey, it is sufficiently visible. It is possible that the vehicle in Figure 7.21.lower may have had an additional impact though the hut is very prominently in the foreground of the image.

\subsubsection{French semantic responses}

Finally, for an initial comparison of semantic responses by people from a culture other than English, responses by French-speaking people have been compiled into a radar graph (Figure 7.22). With 29 respondents and each assessing 30 images, there are on average nearly 12 assessments of each adjective in each EDA region, which is barely sufficient.

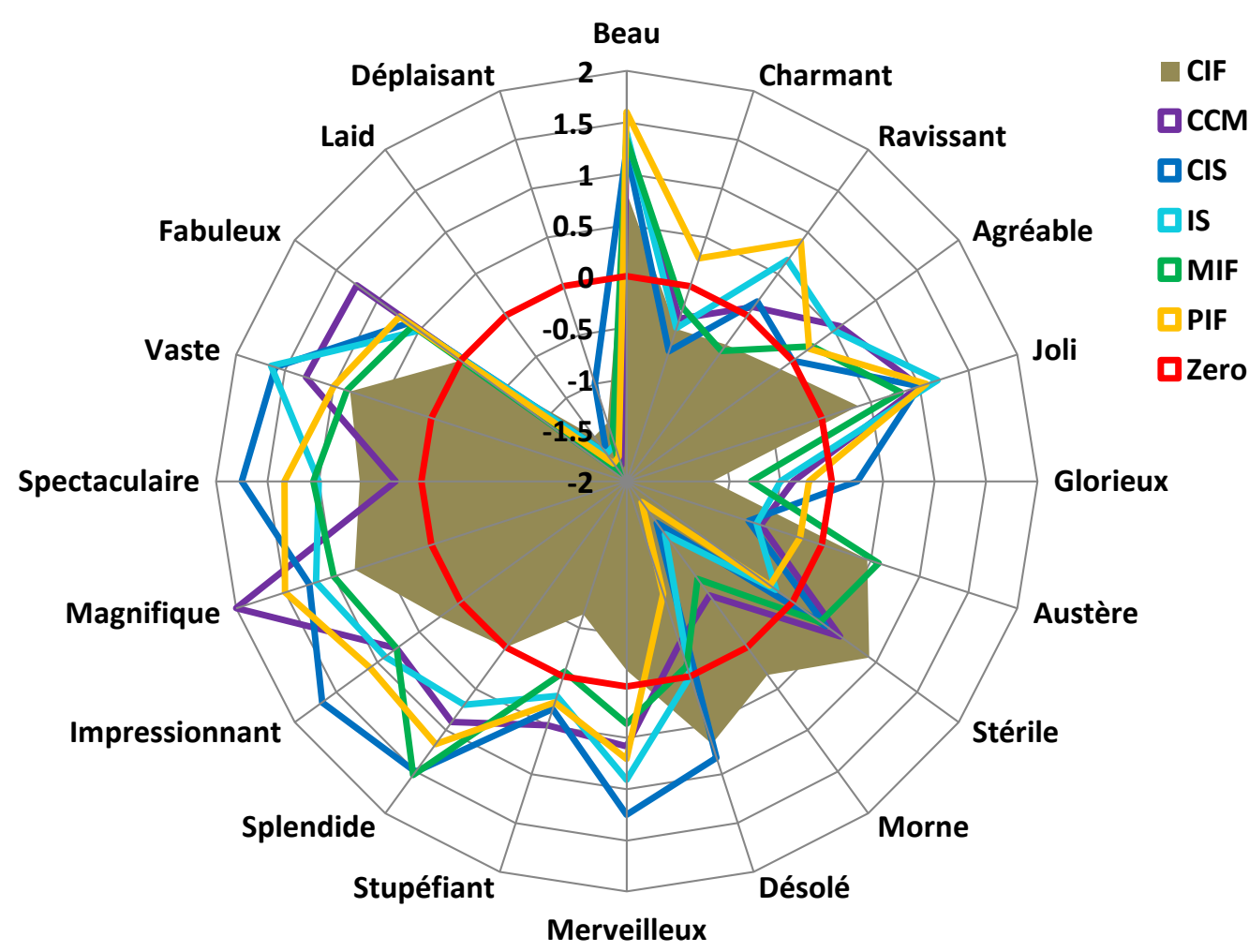

Figure 7.22. Responses to the French version of the semantics component of the survey plotted in a radar graph. The word order is the same as in the English version.

Some adjectives, such as "Beau" ("Beautiful") and "Joli" ("Pretty") were consistently assessed as suitable and "Morne" ("Bleak") as consistently not suitable. "Bleak" was consistently rated as not suitable (by EDA region) by English-speaking respondents also, but not to the same degree as in the French survey. It is notable that the pattern of responses to some regions, for example Peninsula Ice Fields, is similar to that of the English-speaking respondents, others, 
especially Coastal Ice Free is quite different. There were 29 respondents to the French version of the survey (Table 7.14) so with more respondents it is anticipated the more exaggerated responses may be evened out.

\subsubsection{Multidimensional scaling of semantic assessments}

Multidimensional scaling (MDS) is an ordination technique for the exploration of multivariate data. MDS has been widely used in the social sciences to explore the relationships between a number of elements, especially the discovery of structures in the data that are not otherwise readily apparent (Forgas 1979). These capabilities make it ideal to explore the dimensions of meaning in the 20 adjectives of the semantic assessment component of the survey.

To recap: survey respondents were presented with four words, chosen randomly from two lists, one list comprising adjectives associated with the beautiful and the other with the sublime. The lists of words are in Table 7.21 above and the Likert scale responses were converted into scores in the method shown in Table 7.22. Multidimensional scaling was carried out using the ALSCAL algorithm in PASW Statistics 18. The following parameters were selected to investigate the relationships between the adjectives (variables):

- Image set: All images

- Variables: All adjectives

- Level of measurement: Interval

- Conditionality: Matrix

- Dimensions: Three

- Scaling model: Euclidean

- Criteria:

- S-stress convergence: 0.001 .

- Minimum s-stress value: 0.005 .

- Maximum iterations: 30

- Distance matrix: Between variables

As its name implies, multidimensional scaling plots the distances between variables in multidimensional space. Three dimensions were requested in this case and the results, Dimensions 1 and 2, Dimensions 2 and 3 and Dimensions 1 and 3 are plotted as Figure 7.23. a, b \& c. The dimensions are unit-less, i.e. are simply relative distances and plotted as Euclidean distances. Inspection of the Dimensions 1 and 2 indicates that there are five clusters, as indicated in Figure 7.23. Each cluster has been named after one of the adjectives in that group. With the exception of one word, "Impressive", all the words in each cluster are wholly within the positive or negative space of one or other of the dimensions. It is not necessary that clusters should fall into one dimension or the other; it just happens that this is this case here, which 
results in discrete clusters. In Dimension 1, therefore, in positive space there are three clusters: "Ugly", "Pretty" and "Desolate" and in negative space there are two clusters: "Grand" and "Vast". The designations of positive and negative space are used only to identify relative positions in each dimension; there is no implication that one is better in some way than the other. In Dimension 2, there are two clusters in positive space: "Vast" and "Desolate" and in negative space: "Grand", "Pretty" and "Ugly". "Vast" and "Impressive" are too far apart to be grouped together. The way the adjectives have been clustered by the MDS process in this dimension is logically reasonable as the adjectives in each cluster are conceptually similar. Rotating the plot to examine the relationships to include Dimension 3 reveals different clusterings but most notably the separation of "Vast" in conceptual space in all three dimensions.

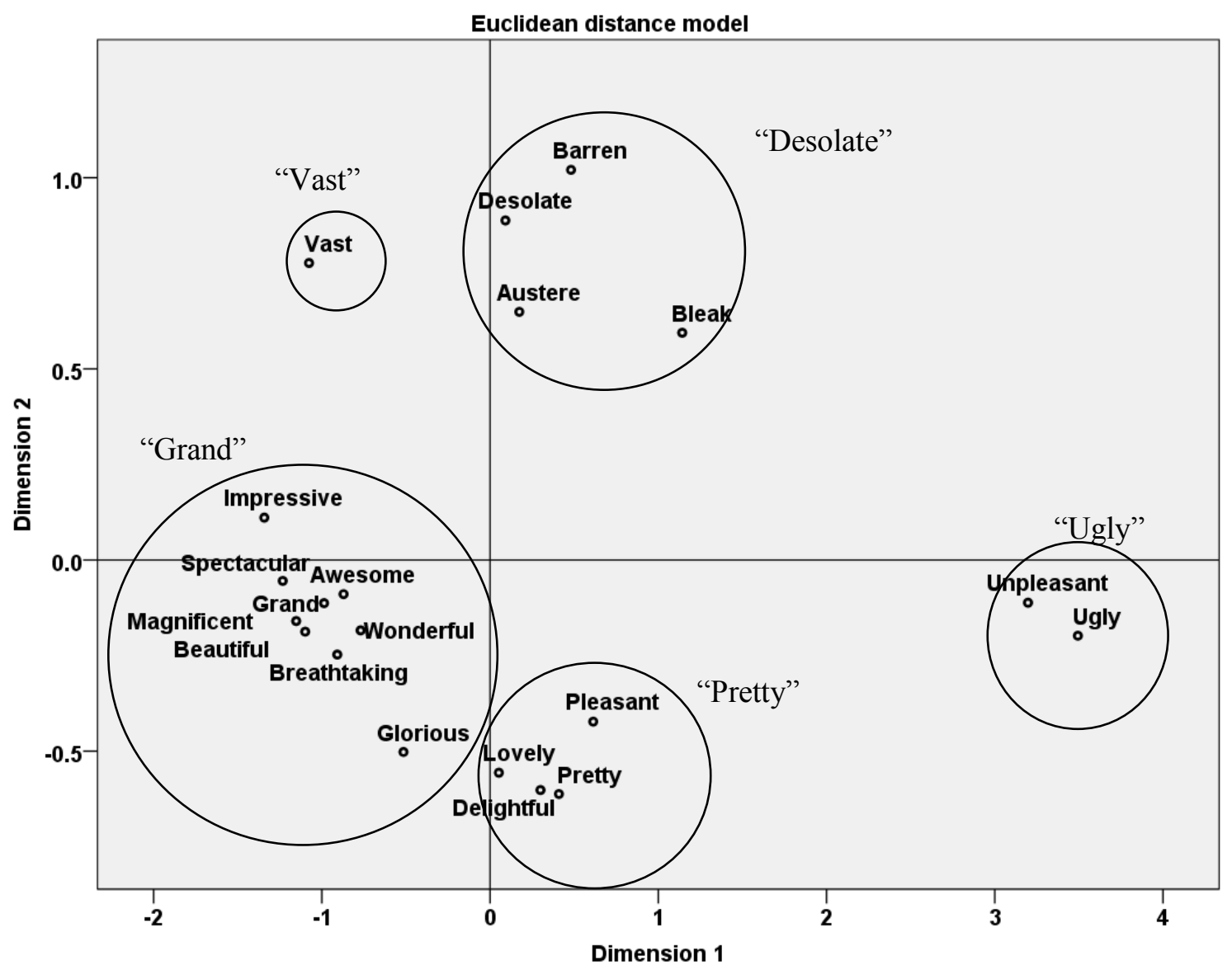

Figure 7.23.a. Plot of the multidimensional scaling output of the 20 adjectives of all images (both with and without human content) to reveal Dimensions 1 and 2. 

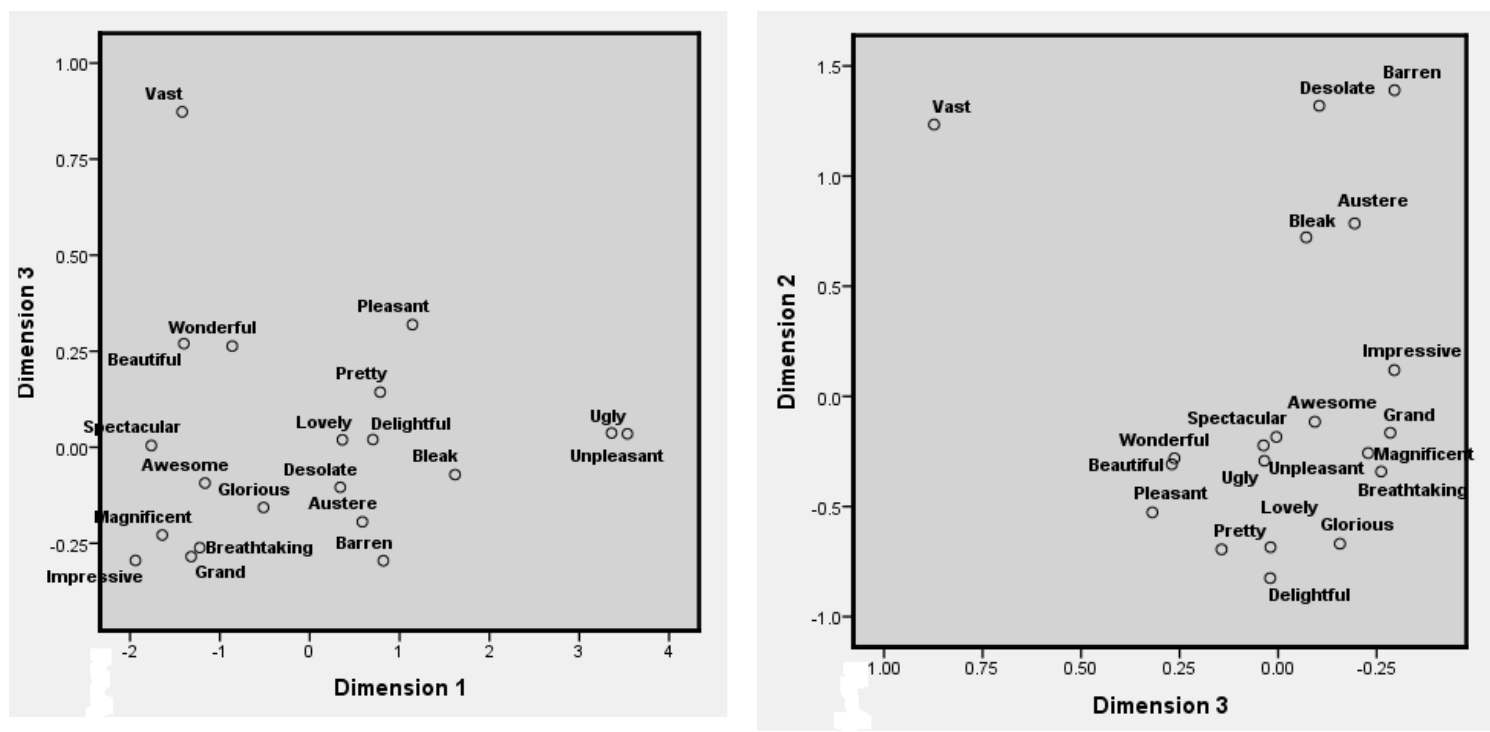

Figure 7.23.b (left) and c (right). Plots of the multidimensional scaling output to reveal Dimension 3 with respect to Dimensions 1 and 2.

In order to compare responses to images with human presence with images without human presence, multidimensional scaling was carried out with images containing human presence and those without together. The result, Figure 7.24, shows Dimensions 1 and 2. The images containing human presence are undifferentiated with respect to the type of human presence, i.e. infrastructure or transient activity. In general terms the adjectives are positioned in more or less the same relationships whether or not they relate to images with human presence or not. There is, however, an expansion in scale in Dimension 2, in other words the adjectives are set farther apart. This does not appear to be the case in Dimension 1. The expansion in scale on Dimension 2 gives a clue to this dimension's meaning in that human presence seems to be a factor. 


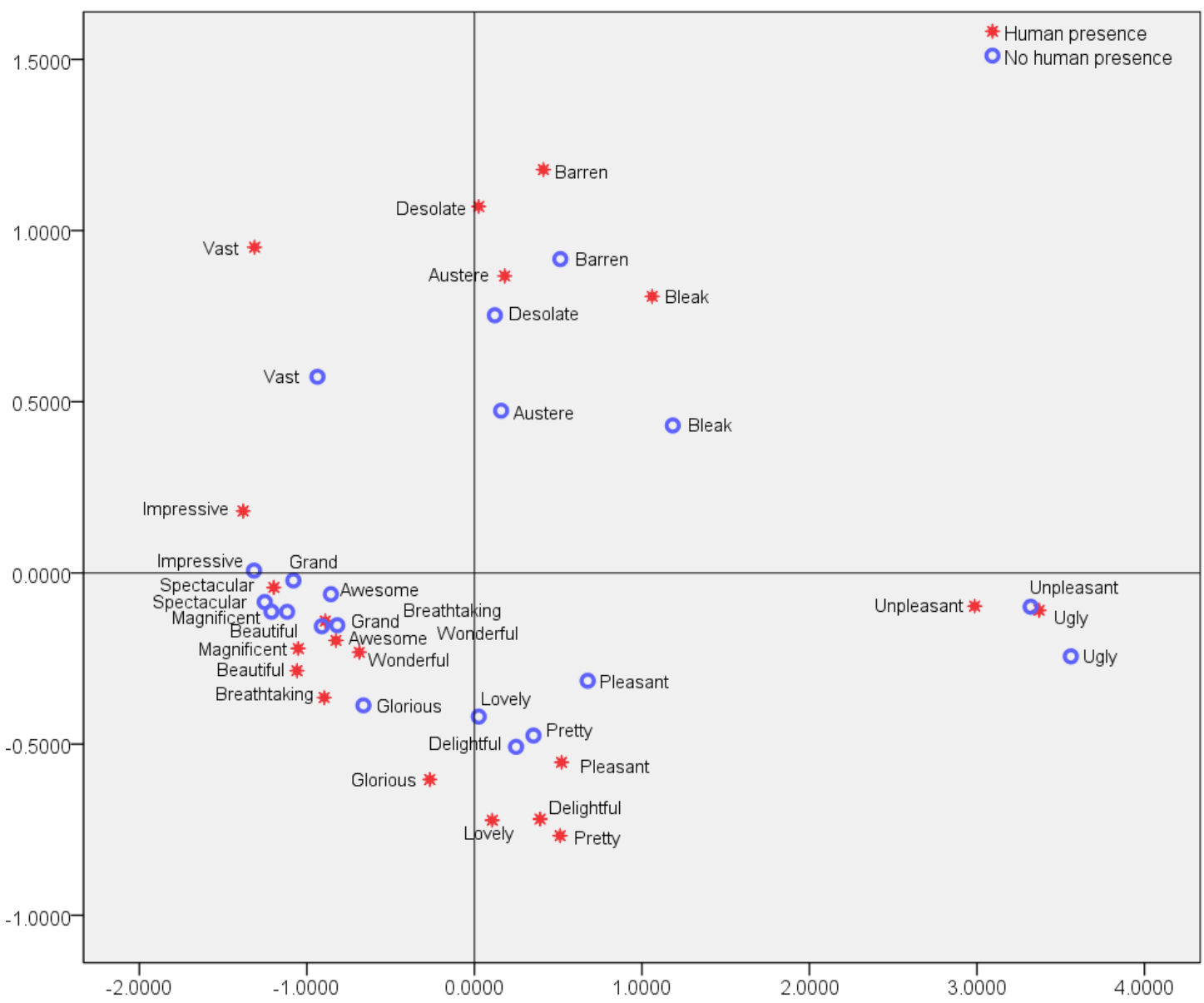

Figure 7.24. Plot of MDS dimensions $1 \& 2$ of human and non-human images separately.

Dimension $1=\mathrm{x}$ axis, Dimension $2=\mathrm{y}$ axis.

In order to compare responses to images by people with and without Antarctic experience, multidimensional scaling was carried out on responses to images by people who have visited Antarctica and those who have not. The results of Dimensions 1 and 2 are in Figure 7.25. The same groupings are evident as in Figure 7.23.a though the adjectives within each group are possibly a bit more dispersed in the responses from people who have not visited Antarctica but apart from that they seem more or less the same and any differences are not systematic. 


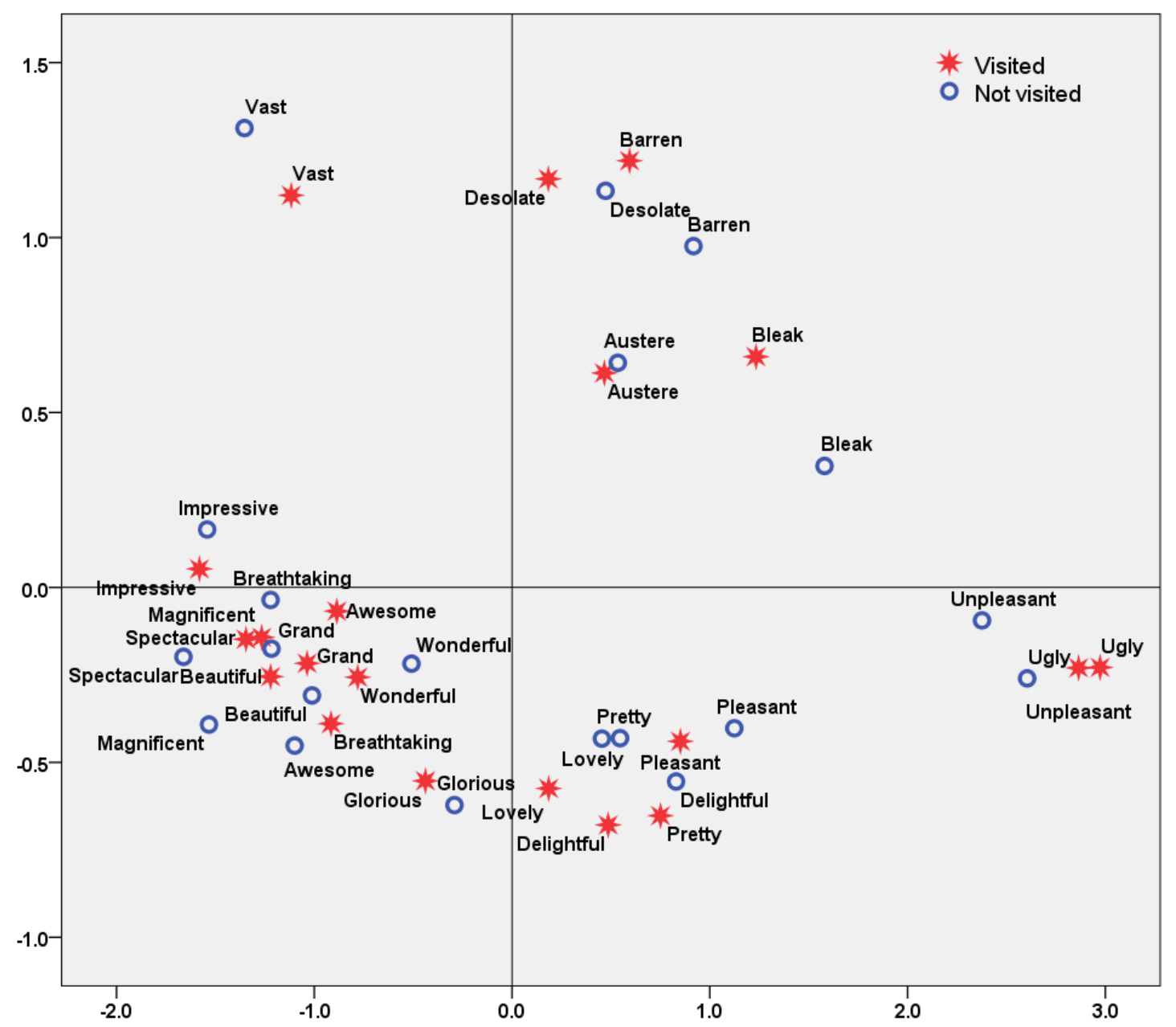

Figure 7.25. Multidimensional scaling of semantic responses to images by people who have visited Antarctica in any capacity (red stars) and those who have not visited Antarctica (blue circles).

In order to investigate the relationship between the MDS outputs, Dimensions 1, 2 and 3, and the adjectives themselves, the outputs were correlated with the adjectives' suitability assessments using Pearson product-moment correlation coefficient. Figure 7.26 shows MDS Dimension 1 correlated only with the adjectives where the significance level was less than 0.05 , i.e. where the correlation was statistically significant. 18 adjectives were significantly correlated; only "Austere" and "Desolate" dropped out. "Ugly" and "Unpleasant" were significantly negatively correlated. This leads to the conclusion that MDS Dimension 1 is an aesthetic dimension. 


\begin{tabular}{|c|c|}
\hline Word & MDS1 \\
\hline Beautiful & -0.932 \\
\hline Delightful & -0.847 \\
\hline Lovely & -0.918 \\
\hline Pleasant & -0.667 \\
\hline Pretty & -0.814 \\
\hline Glorious & -0.922 \\
\hline Barren & 0.322 \\
\hline Bleak & 0.287 \\
\hline Wonderful & -0.937 \\
\hline Breathtaking & -0.938 \\
\hline Grand & -0.932 \\
\hline Impressive & -0.935 \\
\hline Magnificent & -0.958 \\
\hline Spectacular & -0.958 \\
\hline Vast & -0.493 \\
\hline Awesome & -0.922 \\
\hline Ugly & 0.725 \\
\hline Unpleasant & 0.793 \\
\hline
\end{tabular}

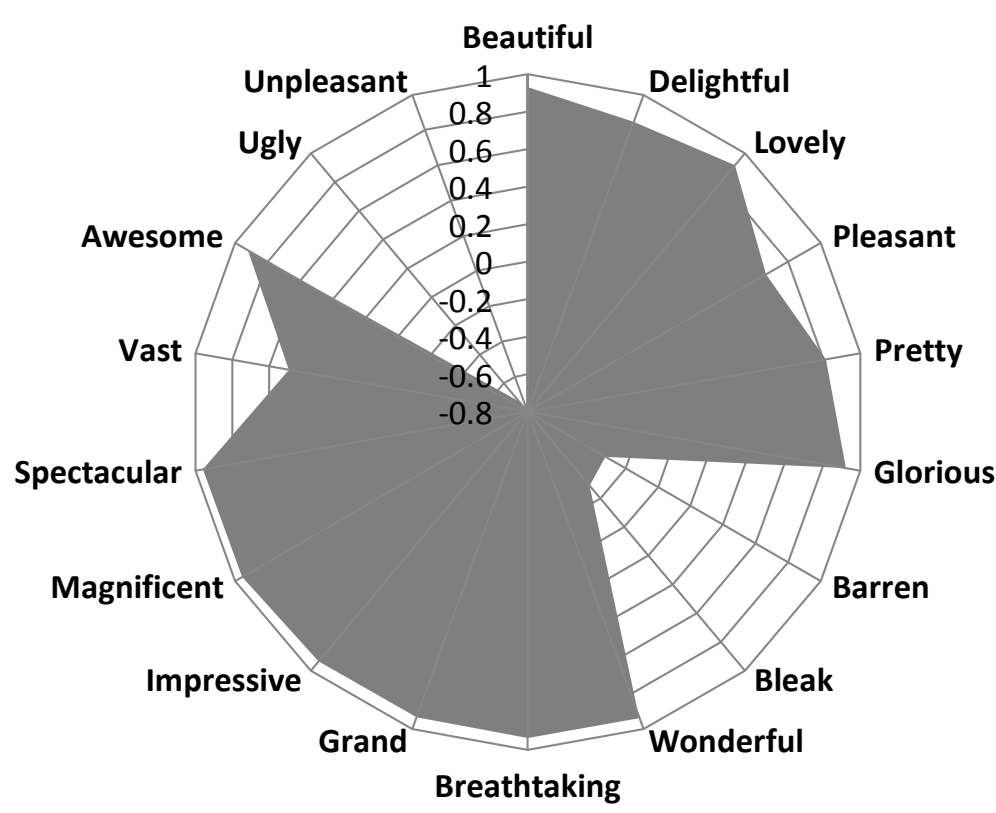

Figure 7.26. Correlations between MDS Dimension 1 and the adjective suitability scores, where the correlation is significant.

There were eight adjectives significantly correlated with MDS Dimension 2, as shown below in Figure 7.27. Of these, five were positively correlated and comprised "Vast", "Desolate", "Bleak", "Barren" and "Austere". "Pretty" and "Pleasant" were negatively correlated.

Six adjectives were significantly positively correlated with MDS Dimension 3: "Austere", "Barren", "Bleak", "Desolate", "Vast" and "Pleasant" (Figure 7.28). It is difficult to reconcile the inclusion of "Pleasant" with the other adjectives in this set. The positive correlation with "Vast" and the negative correlation with the other adjectives (except "Pleasant") reflects the separation between "Vast" and the other "Bleak" adjectives in Dimension 3 in Figure 7.23.c. 


\begin{tabular}{|cc|}
\hline Word & MDS2 \\
\hline Delightful & -0.332 \\
\hline Pleasant & -0.277 \\
\hline Pretty & -0.256 \\
\hline Austere & 0.703 \\
\hline Barren & 0.765 \\
Bleak & 0.679 \\
\hline Desolate & 0.829 \\
\hline Vast & 0.654 \\
\hline
\end{tabular}

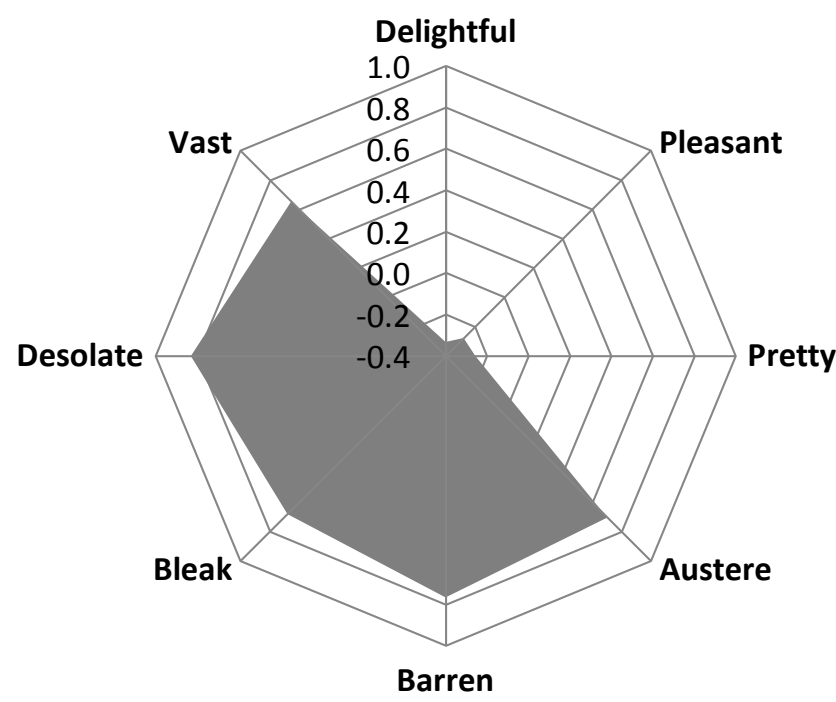

Figure 7.27. Correlations between MDS Dimension 2 and the adjective suitability scores, where the correlation is significant.

\begin{tabular}{|cc|}
\hline Word & MDS3 \\
\hline Austere & -0.268 \\
\hline Barren & -0.315 \\
\hline Bleak & -0.208 \\
\hline Desolate & -0.216 \\
\hline Pleasant & 0.282 \\
\hline Vast & 0.552 \\
\hline
\end{tabular}

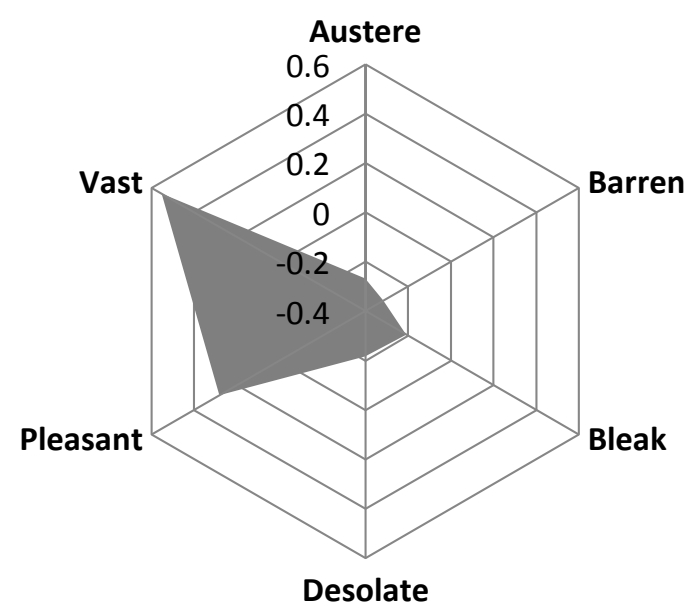

Figure 7.28. Correlations between MDS Dimension 3 and the adjective suitability scores, where the correlation is significant.

\subsubsection{MDS analyses of semantic responses to field huts}

As described above, field huts may evoke ambivalent feelings about intrusion into the wilderness and feelings of shelter and security; they are therefore a potentially sensitive indicator of attitudes to infrastructure. In order to investigate these issues further, the semantic assessment scores were aggregated for nine of the field huts (one was too distant to be clearly 
identifiable as a field hut) and a multidimensional scaling analysis run. The results are show in Figure 7.29. The most noticeable distinction is in Dimension 1 where "Ugly" and "Unpleasant" are separated from the rest of the adjectives and yet they themselves are separated by Dimension 2. Unlike in Figure 7.23.a, "Vast" is grouped with other adjectives. Five of the huts were part of the manipulated pairs set and had counterparts where the images of the huts were removed, or in one case, an image of a hut was digitally added to a scene. Multidimensional scaling was carried out on the two groups separately and the results overlain in order to observe the effect of human presence on the groupings of the adjectives. First, there are some small differences between the groupings in Figure 7.29 and the groupings of the red symbols (images including field huts) in Figure 7.30. This is because Figure 7.29 is of all field huts whereas Figure 7.30 is of just the field huts which have manipulated pairs. Second, the overall pattern is similar to that of all images (Figure 7.23.a), though reversed along Dimension 1 so that "Ugly" and "Unpleasant" are on the left, rather than the right. The direction of the dimensions is unimportant in multidimensional scaling (Forgas 1979).

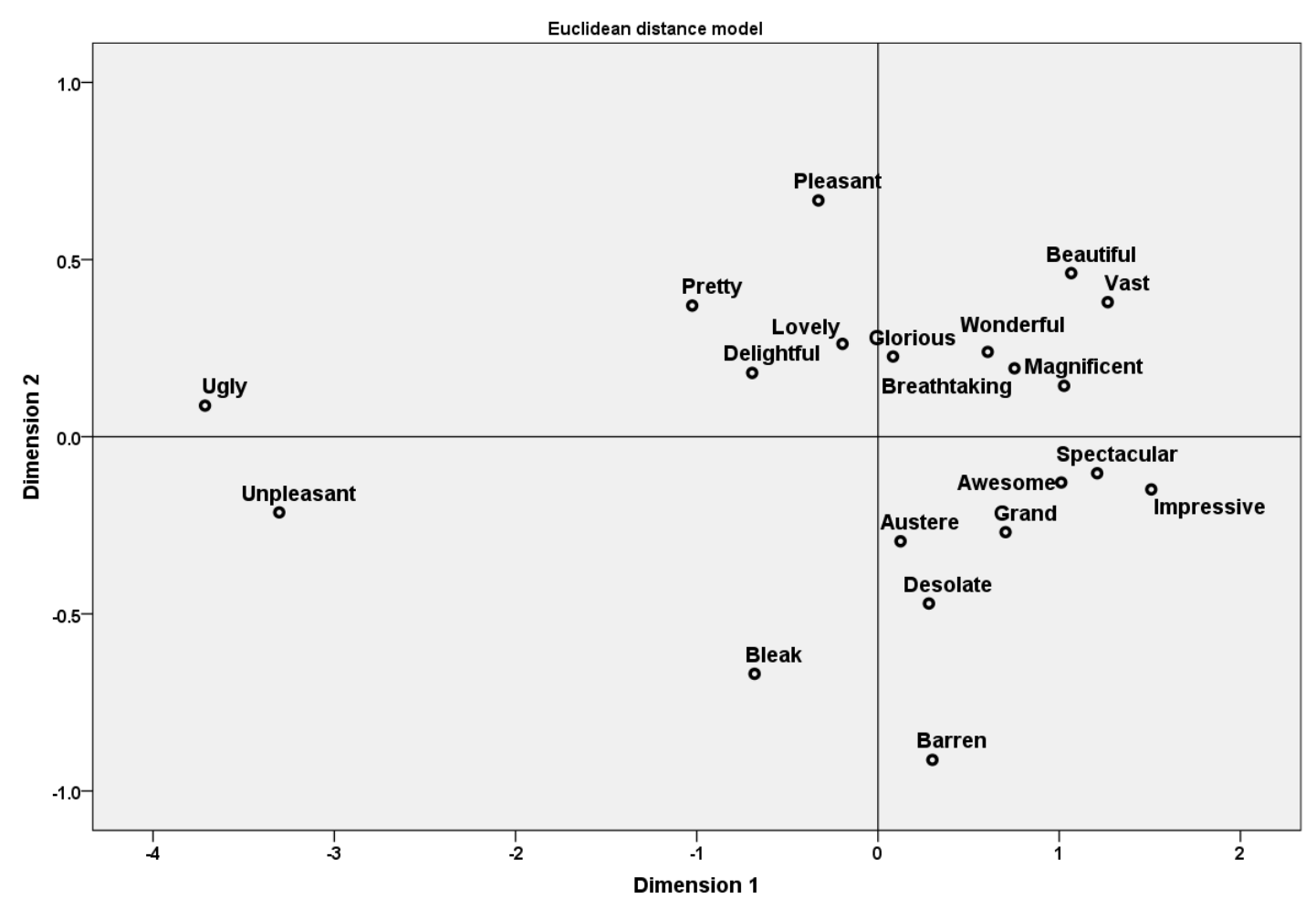

Figure 7.29. Multidimensional scaling of semantic responses to images of nine field huts. 


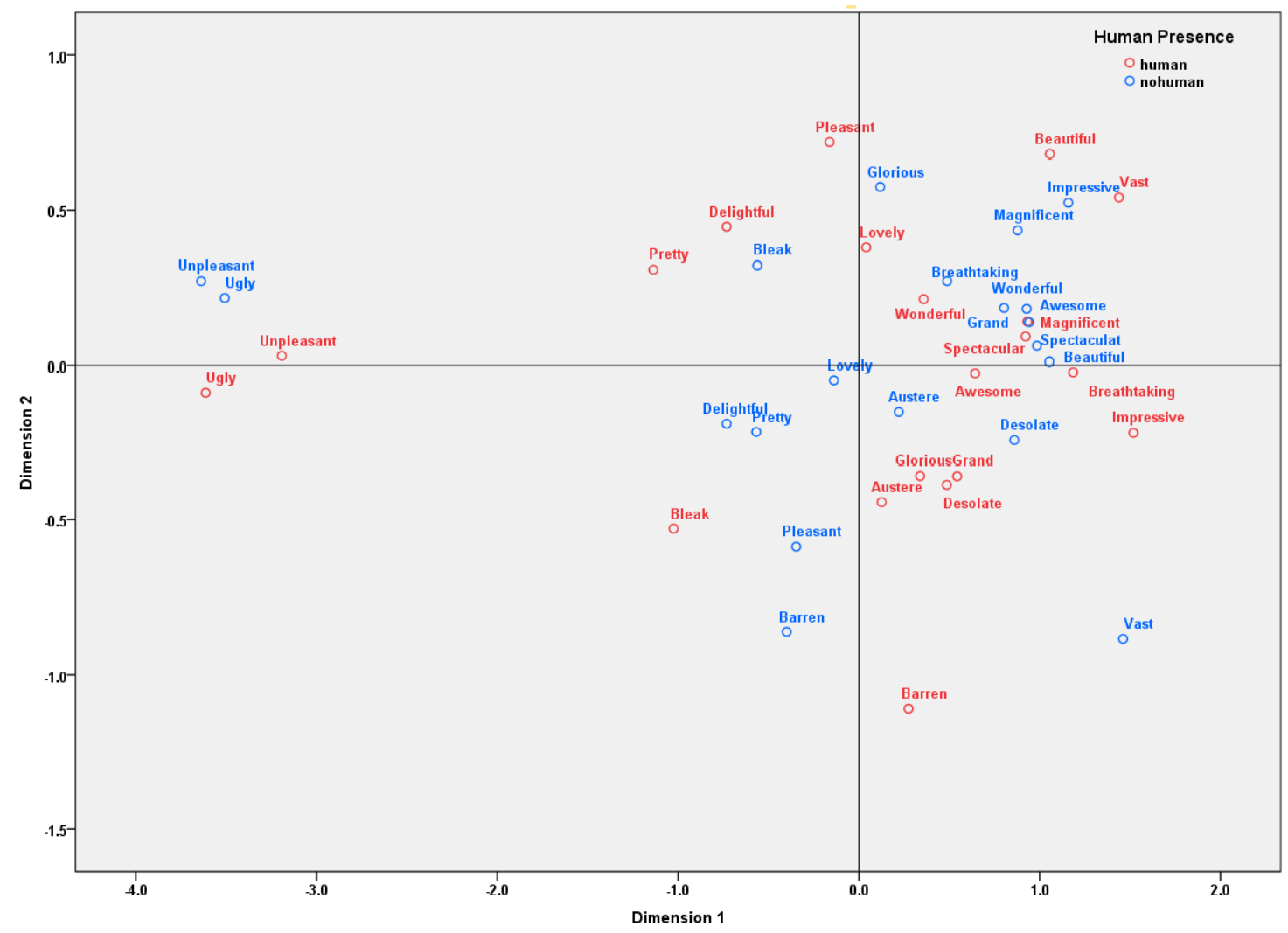

Figure 7.30. Multidimensional scaling of semantic responses to images of five field huts and their manipulated counterparts. Human (red) = images with field huts, no human (blue) = images without field huts.

Third, the effect of human presence is evident. In Figure 7.30, taking the "no human presence" plot (adjectives in blue) as the base condition, it can be seen that the "human presence" plot (in red) is offset, though the direction of offset does not appear to be consistent. "Ugly" and "Unpleasant" have moved "southwards" but are still close together and offset from the rest of the adjectives in Dimension 1. "Pretty", "Pleasant", "Delightful" and "Lovely" have moved "northwards" from negative to positive in Dimension 2 and "Bleak" has moved in the opposite direction. "Austere" and "Desolate" are roughly in the same place though a number of the sublime words such as "Grand" and "Impressive" have also moved into negative space in Dimension 2. The most notable shift has been to "Vast" which has moved from a remote negative position in Dimension 2 to positive, close to "Beautiful". Most of the movement has been in Dimension 2 with little movement in Dimension 2. A similar trend was seen in Figure 7.24. From this one can conclude that Dimension 2 relates either directly or indirectly to human presence and that Dimension 1 is a predominantly aesthetic dimension. 


\subsubsection{Demographic factors in responses to questions of wilderness perception and aesthetic preference}

\subsubsection{Introduction}

There are any number of factors affecting perceptions of wilderness and aesthetic preference. Some basic demographic data was requested as part of all the surveys that were carried out, which included the following in Survey Three:

- Age

- Gender

- Nationality

- Education level achieved

- Whether or not visited Antarctica

- Role in Antarctica: science, science support, operations (e.g. ship or air crew, trade), tourist, tourism industry (e.g. voyage staff, ship's crew) private expedition or other

As a means of exploring the relationships between the demographic factors in aesthetic preference and perceptions of wilderness, a form of classification and regression tree analysis was employed. Classification and regression trees (CART) are a modern statistical technique that have been relatively recently developed for use in ecology (De'ath \& Fabricius 2000). Like with ecological data, the responses of people to landscapes and their aesthetic preference and perceptions of wilderness are complex, possibly unbalanced and relationships between the variables may not be linear (De'ath \& Fabricius 2000).

The final data set comprises 11,281 individual image responses by 435 respondents, noting the possibility of pseudoreplication. The formatting of the input data is shown in Table 7.23. 
Table 7.23. Formatting of input data for classification and regression tree analyses.

\begin{tabular}{|c|c|c|}
\hline Field & \multicolumn{2}{|l|}{ Description } \\
\hline ID & \multicolumn{2}{|l|}{ Unique respondent identifier } \\
\hline Photo No & \multicolumn{2}{|l|}{ Image number in the survey } \\
\hline Age & \multicolumn{2}{|l|}{5 classes: $1-5$} \\
\hline Gender & \multicolumn{2}{|l|}{ Male or female } \\
\hline Group & \multicolumn{2}{|c|}{ Nationality group (See Table 7.24) } \\
\hline Education & \multicolumn{2}{|c|}{ Education level (4 classes) } \\
\hline Visited & \multicolumn{2}{|c|}{2 classes: 'visited 'and 'not visited' } \\
\hline Wilderness & \multicolumn{2}{|c|}{2 classes: 'wilderness' or 'not wilderness' } \\
\hline Raw Aesthetic & \multicolumn{2}{|c|}{7 point scale $(1-7)$} \\
\hline Aesthetic Z score & \multicolumn{2}{|l|}{ Z score } \\
\hline \multirow{9}{*}{$\begin{array}{l}\text { NTI } \\
\text { (No human presence, } \\
\text { Transient, Infrastructure) }\end{array}$} & Human presence type & Coding \\
\hline & None & N0 \\
\hline & Transient - tracks & $\mathrm{T} 1$ \\
\hline & Transient - human figures & $\mathrm{T} 2$ \\
\hline & Transient - small vehicles & $\mathrm{T} 3$ \\
\hline & Transient - large vehicles & $\mathrm{T} 4$ \\
\hline & Minor infrastructure & I1 \\
\hline & Field hut & $\mathrm{I} 2$ \\
\hline & Station/major infrastructure & $\mathrm{I} 3$ \\
\hline \multirow[t]{5}{*}{ Proximity } & Proximity & Coding \\
\hline & $<100 \mathrm{~m}$ & 1 \\
\hline & $>100 \mathrm{~m} \&<1000 \mathrm{~m}$ & 2 \\
\hline & $>1000 \mathrm{~m} \mathrm{\&}<10000 \mathrm{~m}$ & 3 \\
\hline & Not visible & 0 \\
\hline
\end{tabular}

Nationality was grouped into 10 groups as shown in Table 7.24 in order to reduce the numbers of nationalities from 25 to a more manageable number. A number of pragmatic decisions had to be made about groupings, for example, although France is nothing if not European, there were sufficient responses (29) to group French respondents separately. By contrast, there were too few Canadians (10) to retain them separately so they were grouped with the United States. 
Table 7.24. Nationality groupings

\begin{tabular}{|c|c|c|}
\hline Nationality & $\begin{array}{l}\text { Nationality } \\
\text { group }\end{array}$ & $\begin{array}{l}\text { Nationality } \\
\text { group } \\
\text { abbreviation }\end{array}$ \\
\hline Australia & Australia & $A U$ \\
\hline UK & UK & UK \\
\hline France & France & FR \\
\hline Denmark & Europe & EU \\
\hline Germany & Europe & EU \\
\hline Ireland & UK & UK \\
\hline Portugal & Europe & EU \\
\hline Spain & Europe & EU \\
\hline Sweden & Europe & EU \\
\hline Russia & Europe & EU \\
\hline Switzerland & Europe & EU \\
\hline Brazil & Latin America & SA \\
\hline Chile & Latin America & SA \\
\hline Colombia & Latin America & SA \\
\hline Mexico & Latin America & SA \\
\hline Peru & Latin America & SA \\
\hline Argentina & Latin America & SA \\
\hline Japan & Japan & $J P$ \\
\hline US & North America & US \\
\hline Canada & North America & US \\
\hline New Zealand & New Zealand & NZ \\
\hline India & Other & OT \\
\hline South Africa & Other & OT \\
\hline Unknown & Unknown & NK \\
\hline Italy & Europe & EU \\
\hline
\end{tabular}


The "PARTY" algorithm in R (R Development Core Team 2004) was used to analyse and display the relationships between the variables in the demographic data. The algorithm searches for the best point at which to split the results at the first node. The split is made using a greedy algorithm (Hastie et al. 2009) and with a $p$ value greater than 0.05. It then continues searching recursively for the subsequent points at which to split the data with decreasing priority.

\subsubsection{Wilderness}

A classification tree was constructed for perceptions of wilderness (Figure 7.31), which are categorical, i.e. 'yes' or 'no', with a tree depth of 4, i.e. four levels of classification. An unrestricted depth results in a plot that is too large and complex to reproduce on an A4 page. In Figure 7.31, therefore, the first split (Node 1) is made between items in the 'NTI' (No human presence, Transient, Infrastructure) field. Items (Summerson \& Bishop 2011: T1, T2, T3) are split into one group and items [I3, T4] into the other. Thus, the presence of major/complex infrastructure or the presence of heavy transport is the primary distinguishing feature in the data. The split at the second node is again in the NTI field and between [I1, I2 \& T3] and [N0, T1, T2], i.e. between the remaining types of infrastructure and small vehicles on one hand and no human presence, human figures and tracks in the snow on the other. The split at Node 3 is on the basis of proximity between those items of [I1, I2 \& T3] that are less than one kilometre distant and that those that are greater than one kilometre distant. And so the splitting proceeds. The first split on the basis of demographics is at Node 4 between nationality groups [AU, JP, NK, US, UK, SA] and [EU, FR, NZ, OT] at which there are significant differences in perceptions of wilderness between each of these groups. The conclusions to be drawn from this plot are as follows:

1. The types of human presence and their proximity are the most important determinants in perceptions of wilderness.

2. Of the demographic factors, nationality is most important.

3. Landscape type (EDA region) is also important.

4. Other demographic factors such as age, education level, gender and Antarctic experience are relatively unimportant.

\subsubsection{Aesthetic preference}

A regression tree was constructed for aesthetic $\mathrm{Z}$ scores, which are treated as continuous data (Figure 7.32). As with the classification tree plot of wilderness perception, the first split is in the type of human presence with major and minor infrastructure and heavy transport being distinguished from the other types of transient activity, field huts and no human presence. The second split is between the latter types of human presence and no human presence, which is 
then split of the basis of nationality type with all nationality groups on the left and French on the right. The mean aesthetic $\mathrm{Z}$ score for all images without human presence (N0) is slightly less than 0 for the French whereas for all other nationalities it is greater than 0 but with many outliers. The population sizes for these two groups is considerably different but nevertheless the algorithm has determined that the difference is significant $(\mathrm{p}=<0.001)$. The splits between the other types of human presence (I2, T1, T2, etc) and the role of demographic factors can be determined by inspection of the plot.

As with the wilderness classification tree, the regression tree of aesthetic preference shows that human presence and landscape type are the most important factors and that nationality is the most important demographic factor. The other demographic factors, age, etc, are relatively unimportant.

In order to determine the important factors in images without human presence, a second regression tree of aesthetic preference, again as Z scores, was constructed (Figure 7.33). Landscape type is the most important factor, followed by nationality with gender becoming a factor in four landscape types: CCM, IS, CIS \& MIF, males having more nuanced preferences than females. 
Wilderness

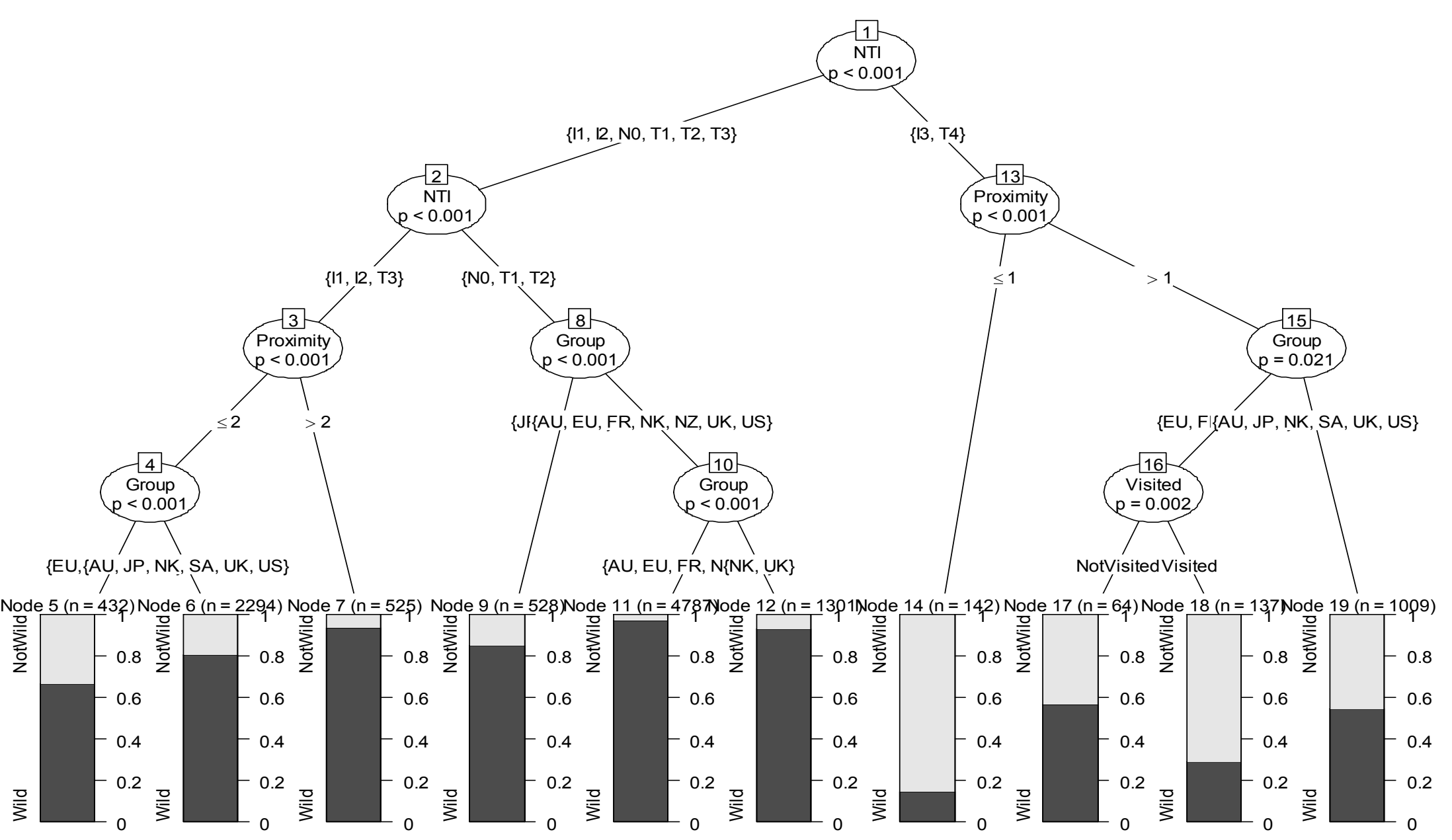

Figure 7.31. Classification tree plot of human presence and demographic factors in perceptions of wilderness. 
Aesthetics Z-Scores NTI model

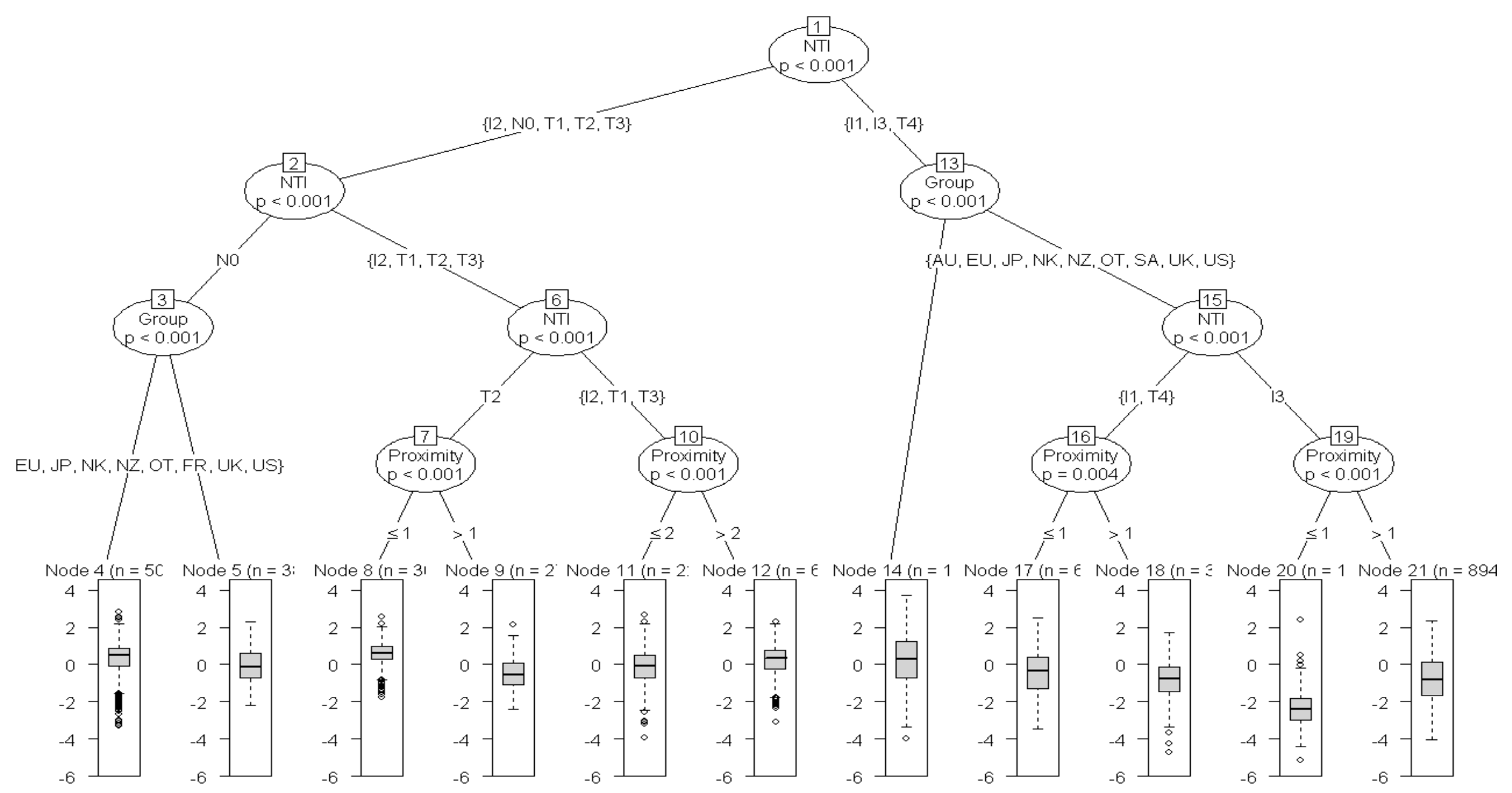

Figure 7.32. Regression tree plot of human presence and demographic factors in aesthetic preference $(\mathrm{Z})$ scores. 


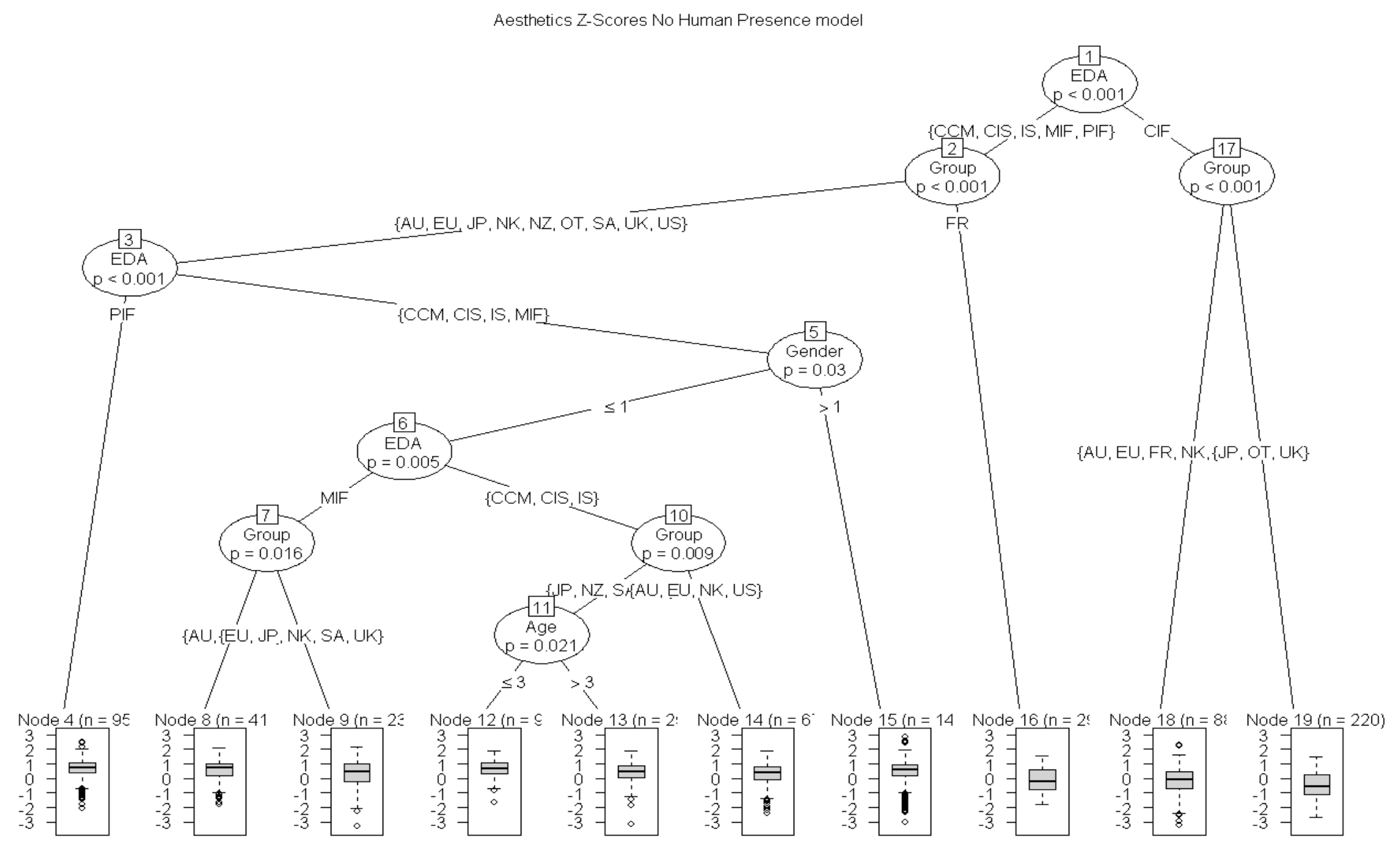

Figure 7.33. Regression tree plot of demographic factors in aesthetic preference (Z) scores for images without human presence. 


\subsubsection{Concluding remarks on demographic factors}

The conclusions to be drawn from this analysis are as follows:

- Human presence and its type, especially the presence of infrastructure, is the most important factor in aesthetic preference;

- When there is human presence the next most important factor is its proximity;

- Of the demographic factors, the most important is nationality.

One of the most frequently asked questions by people commenting on the survey was whether there were any differences in responses between people who have been to Antarctica and those who have not. In order to answer that question, which has implications beyond the curiosity of some individuals, independent samples t-tests were conducted to compare the aesthetic assessments (converted to Z scores) of people who have visited Antarctica, in any capacity, with the assessments of those people who have not visited Antarctica. Table 7.25 lays out the results of three independent samples t-tests comparing first, responses to all images divided into images with and without human presence, second, responses to images of the coastal ice free region, again divided into images with and without human presence and, third, responses to images of the central Antarctic ice sheet, divided into images with and without human presence. As can be seen from Table 7.25, and reinforced by Figure 7.17, in every case there is no significant difference between responses by people who have visited Antarctica and those who have not. This finding is valuable because it demonstrates that Antarctica has universal values, not just to a possibly perceived "elite" who have been fortunate enough to visit the continent. 
Table 7.25. Results of independent samples t-tests of aesthetic preference ratings (as Z scores) of, top, all images combined, centre, images of the coastal ice free region and bottom, images of the central Antarctic ice sheet. Each group of images is divided into images with human presence and those without human presence and comparisons conducted of people who have visited Antarctica and those who have not. $\mathrm{n}=$ sample size; sd = standard deviation; $\mathrm{t}=\mathrm{t}$ statistic; $\mathrm{df}=$ degrees of freedom; $95 \% \mathrm{CI} \mathrm{L} / \mathrm{U}=95 \%$ confidence interval, lower and upper.

\begin{tabular}{|c|c|c|c|c|c|c|c|c|c|c|}
\hline & Visited? & $\mathbf{n}$ & $\begin{array}{l}\text { Mean } \\
\text { Z score }\end{array}$ & sd & $\mathbf{t}$ & df & $\begin{array}{l}\text { Sig. (2 } \\
\text { tailed) }\end{array}$ & $\begin{array}{c}\text { Mean } \\
\text { difference }\end{array}$ & $\begin{array}{c}95 \% \text { CI } \\
\mathrm{L}\end{array}$ & $\begin{array}{c}95 \% \text { CI } \\
U\end{array}$ \\
\hline & \multicolumn{10}{|c|}{ All images combined } \\
\hline \multirow{2}{*}{$\begin{array}{l}\text { Human } \\
\text { presence }\end{array}$} & Yes & 4018 & 0.297 & 1.060 & \multirow{2}{*}{0.270} & \multirow{2}{*}{5609} & \multirow{2}{*}{0.787} & \multirow{2}{*}{0.008} & \multirow{2}{*}{-0.053} & \multirow{2}{*}{0.070} \\
\hline & No & 1593 & 0.288 & 1.054 & & & & & & \\
\hline \multirow{3}{*}{$\begin{array}{l}\text { No human } \\
\text { presence }\end{array}$} & Yes & 4004 & -0.298 & 0.790 & \multirow{2}{*}{-0.358} & \multirow{2}{*}{5589} & \multirow{2}{*}{0.721} & \multirow{3}{*}{-0.008} & \multirow{3}{*}{-0.055} & \multirow{2}{*}{0.038} \\
\hline & No & 1587 & -0.289 & 0.802 & & & & & & \\
\hline & \multicolumn{8}{|c|}{ Images of coastal ice free areas } & & \\
\hline \multirow{4}{*}{$\begin{array}{c}\text { Human } \\
\text { presence } \\
\text { No human } \\
\text { presence }\end{array}$} & $\begin{array}{l}\text { Yes } \\
\text { No }\end{array}$ & $\begin{array}{l}987 \\
393\end{array}$ & $\begin{array}{l}0.924 \\
0.865\end{array}$ & $\begin{array}{l}1.171 \\
1.156\end{array}$ & 0.847 & 1378 & 0.397 & 0.059 & -0.078 & 0.195 \\
\hline & Yes & 893 & 0.248 & 0.800 & \multirow{2}{*}{-0.667} & \multirow{2}{*}{1251} & \multirow{2}{*}{0.505} & \multirow{2}{*}{-0.034} & \multirow{2}{*}{-0.133} & \multirow{2}{*}{0.066} \\
\hline & No & 360 & 0.281 & 0.838 & & & & & & \\
\hline & \multicolumn{10}{|c|}{ Images of central Antarctic ice sheet } \\
\hline \multirow{2}{*}{$\begin{array}{l}\text { Human } \\
\text { presence }\end{array}$} & Yes & 683 & 0.352 & 1.073 & \multirow{2}{*}{0.012} & \multirow{2}{*}{953} & \multirow{2}{*}{0.991} & \multirow{2}{*}{0.001} & \multirow{2}{*}{-0.153} & 0.155 \\
\hline & No & 272 & 0.35 & 1.143 & & & & & & \\
\hline No human & Yes & 285 & -0.433 & 0.724 & & & & & & \\
\hline presence & No & 109 & -0.354 & 0.785 & -0.948 & 392 & 0.344 & -0.079 & -0.243 & 0.085 \\
\hline
\end{tabular}




\subsection{Conclusions on results}

This chapter reports on the results from five surveys, but with most emphasis on the Internet survey, which received by far the greatest number of responses and therefore has yielded the greatest amount of data on perceptions of wilderness, aesthetic preference and semantic assessments of landscapes. The collection of demographic data has also yielded a number of important insights. There is a re-assuring consistency in the results throughout the sequence of surveys which provides confidence that even if though they might not be universal attitudes to these values, they are at least widely held.

The results will be discussed in detail in the next chapter but some initial conclusions are as follows:

1. People prefer natural landscapes. The results in all the statistical tests show that infrastructure detracts from wilderness and also lowers aesthetic preference.

2. Transient human activity may result in a loss of wilderness value and a reduction in aesthetic preference depending on the type of activity. Ships, planes and heavy vehicles have the greatest effect whereas humans on foot have a negligible effect.

3. The manipulated pairs component of the Internet survey provided the most detail on impacts by human activities.

4. The semantic assessments provided some insights into how people respond to Antarctic landscapes. As Summerson and Bishop (2011) concluded, the results of the survey reveal a more complex picture of semantic response to Antarctic landscapes than a simple dichotomy into beautiful or sublime. The separation of 'Vast' from the other adjectives, for example, suggests that it is an important feature of Antarctic landscapes. This has been commented on by other authors, e.g. Brown et al. (1906).

5. Demographic factors seem to be less important than other factors, such as landscape type and the type of and proximity to human presence in how people respond to Antarctic landscapes. Of the demographic factors, nationality seems to be the most important whereas, importantly, whether or not someone has visited Antarctica has little effect on responses. 


\section{Chapter 8. Spatial modelling and mapping of areas of wilderness and aesthetic value}

\subsection{Introduction}

In Chapter 5 I made the case that all Antarctica should be considered to be wilderness except for those areas that have been degraded by human activity, specifically the erection of infrastructure as opposed to some transitory activity. The results of Surveys 2 and 3 (Chapter 7), where responses to images containing infrastructure demonstrate that infrastructure results in loss of wilderness value, show that this approach is widely supported. My aim, therefore, is to map the human footprint and that all else will, by default, be wilderness.

\subsection{Theoretical considerations in spatial modelling of the human footprint}

Two levels of footprint are proposed: the physical footprint of the station, potentially including any satellite infrastructure, and the visibility footprint that extends the physical footprint to the limit of visibility. The footprint of sounds generated by human activity will also be investigated but, a posteriori, visibility extends further than audibility. True wilderness begins at the outer limit of a combination of the station visibility footprint and that of satellite infrastructure.

\subsubsection{The physical footprint of the station}

The term "footprint" has been used in the environmental literature as a metaphor for the spatial extent and intensity of human use of the natural environment. "Footprint" can be applied to physical presence (GERG 2003), the spread of emissions (Walton \& Shears 1994) and, more broadly, the totality of human "load" on the environment (Wackernagel \& Rees 1996). Although the concept of footprint has been widely discussed in Antarctic governance forums, such as the CEP (H. Keys, pers. comm. CEP 2010), there is as yet no agreement on how the physical footprint should be defined. Jabour (2009) notes that there have been attempts to measure the area occupied by stations by different NAPs, but without a common system of measurement the results were not consistent. GERG (2003) used aerial photography to measure the area of physical disturbance at McMurdo Station but this technique may not be feasible for all NAPs.

It is therefore proposed that the physical footprint of a station be defined as the area that is occupied by the buildings, structures, roads and other infrastructure associated with the operation of the station and is physically interconnected by human artefact, such as by road or 
track, cable or pipe. This distinguishes station infrastructure from satellite infrastructure such as field huts which may be reached along a marked route but where the route itself has not been modified by human action.

The three Australian Antarctic stations, Mawson, Davis and Casey, are used as the case studies to demonstrate the concepts involved in determining the shape and size of the human footprint in Antarctica. These stations are a similar size, both in terms of station layout and population but each has its own particular characteristics which are determined by its location and its history. All three stations were re-built in the 1980s with buildings having the same function and similarly sized and coloured. The peak population during the summer research season at Davis and Casey is about 70 and at Mawson it is about 60. Each station has a cluster of field huts nearby and is a base for scientific operations, some of which may be $>100 \mathrm{~km}$ from the station.

It is not certain how typical these stations are of Antarctic stations in general as there is considerable variety in the layout and extent of stations around Antarctica ${ }^{30}$. I have visited 10 Antarctic stations and my estimation is that the Australian stations are larger and have more satellite infrastructure, such as field huts, than most Antarctic stations, with the obvious exception of McMurdo. If a station has satellite field huts, as is the case at all the Australian stations, or other infrastructure such as a fixed-wing aircraft landing field, such as at McMurdo, (US), Mario Zucchelli (Italy) and Casey (Australia), then the footprint will be extended beyond the physical footprint of the station.

The demarcation of the station area - the physical footprint of the station - may be by one of the following methods:

a) Exact mapping of individual structures, equipment, paths, tracks, etc.

b) A minimum bounding rectangle or ellipse around the outer limit of all infrastructure that is physically inter-connected.

c) The perimeter of all the structures of the station formed into a polygon ("convex hull polygon”).

\footnotetext{
${ }^{30}$ Most national Antarctic program websites include photographs of their stations. NAP websites are accessible through the Parties page on the Antarctic Treat Secretariat website:

http://www.ats.aq/devAS/ats_parties.aspx?lang=e
} 
d) An existing boundary. Each Australian station, for example, has "station limits" within which solo travel is permitted but beyond which requires permission from the Station Leader.

It should be noted that mapped infrastructure is unlikely to include all evidence of human occupation of an area; there will inevitably be debris, posts, markers, abandoned equipment and other "stuff" that has not been mapped.

As can be seen in Figure 8.1, the station limits at Casey do not encompass all infrastructure, so the station limits would not make a useful boundary. The "recreational limits" at Casey would not be suitable as they extend far beyond the area where infrastructure has been established but do not, for obvious reasons, extend into ASPA 135 where there is a set of radio masts. Exact mapping of all structures, etc requires either a detailed ground survey or high resolution aerial photography. This is an expensive method and given the large quantities of equipment, stores, etc associated with an Antarctic station and the variable nature of the activities associated with it, such mapping of the footprint would quickly go out of date. The three other methods: minimum bounding rectangle, minimum bounding ellipse and convex hull polygon can all be generated automatically in a GIS. (ArcGIS includes a series of functions to draw minimum bounding geometries). In ArcGIS features have to be in the same data type (point, line or polygon) which can be inconvenient if there is a mixture of different data types. For example, in Figure 8.1, two convex hull polygons have been drawn, the first, around Casey Station and the wharf area is based on the roads polygon, while the second, larger polygon is drawn around the masts, which are points. The simplest solution is a hand drawn least bounding rectangle, as shown in Figure 8.1, as this does not require the data in the map to be in any format. For this reason, the least bounding rectangle is considered to be the best representation of a station's footprint. 


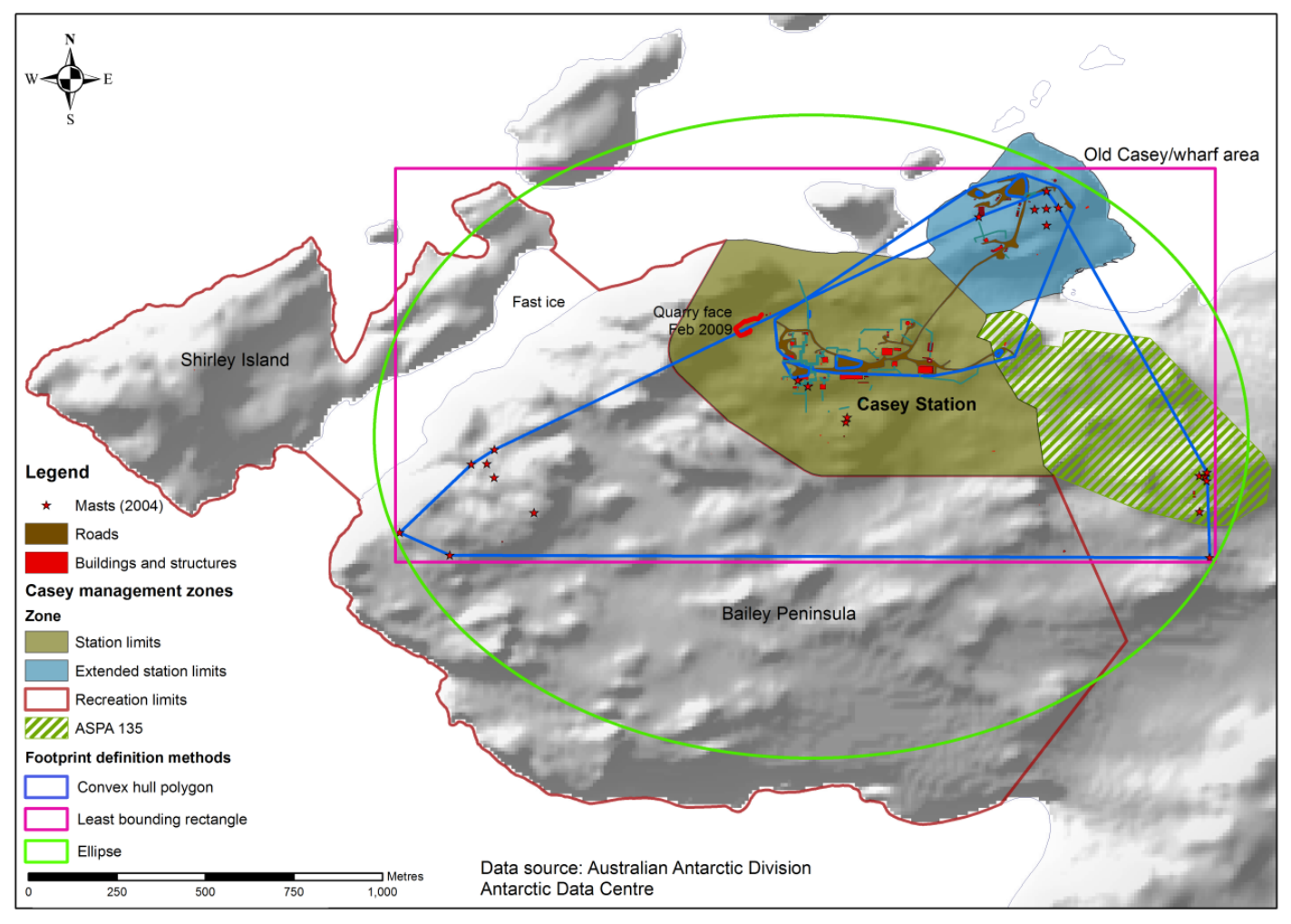

Figure 8.1. Five options defining the footprint of a station: minimum bounding ellipse, minimum bounding rectangle, convex hull polygon, station limits and recreational limits. (Based on a map of Casey Station (AUS)).

\subsubsection{Visibility footprint of the station}

Every station has an area surrounding it where the influence of the station can be sensed. This includes the area from which the station can be seen and activities within it heard. Station activities create a level of noise that can be heard from some distance, such as the reversing alarms on vehicles and the sound of diesel generators. With the exception of exhaust emissions from generators and vehicles, most bio-chemical emissions from stations are in the form of sewage and other liquid wastes ("grey water"). At the $75 \%$ of all stations and permanent facilities that are situated on the coast, these liquids are released into the sea, after varying levels of treatment (COMNAP 2012). In the context of mapping areas of non-wilderness in Antarctica, non-apparent forms of footprint such as emissions of chemical compounds from diesel generators, are not included because they cannot be detected by human sense organs. The term "visibility footprint" is proposed for the area from which infrastructure within the station footprint is visible. This term maintains a semantic link with the physical footprint of the station itself and describes the concept accurately. 
It is a relatively straightforward matter to map the visibility of station infrastructure using the heights of key infrastructure, a digital elevation model and geographical information system software - see below.

\subsubsection{Visibility footprint of satellite infrastructure and other complications}

Casey Station and its environs provide a useful case study for examining the issues related to satellite infrastructure around a station. In the area surrounding Casey Station there are six field huts, though the exact location and number can vary according to operational necessity. Two kilometres north-east of Casey Station is the abandoned Wilkes Station. Wilkes was built by the US Navy in 1957 during "Operation Deepfreeze", the US logistical support program for their participation in the International Geophysical Year (Dufek 1960: 98) and was occupied by them until 1959 when it was handed over to Australia (Clark \& Wishart 1993). It is, however, a popular site for recreational visits from Casey but opinions about it range from “...it's a magic place" (Clark \& Wishart 1993: 84) to "eyesore" (anonymous questionnaire response, 2000). There are a number of buildings still standing, including a hut that is used by expeditioners from Casey as a field hut, a distinctive radio theodolite dome and some radio masts in various states of disrepair. As a consequence, Wilkes has its own visibility footprint.

There are marked routes from Casey to each of the field huts, to an aircraft ski-way $10 \mathrm{~km}$ due east of the station and to Wilkins Airfield $62 \mathrm{~km}$ to the south-east. There is also a marked route to a glaciological drilling site and other glaciological research infrastructure at Law Dome $115 \mathrm{~km}$ to the south-east and at $1250 \mathrm{~m}$ altitude. Wilkins Airfield has been constructed for use by jet aircraft flying direct to and from Australia, whereas the ski-way is designed for use by ski-equipped aircraft flying within Antarctica. There are designated approach and departure routes to and from Wilkins Airfield, all of which create a footprint around the airfield. The station, the old station at Wilkes, the field huts, the airfields and flight paths, marked routes and infrastructure at Law Dome all combine to create a core footprint at the station and a large and complex area of human activity (Figure 8.2). 


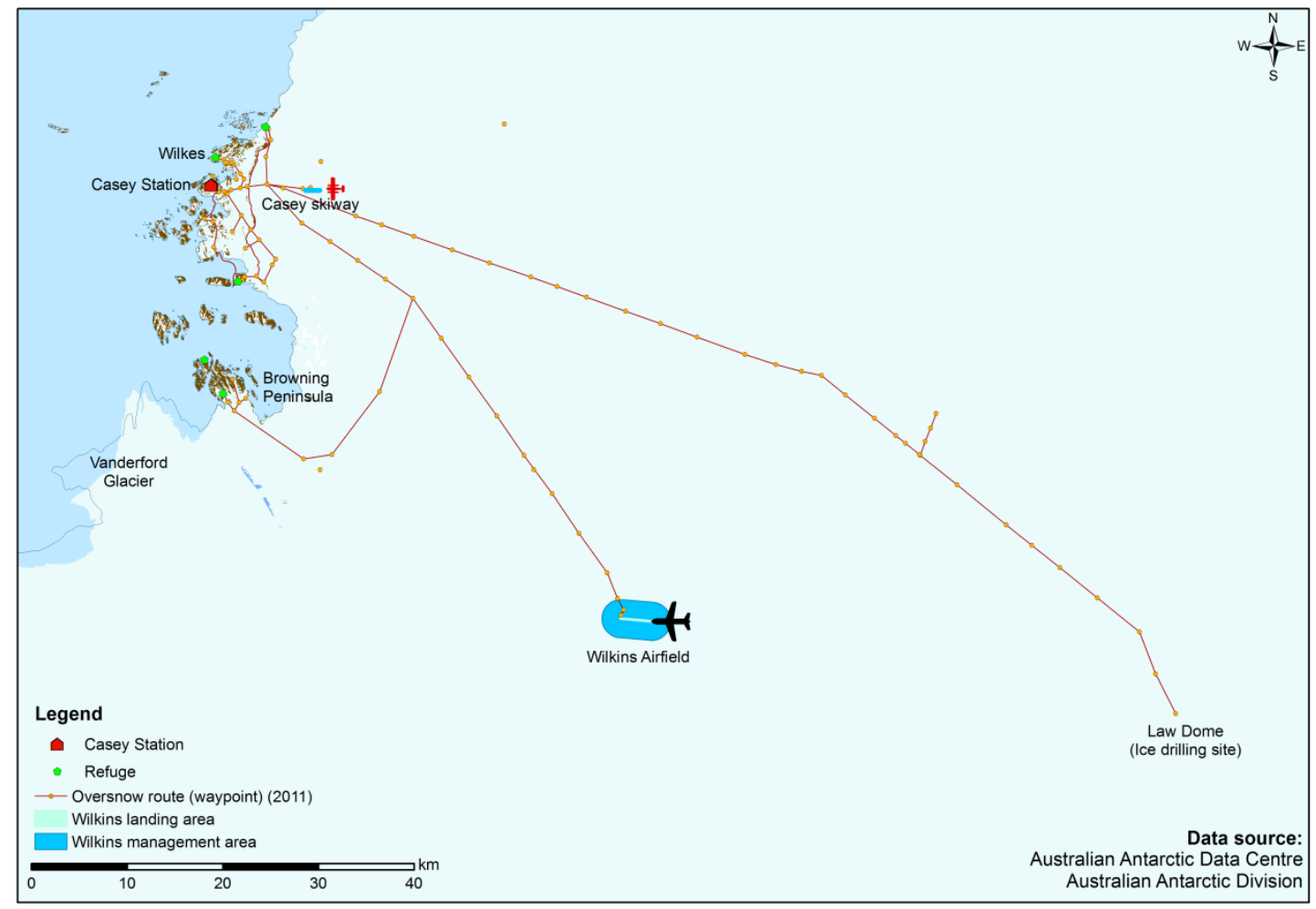

Figure 8.2. Satellite infrastructure around Casey Station (AUS).

As with mapping the visibility footprint of the station, the visibility footprint of the satellite infrastructure can also be mapped using visibility modelling techniques in a geographical information system. There are, however, a number of issues to be considered:

1. Satellite infrastructure tends to be lower in elevation and where field huts are fitted with radio antennae, these are likely to be on a much shorter mast than those in use at the stations. It is important, therefore, to have accurate data on the dimensions, especially the height, of all satellite infrastructure.

2. Many oversnow routes are marked at regular intervals and/or at waypoints, the size and type of marker should be taken into account and included in the visibility modelling.

3. The visibility of airfield runways will depend on how they are marked.

4. Airfield approach and departure routes do not have a permanent impact on wilderness. Wilderness values are only lost over the approach and departure routes when aircraft are expected and are visible or audible. See below for more detail on this question.

There may be some areas within the visibility footprints that have wilderness-like characteristics; a depression in the topography may mean that structures are out of sight; with his or her back turned to the infrastructure the landscape may appear to be like wilderness and at 
the outer fringes of the visibility footprint whatever structures are visible will seem distant and insignificant.

The boundary of the visibility footprint is therefore likely to be indistinct. The conservative approach to address this would be to use a maximum bounding polygon line that encompasses all possible glimpses of infrastructure. Ultimately, however, the decision as to how to address will be the responsibility of environmental managers.

\subsubsection{Beyond the visibility footprint}

If it is accepted that all of Antarctica is wilderness except for those areas under human influence then beyond the visibility and sound footprints lies the Antarctic wilderness. That is not to say that humans will not, nor should not, explore those areas, nor that transient human presence means that that area is no longer wilderness. As noted in the results of the surveys (Chapter 7), it is the construction of infrastructure that degrades wilderness, not transient human activity.

There is an important caveat. It is important to re-iterate that the focus of this section is the presence or absence of a condition described as wilderness, which I have defined as those areas from which human presence is not visible. The loss of wilderness does not necessarily imply loss of other features of the Antarctic environment. The visibility of human structures, especially at the limit of their visibility may have little or no impact on fauna. Loss of wilderness does, however, signify human presence and it is human activity, especially the construction and operation of infrastructure, that is often associated with an impact on the environment.

\subsection{Impacts of infrastructure on perceptions of wilderness}

It can be seen from the results (Chapter 7) that areas within the physical footprint of the station were not considered as wilderness by the majority of respondents. No very distant images of stations or infrastructure were used in the survey because of uncertainty about how many respondents had seen the object and made a rating and how many had not noticed it. These results give confidence to the proposition that the limit of influence of a station is the limit of visibility.

Table 8.1 shows the percentages of assessments wilderness in images of stations. Image 213 was taken within the physical footprint of Davis Station (AUS) and it appears that images 114 (McMurdo (US)), 302 and 303 (both Amundsen-Scott (US)) were also taken within the physical footprints of the station. Although images 302 and 303 were taken of the same station and at roughly the same distance, the low angle the latter was taken from making only the tops of some buildings and the masts visible is probably the reason for the higher percentage perception 
of wilderness. Images 313 (Davis) and 210 (Mawson) were taken outside their physical footprints. No very distant images of stations or infrastructure were used in the survey because of uncertainty about how many respondents had seen the object and made a rating and how many had not noticed it. These results give confidence to the proposition that the limit of influence of a station is the limit of visibility.

Table 8.1. Percentages of assessments of wilderness in images of six stations from Survey 3.

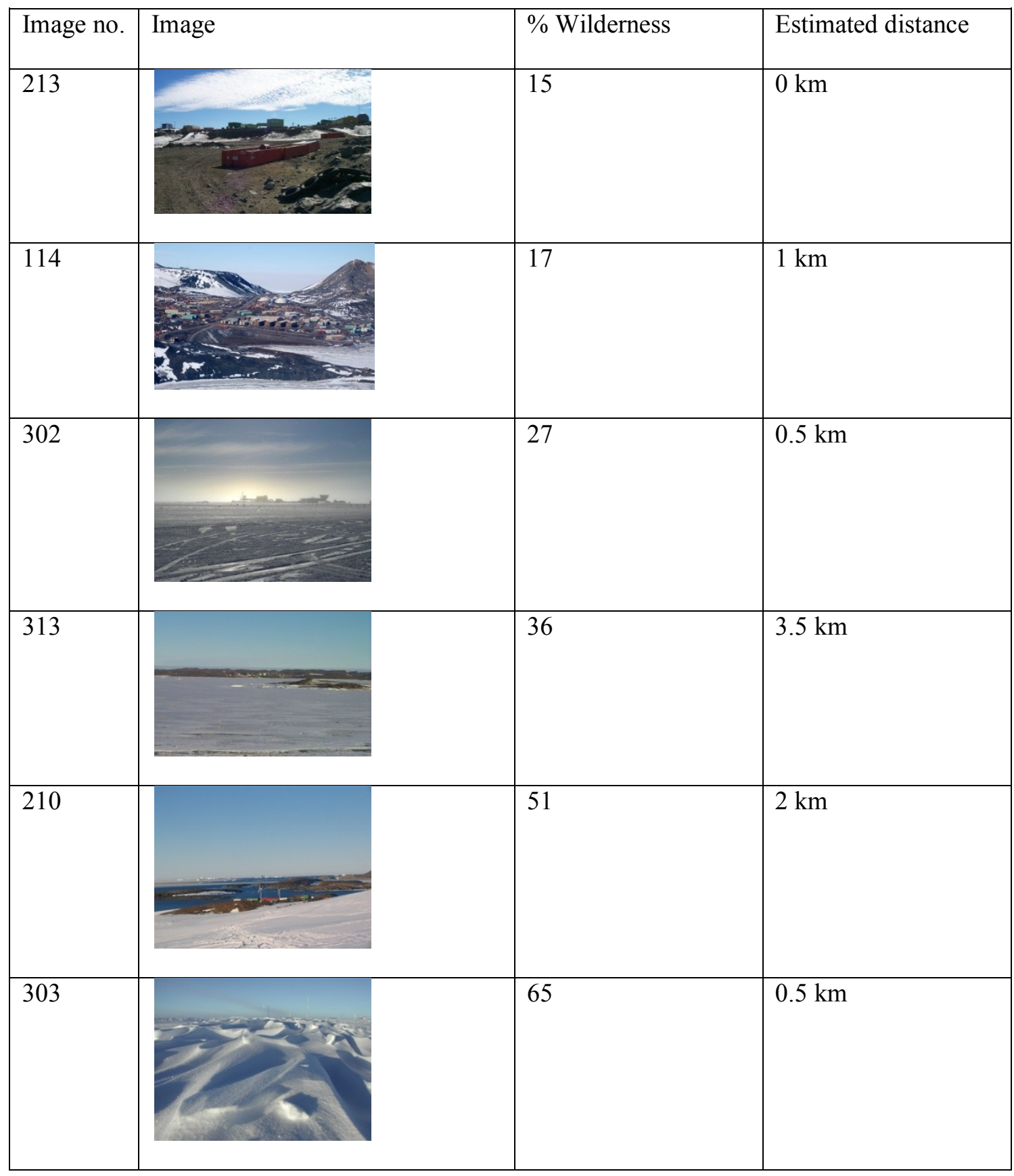




\subsection{Modelling and mapping infrastructure visibility}

Mapping areas from which human infrastructure is visible is a feasible and simple operation which requires two datasets (see below), suitable GIS software and someone trained in the use of GIS.

Three case studies were carried out, in the Windmill Islands (the area around Casey Station $\left(66^{\circ}\right.$ $\left.17^{\prime} \mathrm{S}, 110^{\circ} 31^{\prime} \mathrm{E}\right)$ ), in the Vestfold Hills (the area around Davis Station (68 $\left.35^{\circ} \mathrm{S}, 77^{\circ} 58^{\prime} \mathrm{E}\right)$ ) and in the area around Mawson Station (67 $\left.36^{\prime} \mathrm{S} 62^{\circ} 52^{\prime} \mathrm{E}\right)$, including the Framnes Mountains.

\subsubsection{Data collection}

Two types of data are required to model infrastructure visibility:

1. Location and height of infrastructure; and

2. Elevation data from which to construct a digital elevation model

\subsubsection{Infrastructure data}

Data were provided by the Australian Antarctic Division. The Antarctic Division maintains data on infrastructure for a wide range of purposes, for example:

- Asset maintenance (age and status)

- Flight safety (heights and locations of radio masts and aerials)

- Communications (heights and locations of radio masts and aerials and satellite communications dome)

- Power generation (wind generators at Casey and Mawson Stations)

- Science (e.g. ionosondes ${ }^{31}$ )

- Field party safety (field huts and route markers)

- Heritage (abandoned stations)

As a consequence some data sets are better maintained and more up-to-date than others. The heights of radio masts in the vicinity of stations, for example, have been accurately determined whereas the heights of buildings at Wilkes have not. In the absence of measured heights, the heights of some structures were estimated. Infrastructure data was obtained from the Australian Antarctic Division Antarctic Data Centre.

${ }^{31}$ For obtaining data on the ionosphere 


\subsubsection{Data processing}

Data on human infrastructure were combined into a single data set with a common height attribute (of the top of the feature). Buildings were reduced to a point for each corner and only radio masts were used (Figure 8.3); aerials or antennae slung between them were ignored as being too small in width to be visible at any distance. Every feature that could be identified had a height value ("relative level") ascribed to it, either calculated or estimated.

\subsubsection{Elevation data}

Elevation data were obtained from the Antarctic Division Antarctic Data Centre as contours and spot heights. These were originally obtained from aerial photography flown during the 1990s. The terrain elevation data (contours and spot heights) were used to create a digital elevation model (DEM) - a gridded three-dimensional representation of the surface of the earth. This was done using the TOPOGRID routine in ESRI ${ }^{\mathrm{TM}}$ Arc/INFO. A number of iterations were necessary in order to determine the optimum output from changing the settings and tolerances on the input datasets and in the routine itself. The final digital elevation model of the Windmill Islands (environs of Casey Station) has a spatial resolution (posting) of ten metres.

\subsubsection{Analyses}

In order to determine the area where human infrastructure is visible, the VISIBILITY routine in ESRI $^{\mathrm{TM}}$ ArcInfo GIS was used. This routine uses the heights of features, in this case, the heights of human infrastructure, in conjunction with a DEM to determine the visibility of features.

There are two key settings: the height of the feature (the target) and the height of the observer. The heights of the features were set as an attribute in the infrastructure data set and the height of the observer was set at $1.7 \mathrm{~m}$.

\subsubsection{Results of visibility modelling}

The results from the Windmill Islands are at Figure 8.4, from the Vestfold Hills at Figure 8.5 and from Mawson at Figure 8.7. The output from the VISIBILITY routine is coded so that it is possible to identify how many features contribute to the visibility grid. Analysis of the output shows that the type of feature that contributes most to the visibility of the station itself is, not surprisingly, the radio masts. Radio masts are typically in the order of $20-40 \mathrm{~m}$ high and are typically set out in two arrays, one for transmission and the other for reception. Some scientific studies of the upper atmosphere also require masts (Figure 8.3). At Casey and Mawson wind generators have been installed; the two wind generator towers at Mawson are $34 \mathrm{~m}$ high with a $26 \mathrm{~m}$ diameter blade rotor, i.e. the blades are $13 \mathrm{~m}$ in length (Figure 8.6) (AAD 2000). At Davis a LIDAR (Light Detection and Ranging) instrument has been installed (Figure 4.5 (right)). It is 
a middle atmosphere sounding laser that emits a vertical beam, $50 \mathrm{~mm}$ wide, of green light, which, when operational, is said to be generally only visible from up to approximately $1 \mathrm{~km}$ from the LIDAR building. It has been reported as having been seen from as far away as Watts Hut, which is $11 \mathrm{~km}$ from Davis Station, but only by someone who knew where to look and under optimum conditions (A. Klekociuk 2010 pers. comm.)

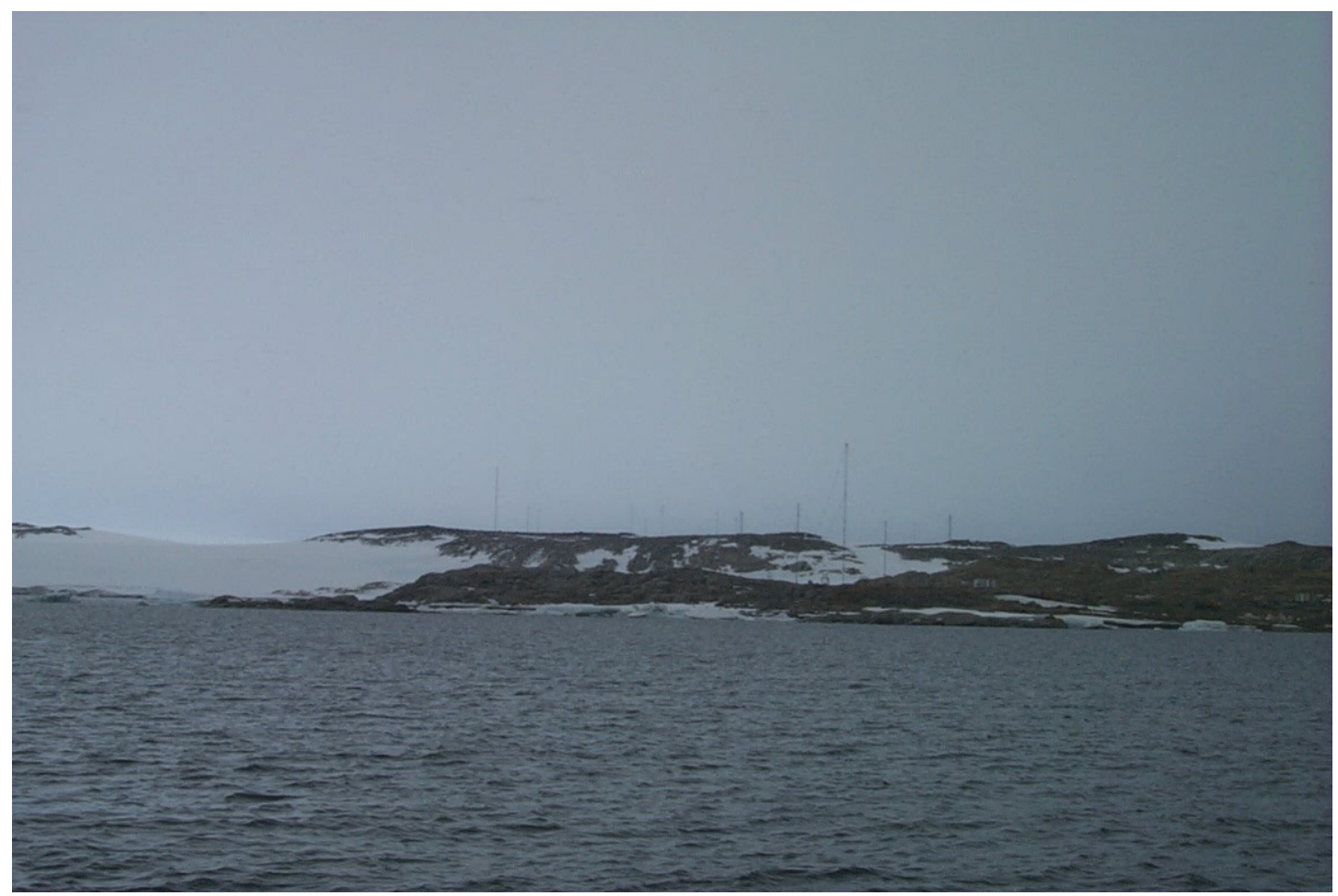

Figure 8.3. Masts at Casey Station (2000). The masts in the foreground are part of an ionosonde array. There are other masts out of the picture. (Photo: Rupert Summerson) 

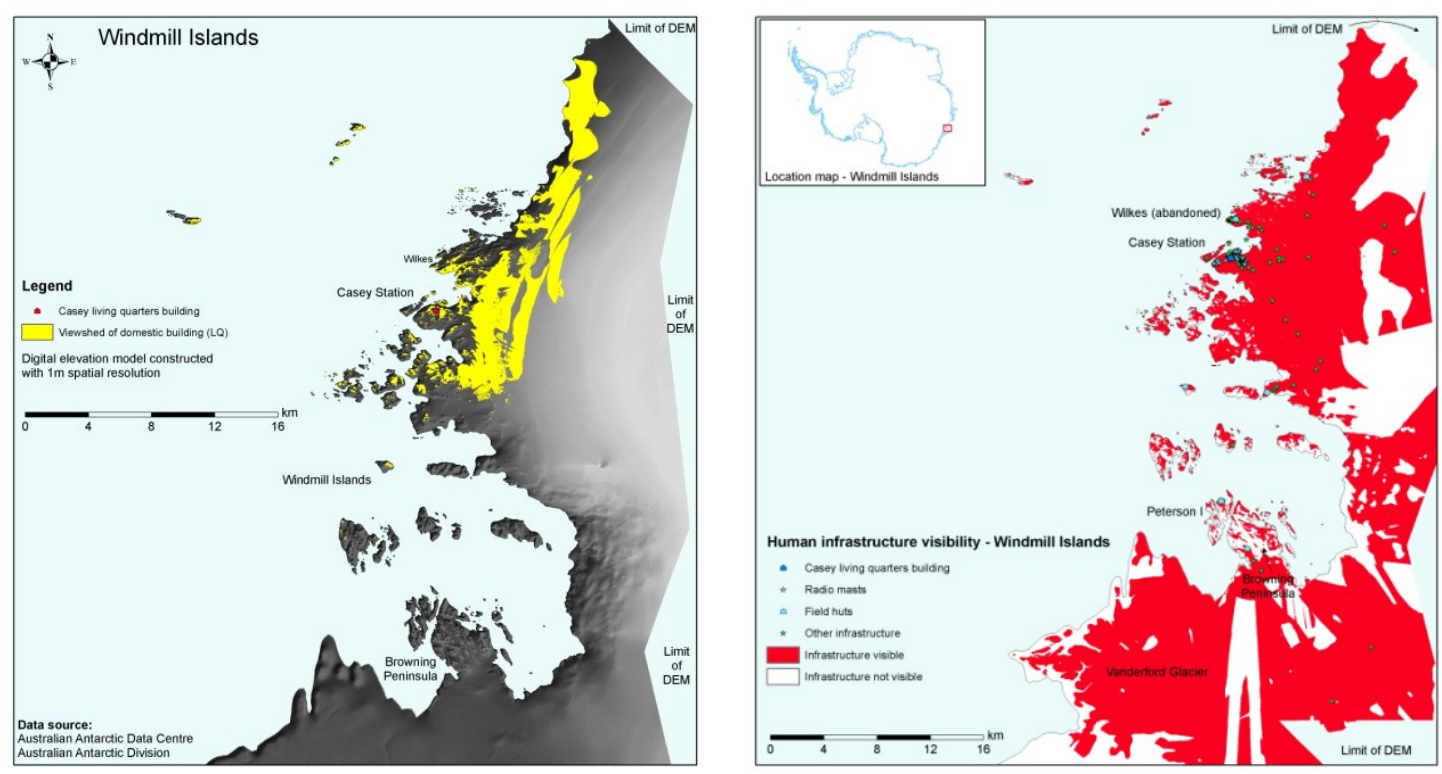

Figure 8.4. Output of the visibility model of station infrastructure (left) and (right) Casey Station and all satellite infrastructure in the Windmill Islands.

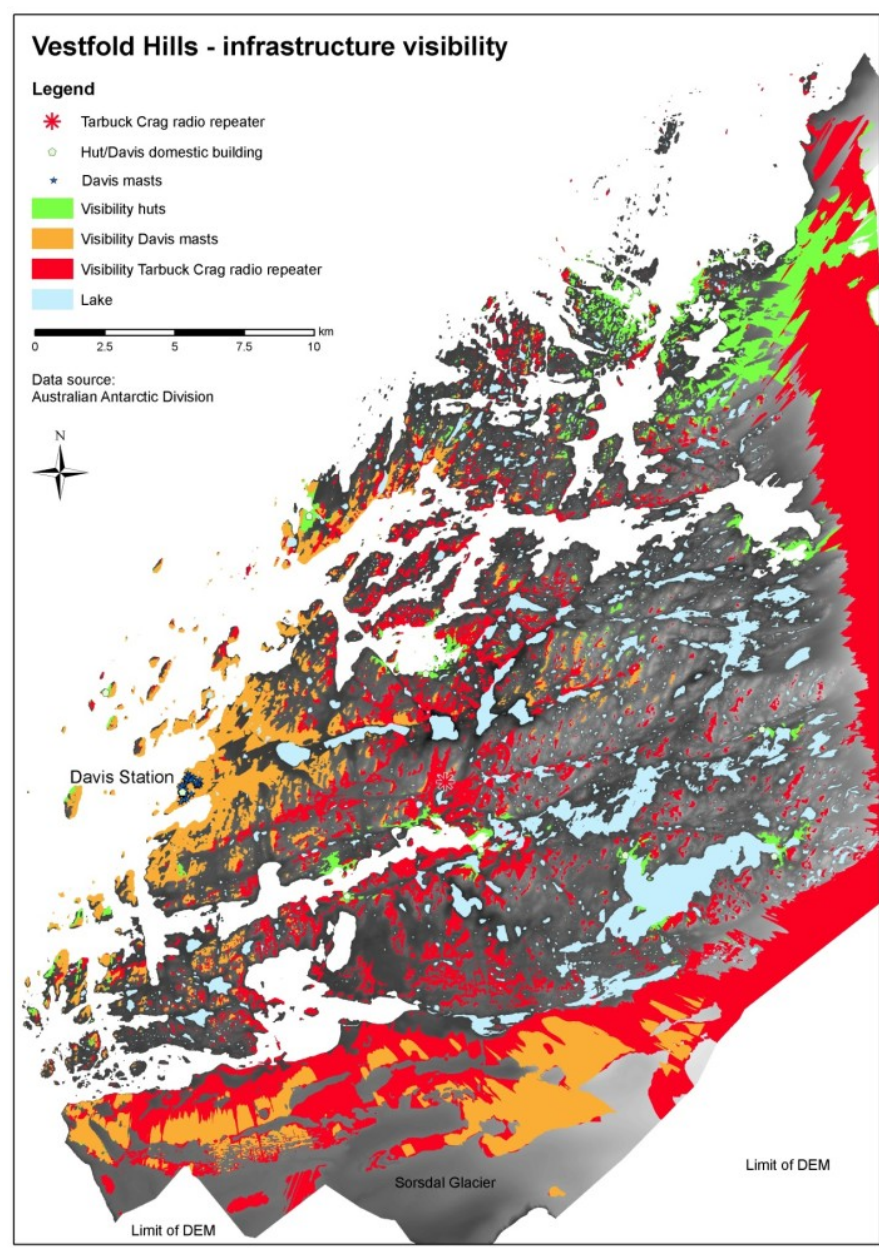

Figure 8.5 . Visibility model of Davis Station, i.e. radio masts at Davis and satellite infrastructure in the Vestfold Hills. 


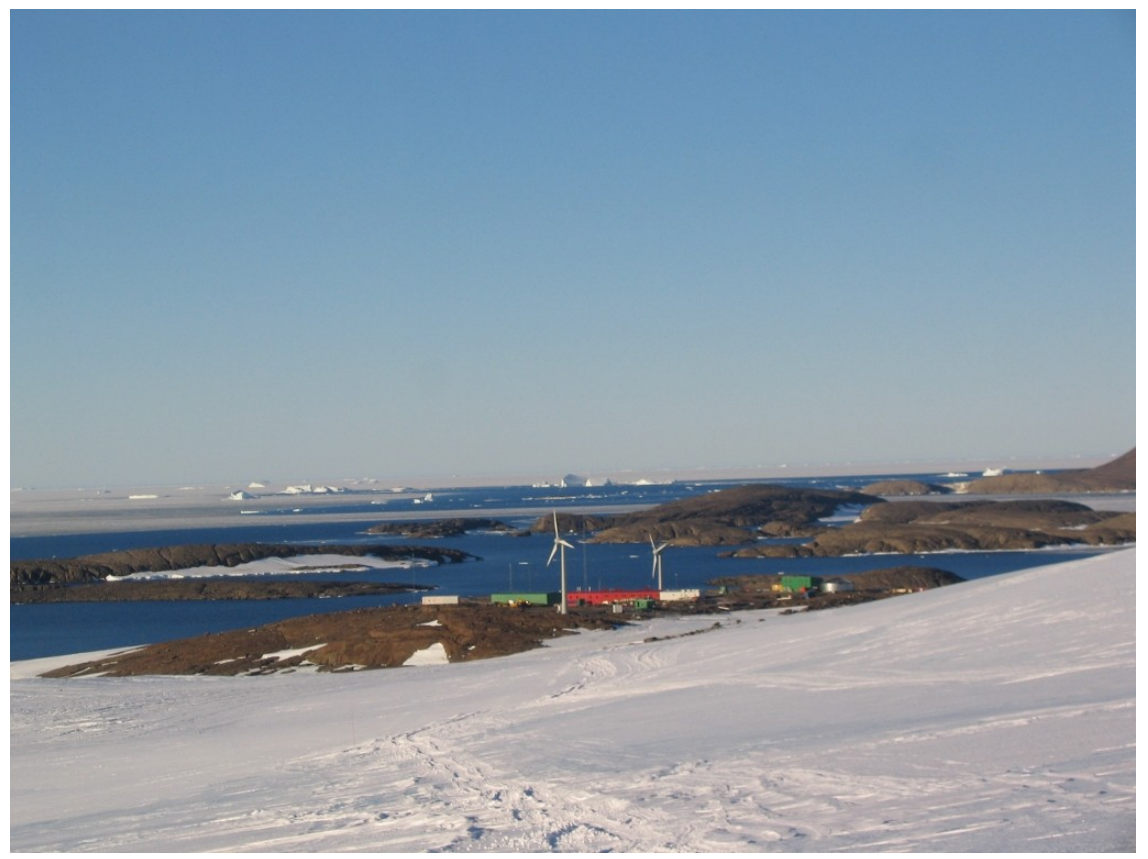

Figure 8.6. Wind turbines at Mawson Station. Photo taken at a range of about 2km. (Photo: Frederique Olivier)

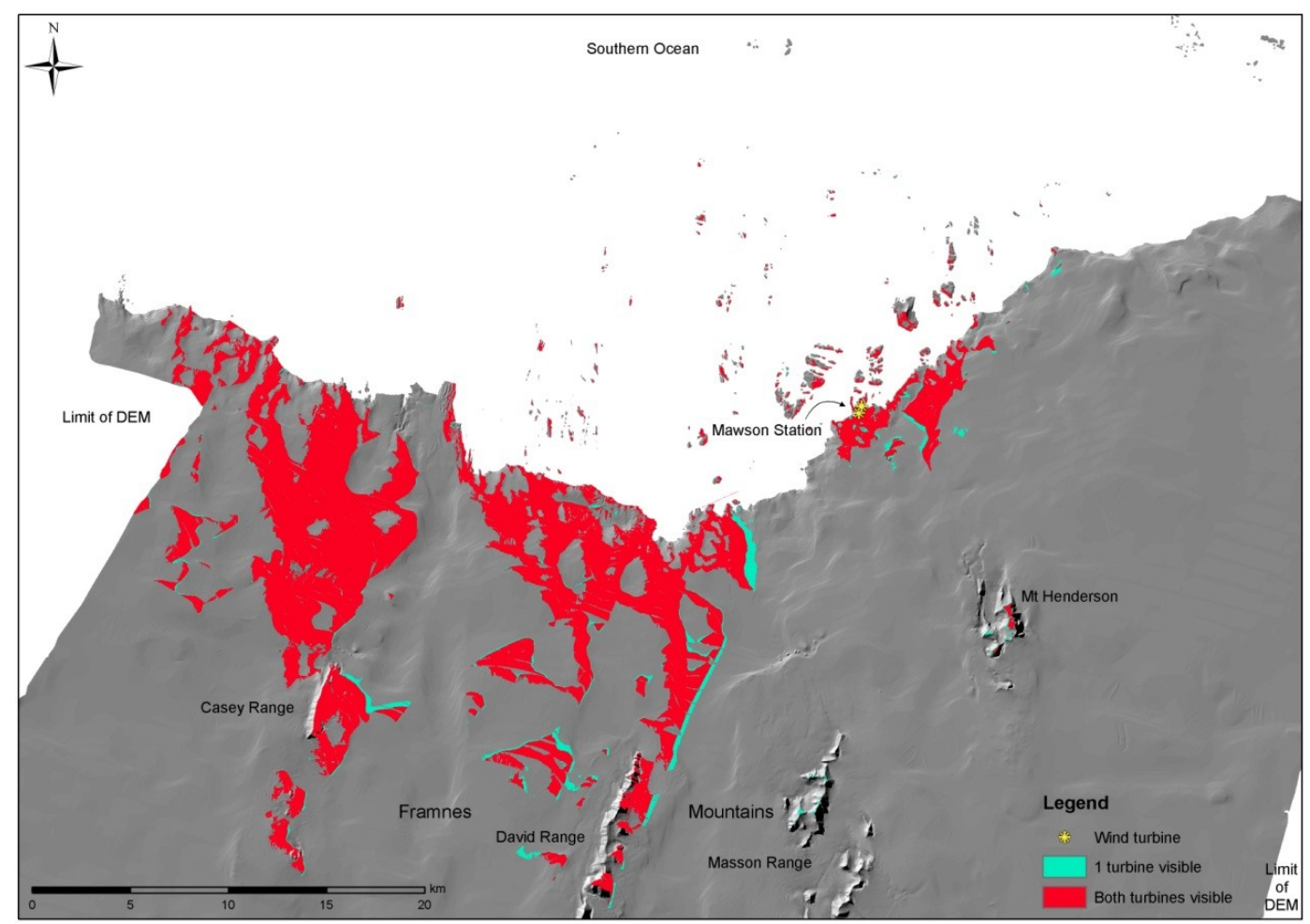

Figure 8.7. Output of the visibility model of the wind turbines at Mawson Station. The visibility of satellite infrastructure in the Framnes Mountains and elsewhere is not included. 


\subsubsection{Field testing}

During the summer of 1999-2000, field testing of the outputs of the visibility model of the Windmill Islands was carried out and the same was done around the Vestfold Hills and the Framnes Mountains in the summer of 2000-2001. It was found that the computer-generated visibility model tended to indicate that infrastructure features were visible more extensively than appeared to be the case in the field. For example, the model indicated that the radio masts around Casey should be visible from the Browning Peninsula (Figure 8.4). No masts were visible from the top of the ridge near Browning Hut which has clear views to the north towards Casey. There are several possible sources of error and, perhaps one reason which this should be the case:

1. Errors in the digital elevation model, especially in the elevation values;

2. Errors in the calculated heights of the masts and their locations;

3. Errors in the visibility model, for example, incorrect assumptions about the acuity of the human eye.

The use of binoculars is not counted as not everyone carries them nor, realistically, would people use them to search for distant infrastructure before deciding whether to describe a landscape as wilderness.

The digital elevation model (DEM) was built from contours and spot heights derived from stereoscopic aerial photography carried out in 1993-94. While it is not to say that the contour heights and feature locations are free from error, they had been in use for several years and no errors had been reported. The routine for generating digital elevation models was developed in the late 1980s as ANUDEM (Hutchinson 1989) and was incorporated by ESRI into Arc/INFO GIS as the TOPOGRID routine. While the TOPOGRID routine allows some interpolation, i.e. allows the terrain to extend higher that the highest feature - for example to round off hill tops where there are no spot heights at the summits, this would tend to round off summits of topographic features higher than they may possibly be and this would tend to truncate visibility rather than cause it to be extended. This may therefore be one reason for the non-visibility of the masts. The masts have been surveyed and their heights calculated with a high degree of accuracy which is necessary for aviation safety so it is unlikely that this is the source of the error. Most radio masts are constructed from open lattice steel sections bolted together in the shape of a triangle in plan view. Each section is $0.3 \mathrm{~m}$ wide so the assembled width of the mast is no more than $0.3 \mathrm{~m}$.

The acuity of the human eye is not easy to determine: the theoretical maximum resolution of objects is complicated in the field by a number of interacting factors, which include: 
- The degree of contrast between the object and the background it is being viewed against;

- The weather and the clarity of the atmosphere at the time;

- The size, shape and colour of the object being viewed; and

- The quality of the observer's eyesight.

Many tests have been devised to measure human eyesight, for example Snellen's test (the conventional eye chart comprising letters laid out with decreasing letter size from top to bottom), the aim of which is to test eye sight quality by the ability to resolve letters of the alphabet, each component of which subtends a precise angle at a standard distance. Thus $6 / 6$ vision (20/20 vision on the original scale) is the ability to identify letters that each subtend five minutes of arc at 6 metres (Rabbetts 1998). The human eye is however able to resolve much finer detail:

Under good conditions, a line subtending as little as 0.5 seconds of arc may be seen, provided that it is sufficiently long (for example, a telephone wire) for its image to cover many receptors. (Rabbetts, 1998).

The theoretical limit of visibility of a mast with a width of $0.3 \mathrm{~m}$ is $15.5 \mathrm{~km}$. This is calculated as follows using simple trigonometry:

Where $\mathrm{A}=$ acuity of the human eye, $\mathrm{a}=$ half the width of a radio mast $(0.15 \mathrm{~m})$ and $\mathrm{b}=$ the distance from the observer to the target. This can be solved to give a maximum range of 15,479 m or about $15.5 \mathrm{~km}$.

There is clearly a difference between the theoretical distance from which features can be seen and the actual distance. The most likely reason for the discrepancy, therefore, is that the ArcGIS visibility model does not take into account the acuity of the human eye but assumes that the target is large enough to be visible. So while an object of the height of a radio mast could be visible at a range of $20 \mathrm{~km}$, the fact that the object is too narrow to be resolved by the eye is not taken into account by the algorithm. Radio masts are generally the tallest structures on stations, though the wind turbines at Mawson are taller. It is not, however, the height of the mast alone that determines the maximum range of visibility but a combination of height and width.

Bishop (2002) and Shang and Bishop (2000) investigated the visual impact of wind turbines, which are much larger structures than radio masts. Bishop (2002) concluded that the rate of recognition of a $50 \mathrm{~m}$ tower with $26 \mathrm{~m}$ blades would have dropped to one person out of five at a range of $10 \mathrm{~km}$. Even in the clarity of the Antarctic atmosphere, a maximum range of $15.5 \mathrm{~km}$ 
for a $0.3 \mathrm{~m}$ cross-section radio mast seems reasonable and this conclusion, that distance must be taken into account because of limiting factors such as the ability for the human eye to make out a long thin feature accords well with Bishop's conclusion that "any impact modelling should not be based purely on line of sight but must take distance into account".

\subsection{Sound footprint}

Silence is a key characteristic of the natural environment in Antarctica (Chapter 5). Noise from human activities therefore has a direct impact on wilderness values. That is not to say that there are no natural sources of sounds; penguin colonies are noisy places during the breeding season, seal mothers and pups are often heard calling to each other and there are sounds of ice falling from ice cliffs and ice movement along the shoreline. It was claimed by a number of individuals during ANARE Voyage 4 (1999-2000) that it was possible to hear sounds from the station at Jack's Donga field hut, which is $8 \mathrm{~km}$ to the north-east of the station. The following section tests that claim.

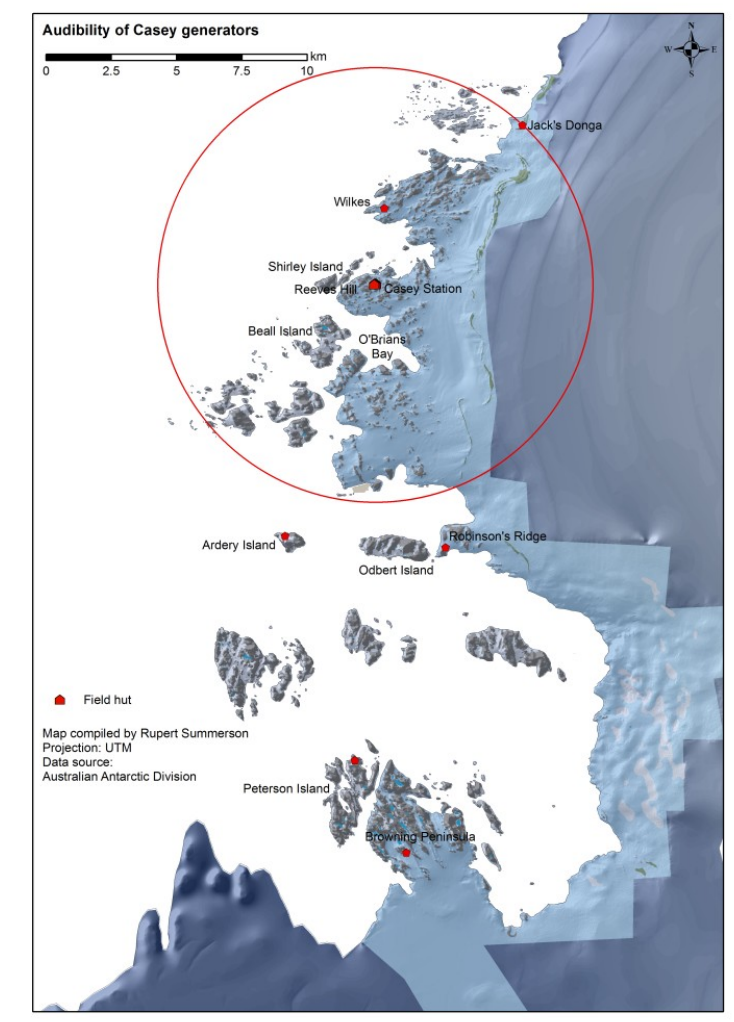

Figure 8.8. Map showing the limit of audibility of the generators at Casey and the location of Jack's Donga field hut. 


\subsubsection{Vehicle sounds}

The most constant sources of human noise are from vehicles, diesel generators and helicopters. There are many types of vehicle in use in Antarctica from "quads" (four-wheeled motorbikes), "utes", Hagglunds oversnow vehicles and heavy vehicles such as bulldozers. It is not practical to attempt to model the noise propagation from all these types of vehicles in all situations. One source of vehicle sound has therefore been modelled. All large vehicles are fitted with a reversing ("back-up") alarm. Reversing alarms are necessary for safety to prevent someone from being accidentally run over by a reversing vehicle, but they are also a universal irritant. The loud high-pitched sound carries for considerable distances but it is the intermittent nature of the sound that causes most annoyance. The characteristics of the type of alarm typically fitted to heavy vehicles at Australian Antarctic stations are as follows:

Make and model: Precomatic $1040^{32}$

Sound pressure: $87-112 \mathrm{~dB}$ self-adjusting so that it is $10+/-4 \mathrm{~dB}(\mathrm{~A})$ above ambient noise Frequency: $1150 \mathrm{~Hz}$

Height mounted on vehicle: $2.2 \mathrm{~m}$

A sound pressure of $112 \mathrm{~dB}$ was used to represent the worst case scenario.

Sounds are attenuated through a number of mediums and the way attenuation is calculated is by determining the level of the sound (sound pressure in $\mathrm{dB}$ ) at source and calculating the amount of attenuation over a given distance. There are four terms for attenuation: divergence, air absorption, attenuation by the ground and attenuation by miscellaneous causes such as temperature and atmospheric pressure. These are added together to determine the total attenuation. Attenuation occurs at different rates for each of these terms. These attenuation calculations assume favourable weather conditions for sound propagation (see below). The calculations below are based on the equations and procedures described in Piercy and Daigle (1991).

The total attenuation of a given sound is calculated with the following equation:

$\mathrm{A}_{\text {total }}=\mathrm{A}_{\text {div }}+\mathrm{A}_{\text {air }}+\mathrm{A}_{\text {ground }}+\mathrm{A}_{\text {misc }}$

The four terms in the equation are attenuation due to geometrical divergence $\left(\mathrm{A}_{\mathrm{div}}\right)$, attenuation due to air absorption $\left(\mathrm{A}_{\text {air }}\right)$, attenuation by the ground $\left(\mathrm{A}_{\text {ground }}\right)$ and attenuation by miscellaneous effects. Other forms of attenuation, such as by foliage, are not relevant in Antarctica. These

\footnotetext{
${ }^{32}$ http://www.precosafety.com/alarms/mid/
} 
terms are added together to give the total amount of attenuation by all effects. The effects of wind will be considered later. To demonstrate the application of the sound attenuation equation (Equation 1.1), an example will be worked through using a reversing alarm in operation at Casey station.

\subsubsection{Vehicle reversing alarm}

\section{Attenuation due to divergence $\left(A_{\text {divergence }}\right)$}

Attenuation due to geometrical divergence $\left(\mathrm{A}_{\text {div }}\right)$ is the spherical spreading of sound from a point source. The equation for attenuation due to divergence is as follows:

$\mathrm{A}_{\mathrm{div}}=20 \log 10 \mathrm{r}+10.9-\mathrm{C}$

Where $\mathrm{r}=$ distance in metres and $\mathrm{C}$ is a correction term to account for atmospheric pressure and temperature. At Casey Station, for example, where the mean daily atmospheric pressure is about $980 \mathrm{mbar}$ and the temperature well below $0^{\circ} \mathrm{C}$ (BoM 2010), this correction term is effectively 0 . If $\mathrm{r}=8000 \mathrm{~m}(8 \mathrm{~km})$, equation 1.2 is solved as follows:

$\mathrm{A}_{\text {div }}=(20 \times(\log 10 \times 8000))+10.9-0$

$\mathrm{A}_{\mathrm{div}}=88.9$

Thus at a distance of $8 \mathrm{~km}$, the attenuation due to divergence is $88.9 \mathrm{~dB}$. This means that from a sound pressure at source of $112 \mathrm{~dB}$, at a range of $8 \mathrm{~km}$ the sound pressure has been reduced to $23.1 \mathrm{~dB}$ by divergence alone.

\section{Attenuation due to air absorption $\left(A_{\text {air }}\right)$}

$\mathrm{A}_{\text {air }}$ is attenuation due to absorption as the sound passes through the air. The formula for calculating $\mathrm{A}_{\text {air }}$ is as follows:

$\mathrm{A}_{\text {air }}=\alpha \mathrm{d} \mathrm{dB}$

Where $\alpha=$ the air attenuation coefficient and $\mathrm{d}$ is the distance in kilometres, in this case, $7 \mathrm{~km}$. $\alpha=4.6$ (Piercy and Daigle 1991. Table 3.1: Temp. $=0^{\circ} \mathrm{C}$, relative humidity $(\mathrm{RH})=70 \%$, Frequency, $\mathrm{Hz}=1000$.)

$\mathrm{A}_{\mathrm{air}}=36.8 \mathrm{~dB}$

Thus at a distance of $8 \mathrm{~km}$, the attenuation due to air absorption is $36.8 \mathrm{~dB}$. Together, attenuation due to divergence and air absorption account for a total loss of $125.7 \mathrm{~dB}$, thus it would not be possible to hear a reversing alarm at that range. 


\subsubsection{Diesel generators}

The other dominant source of noise from the station is the sound of the diesel generators, which are a low frequency sound source. The main power house at Casey is equipped with four Caterpillar 3306 turbo-charged diesel generators, up to three of which may be operating at any one time. The following parameters have been estimated:

Sound pressure output : $90 \mathrm{~dB}$

Sound frequency: $50 \mathrm{~Hz}$

Height above ground: $1.5 \mathrm{~m}$

The sound pressure of $90 \mathrm{~dB}$ is the sound pressure estimated on the outside of the main power house. The noise inside, with up to three generators running simultaneously without soundproof boxes would be considerably higher.

Attenuation due to divergence is unaffected by frequency. Attenuation due to air absorption is affected by frequency. At $0^{\circ} \mathrm{C}$ and $70 \% \mathrm{RH}, \alpha=0.15$.

$\mathrm{A}_{\text {air }}=1.2 \mathrm{~dB}$

It is therefore necessary to apply the third term for attenuation: attenuation by the ground (A $\left.\mathrm{A}_{\text {ground }}\right)$.

\section{Attenuation by the ground $\left(A_{\text {ground }}\right)$}

In this example, attenuation over long range propagation is being calculated. There are three sub-terms for $\mathrm{A}_{\text {ground }}$ : attenuation in the source zone, i.e. in the area around the source of the noise $\left(\mathrm{A}_{\text {source }}\right)$, attenuation in the receiver zone $\left.\mathrm{A}_{\text {receiver }}\right)$, i.e. in the area around the receiver, in this case at Jack's Donga field hut and attenuation over the intervening ground ( $\left.\mathrm{A}_{\text {middle }}\right)$.

$\mathrm{A}_{\text {ground }}=\mathrm{A}_{\text {source }}+\mathrm{A}_{\text {receiver }}+\mathrm{A}_{\text {middle }}$

\section{Attenuation in the source zone ( $\left.A_{\text {source}}\right)$}

The source zone is defined as an area 30x the height of the source.

The height of the source $\left(\mathrm{h}_{\text {source }}\right)$ is approximately $1.5 \mathrm{~m}^{33}$.

$A_{\text {source }}=-1.5 \quad$ (Piercy and Daigle 1991. Table 3.3. Octave band frequency $=63 \mathrm{~Hz}$ )

$\mathrm{A}_{\text {receiver }}=-1.5$

$\mathrm{A}_{\text {middle }}=-3 e$, where $\mathrm{e}=\left(1-\left[30\left(\mathrm{~h}_{\text {source }}+\mathrm{h}_{\text {receiver }}\right) / \mathrm{r}\right]\right)$

\footnotetext{
${ }^{33}$ The height of the generator exhaust manifold on the generator s.
} 
$\mathrm{r}=$ distance from source to receiver $(8000 \mathrm{~m})$

$\mathrm{A}_{\text {middle }}=-2.964$

$\mathrm{A}_{\text {ground }}=-4.94$

$\mathrm{A}_{\text {total }}=88.9+1.2-4.94$

$\mathrm{A}_{\text {total }}=85.16 \mathrm{~dB}$

Therefore at $8 \mathrm{~km}$ distance, the sound pressure will have fallen to $4.84 \mathrm{~dB}$. Note that the threshold of human hearing is $0 \mathrm{~dB}$ which means that the sound of the generators is theoretically audible.

Piercy and Daigle specify three favourable conditions for propagation of sound:

1. Wind speed between $1-5 \mathrm{~m} / \mathrm{s}(3.6-18 \mathrm{~km} / \mathrm{h})$, measured at a height of $3-11 \mathrm{~m}$ above the ground;

2. Wind direction within an angle of $45^{\circ}$ of a straight line between the source of the noise and the receiver; and

3. Propagation under a well-developed ground-based temperature inversion, which causes sound to refract downwards.

The prevailing wind direction at Casey is from the north-east, which is unfavourable for this scenario (Figure 8.8). Favourable conditions are when the wind is blowing from a direction between west and south. Such conditions are relatively rare, occurring on average between five and six days per month, based on data from the period between 1 September 2009 and 15 October 2010 (available on the Bureau of Meteorology website ${ }^{34}$ ). Thus the wind regime at Casey would be favourable for the sound of the generators to be heard at Jack's Donga periodically.

\subsection{Modelling the total spatial extent of the human footprint in Antarctica}

If it is accepted that all Antarctica is wilderness except for those areas that have been degraded by human presence then clearly what is required is to map the extent of human activity - the human "footprint". There are two main contributors to the human footprint: national Antarctic programs and, to a much lesser extent, tourism activity.

\footnotetext{
${ }^{34}$ http://www.bom.gov.au/climate/dwo/IDCJDW9203.latest.shtml
} 


\subsubsection{National Antarctic Programs}

With the limited data available on infrastructure from national Antarctic programs and the low resolution digital elevation model of the Antarctic continent it would be impractical to attempt to calculate total human footprint in Antarctica using a visibility analysis. The results of the pilot projects with the Australian stations can, however, be extended Antarctica-wide by applying what has been learnt about visibility distance. I have proposed that the maximum distance a radio mast with a $0.3 \mathrm{~m}$ cross-section can be seen is about $15.5 \mathrm{~km}$. Other features, such as radio masts with a bigger cross-section, other structures and clusters of buildings, can potentially be seen from a greater distance. Bishop (2002) in considering the visual impact of wind turbines concludes that "visibility modelling out to $20 \mathrm{~km}-30 \mathrm{~km}$ is justified, but effects beyond $20 \mathrm{~km}$ may be rare and depend on exceptional viewing conditions". Infrastructure can be categorised as shown in Table 8.2 below.

Table 8.2. Types of infrastructure.

\begin{tabular}{|l|l|}
\hline Type & Content \\
\hline Year-round stations & Multiple buildings, roads, radio masts \\
\hline Summer-only stations & Multiple buildings, though less extensive, radio masts \\
\hline Field huts \& refuges & Single building. May include radio mast. \\
\hline Abandoned stations & Permanently or temporarily. May be historic sites. \\
\hline Roads/tracks & Deliberately cleared roads/tracks \\
\hline Airfields & May be graded, runway markers, buildings \\
\hline Scientific sites (long term) & Buildings, radio mast, disturbed surfaces \\
\hline Scientific sites (short term) & Temporary buildings, disturbed surfaces \\
\hline Other scientific equipment & Automatic weather stations. Single apparatus \\
\hline Abandoned scientific site & Undifferentiated relics \\
\hline Route markers & Marker canes/poles, flags, etc \\
\hline Wreckage & Mostly aircraft, some vehicles \\
\hline
\end{tabular}

Locating data on infrastructure has been problematic as there is no single source and the status of infrastructure is dynamic: new stations are built, field huts are moved, marked routes are changed, new scientific equipment is deployed, etc. There are two main sources of information: 
- Antarctic Treaty exchange information; and

- COMNAP.

The requirement for the exchange of information by Antarctic Treaty contracting parties is mandated under Article VII of the Antarctic Treaty (ATS 2012). This requires each contracting party to exchange information about its activities by giving advance notice of:

(a) all expeditions to and within Antarctica, on the part of its ships or nationals, and all expeditions to Antarctica organized in or proceeding from its territory;

(b) all stations in Antarctica occupied by its nationals; and

(c) any military personnel or equipment intended to be introduced by it into Antarctica.

There have been, to date, some 40 amendments to the information reporting requirements, including information exchange obligations on environmental matters introduced by the Madrid Protocol. The information to be provided by contracting parties is as follows:

- Pre-season information

- Permanent information

- Annual report

This information is maintained and made available by the Antarctic Treaty Secretariat on their website (ATS 2012).

The information is presented in text form in as many different styles as there are reporting countries and in as many standards of quality so the task of converting it into GIS data is long and laborious. A number of countries now appear to prepare summary information for submission to the Antarctic Treaty Secretariat and list comprehensive information about infrastructure, logistics, etc on their websites. The British Antarctic Survey, for example, lists the names, locations and status of all current and abandoned stations and their associated field huts (BAS 2012). The data made available by COMNAP is mostly on the major items of infrastructure such as year-round and summer stations and airfields. This dataset is made available on the COMNAP website (COMNAP 2012), the latest version is from April 2012. As much data that could be located was compiled into a single GIS dataset. Table 8.3 lists the types of infrastructure and the sources. A total of 622 items of infrastructure were compiled from these sources of information. This is likely to be an underestimate of the amount of infrastructure as there are a number of abandoned stations, the status of which is not known, unregistered or abandoned field camps, current and abandoned sites of scientific research, wrecked aircraft, abandoned vehicles, food and fuel depots and sundry other apparatus (e.g. 
Figure 8.9). For example, it is not known whether there are any parts of Eights Station or Siple Station (both US) that are still visible or whether they are now completely buried under snow.

Table 8.3. Types of infrastructure used to model the human Antarctic visibility footprint and sources of data

\begin{tabular}{|l|l|}
\hline Type of infrastructure & Source \\
\hline Currently occupied stations and facilities & COMNAP \\
\hline Refuges & Antarctic Treaty Exchange Information \\
\hline Automatic weather stations (AWS) & University of Wisconsin \\
\hline Science apparatus & Antarctic Treaty Exchange Information \\
\hline Abandoned buildings and materiel & $\begin{array}{l}\text { Antarctic Treaty Exchange Information and } \\
\text { NAP websites }\end{array}$ \\
\hline Historic sites and monuments & Antarctic Treaty Secretariat website \\
\hline Russian stations & Russian Antarctic Expeditions website \\
\hline
\end{tabular}

It is not possible to determine the visibility for each item of infrastructure, either individually or as a type, as the heights of every building and structure is different; stations vary widely in size, as do field huts and all infrastructure erected on ice becomes buried with snow to varying extents, eventually completely. Visibility was therefore estimated but based on experience from both visibility modelling and from field testing the visibility models. Table 8.4 lists the estimated visibility distances. The visibility distances in this dataset can be refined to improve the accuracy of the visibility model. 


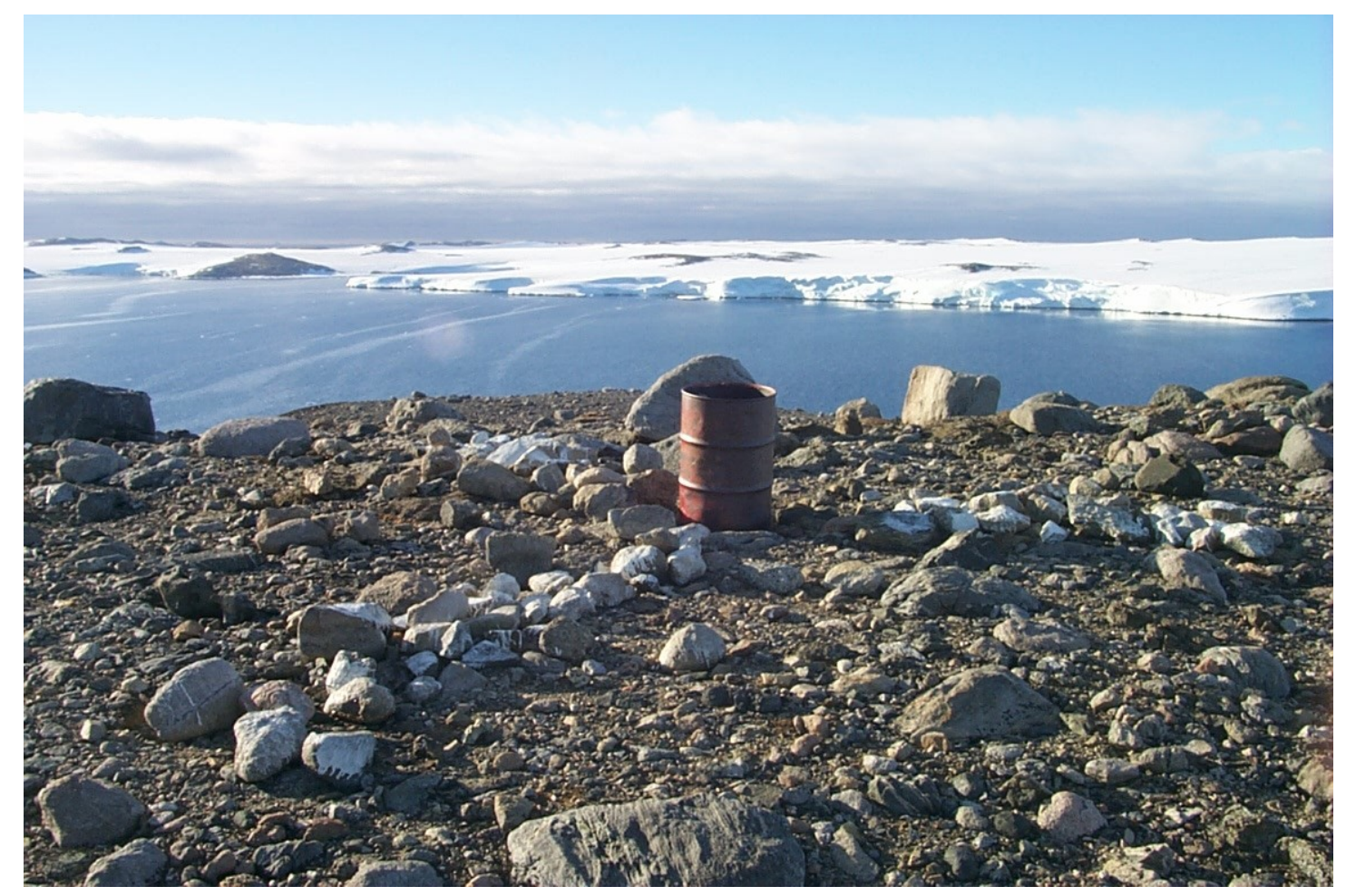

Figure 8.9. An abandoned survey mark in the Windmill Islands; typical of unrecorded infrastructure (Photo: Rupert Summerson)

Table 8.4. Maximum visibility distances. Distances are planar, i.e. no correction was made for curvature of the earth.

\begin{tabular}{|l|l|}
\hline Type of infrastructure & Maximum visibility \\
\hline Station & $20 \mathrm{~km}$ \\
\hline Abandoned station & $10 \mathrm{~km}$ \\
\hline Field camp & $10 \mathrm{~km}$ \\
\hline Refuge/field hut & $5 \mathrm{~km}$ \\
\hline Automatic weather station and science apparatus & Varies from $1-5 \mathrm{~km}$ \\
\hline Historic sites and monuments & Varies from $1-5 \mathrm{~km}$ \\
\hline
\end{tabular}

Having compiled all the infrastructure data into one (point) GIS dataset, a buffer i.e. a line drawn around each point at the distances specified above, was generated. This action was performed with the dataset in Polar Stereographic projection. This dataset represents the 
estimated area of human influence, which is the area that can no longer be considered wilderness. Figure 8.10 shows the buffered distances around all known infrastructure.

The buffered points were then intersected with the EDA polygon dataset (Figure 6.1, right). The new dataset represents the best estimate of the area of human influence or non-wilderness in each of the regions aggregated from the EDA domains (Table 8.5).

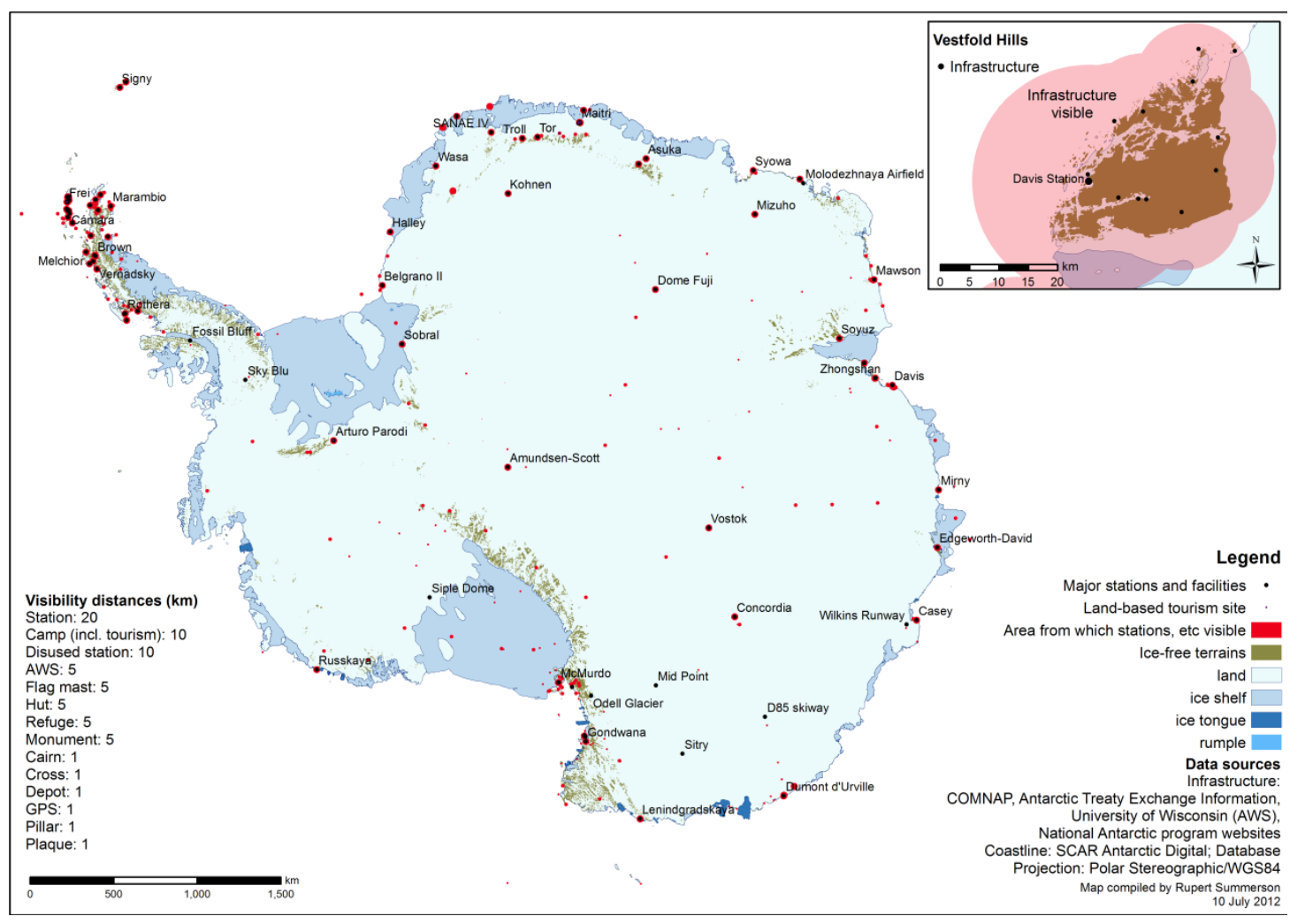

Figure 8.10. Visibility areas of all known infrastructure, calculated by buffering by the distances given in Table 8.4. The visibility areas of the smaller items of infrastructure are not visible at this scale. The inset shows the buffered visibility footprint of all infrastructure in the Vestfold Hills. (Compare with Figure 8.5. Visibility model of Davis Station, i.e. radio masts at Davis and satellite infrastructure in the Vestfold Hills.) 
Table 8.5. Areas of regions aggregated from EDA domains, in $\mathrm{km}^{2}$, and areas and percentages estimated to be non-wilderness.

\begin{tabular}{|l|r|r|r|}
\hline Region & Total Area & $\begin{array}{r}\text { Area not } \\
\text { wilderness }\end{array}$ & $\begin{array}{r}\text { Percentage not } \\
\text { wilderness }\end{array}$ \\
\hline Coastal ice-free & 7,120 & 2,153 & 30 \\
\hline Mountainous ice-free & 148,961 & 8,694 & 0.88 \\
\hline Coastal- Continental Margin & $2,771,174$ & 24,489 & 5 \\
\hline $\begin{array}{l}\text { Antarctic Peninsula Ice } \\
\text { Fields }\end{array}$ & 178,129 & 9,270 & 0.23 \\
\hline Central Antarctic Ice Sheet & $9,024,472$ & 21,113 & 0.88 \\
\hline $\begin{array}{l}\text { Ice shelves \& floating } \\
\text { glaciers }\end{array}$ & $1,546,950$ & 13,537 & 0.58 \\
\hline Whole continent & $13,676,808$ & 79,255 & 5 \\
\hline
\end{tabular}

The total area of Antarctica (whole continent) derived from the EDA is $272,192 \mathrm{~km}^{2}$ less than the total area calculated from the SCAR Antarctic Digital Database (Fox \& Cooper 1994). Although all the input datasets were assembled as $100 \mathrm{~m}$ raster layers (Morgan et al. 2007) and the resolution of final output dataset is $1 \mathrm{~km}$, there seem to have been some dropouts around the margins of the continent, especially on islands.

In order to verify the impact on coastal ice-free areas, which are important areas for wildlife habitat (Jabour 2009), the rock polygon dataset in the Antarctic Digital Database (ADD) (SCAR 2006) was analysed in ArcGIS (version 9.3) to identify all rock polygons that intersect with the coastline. The logic applied here is that coastal stations are almost invariably built on rock. The total area of rock that is immediately adjacent to the coast is $8,340 \mathrm{~km}^{2}$ which is $0.06 \%$ of the whole continent. This is a slightly larger figure than the $0.05 \%\left(6,000 \mathrm{~km}^{2}\right)^{35}$ quoted by Poland et al. (2003) which they define as "ice-free areas within $5 \mathrm{~km}$ of the coast". Presumably this is intended to mean ice-free land immediately adjacent to the sea and no more than $5 \mathrm{~km}$ from it, not ice-free land within $5 \mathrm{~km}$ of the coast but not necessarily adjacent to it. The figure presented

\footnotetext{
${ }^{35}$ There seems to be some confusion about these areas and percentages. Fox and Cooper (1994) give the total area of conterminous Antarctica as $13,949,000 \mathrm{~km}^{2}$. Cooper (2010 pers. comm.) says that this is still the most accurate figure. $6,000 \mathrm{~km}^{2}=0.043 \%$ of the total area of Antarctica.
} 
here excludes areas within rock polygons that are not classified as rock, presumably because they are lakes, snow patches or other features. This figure is an over-estimate of the area that is available for construction as it does not take into account slope, the area of each rock polygon and other factors that determine its suitability such as access to the hinterland and safe approach by sea. It also includes all the contiguous ice-free areas that are adjacent to the sea, which in the case of the Vestfold Hills, for example, extend roughly $25 \mathrm{~km}$ from the coast. Similar caveats arise with the EDA coastal ice-free areas which are about $1,200 \mathrm{~km}^{2}$ smaller than the area calculated from the ADD. There are a number of reasons why this may have happened but the most likely is that during the process of converting the vector data from the ADD in raster format, some data was lost, either through truncation or generalisation. The area figure obtained from the ADD also includes large numbers of islands which, by definition are adjacent to the coast. A number of stations have been built on small islands, for example, Vernadsky (Ukraine) (formerly Faraday Station (UK)) and San Martin (Argentina). The total area of coastal ice-free areas that is under human influence, as derived from the ADD, is $3,368 \mathrm{~km}^{2}$, which equates to $40 \%$ of the total coastal ice free area.

Loss of wilderness value from transient activity is much more difficult to quantify than from fixed infrastructure. In addition to issues of visibility, which with aircraft are complicated by weather, including wind direction, wind speed and cloud cover, contrast and aircraft orientation (Watson et al. 2009) and noise, there are also issues of probability of occurrence and perception of intrusion. Since the respondents to the surveys seem to be ambivalent about the impact of aircraft overflights, it seems safest to note the potential for impact.

\subsubsection{Tourist landings}

IAATO provides detailed information on their website (www.iaato.org) about the patterns of ship-borne tourism activity during each season. Information includes a listing of every site visited, the number of vessels visiting that site and the numbers of visitors and total numbers, including vessel crews, who landed. IAATO also lists separately the name and geographical coordinates of every site that has been visited. By combining the two lists it is possible to map all the sites visited and the intensity of visitation, i.e. the numbers of visitors. Given the large numbers of tourists visiting a relatively small number of sites, it is possible to do a similar analysis of impact on wilderness values by tourism visits. As noted in Chapter 4, tourists typically spend about half a day at each site they visit and without any form of permanent infrastructure. The five sites of land-based tourism are treated in the same way as national Antarctic Program facilities. 
During the 2011-2012 summer tourist season a total of 21,131 tourists (staff, guides and ships' crews are not included) were landed at 167 sites (www.iaato.org/tourism_stats.html). The location of each of these sites was taken from a gazetteer of sites maintained by IAATO and plotted in a GIS (Figure 8.11 and Figure 4.2). Unfortunately these locations are not exactly coincident with the localities as described by Naveen (2005) and the resolution of neither the Antarctic Digital Database coastline coverage nor the EDA dataset matches the maps in the Site Guide which makes it difficult to identify the landing sites precisely. Instead therefore of attempting to calculate the area impacted by tourism operations by spatial analysis, an inductive approach was taken. With a few exceptions where helicopters only are used, tourism landing sites are necessarily from the sea. Mortimer (2004) states that tourists "... are essentially between 100 metres and $2 \mathrm{kms}$ from the shore". If a circle with a two kilometre radius is drawn at each landing site defining the area visited, that gives an area of $6.28 \mathrm{~km}^{2}$. Roughly half of the area of the circle will be sea so that gives an estimated area of impact of $3.14 \mathrm{~km}^{2}$. Tourists are almost invariably landed on ice-free areas to avoid the risk of accidents in crevasses so this area can be confidently classified as coastal ice-free. Of these landing sites, at least 45 are in the vicinity of a station, refuge or other type of infrastructure. The total area impacted by tourists on shipborne landings is therefore in the order of $122 \times 3.14=383 \mathrm{~km}^{2}$. The area temporarily impacted by tourists is therefore less than $0.5 \%$ of that permanently impacted by national Antarctic programs. This area is not, however, impacted evenly. During the 2011-2012 summer season, four sites received over 10,000 visitors (Goudier Island, Neko Harbour, Whalers Bay and Cuverville Island) and a further 24 sites received over 1,000 visitors (Figure 8.11). 73 sites received less than 100 visitors.

In terms of impact on wilderness values, those sites where tourists are landed from ships for a brief period lose their wilderness value while the tourists are ashore and the ship is anchored nearby but do not lose wilderness value permanently. A number of authors have pointed out that the most popular sites are occupied almost continuously during the tourist season, which lasts for approximately 100 days from mid-November to the beginning of March (Naveen et al. 2001). Nonetheless, without permanent infrastructure, those sites retain their wilderness values when the tourists are not there, assuming that the tourists do not cause any damage, such as by trampling vegetation and do not leave any litter. 


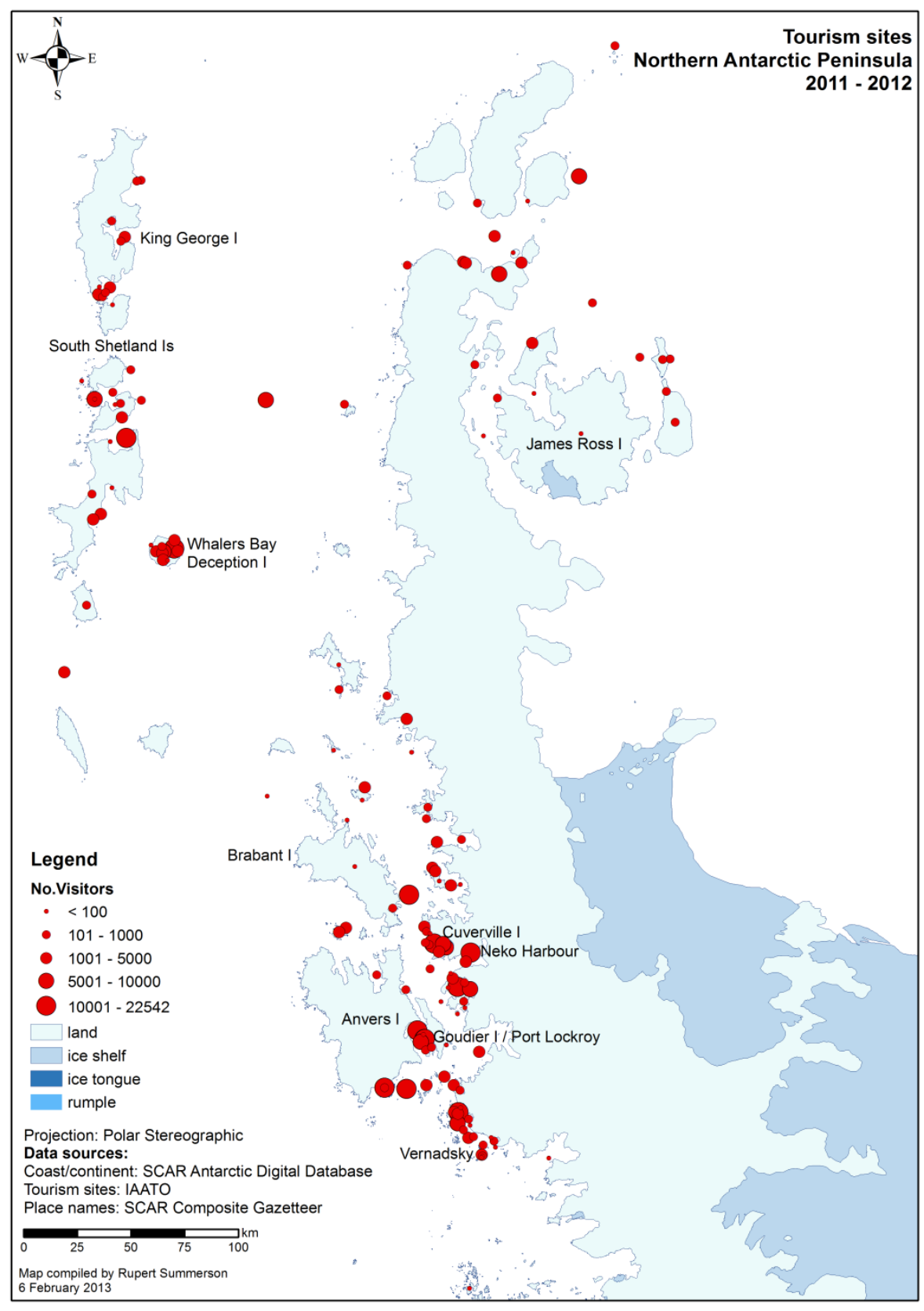

Figure 8.11. Tourism landing sites at the northern end of the Antarctic Peninsula. 


\subsection{Spatial modelling and mapping of areas of aesthetic value}

As described in Chapter 5, a large number of techniques have been developed to assess landscape aesthetic values. As noted, two traditions have developed, an "objectivist" approach which has been adopted by landscape professionals, exemplified by the Landscape Character Assessment technique (Swanwick \& Land Use Consultants 2002), which Codling (2001) applied in Antarctica, and a "subjectivist" approach, exemplified by the techniques developed by Daniel and Boster (1976) and applied in Antarctica by Summerson and Bishop (2012; 2011). (The neat subdivision into objectivist and subjectivist approaches has been adapted from Frank et al. (2013)). A number of methods of identifying the aesthetic values of an area have been described. Two recent studies use techniques that are particularly relevant to assessing the aesthetic values of a small region such as one of the Antarctic coastal ice free areas. Wu et al. (2006) describe a landscape visual quality assessment of Mornington Peninsula, Victoria, combining public perception and expert design and based on four oriented photographs taken at random points along roads through the study area. A landscape composition factor index was compiled from GIS data and aesthetic preference scores were obtained for each photograph at a community workshop. Landscape visual quality was then derived by a process of multiple linear regression of landscape composition with aesthetic preference. The final stage was to interpolate the result across the study area using kriging (a spatial interpolation method). Frank et al. (2013) describe a similar approach in a study region in Saxony in south-east Germany. They used a combined "objectivist" approach of landscape metrics, developed from three indicators of naturalness and diversity with a "subjectivist" survey to validate the results using maps, satellite imagery and photographs. They found that the best results, i.e. the closest correlation, occurred between the landscape metrics-based assessment and landscape photographs.

A similar approach was planned for the Vestfold Hills (the coastal ice-free area around Davis Station) but unfortunately the planned photography campaign did not eventuate. The output of such an approach would be a useful addition to an area management tool, such as an Antarctic Specially Managed Area. The aims and objectives of the Larsemann Hills ASMA include, for example, "maintaining the wilderness and aesthetic values of the Area" (ATS 2007: 3). At present, the aesthetic values remain un-described, except in very broad terms, and unquantified. A combined "objectivist" and "subjectivist" approach developed with a terrain model comprising landscape features (e.g. slopes, elevation, lakes and coast) and a survey of aesthetic preference with input from expeditioners of the five countries with bases in the Larsemann Hills, would yield a landscape aesthetics model that should acceptable to all parties, all having contributed to it. 
The results of the surveys do, however, provide a number of bases for spatial modelling. Table 8.6 shows the range of average aesthetic preference from Survey 3 for each of the six regions of the EDA. In this case, only images without human infrastructure or activity have been used as human presence tends to distort aesthetic preference (Figure 7.6). The region with the highest mean aesthetic preference rating was the Antarctic Peninsula ice fields region, which is a mountainous region and the Mountainous ice-free region had the third highest mean rating. There were also four images in the Ice Shelves region that included distant views of mountains. The four highest rated images for aesthetic preference and eight out of the top ten were images of mountains. Mountains therefore generally have higher aesthetic value than other landscape types. As noted in Chapter 6 (Methods), however, the images in the survey were not randomly distributed through the EDA regions so caution should be exercised in interpolating the results more broadly.

Table 8.6. Mean aesthetic preference (raw scores), standard deviation and image count for each of the six regions of the EDA.

\begin{tabular}{|l|l|l|l|}
\hline Region & $\begin{array}{l}\text { No. } \\
\text { images }\end{array}$ & $\begin{array}{l}\text { Mean aesthetic } \\
\text { preference }\end{array}$ & SD \\
\hline Antarctic Peninsula ice fields & 8 & 6.0 & 1.35 \\
\hline Central Antarctic ice sheet & 3 & 5.79 & 1.5 \\
\hline Mountainous ice-free & 11 & 5.73 & 1.46 \\
\hline $\begin{array}{l}\text { Ice shelves and floating } \\
\text { glaciers }\end{array}$ & 7 & 5.7 & 1.37 \\
\hline Coastal-continental margin & 6 & 5.67 & 1.38 \\
\hline Coastal ice-free & 9 & 4.78 & 1.54 \\
\hline
\end{tabular}

\subsubsection{Modelling mountain visibility}

As noted in Chapter 6, one of the problems with using the EDA regionalisation is that, perceptually, the regions overlap. This is especially true with mountains which can be seen for considerable distances beyond their own EDA regions. Appreciation of an individual or a range of mountains does not only occur from within the boundaries of a mountain range but from some distance away, in other words mountains also have a visibility extent. In order to determine what this extent might be two experimental approaches were carried out using the Ellsworth Mountains as a case study. 
The first technique was to use the general equation for the curvature of the earth, including a constant for refraction (Young 2012):

$$
\mathrm{D}=3.86 \sqrt{ } \mathrm{h}
$$

Where $\mathrm{D}=$ the distance to the horizon, 3.86 is a constant to account for the radius of the earth, including a factor for refraction, and $\mathrm{h}$ is the height of the feature with an observer on the summit. The solution to this equation, where the height of the summit of Vinson Massif is 4892 $\mathrm{m}$, gives a distance to the horizon of $270 \mathrm{~km}$. This is shown as the yellow line in Figure 8.12. The addition of two lower peaks but the highest in the eastern and western parts of the range is shown as the green line in Figure 8.12

The second technique used the VIEWSHED routine in the ArcGIS Spatial Analyst extension. The VIEWSHED routine requires a DEM and one or more observers (point features from which to calculate visibility). For this purpose the RAMP DEM version 2 was used. The first attempt used the summit of Vinson Massif only (the green star in Figure 8.12) which left some gaps at the ends of the ranges. (Vinson Massif is the highest mountain in the Ellsworth Mountains - and in Antarctica). Two other summits, the same as described above (the blue stars in Figure 8.12) were therefore added. The resulting viewshed, i.e. the extent of visibility of the range is shown in Figure 8.12. The limit of visibility matches very closely the distance to the horizon calculated above [1], especially N and NNE from Vinson Massif on the flat terrain of the Ronne Ice Shelf. This is to be expected, firstly because presumably the software uses the same or a similar algorithm to account for the curvature of the earth and secondly, the terrain is relatively flat, which is the case over large areas in Antarctica and is certainly the case over the Ronne Ice Shelf. The accuracy of the equation is verified by personal observation where, in that part of the Ronne Ice Shelf, I was able to see the summit of Vinson Massif quite clearly from a distance of 120 nautical miles $(=222 \mathrm{~km})^{36}$.

\footnotetext{
${ }^{36}$ I was travelling away from the Ellsworth Mountains so was not able to determine the point at which Vinson Massif finally disappeared.
} 


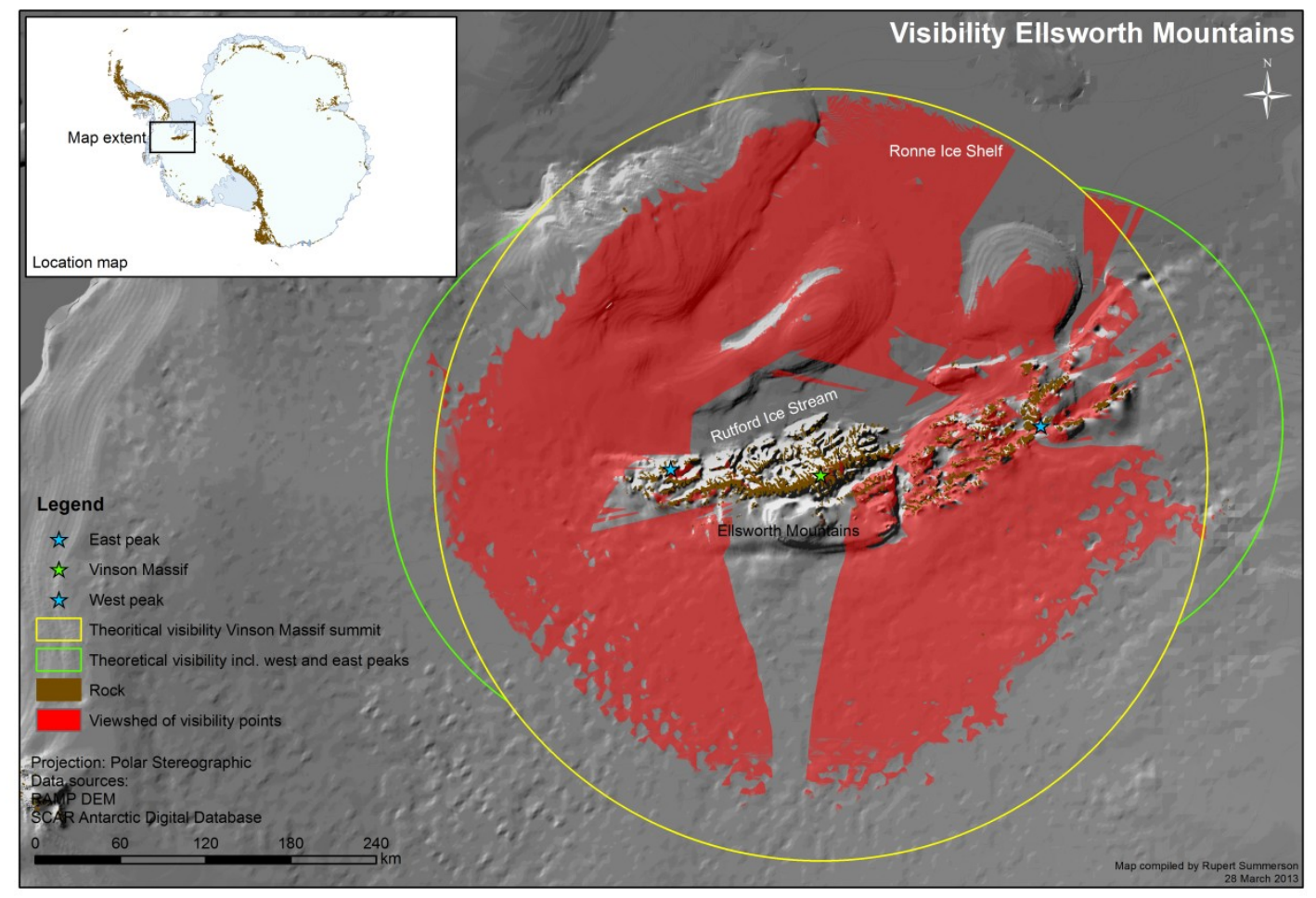

Figure 8.12. Two methods of calculating the limit of visibility of the Ellsworth Mountains: by theoretical distance to the horizon equation from the summit of Vinson Massif, the highest mountain in the range (and in Antarctica) and using the VIEWSHED routine in ArcGIS Spatial Analyst extension.

The diminished viewshed to the south-west to the south-east is presumably due to changes in the topography of the ice cap, the prominent gap in visibility due south of Vinson Massif is an artefact due to flat-topped summit where the highest point is set back from the lip of the summit block.

In conclusion, the theoretical distance to the horizon approximates the calculated visibility but does not need a digital elevation model or raster processing software. The simplicity of distance to the horizon equation is appealing and its implementation in a GIS is simple by using a buffer routine. There are, however, a number of complications:

1. Distance to the horizon calculations should be done at a number of points along a mountain range and their results merged.

2. Some mountain ranges have different terrain heights at their bases on either side of the range, for example the base of the Ellsworth Mountains on the Rutford Ice Stream side 
ranges from c. $165 \mathrm{~m}$ to c. $600 \mathrm{~m}^{37}$, whereas on the Marie Byrd Land side the height varies from c. $1200 \mathrm{~m}$ to $>2000 \mathrm{~m}$. This is particularly the case along the Transantarctic Mountains where the Polar Plateau is at roughly $2000 \mathrm{~m}$ elevation by comparison with the surface of the Ross Ice Shelf, which is mostly a few tens of metres above sea level.

3. Terrain height surveys in Antarctica are limited, unevenly distributed and of varying quality which will result in some inaccuracies.

4. A question arises on whether the theoretical limit of visibility of a mountain range reflects the practical limit of visibility. Should a buffer zone of a shorter distance reflect the distance that a mountain or mountain range begins to impress rather than simply be visible (at a great distance)? If so, what should that distance be? These are questions that need to be canvassed among the broader Antarctic community and among environmental managers.

Nevertheless, applying this technique more broadly, an attempt has been made to map the visibility extent of all mountains in Antarctica. A four-step process was used to identify the visibility of mountains. Mountains are defined here as rock features with an elevation of 1000 $m$ or greater. First, using the Antarctic Digital Database (ADD), contours were intersected with rock polygons from the ADD. Second, the contours were then grouped by the rock polygon unique identifier and the maximum elevation value of all the contours within each rock polygon was then written to a file. Third, the label points for each rock polygon were then joined to the file with the maximum height values. Finally, the label points were then buffered to half the distance to the horizon. The result is shown in Figure 8.13. Although mountainous regions were identified by survey respondents as having the highest aesthetic value and the techniques described above demonstrate how the areas from which mountains can be seen could be mapped, this is not to suggest that this entire area has uniform aesthetic value. It is anticipated that aesthetic value will increase with increasing proximity to the mountains and vice versa.

\footnotetext{
${ }^{37}$ Elevation measurements taken from the RADARSAT Antarctic Mapping Project (RAMP) DEM (http://bprc.osu.edu/rsl/radarsat/).
} 


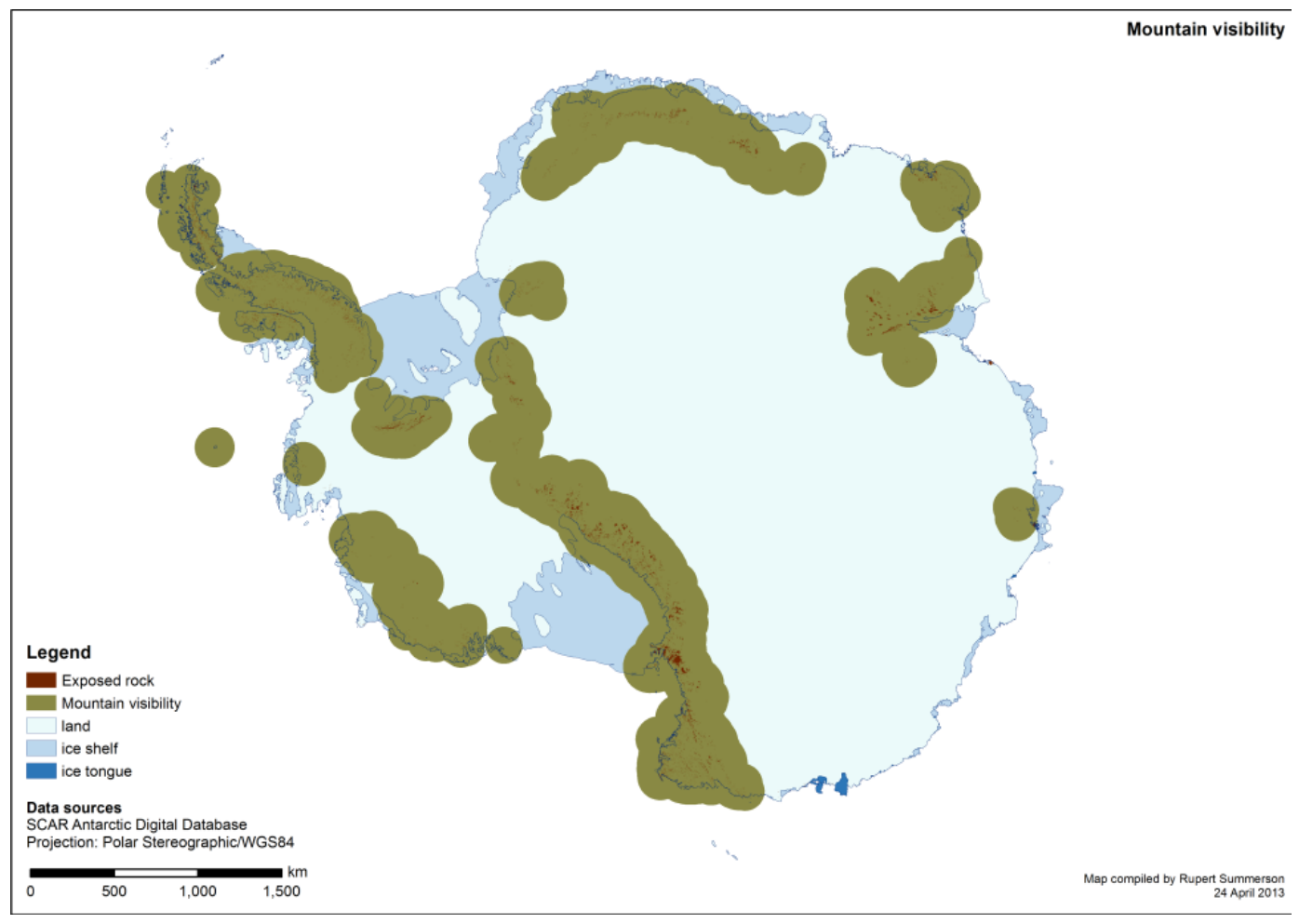

Figure 8.13. Visibility regionalisation of mountains in Antarctica.

Distance to the horizon calculation was chosen in preference to visibility modelling using a DEM until such time as an accurate high resolution DEM becomes available. Half the distance to the horizon was chosen arbitrarily as the visibility distance to account for non-visibility due to intervening land, poor weather and a number of other factors.

Although mountainous regions were identified by survey respondents as having the highest aesthetic value and the techniques described above demonstrate how the areas from which mountains can be seen could be mapped, this is not to suggest that this entire area has uniform aesthetic value. It is anticipated that aesthetic value will increase with increasing proximity to the mountains and vice versa.

In Figure 8.14 the mountain visibility layer is overlaid on the reclassified EDA regions. The addition of the mountain visibility layer to the EDA regions results in a regionalisation that is more suitable for human perception than the original EDA domains. 


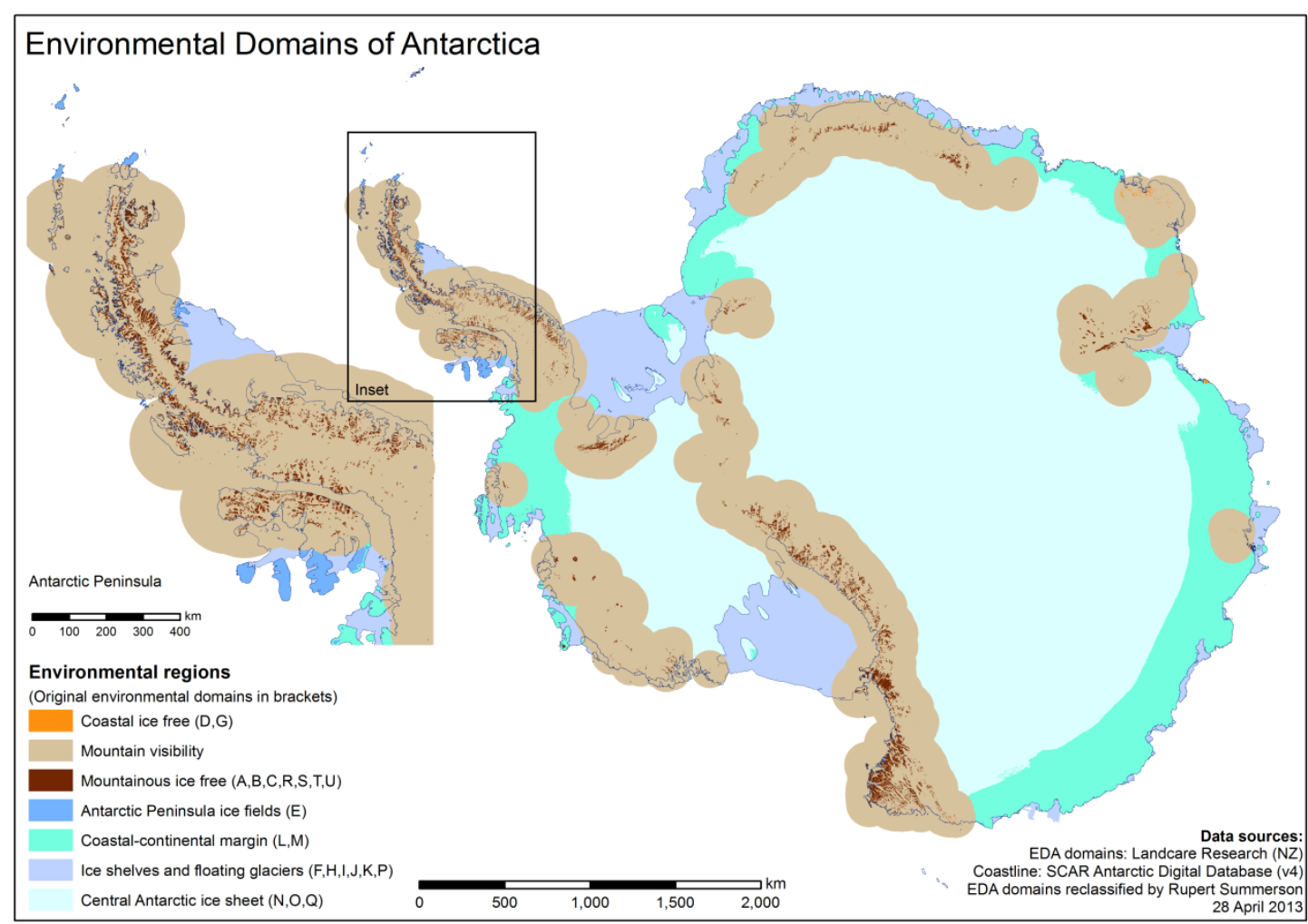

Figure 8.14. The reclassified EDA regions with mountain visibility overlaid. The original mountainous ice free layer is overlain on top of the visibility layer.

As noted above, however, the limit of the visibility extent of mountains should be discussed with environmental managers and others before any agreement on what that distance should be. Even though the coastal ice free EDA region has the lowest mean aesthetic preference rating, it does not mean that there are not localities within it that people do not find beautiful. A number of localities were nominated in the two "favourite places" surveys (Chapter 7): Peterson Island and Browning Peninsula in the Windmill Islands (Casey environs), Trajer Ridge in the Vestfold Hills (Davis environs) and Mount Henderson (near Mawson) were among the places nominated. Such places could be nominated for protected area status on the basis of their aesthetic values. A more rigorous process to determine their aesthetic value would be needed, however, based perhaps on one of the techniques outlined above.

\subsubsection{Sea ice zone}

The sea ice zone is a dynamic and transient, though substantial phenomenon, forming and disappearing over the space of a year. When it is fully formed it can be over two metres thick and strong enough to land large aircraft on (Morris \& Jeffries 1992). The only human activity in the sea ice zone are research vessels, the passage of re-supply vessels to and from Antarctic stations and a rare tourist ship - most tourism traffic takes places after most of the sea ice has 
dispersed. Responsibility for the establishment and management of protected areas lies primarily with CCAMLR, though the CEP has discussed marine protected areas extensively (CEP 2012). The Antarctic Treaty applies to the area south of $60^{\circ} \mathrm{S}$ (ATS 1959); the sea ice zone lies wholly within this band of latitude from about $50^{\circ} \mathrm{W}$ westwards to $105^{\circ} \mathrm{E}$. From $105^{\circ}$ $\mathrm{E}$ westwards to $50^{\circ} \mathrm{W}$ the maximum extent of sea ice extends north of $60^{\circ} \mathrm{S}$ (Doake 1987). There is an annual cycle in the growth and decay of sea ice; it reaches a maximum extent in about September when the area covered by sea ice effectively doubles the area of Antarctic ice. The minimum extent occurs in March in most years. The growth and decay of sea ice and the biological productivity associated with it is a key component of the Southern Ocean ecosystem (El-Sayed 1985).

For travellers passing through the sea ice zone, it is a wonderland of icebergs, animal and bird life, that, together with the adventure of breaking through the ice and the noise and drama that accompanies it, is a notable feature of a sea voyage to Antarctica. The lack of human impact on the sea ice zone and the rich aesthetic values experienced while traversing it make it a logical candidate for inclusion in any system of protected area to protect these values. A number of survey respondents mentioned the sea ice zone as a "favourite place".

\subsection{Conclusions}

The results of the Internet survey (Survey 3 ) indicate that the visibility of infrastructure detracts from wilderness value. Making the assumption that all of Antarctica is wilderness, for reasons expounded in Chapter 5, except for those areas that have been degraded by human activity and that the definition of such areas is that they are areas from which human infrastructure is visible, procedures for delimiting those areas have been described. Visibility modelling in a GIS is a routine method of determining the visibility footprint and requires two data sets: the extent and height of infrastructure and a digital elevation model and GIS software to generate the visibility model. There are two levels of infrastructure: the physical footprint of a station and, where appropriate, the visibility footprint of satellite infrastructure, e.g. field huts and airstrips. Although it is not possible to map the visibility footprint of every item of infrastructure in Antarctica, it is possible to estimate the visibility footprint from the three case studies undertaken. Modelling of human-generated noise indicates that noise does not extend as far as visibility of infrastructure. An attempt has been made to compile a data set of all infrastructure in Antarctica from a number of different sources and from this to create an estimate of the impact of human facilities on wilderness, the first time that this has been attempted. The results of this assessment show that human influence extends over $30-40 \%$ of coastal ice free areas 
but over less than $1 \%$ of the entire continent, suggesting that most of it can still be described as wilderness.

Spatial modelling of aesthetic value has been largely confined to delineating the visibility extent of mountainous areas, which were assessed as having high aesthetic value by Surveys 2 and 3 . The definition of aesthetic value in local or regional areas was not carried out but techniques developed elsewhere, e.g. in Australia (Wu et al. 2006) and Germany (Frank et al. 2013), could readily be applied and would benefit environmental management as required under the Madrid Protocol. 


\section{Chapter 9. Discussion and Conclusions}

\subsection{Introduction}

The genesis of this thesis was the coming into force in January 1998 of the Madrid Protocol, which calls for the protection of the wilderness and aesthetic values of Antarctica, amongst many other environmental measures. In the 15 years since the Protocol came into force, although there has been considerable discussion, especially about wilderness and related topics in the Committee for Environmental Protection, e.g. the human footprint in Antarctica (CEP 2010: 3), there has been little progress with implementation of protection of either of these values.

As described in Chapter 3, the inclusion of wilderness and aesthetic values as values to be protected did not arise at the last minute during the negotiation of the Madrid Protocol, perhaps as an inducement for support by the Green lobby. They were put forward for protection by scientists and promoted by SCAR as important components of the Antarctic environment as early as 1985 (Benninghoff \& Bonner 1985). Indeed, these values had been included in the Convention on the Regulation of Antarctic Mineral Resources Activities (CRAMRA) (ATS 1988), the failure of which precipitated the negotiation of the Madrid Protocol (Jackson \& Boyce 2011). The aesthetic qualities of Antarctic landscapes have been remarked on and recognised since the earliest days of Antarctic exploration from John Biscoe's observation in 1832 of Adelaide Island's "most imposing and beautiful appearance" (Jones 1992: 74) to Stump's "I did not believe that any grouping of summits (the Organ Pipe Peaks) could be so dramatic, beautiful, and perfect" (Stump 2011: 199). No evidence can be found to suggest that appreciation of Antarctic landscapes has declined over the 192 years since the continent was first sighted.

The delay in implementing protection of these values has been ascribed partly to the lack of definitions of wilderness value and aesthetic value in the text of the Madrid Protocol (e.g. ATS 2004; Bastmeijer 2005) and partly to more urgent matters such as management of protected areas and control of non-native species (H. Keys, pers. comm.). The first task must therefore be to prepare workable definitions of wilderness value and aesthetic value that are acceptable to all Antarctic Treaty Consultative Parties. Two implications flow from this: the first is that some compromises will probably be necessary, as is the nature of international diplomacy, and secondly simple definitions will be better than complex definitions, especially since definitions will have to be translated into the three other Antarctic Treaty languages. 


\subsection{How the results of the surveys guide the formulation of definitions}

The empirical basis underpinning this thesis is three surveys on perceptions of wilderness and aesthetic preference in Antarctica. Over 500 people from 24 nationalities contributed to the surveys. Most of the respondents had varying amounts of Antarctic experience, most from time with national Antarctic programs but some as tourists and some from experience with the tourism industry. $25 \%$ of all respondents had not visited Antarctica, however, but an important point to note is that analyses of aesthetic preference and perceptions of wilderness show that there is no statistically significant difference between those people who have visited Antarctica and those who have not (Chapter 7). In other words, Antarctic experience is unimportant when judging wilderness and aesthetic value. This is a valuable finding for the implementation of protection of these values as it shows that wilderness and aesthetic values are widely held, not just by a perceived Antarctic elite.

The Internet survey (Survey 3 (described in Chapter 6)) was the broadest and most sophisticated of the three surveys carried out as part of this research. 435 responses were received and the results derived from these therefore provide the most detail on perceptions of wilderness, aesthetic preference and what detracts from wilderness and aesthetic value. There is a reassuring level of consistency between the three components of the survey: perceptions of wilderness, aesthetic preference and the semantic descriptors component, especially in two key areas: the impact of human activity, i.e. human presence in the images and in responses to the six different landscape types (EDA regions). Similar patterns of human impact can be seen across all three components of the survey, most strikingly in the semantic responses (e.g. Figure 7.18).

There is a clear inverse relationship between human presence, including the type of human presence, and perceptions of wilderness and aesthetic preference ratings. None of the fourteen highest scoring images for aesthetic preference in the Internet survey included human presence and the ten lowest scoring images all included human presence. Nine of the latter images included infrastructure, the other was a low-flying aircraft. The range in mean raw aesthetic scores (on a seven point scale) across all images, including images with human presence and those without, was from 6.32 , the equivalent of a score of over $90 \%$, to 2.28 , the equivalent of a score under $33 \%$. Of the images without human presence, the range in mean raw scores was from 6.32 to 4.08 , the latter the equivalent of a score over $58 \%$. Thus human presence, in its least attractive form, resulted in a depression of aesthetic preference by at least 25 percentage points from the least attractive image with no human presence. The 17 manipulated pairs in survey 3 were the most sensitive to human presence and they therefore give the most reliable 
indicator of impact. There was a statistically significant difference between twelve of the pairs of images in terms of aesthetic preference and between thirteen pairs of images in terms of perceptions of wilderness.

What cannot be determined, however, is how significantly these results will be perceived by policy makers and whether a $30 \%$ decline in aesthetic preference, for example between the two images in Figure 7.18, will be sufficient to sway their decisions. Nevertheless, the evidence shows that people value undisturbed environments and the Madrid Protocol was signed into international law to protect those values.

\subsubsection{Perceptions of wilderness}

As argued in Chapter 5, given the vast size of Antarctica, most of which, unlike much of the settled continents, has been little affected by human activity; the history of the word “wilderness" (Nash 1975; Oelschlaeger 1991; Vest 1985) and its common modern usage to mean, in general terms, the absence of human activity and artefacts; the lack of indigenous humans and a settled human population, it seems reasonable and logical to describe those areas of Antarctica that have not been affected by human presence as wilderness.

Discussions in the Committee for Environmental Protection have largely centred on the concept of "footprint", i.e. the area affected by human activity (ATS 2011b). In a continent that is otherwise more or less untouched by human activity, if planetary level influences are excepted, e.g. climate change, ozone depletion and $20^{\text {th }} \mathrm{C}$ radioactive fallout from nuclear weapons testing, the converse of the human footprint must logically therefore be wilderness. This view is not, however, universally held. Prof. Dr. Lochte, the presenter of the SCAR Lecture at ATCM XXXII in Baltimore in 2009 opened her presentation (ATS 2009) with the following rhetorical question:

Is Antarctica a symbol of the great wilderness and the pristine environment?

And then gave the following reply:

No, Antarctica is inextricably linked to global atmospheric, oceanographic and climatic processes and therefore exposed to the impact of human activities in the rest of the world!

As the results of the survey demonstrate, perception of wilderness is diminished by human presence at every level within the survey, i.e. all images combined, all images combined by EDA region and pairs of manipulated images. The presence of infrastructure consistently diminishes perceptions of wilderness. Other types of human presence, such as transient activity, especially heavy vehicles, also detract from perceptions of wilderness. The converse of this is also true; that people perceive untouched Antarctica to be real wilderness. 
Lothian (1999: 177) suggests that there are two paradigms of landscape aesthetics: "objectivist", which includes assessment "by applying criteria" and "subjectivist", which includes assessment "using psychophysical methods" (p. 178). A similar division occurs within techniques for the assessment of wilderness. The dominant paradigm, which has been widely applied in the settled continents, is the "objectivist" approach, which is the geospatial analysis of mapped data, for example remoteness from settlement (Lesslie and Maslen (1995), Kliskey and Kearsley (1993) and Aschehoug (2000)). The "subjectivist" approach, which is based on subjective perception of wilderness has hardly been applied, c.f. Lutz et al. (1999), but is considered to be the most appropriate method in Antarctica given the thinly scattered human "settlements", the paucity of data on infrastructure and the requirements of the Madrid Protocol (Summerson \& Bishop 2012). This approach established through surveys whether human presence detracts from wilderness.

Survey participants were asked the following question about wilderness: "Does this scene represent wilderness to you?" The response requested was "yes" or "no". The rationale for this binary approach, as opposed to grades of wilderness, was that it has been my observation that people, when asked whether a locality is wilderness, usually reply either "yes" or "no", seemingly based on an observation of their surroundings and a judgment of whether the locality matches their conception of wilderness. In order to test for the impact of infrastructure on perceptions of wilderness, a "yes"/“no" response was considered to be sufficient. The advantages of this approach are that it forces people to decide whether or not the scene represents wilderness and that it provides clarity in that a scene is perceived as either wilderness or not wilderness. The basis for wilderness designation used here, therefore, is subjective judgment, which, in many ways is consistent with Nash's dictum that "wilderness, in the final analysis, is a state of mind" (Nash 1975), though noting also that while it may be a state of mind, 'wilderness' is also used to designate a particular characteristic to a place. The latter is the way wilderness is defined in the US Wilderness Act.

Grades of wilderness can be derived from geospatial data where, in the National Wilderness Inventory approach, for example, the weighted values of the four indicators are summed to arrive at a wilderness quality index (Lesslie \& Maslen 1995: 34). (Bradbury (1996) made some harsh criticisms of the weighting system and application of indicators in the NWI). The underpinning rationale to this is that Nash (1975) proposed that there is "a spectrum of conditions or environments ranging from the purely wild on the one end to the purely civilized on the other - from the primeval to the paved" (Nash 1975). The development of the National Wilderness Inventory (NWI) (Lesslie \& Maslen 1995), for example, is based on this idea. There are, however, a number of problems with this approach in Antarctica: 
1. Wilderness classification schemes such as the NWI, and others, e.g. Kirkpatrick and Haney (1980), Klisky \& Kearsley (1993), are based on mapped data on settlements, roads, land use, etc. The data for most stations is limited to its location, i.e. a single point (COMNAP 2012). Most stations comprise a small cluster of buildings and some piles of stores - and little else.

2. The "wildness continuum" (Helburn 1977) is almost non-existent. There is a relatively safe environment within the station area which dissipates rapidly away from the station almost entirely as the station disappears from view.

3. As argued in Chapter 5, the "default" condition of Antarctica is wilderness. The wilderness definition process is therefore reversed to identify areas of non-wilderness.

As Lesslie \& Taylor (1985) acknowledge: "Nevertheless, at some point towards the wild end of the continuum, a threshold must still be established to distinguish wilderness from nonwilderness" (p 316). Hendee, et al. (1978) also acknowledge that there is a "... threshold on the environmental modification spectrum that separates wilderness from other land uses" ( $p$ 138).

There has been a consistent but small percentage of people in the surveys who have rated entirely natural scenes as not wilderness. The reason for this may be, as some respondents expressed to the author during the second survey, that as they could not view a full $360^{\circ}$ panorama at each site, and could not therefore be sure that there was not some human presence out of sight of the camera, they could not be sure that the location in the image was wilderness. It was not feasible to construct a survey that achieved all the desired objectives that comprised $360^{\circ}$ panoramas. In order to address this concern, respondents in the second survey were asked "... to treat the images as being representative of what you would be able to see around you", in other words not to imagine the presence of things they could not see. At the other end of the spectrum there may easily be people for whom life even on a station is a challenge and that being far from friends and family in an alien environment is like being in a wilderness. I have encountered a number of people with this sort of attitude (pers. obs.).

In conclusion, noting the clear preference for natural environments without human presence and based on the assumption that all Antarctica can be considered as wilderness, except where it has been degraded by human activity and that visibility of infrastructure is a simple method of determining the footprint of human activity, a definition of wilderness in Antarctica could therefore be as follows:

\section{Wilderness in Antarctica comprises all those areas from which human infrastructure cannot be seen.}




\subsubsection{Aesthetic preference}

Aesthetic preference, by contrast, was requested on a seven point scale for the reasons discussed in Chapter 6. Despite the cumbersome expression "aesthetic value" and the potential confusions about what "aesthetic" means (discussed in Chapter 5), survey respondents seemed to have no difficulty in making aesthetic judgements about the images on offer in the survey and no comments were received about any misunderstandings about what was asked of them.

\subsubsection{Ice-free areas}

The consistently different response to landscapes in the coastal ice-free environmental region by comparison with the other environmental regions is notable. The most likely reason is that people do in fact relate to coastal ice-free areas differently to the rest of Antarctica. The Vestfold Hills, where Davis Station is sited, is the largest coastal ice-free area in Antarctica (Ferris et al. 1988). In the Australian Antarctic Program it is popularly known as the "Riviera of the South" (Snowman 1993: 153) as, despite being the farthest south of the Australian stations, it has a relatively benign climate. Even the founder of Davis Station, Dr Phillip Law, described the hinterland of Davis as a "depressing desert" (Law \& Béchervaise 1957: 14). He went on to say that "Except for the icebergs to the west and the narrow rim of plateau ice peeping over the tops of the hills to the east, there is little to remind one of Antarctica." This may be the reason why coastal ice-free areas are judged differently to other Antarctic landscapes; they do not conform to an ideal of what Antarctica should be. This point needs further investigation as coastal ice-free areas are where human activities are concentrated and their impact is greatest (Jabour 2009). It would be unfair not to point out that these attitudes are not universally held, though it has been difficult to find affectionate descriptions of the Vestfold Hills. Despite the presence of an Australian research station there for over 50 years, very little seems to have been written about the landscape qualities. One of the few exceptions is Adamson and Pickard (1986). They wrote:

"The Vestfold Hills are seen by many who visit Davis as a colourless flat landscape of low islands and hills, a landscape of brown rock blasted by sand and salt and snow, a rocky desert where the ice sheet is over $20 \mathrm{~km}$ distant inland. The absence of alpine nunataks like those in Victoria Land or Mawson, adds to the impression of dullness. Like any desert, however, the area is beautiful in its own way and of absorbing interest. Why is so large an area free of ice; how has it developed; is the ice margin now advancing, or retreating, or stable; why is there so much salt about; how have the amazing terraces formed around some of the lakes; how has the ancient geology controlled the present shape of the land surface? The questions are endless" (Adamson \& Pickard 1986: 99).

For a quite different perspective, Jan Senbergs, an artist who participated in an ANARE voyage in 1987, said: 
"The Vestfold Hills are a bit like a moonscape, with rough, earth-coloured jagged rocks with black dyke marks running right across them, and wonderful translucent lakes in the centre. And then the icecap, the dome in the distance, dominating everything, with a beautiful sky. It's dangerously attractive." (Boyer 1988: 35)

The scientific interest in the Vestfold Hills, on the other hand, is evidenced by the extent of the literature on the results of scientific research carried out there. A bibliography of scientific literature on the Vestfold Hills has been compiled by the Australian Antarctic Division (Gibson \& Bourke 2010) which contains over 650 papers, books and other works.

It is notable that many of the people surveyed about their favourite places nominated places in the Vestfold Hills and the Windmill Islands, two coastal ice-free areas (Chapter 7). The reality of much of the scientific work carried out by the Australian Antarctic program, especially the life sciences, is that it is carried out in coastal ice-free areas. Only Mawson Station is situated near mountainous terrain. So while people may express aesthetic preference for big snow covered mountains and the vast icescapes of the interior of Antarctica, for many Australians, their experience of Antarctica has been in the relatively modest surroundings of the Vestfold Hills and the Windmill Islands and they have developed some affection for these terrains through their experiences. Despite the differences in aesthetic preference responses to coastal ice free areas in comparison with the other landscape types in Antarctica, it may not be fair or appropriate to make the assumption that coastal ice free areas are less valued than other terrains. As noted above, the results of the semantic descriptors component of the survey are consistent with the other elements of the survey in terms of perceptions of coastal ice free areas in comparison with other landscape types. They are also consistent with other descriptions of Antarctic landscapes. The high ranking given to 'Vast', for example, is consistent with statements such as:

"It is a vast wonderland laid out on a giant scale, in which littleness has no place; but its very vastness, no less than its beauty ..." (Brown et al. 1906: 78).

"The mountains were formed on such a gigantic scale that, in spite of our vicissitudes in reaching them on the last day of our march, we had begun to form definite notions about their structure and general make-up from as much as 20 miles away" (Gould 1984: 121)

"... and as the mountains were left further behind, we were, once more, amazed by the vastness of pure open space that characterises the Antarctic" (Pearce 2004: 135).

The high rating given to 'Beautiful' is also consistent with frequent comments about the beauty of Antarctica:

"A half moon smudged the sky above the mast-head. Then a halo appeared, illuminating the clouds, the waves and the iceberg itself. We were in raptures, lost in admiration of the truly 
sublime natural beauty of Antarctica" (Shirase Antarctic Expedition Supporters' Association

2011: 129)

In conclusion, noting the clear preference for natural environments without human presence, a definition of aesthetic value in Antarctica could therefore be as follows:

Areas of the natural environment that have been judged by people to be beautiful - taken in a broad sense to encompass a variety of modes of beauty such as the sublime.

\subsubsection{Relationship between wilderness and aesthetic values}

In Chapter 5 I argued that wilderness and aesthetic values are separate sets of values, it is clear, however, that there is a relationship between these sets of values. As also noted in Chapter 5, wilderness areas may have high aesthetic values but that conversely areas of high aesthetic value need not be wilderness. As described in Chapter 7 (Results) a relationship between these values is apparent (Figure 7.7). Summerson and Bishop (2012) noted this relationship but concluded that how the relationship was formed in people's minds and what it represented was an open question. No further research has been carried out in this topic but it is worth noting how both ratings decline with increasing intensity of human presence/activity and that the relationship between positive aesthetic preference ratings and the lack of human presence has been noted elsewhere, e.g. Wu et al.(2006) and Sevenant and Antrop (2009).

\subsubsection{Impacts of human activities on wilderness and aesthetic values}

Summerson and Bishop (2012) investigated the impacts of human activities on wilderness and aesthetic values and their results have been updated in Chapter 7 with more up to date data. The new data confirms their conclusions. Summerson and Bishop (2011) also investigated semantic responses to the Antarctic environment and in particular adjectives describing the beauty of Antarctic landscapes, both in terms of the beautiful and the sublime. The impact of human activity on semantic descriptors was also described (Summerson and Bishop 2011: 237).

\subsection{Application of results to the implementation of protection for wilderness and aesthetic values}

The Madrid Protocol provides two formal mechanisms for the protection of wilderness and aesthetic values. The first of these is through the Environmental Impact Assessment process laid out in Annex 1, the second is through the area protection system laid out in Annex V. There is potentially a third mechanism, which is an ATCM resolution but given that the Protocol has mechanisms already put in place, an ATCM resolution would probably be unnecessary. 
Davis Station in the Vestfold Hills has been occupied for 50 years, with a gap of four years in the 1960s, and has been one of the main foci of scientific research by ANARE during this period. There are 9 field huts in the Vestfold Hills (including Marine Plain) (AAD 2002) and a number of other items of infrastructure such as a radio repeater on Tarbutt Crag, a tent depot at Boulder Lake and a bridge at Ellis Rapids. In addition to these there is widespread evidence of human activity in the form of partially constructed segments of roads (Figure 9.1), cairns, survey marks, sites of scientific activity and litter (pers. obs.). 16 campsites have also been identified and recorded in the place names database. The field huts and other features in the Vestfold Hills are shown in the map in Figure 9.2.

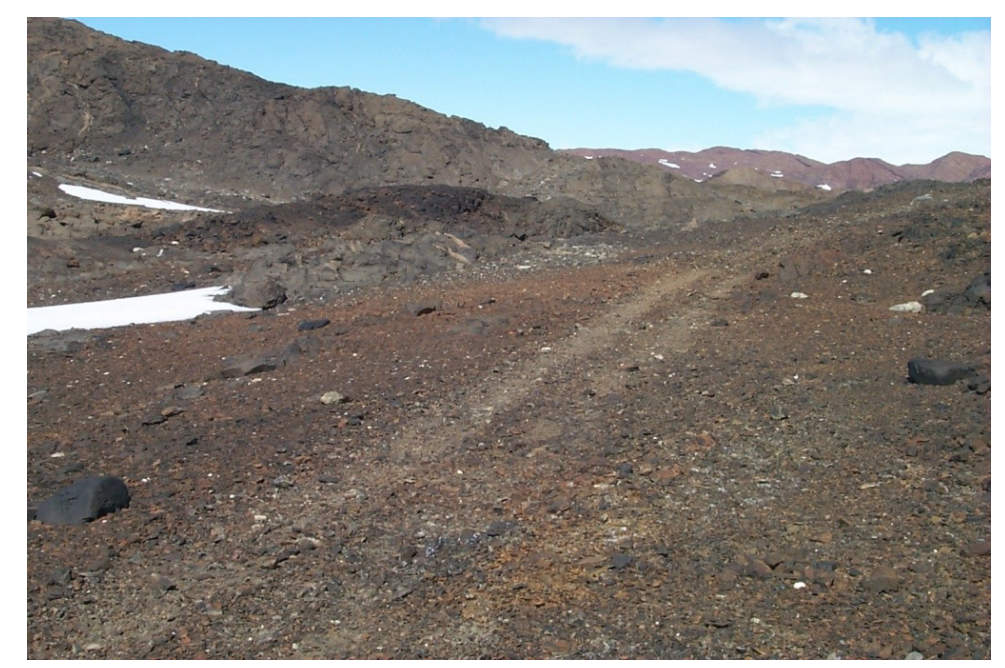

Figure 9.1. Vehicle tracks in the Vestfold Hills. Evidence of widespread human activity. 


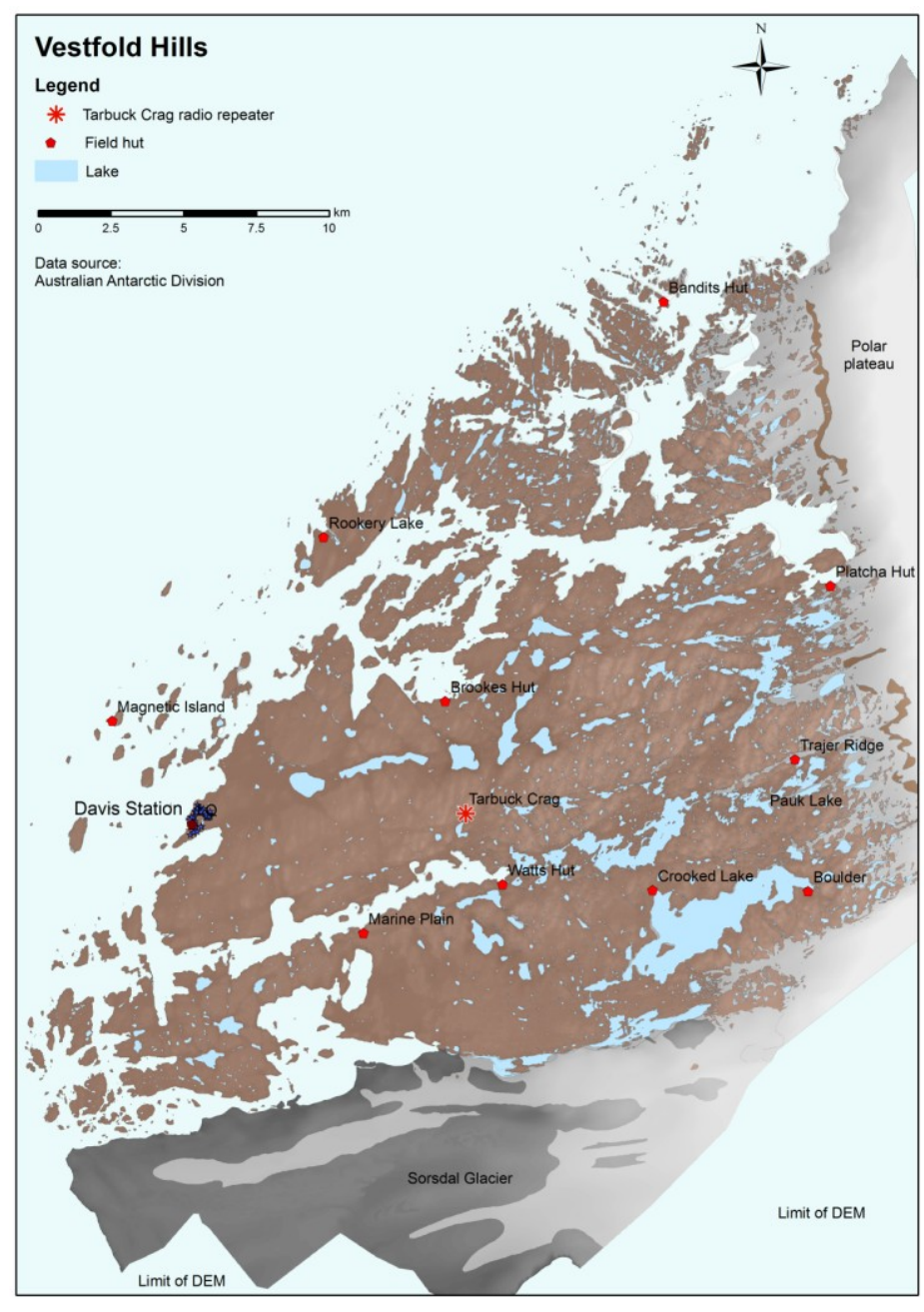

Figure 9.2. Davis Station, the field huts and other features in the Vestfold Hills.

This leads to a polemic: can the Vestfold Hills be described as wilderness? A visibility map of infrastructure only, i.e. Davis Station, the field huts and the Tarbutt Crag radio repeater (Figure 8.5) shows that infrastructure is visible across most of the Vestfold Hills and, together with the other evidence of human activity (e.g. Figure 9.1), would suggest that the Vestfold Hills could not be described as wilderness if a high standard of wilderness preservation is to be maintained in Antarctica. In its present condition the Vestfold Hills should not be considered wilderness. It is considered that it is more important to maintain a high standard of wilderness condition, i.e. pristine, than to accede that some level of degradation of wilderness is acceptable. If that is the case, two equally unpalatable conclusions could be drawn. The first is that if the Vestfold Hills were to be declared as no longer wilderness, that would leave the area vulnerable to further degradation on the basis that since it is already degraded, it no longer matters what happens to it. The alternative conclusion is that, despite the level of degradation that has taken place, if the Vestfold Hills were to be declared as wilderness, it could lead to the conclusion that that level of degradation could be set as a benchmark as still satisfying the criterion of the condition of 
wilderness, so other areas could be degraded to a similar level and still be described as wilderness.

The correct solution to the dilemma is to restore the Vestfold Hills to pristine condition by removing all surplus infrastructure, cleaning up the signs of human occupation, which includes removing the sections of vehicle track and, if possible, hiding the radio repeater on Tarbuck Crag. This could be achieved through the establishment of a management plan in which the restoration of the Vestfold Hills to wilderness is a management objective. Lewis Smith (1994: 33) suggested that the Vestfold Hills (and Larsemann Hills) were regions where Antarctic Specially Protected Areas could be designated to protect wilderness (and other values) on the basis of human impact threatening specific conservation values. That could still be achieved.

\subsubsection{Protection of Wilderness and Aesthetic Values through the}

\section{Environmental Impact Assessment System}

The Madrid Protocol mandates that environmental impact assessments (EIAs) be conducted for all activities in Antarctica prior to their commencement. Article 8 of the Madrid Protocol stipulates that EIAs are required for "scientific research programs, tourism and all other governmental and non-governmental activities", in other words all activities in Antarctica. Annex I of the Madrid Protocol (Environmental Impact Assessment) identifies three levels of potential impacts:

- less than minor or transitory;

- minor or transitory; and

- greater than minor or transitory.

And there are three levels of assessments: Preliminary, Initial and Comprehensive. The decision which level of assessment is required depends on whether the proposed activity will have a less than, equal to, or greater than minor or transitory impact.

It has been one of the criticisms of the Madrid Protocol that none of these terms were defined which leaves open the possibility of different interpretations by different ATCPs (Bastmeijer \& Roura 2008; Huber 2011: 93). Guidelines for environmental impact assessment have been set out (ATS 2005) but they acknowledge that:

"Although the key to decide whether an activity shall be preceded by an IEE or a CEE is the concept of "minor or transitory impact", no agreement on this term has so far been reached. ... The difficulty with defining "minor and transitory impact" thus far appears to be due to the dependence of a number of variables associated with each activity and each environmental context. Therefore the interpretation of this term will need to be made on a case by case site specific basis." (ATS 2005: 2) 
The guidelines state later that " . . it may be useful to consider how similar impacts have been judged in earlier EIAs at similar sites and/or for similar types of activities" (p 12). The ATS maintains a database of over 1000 EIAs at all three levels (PA, IEE and CEE) which can be consulted (ATS 2011a).

The results of this research provide information which can be used to identify which level of EIA is appropriate for potential impacts on wilderness and aesthetic values. The application of each of these levels of EIA will be discussed separately.

\section{Preliminary environmental evaluation}

Annex I (Article 1, Section 2) states that if an activity is determined as having less than a minor or transitory impact, the activity may proceed forthwith.

It is proposed there are two conditions that activities would need to meet to avoid having a minor or transitory impact on wilderness and aesthetic values:

1. The activity is transient only, does not include the construction of infrastructure and leaves no scars on the landscape; or

2. If the construction of infrastructure is proposed, it must be within the existing station footprint (Chapter 8) and must not increase the visibility or auditory footprint.

\section{Initial environmental evaluation (IEE)}

Annex I (Article 2) states that an IEE “....shall contain sufficient detail to assess whether a proposed activity may have more than a minor or transitory impact ..." and that if an IEE "indicates that a proposed activity is likely to have no more than a minor or transitory impact, the activity may proceed, provided that appropriate procedures, which may include monitoring, are put in place to assess and verify the impact of the activity."

The results of the survey indicate where the difference between 'minor' and 'not minor' may lie. In the manipulated pairs component, where differences between images with infrastructure are detectable, but not significant, could be described as minor, noting that there are some differences in whether or not the impact is on wilderness or aesthetic values, for example, there is a significant difference in the impact of the field hut in Pair 14 on wilderness (Table 7.16) but not on aesthetic values (Table 7.20) (noting also that two different statistical techniques were used to determine significance). Where the differences are significant they could be described as more than a minor impact. The method used to carry this out is described in the next section.

\section{Comprehensive environmental evaluation}

A comprehensive environmental evaluation (CEE) is required if the proposed activity will have a more than minor or transitory impact. A CEE, as its name implies, requires a comprehensive 
study of potential impacts as laid out in Annex I to the Madrid Protocol (ATS 1998). 38 CEEs have been carried out since 1988 (ATS 2011a). The following are extracts from recent CEEs in the ATS EIA database (ATS 2011a) to illustrate how potential impacts on wilderness and aesthetic values are typically treated.

Final Comprehensive Environmental Evaluation of New Indian Research Base at Larsemann Hills, Antarctica

6. Identification, Prediction of Impacts and Mitigating Measures

6.3.8 Aesthetic and Wilderness Value

The station is designed as three-storey building covering around $1800 \mathrm{~m} 2$ of area including laboratories, food and storage facilities etc. Operation of the station and movement of the rotor of the wind turbine at the site may slightly affect the aesthetic look of the area to the visitors and also to some extent affect the wilderness value. However, the station will be visible from the sea only if the line of the sight is clear.

Final CEE: Construction and Operation of a new Belgian Research Station, Dronning Maud Land, Antarctica

5.9. Scenery and Aesthetic Natural Values

The proposed site is a region where its exposed bedrock outcrops and glacial moraines, in combination with the Campbell Glacier to the east and Mt. Browning to the northwest, command a stunning scenery.

The station layout is intended to have a minimum impact on landscape and maintain the aesthetics of the region. The buildings and facilities at the station will be contained within the proposed site to reduce an influence on the local scenery as much as possible. Tracked vehicles will only de used on designated routes to minimize disturbances of the land surface.

No mention was made of potential impacts on wilderness values and the document was criticised for that oversight.

Final CEE: Construction and Operation of a new Belgian Research Station, Dronning Maud Land, Antarctica

5.10 Physical Disturbance, Aesthetic Values

The construction of a station on the ridge at Utsteinen Nunatak, an area of outstanding wilderness, will have a minor visual impact in the locality but only within line of sight.

Among the comments noted on this CEE was the following:

ASOC also thanked Belgium for an excellent CEE but expressed its concern about the cumulative impacts on the Antarctic wilderness and other intrinsic values of Antarctica resulting 
from the establishment of new stations in near-pristine areas. The 'no-go' alternative had to be considered carefully, and the alternative to proceed had to be justified on scientific grounds.

It is hard not to come to the conclusion from these examples that little more than superficial consideration was given to potential impacts on wilderness and aesthetic values. Given the very large costs of building a station in Antarctica and the necessity of an ongoing commitment to support it, the decision on whether or not to proceed is often as much political as scientific. The scientific justification for the construction of Bharti Station (the "New Indian Research Base at Larsemann Hills" listed above), for example, which was based on a "sacred geography"; the chosen site being where "the Indian geologists suggest[ed] that their selected promontory in the Larsemann Hills was where the Indian holy river Godavari flowed when the landmasses [of India and Antarctica] were connected" was met with derision when it was announced at ATCM XXIX (2006) (O'Reilly 2011: 226). The rationale, which was perfectly acceptable in India, was not well received in international/scientific circles and must therefore be seen as a political rather than a scientific decision.

\subsubsection{Protection of Wilderness and Aesthetic Values through the Area Protection System}

Annex V of the Madrid Protocol sets out the requirements for developing a system of protected areas within Antarctica. Wilderness and aesthetic values are included in the list of values to be protected:

\section{ARTICLE 3}

\section{ANTARCTIC SPECIALLY PROTECTED AREAS}

1. Any area, including any marine area, may be designated as an Antarctic Specially Protected Area to protect outstanding environmental, scientific, historic, aesthetic or wilderness values, any combination of those values, or ongoing or planned scientific research.

2. Parties shall seek to identify, within a systematic environmental-geographical framework, and to include in the series of Antarctic Specially Protected Areas:

(g) areas of outstanding aesthetic and wilderness value; ...

I argued in Chapter 1 that aesthetic values and wilderness values are different sets of values; it is to be expected therefore that areas to be designated for protection would differ. As noted in the section of implementation of the Madrid Protocol above, however, a number of parties have 
included wilderness and aesthetic values as joint values to be protected in a number of ASPAs and ASMAs.

None of the surveys undertaken above have been developed with the intention of using the results to identify areas that might be proposed for inclusion in the Protected Areas System (PAS). The process whereby such areas are identified and then nominated through the CEP and ratified by an Antarctic Treaty Consultative Meeting is one managed by national Antarctic programs. That process is partly pragmatic, in that an area may be nominated for protection because of an identified threat, impact and response process or it may be political, which is outside the scope of this thesis. As has been noted by others, e.g. Holdgate (1998) and Kakabadse (2000), Antarctica is already protected by the Madrid Protocol itself. The requirement under Annex V of the Madrid Protocol that "Parties shall seek to identify, within a systematic environmental-geographical framework, and to include in the series of Antarctic Specially Protected Areas ..." nine types of protected area, including "areas of outstanding aesthetic and wilderness value" has resulted in several regionalisations, including the Environmental Domains of Antarctica (EDA) (Morgan et al. 2007) (discussed in Chapter 6) and the Antarctic Conservation Biogeographic Regions (Terauds et al. 2012). Neither is suited to identifying "areas of outstanding aesthetic and wilderness value" as discussed in Chapter 6 without major modification. The inclusion of a "mountain visibility" region in the EDA, as discussed in Chapter 8 may go some way to making that regionalisation more suitable.

\subsubsection{Protection of wilderness values}

Holdgate (1998) notes that the Antarctic realm as defined by the IUCN (Udvardy 1975) comprises four biogeographical provinces, two of which comprise the Antarctic continent: Maudlandia (eastern Antarctica) and Marielandia (western Antarctica and the Antarctic Peninsula). He goes on to "conclude that Antarctica has two biogeographical sub-realms and that we should treat them as separate units when it comes to conservation" ( $p$ 15). He discusses the number of protected areas and notes that the combined area makes Antarctica the least well protected continent in terms of the area under formal protection. He then notes the measures introduced by the Madrid Protocol which could make Antarctica the most protected continent except for the lack of formal measures recognised by the IUCN. He believes that “... the Antarctic system must progressively conform with that [protected area system] adopted throughout the rest of the world" ( $p$ 16). Holdgate's vision for the extent of Antarctic protected areas in 2020 is for 100 strict nature reserves covering about 150,000 hectares $\left(1,500 \mathrm{~km}^{2}\right)$ and

“... at least ten very large ASMAs, probably totalling at least 10 million hectares $\left[100,000 \mathrm{~km}^{2}\right]$, covering areas of outstanding scenic quality - and I would expect numerous smaller ASMAs in 
the coastal regions where science, logistics, tourism and an increasing surge of mountaineering and adventurous travel will meet" (p 16).

Holdgate also notes that:

Article 3 of Annex V to the Protocol specifically adds geological, glaciological and geomorphological features and also "areas of outstanding aesthetic and wilderness values" to the criteria for establishing ASPAs. This is important. For National Parks set up to conserve wilderness have generally been huge. ... There is just no way the SCAR matrix can be used as a basis for defining such areas: a quite new approach is needed and with all respect to SCAR, the criteria used around the world to define wilderness and landscape areas are not those in which SCAR has expertise. If the ATCPs are serious, they should ask the World Commission on Protected Areas of IUCN to evaluate and make proposals. (Holdgate 1998)

As argued throughout this thesis all of Antarctica should be considered as wilderness unless it has been degraded by human activity. This situation is quite different to the other settled continents and needs to be emphasised. This argument has been proposed by a number of authors; as noted in Chapter 5, Codling (2001) suggested "that a reasonable working definition of wilderness in the Antarctic is: 'Any part of the Antarctic in which neither permanent habitation nor any other permanent evidence of present or past human presence is visible"' (p. 339). I propose that, with the exception of the areas within sight of human infrastructure, at any point anywhere in Antarctica the terrain is still as wild and hostile today as it was at the time the continent was first discovered. In order to protect the Antarctic wilderness and the values we ascribe to it, it is necessary first to clearly identify the human footprint in Antarctica. It does not make sense to set aside areas of Antarctica to be designated as wilderness when wilderness exists across the whole of Antarctica except for the relatively small patches of human influence. In terms of the requirement to develop a systematic environmental-geographical framework with which to develop a system of protected areas for wilderness values, the system needs to be different to that developed for the protection of fauna, flora, geodiversity, etc. The systematic environmental-geographical framework in this case should be to identify the areas of human activity, the "human footprint", not the other way round. Although the concept of human footprint has been widely discussed in the CEP (Harry Keys pers. comm.) and elsewhere, for example, GERG 2003, the development of a systematic environmental-geographical framework has not been considered in this way.

There are a number of options for designating areas for protection of wilderness:

1. Declare the whole of Antarctica as wilderness except for those areas where human activity means that they can no longer be considered wilderness.

2. Assume that areas of featureless ice cap and ice shelf are self-protecting and concentrate protection on ice-free areas. 
3. Provide protection for those areas that are at risk from human activity, e.g. from construction of stations by NAPs and from tourism and assume that the remoteness of other areas is sufficient to provide them with protection.

It may be argued that the Antarctic Protected Areas System should be developed using a single consistent framework and based on the EDA. Wilderness values are not the same as fauna, flora or geology. The former are concrete, quantifiable and mappable. Wilderness values are not, they exist in the absence of something concrete, namely the physical evidence of human activity. It makes much more sense to identify, quantify and map human activity and use this to act as a "cooker cutter" to map out areas that can no longer be considered as wilderness.

\subsubsection{Protection of aesthetic values}

Aesthetic value, like wilderness value, is not a concrete entity like a penguin colony or a moss bed, but, like wilderness value, is a state of mind or, perhaps more accurately, according to the "integrative approach" (Fenton \& Reser 1988), is the product of the interaction between mind and landscape (Willard 1980: 297). The Antarctic landscape is unique in many respects and since most of it has been undisturbed by human activity it has retained its natural aesthetic value. The surveys demonstrate that some features of the landscape are more highly valued than others, however. About $88 \%$ of the Antarctic continent is covered with grounded ice sheet (Fox $\&$ Cooper 1994) but, except for the edges, from which mountains, the coast and other features are visible, most of this is featureless with one part not much distinguishable from another. Markov et al. (1970: 333) suggest some differentiation on the basis of micro-relief in the surface caused by strong winds carving out sastrugi (Armstrong et al. 1973: 34) (Figure 1.3) and the effect of altitude and latitude should not be forgotten. Nevertheless, there is over 12,000,000 $\mathrm{km}^{2}$ of more or less featureless ice cap.

The designation of areas for the protection of aesthetic values should be approached in a more conventional way. The results from the survey show that mountainous areas have consistently higher aesthetic value than non-mountainous areas, i.e. the vast Antarctic ice-caps and iceshelves. As demonstrated in Chapter 8, the area perceived as being mountainous extends for some distance from the limits of the mountains themselves. Exactly how that distance should be calculated and what it should represent is yet to be determined. The question remains, though, how much of Antarctica's mountainous regions should be protected:

- Protect all mountain ranges, including their visibility area?

- Protect mountainous areas that are perceived to be under threat?

- Develop a process to identify certain mountainous areas that are perceived as having exceptional aesthetic value? 
The last question conforms best with the requirements of Annex V, which is to protect "areas of outstanding aesthetic and wilderness value". No single national Antarctic program has the reach to assess all the mountains in Antarctica so this question would be best put up to the CEP to be addressed cooperatively and multi-nationally.

The favourite places surveys identified a number of individual localities that should warrant further investigation into protection for their aesthetic values; Trajer Ridge in the Vestfold Hills, Browning Peninsula and Peterson Island in the Windmill Islands and Mount Henderson near Mawson were all nominated. These places could be used as case study areas for the development of ASPAs to protect aesthetic values. The survey methods described in this research (Chapter 6 ) would be a simple and proven way of proceeding. The tables compiled by Cohen (1988: 54) provide a simple way of estimating the sample size needed. To determine an effect size (see Table 7.20 for example) of 0.5 (a moderate effect) with a power level $=0.8$ (Cohen's "default" setting (p. 56)) and a significance level of 0.05 , the sample size would need to be 50. A similar procedure could be used to determine the potential impacts of a project that needed a CEE but with several manipulated pairs of images. In this case images of the proposed structure or structures would be added to images of the locality where the proposed structure is to be built and would be exposed to survey respondents in two sets of images as per the design of Survey 3. Survey respondents should be recruited from a wide base not just from within the institution for the results to be credible.

\subsubsection{Contribution to aesthetic theory}

The results of the survey indicate a significant difference in aesthetic preference between responses to coastal ice free areas and all other landscape types (Chapter 7). There have been a number of theories suggesting that aesthetic preference has an underlying evolutionary basis e.g. Appleton (1975), Kaplan (1987) and Orians and Heerwagen (1992). The aesthetic preference shown for landscapes other than coastal ice free areas in the research described here tends to undermine such habitat theories given that a) coastal ice free areas often abound with wildlife and sources of food, b) they are much safer and easier to travel through than icecovered terrains and c) are adjacent to the coast and therefore to access by ships. The reason for the preference for mountainous and snow and ice terrains over coastal ice-free terrains is unknown but should be the subject of further research.

The presence of water has also been theorised as being an important contributing factor to elevated aesthetic preference. Burmil et al. (1999), for example, state that "Water features have consistently been found to be important to human perceptual evaluations of landscape scenic 
quality ..." (p 99). Of the nine images of coastal ice free regions without human presence in Survey 3 three included water: a hypersaline lake, a freshwater lake (Figure 9.3) and sea in the middle distance with an island beyond. Most respondents would probably have found it difficult to determine the type of water body given the lack of familiar features people may associate with particular water bodies, such as trees.

In order to determine whether there was a significant difference in aesthetic preferences for images with water and those without an independent samples t-test was carried out to compare aesthetic preferences of images with water to those without. A significant difference was found between scores for images with water $(\mathrm{M}=-0.132, \mathrm{SD}=0.725)$ and scores for images without water $(\mathrm{M}=-0.324, \mathrm{SD}=0.872) ; \mathrm{t}(879)=-3.89, p=0.000$, two-tailed $)$. The higher mean score for images with water $(-0.132)$ than for images without water $(-0.324)$ shows that images with water were more preferred. The magnitude of the differences in the means (mean difference $=$ $0.192,95 \%$ CI: -0.29 to -0.095 ) was small (Cohen's $d=0.23$ ). This result supports the theory that water features contribute to higher aesthetic preferences - in Antarctica as well as in other environments.

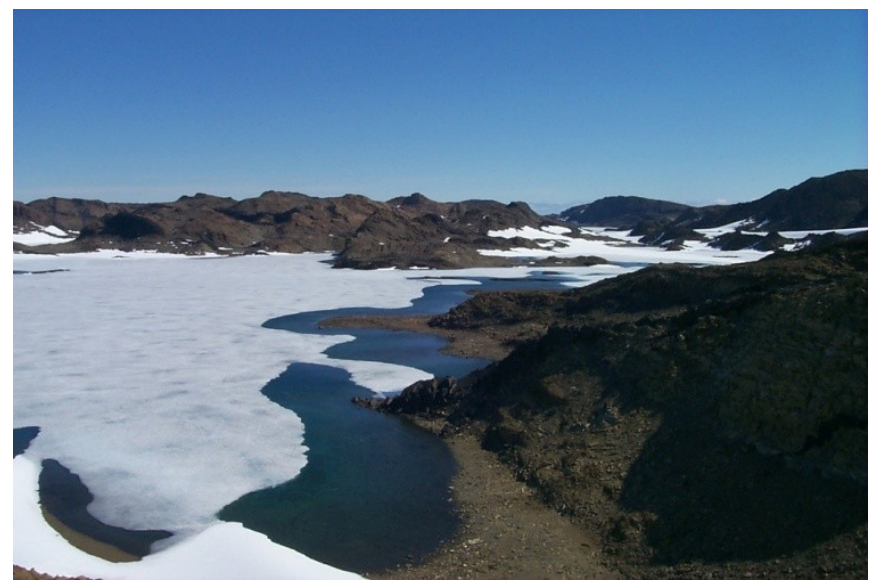

Figure 9.3. Image of a coastal ice free region including water. (Pauk Lake, a freshwater lake in the Vestfold Hills. Photo: Rupert Summerson.)

\subsection{Conclusions}

Five research questions were posed at the beginning of this research (Chapter 6):

1. What is wilderness in the Antarctic context - and therefore what area or areas can be designated as wilderness?

2. How can human impacts on wilderness values be defined and measured?

3. What are aesthetic values in the Antarctic context? 
4. Are some landscape types more highly valued aesthetically than others?

5. How can human impacts on aesthetic values be defined and measured?

The conclusions from this research and how they provide answers to these questions can be summarised as follows:

1. A strong case can be made to consider that the whole of Antarctica is wilderness unless it has been degraded by human activities;

2. While the determination of wilderness is subjective, the identification of non-wilderness areas in Antarctica can be easily determined by objective procedures in a geographical information system, i.e. through visibility analyses;

3. The impact of human activity in Antarctica on wilderness in coastal ice free areas is more extensive than had been anticipated;

4. While there are some differences in aesthetic responses to Antarctic landscapes, people clearly preferred natural landscapes, i.e. without evidence of human activity;

5. Mountainous terrains were the most aesthetically preferred landscapes, followed by snow and ice-covered landscapes;

6. Coastal ice-free terrains were the least aesthetically preferred landscapes but that should not be taken to mean that coastal ice-free terrains were not valued, just relatively less valued;

7. Infrastructure and heavy vehicle movements detract from both wilderness and aesthetic values;

8. People on foot and with light vehicles do not generally detract significantly from wilderness and aesthetic values;

9. While there is a detectable relationship between perceptions of wilderness and aesthetic preference and human presence is a factor, how the relationship is formed in people's minds is not known;

10. Demographic factors in the assessment of wilderness and aesthetic seem to be relatively unimportant, for example, there was no significant difference between tourists, experienced Antarctic veterans and people who have not visited Antarctica in aesthetic preference or perceptions of wilderness;

11. A survey on the Internet is able to provide a large sample size and therefore provide a high degree of statistical power which gives confidence to the results.

A number of problems were encountered which it would be useful to address: 
1. It was surprisingly difficult to obtain reliable and accurate information about human infrastructure and artefacts in Antarctica. A comprehensive audit of all infrastructure, artefacts, abandoned equipment and sites, depots, marked routes, etc would enable an accurate baseline of the human footprint in Antarctica to be established and a calculation of the extent and the area of wilderness remaining.

2. It was also difficult to obtain access to Antarctic tourists to contribute to a survey. A strategic approach to research on Antarctic tourism to be developed in conjunction with IAATO is warranted.

As with most research a number of questions have become apparent that would benefit by more research:

1. The reasons for the differences in valuation of coastal ice-free terrains and others;

2. More detailed analyses of the semantic component of the survey and exploration of relationships with aesthetic preference and perception of wilderness would yield more insights into how people relate to Antarctic landscapes;

3. Further research is needed on demographic factors in responses to wilderness and aesthetic values, especially nationality and presumably, therefore, culture;

4. More research is needed on methods of implementing protection for wilderness and aesthetic values in Antarctica.

The findings of this research, as reported in this thesis, are the most comprehensive set of broadly based information on what actually constitutes the wilderness and aesthetic values of Antarctica. Despite identified deficiencies they have already started to provide a sound basis for policy development and implementation under the Madrid Protocol and, hopefully, will continue to do so. 


\section{Antarctic glossary and acronym list}

\section{Glossary}

Agreed Measures. Agreed Measures on the Conservation of Antarctic Flora and Fauna. 1966.

Madrid Protocol. Protocol on Environmental Protocol to the Antarctic Treaty. Signed in 1991, ratified in 1998.

Antarctican, also ex-Antarctican. Someone with experience of Antarctica, usually for an extended period with a national Antarctic program.

Winterer. Someone who has spent a winter in Antarctica.

\section{Acronyms}

AAD. Australian Antarctic Division

ALCI. Antarctic Logistics Centre International

AFIM. Antarctic Flight Information Manual

ANARE. Australian National Antarctic Research Expeditions

ANI. Adventure Network International

ALE. Antarctic Logistics and Expeditions

ASMA. Antarctic Specially Managed Area

ASOC. Antarctic and Southern Ocean Coalition

ASPA. Antarctic Specially Protected Area

ATCM. Antarctic Treaty Consultative Meeting

ATCP. Antarctic Treaty Consultative Party

ATS. Antarctic Treaty System also Antarctic Treaty Secretariat

AWS. Automatic weather station

BAS. British Antarctic Survey

CCAMLR. Convention on the Conservation of Antarctic Marine Living Resources

CEP. Committee for Environmental Protection

COMNAP. Council of Managers of National Antarctic Programs

CRAMRA. Convention on the Regulation of Antarctic Mineral Resources Activities

DROMLAN. Dronning Maud Land air network

EDA. Environmental Domains of Antarctica

GIS. Geographical Information System

IAATO. International Association of Antarctic Tour Operators

IGY. International Geophysical Year

MDS. Multidimensional scaling 
NAP. National Antarctic program

NSF. (US) National Science Foundation

SATCM. Special Antarctic Consultative Meeting

SCAR. Scientific Committee on Antarctic Research

SPA. Specially Protected Area

SSSI. Site of Special Scientific Interest

USAP. United States Antarctic Program 


\section{References}

AAD. 2000. Initial Environmental Evaluation of the proposal to install a four turbine wind farm at Australia's Mawson Station at MacRobertson Land Antarctica. Kingston, TAS: Australian Antarctic Division.

AAD. 2002. Field huts around Davis. Kingston, TAS: Australian Antarctic Division. http://www.antarctica.gov.au/living-and-working/stations/davis/environment/field-huts. Accessed 3 March 2010.

ABS (Australian Bureau of Statistics ). 2012. Australian Bureau of Statistics. Household Use of Information Technology, Australia, 2010-11. Cat. no. 8146.0. Australian Bureau of Statistics 8146.0.

http://www.ausstats.abs.gov.au/Ausstats/subscriber.nsf/0/9B44779BD8AF6A9CCA25768D002 1EEC3/\$File/81460_2008-09.pdf. Accessed 20 December 2012.

Adams, R. (ed.) 1990. Antarctica. Voices from the silent continent. Sevenoaks, Kent, UK: Hodder and Stoughton.

Adamson, D.A. \& Pickard, J. 1986. Physiography and geomorphology of the Vestfold Hills. In Pickard, J. (ed.) Antarctic Oasis: terrestrial environments and history of the Vestfold Hills, 99108. Sydney: Academic Press.

Afeissa, H-S. 2009. Intrinsic and Instrumental Value. In Callicott, J.B. \& Frodeman, R. (eds.) Encyclopedia of Environmental Ethics and Philosophy. Farmington Hills, MI: Gale Cengage Learning/Macmillan Reference USA.

ALE (Antarctic Logistics and Expeditions). 2012. 2011 expeditions. Antarctic Logistics and Expeditions. http://www.antarctic-logistics.com/news.html\#10. Accessed 29 December 2012. Amundsen, R. 1912. The South Pole. London: John Murray.

Anderson, M. A. 1980. The land pattern of areas of outstanding natural beauty in England and Wales. Landscape Planning. 7. 1-22.

Appleton, J. 1975. The Experience of Landscape. London: John Wiley \& Sons Ltd.

Appleton, J. 2006. Some speculative thoughts on the application of prospect-refuge theory to the landscapes of Antarctica. 3. Unpublished manuscript.

Ariadne. 1987. New Scientist. 115, 1575. 88.

Armstrong, T., Roberts, B.B. \& Swithinbank, C. 1973. Illustrated glossary of snow and ice. Cambridge: Scott Polar Research Institute. 
Arriaza, M., Canas-Ortega, J.F., Canas-Madueno, J.A. \& Ruiz-Aviles, P. 2004. Assessing the visual quality of rural landscapes. Landscape and Urban Planning. 69. 115-125.

Arthur, L.M., Daniel, T.C. \& Boster, R.S. 1977. Scenic assessment: an overview. Landscape Planning. 4. 109-129.

Arthur, L.M. 1977. Predicting scenic beauty of forest environments: some empirical tests. Forest Science. 23.151-160.

Aschehoug, M. 2000. Using GIS to map wilderness areas in the Barents Region. Stirling, Scotland: University of Stirling. Unpublished MSc thesis.

ATS. 1959. Text of the Antarctic Treaty. Buenos Aires: Antarctic Treaty Secretariat. http://www.ats.aq/documents/ats/treaty_original.pdf. Accessed 22 November 2011.

ATS. 1964. Agreed measures on the conservation of Antarctic fauna and flora. Buenos Aires: Antarctic Treaty Secretariat. http://www.ats.aq/documents/recatt/att080_e.pdf. Accessed 1 November 2010.

ATS. 1972. Recommendation ATCM VII-6 (Wellington, 1972). Study and discussion of the exploitation of Antarctic mineral resources. Buenos Aires: Antarctic Treaty Secretariat. http://www.ats.aq/devAS/info_measures_listitem.aspx?lang=e\&id=97. Accessed 22 April 2011. ATS. 1983. Man's Impact on the Antarctic Environment. Buenos Aires: Antarctic Treaty Secretariat. http://www.ats.aq/devAS/ats_meetings meeting_measure.aspx?lang=e. Accessed 21 March 2011.

ATS. 1988. Convention on the Regulation of Antarctic Mineral Resource Activities. Buenos Aires: Antarctic Treaty Secretariat. http://www.ats.aq/documents/recatt/Att311 e.pdf. Accessed 1 December 2012.

ATS. 1989. Recommendation ATCM XV-1 (Paris, 1989). Buenos Aires: Antarctic Treaty Secretariat. http://www.ats.aq/devAS/ats_meetings_meeting_measure.aspx?lang=e. Accessed 23 March 2009.

ATS. 1994. Guidance for Visitors to the Antarctic. Buenos Aires: Antarctic Treaty Secretariat. http://www.ats.aq/documents/recatt/att245 e.pdf. Accessed 19 September 2011.

ATS. 1998. Text of the Protocol on Environmental Protection to the Antarctic Treaty. Buenos Aires: Antarctic Treaty Secretariat. http://www.ats.aq/documents/recatt/Att006_e.pdf. Accessed 1 November 2010.

ATS. 2004. Final Report of XXVII ATCM. Annex 1. Report of the Committee for Environmental Protection (CEP VII). Antarctic Treaty Secretariat. 
http://www.ats.aq/documents/cep/cep\%20documents/atcm27_cepvii_e.pdf. Accessed 22 September 2011.

ATS. 2005. Guidelines for Environmental Impact Asessment in Antarctica. Buenos Aires: Antarctic Treaty Secretariat. http://www.ats.aq/documents/recatt/att266_e.pdf. Accessed 4 June 2011.

ATS. 2007. Management Plan for Antarctic Specially Managed Area No. 6. Larsemann Hills, East Antarctica. Buenos Aires: Antarctic Treaty Secretariat. http://www.ats.aq/documents/recatt/Att358_e.pdf. Accessed 14 August 2012.

ATS. 2008. Resolution 3 (2008) - ATCM XXXI - CEP XI, Kyiv. Environmental Domains Analysis for the Antarctic Continent. Buenos Aires: Antarctic Treaty Secretariat. Resolution: http://www.ats.aq/devAS/info_measures_listitem.aspx?lang=e\&id=412. Annex: http://www.ats.aq/documents/recatt/att408_e.pdf. Accessed 22 April 2011.

ATS. 2009. The SCAR lecture - Marine life and change in the Southern Ocean. Buenos Aires: Antarctic Treaty Secretariat. http://www.ats.aq/documents/ATCM32/ip/ATCM32_ip071_e.doc. Accessed 3 March 2010.

ATS. 2010. Report of the Norwegian Antarctic Inspection under Article VII of the Antarctic Treaty. February 2009. Buenos Aires: Antarctic Treaty Secretariat. http://www.ats.aq/documents/ATCM33/att/ATCM33_att067_e.pdf. Accessed 22 May 2012. ATS. 2011. Liability Arising from Environmental Emergencies. Buenos Aires: Antarctic Treaty Secretariat. http://www.ats.aq/e/ep_liability.htm. Accessed 3 June 2012.

ATS. 2011. EIA database. Buenos Aires: Antarctic Treaty Secretariat. http://www.ats.aq/devAS/ep_eia_list.aspx?lang=e. 12 March 2013.

ATS. 2011. The Antarctic Treaty Consultative Meeting (ATCM). Buenos Aires: Antarctic Treaty Secretariat. http://www.ats.aq/e/ats_meetings_atcm.htm. Accessed 14 April 2012. ATS. 2011. Data Collection and Reporting on Yachting Activity in Antarctica in 2010/11. http://www.ats.aq/documents/ATCM35/ip/ATCM35_ip042_e.doc. Accessed 29 January 2013 ATS. 2011. Report of the Committee for Environmental Protection (CEP XIV). Buenos Aires, June 20-24 2011 Buenos Aires: Antarctic Treaty Secretariat. http://www.ats.aq/documents/ATCM34/rp/atcm34_rp001_rev2_e.pdf. Accessed 9 September 2012.

ATS. 2012. Antarctic Treaty Information Exchange. Buenos Aires: Antarctic Treaty Secretariat. http://www.ats.aq/e/ie.htm. Accessed 23 April 2011. 
ATS. 2012. Parties. Buenos Aires: Antarctic Treaty Secretariat.

http://www.ats.aq/devAS/ats_parties.aspx?lang=e. Accessed 29 June 2012.

ATS. 2012a. Antarctic Treaty Electronic Information Exchange System. Party: Australia. 2012/2013 Pre-Season Information. Buenos Aires: Antarctic Treaty Secretariat.

http://eies.ats.aq/Ats.IE/ieGenRpt.aspx?idParty=2\&period=1\&idYear=2012. Accessed 12 January 2013.

ATS. 2012c. Status of the Antarctic Treaty and Status of the Protocol on Environmental Protection to the Antarctic Treaty. Buenos Aires: Antarctic Treaty Secretariat. http://www.ats.aq/documents/atcm35/ww/atcm35_ww015_e.pdf. Accessed 29 December 2012. Auburn, F. 1984. The Antarctic minerals regime: sovereignty, exploration, institutions and environment. In Harris, S. (ed.) Australia's Antarctic Policy Options, 271-306. Canberra: Centre for Resource and Environmental Studies (CRES).

Baggini, J. \& Southwell, G. 2012. Philosophy: Key Themes. Second Edition. London: Palgrave Macmillan.

BAS. 2012. British Research Stations and Refuges - History. Cambridge: British Antarctic Survey. http://www.antarctica.ac.uk/about_bas/our_history/stations_and_refuges/index.php. Accessed 1 February 2012.

Bastmeijer, K \& Roura, R. 2008. Environmental Impact Assessments in Antarctica. In Bastmeijer, K. \& Koivurova, T. (eds.) Theory and Practice of Transboundary Environmental Impact Assessment, 175-219. Leiden: Martinus Nijhoff.

Bastmeijer, K. I. 2008. Protecting Polar Wilderness: Just a Western Philosophical Idea or a Useful Concept for Regulating Human Activities in the Polar Regions? Paper presented at the Looking beyond the International Polar Year: emerging and re-emerging issues in International Law and Policy in the Polar Year, University of Akureyri, Iceland. In Gudmundur Alfredsson and Timo Koivurova (eds.) The Yearbook of Polar Law, Vol. 1. Leiden: Martinus Nijhoff. Bastmeijer, K., Lamers, M. \& Harcha, J. 2008. Permanent Land-based Facilities for Tourism in Antarctica: The Need for Regulation. Review of European Community \& International Environmental Law 17. 84-99.

Bastmeijer, K. 2005. Managing human activities in Antarctica: should wilderness protection count? New Zealand Yearbook of International Law 2. 335-353.

Beaglehole, J.C. 1974. The Life of Captain James Cook. Stanford, California: Stanford University Press. 
Beeby, C.D. 1983. An overview of the problems which should be addressed in the preparation of a regime governing the mineral resources of Antarctica. In Vicuña, F.O. (ed.) Antarctic Resources Policy. Scientific, legal and political issues, 191-198. Cambridge: Cambridge University Press.

Beeby, C.D. 1990. The Convention on the Regulation of Antarctic Mineral Resource Activities and its Future. In Herr, R.A., Hall, H.R. \& Haward, M.G. (eds.) Antarctica's future: continuity or change? 47-60. Hobart: Australian Institute of International Affairs.

Benninghoff, W.S. \& Bonner, W.N. 1985. Man's impact on the Antarctic environment: a procedure for evaluating impacts from scientific and logistic activities. Cambridge: Scientific Committee on Antarctic Research, Scott Polar Research Institute.

Benninghoff, W.S. 1974. Macrobiology and Ecology in Polar Deserts. In Smiley, T.L. \& Zumberge, H.H. (eds.) Polar Deserts and Modern Man, 91-97. Tucson, Arizona: The University of Arizona Press.

Berleant, A. 1992. The Aesthetics of Environment. Philadelphia: Temple University Press. Berleant, A. 2004. The Aesthetics of Art and Nature. In Carlson, A. \& Berleant, A. (eds.) The Aesthetics of Natural Environments, 76-88. Peterborough, Ontario: Broadview Press.

Bernacchi, L. 1991 [1901]. To the South Polar Regions. Harleston, Norfolk: Bluntisham Books and The Erskine Press.

Bishop, I.D. \& Hulse, D.W. 1994. Prediction of scenic beauty using mapped data and geographic information systems. Landscape and Urban Planning 30. 59-70.

Bishop, I. D. 2002. Determination of thresholds of visual impact: the case of wind turbines. Environment and Planning B: Planning and Design 29. 707-718.

Bonner, W.N., Benninghoff, W.S., Gallardo, V.A., Kerry, K.R., Parker, B.C. \& Prevost. J. 1986. A visitor's introduction to the Antarctic and its environment. Canberra: Australian Antarctic Division,

Borchgrevink, C. 1901. First on the Antarctic continent. London: Newnes.

Bowman, M. 2002. Biodiversity, Intrinsic Value, and the Definition and Valuation of Environmental Harm. In Bowman, M. \& Boyle, A. (eds.) Environmental Damage in International and Comparative Law, 41-61. Oxford: Oxford University Press.

Boyce, P. \& Press, A. 2011. Diplomacy. In Haward, M. \& Griffiths, T. (eds.) Australia and the Antarctic Treaty System: 50 years of influence, 274-299. Sydney: University of New South Wales Press. 
Boyer, P. 1988. Antarctic Journey. Three Artists in Antarctica. Canberra: Australian Government Publishing Service.

Bradbury, R. 1996. Are indicators yesterday's news? Paper presented to the Tracking Progress Conference. 1996 Australian Academy of Science Fenner Conference on the Environment, Institute of Environmental Studies University of NSW, 1996.

Bradley, A.C. 1950. The Sublime. Oxford Lectures on Poetry. London: Macmillan Brady, E. 2004. Imagination and the Aesthetic Appreciation of Nature. In Carlson, A. \& Berleant, A. (eds.) The Aesthetics of Natural Environments, 156-169. Peterborough, Ontario: Broadview Press.

Brewster, B. 1982. Antarctica: Wilderness at risk. Melbourne: Sun Books.

Brown, P. 1991. The Last Wilderness. 80 days in Antarctica. London: Random Century. Brown, R.N.R., Mossman, R.C. \& Pirie, J.H.H. 1906. The Voyage of the "Scotia". Edinburgh: William Blackwood and Sons.

BSES. 2012. British Services Antarctic Expedition 2012. British Services Antarctic Expedition. http://www.bsae2012.co.uk/. Accessed 27 January 2013.

Buckley, R. 2000. The weakness of wilderness protection policy. Environmental Policy and Law. 30. 196-99.

Burgess, F.H. 1961. A Dictionary of Sailing. London: Penguin.

Burke, E. 1998 [1759]. A philosophical enquiry into the origin of our ideas of the sublime and the beautiful, ed. by Womersley, D. 50-199. London: Penguin.

Burmil, S., Daniel, T.C. \& Hetherington, J.D. 1999. Human values and perceptions of water in arid landscapes. Landscape and Urban Planning. 44. 99-109.

Burton, R. 2008. The Story of Port Lockroy. United Kingdom Antarctic Heritage Trust.

Byrd, R.E. 1939. Alone. London: Readers Union Ltd \& Putnam \& Co Ltd.

Callicott, J.B. \& Ames, R.T. (eds.) 1989. Nature in Asian Traditions of Thought: Essays in Environmental Philosophy. Albany, NY: SUNY Press.

Callicott, J.B. \& Nelson, M.P. (eds.) 1998. The Great New Wilderness Debate. Athens, Georgia, USA: University of Georgia Press.

Callicott, J.B. 1992. Rolston on intrinsic value: a deconstruction. Environmental Ethics. 14. 129-143. 
Capdevila, R. 1984. Las primeras mujeres que estuvieron en las Orcadas fueron Argentinas (The first women who were in the Orkneys were Argentineans). Antartida 13.

Carlson, A.A. 1977. On the possibility of quantifying scenic beauty. Landscape Planning 4. 131-172.

Carlson, A.A. 2009. Nature and landscape. An introduction to environmental aesthetics. New York: Columbia University Press.

Carrick, R. 1960. Conservation of nature in the Antarctic. Polar Record. 10. 299-306.

CEP. 2010. Committee for Environmental Protection Five Year Work Plan: Committee for Environmental Protection. http://www.ats.aq/documents/ATCM33/Att/atcm33_att117_e.pdf. Accessed 9 September 2010.

CEP. 2012. Summary of the work of the CEP on Marine Protected Areas. Buenos Aires: Antarctic Treaty Secretariat. http://www.ats.aq/documents/ATCM35/ww/atcm35_ww007_e.pdf. Accessed 23 March 2013. Christoff, P., Dryzek, J.S., Eckersley, R., Goodin, R.E. \& Plumwood ,V. 2001. Green Thinking - from Australia. Environmental Politics. 10. 85-102.

CIA. 2013. World Fact Book. Langley, Virginia: Central Intelligence Agency.

Clark, L \& Wishart, E. 1993. 66 ${ }^{\circ}$ South. Tales from an Antarctic Station. Launceston: Queen Victoria Museum and Art Gallery.

Codling, R. 1998. Wilderness and Aesthetic Values in Antarctica. ATCM XXII, Tromso. IP2. Codling, R. 1999. Wilderness and Aesthetic Values in the Antarctic: Open University, UK Unpublished $\mathrm{PhD}$ thesis.

Codling, R. 2001a. Aspects of Environmental Planning in the Antarctic. Journal of Environmental Planning and Management. 44.129-141.

Codling, R. 2001b. Wilderness and aesthetic values in the Antarctic. Polar Record. 37. 337352.

Codling, R.J. 1995. The Precursors of Tourism in the Antarctic. In Hall, C.M. \& Johnston, M.E. (eds.) Polar Tourism, 167-177. Chichester, UK: John Wiley \& Sons.

Cohen, J. 1988. Statistical power analysis for the behavioral sciences. New York: Psychology Press.

Cole, D.N. 2005. Symbolic Values. The Overlooked Values That Make Wilderness Unique. International Journal of Wilderness. 11. 23-27 
Colley, A. \& Gold, H. 2004. Blue Mountains World Heritage. Sydney: The Colong Foundation for Wilderness.

Colong Foundation. 2013. Colong Foundation for Wilderness. Sydney: Colong Foundation. http://www.colongwilderness.org.au. Accessed 3 March 2013.

COMNAP. 1995. AFIM: Antarctic Flight Information Manual. (ed.) Council of Managers of National Antarctic Programs.

COMNAP. 2012. COMNAP list of Antarctic facilities: Council of Managers of National Antarctic Programs.

https://www.comnap.aq/Members/Shared\%20Documents/Antarctic_Facilities_List_1April2012 .xls. Accessed 21 April 2012.

Cook, F.A. 1980 [1900]. Through the First Antarctic Night 1898-1899: a narrative of the voyage of the "Belgica' among newly discovered lands and over an unknown sea about the South Pole. Canberra: C. Hurst, ANU Press.

Cook, G. (ed.) 1990. The future of Antarctica - exploitation versus preservation. Manchester: Manchester University Press.

Cooper, D. E. 1998. Aestheticism and Environmentalism. In Cooper, D.E. \& Palmer, J.A. (eds.) Spirit of the Environment. Religion, value and environmental concern, 100-112. London: Routledge.

Cronon, W. 1995. The Trouble with Wilderness, or, Getting Back to the Wrong Nature. In Callicott, J.B. \& Nelson, M.P. (eds.) The Great New Wilderness Debate, 471-499. Athens, Georgia: The University of Georgia Press.

Daniel, T.C. \& Boster, R.S. 1976. Measuring landscape esthetics: the scenic beauty estimation method. United States Department of Agriculture Forest Service.

Daniel, T.C. 1990. Measuring the quality of the natural environment, a psychophysical approach. American Psychologist. 45. 637-641.

Daniel, T.C. \& Vining, J. 1983. Methodological issues in the assessment of landscape quality. In Altman, I. \& Wohlwill, J.F. (eds.) Behavior and the Natural Environment, 346. New York: Plenum Press.

Daniel, T.C. 2001. Whither scenic beauty? Visual landscape quality assessment in the $21 \mathrm{st}$ century. Landscape and Urban Planning. 54. 267-281.

David, T. and Associates. 2007. Identifying the Special Qualities of Scotland's National Scenic Areas. Commissioned Report No.255. Scottish Natural Heritage. 
Davis, B.W. 1990. Science and politics in Antarctic and Southern Oceans policy: A critical assessment. In Herr, R.A., Hall, H.R. \& Haward, M.G. (eds.) Antarctica's future: continuity or change? 39-45. Hobart: Australian Institute of International Affairs.

de Gerlache, A. 1902. Quinze mois dans L'Antarctique. Paris: Hachette.

De'ath, G. \& Fabricius, K. E. 2000. Classification and regression trees: a powerful yet simple technique for ecological data analysis. Ecology 81.3178-3192.

Debenham, F. (ed.) 1945. The voyage of Captain Bellingshausen to the Antarctic seas 18191821. London: Hakluyt Society.

Denevan, W. M. 1995. The Pristine Myth. The Landscapes of the Americas in 1492. In Callicott, J.B. \& Nelson, M.P. (eds.) The Great New Wilderness Debate. 414-442. Athens, Georgia.: The University of Georgia Press.

DFAT. 2000. Treaty making process. Canberra: Department of Foreign Affairs and Trade.

Doake, C.S.M. 1987. Sea ice and icebergs. In Walton, D.W.H (ed.) Antarctic Science, 140-50. Cambridge: Cambridge University Press.

Drewry, D.J. 1982. Antarctica : glaciological and geophysical folio. Cambridge: University of Cambridge, Scott Polar Research Institute.

Dudley, N. (ed.) 2008. Guidelines for Applying Protected Area Management Categories. Gland, Switzerland: IUCN.

Dufek, G.J. 1960. Through the frozen frontier. Leicester: Brockhampton Press.

Eijgelaar, E., Thaper, C. \& Peeters, P. 2010. Antarctic cruise tourism: the paradoxes of ambassadorship, "last chance tourism" and greenhouse gas emissions. Journal of Sustainable Tourism. 18. 337-354.

El-Sayed, S.Z. 1985. Plankton of the Antarctic Seas. In Bonner, W.N. \& Walton, D.W.H. (eds.) Key Environments Antarctica, 381. Oxford: Pergamon Press.

Enzenbacher, D.J. 1992. Tourists in Antarctica: numbers and trends. Polar Record. 28. 17-22. EPBC. 1999. Environment Protection and Biodiversity Conservation Act. Canberra: ComLaw. http://www.comlaw.gov.au/Details/C2012C00801/8f60fdd3-6f14-4161-a149-a063a82fdd10. Accessed 5 February 2013.

Fenton, D.M. \& Reser, J.P. 1988. The assessment of landscape quality: an integrative approach. In Nasar, J.L. (ed.) Environmental Aesthetics: theory, research and applications, 108-119. Cambridge: Cambridge University Press. 
Ferris, J.M., Burton, H.R., Johnstone, G.W. \& Bayly I.A.E. (eds.) 1988. Biology of the Vestfold Hills, Antarctica. Dordrecht: Kluwer Academic Publishers.

Fiennes, R. 2003. Captain Scott. London: Hodder and Stoughton.

Fifield, R. 1987. International Research in the Antarctic. Oxford: Oxford University Press.

Fogg, G.E. \& Smith, D. 1990. The Explorations of Antarctica. London: Cassell.

Fogg, G.E. 1992. A history of Antarctic science. Cambridge: Cambridge University Press.

Forgas, J. P. 1979. Multidimensional scaling: a discovery method in social psychology. In

Ginsburg, G.P. (ed.) Emerging strategies in social psychological research, 253-287. Chichester:

Wiley.

Fox, A.J. \& Cooper, A.P.R. 1994. Measured properties of the Antarctic ice sheet derived from the SCAR Antarctic digital database. Polar Record. 30. 201-206.

Fox, W. 1990. Towards a Transpersonal Ecology. Boston: Shambala.

Fox, W.L. 2005. Terra Antarctica. Looking into the Emptiest Continent. San Antonio, Texas:

Trinity University Press.

Frank, S., Fürst, C., Koschke, L., Witt, A. \& Makeschin, F. 2013. Assessment of landscape aesthetics - Validation of a landscape metrics-based assessment by visual estimation of the scenic beauty. Ecological Indicators. 32. 222-231.

Gair, N.P. 1999. Out into the Wilderness: The Inspirational or Spiritual Effects of the Outdoors. Horizons. 6. 17-20

GERG. 2003. Spatial and Temporal Scales of Human Disturbance at McMurdo Station, Antarctica. Geochemical and Environmental Research Group and Department of Geography, Texas A\&M University Marine Science Institute, University of Texas.

Gescheider, G.A. 1976. Psychophysics: method and theory. Hillsdale, New Jersey: Lawrence Erlbaum Associates.

Gibson, J. \& Bourke, D. 2010. Scientific bibliography of the Vestfold Hills: Australian Antarctic Division.

GIMP. 2009. GNU Image Manipulation Program Version 2.6.6. http://www.gimp.org/.

Glacken, C.J. 1967. Traces on the Rhodian Shore. Berkeley and Los Angeles: University of California Press.

Gobster, P.H., Nassauer, J.I., Daniel, T.C. \& Fry, G. 2007. The shared landscape: what does aesthetics have to do with ecology? Landscape Ecology. 22. 959-972. 
Godfrey-Smith, W. 1979. The value of wilderness. Environmental Ethics. 1. 309-319.

Godfrey-Smith, W. 1980. The rights of non-humans and intrinsic value. In Mannison, D., McRobbie, M. \& Routley, R. (eds.) Environmental Philosophy, 30-47. Canberra: Australian National University.

Gorman, J. 1995. Ocean Enough and Time. Discovering the Waters around Antarctica. New York: HarperCollins.

Gould, L.M. 1984. Cold. The Record of an Antarctic Sledge Journey. Northfield, MN: Carleton College.

Gravetter, F.J. \& Wallnau, L.B. 2010. Statistics for the Behavioral Sciences. Ninth Edition. Belmont, CA: Wadsworth.

Green, W. 1995. Water Ice and Stone. New York: Harmony Books.

Grêt-Regamey, A., Bishop, I.D. \& Bebi, P. 2007. Predicting the scenic beauty value of mapped landscape changes in a mountainous region through the use of GIS. Environment and Planning B: Planning and Design. 34. 50-67.

Griffiths, T. 2007. Slicing the silence. Sydney: University of New South Wales Press.

Guha, R. 1989. Radical American Environmentalism and Wilderness Preservation: A Third World Critique. In Callicott, J.B. \& Nelson, M.P. (eds.) The Great New Wilderness Debate. Athens, Georgia: The University of Georgia Press.

Gurney, A. 1997. Below the Convergence. Voyages towards Antarctica 1699 - 1839. New York: W.W. Norton \& Co.

Gurney, A. 2000. The Race to the White Continent. New York: W.W. Norton \& Co.

Guyer, P. 1998. Baumgarten, Alexander Gottlieb. In Kelly, M. (ed.) Encyclopedia of Aesthetics, 227-228. New York: Oxford University Press.

Habron, D. 1998. Visual perception of wildland in Scotland. Landscape and Urban Planning. 42. 45-56.

Hall, C. M. 1992. Tourism in Antarctica: activities, impacts, and management. Journal of Travel Research. 30. 2-9.

Hall, C.M. (ed.) 1992. Wasteland to World Heritage. Melbourne: Melbourne University Press. Hardin, G. 1968. The Tragedy of the Commons. Science. 162. 1243-1248.

Hargrove, E.C. 1992. Weak Anthropocentric Intrinsic Value. The Monist. 75. 183-207. 
Harris, S. (ed.) 1984. Australia's Antarctic Policy Options. CRES Monograph 11. Canberra: Centre for Resource and Environmental Studies (CRES).

Harvey, M.W.T. 2005. Wilderness Forever: Howard Zahniser and the path to the Wilderness Act. Seattle: University of Washington Press.

Hastie, T., Tibshirani R. \& Friedman, J. 2009. The Elements of Statistical Learning. New York: Springer.

Hawke, R.J.L. 1990. Australia's policy in Antarctica. In Herr, R.A., Hall, H.R. \& Haward, M.G. (eds.) Antarctica's future: continuity or change? 17-20. Hobart: Australian Institute of International Affairs.

Headland, R.K. 2009. A Chronology of Antarctic Exploration. London: Quaritch.

Heap, J. 1990. The political case for the Minerals Convention. In Cook, G. (ed.) The future of Antarctica - exploitation versus preservation, 44-52. Manchester: Manchester University Press.

Helburn, N. 1977. The Wildness Continuum. The Professional Geographer 29. 333-337.

Hendee, J. C., Stankey, G.H. \& Lucas, R.C. 1978. Wilderness Management: US Department of Agriculture Forest Service.

Hepburn, R. 2004 [1966]. Contemporary Aesthetics and the Neglect of Natural Beauty. In Carlson A. \& Berleant, A. (eds.) The Aesthetics of Natural Environments, 312. Peterborough, Ontario, Canada: Broadview Press.

Herr, R.A., Hall, H.R. \& Haward, M.G. (eds.) 1990. Antarctica's future: continuity or change? Hobart: Australian Institute of International Affairs.

Hetherington, J., Daniel, T.C. \& Brown, T.C. 1994. Anything goes means everything stays: The perils of uncritical pluralism in the study of ecosystem values. Society \& Natural Resources. 7. $535-546$.

Hill, D. \& Daniel, T.C. 2008. Foundations for an Ecological Aesthetic: Can Information Alter Landscape Preferences? Society \& Natural Resources. 21. 34-49.

Hince, B. 2000. The Antarctic Dictionary. Melbourne: CSIRO Publishing.

Holdgate, M. W. 1970. Conservation in the Antarctic. In Holdgate, M.W. (ed.) Antarctic Ecology, 924-945. London: Academic Press.

Holdgate, M.W. 1983. Environmental factors in the development of Antarctica. In Vicuña, F.O. (ed.) Antarctic Resources Policy. Scientific legal and political issues, 77-101. Cambridge: Cambridge University Press. 
Holdgate, M. 1998. The Antarctic protected areas system in the new millennium. In Njaastad, B. (ed.) Antarctic Protected Areas Workshop, 8-19. Tromso: Norsk Polarinstitutt.

Huber, J. 2011. The Antarctic Treaty: Toward a New Partnership. In Berkman, P.A., Lang, M.A., Walton, D.W.H. \& Young, O.R. (eds.) Science diplomacy: science, Antarctica, and the governance of international spaces, 89-95. Washington, DC: Smithsonian Institution Scholarly Press.

Hull, R. B. IV, \& Stewart, W.P. 1992. Validity of photo-based scenic beauty judgements. Journal of Environmental Psychology. 12. 101-114.

Hull, R. B. IV, Buhyoff, G.J. \& Daniel, T.C. 1984. Measurement of scenic beauty: the law of comparative judgment and scenic beauty estimation procedures. Forest Science. 30. 1084-1096. Hunter Christie, E. W. 1951. The Antarctic Problem: an historical and political study. London: Allen \& Unwin.

Hurlbert, S. H. 1984. Pseudoreplication and the design of ecological field experiments. Ecological Monographs. 54. 187-211.

Hurlbert, S.H. 2004. On misinterpretations of pseudoreplication and related matters: a reply to Oksanen. Oikos. 104. 591-597.

Hutchinson, M.F. 1989. A new procedure for gridding elevation and stream line data with automatic removal of spurious pits. J. Hydrol. 106. 211-232.

IAATO. 2010. What is IAATO: International Association of Antarctica Tourism Operators. http://www.iaato.org/what-is-iaato. Accessed 5 September 2010.

IAATO. 2012a. IAATO Member vessel directory 2012-2013: International Association of Antarctica Tourism Operators.

http://apps.iaato.org/iaato/vessel/listVessels.jsp?sortBy=categoryA. Accessed 29 December 2012.

IAATO. 2012b. Tourism statistics: International Association of Antarctica Tourism Operators. http://iaato.org/tourism-statistics. Accessed 29 December 2012.

IUCN. 1980. World Conservation Strategy: living resource conservation for sustainable development. Morges, Switzerland: International Union for the Conservation of Nature with United Nations Environment Programme (UNEP) and the World Wildlife Fund (WWF). Jabour, J. 2009. National Antarctic Programs and their Impact on the Environment. In Kerry, K.R. \& Riddle, M. (eds.) Health of Antarctic Wildlife. A Challenge for Science and Policy, 211229. London: Springer. 
Jackson, A. \& Kriwoken, L. 2011. The Protocol in action, 1991-2010. In Haward, M. \& Griffiths, T. (eds.) Australia and the Antarctic Treaty System: 50 years of influence, 300-319. Sydney: University of New South Wales Press.

Jackson, A. \& Boyce, P. 2011. Mining and 'World Park Antarctica', 1982-1991. In Haward, M. \& Griffiths, T. (eds.) Australia and the Antarctic Treaty System: 50 years of influence, 243-273. Sydney: University of New South Wales.

Johnson, L. E. 2003. Reflections on Distant Ice. Flinders University of South Australia. Unpublished report.

Jones, A.G.E. 1982. Antarctica observed: who discovered the Antarctic continent? Whitby, Yorkshire: Caedmon of Whitby.

Jones, A.G.E. 1992. Polar Portraits. Whitby: Caedmon of Whitby. Joyner, C.C. 1987. The Antarctic minerals negotiating process. American Journal of International Law. 81. 888-905.

Kakabadse, Y. 2000. The Antarctic Protected Areas System: Challenges and practice. Paper presented at the Second Antarctic Protected Areas Workshop, Lima, Peru.

Kant, I. 1987 [1776]. The Critique of Judgment. Indianapolis, Indiana: Hackett Publishing Company.

Kaplan, R. \& Kaplan, S. 1995. The experience of nature - a psychological perspective. Ann Arbor, Michigan: Ulrich's Bookstore.

Kaplan, S. 1987. Aesthetics, Affect, and Cognition: Environmental Preference from an Evolutionary Perspective. Environment and Behavior. 19. 3-32.

Katz, E. 1991. Ethics and Philosophy of the Environment: A Brief Review of the Major Literature. Environmental History Review 15. 79-86.

Keys, H. 1999. Towards the designation of Antarctic wilderness areas. In Towards additional protection of Antarctic wilderness areas. Buenos Aires: Antarctic Treaty Secretariat.

King, H.G.R. 1969. The Antarctic. London: Blandford Press.

Kirkpatrick, J.B. \& Haney, R.A.. 1980. The quantification of developmental wilderness loss. Search. 11. 331-335.

Kliskey, A.D. \& Kearsley, G.W. 1993. Mapping multiple perceptions of wilderness in southern New Zealand. Applied Geography. 13. 203-223. 
Kliskey, A.D. 1998. Linking wilderness perception mapping concept to the recreation opportunity. Environmental Management. 22. 79-88.

Knight, W. 1903. The Philosophy of the Beautiful being outlines of the history of aesthetics. London: John Murray.

Kormos, C.F. \& Locke, H. 2008. Introduction. In Kormos, C.F. (ed.) A Handbook on International Wilderness Law and Policy, 3-29. Golden, CO: Fulcrum.

Krebs, A. 1999. Ethics of Nature: a map. Berlin: Walter de Gruyter.

Kroh, D.P. \& Gimblett R.H. 1992. Comparing live experience with pictures in articulating landscape preference. Landscape Research. 17. 58-69.

Lamers, M. 2009. The future of tourism in Antarctica: challenges for sustainability. Maastricht: University of Maastricht.

Landau, D. 2011. International Cooperation and Management of Tourism: A World within a World. In Berkman, P.A., Lang, M.A., Walton, D.W.H. \& Young, O.R. (eds.) Science diplomacy: science, Antarctica, and the governance of international spaces, 241-44.

Washington, DC: Smithsonian Institution Scholarly Press.

Landres, P., Barr, B. \& Kormos C.F. 2008. The Matrix. A comparison of international wilderness laws. In Kormos, C.F. (ed.) A Handbook on International Wilderness Law and Policy, 31-54. Golden, Colorado: Fulcrum Publishing.

Law, P. \& Béchervaise, J. 1957. ANARE: Australia's Antarctic outposts. Melbourne: Oxford University Press.

Law, P. 1959. The IGY in Antarctica. The Australian Journal of Science. June 1959. 285-94. Law, P. 1990. The Antarctic Wilderness - a Wild Idea! In Herr, R.A., Hall, H.R. \& Haward, M.G. (eds.) Antarctica's future: continuity or change? 71-80. Hobart: Australian Institute of International Affairs.

Lee, K. 2007. Biotic and abiotic nature: how radical is Rolston's environmental philosophy? In Preston, C.J. \& Ouderkirk, W. (eds.) Nature, Value, Duty. Life on Earth with Holmes Rolston III, 17-28. Dordrecht, The Netherlands: Springer.

Lesslie, R \& Maslen, M. 1995. National Wilderness Inventory. Canberra: Australian Heritage Commission.

Lesslie, R.G. \& Taylor, S.G. 1985. The wilderness continuum concept and its implications for Australian wilderness preservation policy. Biological Conservation. 32. 309-333. 
Lewis Smith, R.I. 1994. Environmental-Geographic Basis for the Protected Area System. In Lewis Smith, R.I., Walton, D.W.H. \& Dingwall, P.R. (eds.) Developing the Antarctic Protected Area System. Gland, Switzerland and Cambridge: IUCN.

Lopez, B. 1999. About this life. London: The Harvill Press.

Lothian, A. 1999. Landscape and the philosophy of aesthetics: is landscape quality inherent in the eye of the beholder? Landscape and Urban Planning. 44. 177-198.

Low, T. 2002. The New Nature. Camberwell, Victoria: Viking.

Lutz, A.R., Simpson-Housley, P. \& Deman A.F. 1999. Wilderness: Rural and Urban Attitudes and Perceptions. Environment and Behavior. 31. 259-266.

Lynch, H.J., Crosbie, K., Fagan, W.F. \& Naveen, R. 2009. Spatial patterns of tour ship traffic in the Antarctic Peninsula region. Antarctic Science.

Machado, A. 2004. An index of naturalness. Journal for Nature Conservation. 12. 95-110.

Marchant, H.J., Lugg, D.J. \& Quilty, P.G. (eds.) 2002. Australian Antarctic Science : the first 50 years of ANARE. Kingston, Tasmania: Australian Antarctic Division.

Markov, K.K., Bardin, V.I., Lebedev, V.L., Orlov, A.I. \& Suetova, I.A. (eds.) 1970. The

Geography of Antarctica. Jerusalem: Israel Program for Scientific Translation.

Martin, S. 1996. A History of Antarctica. Sydney: State Library of New South Wales Press.

Mawson, D. 1915. The Home of the Blizzard. London: William Heinemann.

May, J. 1989. The Greenpeace Book of Antarctica. Sydney: Child \& Associates Publishing Pty Ltd.

Mayton, D.M. II, Ball-Rokeach, S.J. \& Loges, W.E. 1994. Human Values and Social Issues: An Introduction. Journal of Social Issues. 50. 1-8.

McGonigal, D. \& Woodworth, L. 2001. Antarctica: the complete story. Noble Park, Victoria.: Five Mile Press.

McShane, K. 2007. Why environmental ethics shouldn't give up on intrinsic value.

Environmental Ethics. 29. 43-61.

Mellor, M. 1993. Notes on Antarctic Aviation. US Army Cold Regions Research and Engineering Laboratory (CRREL).

Miller, P.A. 1984. A Comparative Study of the BLM Scenic Quality Rating Procedure and Landscape Preference Dimensions. Landscape Journal. 3. 123-135. 
Morgan, F., Barker, G., Briggs, C., Price, R. \& Keys, H. 2007. Environmental Domains of Antarctica. Version 2.0 Final Report.

Morgan, M. 2006. Regarding Beauty. In Jones, A. (ed.) A Companion to Contemporary Art since 1945. Oxford: Blackwell Publishing.

Morito, B. 2003. Intrinsic Value: A Modern Albatross for the Ecological Approach.

Environmental Values. 12.317-336.

Morris, K. \& Jeffries, M.O. 1992. Ice thickness variability of the McMurdo Sound landfast ice runway. Antarctic Journal of the United States. 27. 83-86.

Mortimer, G. 2004. Antarctic Tourism - Past, Present and Future:

http://www.development.tas.gov.au/_data/assets/pdf file/0014/2093/2004_-

Greg_Mortimer__ Phillip_Law Lecture.pdf.

Mosley, G. 1986. Antarctica. Our last great wilderness. Melbourne: Australian Conservation Foundation.

Nash, R. 1975. Wilderness and the American Mind. New Haven: Yale University Press.

Nash, R. 1990. The Rights of Nature. Leichhardt, NSW, Australia: Primavera Press.

Natural England. 2013. Areas of Outstanding Natural Beauty. Sheffield: Natural England.

Naveen, R., Forrest, S.C., Dagit, R.G., Blight, L.K., Trivelpiece, W.Z. \& Trivelpiece, S.G. 2001. Zodiac landings by tourist ships in the Antarctic Peninsula region, 1989-99. Polar Record. 37. 121-132.

Naveen, R. 2005. The Oceanites Site Guide to the Antarctic Peninsula. Second Edition. Chevy Chase, Maryland: Oceanites Inc.

NEPA. 1969. National Environmental Policy Act. Washington, DC: Council on Environmental Quality.

Neufeld, E., O’Reilly, J., Summerson, R. \& Tin, T. 2013. Valuing Antarctica: Emerging Views from International Studies. In Tin, T., Liggett, D., Maher, P. \& Lamers, M. (eds.) Antarctic futures: Human engagement with the Antarctic environment, ed. by Dordrecht: Springer.

Neumann, A. \& Bunge T. 2006. New Challenges Pose New Management Problems - The Permanent Installation of a Bronze Sculpture. Environmental Policy and Law 36.158-163. OED. 1989. The Oxford English Dictionary. Oxford: Clarendon Press.

Oelschlaeger, M. 1991. The Idea of Wilderness. New Haven: Yale University Press. 
Oksanen, L. 2001. Logic of experiments in ecology: is pseudoreplication a pseudoissue? Oikos. 94. 27-38.

O'Neill, J. 1992. The varieties of intrinsic value. The Monist. 75. 119-133.

O'Reilly, J. 2011. Tectonic History and Gondwanan Geopolitics in the Larsemann Hills, Antarctica. PoLAR: Political and Legal Anthropology Review. 34. 214-232.

Orians, G.H. \& Heerwagen, J.H. 1992. Evolved responses to landscapes. In Barkow, J.H., Cosmides, L. \& Tooby, J. (eds.) The Adapted Mind: evolutionary psychology and the generation of culture, 555-579. New York: Oxford University Press.

O'Rourke, R. 2012. Coast Guard Polar Icebreaker Modernization: Background and Issues for Congress. Congressional Research Service.

Pallant, J. 2011. SPSS Survival Manual, $4^{\text {th }}$ edition. Sydney: Allen \& Unwin.

Palmer, J.F. \& Hoffman, R.E. 2001. Rating reliability and representation validity in scenic landscape assessments. Landscape and Urban Planning. 54. 149-161.

Parsons, G. 2008. Aesthetics and Nature. London: Continuum.

Pearce, C. 2004. The Silent Sound. Lewes, Sussex: The Book Guild.

Perry, R.B. 1926. General Theory of Value: its meaning and basic principles construed in terms of interest. New York: Longmans, Green and Co.

Pickard, J. (ed.) 1986. Antarctic Oasis: terrestrial environments and history of the Vestfold Hills. Sydney: Academic Press.

Pickard, J. 1986. Antarctic oases, Davis station and the Vestfold Hills. In Pickard, J. (ed.) Antarctic Oasis: terrestrial environments and history of the Vestfold Hills, 1-19. Sydney: Academic Press.

Piercy, J.E. \& Daigle, G.A. 1991. Sound propagation in the open air. In Harris, C.M. (ed.) Handbook of Acoustical Measurements and Noise Control, 3.1-3.26. New York: McGraw-Hill. Plumwood, V. 1991. Ethics and instrumentalism: a response to Joanna Thompson. Environmental Ethics. 13. 139-149.

Poland, J.S., Riddle, M.J. \& Zeeb, B.A. 2003. Contaminants in the Arctic and the Antarctic: a comparison of sources, impacts, and remediation options. Polar Record. 39. 369-383.

Porteous, J.D. 1996. Environmental Aesthetics. Ideas, politics and planning. London: Routledge.

Pyne, S.J. 1987. The Ice. A Journey to Antarctica. London: Arlington Books. 
R Development Core Team. 2004. R: A language and environment for statistical computing. Vienna, Austria. : R Foundation for Statistical Computing.

Rabbetts, R.B. 1998. Bennett and Rabbetts' Clinical Visual Optics. Edinburgh: ButterworthHeinemann.

Reader's Digest. 1985. Antarctica. Great stories from the frozen continent. Sydney: Reader's Digest.

Reips, U.-D. 2002. Standards for Internet-Based Experimenting. Experimental Psychology. 49. 243-256.

Riffenburgh, B. 2004. Nimrod. London: Bloomsbury.

Rodiek, S.D. \& Fried, J.T. 2005. Access to the outdoors: using photographic comparison to assess preferences of assisted living residents. Landscape and Urban Planning. 73. 184-199.

Rokeach, M. 1973. The Nature of Human Values. New York: The Free Press.

Rolston, H. III. 2002. Environmental ethics in Antarctica. Environmental Ethics. 24. 115-114.

Rolston, H. III. 1982. Are Values in Nature Subjective or Objective? Environmental Ethics. 4. 125-151.

Rolston, H. III. 1988. Environmental Ethics. Duties to and values in the natural world.

Philadelphia: Temple University Press.

Rosenman, H. 1992. Two Voyages to the South Seas. Captain Jules S.-C. Dumont D'Urville. Melbourne: Melbourne University Press.

Rosove, M.H. 2001. Antarctica, 1772-1922. Freestanding publications through 1999. Santa Monica, California: Adelie Books.

Ross, J.C. 1969 [1847]. A Voyage of Research and Discovery in the Southern and Antarctic Regions during the years 1839-1843. Newton Abbot: David and Charles.

Ross, M. J. 1994. Polar pioneers: John Ross and James Clark Ross. Montreal: McGill-Queen's University Press.

Roth, M. 2006. Validating the use of Internet survey techniques in visual landscape assessment—an empirical study from Germany. Landscape and Urban Planning. 78. 179-192. Rubin, J. 1996. Antarctica. Melbourne: Lonely Planet.

Saito, Y. 1998. The aesthetics of unscenic nature. Journal of Aesthetics and Art Criticism. 56. 101-110. 
SCAR ad hoc Group on Additional Protective Measures. 1987. The Protected Area System in the Antarctic. Scientific Committee on Antarctic Research.

SCAR. 2006. Antarctic Digital Database. http://www.add.scar.org/. Accessed 2 January 2009. SCAR. 2010. Principles of Protection of the Antarctic Environment recommended by SCAR. Cambridge UK: Scientific Committee on Antarctic Research.

http://www.scar.org/about/constitution/antarcticprotection.html. Accessed 1 November 2010 Schama, S. 1995. Landscape and Memory. London: Harper Collins.

Schofield, E. 1972. Preserving the scientific value of cold desert ecosystems: past and present practices and a rationale for the future. In Parker, B.C. (ed.) Proceedings of the Colloquium on Conservation Problems in Antarctica, 193-223. Blacksburg, Virginia: Virginia Polytechnic Institute and State University.

Schroeder, H.W. 1984. Environmental perception rating scales. A case for simple methods of analysis. Environment and Behavior. 16. 573-598.

Schwartz, S.H. 1994. Are there universal values in the structure and contents of human values? Journal of Social Issues. 20. 19-45.

Scott, R.F. 1913. Scott's Last Expedition. London: John Murray.

Scott, R.F. 1905. The Voyage of the Discovery. London: Smith Elder.

Scruton, R. 2001. Kant: A very short introduction. Oxford: Oxford University Press.

Scruton, R. 2007. In search of the aesthetic. British Journal of Aesthetics. 47. 232-50.

Scruton, R. 2009a. The Aesthetic Gaze. In Dooley, M. (ed.) The Roger Scruton Reader, 137151. London: Continuum.

Scruton, R. 2009b. Beauty. Oxford: Oxford University Press.

Scruton, R. 2012. Green philosophy. London: Atlantic Books.

Scully, R.T. 2011. The Development of the Antarctic Treaty System. In Berkman, P.A., Lang, M.A., Walton, D.W.H. \& Young, O.R. (eds.) Science diplomacy: science, Antarctica, and the governance of international spaces, 29-38. Washington, DC: Smithsonian Institution Scholarly Press.

Sepanmaa, Y. 1986. The Beauty of Environment. Helsinki: Academia Scientarum Fennica.

Sevenant, M. \& Antrop, M. 2009. Cognitive attributes and aesthetic preferences in assessment and differentiation of landscapes. Journal of Environmental Management. 90. 2889-2899. 
Sevenant, M. \& Antrop, M. 2011. Landscape Representation Validity: A Comparison between On-site Observations and Photographs with Different Angles of View. Landscape Research. 36. 363-385.

Shafer, E.L. \& Brush, R.O. 1977. How to measure preferences for photographs of natural landscapes. Landscape Planning. 4. 237-256.

Shang, H. \& Bishop, I.D. 2000. Visual thresholds for detection, recognition and visual impact in landscape settings. Journal of Environmental Psychology. 20. 125-40.

Shaw, P. 2006. The Sublime. Abingdon: Routledge.

Shirase Antarctic Expedition Supporters' Association (eds.) 2011. The Japanese South Polar Expedition 1910-12. A Record of Antarctica. Norwich, England: Erskine Press and Bluntisham Books.

Shurley, J.T. 1972. Pollution in Antarctica: I. The island stations with remarks on some emerging psycho-ecological viewpoints. In Parker, B.C. (ed.) Proceedings of the Colloquium on Conservation Problems in Antarctica, 257-263. Blacksburg, Virginia: Virginia Polytechnic Institute and State University.

Shuttleworth, S. 1980. The use of photographs as an environment presentation medium in landscape studies. Journal of Environmental Management. 11. 61-76.

Sloan, N. A. 2002. History and Application of the Wilderness Concept in Marine Conservation. Conservation Biology. 16. 294-305.

Smith, A. 1978. Wilderness. London: George Allen \& Unwin.

Smith, B. H. 1998. Value. In Kelly, M. (ed.) Encyclopedia of Aesthetics, 429-431. Oxford: Oxford University Press.

Smith, B. \& Thomas, A. 1998. Axiology. In Craig, E. (ed.) Routledge Encyclopedia of Philosophy, 608-612. London: Routledge.

Smith, P. M. \& Watson, R.A. 1979. New wilderness boundaries. Environmental Ethics. 1. 6164.

Smith, R. 2009. Life on the Ice. No One Goes to Antarctica Alone. Washington, DC: National Geographic.

SNH. 2013. National Scenic Areas. Inverness: Scottish Natural Heritage. http://www.snh.gov.uk/protecting-scotlands-nature/protected-areas/national-designations/nsa/. Accessed 4 February 2013. 
Snowman, D. 1993. Pole Positions. The polar regions and the future of the planet. London: Hodder and Stoughton.

Splettstoesser, J. \& Folks M.C. 1994. Environmental guidelines for tourism in Antarctica. Annals of Tourism Research 21. 231-244.

Spufford, F. 1996. I may be some time. Ice and the English imagination. London: Faber and Faber.

Stackpole, E.A. 1955. The voyage of the Huron and the Huntress : the American sealers and the discovery of the continent of Antarctica. Mystic, Connecticutt: Marine Historical Association.

Stamps, A.E., III. 1990. Use of photographs to simulate environments: a meta-analysis.

Perceptual and Motor Skills. 71. 907-913.

Steffen, L.H. 1992. In Defense of Dominion. Environmental Ethics. 14. 63-80.

Stewart, T.R., Middleton, P, Downton, M. \& Ely, D. 1984. Judgments of photographs vs. field observations in studies of perception and judgment of the visual environment. Journal of Environmental Psychology. 4. 283-302.

Stolnitz, J. 1961. On the Origins of "Aesthetic Disinterestedness". Journal of Aesthetics and Art Criticism 20.131-144.

Stolnitz, J. 1965. Aesthetics. New York: The Macmillan Company.

Stump, E. 2011. The roof at the bottom of the world. New Haven: Yale University Press.

Summerson, R. \& Riddle, M.J. 2000. Assessing wilderness and aesthetic values in Antarctica. In Davison, W., Howard-Williams, C. \& Broady, P. (eds.) Antarctic Ecosystems: Models for wider understanding, 303-307. Christchurch, NZ: University of Canterbury.

Summerson, R. \& Bishop, I.D. 2011. Aesthetic value in Antarctica: beautiful or sublime? The Polar Journal. 1.225-50.

Summerson, R. 2012. Protection of Wilderness and Aesthetic Values in Antarctica. In Huettmann, F. (ed.) Protection of the Three Poles, 79-111. Tokyo: Springer.

Summerson, R. \& Bishop, I. 2012. The impact of human activities on wilderness and aesthetic values of Antarctica. Polar Research. 31.10858.

Surowiecki, J. 2012. The Wisdom of Crowds. London: Abacus.

Suter, K. 1991. Antarctica. Private property or public heritage? Sydney: Pluto Press. 
Swanwick, C. \& Land Use Consultants. 2002. Landscape Character Assessment Guidance for England and Scotland. http://publications.naturalengland.org.uk/file/2672917. Accessed 28 January 2013.

Swithinbank, C. 1991. Potential Airfield Sites in Antarctica for Wheeled Aircraft. Division of Polar Programs, National Science Foundation.

Taylor, P.W. 1986. Respect for Nature. A Theory of Environmental Ethics. Princeton, New Jersey: Princeton University Press.

Tepper, R. \& Haward, M. 2005. The development of Malaysia's position on Antarctica: 1982 to 2004. Polar Record. 41. 113-124.

Terauds, A, Chown S.L., Morgan, F., Peat, H. J., Watts, D.J., Keys, H., Convey, P. \& Bergstrom, D.M. 2012. Conservation biogeography of the Antarctic. Diversity and Distributions.1-16. DOI: 10.1111/j.1472-4642.2012.00925.x

Thomas, A. 1998. Values. In Routledge Encyclopedia of Philosophy (ed.) E. Craig. London: Routledge.

Thomas, K. (ed.) 1984. Man and the Natural World. London: Penguin Books.

Thompson, J. 1990. A Refutation of Environmental Ethics. Environmental Ethics. 12. 147-60. Thomson, A. 2003. Antarctica on a plate. Sydney: Random House Australia.

Thoreau, H.D. 1972. The Maine Woods. Princeton: Princeton University Press.

Tin, T. \& Hemmings, A.D. 2011. Challenges in Protecting the Wilderness of Antarctica. Paper presented at the Science and Stewardship to Protect and Sustain Wilderness Values, 147-152.

Ninth World Wilderness Congress Symposium., Meridá, Yucatán, Mexico.

Tuan, Y-F. 1974. Topophilia. A study of environmental perception, attitudes and values. Eaglewood Cliffs, New Jersey: Prentice-Hall.

Udvardy, M.D.F. 1975. A classification of the biogeographical provinces of the world. International Union for Conservation of Nature and Natural Resources.

UNESCO. 2011. Convention Concerning the Protection of the World Cultural and Natural Heritage (World Heritage Convention) 1972. Paris: UNESCO.

Velasquez, M. 2005. Philosophy. A Text with Readings. Ninth Edition. Belmont, CA: Thomson Wadworth.

Vest, J.H.C. 1985. Will-of-the-Land: Wilderness among Primal Indo-Europeans. Environmental Review. 9. 323-329. 
Vicuña, F.O. (ed.) 1983. Antarctic Resources Policy. Scientific, legal and political issues. Cambridge: Cambridge University Press.

Vilkka, L. 1997. The Intrinsic Value of Nature. Amsterdam: Editions Rodopi.

Vistad, O.I. \& Vorkinn, M. 2012. The Wilderness Purism Construct - Experiences from Norway with a simplified version of the purism scale. Forest Policy and Economics. 19. 39-47.

Wackernagel, M. \& Rees, W. 1996. Our Ecological Footprint. Reducing Human Impact on the Earth. Gabriola Island, B.C., Canada: New Society Publishers.

WAIS. 2012. West Antarctic Ice Sheet Divide Ice Core. http://www.waisdivide.unh.edu/. Accessed 28 May 2012.

Walton, D.W.H. (ed.) 1987. Antarctic Science. Cambridge: Cambridge University Press. Walton, D.W.H. \& Shears, J. 1994. The Need for Environmental Monitoring in Antarctica: Baselines, Environmental Impact Assessments, Accidents and Footprints. International Journal of Environmental Analytical Chemistry. 55. 77-90.

Walton, D.W.H. 2011. The Scientific Committee on Antarctic Research and the Antarctic Treaty. In Berkman, P.A., Lang, M.A., Walton, D.W.H. \& Young, O.R. (eds.) Science diplomacy: science, Antarctica, and the governance of international spaces, 75-88.

Washington, DC: Smithsonian Institution Scholarly Press.

Walton, E.W.K. 1957. Two Years in the Antarctic. London: Panther.

Washington, H. 2006. The Wilderness Knot. Sydney: University of Western Sydney. Unpublished $\mathrm{PhD}$ thesis.

Watson, A., Ramirez, C.V. \& Salud, E. 2009. Predicting Visibility of Aircraft. PLOS ONE. 4. 116.

Weddell, J. 1827. A voyage towards the South Pole, performed in the years 1822-24: containing an examination of the Antarctic Sea. London: Longman.

Wheeler, S. 1997. Antarctica, the Falklands and South Georgia. London: Cadogan Books.

Wherrett, J.R. 1999. Issues in using the Internet as a medium for landscape preference research. Landscape and Urban Planning. 45. 209-217.

Wherrett, J.R. 2000. Creating landscape preference models using Internet survey techniques. Landscape Research. 25. 79-96.

White, L. 1967. The historical roots of our ecologic crisis. Science. 155. 1203-1207. 
Wild. 2013. What is a Wilderness Area? Boulder, CO: The Wild Foundation.

http://www.wild.org/main/how-wild-works/policy-research/what-is-a-wilderness-area/.

Accessed 3 May 2013.

Wilderness Society. 2009. The Wilderness Act. Washington, DC: The Wilderness Society. http://wilderness.org/article/wilderness-act-0. Accessed 21 March 2009.

Wilderness. 1996. Wilderness.net. Missoula, MT: Wilderness Institute, College of Forestry and Conservation, University of Montana. http://wilderness.net/. Accessed 22 May 2012

Wilkes, C. 1844. Narrative of the United States Exploring Expedition : during the years 1838, 1839, 1840, 1841, 1842. Philadelphia.

Willard, L.D. 1980. On Preserving Nature's Aesthetic Features. Environmental Ethics. 2. 293310.

Wu, Y., Bishop, I., Hossain, H. \& Sposito, V. 2006. Using GIS in landscape visual quality assessment. Applied GIS. 2. 18.1-18.20.

Young, A.T. 2012. Distance to the Horizon. San Diego: San Diego State University Department of Astronomy.

Zimmerman, M.J. 2001. The Nature of Intrinsic Value. Lanham, Maryland: Rowman and Littlefield.

Zimmerman, M.J. 2010. Intrinsic vs. Extrinsic Value. In Zalta, E.N. (ed.) The Stanford Encyclopedia of Philosophy (Winter 2010 Edition).

http://plato.stanford.edu/archives/win2010/entries/value-intrinsic-extrinsic/.

Zube, E.H., Sell, J.L. \& Taylor, J.G. 1982. Landscape perception: research, application and theory. Landscape Planning. 9. 1-32. 


\title{
Appendix 1. First survey questionnaire
}

(Appendix 1a. Experienced expeditioners)

\author{
QUESTIONNAIRE ON \\ WILDERNESS AND AESTHETIC VALUES OF ANTARCTICA
}

\section{Introduction}

The Protocol on Environmental Protection to the Antarctic Treaty came into force on 14 January 1998. The environmental principles of the Protocol (Article 3) include protection for the aesthetic and wilderness values of the Antarctic:

1. The protection of the Antarctic environment and dependent and associated ecosystems and the intrinsic value of Antarctica, including its wilderness and aesthetic values and its value as an area for the conduct of scientific research, ..., shall be fundamental considerations in the planning and conduct of all activities in the Antarctic Treaty area.

2. To this end:

(b) activities in the Antarctic Treaty area shall be planned and conducted so as to avoid:

degradation of, or substantial risk to, areas of biological, scientific, historic, aesthetic or wilderness significance.

No guidance is given in the Protocol, however, on what these values are, nor how should impacts should be assessed.

My research is to determine what these values are, how they might be measured and to establish a methodology to help develop new Environmental Impact Assessments (EIAs) for wilderness and aesthetic values.

\begin{abstract}
Aim
The aim of this questionnaire is to explore your responses to wilderness and aesthetic values and to help determine what the Antarctic community values.
\end{abstract}

This is also a trial on how future questionnaires should be constructed. If you have any comments on the structure, format or questions, they will be gratefully received. There is space for comments on the last page.

The questionnaire should take about $10-15$ minutes to complete. Please return to Rupert Summerson in Cabin D10.

All completed questionnaires will be treated with the strictest confidence.

Thank you for your contribution. 


\section{WILDERNESS}

There is no single definition of what wilderness means, your understanding of what it means is important. Please answer the following questions.

\begin{tabular}{|l|l|}
\hline $\begin{array}{l}\text { Part 1. Would you consider that } \\
\text { wilderness, in an Antarctic } \\
\text { context, means: }\end{array}$ & Response \\
\hline $\begin{array}{l}\text { Q 1. No sign, sound or any other } \\
\text { evidence of human presence: }\end{array}$ & \\
\hline $\begin{array}{l}\text { Q 2. Sight or sound or human } \\
\text { activity is acceptable so long as } \\
\text { they do not dominate the landscape }\end{array}$ & \\
\hline $\begin{array}{l}\text { Q 3. Antarctica is such a harsh } \\
\text { place that even station areas are } \\
\text { part of the wilderness }\end{array}$ & \\
\hline Any other comments & \\
\hline
\end{tabular}

If you have responded to Q 1, please answer the questions in $\mathrm{W} 1$; if you have responded to $\mathrm{Q} 2$, please go to $\mathrm{W} 2$ and if you have responded to Q 3, please go to W 3. Please then move on to Aesthetics.

\section{W 1: You have indicated that wilderness, in an Antarctic context means " No sign, sound or any other evidence of human presence", but:}

1. Would the knowledge that the snow contains (sometimes minute) traces of human activities (eg radioactive fallout from nuclear weapons testing in the 1950s) detract from wilderness?

2. Would you consider that if a single distant feature, such as a radio mast, was visible, even though you could turn your back on it and see no other evidence of human activities, it would still detract from your appreciation of wilderness?

3. Do you consider that temporary traces of human activity eg vehicle or foot tracks in the snow detract from wilderness?

4. Do you consider that your safety overrides the maintenance of wilderness? eg, would you consider a route marker an infringement on wilderness? 
5. Would vapour trails from high

flying aircraft detract from your

sense of wilderness?

6. Any other comments? W 2. If you think that Wilderness, in an Antarctic context, means that "Sight or
sound of human activity is acceptable so long as they do not dominate the
landscape", please answer the following questions:

1. Would any of the following infringe on your perception of

wilderness?:

Route marker

Vehicle track in ice free area

Signs of past scientific activity eg

taking of rock samples

Field hut

Vehicle track in snow

Signs of camp sites

2. Would your safety influence

your perception of wilderness?

3. What level of noise emanating

from human activities (eg

helicopters, reversing alarms)

would be acceptable

eg none, just audible, clearly

audible?

4. Any comments?

\section{W 3. Antarctica is such a harsh place that even station areas are part of the} wilderness

1. Would you feel that the presence of roads, vehicles and buildings were part of wilderness?

2. Would you consider that the presence of humans enhances the sensation of wilderness through the contrast between the small size of human settlement and the vast size of Antarctica? 3. Do you think that humans have as much right to be in the wilderness as other species?

4. What level of activity would change this view eg the construction of an airport, hotel, mining/industrial complex? 
5. Any other comments?

\section{AESTHETICS}

This section explores your responses to the scenic beauty of the Antarctic landscape. There is no need to just answer Yes or No. Please respond in whichever way best conveys your expectations or feelings.

\section{A1. What elements of the Antarctic landscape do you find most pleasing:}

\begin{tabular}{|l|l|}
\hline Icebergs & \\
\hline Ice cliffs & \\
\hline Crevasse fields & \\
\hline Glaciers & \\
\hline Ice shelves & \\
\hline Ice cap & \\
\hline Pack ice & \\
\hline Rocky areas & \\
\hline Snow-covered mountains & \\
\hline Historic sites & \\
\hline Antarctic wildlife & \\
\hline Sites of human activities & \\
\hline $\begin{array}{l}\text { Combinations of the } \\
\text { above }\end{array}$ & \\
\hline Other & \\
\hline
\end{tabular}

A2. Do you have a favourite place you like to visit? Please describe in the left hand column the location and the right hand column what you like about it

\begin{tabular}{|l|l|}
\hline Location & Description \\
\hline $\begin{array}{l}\text { Example: Jack's } \\
\text { Donga }\end{array}$ & Great views out to sea and the only sound I can hear is ..... \\
\hline & \\
& \\
\hline
\end{tabular}




\begin{tabular}{|l|l|}
\hline A3. Other responses & \\
\hline 1. Do you know of & \\
any paintings or & \\
drawings of & \\
Antarctica? If there is & \\
one you particularly & \\
like, please describe & \\
the subject and why & \\
you like it. & \\
\hline 2. Please describe & \\
your favourite & \\
photographic image of & \\
Antarctica? & \\
\hline 3. Do you have a & \\
favourite book about & \\
Antarctica? If so, & \\
please give the & \\
title/author and why & \\
you like it. & \\
\hline 4. What sort of music & \\
do you associate with & \\
Antarctica? & \\
\hline 5. Do you know any & \\
poetry which conveys & \\
something about & \\
Antarctica well? If & \\
so, please tell me & \\
something about it. & \\
\hline 6. Any other & \\
comments? & \\
\hline
\end{tabular}

\section{A4. Response to historic (or old) buildings}

1. If there was an abandoned base nearby, would you like to go and visit it?

2. If you have visited an abandoned base during one of your visits to Antarctica, could you describe, briefly, what it was that interested you about it? 
3. Do you consider that an abandoned base detracts from wilderness - or has reverted back to wilderness?

4. Can you describe any abandoned base that you have either visited or seen in photos which you would consider visibly attractive?

\section{COMMENTS}

Your comments on the layout, content, omission or any other aspect of this questionnaire will be invaluable in designing better forms in the future. Please use the back of the page. Thank you. 
Appendix 1b. First-time visitors

\section{QUESTIONNAIRE \\ ON}

\section{WILDERNESS AND AESTHETIC VALUES OF ANTARCTICA}

\section{Introduction}

The Protocol on Environmental Protection to the Antarctic Treaty came into force on 14 January 1998. The environmental principles of the Protocol (Article 3) include protection for the aesthetic and wilderness values of the Antarctic:

1. The protection of the Antarctic environment and dependent and associated ecosystems and the intrinsic value of Antarctica, including its wilderness and aesthetic values and its value as an area for the conduct of scientific research, ..., shall be fundamental considerations in the planning and conduct of all activities in the Antarctic Treaty area.

2. To this end:

(b) activities in the Antarctic Treaty area shall be planned and conducted so as to avoid:

(vi) degradation of, or substantial risk to, areas of biological, scientific, historic, aesthetic or wilderness significance.

$\cdots$

No guidance is given in the Protocol, however, on what these values are, nor how should impacts should be assessed.

My research is to determine what these values are, how they might be measured and to establish a methodology to help develop new Environmental Impact Assessments (EIAs) for wilderness and aesthetic values.

\section{Aim}

The aim of this questionnaire is to explore what your expectations are of wilderness and aesthetic values before your first visit to Antarctica.

This information will be very useful to help determine what wilderness and aesthetic values are, across a broad section of the community, and how the reality meets your expectations, particularly with regard to human impacts. To this end, I would like to give you another questionnaire when you return. If you agree to participate, please provide a contact address (email would be preferred) here:

Contact:

This is also a trial on how future questionnaires should be constructed. If you have any comments on the structure, format or questions, they will be gratefully received. There is space for comments on the last page. 
The questionnaire should take about $10-15$ minutes to complete. Please return to Rupert Summerson in Cabin D10.

All completed questionnaires will be treated with the strictest confidence.

Thank you for your contribution.

\section{QUESTIONNAIRE}

This questionnaire aims to explore the expectations of first-time visitors to Antarctica of wilderness and aesthetic values.

\section{WILDERNESS}

There is no single definition of what wilderness means, your understanding of what it means is important. Please answer the following questions, preferably giving brief reasons.

\begin{tabular}{|l|l|}
\hline $\begin{array}{l}\text { Part 1. Would you consider that } \\
\text { wilderness, in an Antarctic } \\
\text { context, means: }\end{array}$ & Response \\
\hline $\begin{array}{l}\text { Q 1. No sign, sound or any other } \\
\text { evidence of human presence: }\end{array}$ & \\
\hline $\begin{array}{l}\text { Q 2. Sight or sound or human } \\
\text { activity is acceptable so long as } \\
\text { they do not dominate the } \\
\text { landscape }\end{array}$ & \\
\hline $\begin{array}{l}\text { Q 3. Antarctica is such a harsh } \\
\text { place that even station areas are } \\
\text { part of the wilderness }\end{array}$ & \\
\hline Any other comments & \\
\hline
\end{tabular}

If you have responded to Q 1, please answer the questions in $\mathrm{W} 1$; if you have responded to $\mathrm{Q} 2$, please go to W 2 and if you have responded to Q 3, please go to W 3 and then move on to Aesthetics. 
W 1: You have indicated that wilderness, in an Antarctic context means " No sign, sound or any other evidence of human presence", but:

1. Would the knowledge that the snow contains (sometimes minute) traces of human activities (eg radioactive fallout from nuclear weapons testing in the 1950s) detract from wilderness?

2. Would you consider that if a single distant feature, such as a radio mast, was visible, even though you could turn your back on it and see no other evidence of human activities, it would still detract from your appreciation of wilderness?

3. Do you consider that temporary traces of human activity eg vehicle or foot tracks in the snow detract from wilderness?

4. Do you consider that your safety overrides the maintenance of wilderness? eg, would you consider a route marker an infringement on wilderness?

5. Would vapour trails from high flying aircraft detract from your sense of wilderness?

6. Any other comments?

W 2. If you think that Wilderness, in an Antarctic context, means that "Sight or sound of human activity is acceptable so long as they do not dominate the landscape", please answer the following questions:

1. Would any of the following infringe on your perception of wilderness?:

\begin{tabular}{|c|c|}
\hline \\
\hline \multicolumn{2}{|l|}{$\begin{array}{l}\text { Route marker } \\
\text { Vehicle track in ice free area }\end{array}$} \\
\hline \multicolumn{2}{|l|}{$\begin{array}{l}\text { Signs of past scientific activity eg } \\
\text { taking of rock samples }\end{array}$} \\
\hline \multicolumn{2}{|l|}{ Field hut } \\
\hline \multicolumn{2}{|l|}{ Vehicle track in snow } \\
\hline \multicolumn{2}{|l|}{ Signs of camp sites } \\
\hline \multicolumn{2}{|l|}{$\begin{array}{l}\text { 2. Would your safety influence } \\
\text { your perception of wilderness? }\end{array}$} \\
\hline $\begin{array}{l}\text { 3. What level of noise emanating } \\
\text { from human activities (eg } \\
\text { helicopters, reversing alarms) } \\
\text { would be acceptable }\end{array}$ & \\
\hline
\end{tabular}


eg none, just audible, clearly audible?

4. Any comments?

W 3. Antarctica is such a harsh place that even station areas are part of the wilderness

1. Would you feel that the presence of roads, vehicles and

buildings were part of

wilderness?

2. Would you consider that the presence of humans enhances the sensation of wilderness through the contrast between the small size of human settlement and the vast size of Antarctica?

3. Do you think that humans have as much right to be in the wilderness as other species?

4. What level of activity would change this view eg the construction of an airport, hotel, mining/industrial complex?

5. Any other comments? 


\section{AESTHETICS}

This section explores your expectations of the scenic beauty of the Antarctic landscape. There is no need to just answer Yes or No. Please respond in whichever way best conveys your expectations or feelings.

\begin{tabular}{|l|l|}
\hline A1. What elements of the Antarctic landscape are you hoping to experience: \\
\hline Icebergs & \\
\hline Ice cliffs & \\
\hline Crevasse fields & \\
\hline Glaciers & \\
\hline Ice shelves & \\
\hline Ice cap & \\
\hline Pack ice & \\
\hline Rocky areas & \\
\hline $\begin{array}{l}\text { Snow-covered } \\
\text { mountains }\end{array}$ & \\
\hline Historic sites & \\
\hline Antarctic wildlife & \\
\hline Sites of human activities & \\
\hline Other & \\
\hline
\end{tabular}

\section{A2. What sources of inspiration did you have for coming to the Antarctic?}

Antarctic literature

TV programs

Magazine articles

Word of mouth

Lectures

Advertisements

Work prospects

Other

A3. What sorts of landscapes inspire you?

\begin{tabular}{|l|l|}
\hline Mountains & \\
\hline Deserts & \\
\hline Polar landscapes & \\
\hline Tropical rainforests & \\
\hline Pastoral landscapes & \\
\hline Coastal landscapes & \\
\hline Agriculture & \\
\hline Forests & \\
\hline Other & \\
\hline
\end{tabular}




\begin{tabular}{|l|l|}
\hline A4. Other responses & \\
\hline Please describe your & \\
favourite image of & \\
Antarctica? & \\
\hline What image or & \\
images would you & \\
like to take back & \\
home with you? & \\
\hline What experience are & \\
you looking forward & \\
to telling your friends & \\
or family about? & \\
\hline $\begin{array}{l}\text { If you have a } \\
\text { favourite book about } \\
\text { Antarctica please tell } \\
\text { me about it }\end{array}$ & \\
\hline What sort of music do & \\
you associate with & \\
Antarctica? & \\
\hline If you know of any & \\
poetry which conveys & \\
something well about & \\
Antarctica, please tell & \\
me something about it & \\
\hline Any other comments? & \\
& \\
\hline
\end{tabular}

\section{COMMENTS}

Your comments on the layout, content, omission or any other aspect of this questionnaire will be invaluable in designing better forms in the future. Please use the space below for your comments. Thank you.

\begin{tabular}{|l|l|}
\hline Issue & Comment \\
\hline & \\
\hline
\end{tabular}




\section{Appendix 2. Text of Survey 2 questionnaire}

\section{ANTARCTICA WILDERNESS QUESTIONNAIRE}

\begin{tabular}{|c|c|c|c|}
\hline $\begin{array}{c}\text { NAME/STATION } \\
(\text { OptIONAL })\end{array}$ & AGE & GENDER & NATIONALITY \\
\hline \multirow{3}{*}{} & $\square 18-25 \square 26-35$ & $\square$ MALE $\square$ FEMALE & \\
& $\square 36-45 \square 46-55 \square 55+$ & & \\
\hline
\end{tabular}

\begin{tabular}{|l|l|l|l|}
\hline \multicolumn{1}{|c|}{ CHILDHOOD } & \multicolumn{1}{|c|}{ EDUCATIONAL } & \multicolumn{1}{c|}{ POSITION IN ANARE } & \multicolumn{1}{c|}{ PREVIOUS VISITS } \\
\hline$\square$ RURAL & $\square$ SECONDARY & $\begin{array}{l}\text { SCIENTIST \& SCIENTIFIC } \\
\text { SUPPORT }\end{array}$ & $\square$ NUMBER OF VISITS \\
$\square$ URBAN & $\square$ COLLEGE & $\square$ TRADES & \\
$\square$ SUBURBAN & $\square$ TERTIARY & $\square$ OPERATIONS & \\
$\square$ MIXED & $\square$ HIGHER DEGREE & $\square$ SHIP’S CREW $\square$ OTHER & \\
& & & \\
\hline
\end{tabular}

\begin{tabular}{|c|c|c|c|c|c|c|c|c|c|}
\hline \multirow[t]{3}{*}{ IMAGE \# } & \multicolumn{7}{|c|}{ SCENIC BEAUTY RATING } & \multirow{2}{*}{\multicolumn{2}{|c|}{ WILDERNESS? }} \\
\hline & \multicolumn{6}{|l|}{ LOW } & \multirow{2}{*}{$\begin{array}{l}\text { HIGH } \\
7\end{array}$} & & \\
\hline & 1 & 2 & 3 & 4 & 5 & 6 & & & \\
\hline 1. & $\square$ & $\square$ & $\square$ & $\square$ & $\square$ & $\square$ & $\square$ & $\square$ YES & $\square \mathrm{No}$ \\
\hline 2. & $\square$ & $\square$ & $\square$ & $\square$ & $\square$ & $\square$ & $\square$ & $\square$ YES & $\square \mathrm{No}$ \\
\hline 45. & $\square$ & $\square$ & $\square$ & $\square$ & $\square$ & $\square$ & 口 & $\square$ YES & $\square \mathrm{No}$ \\
\hline
\end{tabular}

\begin{tabular}{|l|l|}
\hline \multicolumn{2}{|c|}{ SOME QUESTIONS IN REVIEW } \\
\hline $\begin{array}{l}\text { What was it in the scenes } \\
\text { that you thought made } \\
\text { them "non wilderness"? }\end{array}$ & \\
\hline $\begin{array}{l}\text { What was it in the scenes } \\
\text { that made some } \\
\text { especially beautiful? }\end{array}$ & \\
\hline Any comments? & \\
\hline
\end{tabular}




\title{
Appendix 3. Disposable camera experiment
}

Rupert Summerson

ASAC Project 2250

\author{
WILDERNESS AND AESTHETIC VALUES OF ANTARCTICA \\ DISPOSABLE CAMERA EXPERIMENT \\ LANDSCAPE AESTHETICS
}

\section{Introduction}

The Protocol on Environmental Protection to the Antarctic Treaty came into force on 14 January 1998. The environmental principles of the Protocol (Article 3) include protection for the aesthetic and wilderness values of the Antarctic:

1. The protection of the Antarctic environment and dependent and associated ecosystems and the intrinsic value of Antarctica, including its wilderness and aesthetic values and its value as an area for the conduct of scientific research, ..., shall be fundamental considerations in the planning and conduct of all activities in the Antarctic Treaty area.

2. To this end:

(b) activities in the Antarctic Treaty area shall be planned and conducted so as to avoid:

(vi) degradation of, or substantial risk to, areas of biological, scientific, historic, aesthetic or wilderness significance.

No guidance is given in the Protocol, however, on what these values are, nor how impacts should be assessed.

Annex V to the Protocol (Area Protection and Management) (Article 3. Antarctic Specially Protected Areas) further stipulates:

1. Any area, including any marine area, may be designated as an Antarctic Specially Protected Area to protect outstanding environmental, scientific, historic, aesthetic or wilderness values, any combination of those values, or ongoing or planned scientific research.

2. Parties shall seek to identify, within a systematic environmental-geographical framework, and to include in the series of Antarctic Specially Protected Areas: 
(g) areas of outstanding aesthetic and wilderness value; ....

My research

My research is to determine what these values are, how they might be measured and to establish a methodology to help develop new Environmental Impact Assessments (EIAs) which incorporate potential impacts on wilderness and aesthetic values. I will also seek to determine what the Antarctic community values in terms of wilderness and aesthetics and what areas might therefore be provided with additional protection.

\begin{abstract}
Aim
The aim of this experiment with disposable cameras is to gain some insights on what ANARE expeditioners find beautiful in the Antarctic landscape and what they find ugly. Each person with the camera will have the opportunity to take six photos of places or scenes they find scenically beautiful and six scenes which they find ugly.
\end{abstract}

\title{
INSTRUCTIONS
}

The camera should be shared by two people. The first user should take all 12 photos before handing over to the second user.

A notebook accompanies each camera.

Each user should write down his/her demographic information in the notebook (Name \& station (optional), ANARE occupation, age band, nationality, educational background, gender, whether or not they have previously visited Antarctica and childhood background)

Each user is allowed 12 photos each. The aim is to photograph 6 scenes that the user particularly likes and 6 scenes they don't like.

Each photograph should be accompanied by an entry in the log book on: the place the photo was taken (either map coords, a place name or a sketch map); the direction the photo was taken in (either a compass bearing (please specify whether magnetic or true) or a description eg "towards the station");

a brief description of what is in the scene (to help identify it);

a brief explanation of why this photo was taken and what in the scene they like or don't

like. It is important for me to be able to distinguish between what you like and don't like!

At the end of the first user's turn, please take a photo of the sky in order to distinguish between one user and the next.

If the first user is sensitive about what he or she has photographed or written, their section could be sealed with a piece of sticky tape.

Participants should sign the attached Human Ethics consent form and enclose it with the camera.

When both sets of people have had their turn, please RTA the camera in an envelope to the following address:

If you have any questions please contact Rupert Summerson, either personally or by email at: rupert.summerson@aurora.aad.gov.au or rupert.summerson@brs.gov.au

Thank you! 


\section{Appendix 4. Surveys $2 \& 3$ photos $\&$ summary results}

\section{Survey Two (first visual survey - one set of 45 images)}

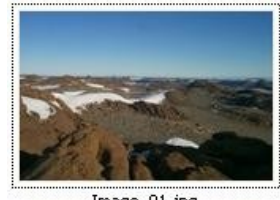

Image_01.jpg

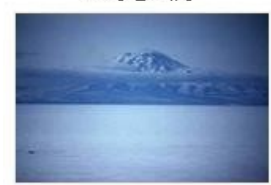

Image_06.jpg

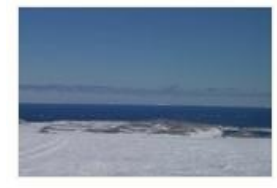

Image_11.jpg

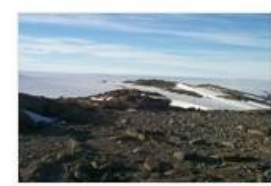

Image_02.jpg

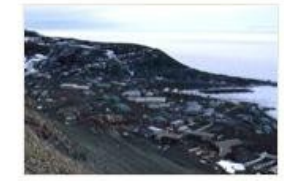

Image_07.jpg

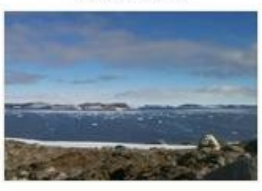

Image_12.jpg

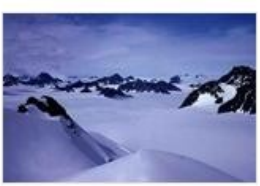

Image_03.jpg

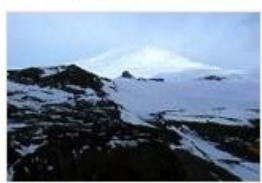

Image_08.jpg

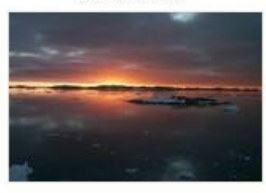

Image_13.jpg

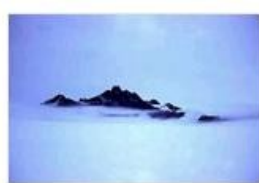

Image_04.jpg

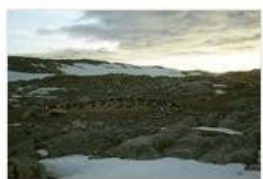

Image_09.jpg

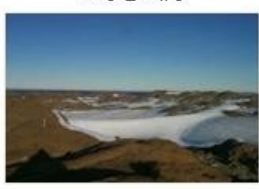

Image_14.jpg

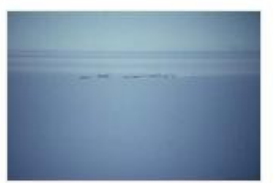

Image_05.jpg

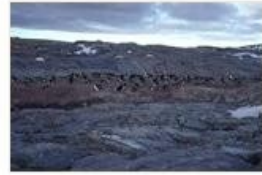

Image_10.jpg

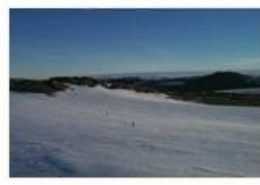

Image_15.jpg

\begin{tabular}{|c|c|c|c|c|c|}
\hline Photo number & 1 & 2 & 3 & 4 & 5 \\
\hline Av. aesthetic rating*: & -0.152 & -0.451 & 0.891 & 0.604 & -1.119 \\
\hline Aesthetic ranking: & 29 & 33 & 3 & 11 & 43 \\
\hline Percentage wilderness: & 98 & 65 & 100 & 98 & 84 \\
\hline Photo number & 6 & 7 & 8 & 9 & 10 \\
\hline Av. aesthetic rating: & 0.73 & -2.277 & -0.064 & -0.658 & -0.382 \\
\hline Aesthetic ranking: & 8 & 45 & 25 & 36 & 31 \\
\hline Percentage wilderness: & 100 & 14 & 90 & 60 & 92 \\
\hline Photo number & 11 & 12 & 13 & 14 & 15 \\
\hline Av. aesthetic rating: & -0.691 & 0.294 & 0.85 & -0.285 & -0.119 \\
\hline Aesthetic ranking: & 38 & 19 & 5 & 30 & 28 \\
\hline Percentage wilderness: & 42 & 100 & 100 & 78 & 98 \\
\hline
\end{tabular}

* Average aesthetic ratings are given as a $\mathrm{Z}$ score. 


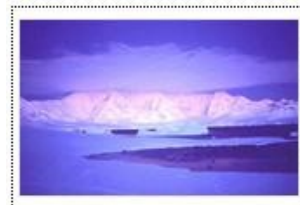

Image_16.jpg

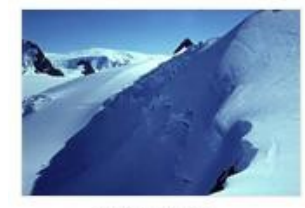

Image_21.jpg

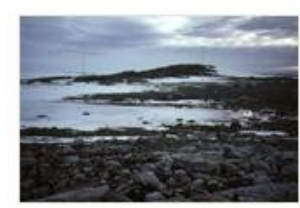

Image_26.jpg

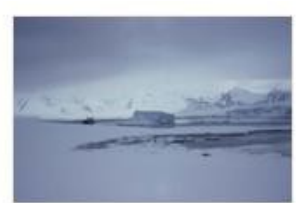

Image_17.jpg

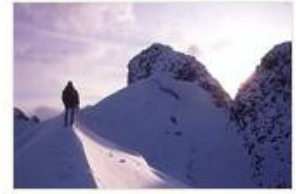

Image_22.jpg

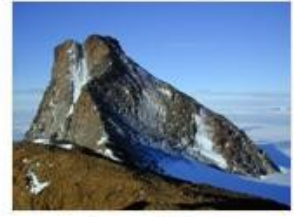

Image_27.jpg

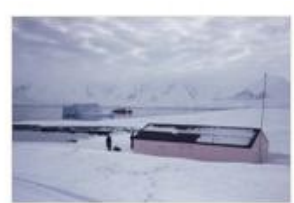

Image_18.jpg

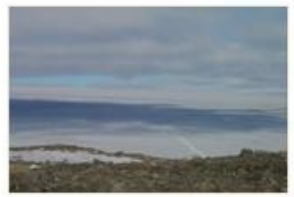

Image_23.jpg

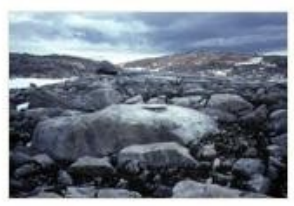

Image_28.jpg

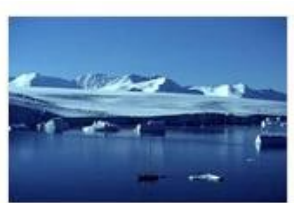

Image_19.jpg

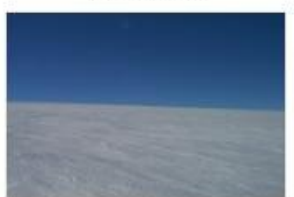

Image_24.jpg

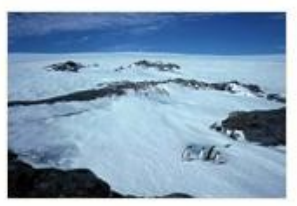

Image_29.jpg

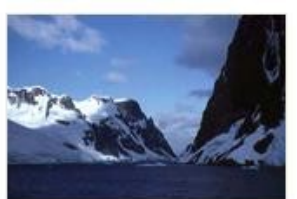

Image_20.jpg

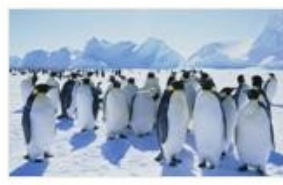

Image_25.jpg

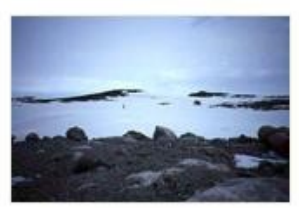

Image_30.jpg

\begin{tabular}{|c|c|c|c|c|c|}
\hline Photo number & 16 & 17 & 18 & 19 & 20 \\
\hline Av. aesthetic rating: & 0.973 & 0.573 & -0.112 & 0.847 & 0.86 \\
\hline Aesthetic ranking: & 2 & 12 & 27 & 6 & 4 \\
\hline Percentage wilderness: & 100 & 96 & 63 & 94 & 98 \\
\hline Photo number & 21 & 22 & 23 & 24 & 25 \\
\hline Av. aesthetic rating: & 0.746 & 0.277 & -0.577 & -0.678 & 1.053 \\
\hline Aesthetic ranking: & 7 & 21 & 35 & 37 & 1 \\
\hline Percentage wilderness: & 94 & 94 & 88 & 98 & 96 \\
\hline Photo number & 26 & 27 & 28 & 29 & 30 \\
\hline Av. aesthetic rating: & -1.41 & 0.698 & -0.74 & 0.21 & -0.943 \\
\hline Aesthetic ranking: & 44 & 9 & 39 & 23 & 41 \\
\hline Percentage wilderness: & 51 & 96 & 65 & 98 & 52 \\
\hline
\end{tabular}




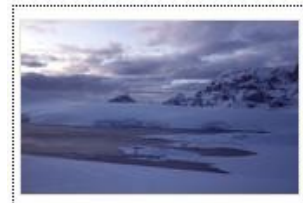

Image_31.jpg

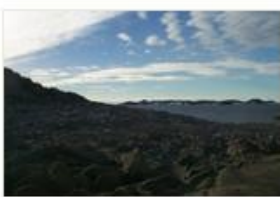

Image_36.jpg

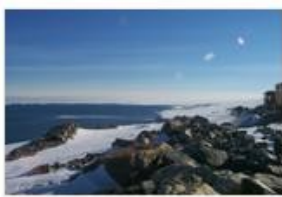

Image_41.jpg

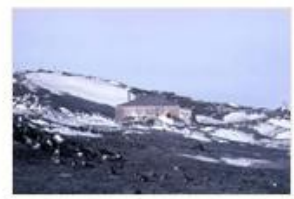

Image_32.jpg

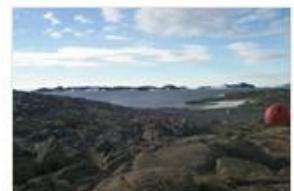

Image_37.jpg

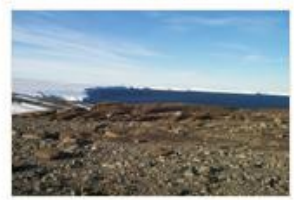

Image_42.jpg

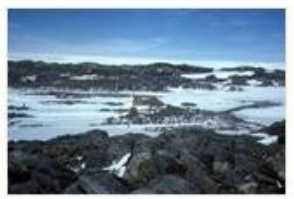

Image_33.jpg

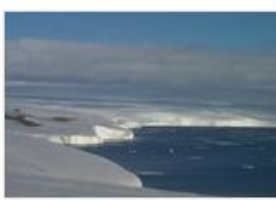

Image_38.jpg

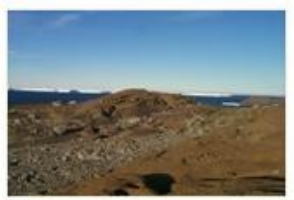

Image_43.jpg

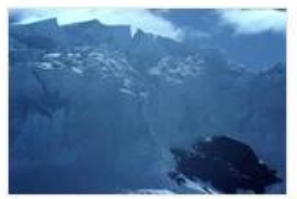

Image_34.jpg

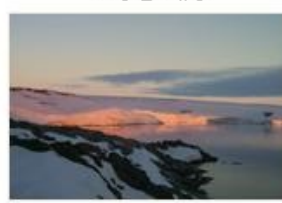

Image_39.jpg

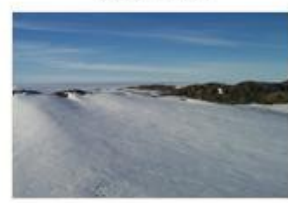

Image_44.jpg

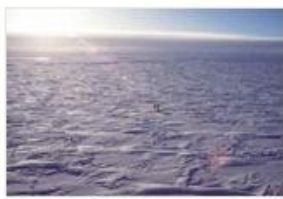

Image_35.jpg

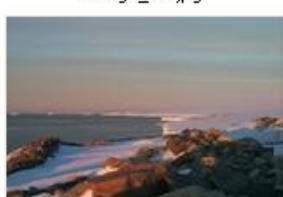

Image_40.jpg

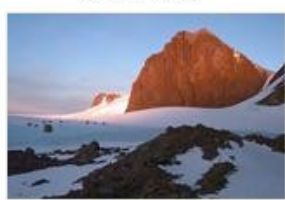

Image_45.jpg

\begin{tabular}{|c|c|c|c|c|c|}
\hline Photo number & 31 & 32 & 33 & 34 & 35 \\
\hline Av. aesthetic rating: & 0.512 & -0.96 & -0.888 & 0.291 & 0.24 \\
\hline Aesthetic ranking: & 14 & 42 & 40 & 20 & 22 \\
\hline Percentage wilderness: & 86 & 49 & 41 & 90 & 100 \\
\hline Photo number & 36 & 37 & 38 & 39 & 40 \\
\hline Av. aesthetic rating: & -0.411 & -0.48 & 0.417 & 0.644 & 0.513 \\
\hline Aesthetic ranking: & 32 & 34 & 15 & 10 & 13 \\
\hline Percentage wilderness: & 96 & 82 & 100 & 98 & 98 \\
\hline Photo number & 41 & 42 & 43 & 44 & 45 \\
\hline Av. aesthetic rating: & 0.129 & 0.362 & 0.311 & -0.1 & 0.347 \\
\hline Aesthetic ranking: & 24 & 16 & 18 & 26 & 17 \\
\hline Percentage wilderness: & 84 & 100 & 100 & 96 & 78 \\
\hline
\end{tabular}

\section{Photo sources:}

All Rupert Summerson, except:

25: Dr Barbara Wienecke

27: Kym Newbery

32: Robert Swan

35: Dr Barbara Wienecke

45: Australian Antarctic Division photo library 


\section{Survey Three (Internet survey) (Set One)}

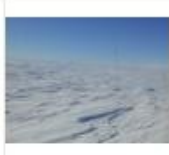

101.jpg

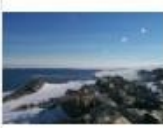

107.jpg

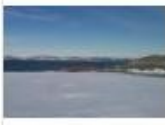

113.jpg

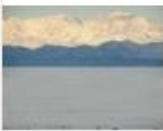

119.jpg

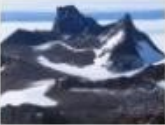

$125 . j p g$

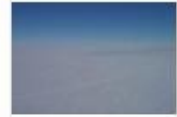

102.jpg

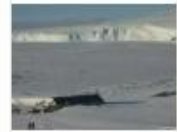

108.jpg

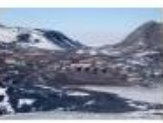

114.jpg

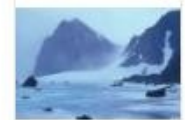

120.jpg

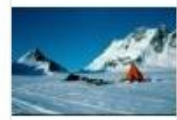

126.jpg

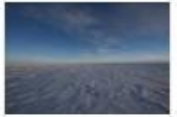

103.jpg

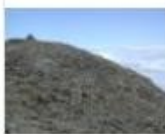

$109 . j p g$

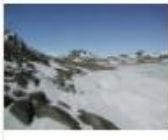

$115 . j p g$

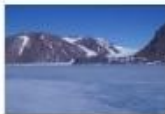

121.jpg

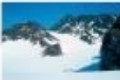

127.jpg

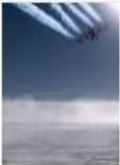

104.jpg

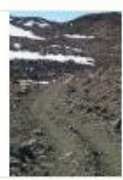

110.jpg

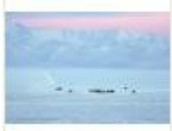

116.jpg

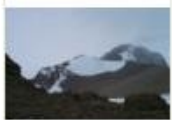

122.jpg

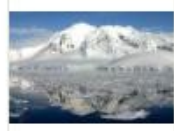

128.jpg

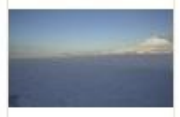

105.jpg

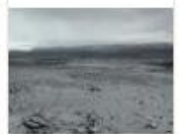

111.jpg

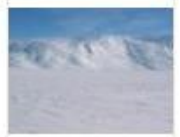

117.jpg

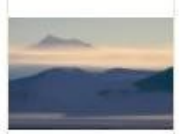

123.jpg

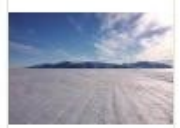

129.jpg

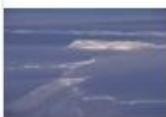

106.jpg

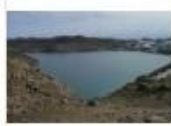

112.jpg

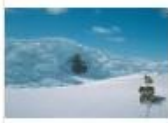

118.jpg

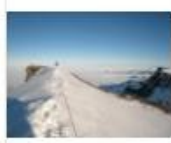

124.jpg

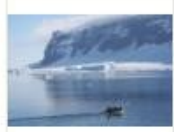

130.jpg

\begin{tabular}{|c|c|c|c|c|c|c|}
\hline Photo number & 101 & 102 & 103 & 104 & 105 & 106 \\
\hline Av. aesthetic rating: & -0.308 & -0.266 & 0.483 & -0.885 & 0.309 & 0.727 \\
\hline Aesthetic ranking: & 67 & 65 & 24 & 83 & 34 & 6 \\
\hline Percent wilderness: & 90 & 94 & 99 & 46 & 97 & 98 \\
\hline Photo number & 107 & 108 & 109 & 110 & 111 & 112 \\
\hline Av. aesthetic rating: & 0.236 & -0.299 & -0.382 & -1.381 & -0.325 & -0.262 \\
\hline Aesthetic ranking: & 37 & 66 & 71 & 88 & 68 & 64 \\
\hline Percent wilderness: & 98 & 67 & 84 & 49 & 97 & 88 \\
\hline Photo number & 113 & 114 & 115 & 116 & 117 & 118 \\
\hline Av. aesthetic rating: & -0.447 & -1.78 & 0.061 & -0.158 & 0.157 & -0.006 \\
\hline Aesthetic ranking: & 75 & 89 & 45 & 60 & 40 & 52 \\
\hline Percent wilderness: & 81 & 17 & 98 & 72 & 97 & 89 \\
\hline Photo number & 119 & 120 & 121 & 122 & 123 & 124 \\
\hline Av. aesthetic rating: & 0.601 & 0.661 & 0.31 & -0.073 & 0.71 & 0.58 \\
\hline Aesthetic ranking: & 15 & 10 & 33 & 54 & 9 & 19 \\
\hline Percent wilderness: & 98 & 99 & 100 & 95 & 97 & 95 \\
\hline Photo number & 125 & 126 & 127 & 128 & 129 & 130 \\
\hline Av. aesthetic rating: & 0.337 & 0.097 & 0.015 & 0.879 & 0.17 & 0.293 \\
\hline Aesthetic ranking: & 30 & 41 & 50 & 2 & 39 & 35 \\
\hline Percent wilderness: & 99 & 85 & 96 & 98 & 84 & 80 \\
\hline
\end{tabular}




\section{Survey Three (Set Two)}

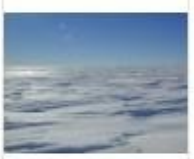

201.jpg

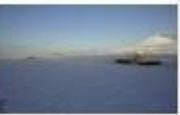

207.jpg

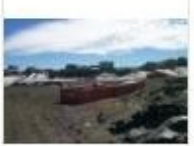

213.jpg

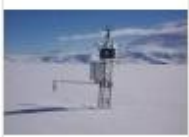

219.jpg

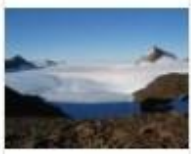

225.jpg

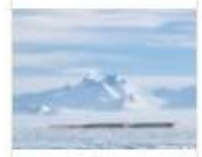

202.jpg

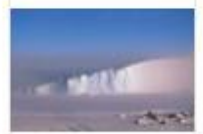

208.jpg

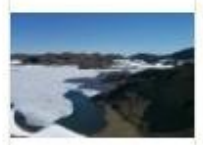

214.jpg

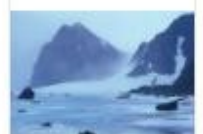

$220 . j p g$

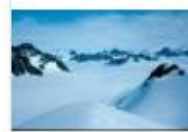

226.jpg

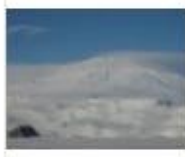

203.jpg

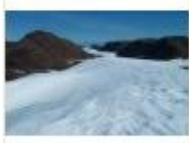

209.jpg

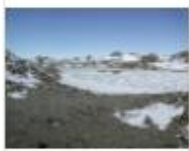

215.jpg

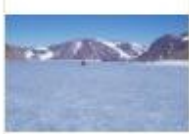

221.jpg

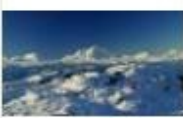

227.jpg

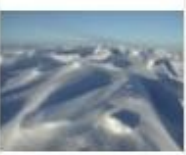

204.jpg

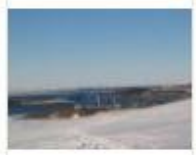

210.jpg

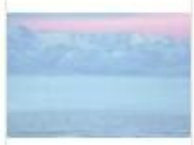

216.jpg

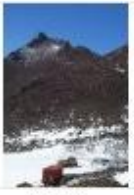

222.jpg

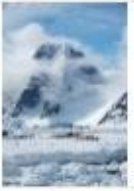

228.jpg

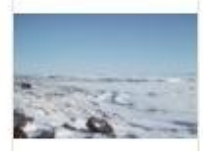

205.jpg

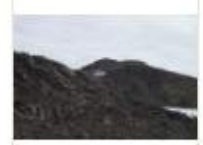

211.jpg

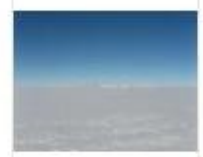

217.jpg

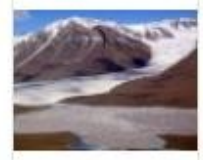

223.jpg

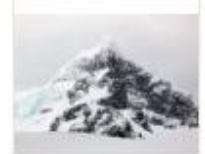

229.jpg

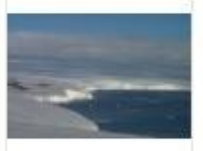

206.jpg

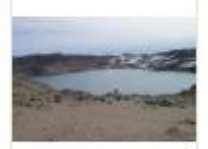

212.jpg

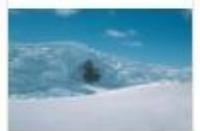

218.jpg

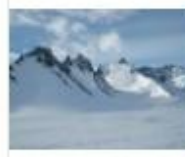

224.jpg

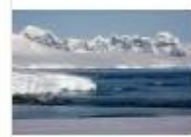

230.jpg

\begin{tabular}{|c|c|c|c|c|c|c|}
\hline Photo number & 201 & 202 & 203 & 204 & 205 & 206 \\
\hline Av. aesthetic rating: & 0.175 & 0.034 & 0.291 & 0.605 & -0.413 & 0.323 \\
\hline Aesthetic ranking: & 38 & 48 & 36 & 14 & 73 & 32 \\
\hline Percent wilderness: & 93 & 75 & 95 & 95 & 87 & 96 \\
\hline Photo number & 207 & 208 & 209 & 210 & 211 & 212 \\
\hline Av. aesthetic rating: & -0.473 & 0.499 & 0.005 & -0.826 & -0.787 & -0.438 \\
\hline Aesthetic ranking: & 76 & 23 & 51 & 81 & 80 & 74 \\
\hline Percent wilderness: & 66 & 94 & 88 & 51 & 83 & 87 \\
\hline Photo number & 213 & 214 & 215 & 216 & 217 & 218 \\
\hline Av. aesthetic rating: & -2.205 & 0.062 & -0.245 & 0.634 & -0.079 & 0.093 \\
\hline Aesthetic ranking: & 90 & 43 & 62 & 11 & 55 & 42 \\
\hline Percent wilderness: & 15 & 93 & 88 & 94 & 97 & 90 \\
\hline Photo number & 219 & 220 & 221 & 222 & 223 & 224 \\
\hline Av. aesthetic rating: & -0.959 & 0.372 & -0.125 & -0.958 & 0.39 & 0.547 \\
\hline Aesthetic ranking: & 85 & 29 & 57 & 84 & 28 & 21 \\
\hline Percent wilderness: & 61 & 91 & 82 & 61 & 95 & 95 \\
\hline Photo number & 225 & 226 & 227 & 228 & 229 & 230 \\
\hline Av. aesthetic rating: & 0.464 & 0.611 & 0.48 & 0.783 & 0.422 & 0.714 \\
\hline Aesthetic ranking: & 26 & 12 & 25 & 3 & 27 & 8 \\
\hline Percent wilderness: & 95 & 96 & 95 & 97 & 93 & 97 \\
\hline
\end{tabular}




\section{Survey Three (Set Three)}

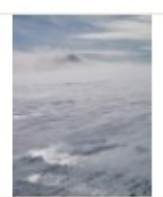

301.jpg

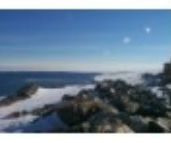

307.jpg

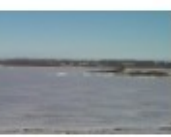

313.jpg

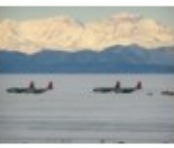

319.jpg

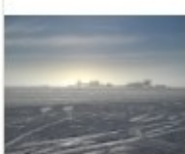

302.jpg

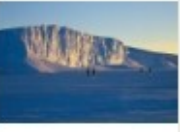

308.jpg

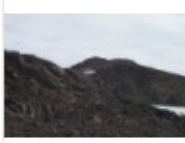

314.jpg

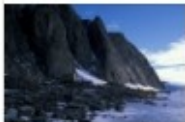

$320 . j p g$

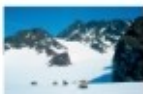

326.jpg

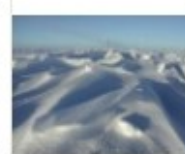

303.jpg

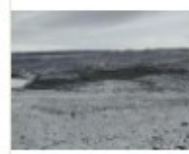

309.jpg

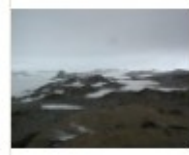

315.jpg

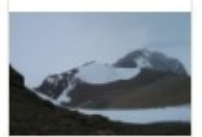

321.jpg

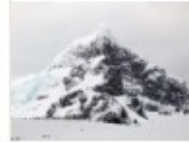

327.jpg

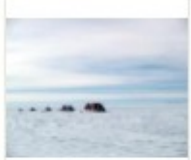

304.jpg

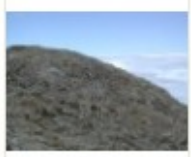

310.jpg

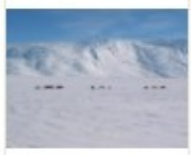

316.jpg

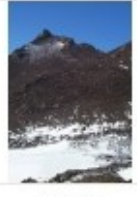

322.jpg

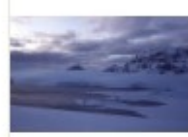

328.jpg

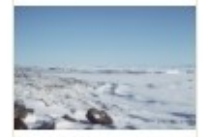

305.jpg

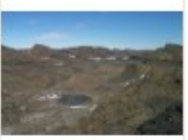

311.jpg

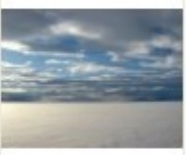

317.jpg

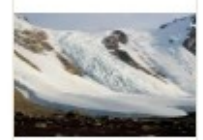

323.jpg

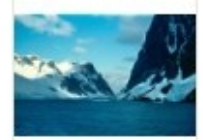

329.jpg 306.jpg
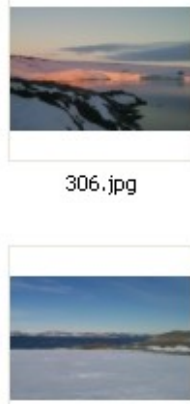

312.jpg

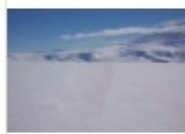

318.jpg

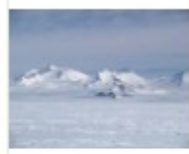

324.jpg

\begin{tabular}{|c|c|c|c|c|c|c|}
\hline Photo number & 301 & 302 & 303 & 304 & 305 & 306 \\
\hline Av. aesthetic rating: & 0.584 & -1.298 & -0.181 & -0.593 & 0.062 & 0.718 \\
\hline Aesthetic ranking: & 18 & 87 & 61 & 78 & 44 & 7 \\
\hline Percent wilderness: & 96 & 27 & 65 & 75 & 99 & 99 \\
\hline Photo number & 307 & 308 & 309 & 310 & 311 & 312 \\
\hline Av. aesthetic rating: & 0.032 & 0.597 & -0.573 & -0.675 & -0.132 & -0.261 \\
\hline Aesthetic ranking: & 49 & 16 & 77 & 79 & 58 & 63 \\
\hline Percent wilderness: & 79 & 92 & 92 & 88 & 98 & 91 \\
\hline Photo number & 313 & 314 & 315 & 316 & 317 & 318 \\
\hline Av. aesthetic rating: & -1.256 & -0.871 & 0.048 & -0.026 & 0.572 & 0.331 \\
\hline Aesthetic ranking: & 86 & 82 & 46 & 53 & 20 & 31 \\
\hline Percent wilderness: & 36 & 58 & 98 & 87 & 93 & 98 \\
\hline Photo number & 319 & 320 & 321 & 322 & 323 & 324 \\
\hline Av. aesthetic rating: & -0.33 & -0.099 & 0.034 & -0.4 & 0.588 & 0.976 \\
\hline Aesthetic ranking: & 69 & 56 & 47 & 72 & 17 & 1 \\
\hline Percent wilderness: & 56 & 79 & 96 & 94 & 95 & 98 \\
\hline Photo number & 325 & 326 & 327 & 328 & 329 & 330 \\
\hline Av. aesthetic rating: & 0.772 & -0.135 & 0.736 & 0.535 & 0.607 & -0.351 \\
\hline Aesthetic ranking: & 4 & 59 & 5 & 22 & 13 & 70 \\
\hline Percent wilderness: & 98 & 83 & 98 & 95 & 94 & 76 \\
\hline
\end{tabular}


Photo sources:

\begin{tabular}{|c|c|c|c|c|c|}
\hline $\begin{array}{l}\text { Photo } \\
\text { no. }\end{array}$ & Source & $\begin{array}{l}\text { Photo } \\
\text { no. }\end{array}$ & Source & $\begin{array}{l}\text { Photo } \\
\text { no. }\end{array}$ & Source \\
\hline 101 & Davis2000 & 102 & $\mathrm{RS}$ & 103 & USAPL \\
\hline 104 & USAPL & 105 & USAPL* & 106 & AAD \\
\hline 107 & RS* & 108 & BV & 109 & EMcI/AAD \\
\hline 110 & $\mathrm{RS}$ & 111 & EMcI/AAD & 112 & RS \\
\hline 113 & RS & 114 & USAPL & 115 & FO \\
\hline 116 & USAPL & 117 & USAPL* & 118 & RS \\
\hline 119 & USAPL* & 120 & AAD* & 121 & AAD \\
\hline 122 & $\mathrm{RS}$ & 123 & $\mathrm{RB}$ & 124 & USAPL \\
\hline 125 & FO & 126 & RS & 127 & RS* \\
\hline 128 & USAPL & 129 & AMRC/UW & 130 & $\mathrm{RB}$ \\
\hline 201 & Davis2000 & 202 & USAPL & 203 & $\mathrm{BV}$ \\
\hline 204 & $\mathrm{BV}^{*}$ & 205 & AAD* & 206 & $\mathrm{RS}$ \\
\hline 207 & USAPL & 208 & AAD & 209 & Davis2000 \\
\hline 210 & FO & 211 & $\mathrm{RS}^{*}$ & 212 & $\mathrm{RS}$ \\
\hline 213 & $\mathrm{RS}$ & 214 & RS & 215 & FO \\
\hline 216 & USAPL* & 217 & USAPL & 218 & RS* \\
\hline 219 & AMRC/UW & 220 & $\mathrm{AAD}$ & 221 & AAD \\
\hline 222 & RS & 223 & USAPL & 224 & USAPL \\
\hline 225 & FO & 226 & RS & 227 & USAPL \\
\hline 228 & USAPL & 229 & USAPL* & 230 & USAPL \\
\hline 301 & USAPL & 302 & USAPL & 303 & BV \\
\hline 304 & USAPL & 305 & $\mathrm{AAD}$ & 306 & RS \\
\hline 307 & RS & 308 & AAD & 309 & EMcI/AAD \\
\hline 310 & EMcI/AAD* & 311 & $\mathrm{RS}$ & 312 & $\mathrm{RS}^{*}$ \\
\hline 313 & RS & 314 & RS & 315 & FO \\
\hline 316 & USAPL & 317 & USAPL & 318 & AMRC/UW* \\
\hline 319 & USAPL & 320 & AAD & 321 & RS \\
\hline 322 & $\mathrm{RS}^{*}$ & 323 & USAPL & 324 & USAPL \\
\hline 325 & FO* & 326 & RS & 327 & USAPL \\
\hline 328 & $\mathrm{RS}$ & 329 & $\mathrm{RS}$ & 330 & $\mathrm{RB}$ \\
\hline
\end{tabular}

$\mathrm{AAD}=$ Australian Antarctic Division photo library (10 images)

$\mathrm{BV}=$ Brian Vasel (NOAA) (4 images)

Davis2000 $=$ Winterers at Davis Station in 2000 (3 images)

EMcI/AAD = Ewan McIvor / Australian Antarctic Division (4 images)

$\mathrm{FO}=$ Frédérique Oliver $(7$ images $)$

$\mathrm{RB}=$ Richard Barwick (3 images)

$\mathrm{RS}=$ Rupert Summerson (28 images)

USAPL $=$ USAP Antarctic Photo Library (28 images)

$\mathrm{AMRC} / \mathrm{UW}=$ Antarctic Meteorological Research Center, University of Wisconsin (3 images)

$*$ = digitally manipulated 


\title{
Appendix 5. Publications from this research.
}

\author{
Summerson, R. \& Riddle, M., J. (2000) Assessing wilderness and aesthetic values in
} Antarctica. In Davison, W., Howard-Williams, Clive and Broady, Paul (Ed.) Antarctic

Ecosystems: Models for wider understanding. Christchurch, NZ, University of Canterbury. $303-307$.

\section{Abstract}

The Protocol on Environmental Protection to the Antarctic Treaty (the Madrid Protocol) introduces the requirement to plan and conduct activities to avoid or minimise degradation of the wilderness and aesthetic values of Antarctica. This paper describes a preliminary study to explore the practicalities of fulfilling this requirement. The concepts of wilderness and aesthetics in Antarctica are explored and ways of assessing the impacts of proposed activities on Antarctic wilderness are suggested. It is proposed that all of Antarctica can be defined as wilderness unless modified or degraded by human activities from within Antarctica. It is also proposed that if human activities or the result of these activities can be sensed, either by sight or sound, then the areas from which those activities can be sensed have been modified. The methods by which activities can be sensed are described and the methodology suggested as the basis of a process for assessing the potential impacts of future activities on wilderness.

Research continues on methods for assessing potential impacts on aesthetic values.

Summerson, R. \& Tin, T. (2011) Protection of the Wilderness and Aesthetic Values of Antarctica: Geographical Information Systems (GIS) as a Tool. In Watson, A., MurrietaSaldivar, J. \& Mcbride, B. (Eds.) Ninth World Wilderness Congress. Merida, Mexico, USDA Forest Service. 178-181.

\begin{abstract}
Antarctica is designated by the Antarctic Treaty System as a "natural reserve devoted to peace and science" (http://www.ats. aq/index_e.htm). Multiple, and sometimes conflicting, values are protected. In a place where wilderness protection and certain forms of human activity are both prized, a discussion of the protection of the Antarctic wilderness necessarily leads to the question of the present and future human footprint in Antarctica. A comprehensive and systematic assessment of the human footprint in Antarctica has never been done, and in this paper the authors explore the opportunities and challenges in conducting such an assessment. On examining the exchange of information conducted under the Antarctic Treaty System, one finds that the information on human activity in Antarctica is relatively centralized, and that with
\end{abstract}


the right permissions, together with dedicated and significant effort, it should be possible to assemble all information in one place. After that, the next challenge lies in the representation of this data in a coherent manner that would be useful for planning purposes. Geographical Information Systems (GIS) are a useful tool for representing this data; however, much work still needs to be done to arrive at a system that is clear, transparent, and reproducible and can illustrate the impacts of human activities on wilderness character or values.

\title{
Summerson, R. \& Bishop, I. D. (2011) Aesthetic value in Antarctica: beautiful or sublime?
} The Polar Journal, 1, 225-250.

\begin{abstract}
Protection of the wilderness and aesthetic values of Antarctica is mandated by the Protocol on Environmental Protection to the Antarctic Treaty, the "Madrid Protocol," which came into force in 1998. Despite the passage of over 13 years, systematic protection for these values has not yet been put in place, due, in part, to the absence of suitable definitions for terms such as "aesthetic values." This paper describes a semantic assessment that was part of a large-scale Internet survey on perceptions of wilderness and aesthetic values in Antarctica. The aim of this part of the survey was to provide insights into aesthetic responses beyond simple aesthetic preferences. Respondents were asked to assess the suitability of 20 adjectives for 90 images of Antarctic landscapes. Taking the distinction between the beautiful and the sublime as the starting point, the adjectives were divided into two lists: words associated with the beautiful and words associated with the sublime. Over 315 respondents from 21 countries took part in the survey, resulting in over 33,000 semantic assessments. The landscapes in the images were classified into environmental regions, a modification of the Environmental Domains of Antarctica regionalization. The results reveal amongst other things that responses to coastal ice-free regions differ markedly to all other regions and that human presence has a strong negative effect on semantic assessments. Multidimensional scaling reveals a complex range of semantic responses that provide insights into how people respond to Antarctic landscapes.
\end{abstract}

\section{Summerson, R. (2012) Protection of Wilderness and Aesthetic Values in Antarctica. In Huettmann, F. (Ed.) Protection of the Three Poles. Tokyo, Springer. 79-111.}

No abstract 
Summerson, R. \& Bishop, I. (2012) The impact of human activities on wilderness and aesthetic values of Antarctica. Polar Research, 31, 10858.

\begin{abstract}
There has been little progress in implementing protection of wildernessand aesthetic values in Antarctica since the coming into force of the Protocol on Environmental Protection to the Antarctic Treaty in 1998. This can in part be attributed to a lack of research defining these values and showing how they may be assessed. In 2009, a survey comprising 90 images of Antarctic landscapes was established on the Internet to canvass as wide a cross-section of people with an interest in Antarctica as possible on their perceptions of wilderness and their aesthetic preference. At the time of writing, over 337 respondents from 23 nationalities have taken part in the survey. Responses were analysed to determine the effect of human presence, both transient and as infrastructure, on perceptions of wilderness and aesthetic values. The analysis was in three parts: (1) all images combined; (2) images grouped by landscape type, derived from the Environmental Domains of Antarctica regionalization; and (3) 16 pairs of digitally manipulated images of which respondents were shown either an original image or one in which human presence had been either digitally removed or added. Responses to images grouped by landscape type show that coastal and ice-free areas are less valued both aesthetically and as wilderness than mountainous and ice-covered terrains. Signs of human presence were found to make images significantly less likely to be considered as wilderness and also reduced their aesthetic rating. This demonstrates that human impacts on these values are measureable.

Summerson, R. (2013) Wilderness and Aesthetic Values of Antarctica. In Liggett, D. \& Hemmings, A. D. (Eds.) Exploring Antarctic Values. Proceedings of the workshop "Exploring Linkages between Environmental Management and Value Systems: The Case of Antarctica". Christchurch, New Zealand, Gateway Antarctic Special Publication Series.
\end{abstract} 22-48.

No abstract

Neufeld, E., O'Reilly, J., Summerson, R. \& Tin, T. (2013) Valuing Antarctica: Emerging Views from International Studies. In Tin, T., Liggett, D., Maher, P. \& Lamers, M. (Eds.) Antarctic futures: Human engagement with the Antarctic environment. Dordrecht, Springer. Chapter 10.

No abstract 
